
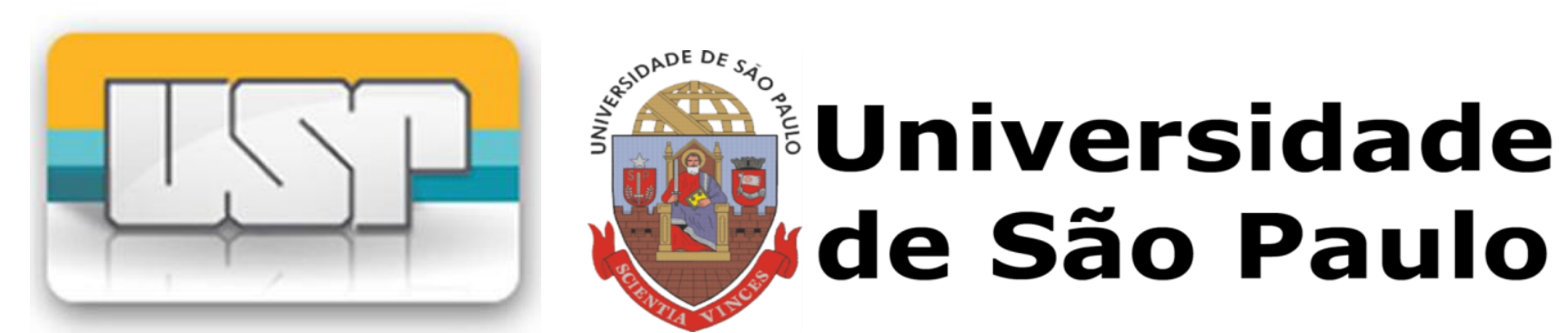

PROGRAMA DE PÓS-GRADUAÇÃO INTERUNIDADES EM ENSINO DE CIÊNCIAS

INSTITUTO DE QUÍMICA INSTITUTO DE BIOCIÊNCIAS
INSTITUTO DE FÍSICA

FACULDADE DE EDUCAÇÃO

\title{
Desenvolvimento de Competências e Habilidades apontadas no ENEM para a área de Química: ensino por meio de Situações-problema.
}




\section{Desenvolvimento de Competências e Habilidades apontadas no ENEM para a área de Química: ensino por meio de Situações-problema.}

Dissertação apresentada ao Programa de Pós Graduação Interunidades em Ensino de Ciências - IQ/IF/ICB/FE - da Universidade de São Paulo, como requisito para a obtenção do título de Mestre em Ensino de Ciências. Versão original. Esta versão encontra-se disponível tanto na Biblioteca da Unidade que aloja o Programa quanto na Biblioteca Digital de Teses e Dissertações da USP (BDTD).

Área de Concentração: Ensino de Química

Orientadora: Prof ${ }^{a}$. Dra. Maria Eunice Ribeiro Marcondes 


\section{FICHA CATALOGRÁFICA}

\section{Preparada pelo Serviço de Biblioteca e Informação do Instituto de Física da Universidade de São Paulo}

Luigi, Camila Alexandra Rodrigues

Desenvolvimento de competências e habilidades apontadas no ENEM para a área de química: ensino por meio de Situações-problema. São Paulo, 2018.

Dissertação (Mestrado) - Universidade de São Paulo. Faculdade de Educação, Instituto de Física, Instituto de Química e Instituto de Biociências.

Orientador: Profa. Dra. Maria Eunice Ribeiro Marcondes.

Área de Concentração: Ensino de Química.

Unitermos: 1. Química - Estudo e ensino; 2. Ensino e aprendizagem; 3. Prática de ensino; 4. Ciências - Estudo e ensino. 
Não é suficiente saber o conteúdo, o que realmente interessa é a capacidade de aplicar o conhecimento à resolução de situações ou problemas reais. Nesse "nível, as mudanças que as competências representam para o ensino são profundas". 


\section{PROFESSORA MARIA EUNICE,}

Vivendo um turbilhão de emoções ao descobrir que em breve me tornaria mãe vi a minha vida mudar por completo. Ao mesmo tempo estava realizando um sonho de depois de seis anos voltar para a USP sendo orientada pela minha eterna orientadora, prof $^{a}$ Maria Eunice, do programa de Bolsa Trabalho, lá em 2006. Já tinha sido membro do GEPEQ e sabia da responsabilidade que era voltar a fazer parte de um grupo tão importante para a educação. E agora? Será que conseguiria não decepcionar a professora Maria Eunice, que me acolheu prontamente em seu grupo? Não sei! Espero que sim! O que sei é que ela me deu um suporte TÃO GRANDE ao longo de toda a caminhada no desenvolvimento do meu trabalho, que sem sombra de dúvidas não teria conseguido chegar até aqui sem o seu apoio. Sempre muito carinhosa, atenciosa, ORIENTADORA e paciente diante dos meus erros.

Sem falar nas horas de orientações. Quanto aprendizado! Quantas vezes chegava lá com tantas dúvidas e perdida, pensando nossa como vou sair disso, o que fazer, preciso pensar em uma saída, afinal estou aprendendo a pesquisar! Ela nunca determinou, sempre sugeriu, orientou, ensinou e nos fez refletir! Com dicas e sutilezas nas sugestões abria sempre um caminho na pesquisa! Clareava nossos pensamentos e tirava nossas angústias! Realmente ensina o aluno a pesquisar! Ao final da caminhada, no momento da escrita, a aprendizagem foi gigantesca! Cada etapa do trabalho passou a ter um novo sentido! Espero ter conseguido e também poder ter a honra de compartilhar outros trabalhos com a senhora!

Como disse nossa colega Terezinha Iolanda, é uma professora na essência da palavra e orientadora por natureza!

Professora as palavras não serão suficientes diante da gratidão, do carinho e da admiração que tenho pela senhora. 


\section{AGRADECIMENTOS}

Ao meu querido esposo, André, companheiro de uma vida, parceiro, sempre me incentivando e me ajudando a ultrapassar cada obstáculo com firmeza e sem jamais desistir. Cúmplice das minhas alegrias e também das derrotas. Te amo!

Ao meu filho, Miguel, minha maior alegria, meu sonho realizado! Que mesmo sem saber tem me ajudado muito nas horas em que mais preciso escrever, ler e refletir! Te amo!

À minha avó que me criou, acreditou em mim, e me proporcionou muitas oportunidades na vida! Aos meus pais que tanto amo, que me fortalecem e estão ao meu lado sempre! Ao meu irmão, amigo, que amo tanto! A minha cunhada Renata pela amizade e carinho e aos meus amados sobrinhos Gaby e Henry! À minha sogra, Lourdes e meu sogro Darcy por me acolher em sua família, pelo grande amparo e ajuda em todos os sentidos! À minha cunhada, Cibele, pela amizade, e por me ajudar em momentos decisivos! Ao meu cunhado Rodrigo, também pela amizade.

Aos meus colegas e parceiros do GEPEQ, Luciane, Fábio, Lílian, Miriam, Susan, Naãma, Isabella, Terezinha, Caroline, Lara, Débora, Thaís e Matheus pelas ideias, sugestões, críticas e contribuições durante nossas reuniões e conversas.

Ao cursinho popular comunitário por abrir suas portas para que eu pudesse aplicar minha pesquisa. E aos alunos pela imensa colaboração e boa vontade.

À amiga Renata Ruiz também pelo interesse e disponibilidade em me ajudar na aplicação do meu trabalho.

Às amigas Cássia Batalha, Renata Vecina e Luciane Akahoshi por me ajudarem ao longo da caminha acadêmica em momentos decisivos.

Aos professores das disciplinas cursadas no programa de Pós Graduação. Obrigada pelo grande aprendizado durante as aulas e discussões.

Aos amigos Henrique Frey, Ricardo e Júlio pelas longas conversas e por me ouvirem com paciência e me aconselharem com sabedoria.

Aos amigos e parceiros de trabalho Eliane, Renata, Valéria, Silvana Pereira, Benilde Anderson, e Zago por me darem suporte, conselhos, sugestões e acreditarem em mim.

Às professoras Elaine Pavini Cintra, Mayra Ferreira e Rita de Cássia Suart, pela participação e dedicação nas correções. Também pelas críticas e sugestões proferidas em minha qualificação e na defesa. 


\section{RESUMO}

LUIGI, Camila Alexandra Rodrigues. Desenvolvimento de Competências e Habilidades apontadas no ENEM para a área de Química: ensino por meio de Situações-problema. 2008274 f. Dissertação (Mestrado). Programa Interunidades em Ensino de Ciências Instituto de Física, Instituto de Química, Instituto de Ciências Biológicas e Faculdade de Educação, Universidade de São Paulo, São Paulo, 2018.

Considerando que o Exame Nacional do Ensino Médio influencia práticas de ensino, este trabalho tem como proposta verificar como Situações-problema (ZABALA e ARNAU, 2010) articuladas ao Ensino de Química podem promover o desenvolvimento de Competências e Habilidades exigidas pelo ENEM. Desenvolvemos e aplicamos uma sequência de atividades em um Cursinho Popular Comunitário. Os objetivos de trabalho consistiram em analisar as atividades procurando evidenciar as principais dificuldades conceituais e cognitivas dos alunos na resolução dos problemas, realizar um acompanhamento individual dos estudantes para verificar evoluções ou superações das dificuldades, contribuir com práticas pedagógicas no Ensino de Química, e desenvolver um estudo dos principais documentos oficiais. De forma contraditória as próprias questões do ENEM nem sempre desenvolvem Competências e Habilidades, apresentando um caráter conteudista. Assim, criamos e aplicamos situações que problematizaram o ensino. Os dados deste trabalho foram obtidos através da resolução de questões reelaboradas do próprio ENEM e outras criadas. Como análise de dados foi empregada a ferramenta Análise de Conteúdos proposta por Bardin (1977), apoiando-se em referenciais teóricos que investigam o desenvolvimento de habilidades cognitivas de alta e baixa ordem para a criação de categorias (MARCONDES E SUART (2008) e ZOLLER, (1993)). Os alunos apresentaram melhores rendimentos em questões de baixa ordem cognitiva que, segundo Zoller (1993), significa maior facilidade em recordar a informação, aplicar conhecimentos ou algoritmos memorizados. Quanto ao rendimento em questões que demandaram alta cognição, incialmente apresentou-se baixo, mas após a participação nas sequências de atividades, houve um aumento gradual e significativo. O que representou o domínio de investigação e resolução de problemas muitas vezes pouco familiares aos alunos e a tomada de decisões (ZOLLER, 1993). Acreditamos que conhecer o aluno de forma individualizada foi importante para que pudéssemos acompanhar suas dificuldades e avanços. Diversas foram as razões que comprometeram a resolução adequada dos problemas propostos, como o nível de envolvimento e compreensão dos alunos, a forma de aplicação dos conhecimentos adquiridos, e também, dificuldades conceituais e de raciocínios matemáticos. Apesar das dificuldades, ensinar por meio de competências e habilidades certamente correspondem à forma ideal de ensino. E como educadores temos a obrigação de enfrentar os desafios cotidianos da educação.

Palavras chave: Ensino de Química. Habilidades cognitivas. Aprendizagem. ENEM. Situações-problema. 


\begin{abstract}
LUIGI, Camila Alexandra Rodrigues. Development of Competencies and Skills pointed out in the ENEM for the Chemistry area: teaching through Problem Situations. 2008 $274 \mathrm{f}$. Thesis (Master). Interuniversity in Science Teaching Program - Institute of Physics, Institute of Chemistry, Institute of Biological Sciences and Faculty of Education, University of São Paulo, São Paulo, 2018.

Considering that the National Examination of Secondary Education influences teaching practices, this work has as a proposal to verify as Problem Situations (ZABALA e ARNAU, 2010) articulated to the teaching of Chemistry can promote the development of Competences and Skills required by ENEM. We developed and aplied a sequence of activities in a Community Popular Course. The objectives of the study were to analyze the activities seeking to highlight the main conceptual and cognitive difficulties of the students in solving problems, to carry out an individual follow-up of the students to verify evolutions or overcome difficulties, to contribute with pedagogical practices in the teaching of Chemistry, and to develop a study of the main official documents. In a contradictory way the very issues of the E do not always develop Skills and Abilities, presenting a content character. Thus, we create and apply Situations that problematized the teaching. The data of this work were obtained through the resolution of reworked questions of the ENEM itself and other created ones. The data analysis tool was proposed by Bardin (1977), based on theoretical references that investigate the development of high and low order cognitive abilities for the creation of categories (MARCONDES AND SUART (2008) and ZOLLER, (1993)).According to Zoller (1993), the students presented better performance in questions of low order of cognition, which means that it is easier to remember the information, to apply memorized knowledge or algorithms. Concerning income in questions that demand high cognition, it was initially low, but after participation in the sequences of activities, there was a gradual and significant increase. What represented the domain of investigation and resolution of problems often unfamiliar to students and the decision-making (ZOLLER, 1993). We believe that knowing the student in an individualized way was important so that we could follow his difficulties and advances. There were several reasons that compromised the adequate resolution of the proposed problems, such as the level of student involvement and understanding, the application of acquired knowledge, and also conceptual difficulties and mathematical reasoning. Despite the difficulties, teaching through skills and abilities certainly correspond to the ideal form of teaching. And as educators we have an obligation to face the everyday challenges of education.
\end{abstract}

Keywords: Chemistry teaching. Cognitive abilities. Learning. ENEM. Situations-problems 


\section{LISTA DE FIGURAS}

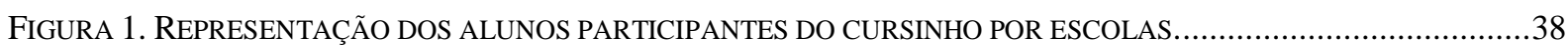

FIGURA 2. REPRESENTAÇÃO DOS ALUNOS PARTICIPANTES DO CURSINHO POR CIDADE DE ORIGEM.......................39

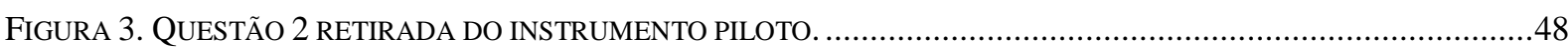

FIGURA 4. NÚMERO DE ALUNOS POR CATEGORIAS REFERENTES À QUESTÃO 1 DO INSTRUMENTO PILOTO..............55

FIGURA 5. NÚMERO DE ALUNOS POR DECODIFICAÇÕES REFERENTES À QUESTÃO 1 DO INSTRUMENTO PILOTO.......57

FIGURA 6. NÚMERO DE ALUNOS POR CATEGORIAS REFERENTES À QUESTÃO 2 DO INSTRUMENTO PILOTO..............59

FIGURA 7. NÚMERO DE ALUNOS POR DECODIFICAÇÕES REFERENTES À QUESTÃO 2 DO INSTRUMENTO PILOTO.......61

FIGURA 8. NÚMERO DE ALUNOS POR CATEGORIAS REFERENTES À QUESTÃo 3 DO INSTRUMENTO PILOTO..............64

FIGURA 9. NÚMERO DE ALUNOS POR DECODIFICAÇÕES REFERENTES À QUESTÃO 3 DO INSTRUMENTO PILOTO.......66

FIGURA 10. NÚMERO DE ALUNOS POR CATEGORIAS REFERENTES À QUESTÃO 4 DO INSTRUMENTO PILOTO............69

FIGURA 11. NÚMERO DE ALUNOS POR DECODIFICAÇÕES REFERENTES À QUESTÃO 4 DO INSTRUMENTO PILOTO.....71

FIGURA 12. NÚMERO DE ALUNOS POR CATEGORIAS REFERENTES À QUESTÃO 5 DO INSTRUMENTO PILOTO............73

FIGURA 13. NÚMERO DE ALUNOS POR DECODIFICAÇÕES REFERENTES À QUESTÃO 5 DO INSTRUMENTO PILOTO. ....76

FIGURA 14. NÚMERO DE ALUNOS POR CATEGORIAS REFERENTES À QUESTÃO 6 DO INSTRUMENTO PILOTO............79

FIGURA 15. NÚMERO DE ALUNOS POR DECODIFICAÇÕES REFERENTES À QUESTÃO 6 DO INSTRUMENTO PILOTO.....82

FIGURA 16. NÚMERO DE ALUNOS POR CATEGORIAS REFERENTES À QUESTÃO 7 DO INSTRUMENTO PILOTO............84

FIGURA 17. DECODIFICAÇÕES DAS RESPOSTAS DOS ALUNOS REFERENTES À QUESTÃO 7 DO INSTRUMENTO PILOT 85 FIGURA 18. NÚMERO DE ALUNOS POR DECODIFICAÇÕES REFERENTES À QUESTÃO 7 DO INSTRUMENTO PILOTO. ....87

FIGURA 19. NÚMERO DE ALUNOS POR CATEGORIAS REFERENTES A QUESTÃO 8 DO INSTRUMENTO PILOTO............89

FIGURA 20. NÚMERO DE ALUNOS POR DECODIFICAÇÕES REFERENTES À QUESTÃO 8 DO INSTRUMENTO PILOTO.....92

FIGURA 21. NÚMERO DE ALUNOS POR CATEGORIAS REFERENTES À QUESTÃO 9 DO INSTRUMENTO PILOTO............94

FIGURA 22. NÚMERO DE ALUNOS POR DECODIFICAÇÕES REFERENTES À QUESTÃO 9 DO INSTRUMENTO PILOTO.....96

FIGURA 23. NÚMERO DE ALUNOS POR CATEGORIAS REFERENTES À QUESTÃO (I) DO INSTRUMENTO 3................106

FIGURA 24. NÚMERO DE ALUNOS POR CATEGORIAS REFERENTES À QUESTÃO 1 (II) DO INSTRUMENTO 3.............107

FIGURA 25. NÚMERO DE ALUNOS POR CATEGORIAS REFERENTES À QUESTÃO 1(II) DO INSTRUMENTO 3.............108

FIGURA 26. NÚMERO DE ALUNOS POR CATEGORIAS REFERENTES À QUESTÃO 1 (IV) DO INSTRUMENTO 3............109

FIGURA 27. NÚMERO DE ALUNOS POR CATEGORIAS REFERENTES À QUESTÃO 1 (V) DO INSTRUMENTO $3 \ldots . . . . . . . . .110$

FIGURA 28. NÚMERO DE ALUNOS POR CATEGORIAS REFERENTES À QUESTÃO 1 (VI) DO INSTRUMENTO 3...........111

FIGURA 29. NÚMERO DE ALUNOS POR CATEGORIAS REFERENTES À QUESTÃO 2 DO INSTRUMENTO 3..................114

FIGURA 30. NÚMERO DE ALUNOS POR CATEGORIAS REFERENTES À QUESTÃO 3 DO INSTRUMENTO 3..................117

FIGURA 31. NÚMERO DE ALUNOS POR CATEGORIAS REFERENTES À QUESTÃO 4 DO INSTRUMENTO 3 ..................119

FIGURA 32. NÚMERO DE ALUNOS POR CATEGORIAS REFERENTES À QUESTÃO 5 (A) DO INSTRUMENTO 3............121

FIGURA 33. NÚMERO DE ALUNOS POR CATEGORIAS REFERENTES À QUESTÃO 5 DO INSTRUMENTO 3 ..................123

FIGURA 34. NÚMERO DE ALUNOS POR CATEGORIAS REFERENTES À QUESTÃO 6 DO INSTRUMENTO 3 ..................124

FIGURA 35. NÚMERO DE ALUNOS POR CATEGORIAS REFERENTES À QUESTÃO 7 DO INSTRUMENTO 3..................127

FIGURA 36. NÚMERO DE ALUNOS POR CATEGORIAS REFERENTES À QUESTÃO 8 DO INSTRUMENTO 3..................129

FIGURA 37. NÚMERO DE ALUNOS POR CATEGORIAS REFERENTES À QUESTÃO 9 DO INSTRUMENTO 3 ..................131

FIGURA 38. NÚMERO DE ALUNOS POR CATEGORIAS REFERENTES À QUESTÃO 10 DO INSTRUMENTO 3................133 
FIGURA 39. NÚMERO DE ALUNOS POR CATEGORIAS REFERENTES À QUESTÃO 11 DO INSTRUMENTO 3.

FIGURA 40. NÚMERO DE ALUNOS POR CATEGORIAS REFERENTES À QUESTÃO 1 (EXEMPLOS) DO INSTRUMENTO .137 FIGURA 41. NÚMERO DE ALUNOS POR CATEGORIAS REFERENTES À QUESTÃO 1 (JUSTIFICATIVAS) DO INSTRUMENTO 4. 139

FIGURA 42. NÚMERO DE ALUNOS POR CATEGORIAS REFERENTES À QUESTÃO 2 DO INSTRUMENTO 4 140 FIGURA 43. NÚMERO DE ALUNOS POR CATEGORIAS REFERENTES À QUESTÃO 3 DO INSTRUMENTO 4 142 FIGURA 44. NÚMERO DE ALUNOS POR CATEGORIAS REFERENTES À QUESTÃO DE SÍNTESE DO INSTRUMENTO 7....144 FIGURA 45. NÚMERO DE ALUNOS POR CATEGORIAS REFERENTES À QUESTÃO 1 DO INSTRUMENTO 9. .148 FIGURA 46. NÚMERO DE ALUNOS POR CATEGORIAS REFERENTES À QUESTÃO 2 (A) DO INSTRUMENTO 9............150 FIGURA 47. NÚMERO DE ALUNOS POR CATEGORIAS REFERENTES À QUESTÃO 2 (B) DO INSTRUMENTO 9. .151 FIGURA 48. NÚMERO DE ALUNOS POR CATEGORIAS REFERENTES À QUESTÃO 2 (C) DO INSTRUMENTO 9 152 FIGURA 49. NÚMERO DE ALUNOS POR CATEGORIAS REFERENTES À QUESTÃO DE SÍNTESE DO INSTRUMENTO 10..156 FIGURA 50. NÚMERO DE ALUNOS POR CATEGORIAS REFERENTES À QUESTÃO 1 (A) DO INSTRUMENTO 12...........159 FIGURA 51. NÚMERO DE ALUNOS POR CATEGORIAS REFERENTES À QUESTÃO 1(B) DO INSTRUMENTO 12............160 FIGURA 52. NÚMERO DE ALUNOS POR CATEGORIAS REFERENTES À QUESTÃO 2 (A) DO INSTRUMENTO 12...........162 FIGURA 53. NÚMERO DE ALUNOS POR CATEGORIAS REFERENTES À QUESTÃO 2 (B) DO INSTRUMENTO 12..........163 FIGURA 54. NÚMERO DE ALUNOS POR CATEGORIAS REFERENTES À QUESTÃO 2 (C) DO INSTRUMENTO 12..........164 FIGURA 55. NÚMERO DE ALUNOS POR CATEGORIAS REFERENTES À QUESTÃO 3 (I) DO INSTRUMENTO 12............167 FIGURA 56. NÚMERO DE ALUNOS POR CATEGORIAS REFERENTES À QUESTÃO 3 (II) DO INSTRUMENTO 12 ...........168 FIGURA 57. NÚMERO DE ALUNOS POR CATEGORIAS REFERENTES À QUESTÃO 2 (III) DO INSTRUMENTO 12..........169 FIGURA 58. NÚMERO DE ALUNOS POR CATEGORIAS REFERENTES À QUESTÃO 1 (I) DO INSTRUMENTO 13...........171 FIGURA 59. NÚMERO DE ALUNOS POR CATEGORIAS REFERENTES À QUESTÃO 1 (II) DO INSTRUMENTO $13 . . . . . . . . .172$ FIGURA 60. NÚMERO DE ALUNOS POR CATEGORIAS REFERENTES À QUESTÃO 1 (III) DO INSTRUMENTO 13..........173 FIGURA 61. NÚMERO DE ALUNOS POR CATEGORIAS REFERENTES À QUESTÃO 1 (IV) DO INSTRUMENTO 13.........174 FIGURA 62. NÚMERO DE ALUNOS POR CATEGORIAS REFERENTES À QUESTÃO 1 (V) DO INSTRUMENTO 13...........175 FIGURA 63. NÚMERO DE ALUNOS POR CATEGORIAS REFERENTES À QUESTÃO 1 (VI) DO INSTRUMENTO 13..........176 FIGURA 64. NÚMERO DE ALUNOS POR CATEGORIAS REFERENTES À QUESTÃO 1 (VII) DO INSTRUMENTO 13........177 FIGURA 65. NÚMERO DE ALUNOS POR CATEGORIAS REFERENTES À QUESTÃO 1 (VIII) DO INSTRUMENTO 13.......178 FIGURA 66. NÚMERO DE ALUNOS POR CATEGORIAS REFERENTES À QUESTÃO 2(A) DO INSTRUMENTO 13............181 FIGURA 67. NÚMERO DE ALUNOS POR CATEGORIAS REFERENTES À QUESTÃO 3 (A) DO INSTRUMENTO 13...........183 FIGURA 68. NÚMERO DE ALUNOS POR CATEGORIAS REFERENTES À QUESTÃO 3 (B) DO INSTRUMENTO 13...........184 FIGURA 69. NÚMERO DE ALUNOS POR CATEGORIAS REFERENTES À QUESTÃO 4 (A) DO INSTRUMENTO 13...........186 FIGURA 70. NÚMERO DE ALUNOS POR CATEGORIAS REFERENTES À QUESTÃO 4 (B) DO INSTRUMENTO 13...........187 FIGURA 71. NÚMERO DE ALUNOS POR CATEGORIAS REFERENTES À QUESTÃO 5 DO INSTRUMENTO 13................189 FIGURA 72. NÚMERO DE ALUNOS POR CATEGORIAS REFERENTES À QUESTÃO 6 (B) DO INSTRUMENTO 13..........191 FIGURA 73. NÚMERO DE ALUNOS POR CATEGORIAS REFERENTES À QUESTÃO 6 (C) DO INSTRUMENTO 13...........192 


\section{LISTA DE QUADROS}

QUADRO 1: RELAÇÃO ENTRE COMPETÊNCIAS GERAIS E ESPECÍFICAS NO ENSINO DE QUÍMICA DESCRITAS NOS $\mathrm{PCN}+$ 15

QUADRO 2: EIXOS COGNITIVOS PRESENTES NA MATRIZ CURRICULAR DO ENEM.

QuAdro 3: COMPETÊNCIAS DE ÁREA DAS CIÊNCIAS DA NATUREZA E A RELAÇÃO COM AS HABILIDADES ESPECÍFICAS PRESENTES NA MATRIZ CURRICULAR DO ENEM.

QUADRO 4. COMPETÊNCIAS E HABILIDADES DO ENEM UTILIZADAS NA ELABORAÇÃO DO INSTRUMENTO PILOTO. 31 QUADRO 5. ARTICULAÇÃO ENTRE AS HABILIDADES DO ENEM E AS ETAPAS DE UMA SiTUAÇÃO-PROBLEMA.........33 QUADRO 6. ORGANIZAÇÃO DOS TEMAS NORTEADORES DAS ATIVIDADES PROBLEMATIZADORAS...........................34 QUADRO 7. COMPETÊNCIAS E HABILIDADES DO ENEM UTILIZADAS NA ELABORAÇÃO DA SEQUÊNCIA DE ENSINO.35 QUADRO 8. DESCRIÇÃO DAS SITUAÇÕES-PROBLEMA E COMPETÊNCIAS EXIGIDAS NO PRIMEIRO MÓDULO. ............40 QUADRO 9. DESCRIÇÃO DAS SITUAÇÕES-PROBLEMA E COMPETÊNCIAS EXIGIDAS NO SEGUNDO MÓDULO. .............41 QUADRO 10. DESCRIÇÃO DAS SITUAÇÕES-PROBLEMA E COMPETÊNCIAS EXIGIDAS NO TERCEIRO MÓDULO. ..........41 QUADRO 11. DESCRIÇÃO DAS SITUAÇÕES-PROBLEMA E COMPETÊNCIAS EXIGIDAS NO QUARTO MÓDULO. ............42 QUADRO 12. INSTRUMENTOS APLICADOS E OBJETIVOS PRETENDIDOS COM AS ATIVIDADES DA SEQUÊNCIA DE ENSINO.

QUADRO 13. ORGANIZAÇÃO DOS MÓDULOS DE ACORDO COM OS TEMAS E INSTRUMENTOS UTILIZADOS EM CADA ETAPA.

QUADRO 14. RELAÇÃO DAS HABILIDADES ESCOLHIDAS, DECODIFICAÇÕES E CATEGORIAS ESTABELECIDAS A PARTIR DA ANÁLISE DA QUESTÃO 1 DO INSTRUMENTO PILOTO.

QUADRO 15. RELAÇÃO DAS HABILIDADES ESCOLHIDAS, DECODIFICAÇÕES E CATEGORIAS ESTABELECIDAS A PARTIR DA ANÁLISE DA QUESTÃO 1 DO INSTRUMENTO PILOTO.

QUADRO 16. RELAÇÃO DAS HABILIDADES ESCOLHIDAS, DECODIFICAÇÕES E CATEGORIAS ESTABELECIDAS A PARTIR DA ANÁLISE DA QUESTÃO 2 DO INSTRUMENTO PILOTO.

QUADRO 17. RELAÇÃO DAS HABILIDADES ESCOLHIDAS, DECODIFICAÇÕES E CATEGORIAS ESTABELECIDAS A PARTIR DA ANÁLISE DA QUESTÃO 3 DO INSTRUMENTO PILOTO.

QUADRO 18. RELAÇÃO DAS HABILIDADES ESCOLHIDAS, DECODIFICAÇÕES E CATEGORIAS ESTABELECIDAS A PARTIR DA ANÁLISE DA QUESTÃO 4 DO INSTRUMENTO PILOTO.

QUADRO 19. RELAÇÃO DAS HABILIDADES ESCOLHIDAS, DECODIFICAÇÕES E CATEGORIAS ESTABELECIDAS A PARTIR DA ANÁLISE DA QUESTÃO 5 DO INSTRUMENTO PILOTO.

QUADRO 20. RELAÇÃO DAS HABILIDADES ESCOLHIDAS, DECODIFICAÇÕES E CATEGORIAS ESTABELECIDAS A PARTIR DA ANÁLISE DA QUESTÃO 6 DO INSTRUMENTO PILOTO.

QuAdRO 21. RELAÇÃO DAS HABILIDADES ESCOLHIDAS, DECODIFICAÇÕES E CATEGORIAS ESTABELECIDAS A PARTIR DA ANÁLISE DA QUESTÃO 7 DO INSTRUMENTO PILOTO.

QUADRO 22. RELAÇÃO DAS HABILIDADES ESCOLHIDAS, DECODIFICAÇÕES E CATEGORIAS ESTABELECIDAS A PARTIR DA ANÁLISE DA QUESTÃO 8 DO INSTRUMENTO PILOTO.

QUADRO 23. RELAÇÃO DAS HABILIDADES ESCOLHIDAS, DECODIFICAÇÕES E CATEGORIAS ESTABELECIDAS A PARTIR DA ANÁLISE DA QUESTÃO 9 DO INSTRUMENTO PILOTO. 
QUADRO 25. ACOMPANHAMENTO INDIVIDUAL NA CONSTRUÇÃO DE CONHECIMENTOS CONCEITUAIS E COGNITIVOS

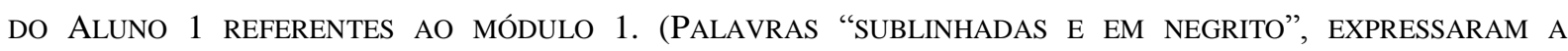
CONSTRUÇÃO DE CONHECIMENTOS ADEQUADAMENTE E COM MUDANÇAS SIGNIFICATIVAS; PALAVRAS EM ITÁLICO E NEGRITO" INDICARAM RESPOSTAS QUE NÃO UTILIZARAM OS CONCEITOS CORRETOS, A PARTIR DOS PADRÕES CIENTÍFICOS). “

QUADRO 26. ACOMPANHAMENTO INDIVIDUAL NA CONSTRUÇÃO DE CONHECIMENTOS CONCEITUAIS E COGNITIVOS Do Aluno 1 Referentes aO módulo 2. (PAlavras "Sublinhadas e em negrito", expressaram a CONSTRUÇÃO DE CONHECIMENTOS ADEQUADAMENTE E COM MUDANÇAS SIGNIFICATIVAS; PALAVRAS EM ITÁLICO E NEGRITO" INDICARAM RESPOSTAS QUE NÃO UTILIZARAM OS CONCEITOS CORRETOS, A PARTIR DOS PADRÕES CIENTÍFICOS). “

QUADRO 27. ACOMPANHAMENTO INDIVIDUAL NA CONSTRUÇÃO DE CONHECIMENTOS CONCEITUAIS E COGNITIVOS

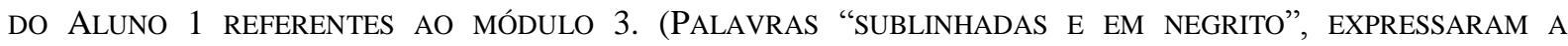
CONSTRUÇÃO DE CONHECIMENTOS ADEQUADAMENTE E COM MUDANÇAS SIGNIFICATIVAS; PALAVRAS EM ITÁLICO E NEGRITO" INDICARAM RESPOSTAS QUE NÃO UTILIZARAM OS CONCEITOS CORRETOS, A PARTIR DOS PADRÕES CIENTÍFICOS). “

QUADRO 28. ACOMPANHAMENTO INDIVIDUAL NA CONSTRUÇÃO DE CONHECIMENTOS CONCEITUAIS E COGNITIVOS do Aluno 2 Referentes ao módulo 1. (PAlavras "Sublinhadas E em negrito", eXpressaram a CONSTRUÇÃO DE CONHECIMENTOS ADEQUADAMENTE E COM MUDANÇAS SIGNIFICATIVAS; PALAVRAS EM "ITÁLICO E NEGRITO" INDICARAM RESPOSTAS QUE NÃO UTILIZARAM OS CONCEITOS CORRETOS, A PARTIR DOS PADRÕES CIENTÍFICOS). .210

QUADRO 29. ACOMPANHAMENTO INDIVIDUAL NA CONSTRUÇÃO DE CONHECIMENTOS CONCEITUAIS E COGNITIVOS

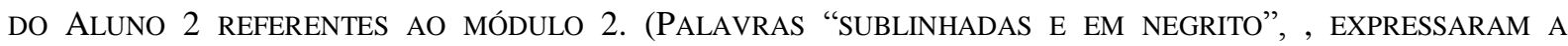
CONSTRUÇÃO DE CONHECIMENTOS ADEQUADAMENTE E COM MUDANÇAS SIGNIFICATIVAS; PALAVRAS EM "ITÁLICO E NEGRITO" INDICARAM RESPOSTAS QUE NÃO UTILIZARAM OS CONCEITOS CORRETOS, A PARTIR DOS PADRÕES CIENTÍFICOS). .212

QUADRO 30. ACOMPANHAMENTO INDIVIDUAL NA CONSTRUÇÃO DE CONHECIMENTOS CONCEITUAIS E COGNITIVOS Do Aluno 2 Referentes ao módulo 3. (PAlavras "Sublinhadas e eM nEgrito", expressaram a CONSTRUÇÃO DE CONHECIMENTOS ADEQUADAMENTE E COM MUDANÇAS SIGNIFICATIVAS; PALAVRAS EM "ITÁLICO E NEGRITO" INDICARAM RESPOSTAS QUE NÃO UTILIZARAM OS CONCEITOS CORRETOS, A PARTIR DOS PADRÕES CIENTÍFICOS). .213

QUADRO 31. ACOMPANHAMENTO INDIVIDUAL NA CONSTRUÇÃO DE CONHECIMENTOS CONCEITUAIS E COGNITIVOS

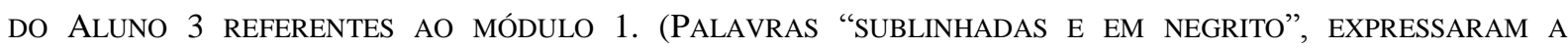
CONSTRUÇÃO DE CONHECIMENTOS ADEQUADAMENTE E COM MUDANÇAS SIGNIFICATIVAS; PALAVRAS EM "ITÁLICO E NEGRITO" INDICARAM RESPOSTAS QUE NÃO UTILIZARAM OS CONCEITOS CORRETOS, A PARTIR DOS PADRÕES CIENTÍFICOS).

QUADRO 32. ACOMPANHAMENTO INDIVIDUAL NA CONSTRUÇÃO DE CONHECIMENTOS CONCEITUAIS E COGNITIVOS

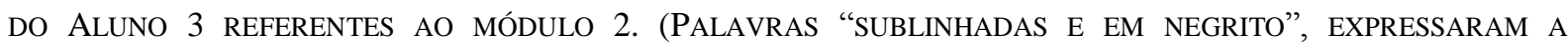
CONSTRUÇÃO DE CONHECIMENTOS ADEQUADAMENTE E COM MUDANÇAS SIGNIFICATIVAS; PALAVRAS EM "ITÁLICO E NEGRITO" INDICARAM RESPOSTAS QUE NÃO UTILIZARAM OS CONCEITOS CORRETOS, A PARTIR DOS PADRÕES CIENTÍFICOS). 
QUADRO 33. ACOMPANHAMENTO INDIVIDUAL NA CONSTRUÇÃO DE CONHECIMENTOS CONCEITUAIS E COGNITIVOS

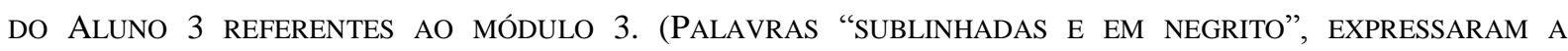
CONSTRUÇÃO DE CONHECIMENTOS ADEQUADAMENTE E COM MUDANÇAS SIGNIFICATIVAS; PALAVRAS EM "ITÁLICO E NEGRITO" INDICARAM RESPOSTAS QUE NÃO UTILIZARAM OS CONCEITOS CORRETOS, A PARTIR DOS PADRÕES CIENTÍFICOS). 


\section{LISTA DE TABELAS}

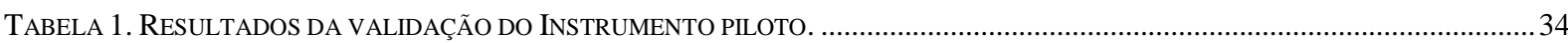

TABELA 2. DECODIFICAÇÕES DAS RESPOSTAS DOS ALUNOS REFERENTES À QUESTÃO 1 DO INSTRUMENTO PILOTO. .........................51

TABELA 3. DECODIFICAÇÕES DAS RESPOSTAS DOS ALUNOS REFERENTES À QUESTÃo 1 DO INSTRUMENTO PILOTO. .........................55

TABELA 4. DECODIFICAÇÕES DAS RESPOSTAS DOS ALUNOS REFERENTES A QUESTÃo 2 DO INSTRUMENTO PILOTO. .........................60

TABELA 5. DECODIFICAÇÕES DAS RESPOSTAS DOS ALUNOS REFERENTES À QUESTÃO 3 DO INSTRUMENTO PILOTO. .........................65

TABELA 6. DECODIFICAÇÕES DAS RESPOSTAS DOS ALUNOS REFERENTES À QUESTÃO 4 DO INSTRUMENTO PILOTO. .........................70

TABELA 7. DECODIFICAÇÕES DAS RESPOSTAS DOS ALUNOS REFERENTES À QUESTÃO 5 DO INSTRUMENTO PILOTO. .........................74

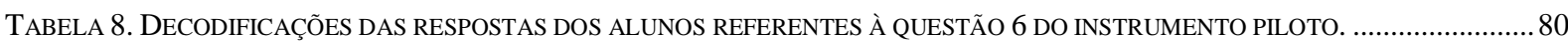

TABELA 9. DECODIFICAÇÕES DAS RESPOSTAS DOS ALUNOS REFERENTES À QUESTÃo 8 DO INSTRUMENTO PILOTO. .........................90

TABELA 10. DECODIFICAÇÕES DAS RESPOSTAS DOS ALUNOS REFERENTES À QUESTÃO 9 DO INSTRUMENTO PILOTO. .......................95

TABELA 11. RENDIMENTOS DAS QUESTÕES REFERENTES AO INSTRUMENTO PILOTO...................................................................97

TABELA 12. RESULTADOS DA VALIDAÇÃO DO INSTRUMENTO DIAGNÓSTICO............................................................................. 101

TABELA 13. CLASSIFICAÇãO DAS QUESTÕES DOS DEMAIS INSTRUMENTOS APLICADOS NA SEQUÊNCIA. .........................................101

TABELA 14. CATEGORIZAÇÃO DAS RESPOSTAS DOS ALUNOS REFERENTES À QUESTÃO 1 (I) DO INSTRUMENTO 3 ..........................105

TABELA 15. CATEGORIZAÇÃO DAS RESPOSTAS DOS ALUNOS REFERENTES À QUESTÃO 1 (II) DO INSTRUMENTO 3 .........................106

TABELA 16. CATEGORIZAÇ̃̃O DAS RESPOSTAS DOS ALUNOS REFERENTES À QUESTÃO 1 (III) DO INSTRUMENTO 3 .......................107

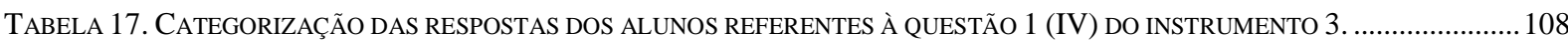

TABELA 18. CATEGORIZAÇÃO DAS RESPOSTAS DOS ALUNOS REFERENTES À QUESTÃO 1 (V) DO INSTRUMENTO 3........................109

TABELA 19. CATEGORIZAÇÃO DAS RESPOSTAS DOS ALUNOS REFERENTES À QUESTÃO 1 (VI) DO INSTRUMENTO 3 .......................110

TABELA 20. CATEGORIZAÇÃO DAS RESPOSTAS DOS ALUNOS REFERENTES À QUESTÃO 2 DO INSTRUMENTO 3...............................113

TABELA 21. CATEGORIZAÇ̃̃O DAS RESPOSTAS DOS ALUNOS REFERENTES À QUESTÃO 3 DO INSTRUMENTO 3 ...............................116

TABELA 22. CATEGORIZAÇ̃̃O DAS RESPOSTAS DOS ALUNOS REFERENTES À QUESTÃO 4 DO INSTRUMENTO 3 ................................118

TABELA 23. CATEGORIZAÇão DAS RESPOSTAS DOS ALUNOS REFERENTES À QUESTÃO 5 (A) DO INSTRUMENTO 3........................120

TABELA 24. CATEGORIZAÇÃO DAS RESPOSTAS DOS ALUNOS REFERENTES À QUESTÃO 5 (B) DO INSTRUMENTO 3..........................122

TABELA 25. CATEGORIZAÇÃO DAS RESPOSTAS DOS ALUNOS REFERENTES À QUESTÃO 6 DO INSTRUMENTO 3.................................124

TABELA 26. CATEGORIZAÇÃO DAS RESPOSTAS DOS ALUNOS REFERENTES À QUESTÃO 7 DO INSTRUMENTO 3...............................126

TABELA 27. CATEGORIZAÇÃO DAS RESPOSTAS DOS ALUNOS REFERENTES À QUESTÃO 8 DO INSTRUMENTO 3 ...............................128

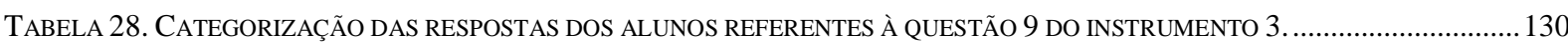

TABELA 29. CATEGORIZAÇÃO DAS RESPOSTAS DOS ALUNOS REFERENTES À QUESTÃO 10 DO INSTRUMENTO 3..............................132

TABELA 30. CATEGORIZAÇÃO DAS RESPOSTAS DOS ALUNOS REFERENTES À QUESTÃO 11 DO INSTRUMENTO 3..............................135

TABELA 31. CATEGORIZAÇÃO DAS RESPOSTAS DOS ALUNOS REFERENTES À QUESTÃo 1 (EXEMPLOS) DO INSTRUMENTO 4..........137

TABELA 32. CATEGORIZAÇÃO DAS RESPOSTAS DOS ALUNOS REFERENTES À QUESTÃO 1 (JUSTIFICATIVAS) DO INSTRUMENTO 4. . 138

TABELA 33. CATEGORIZAÇÃO DAS RESPOSTAS DOS ALUNOS REFERENTES À QUESTÃO 2 DO INSTRUMENTO 4................................140

TABELA 34. CATEGORIZAÇÃO DAS RESPOSTAS DOS ALUNOS REFERENTES À QUESTÃO 3 DO INSTRUMENTO 4 ................................141

TABELA 35. CATEGORIZAÇÃO DAS RESPOSTAS DOS ALUNOS REFERENTES À QUESTÃO DE SÍNTESE DO INSTRUMENTO 7 ...............143

TABELA 36. CATEGORIZAÇÃO DAS RESPOSTAS DOS ALUNOS REFERENTES À QUESTÃO 1 DO INSTRUMENTO 9................................147

TABELA 37. CATEGORIZAÇÃO DAS RESPOSTAS DOS ALUNOS REFERENTES À QUESTÃO 2 (A) DO INSTRUMENTO 9........................150

TABELA 38. NÚMERO DE ALUNOS CATEGORIAS REFERENTES À QUESTÃO 2 (B) DO INSTRUMENTO 9...........................................151

TABELA 39. CATEGORIZAÇÃO DAS RESPOSTAS DOS ALUNOS REFERENTES À QUESTÃO 2 (C) DO INSTRUMENTO 9.........................152

TABELA 40. CATEGORIZAÇão DAS RESPOSTAS DOS ALUNOS REFERENTES À QUESTÃO DE SÍNTESE DO INSTRUMENTO 10..............154

TABELA 41. CATEGORIZAÇÃO DAS RESPOSTAS DOS ALUNOS REFERENTES À QUESTÃO 1 (A) DO INSTRUMENTO 12 ......................159

TABELA 42. CATEGORIZAÇÃO DAS RESPOSTAS DOS ALUNOS REFERENTES À QUESTÃO 1 (B) DO INSTRUMENTO 12 ......................160

TABELA 43. CATEGORIZAÇão DAS RESPOSTAS DOS ALUNOS REFERENTES À QUESTÃO 2 (A) DO INSTRUMENTO 12.....................162 
TABEla 44. CATEGORIZAÇÃO DAS RESPOSTAS DOS ALUNOS REFERENTES À QUESTÃo 2 (B) DO INSTRUMENTO 12.

TABELA 45. CATEGORIZAÇÃO DAS RESPOSTAS DOS ALUNOS REFERENTES À QUESTÃO 2 (C) DO INSTRUMENTO 12.

TABELA 46. CATEGORIZAÇ̃̃o DAS RESPOSTAS DOS ALUNOS REFERENTES À QUESTÃo 3 (I) DO INSTRUMENTO 12.

TABELA 47. CATEGORIZAÇÃO DAS RESPOSTAS DOS ALUNOS REFERENTES À QUESTÃO 3 (II) DO INSTRUMENTO 12 ......................167

TABELA 48. CATEGORIZAÇÃO DAS RESPOSTAS DOS ALUNOS REFERENTES À QUESTÃO 3 (III) DO INSTRUMENTO 12 ......................168

TABELA 49. CATEGORIZAÇÃO DAS RESPOSTAS DOS ALUNOS REFERENTES À QUESTÃo 1 (I) DO INSTRUMENTO 13.........................171

TABELA 50. CATEGORIZAÇÃO DAS RESPOSTAS DOS ALUNOS REFERENTES À QUESTÃO 1 (II) DO INSTRUMENTO 13......................171

TABELA 51. CATEGORIZAÇÃO DAS RESPOSTAS DOS ALUNOS REFERENTES À QUESTÃO 1 (III) DO INSTRUMENTO 13.....................173

TABELA 52. CATEGORIZAÇÃO DAS RESPOSTAS DOS ALUNOS REFERENTES À QUESTÃO 1 (IV) DO INSTRUMENTO 13.....................174

TABELA 53. NÚMERO DE ALUNOS POR CATEGORIAS REFERENTES À QUESTÃO 1 (V) DO INSTRUMENTO 13...................................175

TABELA 54. CATEGORIZAÇÃO DAS RESPOSTAS DOS ALUNOS REFERENTES À QUESTÃo 1 (VI) DO INSTRUMENTO 13......................176

TABELA 55. CATEGORIZAÇÃO DAS RESPOSTAS DOS ALUNOS REFERENTES À QUESTÃO 1 (VII) DO INSTRUMENTO 13...................177

TABELA 56. CATEGORIZAÇÃO DAS RESPOSTAS DOS ALUNOS REFERENTES À QUESTÃO 1 (VIII) DO INSTRUMENTO 13...................178

TABELA 57. CATEGORIZAÇÃO DAS RESPOSTAS DOS ALUNOS REFERENTES À QUESTÃO 2 (A) DO INSTRUMENTO 13......................180

TABELA 58. CATEGORIZAÇÃO DAS RESPOSTAS DOS ALUNOS REFERENTES À QUESTÃO 2 (B) DO INSTRUMENTO 13.......................181

TABELA 59. CATEGORIZAÇÃO DAS RESPOSTAS DOS ALUNOS REFERENTES À QUESTÃo 3 (A) DO INSTRUMENTO 13......................182

TABELA 60. CATEGORIZAÇÃO DAS RESPOSTAS DOS ALUNOS REFERENTES À QUESTÃo 3 (B) DO INSTRUMENTO 13......................183

TABELA 61. CATEGORIZAÇÃO DAS RESPOSTAS DOS ALUNOS REFERENTES À QUESTÃO 4 (A) DO INSTRUMENTO 13......................185

TABELA 62. CATEGORIZAÇÃO DAS RESPOSTAS DOS ALUNOS REFERENTES À QUESTÃO 4 (B) DO INSTRUMENTO 13......................186

TABELA 63. CATEGORIZAÇÃO DAS RESPOSTAS DOS ALUNOS REFERENTES À QUESTÃO 5 DO INSTRUMENTO 13..............................188

TABELA 64. CATEGORIZAÇÃO DAS RESPOSTAS DOS ALUNOS REFERENTES À QUESTÃo 6 (A) DO INSTRUMENTO 13 .......................190

TABELA 65. CATEGORIZAÇÃO DAS RESPOSTAS DOS ALUNOS REFERENTES À QUESTÃo 6 (B) DO INSTRUMENTO 13......................191

TABELA 66. CATEGORIZAÇÃO DAS RESPOSTAS DOS ALUNOS REFERENTES À QUESTÃo 6 (C) DO INSTRUMENTO 13 .......................192

TABela 67. RelaÇÕES COGNITIVAS ENTRE OS NíveIS DAS RESPOSTAS dOS ALUNOS E AS HABILIDADES MOBILIZADAS NA

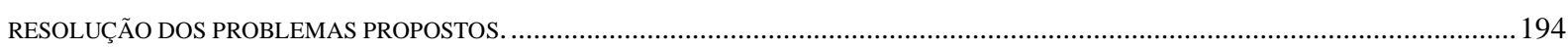

TABELA 68. HABILIDADES, NÍVEIS COGNITIVOS E RENDIMENTO DOS ALUNOS NAS SITUAÇÕES-PROBLEMA. .................................196 


\section{LISTA DE SIGLAS}

UNESCO: Organizações das Nações Unidas para Educação, Ciência e Cultura

LDB: Lei de Diretrizes e Bases da Educação Nacional

ENEM: Exame Nacional do Ensino Médio

EPA: Educação Popular em Ação

PCN: Parâmetros Curriculares Nacionais

PCN+: Parâmetros Curriculares Nacionais mais

IF: Instituto Federal de Educação, Ciência e Tecnologia

PCNEM: Parâmetro Curricular Nacional do Ensino Médio

PCNEM+: Parâmetro Curricular Nacional do Ensino Médio mais

INEP: Instituto Nacional de Estudos e Pesquisas Educacionais Anísio Teixeira

SAEB: Sistema Nacional de Avaliação da Educação Básica

PROUNI: Programa Universidade para Todos

DCNEM: Diretrizes Curriculares Nacionais do Ensino Médio

SISU: Sistema de Seleção Unificada

EJA: Educação de Jovens e Adultos

ENCCEJA: Exame Nacional para Certificação de Competências de Jovens e Adultos

ONG: Organização não governamental

GEPEQ: Grupo de Pesquisa em Ensino de Química

VUNESP: Vestibular da Universidade Estadual Paulista

UNICAMP: Universidade de Campinas

COMVEST: Comissão Permanente para os Vestibulares 
APRESENTAÇÃ

CAPÍTULO 1 - FUNDAMENTAÇÃO TEÓRICA ...................................................................9

1.1. COMPETÊNCIAS E HABILIDADES NA EDUCAÇÃO .....................................................

1.2. COMPETÊNCIAS E HABILIDADES NO ENEM………………..................................

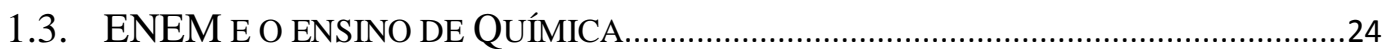

CAPÍTULO 2 - METODOLOGIA..................................................................................... 31

2.1 ELABORAÇÃO DE SITUAÇÕES-PROBLEMA............................................................

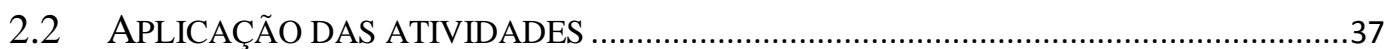

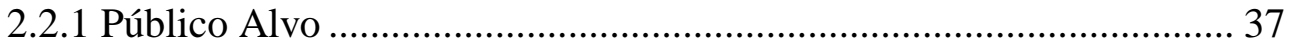

2.2.2 Descrição da aplicação das atividades ............................................... 39

2.3 INSTRUMENTOS DE COLETA DE DADOS …………..............................................

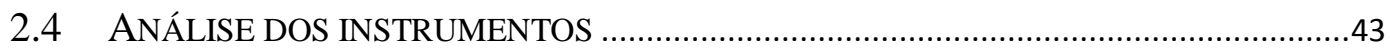

CAPÍTULO 3: RESULTADOS..............................................................................................5 53

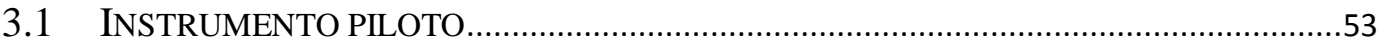

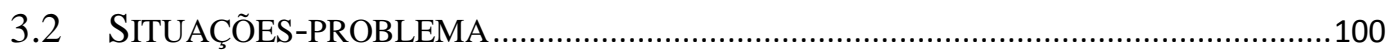

3.2.1. Resultados das aplicações dos instrumentos................................... 104

3.2.1.1. Instrumento 3 - Instrumento diagnóstico de verificação de habilidades específicas.

3.2.1.2. Instrumento 4 - Instrumento de coleta de dados sobre ideias iniciais a respeito de transformações químicas.

3.2.1.3. Instrumento 7 - Instrumento de coleta de dados sobre a síntese dos alunos a respeito de toda discussão estabelecida.

3.2.1.4. Instrumento 9 - Reflexões sobre a Lei de Conservação das massas estabelecida por Lavoisier.

3.2.1.5. Instrumento 10 - Síntese do conteúdo descrita pelos alunos.......................... 153

3.2.1.6. Instrumento 12 - Reflexões sobre a Lei de Conservação das massas estabelecida por Lavoisier e a Lei das Proporções de Proust.

3.2.1.7 Instrumento 13 - instrumento de verificação de conhecimentos e habilidades construídas.

3.2.2. Resultados das aplicações por aluno 203

CONSIDERAÇÕES FINAIS 222

DOCUMENTOS 225

BIBLIOGRAFIA 226 
APRESENTAÇÃO

Graduada no ano de 2010 em Licenciatura em Química pela Universidade de São Paulo retornei à minha cidade de origem, Itu, e iniciei minha jornada em sala de aula. Até o momento lecionei na rede pública estadual e municipal e também na rede particular de ensino. Em 2012, juntamente com meu esposo e mais duas professoras, assumimos a coordenação de um projeto social que já existia há cinco anos na cidade, o Cursinho Popular Comunitário.

Em uma parceria com a Fatec de Itu, inicialmente conseguimos abrir duas salas de aulas com aproximadamente 60 alunos em cada. No ano seguinte, para formalizar esta parceria, fundamos uma ONG e regularizamos o cursinho como um projeto dentro desta organização. Ao longo desses anos, o número de alunos sempre aumentou, e chegamos a ter quatro salas de aulas funcionando, com um grupo de 10 à 12 professores voluntários. Alunos inclusive de cidades vizinhas, sempre procuraram participar do projeto. Diante da demanda e realizando algumas pesquisas internas percebemos que grande parte dos alunos procuram o cursinho para se preparar para o ENEM. Entretanto, como o perfil dos alunos sempre se manteve bastante heterogêneo, sendo a maioria de escolas públicas, mas também alguns de escolas técnicas e pouquíssimos particulares, pois todos têm acesso à participação, encontramos algumas dificuldades no ensino. Em complemento a tais dificuldades, o projeto é desenvolvido somente aos sábados, o que limita um pouco o tempo de aprendizagem, mas temos um fator muito favorável, a flexibilidade da grade de ensino. Nesse tempo de funcionamento do projeto, foram realizadas muitas Oficinas e Projetos Pedagógicos, o que sempre estimularam os alunos e contribuíram de forma significativa na aprendizagem. Foi nesse cenário que, como professora de Química do Cursinho, me interessei em desenvolver e aplicar uma sequência de ensino que pudesse problematizar um tema de interesse da Química e ao mesmo tempo contribuísse no desenvolvimento e aprimoramentos das habilidades cognitivas exigidas aos alunos pelo ENEM.

A concepção de um ensino por competências e desenvolvimento de habilidades se consolidou no sistema educacional brasileiro através da Lei de Diretrizes e Bases da Educação Nacional (LDB) - Lei 9394 de 1996. Sua adoção refletiu uma tendência global de alinhamento aos termos da Conferência Mundial de Educação para Todos, realizada em Jomtien, na Tailândia, em 1990, organizada pela UNESCO. A partir da LDB, o ensino por competências e habilidades se desdobrou nos Parâmetros Curriculares Nacionais (PCN) e no 
Exame Nacional do Ensino Médio (ENEM). Baseando-se nesses documentos popularizou-se a ideia de um ensino por competências e habilidades nos sistemas de ensino.

Tal processo se intensificou em 2008, quando o ENEM deixou de ser somente um exame diagnóstico do ensino médio para se tornar o maior processo seletivo de acesso ao ensino superior do Brasil. Os processos seletivos para ingresso no ensino superior público, os chamados vestibulares, têm grande poder de determinação dos currículos da Educação Básica no Brasil. Dessa forma, o ENEM, ao se tornar a única porta de acesso às Instituições Federais de Educação Superior (IFES), se tornou uma referência para a organização dos sistemas escolares e, consequentemente, passou a influenciar diretamente a atuação docente em sala de aula. Por esse motivo, passou a ser comum a associação da qualidade do ensino de uma instituição escolar ao desempenho no ENEM.

Entretanto, o ensino por competências e habilidades permanece sendo um desafio para a maior parte dos educadores. O cotidiano da sala de aula compartimentado em disciplinas, currículos "conteudistas", bem como materiais didáticos e paradidáticos que, mesmo se referindo às competências e habilidades, pouco exploram seu potencial pedagógico, traçam um panorama que dificulta a apropriação dessa concepção pedagógica.

No caso específico do ensino de Química, agora redefinido como um campo da área de Ciências da Natureza, o desafio do ensino por competências e habilidades é ainda maior diante da complexidade e abstração dos conceitos químicos. Os alunos entenderem os fenômenos, construírem explicações e utilizarem a linguagem própria dessa ciência é uma tarefa bastante difícil. Para os professores, a falta de formação inicial e também continuada criam obstáculos que devem ser superados.

Logo, é necessário se pensar nas questões que mediam a aprendizagem desse aluno, ou seja, nas estratégias empregadas na construção do conhecimento. $\mathrm{O}$ ensino por meio de questões abertas e problemas pode aliar conhecimentos e competências, uma vez que exige do estudante uma postura ativa na busca de respostas. Na tentativa de solucionar os problemas, os alunos deverão mobilizar conhecimentos já adquiridos e habilidades cognitivas como comparação, classificação, controle de variáveis, formulação de hipóteses, dentre outras, para que o estudante possa apresentar uma solução (POZO, 1998).

Neste sentido, certas atividades experimentais de natureza investigativa podem ser de grande valia. Tais propostas de aulas fundamentam-se na resolução de problemas, na construção de hipóteses, na investigação de conhecimentos do aluno, na coleta de dados e na 
construção de conclusões a partir da atividade prática realizada (SUART E MARCONDES, 2008).

Considerando que os estudantes que procuram o cursinho estão interessados, em sua maioria, em realizar as provas do ENEM como forma de ingresso em Universidades e Institutos Federais. E também o fato do Cursinho Popular ser um espaço não formal, no qual existe uma flexibilidade na grade de conteúdos e também, a partir de nossa experiência em sala de aula percebendo as dificuldades conceituais e de raciocínio dos alunos, o propósito dessa pesquisa foi investigar: Como atividades problematizadoras no ensino de Química podem promover o desenvolvimento de competências e habilidades apresentadas na matriz de referência do ENEM?

- Para isso, o objetivo geral deste trabalho foi verificar como uma sequência de atividades problematizadoras, proposta em um cursinho popular pode, contribuir para o desenvolvimento de habilidades específicas do ensino de Química, presentes na Matriz de Referência de Ciências da Natureza e suas Tecnologias (BRASIL, 2009), e de habilidades de alta ordem cognitiva que se relacionam diretamente com as habilidades do ENEM.

A partir do objetivo geral ramificaram-se alguns objetivos específicos:

- Contribuir para o desenvolvimento de práticas pedagógicas para o ensino de Química em nível de Ensino Médio.

- Desenvolver e aplicar uma sequência de atividades que problematizem o ensino de Química através do desenvolvimento de habilidades e competências;

- Analisar cada uma das atividades aplicadas por meio das situações problematizadoras procurando evidenciar, de forma geral, quais são as principais dificuldades apresentadas pelos alunos e as habilidades desenvolvidas através da resolução das questões.

- Realizar um acompanhamento por aluno ao longo de toda a sequência de atividades para investigar possíveis evoluções ou superações das dificuldades conceituais e o desenvolvimento ou aprimoramento das habilidades cognitivas utilizadas para a resolução das questões.

A hipótese principal do nosso trabalho é que uma sequência que problematize através de atividades experimentais, reflexões coletivas e individuais, relatos escritos do 
conhecimento construído e problemas propostos como reflexão do conhecimento, podem contribuir para o desenvolvimento de competências e habilidades exigidas pelo ENEM na área de ciências da natureza.

O material de pesquisa foi coletado por meio de questionários e sínteses produzidos pelos alunos. A análise dos dados seguiu o método da Análise de Conteúdos proposto por Bardin (1977), apoiando-se em referenciais teóricos que investigam o desenvolvimento de habilidades cognitivas de alta e baixa ordem para a proposição de categorias (SUART E MARCONDES, 2008; ZOLLER, 1993). 


\section{CAPÍTULO 1 - FUNDAMENTAÇÃO TEÓRICA}

Como fundamentação teórica do nosso trabalho, neste capítulo primeiramente realizamos um recorte conceitual sobre Competências e Habilidades. Em seguida apresentamos os principais documentos oficiais que se relacionaram e influenciaram as concepções do maior exame de larga escala aplicado no Brasil, o Exame Nacional do Ensino Médio, ENEM. Também descrevemos brevemente o ENEM desde sua criação, passando pela reestruturação de 2009 até o modelo atual. E por fim, fizemos uma revisão bibliográfica sobre o ensino de Química e o ENEM.

\subsection{Competências e habilidades na Educação}

Partilhando de algumas ideias apresentadas por Macedo (2012), entendemos que a educação, mesmo passando por processos de intensas mudanças, ainda é empregada como um "veículo de controle social” (Ibid., p. 721) com interesse no preparo do indivíduo para o mercado de trabalho e também para atender necessidades imediatas da população.

Entretanto, Freire (1999) nos direciona a pensar em um ensino "libertador", ou seja, em que o aluno possa ser capaz de participar de forma ativa do seu processo de ensino e aprendizagem, a investir em sua formação não somente para o trabalho, mas também como um cidadão reflexivo que tenha o poder de escolha e decisão, e atrelar os conhecimentos de ciências de forma integrada à realidade e às ações cotidianas dos indivíduos.

Com o propósito de oferecer não somente uma nova organização curricular mas também uma forma de desenvolver o ensino atrelado ao conhecimento prático, as primeiras ideias de um ensino por competência, instituíram-se no Brasil entre os anos de 1960 e 1970 (ROPÉ e TANGUY, 1997).

Inicialmente atrelado a um ensino profissionalizante, uma das principais ideias das competências era a de qualificação do indivíduo para o mercado de trabalho, "qualificação acrescida de um saber-fazer" (RICARDO, 2010, p. 606), que incluía atitudes do empregado no ambiente de trabalho. Assim, a escola torna-se o melhor meio de qualificação para o trabalho (RICARDO, 2010).

Para Apple (1995), o ensino por competência, por vir a resultar em um esvaziamento do espaço do conteúdo dos diferentes conhecimentos em relação a uma preocupação de como desenvolver a atividade de ensino, valoriza, segundo o autor, o desempenho, o resultado e a eficiência do aluno. 
Complementando as críticas apresentadas, o propósito de um ensino por competência era o de formar uma escola mais voltada à comunidade. Entretanto, ainda existia a preocupação em capacitar o aluno para inseri-lo no mundo atual, ou seja, em diferentes contextos de trabalho, apresentados a partir de constantes mudanças.

Mas será que conseguimos delimitar o ensino e o papel das competências somente a critérios profissionais?

A sua consolidação no ensino tem-se alterado diante das diversas mudanças ocorridas ao longo desses anos, em que a demanda do ensino não se remete prioritariamente ao mercado de trabalho (RICARDO, 2010). A forma com que se estava trabalhando com as competências vinculadas à um ensino para obtenção de rendimento, tanto em relação ao professor quanto ao aluno, não estava propiciando um desenvolvimento favorável da competências. E tanto os documentos oficias quanto alguns teóricos sugerem modificações do ensino por competência já na essência de seu termo. Os conceitos de habilidades e competências podem ser encontrados em alguns documentos oficiais, conforme será apresentado adiante nesta dissertação.

Segundo Zabala (1998), o professor precisa compreender e saber trabalhar com diversidade em sala de aula. Assim, uma aula organizada e desenvolvida somente a partir de conteúdos não é suficiente para que ocorra a aprendizagem. Para o autor, é preciso relacionar conhecimentos já dominados por parte dos alunos com os conhecimentos a serem construídos, de forma que o aluno possa aprendê-los.

Nesse momento, podemos dizer que está ocorrendo uma aprendizagem significativa (AUSUBEL, 2003). Ou seja, o aluno, com a ajuda do professor, consegue estabelecer relações entre seus conhecimentos prévios e os novos apresentados em sala de aula. Assim, planejar como os conceitos serão construídos em sala de aula torna-se fundamental no processo de construção de novos conhecimentos.

Os professores precisam se sentir responsáveis pela formação de seus alunos. Para Perrenoud (1999), os professores que assumem o ensino por competências se apropriam de responsabilidades na escolha de práticas sociais.

Para Perrenoud (1999), trabalhar com competências significa que o aluno irá mobilizar conhecimentos. Para o autor, competência é a "capacidade de agir eficazmente em um determinado tipo de situação, apoiada em conhecimentos, mas sem limitar-se a eles" (PERRENOUD, 1999, p. 07). As competências devem ser construídas e adquiridas. E o aluno 
deverá saber mobilizar conhecimentos também de ordem disciplinar, conseguindo transpor os conhecimentos de diferentes áreas:

Se esse aprendizado não for associado a uma ou mais práticas sociais, suscetíveis de ter um sentido para os alunos, será rapidamente esquecido, considerado como um dos obstáculos a serem vencidos para conseguir um diploma, e não como uma competência a ser assimilada para dominar situações da vida (PERRENOUD, 1999, p. 11).

Também torna-se necessário conceituar habilidade, e segundo o autor, trata-se de uma série de procedimentos mentais que o indivíduo aciona para resolver uma situação real, onde ele precisa tomar uma decisão (PERRENOUD, 2000). Alguns anos mais tarde ele amplia o conceito de competência:

Competência é a aptidão para enfrentar, de modo eficaz, uma família de situações análogas, mobilizando a consciência, de maneira cada vez mais rápida, pertinente e criativa, múltiplos recursos cognitivos: saberes, capacidades, microcompetências, informações, valores, atitudes, esquemas de percepção, de avaliação e de raciocínio (PERRENOUD, 2000, p. 54).

Dois autores dialogam com as ideias de Perrenoud sobre competência e ainda propõem possibilidades de ensino. Zabala e Arnau (2010) possuem uma interpretação a respeito dos termos muito semelhantes a de Perrenoud. "Ser competente é, ao agir, mobilizar, de forma integrada, conhecimentos e atitudes mediante uma Situação-problema, de forma que a situação seja resolvida com eficácia" (ZABALA E ARNAU, 2010, p. 41) Os autores empregam os princípios do ensino por competência como saída para a resolução de atividades ou situações de seu cotidiano, durante toda a vida. Segundo eles, ao desenvolver competência para resolver Situações-problema presentes em seu cotidiano, o aluno utiliza "componentes atitudinais, conceituais e procedimentais" (ibdem, 2010, p.36). Também para os autores, diferente dos exercícios, os problemas envolvem o planejamento, a tomada de decisões, a análise do contexto, e o desenvolvimento de habilidades e competências.

Em conjunto as ideias articuladas, Macedo (1999) argumenta que os problemas se diferenciam dos exercícios. Para os autores, problema "é aquilo que se enfrenta e cuja solução, já conhecida ou incorporada, não é suficiente, ao menos como conteúdo" (ibidem, p.15). Os problemas precisam ter um caráter surpreendente, estimulante, em que o estudante estará sendo desafiado a resolver conflitos por meio da tomada de decisões e do contexto dos enunciados das questões.

Em complemento, Maceno (2011) argumenta que o ensino está fundamentado na capacidade do sujeito em resolver os problemas, sejam eles pessoais ou sociais. Desta forma, a linguagem é priorizada como meio de construção do conhecimento e aprendizagem, e 
menciona que, através da problematização os alunos serão capazes de justificar, argumentar, comunicar e defender seu ponto de vista.

Por fim, partilhando das ideias de Silva e Felicetti (2014), as Situações-problema precisam ser criadas, inovadas e ter relação com o cotidiano do aluno.

\subsection{Competências e habilidades no ENEM}

Competências e habilidades são termos que, no Brasil, ao serem apropriadas pela legislação, assumiram características singulares. Assim, torna-se necessário um estudo sobre tais apropriações para compreendermos quais os sentidos dados a estes termos no Exame Nacional do Ensino Médio.

A primeira referência aos termos Competência e Habilidade na legislação nacional é da Lei de Diretrizes e Bases de 1996. Os Parâmetros Curriculares Nacionais e, posteriormente, o Exame Nacional do Ensino Médio, consolidaram a concepção de Competência e Habilidade lançada pela LDB. Concepção esta que será abordada de forma distinta a partir de 2004, com a troca de governo federal, como bem representam as Diretrizes Curriculares Nacionais e o chamado Novo ENEM.

A Constituição de 1988, conhecida como a constituição dos direitos sociais, estabeleceu os fundamentos da educação escolar pautados nos princípios da qualidade, gratuidade e gestão democrática, deixando, porém, indicado que as diretrizes da educação nacional seriam estabelecidas posteriormente. Assim, nesse mesmo ano, se instalou na Câmara Federal um processo de elaboração do projeto de lei que estabelecesse as diretrizes e bases da educação nacional. Um longo processo se instaurou até a criação da LDB. Segundo Demerval Saviani (1999), o projeto de LDB construído pelo Governo Federal refletia o processo internacional de reorganização da educação. Sem dialogar ou respeitar todo o trâmite do projeto anteriormente construído na Câmara ao longo de oito anos, o Governo Federal pressiona e consegue aprovar sua versão da LDB em 1996 como Lei 9.394. Toda essa discussão se iniciou com a Conferência Mundial da Educação para Todos, organizada em 1990 pela UNESCO. A Conferência Mundial teve grande influência nos novos rumos tomados pela educação brasileira.

No ano seguinte à Conferência, a UNESCO convocou uma Comissão Internacional com representantes de todas as partes do mundo. A comissão elaborou um relatório sob a coordenação de Jacques Delors, publicado como o livro - Educação: Um Tesouro a Descobrir (DELORS, 2010). Segundo esse relatório, o século XXI apresentava desafios que somente a 
educação poderia superar. Mas não a educação pautada em conteúdos apenas, que forma pessoas bem informadas, mas sim uma educação ativa, capaz de formar cidadãos competentes para intervir e criar soluções para os desafios que se apresentam. Ou seja, uma educação onde quem aprende não é passivo, mas sim ativo, na medida em que desenvolve habilidades que o tornarão competente para intervir e melhorar sua própria realidade (DELORS, 2010).

Com o intuito de viabilizar a organização do currículo para dar conta de promover a todos a formação básica comum, a LDB estabelece diretrizes e bases empregadas na educação. A forma de organização do documento define questões importantes como: os princípios e fins da educação nacional, os direitos e deveres à educação, a organização da educação nacional, dentre outros.

Segundo descrito no artigo 22 do documento, a "educação básica tem por finalidades desenvolver o educando, assegurar lhe a formação comum indispensável para o exercício da cidadania e fornecer-lhe meios para progredir no trabalho e em estudos posteriores." Assim, o ensino não deveria ser apenas formal, pautado na transmissão e acúmulo de conhecimentos. E sim, por conhecimentos gerados por meio de vivência a partir de certas Situações-problema (BRASIL, 1996).

De acordo com o Art. $9^{\circ}$ do Título IV, verificam-se como alguns deveres à educação: elaborar o Plano Nacional de Educação; estabelecer competências e diretrizes para a educação Infantil, o Ensino Fundamental e o Ensino Médio, que nortearão os currículos e seus conteúdos mínimos, de modo a assegurar formação básica comum; coletar, analisar e disseminar informações sobre a educação; assegurar processo nacional de avaliação do rendimento escolar no Ensino Fundamental, Médio e Superior, em colaboração com os sistemas de ensino, objetivando a definição de prioridades e a melhoria da qualidade do ensino; sendo que na estrutura educacional, haverá um Conselho Nacional de Educação, com funções normativas e de supervisão e atividade permanente, criado por lei. (BRASIL, 1996).

O Art. $23^{\circ}$ acrescenta sugestões à forma de organização da educação nacional: A educação básica poderá organizar-se em séries anuais, períodos semestrais, ciclos, alternância regular de períodos de estudos, grupos não seriados, com base na idade, na competência e em outros critérios, ou por forma diversa de organização, sempre que o interesse do processo de aprendizagem assim o recomendar. (BRASIL, 1996).

Foi na LDB o primeiro momento em que o termo competência tornou-se palavra de ordem na educação brasileira. No campo do trabalho, o termo competência substitui a ideia de qualificação, no campo da educação substitui as ideias de saberes e conhecimentos. É 
importante ressaltar que a pedagogia voltada para o ensino por competências não descarta a importância e necessidade de se enfocarem os conteúdos, pois não se trata de um esvaziamento de conceitos, mas uma forma de repensar sua aprendizagem.

Em 1997, ano seguinte à aprovação da LDB, foram apresentados os Parâmetros Curriculares Nacionais (PCN). Segundo o Ministro da Educação, "os parâmetros têm o objetivo de auxiliar a criança brasileira a ter pleno acesso aos recursos culturais relevantes para que ela possa conquistar a sua cidadania, desenvolvendo-se como cidadão participativo, reflexivo e autônomo, conhecedor de seus direitos e deveres" (BRASIL, 1997).

Dentre os propósitos que nortearam os PCN, encontram-se o domínio de conhecimentos, habilidades e capacidades mais amplas para que os alunos possam compreender o seu cotidiano e defender seus interesses. No documento é reconhecida a importância da participação dos alunos na construção de seus conhecimentos e a intervenção do professor na aprendizagem de conteúdo. Desta forma, o documento seria um suporte capaz de incentivar a elaboração de projetos educativos e o de planejamento das aulas, que consiste na reflexão sobre as práticas educativas, na análise do material didático e no desenvolvimento de capacidades necessárias a formação do indivíduo.

O centro das atividades não seria nem o professor, que passará a organizar as situações de aprendizagem, nem os conteúdos, mas sim o próprio aluno como ser ativo durante seu processo de aprendizagem (BRASIL,1997). A orientação proposta nos Parâmetros Curriculares Nacionais reconhece:

a importância da participação construtiva do aluno e, ao mesmo tempo, da intervenção do professor para a aprendizagem de conteúdos específicos que favoreçam o desenvolvimento das capacidades necessárias à formação do indivíduo. Ao contrário de uma concepção de ensino e aprendizagem como um processo que se desenvolve por etapas, em que a cada uma delas o conhecimento é "acabado", o que se propõe é uma visão da complexidade e da provisoriedade do conhecimento. De um lado, porque o objeto de conhecimento é "complexo" de fato e reduzi-lo seria falsificá-lo; de outro, porque o processo cognitivo não acontece por justaposição, senão por reorganização do conhecimento. É também "provisório", uma vez que não é possível chegar de imediato ao conhecimento correto, mas somente por aproximações sucessivas que permitem sua reconstrução (BRASIL, 1997, p. 37).

Após muitos debates e reuniões, um novo documento foi elaborado. O ponto de partida foi a LDB, seguida dos PCN. Foi elaborado, em 1999, o PCNEM (Parâmetro Curriculares Nacionais para o Ensino Médio). O documento estabelecido para o Ensino Médio "propõe uma aprendizagem permanente, com uma formação continuada, para a construção da cidadania e dos processos sociais através da ética; e o desenvolvimento das competências básicas que permitam estimular o pensamento crítico e a capacidade intelectual do estudante". As mudanças curriculares estão pautadas principalmente na necessidade de 
desenvolvimento "de capacidades de pesquisar, buscar informações, analisá-las e selecionálas; a capacidade de aprender, criar, formular, ao invés do simples exercício de memorização" (BRASIL, 2000a). Ainda em relação à finalidade dos PCNEM destacam-se que "na perspectiva da nova Lei, o Ensino Médio, como parte da educação escolar, deverá vincular-se ao mundo do trabalho e à prática social" (Art. $1^{\circ}$ e $2^{\circ}$ da Lei no 9.394/96).

No final do governo de Fernando Henrique Cardoso foram criadas as Orientações Curriculares Complementares aos Parâmetros Curriculares Nacionais (PCNEM+). Nas Orientações Curriculares as disciplinas estão organizadas em três áreas do conhecimento: Ciências da Natureza e Matemática, Ciências Humanas e Linguagens e Códigos. Sua proposta é articular competências gerais a conhecimentos disciplinares a partir de três competências aplicadas à todas as áreas: 1) representação e comunicação; 2) investigação e compreensão e; 3) contextualização sociocultural. Os Parâmetros também apresentam sugestões de práticas educativas e exemplos de organização dos currículos. Indicam, ainda, como as competências de área do conhecimento se articula com os “temas estruturadores” (BRASIL, 2002).

Conforme descrito no documento, a proposta central dos temas baseia-se no desenvolvimento de conhecimentos de forma articulada com "objetos de estudos, conceitos, linguagens, habilidades e procedimentos próprios" (BRASIL, 2002, p. 93).

As competências gerais apresentadas pelo $\mathrm{PCN}+$ dialogam com as cinco competências gerais do Exame Nacional do Ensino Médio (ENEM): dominar diferentes linguagens, compreender processos, diagnosticar e enfrentar problemas reais, construir argumentações e elaborar proposições solidárias.

Especificamente em relação ao ensino de Química, o PCN+ propõe uma articulação de três pilares, tanto de conhecimentos químicos (transformações químicas, materiais e suas propriedades e modelos explicativos) como de práticas pedagógicas (contextualização, desenvolvimento cognitivo e afetivo e desenvolvimento de competências e habilidades). $\mathrm{O}$ quadro 1 apresenta as relações existentes entre cada uma das competências gerais da área de Ciências da Natureza e as competências específicas da disciplina de Química.

Quadro 1: Relação entre competências gerais e específicas no ensino de Química descritas nos PCN+.

\begin{tabular}{|c|l|}
\hline $\begin{array}{c}\text { Competências gerais da área } \\
\text { de Ciências da Natureza }\end{array}$ & \multicolumn{1}{|c|}{$\begin{array}{c}\text { Competências específicas da disciplina de } \\
\text { Química }\end{array}$} \\
\hline $\begin{array}{c}\text { REPRESENTAÇÃO E } \\
\text { COMUNICAÇÃO }\end{array}$ & $\begin{array}{l}\text { • Símbolos, códigos e nomenclatura de ciências e } \\
\text { tecnologia; } \\
\text { • Articulação dos símbolos e códigos de ciência e } \\
\text { tecnologia; }\end{array}$ \\
Objetivos gerais: a leitura e
\end{tabular}




\begin{tabular}{|c|c|}
\hline $\begin{array}{l}\text { interpretação de códigos, } \\
\text { nomenclaturas e textos } \\
\text { próprios da Química e da } \\
\text { Ciência, a transposição entre } \\
\text { diferentes formas de } \\
\text { representação, a busca de } \\
\text { informações, a produção e } \\
\text { análise crítica de diferentes } \\
\text { tipos de textos; }\end{array}$ & $\begin{array}{l}\text { - Análise e interpretação de textos e outras } \\
\text { comunicações de ciência e tecnologia; } \\
\text { - Elaboração de comunicações; } \\
\text { - Discussão e argumentação de temas de interesse } \\
\text { de ciência e tecnologia. }\end{array}$ \\
\hline $\begin{array}{l}\text { INVESTIGAÇÃO E } \\
\text { COMPREENSÃO } \\
\text { Objetivos gerais: o uso de } \\
\text { ideias, conceitos, leis, modelos } \\
\text { e procedimentos científicos } \\
\text { associados a essa disciplina }\end{array}$ & $\begin{array}{l}\text { - Estratégias para enfrentamento de Situações- } \\
\text { problema; } \\
\text { - Interações, relações e funções: invariantes e } \\
\text { transformações; } \\
\text { - Medidas, quantificações, grandezas e escalas; } \\
\text { - Modelos explicativos e representativos; } \\
\text { - Relações entre conhecimentos disciplinares, } \\
\text { interdisciplinares e interáreas; }\end{array}$ \\
\hline $\begin{array}{l}\text { CONTEXTUALIZAÇÃO } \\
\text { SÓCIO-CULTURAL } \\
\text { Objetivos gerais: a inserção } \\
\text { do conhecimento disciplinar } \\
\text { nos diferentes setores da } \\
\text { sociedade, suas relações com } \\
\text { os aspectos políticos, } \\
\text { econômicos e sociais de cada } \\
\text { época e com a tecnologia e } \\
\text { cultura contemporâneas }\end{array}$ & $\begin{array}{l}\text { - Ciência e tecnologia na história; } \\
\text { - Ciência e tecnologia na cultura contemporânea; } \\
\text { - Ciência e tecnologia na atualidade; } \\
\text { - Ciência e tecnologia, ética e cidadania. }\end{array}$ \\
\hline
\end{tabular}

Fonte: Brasil, 2002.

Também proposto nos PCN+, especificamente no ensino de Química, tendo como foco de estudo as "Transformações Químicas", foram sugeridos nove "temas estruturadores". Dentro de cada tema foram propostas "unidades temáticas", sendo sugeridos alguns dos principais conteúdos a serem abordados e relacionados com os temas. Também, para cada tema foram descritas no documento as "competências gerais que poderiam ser desenvolvidas.

No documento também fica evidenciado a preocupação em trabalhar com situações problemáticas, ou seja,

Não se procura uma ligação artificial entre o conhecimento químico e o cotidiano, restringindo-se a exemplos apresentados apenas como ilustração ao final de algum conteúdo; ao contrário, o que se propõe é partir de situações problemáticas reais e buscar o conhecimento necessário para entendê-las e procurar solucioná-las (BRASIL, 2002, p. 93).

Diversas são as contribuições deste documento à sociedade. Seja enquanto proposta de currículo, como plano de ensino ou como propagação de novos conceitos que favoreçam o 
ensino e a aprendizagem do aluno. Como um todo, o documento apresentou possibilidades de articular conceitos a um ensino por competências. Os "temas estruturadores" para o ensino da Química são alternativas sólidas para a organização do trabalho escolar. Por fim, partilhando das ideias de Oliveira, Mourão e Maciel (2011), o documento ainda se aproxima mais do professor, incentivando o mesmo a deixar de ser somente um executor das orientações curriculares, assumindo papel reflexivo, investigativo e crítico junto com seus aprendizes.

O Exame Nacional do Ensino Médio foi criado em maio de 1998. Instituído pelo MEC (Ministério da Educação e Cultura) e pelo INEP (Instituto Nacional de Estudos e Pesquisas Educacionais), ele é parte do Sistema Nacional de Avaliação da Educação Básica (SAEB). Foi baseado em princípios instituídos pela LDB e pelos PCN's.

Segundo documentos oficiais, de caráter voluntário e individual, trata-se de uma avaliação que tem como propósito central contribuir com a melhoria do ensino, desempenhando primeiramente o objetivo de "avaliar o desempenho do aluno ao término da escolaridade básica, para aferir o desenvolvimento de competências fundamentais ao exercício pleno da cidadania" (MEC, 2002, pg. 5).

Outros objetivos do ENEM, divulgados pelo INEP para o ano de 1999 e ainda em vigência, são:

- $\quad$ oferecer uma referência para que cada cidadão possa proceder a sua auto avaliação com vistas às suas escolhas futuras, tanto em relação ao mercado de trabalho quanto em relação à continuidade dos estudos;

- $\quad$ estruturar uma avaliação da educação básica que sirva como modalidade alternativa ou complementar aos processos de seleção nos diferentes setores do mundo do trabalho;

- $\quad$ estruturar uma avaliação da educação básica que sirva como modalidade alternativa ou complementar aos exames de acesso aos cursos profissionalizantes pós-médios e ao Ensino Superior (BRASIL, 2000b).

Para Primi et al (2001), existem três características gerais que distinguem o ENEM de provas tradicionais utilizadas em vestibulares:

a) "Um primeiro aspecto refere-se à mudança de ênfase de avaliação de conteúdos memorizados para a avaliação de processos gerais de raciocínio";

b) "utilização de Situações-problema contextuadas" e;

c) "Uma terceira característica importante do ENEM refere-se à interdisciplinaridade das questões" (PRIMI, 2001, p. 152 - 153.).

O exame está organizado a partir de uma matriz de referência, estruturada por cinco competências básicas: domínio de linguagens, compreensão de fenômenos, capacidade de 
enfrentar Situações-problema, construção de argumentações e elaboração de propostas, descritas no Quadro 2.

Quadro 2: Eixos cognitivos presentes na Matriz Curricular do ENEM.

\section{EIXOS COGNITIVOS}

Dominar linguagens (DL): dominar a norma culta da Língua Portuguesa e fazer uso das linguagens matemática, artística e científica e das línguas espanhola e inglesa.

Compreender fenômenos (CF): construir e aplicar conceitos das várias áreas do conhecimento para a compreensão de fenômenos naturais, de processos histórico-geográficos, da produção tecnológica e das manifestações artísticas.

Enfrentar Situações-problema (SP): selecionar, organizar, relacionar, interpretar dados e informações representadas de diferentes formas, para tomar decisões e enfrentar Situações-problema.

Construir argumentação (CA): relacionar informações, representadas em diferentes formas, e conhecimentos disponíveis em situações concretas, para construir argumentação consistente.

Elaborar propostas (EP): recorrer aos conhecimentos desenvolvidos na escola para elaboração de propostas de intervenção solidária na realidade, respeitando os valores humanos e considerando a diversidade sociocultural.

Fonte: Brasil (2012).

Somadas a essas competências, o ENEM estabeleceu um conjunto de 21 habilidades, aplicadas às áreas de conhecimento ou disciplinas. Até 2008 a prova era organizada em uma prova objetiva, compreendida por 63 questões de múltipla escolha (FERREIRA, 2014).

Em complemento, iniciou-se um trabalho, por parte dos organizadores do ENEM, para que as universidades brasileiras passassem a utilizar o desempenho dos alunos na avaliação como forma de ingresso ou como parte dele em seus cursos superiores. (BRASIL, 2000b; p.25). O número de inscritos aumenta proporcionalmente ao número de universidades que aderem a proposta e também a partir desse ano que alunos egressos de escolas públicas passam a ter gratuidade para realização do exame. Mesmo diante de tais mudanças, as competências básicas e as 21 habilidades mantiveram-se as mesmas. 
Em 2009 o ENEM passou por uma reestruturação. Podemos dizer que as reformulações do ENEM, apesar do diálogo com os $\mathrm{PCN}+$, seguiram o projeto apresentado posteriormente pelas Diretrizes Curriculares Nacionais para a Educação Básica e para o Ensino Médio. A interdisciplinaridade se manteve na divisão dos componentes curriculares por Áreas do Conhecimento, bem como pela articulação de todas as áreas através de Eixos Cognitivos. A dimensão investigativa e prática do ensino se manifestou pela manutenção da lógica do ensino por competências e habilidade. Entretanto, há uma ênfase maior no aspecto social e crítico na formação dos estudantes, bem como na necessidade de desenvolver um engajamento social e ambiental.

Em 13 de julho de 2010, sob a resolução $\mathrm{n}^{\circ}$ 4, no Art. 1, foram definidas as Diretrizes Curriculares Nacionais para a Educação Básica (DCN) (BRASIL, 2010). Verificase no $13^{\circ}$ artigo em que se definem as formas de organização do currículo, que o mesmo é definido "como o conjunto de valores e práticas que proporcionam a produção, a socialização de significados no espaço social e contribuem intensamente para a construção de identidades socioculturais dos educandos”. O Ensino Médio, de acordo como o $26^{\circ}$ artigo é orientado por princípios e finalidades que preveem:

A consolidação e o aprofundamento dos conhecimentos adquiridos no Ensino Fundamental, possibilitando o prosseguimento de estudos; a preparação básica para a cidadania e o trabalho, tomado este como princípio educativo, para continuar aprendendo, de modo a ser capaz de enfrentar novas condições de ocupação e aperfeiçoamento posteriores; o desenvolvimento do educando como pessoa humana, incluindo a formação ética e estética, o desenvolvimento da autonomia intelectual e do pensamento crítico; a compreensão dos fundamentos científicos e tecnológicos presentes na sociedade contemporânea, relacionando a teoria com a prática (BRASIL, 2010, p. 9).

Em complemento ao documento, em 30 de janeiro de 2012, sob a resolução $n^{\circ} 2$, foram definidas as Diretrizes Curriculares Nacionais para o Ensino Médio (DCNEM) (BRASIL, 2012), A organização curricular, segundo o documento, também ocorre a partir de áreas de conhecimento: Linguagens: Língua Portuguesa; Língua Materna, para populações indígenas; Língua Estrangeira moderna; Arte, em suas diferentes linguagens, Educação Física; Matemática; Ciências da Natureza: Biologia; Física; Química; e Ciências Humanas: História; Geografia; Filosofia; Sociologia. No artigo 21, de importante conhecimento para o nosso trabalho, afirma-se como necessário que o Exame Nacional do Ensino Médio (ENEM) deve compor o Sistema de Avaliação da Educação Básica (SAEB). Cabe destacar que mesmo mantendo a estrutura de Áreas do Conhecimento, Eixos Cognitivos, Competências e Habilidades, as Diretrizes Curriculares Nacionais para o Ensino Médio buscam se diferenciar da legislação curricular produzida por governos anteriores ao do Partido dos Trabalhadores: 
Entre múltiplos fatores que podem ser destacados, acentua-se que, para alguns educadores que se manifestaram durante os debates havidos em nível nacional, tendo como foco o cotidiano da escola e as diretrizes curriculares vigentes, há um entendimento de que tanto as diretrizes curriculares, quanto os Parâmetros Curriculares Nacionais (PCN), implementados pelo MEC de 1997 a 2002, transformaram-se em meros papéis. Preencheram uma lacuna de modo equivocado e pouco dialógico, definindo as concepções metodológicas a serem seguidas e o conhecimento a ser trabalhado no Ensino Fundamental e no Médio. Os PCNs teriam sido editados como obrigação de conteúdos a serem contemplados no Brasil inteiro, como se fossem um roteiro, sugerindo entender que essa medida poderia ser orientação suficiente para assegurar a qualidade da educação para todos. Entretanto, a educação para todos não é viabilizada por decreto, resolução, portaria ou similar, ou seja, não se efetiva tão somente por meio de prescrição de atividades de ensino ou de estabelecimento de parâmetros ou diretrizes curriculares: a educação de qualidade social é conquista e, como conquista da sociedade brasileira, é manifestada pelos movimentos sociais, pois é direito de todos (BRASIL, 2012, p. 14)

Além dos conteúdos, também foram definidas competências específicas para cada componente curricular. No quadro 3 estão organizadas as habilidades específicas desenvolvidas de acordo com cada competência da área de Ciências da Natureza (BRASIL, 2009 e 2012).

Quadro 3: Competências de área das Ciências da Natureza e a relação com as habilidades específicas presentes na Matriz Curricular do ENEM.

\begin{tabular}{|c|c|}
\hline Competências de área - Ciências da Natureza & $\begin{array}{l}\text { Habilidades } \\
\text { Específicas }\end{array}$ \\
\hline $\begin{array}{l}\text { Competência de área } \mathbf{1} \text { - Compreender as ciências naturais e as } \\
\text { tecnologias a elas associadas como construções humanas, percebendo seus papéis } \\
\text { nos processos de produção e no desenvolvimento econômico e social da } \\
\text { humanidade. }\end{array}$ & $\begin{array}{r}\text { H } 1 \\
\text { H } 2 \\
\text { H } 3 \\
\text { H } 4 \\
\end{array}$ \\
\hline $\begin{array}{l}\text { Competência de área } \mathbf{2} \text { - Identificar a presença e aplicar as } \\
\text { tecnologias associadas às ciências naturais em diferentes contextos. }\end{array}$ & $\begin{array}{l}\text { H } 5 \\
\text { H } 6 \\
\text { H } 7\end{array}$ \\
\hline $\begin{array}{l}\text { Competência de área } 3 \text { - Associar intervenções que resultam em } \\
\text { degradação ou conservação ambiental a processos produtivos e sociais e a } \\
\text { instrumentos ou ações científico-tecnológicos. }\end{array}$ & $\begin{array}{r}\text { H } 8 \\
\text { H } 9 \\
\text { H } 10 \\
\text { H } 11 \\
\text { H } 12 \\
\end{array}$ \\
\hline $\begin{array}{l}\text { Competência de área } 4 \text { - Compreender interações entre organismos } \\
\text { e ambiente, em particular aquelas relacionadas à saúde humana, relacionando } \\
\text { conhecimentos científicos, aspectos culturais e características individuais. }\end{array}$ & $\begin{array}{l}\text { H } 13 \\
\text { H } 14 \\
\text { H } 15 \\
\text { H } 16\end{array}$ \\
\hline $\begin{array}{l}\text { Competência de área } \mathbf{5}-\text { Entender métodos e procedimentos } \\
\text { próprios das ciências naturais e aplicá-los em diferentes contextos. }\end{array}$ & $\begin{array}{l}\text { H } 17 \\
\text { H } 18 \\
\text { H } 19\end{array}$ \\
\hline $\begin{array}{l}\text { Competência de área } 6 \text { - Apropriar-se de conhecimentos da física } \\
\text { para, em Situações-problema, interpretar, avaliar ou planejar intervenções } \\
\text { científico-tecnológicas. }\end{array}$ & $\begin{array}{l}\text { H } 20 \\
\text { H } 21 \\
\text { H } 22 \\
\text { H } 23\end{array}$ \\
\hline $\begin{array}{l}\text { Competência de área } 7 \text { - Apropriar-se de conhecimentos da } \\
\text { química para, em Situações-problema, interpretar, avaliar ou planejar intervenções } \\
\text { científico-tecnológicas. }\end{array}$ & $\begin{array}{l}\text { H } 24 \\
\text { H } 25 \\
\text { H } 26 \\
\text { H } 27\end{array}$ \\
\hline
\end{tabular}




\begin{tabular}{|l|l|}
\hline Competência de área 8 - Apropriar-se de conhecimentos da & H 28 \\
biologia para, em Situações-problema, interpretar, avaliar ou planejar intervenções \\
científico-tecnológicas.
\end{tabular}

Alguns autores problematizam a relação entre o ENEM o ensino de Química voltado para o desenvolvimento de competências e habilidades. Maceno et al (2011, p. 154) afirmam que para a ocorrência de um ensino por competências e habilidades recomenda-se a articulação entre o conhecimento científico, tecnologia e a mobilização de saberes para a resolução de Situações-problema do cotidiano do aluno. Tais articulações possibilitam uma compreensão global das atividades humanas no ambiente e na sociedade, além de desenvolver a ideia da Ciência como construção humana. Porém, os autores argumentam que a apresentação de uma lista de conteúdos no final da matriz inviabiliza todo o processo descrito, bem como o desenvolvimento de eixos cognitivos, uma vez que:

[...] tal listagem apresenta-se numa forma tradicional tal como é criticada pela comunidade de educadores químicos. Diante de tal lista, nossa hipótese é de que os professores reforcem seus programas de ensino, mantendo as práticas pedagógicas condicionadas a dar conta de uma lista de conteúdos, o que pode anular os avanços conseguidos ao que se refere à superação do ensino propedêutico e ser contrário ao que a própria proposta do ENEM defende (MACENO et al, 2011, p. 154).

Também com as mudanças propostas em 2009 a avaliação passou a ser aplicada em dois dias, composta por uma redação e 180 questões, sendo utilizado como método de avaliação e análise a Teoria de Resposta ao Item ${ }^{1}$. Os principais objetivos passaram a ser: “[...] democratizar as oportunidades de acesso às vagas federais de Ensino Superior, possibilitar a mobilidade acadêmica e induzir a reestruturação dos currículos do Ensino Médio" (BRASIL, 2012).

Assim, o ENEM passou a desempenhar as principais funções: classificatória, certificatória e sistêmica (MOEHLECKE, 2012, p.46).

1 A TRI é um conjunto de modelos matemáticos no qual a probabilidade de resposta a um item é modelada como função da proficiência (habilidade) do aluno (variável latente, não observável) e de parâmetros que expressam certas propriedades dos itens. Quanto maior a proficiência do aluno, maior a probabilidade de ele acertar o item. Uma das propriedades importantes da TRI é o fato dos parâmetros dos itens e as proficiências dos indivíduos serem invariantes. Tanto os parâmetros dos itens obtidos de grupos diferentes de alunos testados quanto os parâmetros de proficiência baseados em grupos diferentes de itens são invariantes, exceto pela escolha de origem e escala. Graças a essa propriedade, a TRI, associada a outros procedimentos estatísticos, permite comparar alunos, estimar a distribuição de proficiências da população e subpopulações e ainda monitorar os progressos de um sistema educacional (KLEIN, 2009, p.127). 
Ademais, o fato de o ENEM passar a ser articulado ao Sistema de Seleção Unificada (SISU) e Programa Universidade para Todos (PROUNI), acabou por se tornar uma referência de padronização curricular dos sistemas de ensino que operam com o objetivo de promover o acesso ao Ensino Superior.

Como avaliação classificatória, o estudante que participa do ENEM tem a possibilidade de se inscrever em sistemas de seleção para o ingresso e financiamento do Ensino Superior (SISU, PROUNI e FIES) ${ }^{2}$. Acreditamos ser um avanço todas essas mudanças, visto que o ENEM passar a desempenhar um importante papel social para os jovens, inclusive os menos favorecidos, uma vez que pode significar cursar uma Ensino Superior (SILVEIRA, BARBOSA E SILVA, 2015).

Tratando-se de uma função de avaliação certificatória, de acordo com a PORTARIA No 179, DE 28 DE ABRIL DE 2014 (BRASIL, 2014) o participante com idade mínima de 18 anos completos poderá obter a certificação de conclusão do Ensino Médio e a declaração de proficiência com base no exame, se atingir o mínimo de 450 (quatrocentos e cinquenta) pontos em cada uma das áreas do conhecimento e o mínimo de 500 (quinhentos) pontos na redação. $\mathrm{O}$ exame também passa a ser utilizado como certificação em cursos de Educação de Jovens e Adultos (EJA), substituindo o Exame Nacional para certificação de competências de Jovens e Adultos (ENCCEJA). Além disso, é possível também utilizar os resultados de rendimento de cada aluno na certificação em nível de conclusão do Ensino Médio, tratando-se de uma função de avaliação certificatória.

Por fim, a função como avaliação sistêmica consiste em subsidiar a formulação de políticas públicas (MOEHLECKE, 2012).

Entretanto, em 2016, houve uma nova alternância do grupo hegemônico no governo federal, cujas consequências influenciam neste momento a esfera educacional. No início de 2017 foram divulgadas algumas mudanças na avaliação. A avaliação passou a ser aplicada em dois finais de semana, permanecendo com o mesmo mecanismo de acesso ao Ensino Superior, entretanto não sendo mais utilizada como certificação de nível de ensino. Os resultados da prova foram divulgados somente por área de conhecimento, rendimento do aluno e base

2 O Sistema de Seleção Unificada (SISU), o Programa Universidade para todos (PROUNI) e a Fundação do Financiamento Estudantil (FIES) são programas que atuam como sistemas de seleção para o ingresso e financiamento do Ensino Superior. 
consolidada para o uso de programas governamentais (SISU, PROUNI, FIES), pois segundo a presidente do Inep, Maria Inês Fini, a função do ENEM é avaliar os estudantes e não a escola. ${ }^{3}$ Ainda assim, permanece a proposta de utilizar o exame como um instrumento de auto avaliação do aluno ao fim do Ensino Médio.

Mesmo a emissão dos boletins anuais de rendimentos das escolas não fazendo mais parte da nova reformulação do documento estabelecido em 2017, por muito tempo houve uma acirrada disputa entre as instituições de ensino. Tal boletim tornou-se propaganda de escolas particulares e também como forma de cobrança de rendimentos na rede pública. Assim, foi gerada uma confusão na comunidade escolar a respeito da finalidade e da proposta do exame, sendo talvez este um fator muito importante a ser resolvido. As escolas passaram a pressionar seus alunos para obtenção de um bom rendimento no ENEM, entretanto, não inseriram tais anseios como parte do planejamento escolar anual, se restringindo a algum trabalho somente às vésperas do exame. Então, como inserir a proposta de um ensino pautado no desenvolvimento de competências e habilidades no currículo escolar, sendo esta uma necessidade momentânea? Assim, diante do curto espaço de tempo, e também muitas vezes do desconhecimento e despreparo docente em relação a metodologia de ensino por competências e situações de ensino que articulam o desenvolvimento de tais competências, os professores acabam por basearem suas práticas de ensino no cumprimento da listagem de conteúdos apresentada na matriz do ENEM.

De forma alguma estamos propondo a retirada de conteúdos do ensino, especificamente do ensino de Química. O que acreditamos é ser necessário uma efetiva a articulação entre as competências, habilidades e conteúdos. Da forma como está descrito, ou seja, anexado à proposta da matriz, acaba por contribuir com a ideia de que um ensino por competências não necessita articular conhecimentos conceituais a proposta de ensino.

\footnotetext{
${ }^{3}$ Portaria $n^{\circ} 468$ de 4 de Abril de 2017.
} 


\subsection{ENEM e o ensino de Química}

Com o propósito de investigar possíveis contribuições com pesquisas relacionadas ao ENEM, especificamente na área de Química, realizamos uma pesquisa de caráter bibliográfico. Segundo Ferreira (2002, p. 257), esse tipo de pesquisa:

[...] parece trazer em comum o desafio de mapear e de discutir uma certa produção acadêmica em diferentes campos do conhecimento, tentando responder que aspectos e dimensões vêm sendo destacados e privilegiados em diferentes épocas e lugares, de que formas e em que condições têm sido produzidas certas dissertações de mestrado, teses de doutorado, publicações em periódicos e comunicações em anais de congressos e de seminários.

Broietti, Santini Filho e Passos (2014) realizaram um mapeamento dos trabalhos científicos a respeito do ENEM no período de 1998 a 2011. Os autores utilizaram o Banco de Teses da Capes, sendo o critério de busca no banco as palavras ENEM e Exame Nacional de Ensino Médio. Em um primeiro momento foram selecionadas 239 produções. Após um refinamento, verificaram que treze trabalhos relacionavam ENEM à área de Ciências da Natureza. Dentre estes, foi verificado que apenas quatro abordavam especificamente Química, os quais estão brevemente apresentados nas linhas que seguem.

Amauro (2004) identificou e caracterizou o nível de compreensão do conhecimento químico exigido dos alunos egressos do Ensino Médio. Tal investigação foi feita através de análises de questões que solicitavam conhecimentos de Química no ENEM e nas provas para os vestibulares da Fundação Universitária para o Vestibular (FUVEST), da Universidade Estadual Paulista (VUNESP) e da Comissão Permanente para o Vestibular e Programas Educacionais da Universidade de Campinas (COMVEST). Como forma de análise foram utilizados três itens: os conteúdos das provas de Química, os conhecimentos, as capacidades e as habilidade intelectuais exigidas na resolução das questões e a adequação das questões aos princípios pedagógicos da educação básica, contextualização e de interdisciplinaridade. O estudo revelou que o ENEM demanda uma compreensão generalista dos conhecimentos químicos contextualizados, descrita apenas pela utilização de fatos do cotidiano. A COMVEST demanda o entendimento de aspectos gerais do conteúdo da disciplina de Química, a FUVEST verifica se o candidato possui compreensão mais detalhada dos conhecimentos químicos e a VUNESP avalia se o candidato compreende as leis, as fórmulas e o comportamento específico da matéria.

Mascio (2009) analisou, a partir do Exame Nacional do Ensino Médio, as articulações entre a educação Ciência, Tecnologia e Sociedade (CTS) e a proposta nacional para o ensino de Química. Foram analisados o conteúdo e a estrutura das questões do ENEM 
na disciplina de química de 2004 a 2007. Os objetivos principais do trabalho foram identificar a aproximação das questões a uma perspectiva curricular CTS da educação científica, bem como analisar se tais questões avaliam as habilidades e competências necessárias a promoção da alfabetização científica a partir de uma abordagem CTS. E, também, verificar possíveis relações das competências e habilidades solicitadas nas questões do ENEM referentes à área de química com documentos oficiais do país relacionados ao Ensino Médio. Por meio de uma análise textual discursiva das questões do ENEM e de relatórios técnicos do exame de 2004 a 2007, foi observada, segundo o autor, que na teoria existem relações entre a matriz de referência do ENEM, dos documentos oficiais estudados e dos pressupostos CTS. Entretanto, existe uma distância, entre o proposto e o praticado, quanto à existência de uma relação CTS nas questões apresentadas pelo ENEM. Quanto as habilidades avaliadas nas questões, verificou-se que as mesmas não são empregadas em sua potencialidade, ou seja, sendo avaliada apenas uma parte da habilidade que se dispõe na questão.

Em seu trabalho Fernandes (2011) analisou possíveis compreensões da contextualização no ENEM, com o propósito de sinalizar subsídios para práticas docentes, reflexões pedagógicas e curriculares no ensino. Como forma de investigação foram elaboradas e realizadas entrevistas semiestruturadas com elaboradores dos textos teóricos e metodológicos do ENEM, especificamente relacionados as áreas de Ciências da Natureza e Matemática. E também, observada a noção de contextualização nas questões de cinco edições do ENEM (2005 a 2009). Seguindo os pressupostos da Análise Textual Discursiva, em relação as análises das questões do exame, a autora afirma que a contextualização de forma geral ou é abordada como um pretexto para uma abordagem conceitual ou limita-se a utilização de contextos apenas de aspectos da localidade dos estudantes.

No mesmo ano, Barros (2011) também apresentou contribuições na área propondo analisar diferentes textualizações do ciclo do carbono. Ou seja, segundo a autora, materiais que permitem produzir sentidos sobre esse assunto, sendo tanto na forma de imagens quanto na forma verbal escrita. Para tal propósito utilizou livros didáticos e questões o ENEM que tratavam especificamente desse tema utilizando como metodologia a Análise de Discurso de origem francesa. Foi observada grande complexidade e diversidade do assunto dentre currículos, imagens, representações e avaliações que estivessem ligadas ao tema. Entretanto, a autora problematizou em sua pesquisa o fato de que dentre inúmeras representações do ciclo do carbono, a maioria das vezes um único sentido foi escolhido e trabalhado sobre o assunto, sendo o carbono visto como o grande "vilão" das mudanças climáticas. 
Broietti (2013) também contribui com um trabalho a respeito da investigação das questões de Química do ENEM e do vestibular da Universidade Estadual de Londrina, referentes aos anos de 2009 a 2011. Foi proposta uma análise a partir de quatro critérios: os conhecimentos/conteúdos químicos necessários para a sua resolução; as competências/habilidades nelas exigidas, os aspectos contextuais e estruturais contemplados na elaboração dessas questões. Também investigou-se quais as ideias de ensino e aprendizagem estavam expressas nessas questões e que fundamentavam a prática avaliativa desses exames. Como procedimento metodológico foram empregadas uma análise textual discursiva e de conteúdo. Em relação aos conhecimentos/conteúdos químicos, verificou-se que as questões do ENEM contemplam tópicos ligados a aplicações cotidianas do conhecimento científico e a problemas sociais e ambientais. E quanto ao vestibular, não foram encontrados correspondentes explícitos nos programas da disciplina de Química. Referentes às competências e habilidades, constatou-se uma exigência de forma ampla e diversificada no ENEM. Enquanto no vestibular a autora identificou apenas três competências, e habilidades associadas à utilização de códigos e nomenclatura da química, sem analogias mais complexas. Quanto aos contextos, foram constatadas diferenças significativas entre as questões dos dois exames. As questões do ENEM apresentaram 98\% de algum tipo de contexto, principalmente problemas socioambientais e questões relacionadas à tecnologia, diferente das questões do Vestibular que apresentaram $41 \%$ das questões sem qualquer tipo de contextualização. E quanto aos aspectos estruturais, foram notadas que 50\% das questões em ambos os exames apresentaram algum tipo de representação, sendo que no ENEM todas as representações listadas (esquemas, estrutura química, equação química, figura, gráfico, tabela, quadro e tirinha-histórica em quadrinhos) foram contemplas e nos Vestibulares não foram encontrados esquemas e tirinhas. Por fim, quanto as ideias de ensino e aprendizagem expressas nas questões, no Vestibular da UEL foi observado maior número de questões com caráter reprodutivo. Diferente do ENEM, em que houve predomínio de questões produtivas, com algum contexto e proposição de novas situações, com relação de diferentes variáveis.

Com interesse em investigar a articulação entre o ENEM e um ensino de Química baseado no enfoque Ciência, Tecnologia e Sociedade, Souza (2016) investigou como ocorreram as aproximações entre os pressupostos teóricos do enfoque CTS com as competências e habilidades descritas na matriz de referência do ENEM, especificamente na área Ciências da Natureza e suas Tecnologias. Foram analisados o conteúdo e a estrutura das questões associadas ao ensino de Química deste exame entre 2009 a 2015. Foram utilizadas 
observação, verificação de documentos oficiais da educação brasileira e análise do novo ENEM, utilizando como instrumento de análise das questões a Análise Textual Discursiva. A análise dos resultados apontaram uma forte associação entre as Competências e Habilidades com os pressupostos da perspectiva educacional CTS. Já as questões do novo ENEM apresentaram aproximações em diferentes níveis dos princípios teóricos do enfoque CTS. Das 156 questões analisadas, 46,1\% não apresentaram aproximação com os princípios do enfoque CTS, 32,1\% mostraram aparente relação e 21,8\% estão associadas aos princípios do enfoque CTS.

Sobre os professores de Química, encontramos o trabalho de Dias (2003), que analisou como o ENEM tem impactado na prática pedagógica dos professores de Química, segundo a visão dos mesmos. Partindo de um estudo de caso, foram aplicados questionários e entrevistas a 14 docentes que lecionam Química no terceiro ano do Ensino Médio. Segundo os depoimentos dos docentes, a principal ideia é que mesmo a partir de uma proposta de mudanças quanto ao tratamento dos conteúdos no ensino de Química, o ENEM não apresentou o impacto desejado pelo discurso oficial. Conforme preconizado pelo ENEM, a justificativa fundamenta-se na falta de preparação dos professores para um ensino contextualizado.

Ellery (2014) desenvolve uma pesquisa em que o principal objetivo, através da análise de todas as questões de Química aplicadas no exame de 2009 a 2012, foi relacionar as Competências, Habilidades e conteúdos de Química. Através de um levantamento bibliográfico fez-se um estudo teórico sobre as competências e habilidades, e posteriormente uma análise estatística das questões de Química, presentes nas avaliações do novo ENEM. Por fim, aplicou-se um questionário à alunos de terceiro ano do Ensino Médio a respeito das competências e habilidades definidas pelo INEP. O produto do presente trabalho resultou em um manual contendo todas as questões de química do Novo ENEM, detalhando seus objetos de conhecimento, competências e habilidades.

A partir de uma análise documental, Ciszevski (2016) pesquisou sobre a correlação entre os conceitos de Química do Currículo Oficial do Estado de São Paulo e do material didático pedagógico (Caderno do Aluno e o Caderno do Professor) e as questões do ENEM entre 2009 a 2013. O objetivo da pesquisa foi verificar se o material didático auxilia os alunos na resolução das Situações-problema apresentadas nas questões do ENEM. Com a análise do material concluiu-se que os conteúdos programáticos apresentados nos Cadernos do Aluno e do Professor abordam a grande maioria dos conceitos exigidos para a resolução das questões 
contidas no exame nos anos avaliados. Desta forma, entende-se que o exame pode ser considerado uma opção para a construção dos conhecimentos nas salas de aula de Ensino Médio, podendo servir como instrumento de apoio ao professor e ao alunos no processo de ensino e aprendizagem na disciplina de Química. Ao final deste trabalho foi produzido um Relatório Pedagógico com o propósito de servir como referência para a reflexão sobre este exame e sua influência na ambiente e nas atividades escolares.

Por fim, Santos (2017) propõe uma intervenção didática, de forma contextualizada, com o objetivo de planejar, desenvolver e analisar propostas contextualizadas para o ensino de Química em um Curso de Educação Popular preparatório para o ENEM. Para planejar a intervenção foram analisadas questões de Química do ENEM de 2010 a 2015 e fichas sobre o perfil dos alunos. Também foi feito um estudo de alguns documentos oficiais e uma revisão da literatura da área. Foram desenvolvidas atividades em um Projeto-piloto para alunos do Cursinho de Educação Popular por meio de Situações de Estudo. O tema Química e Meio Ambiente foi aplicado para a turma do Curso Intensivo de quatro meses e a temática de ensino sobre a Química e o Cotidiano no contexto para o Curso Extensivo. Tanto registros feitos em um diário de bordo quanto questionários aplicados em aula foram analisados por meio de Análise de Conteúdo. Os resultados indicaram primeiramente que a proposta de ensino motivou os alunos verificando-se elevado interesse e a participação ativa dos mesmos nas atividades realizadas. Quanto a proposta de um ensino contextualizado, este propiciou maior confiança dos alunos no momento de realização da prova. E por fim, a docente que também desenvolveu o projeto sentiu-se motivada em relação a proposição das intervenções didáticas, considerando o ensino de Química contextualizado como responsável por uma aprendizagem mais significativa.

Em comum, todos estes estudos partilham do pressuposto de que o exame tem grande "potencial de direcionar o que, como e para que ensinar" (BONAMINO; SOUZA, 2012, pg. 386).

Em complemento, Cintra, Marques Júnior e Sousa (2016), afirmam que em sua matriz, o ENEM apresenta uma proposta que articula as competências e habilidades com um ensino contextualizado e interdisciplinar. O propósito é promover maior articulação entre o conhecimento e a tecnologia exigindo do aluno uma mobilização dos saberes para a resolução das situações proposta nas questões. Entretanto, os autores também acreditam que não só os conteúdos no final da matriz, mas também questões com propostas distintas à matriz curricular podem comprometer a proposta inicial do exame. Com o objetivo de verificar a 
existência ou não de uma concordância entre as provas e a matriz de referência, os autores se propõem a analisar as questões de Química presentes nas avaliações do ENEM de 2009 a 2013. E também as orientações presentes na matriz de referência do exame, com o propósito de estabelecer uma classificação das demandas cognitivas e da dimensão do conhecimento solicitado em cada questão. Utilizando a Taxonomia de Bloom Revisada foram analisadas trinta habilidades da área de Ciências da Natureza e suas Tecnologias sendo que as mesmas classificadas nas dimensões do Conhecimento e da Demanda Cognitiva. Em relação a demanda cognitiva, cerca de $81 \%$ das questões foram classificadas com domínios de baixa ordem cognitiva, em contraste com a análise da Matriz de Referência, que sugere uma proporção entre 64 a 71\% para questões com essas características. Ou seja, para resolver as questões do ENEM os alunos demandam simples lembrança de informações, utilizam de fórmulas ou de algoritmos, sendo bem diferente das exigências presentes na Matriz. Ou seja, os autores comprovaram a existência de um distanciamento entre as exigências do matriz e o que se observa nas questões propostas na avaliação.

Entretanto, os autores argumentam que a listagem de conteúdos disposta no final da matriz acaba por engessar toda essa tentativa de mudança inviabilizando o desenvolvimento do eixo cognitivo e das habilidades e competências. Compartilhando das afirmações, entendemos que com uma lista de conteúdo a ser cumprida, o professor ficará indeciso em relação à suas escolhas metodológicas, e sob influência de trabalhar com aulas expositivas, o que poderá certamente anular todos os avanços conseguidos pelo ENEM. O espaço existente para que se possa desenvolver e trabalhar habilidades e tentar preparar o aluno para enfrentar e propor soluções diante de questionamentos cotidianos ainda é predominantemente a sala de aula. Com a preocupação do professor em transmitir todo o conteúdo para o seu aluno, vinculada às suas dificuldades em trabalhar com um ensino baseado no desenvolvimento de competências, deve comprometer a relação de ensino e aprendizagem entre os agentes.

Conforme mencionado anteriormente, Santos (2017) realizou uma pesquisa das questões aplicadas no ENEM no período de 2010 a 2015. Dentre os critérios de categorização foi considerado o envolvimento de uma situação ou problema social ou cotidiano, sendo a compreensão do enunciado necessária na busca por soluções e explicações no conhecimento químico. Os principais objetivos da pesquisa foram verificar conhecimentos envolvidos e a presença ou não de questões contextualizadas. De forma resumida, as análises dos resultados indicaram questões com características muito semelhantes, ou seja, menos contextualizadas, 
com exigências de conhecimentos específicos e com crescente nível de dificuldade na solução das questões.

O fato de diagnosticarmos tais problemas na matriz de referência e nas questões do ENEM não significa que não seja possível realizar um ensino baseado no desenvolvimento de competências e habilidades exigidas pelo ENEM. Neste sentido, as propostas de construção de conhecimentos neste trabalho objetivaram atender às necessidades dos alunos para prestar o exame, existindo chances reais dos mesmos ingressarem em um curso superior de ensino. Desta forma, nossas motivações estenderam-se no planejamento das atividades e na escolha de uma metodologia de ensino que contemplasse todas ideias apresentadas.

Assim, diante do exposto, optamos pela elaboração de Situações-problema que desenvolvessem as competências e habilidades exigidas na Matriz de Referência do ENEM, ao invés de simplesmente aplicar as questões do ENEM.

As atividades constituintes da Situações-problema foram organizadas em quatro módulos de ensino, os quais estão apresentados no capítulo de metodologia deste trabalho. Com o desígnio de promover a construção de conhecimentos conceituais sobre a transformação, conservação e proporção dos materiais através da mobilização de conhecimentos cognitivos como a leitura, interpretação de fenômenos e situações, o estabelecimento de cálculos matemáticos e a criação de estratégias de resoluções, foram organizadas questões problemas, atividades experimentais e textos que complementaram as discussões sobre o tema.

Quanto às questões que problematizaram as atividades, tínhamos priorizado a escolha somente de questões do ENEM, já que o nosso foco foi o desenvolvimento de habilidades e competência específicas do exame. Entretanto, conforme já discutido, verificamos que as questões, de anos diversificados, realmente estão estruturadas em conhecimentos muito específicos de química, o que entendemos que difere da proposta da matriz e também dos objetivos do nosso trabalho. A partir da escolha de algumas habilidades do ENEM reestruturamos questões do exame, elaboramos outras e utilizamos também algumas de exames vestibulares que correspondiam aos nossos objetivos. 


\subsection{Elaboração de Situações-problema}

As situações que problematizaram conteúdos e mobilizaram habilidades dos alunos em suas resoluções foram organizadas e aplicadas em duas etapas.

A primeira etapa aconteceu no segundo semestre de 2015, com o desenvolvimento e aplicação de um instrumento, "instrumento piloto", o qual direcionou a etapa seguinte. Para compor este instrumento, que contemplava alguns dos principais temas envolvidos no ensino de Química, organizamos um questionário contendo 9 questões, sendo 4 objetivas e 5 discursivas (Apêndice 1). Algumas delas foram elaboradas por nós, outras retiradas de alguns exames vestibulares e algumas do ENEM. Os principais objetivos da atividade foram verificar o domínio de certas habilidades dos alunos e possíveis dificuldades conceituais diante das questões que diversificavam os conceitos químicos trazendo-os a partir de situações reais.

Para investigar tais habilidades foi necessária a escolha das mesmas anteriormente à elaboração das questões. Este mesmo procedimento foi aplicado para todas as atividades que constituíram a sequência de atividades. Baseando-se na matriz de referência do ENEM, optamos por utilizar questões em que os alunos deveriam mobilizar habilidades descritas na área de Ciências da Natureza, especificamente nas competências de áreas 5 e 7, conforme descritas no quadro que se segue (Quadro 4).

Quadro 4. Competências e habilidades do ENEM utilizadas na elaboração do instrumento piloto.

\section{Competências de área - Ciências da Natureza}

Competência de área 5 - Entender métodos e procedimentos próprios das ciências naturais e aplicá-los em diferentes contextos.

\section{- $\quad$ Habilidade 17}

Relacionar informações apresentadas em diferentes formas de linguagem e representações usadas nas ciências físicas, químicas ou biológicas, como texto discursivo, gráficos, tabelas, relações matemáticas ou linguagens.

\section{- $\quad$ Habilidade 18}

Relacionar propriedades físicas, químicas ou biológicas de produtos, sistemas ou procedimentos tecnológicos às finalidades a que se destinam.

\section{- $\quad$ Habilidade 19}

Avaliar métodos, processos ou procedimentos das ciências naturais que contribuam para diagnosticar ou solucionar problemas de ordem social, econômica ou ambiental. 
Competência de área 7 - Apropriar-se de conhecimentos da química para, em Situações-problema, interpretar, avaliar ou planejar intervenções científicotecnológicas.

\section{- $\quad$ Habilidade 24}

Utilizar códigos e nomenclatura da química para caracterizar materiais, substâncias ou transformações químicas.

\section{- $\quad$ Habilidade 25}

Caracterizar materiais ou substâncias, identificando etapas, rendimentos ou implicações biológicas, sociais, econômicas ou ambientais de sua obtenção ou produção.

\section{- $\quad$ Habilidade 26}

Avaliar implicações sociais, ambientais e/ou econômicas na produção ou no consumo de recursos energéticos ou minerais, identificando transformações químicas ou de energia envolvidas nesses processos.

\section{- $\quad$ Habilidade 27}

Avaliar propostas de intervenção no meio ambiente aplicando conhecimentos químicos, observando riscos ou benefícios.

Fonte: Brasil, 2012.

Os nossos critérios de escolha de certas habilidades foram definidos de acordo com a nossa disciplina e também diante da recorrência e flexibilidade de utilização de algumas delas. A competência de área 7 remete-se especificamente à Química, sendo fundamental a mobilização das habilidades específicas por parte dos alunos para resolução de questões da área. Especificamente, tem como proposta o trabalho com Situações-problema para que os alunos possam apropriarem-se dos conhecimentos de forma a mobilizar ações como interpretar, avaliar ou planejar intervenções. Relacionam-se com a nossa pesquisa, visto que para a realização de nossas atividades será necessária uma apropriação de conhecimentos de química para que possamos encontrar soluções para Situações-problema também mobilizando de forma eficaz ações como interpretação, avaliação e planejamento. Já a competência de área 5, apesar de se remeter à Ciência de forma geral, propõe, ao nosso entendimento, o domínio de habilidades fundamentais para toda as áreas de Ciências da Natureza. Ou seja, as habilidades 17, 18 e 19 são amplamente mobilizadas, visto que diversas são as situações em que os alunos devem ser capazes de relacionar informações em diferentes linguagens (gráfico, tabela, figura, etc.), bem como relacionar propriedades dos materiais e por fim, de avaliar métodos que os auxiliem no diagnóstico e solução de problemas. 
Todas as habilidades mencionadas relacionam-se de forma a se integrar à sequência de uma Situação-problema proposta por Zabala e Arnau (2010) conforme apresentado no quadro que se segue (Quadro 5).

Quadro 5. Articulação entre as habilidades do ENEM e as etapas de uma Situação-problema.

\begin{tabular}{|c|l|c|}
\hline $\begin{array}{c}\text { Avaliação das Competências } \\
\text { proposta por Zabala e Arnau (2010) }\end{array}$ & $\begin{array}{c}\text { Sequência de realização de uma } \\
\text { Situação-problema proposta por } \\
\text { Zabala e Arnau (2010) }\end{array}$ & $\begin{array}{c}\text { Habilidades do } \\
\text { ENEM }\end{array}$ \\
\hline $\begin{array}{c}\text { Capacidade de Compreensão e Análise } \\
\text { da Situação-problema }\end{array}$ & $\begin{array}{l}\text { Analisar a situação e compreender suas } \\
\text { características e o tipo de problemas ou } \\
\text { questões propostos. }\end{array}$ & H 17 \\
\hline \multirow{2}{*}{$\begin{array}{c}\text { Capacidade de conhecimento e seleção } \\
\text { de esquema proposto na Situação- } \\
\text { problema }\end{array}$} & $\begin{array}{l}\text { Dispor de conhecimento sobre os } \\
\text { diferentes esquemas de atuação em } \\
\text { relação aos diversos problemas. }\end{array}$ & H 18 \\
\cline { 2 - 3 } & $\begin{array}{l}\text { Capacidade de selecionar o esquema ou } \\
\text { os esquemas de atuação mais apropriados } \\
\text { para resolvê-los. }\end{array}$ & H 19 \\
\hline \multirow{2}{*}{$\begin{array}{c}\text { Competência - avaliação da resposta } \\
\text { diante da Situação-problema }\end{array}$} & $\begin{array}{l}\text { Aplicar uma ação competente em função } \\
\text { das características específicas das }\end{array}$ & H 27 \\
\hline Situações-problema. & H 27 \\
\hline
\end{tabular}

A partir da proposta dos autores de como desenvolver e avaliar uma Situaçãoproblema (Quadro 4), entendemos que as habilidades 17, 18 e 24 podem ser mobilizadas inicialmente em uma Situação-problema, visto que os alunos geralmente iniciam a investigação de um problema tentando analisar e compreender a situação para na sequência, utilizarem de conhecimentos e habilidades de resolução. Entretanto, para que eles consigam, segundo os autores, selecionar esquemas de atuação para resolvê-la, acreditamos que terão de mobilizar habilidades de maior complexidade, ou seja, as habilidades 19, 26 ou 27, dependendo do que esteja sendo exigido. E por fim para aplicar uma ação competente em características específicas, podem ser mobilizadas as habilidades 25 e 27, também de alta complexidade.

Para tornar nosso trabalho ainda mais consistente, as habilidades atribuídas às questões do instrumento piloto foram validadas por um grupo de pesquisadores. A validação foi realizada por 8 membros do GEPEQ, grupo de pesquisa do qual faço parte. Dentre eles participaram da validação a professora responsável pelo grupo e minha orientadora, 3 alunos de Mestrado, e 1 aluno de Doutorado, 2 mestres e 2 doutores. Apesar de discussões intensas, foram altos os índices de concordância entre os membros do grupo. Após a organização dos dados foram verificados os seguintes resultados (Tabela 1): 
Tabela 1. Resultados da validação do Instrumento piloto.

\begin{tabular}{|l|l|}
\hline \multicolumn{2}{|c|}{ INSTRUMENTO PILOTO } \\
\hline \multicolumn{1}{|c|}{ Questões } & Habilidades cognitivas \\
\hline 1 & H17 e H25 \\
\hline $3,6,7,8$ e 9 & H17, H19 e H25 \\
\hline 4 & H24, H26 e H27 \\
\hline 5 & H17, H18 e H24 \\
\hline 2 & H18, H19 e H24 \\
\hline
\end{tabular}

Após a aplicação do instrumento e com base nos resultados obtidos das análises das questões, observamos as maiores dificuldades conceituais e também cognitivas dos alunos referentes às "Grandezas Químicas" com abrangência às "Relações Quantitativas". Verificamos que a grande dificuldade estava em resolver as questões que abordavam raciocínios matemáticos e, também, a partir dos enunciados das mesmas traçar uma estratégia de resolução. Tais dificuldades foram verificadas em questões que abordaram conteúdos relacionados à Conservações e Proporções dos materiais. Atualmente questões envolvendo cálculos matemáticos e relações quantitativas estão entre os conteúdos de maior exigência nas questões propostas pelo ENEM.

A partir da investigação das principais dificuldades conceituais e cognitivas dos alunos durante a resolução de problemas que envolveram conhecimentos de diversos conteúdos químicos, iniciou-se a segunda etapa do trabalho no primeiro semestre de 2017, com a elaboração e aplicação de uma sequência de atividades que problematizaram tais dificuldades. A sequência foi organizada em quatro módulos, de modo que o aluno realizasse a construção do conhecimento de forma contínua e evolutiva, avançando escalonadamente no domínio de habilidades. A organização dos módulos pode ser vista nas linhas que se seguem (Quadro 6).

Quadro 6. Organização dos temas norteadores das atividades problematizadoras.

\begin{tabular}{|c|c|c|c|}
\hline MÓDULO 1 & MÓDULO 2 & MÓDULO 3 & MÓDULO 4 \\
\hline $\begin{array}{c}\text { Transformações } \\
\text { Químicas - } \\
\text { reconhecimento e } \\
\text { conceituação }\end{array}$ & $\begin{array}{c}\text { Conservação das } \\
\text { massas numa } \\
\text { transformação } \\
\text { química }\end{array}$ & $\begin{array}{c}\text { Proporções entre } \\
\text { as massas numa } \\
\text { transformação } \\
\text { química }\end{array}$ & $\begin{array}{c}\text { Aplicação geral dos } \\
\text { conhecimentos e das } \\
\text { habilidade }\end{array}$ \\
\hline
\end{tabular}


Em contribuição à construção dos conhecimentos, as atividades elaboradas foram diversificadas. Foram desenvolvidas atividades experimentais realizadas pelos alunos, bem como também aquelas demonstradas pela professora, questões respondidas anterior e posteriormente à aplicação das atividades, leitura e discussão de texto, síntese das ideias principais, e situações propostas no último módulo como forma de verificação da construção de conhecimentos e de habilidades cognitivas.

Para dar início a segunda etapa da sequência de situações problematizadoras, os alunos responderam a uma ficha com informações pessoais (Apêndice 2), e a um questionário diagnóstico, "Instrumento diagnóstico" (Apêndice 3). Com o mesmo propósito do questionário piloto, de averiguar conhecimentos e habilidades específicos, entretanto, neste momento a respeito somente de conhecimentos sobre os conteúdos de Transformações químicas, Conservações e Proporções dos materiais. Organizamos um questionário contendo 11 questões, sendo $\mathrm{X}$ objetivas e $\mathrm{Y}$ discursivas, sendo algumas delas elaboradas por nós, outras retiradas de alguns exames vestibulares e também do ENEM.

Nesta segunda etapa da pesquisa decidimos ampliar, em relação ao instrumento piloto, a escolha das habilidades presentes na Matriz de Referência do ENEM e especificamente contidas na área de Ciências da Natureza. Seguimos os mesmos critérios de escolha já descritos anteriormente, entretanto, durante a análise do piloto e da elaboração do diagnóstico entendemos que o aluno poderia não só mobilizar habilidades presentes nas competências de áreas 5 e 7, mas também os questionamentos que estavam sendo propostos permitiam a mobilização de habilidades contidas nas competências de áreas 1 e 3, conforme descritas no quadro 7.

Quadro 7. Competências e habilidades do ENEM utilizadas na elaboração da sequência de ensino.

\section{Competências de área - Ciências da Natureza}

Competência de área 1 - Compreender as ciências naturais e as tecnologias a elas associadas como construções humanas, percebendo seus papéis nos processos de produção e no desenvolvimento econômico e social da humanidade.

- Habilidade 3

Confrontar interpretações científicas com interpretações baseadas no senso comum, ao longo do tempo ou em diferentes culturas.

Competência de área 3 - Associar intervenções que resultam em degradação ou 
conservação ambiental a processos produtivos e sociais e a instrumentos ou ações científico-tecnológicos.

\section{- $\quad$ Habilidade 8}

Identificar etapas em processos de obtenção, transformação, utilização ou reciclagem de recursos naturais, energéticos ou matérias-primas, considerando processos biológicos, químicos ou físicos neles envolvidos.

Competência de área 5 - Entender métodos e procedimentos próprios das ciências naturais e aplicá-los em diferentes contextos.

\section{- $\quad$ Habilidade 17}

Relacionar informações apresentadas em diferentes formas de linguagem e representações usadas nas ciências físicas, químicas ou biológicas, como texto discursivo, gráficos, tabelas, relações matemáticas ou linguagens.

\section{- $\quad$ Habilidade 18}

Relacionar propriedades físicas, químicas ou biológicas de produtos, sistemas ou procedimentos tecnológicos às finalidades a que se destinam.

\section{- $\quad$ Habilidade 19}

Avaliar métodos, processos ou procedimentos das ciências naturais que contribuam para diagnosticar ou solucionar problemas de ordem social, econômica ou ambiental.

Competência de área 7 - Apropriar-se de conhecimentos da química para, em Situações-problema, interpretar, avaliar ou planejar intervenções científicotecnológicas.

\section{- $\quad$ Habilidade 24}

Utilizar códigos e nomenclatura da química para caracterizar materiais, substâncias ou transformações químicas.

\section{- $\quad$ Habilidade 25}

Caracterizar materiais ou substâncias, identificando etapas, rendimentos ou implicações biológicas, sociais, econômicas ou ambientais de sua obtenção ou produção.

\section{- $\quad$ Habilidade 26}

Avaliar implicações sociais, ambientais e/ou econômicas na produção ou no consumo de recursos energéticos ou minerais, identificando transformações químicas ou de energia envolvidas nesses processos.

\section{- $\quad$ Habilidade 27}

Avaliar propostas de intervenção no meio ambiente aplicando conhecimentos químicos, observando riscos ou benefícios.

Fonte: Brasil, 2012.

Por conta do tempo e de nossa proposta, em nossas Situações-problema não tivemos como foco o estudo e construção de conceitos microscópicos. Objetivamos a construção de 
conhecimentos a nível macroscópico das transformações dos materiais e também no cálculo de quantidades de componentes envolvidos nas reações químicas.

Nem todos os instrumentos da sequência foram analisados. Optamos por não analisar os instrumentos em que as atividades foram realizadas em grupo, pois não seria possível descrever a participação de cada aluno nas atividades escritas. As filmagens também não foram utilizadas, pois não foi possível, muitas das vezes, se atribuir a fala a uma aluno em particular, dada a disponibilidade de apenas uma câmera.

\subsection{Aplicação das atividades}

\subsubsection{Público Alvo}

As atividades foram aplicadas aos alunos do cursinho popular comunitário EPA. No início de 2015, ano em que o questionário piloto foi aplicado, os alunos estavam organizados em duas turmas de 60 pessoas. Entretanto, em setembro do mesmo ano, mês de aplicação do instrumento, as turmas continham 25 e 24 alunos respectivamente. Os perfis das turmas eram de alunos de escolas públicas estaduais, federais (IFSP), técnicas (ETEC), pouquíssimos alunos de escolas particulares e alguns alunos que já estavam afastados há algum tempo da escola mas com o desejo de ingressar no Ensino Superior. O instrumento foi aplicado em uma aula da grade normal de horários.

Em 2016, houve uma tentativa de continuidade de aplicação da pesquisa. Por motivos adversos, como a presença de feriados e uma licença maternidade da pesquisadora, não foi concluída a aplicação da sequência naquele ano. Mas, a aplicação parcial foi de grande valia para diagnosticarmos algumas dificuldades de realização da mesma e conseguirmos proceder a pequenos ajustes do material.

Em 2017, ano de continuidade da aplicação formaram-se duas novas turmas de aproximadamente 60 alunos. A aplicação do instrumento diagnóstico foi realizada em conjunto para as duas novas turmas, sendo que 70 alunos participaram da aplicação. No momento da aplicação do instrumento diagnóstico foi entregue aos alunos uma ficha que utilizamos para identificar e conhecer um pouco o perfil dos participantes (Apêndice 2). Uma das questões elaboradas foi a respeito da origem dos alunos (Figura 1) e os dados mostraram que a grande maioria dos mesmos vieram de escolas públicas, havendo um aumento percentual em comparação ao ano anterior. Em seguida tivemos uma grande procura dos alunos do Centro Paula Souza - ETEC/Itu, visto que a ETEC é a escola técnica pertencente ao 
Centro Paula Souza e a FATEC é a faculdade de Tecnologia do mesmo Centro. Também, organizamos as informações referentes às cidades de origem (Figura 2). A grande maioria dos estudantes que frequentaram o cursinho neste ano eram moradores da cidade de Itu e Salto, que trata-se de uma cidade vizinha à Itu. Quanto à idade, a maior parte dos alunos participantes possuía de 17 à 18 anos. Mas também tivemos um público mais velho que procurou e espaço como formação complementar e forma de retornar aos estudos. Os dados que se seguem ilustram os resultados que foram detalhados.

Figura 1. Representação dos alunos participantes do cursinho por escolas.

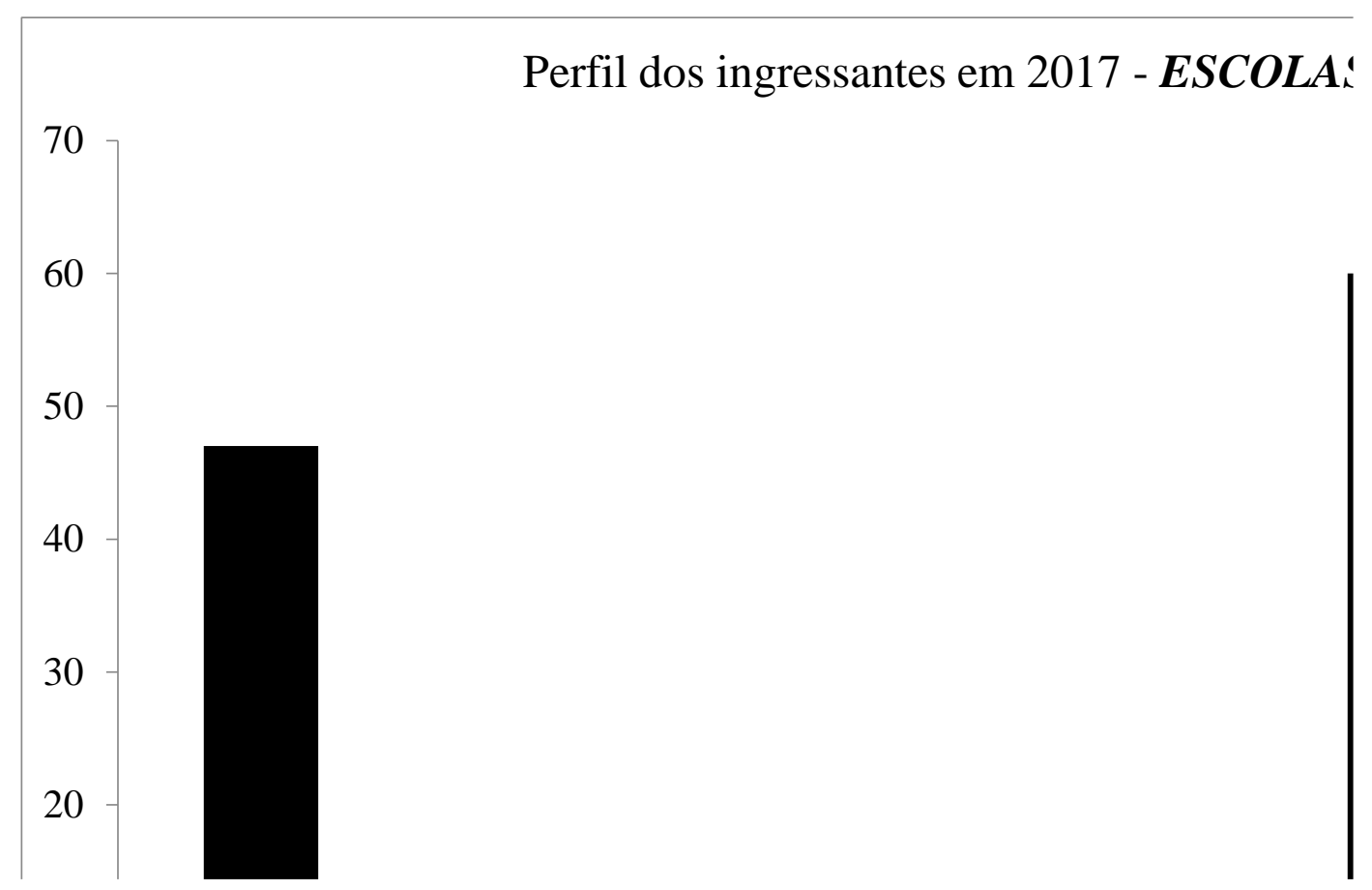


Figura 2. Representação dos alunos participantes do cursinho por cidade de origem.

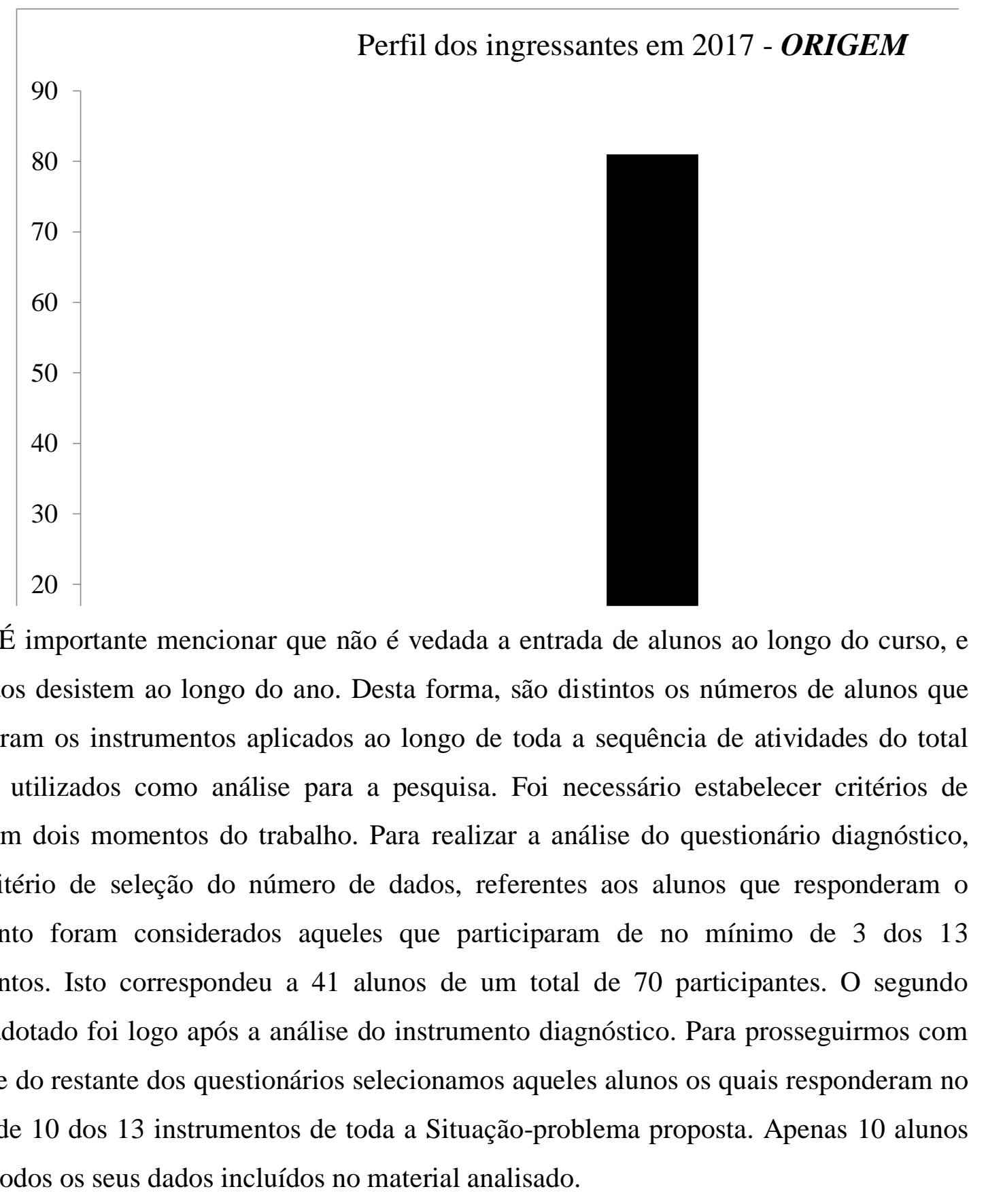

que muitos desistem ao longo do ano. Desta forma, são distintos os números de alunos que responderam os instrumentos aplicados ao longo de toda a sequência de atividades do total daqueles utilizados como análise para a pesquisa. Foi necessário estabelecer critérios de análise em dois momentos do trabalho. Para realizar a análise do questionário diagnóstico, como critério de seleção do número de dados, referentes aos alunos que responderam o instrumento foram considerados aqueles que participaram de no mínimo de 3 dos 13 instrumentos. Isto correspondeu a 41 alunos de um total de 70 participantes. O segundo critério adotado foi logo após a análise do instrumento diagnóstico. Para prosseguirmos com as análise do restante dos questionários selecionamos aqueles alunos os quais responderam no mínimo de 10 dos 13 instrumentos de toda a Situação-problema proposta. Apenas 10 alunos tiveram todos os seus dados incluídos no material analisado.

\subsubsection{Descrição da aplicação das atividades}

As aulas no cursinho são oferecidas somente aos sábados das 08h00min às 18h00min. Em 2015, ano de aplicação do instrumento diagnóstico, eram desenvolvidas duas aulas de 100 minutos no período da manhã, com um intervalo para almoço, mais duas aulas de 100 minutos no período da tarde, outro pequeno intervalo e uma última aula de 90 minutos. A proposta dessa última aula era que o professor pudesse desenvolver oficinas, palestras, 
saraus, projetos temáticos, debates, enfim, uma flexibilização curricular. O questionário diagnóstico foi aplicado justamente na última aula. Os alunos organizaram-se em fileiras e individualmente responderam cada uma das questões. Não houve qualquer consulta de material ou conversa entre os mesmos. A medida que terminavam de responder deveriam deixar a sala.

Em 2017 ocorreram algumas alterações. Neste ano as atividades foram aplicadas em aulas da grade normal e também em aulas denominadas "aulas do meio", sendo horários especiais com flexibilidade para o desenvolvimento de projetos pedagógicos. Diferentemente de 2015, as aulas favoráveis ao desenvolvimento de projetos agora foram trazidas em um intervalo entre o período da manhã e o da tarde, assim denominadas "aulas do meio". O principal motivo foi que os alunos acabavam se sentindo muito cansados no final do dia e não estavam apresentando um envolvimento integral nas atividades que estavam sendo desenvolvidas.

Os quadros 8, 9, 10 e 11 trazem um resumo dos conteúdos dos instrumentos, uma breve descrição das aplicações das atividades e as competências gerais e específicas recorrentes em cada módulo.

Quadro 8. Descrição das Situações-problema e competências exigidas no primeiro módulo.

\begin{tabular}{|c|c|}
\hline \multicolumn{2}{|r|}{$1^{\circ}$ MÓDULO } \\
\hline \multicolumn{2}{|l|}{ Número de aulas: 5 aulas } \\
\hline $\begin{array}{c}\text { Competências } \\
\text { gerais }\end{array}$ & $\begin{array}{l}\text { Ao final deste módulo o aluno deverá dominar e fazer uso da linguagem científica } \\
\text { que aborde especificamente o conceito transformações químicas. Entender o } \\
\text { fenômeno e reconhecê-lo em diferentes contextos. Construir e aplicar conceitos } \\
\text { para a compreensão de fenômenos naturais. }\end{array}$ \\
\hline $\begin{array}{l}\text { Competências } \\
\text { específicas }\end{array}$ & $\begin{array}{l}\text { Reconhecer a ocorrência de transformações químicas no dia a dia e saber } \\
\text { diferenciar tais transformações. Verificar a ocorrência das transformações } \\
\text { químicas por meio de evidências macroscópicas e da formação de novos materiais } \\
\text { (produtos) com propriedades distintas dos materiais de partida (reagentes). }\end{array}$ \\
\hline Habilidades do ENEM & $\begin{array}{l}\text { H } \mathbf{3} \text { = Confrontar interpretações científicas com interpretações baseadas no senso } \\
\text { comum, ao longo do tempo ou em diferentes culturas. } \\
\text { H } 8 \text { = Identificar etapas em processos de obtenção, transformação, utilização ou } \\
\text { reciclagem de recursos naturais, energéticos ou matérias-primas, considerando } \\
\text { processos biológicos, químicos ou físicos neles envolvidos. } \\
\text { H } \mathbf{1 7}=\text { Relacionar informações apresentadas em diferentes formas de linguagem } \\
\text { e representações usadas nas ciências físicas, químicas ou biológicas, como texto } \\
\text { discursivo, gráficos, tabelas, relações matemáticas ou linguagens. } \\
\text { H } \mathbf{2 4}=\text { Utilizar códigos e nomenclatura da química para caracterizar materiais, } \\
\text { substâncias ou transformações químicas. }\end{array}$ \\
\hline $\begin{array}{l}\text { Descrição das } \\
\text { atividades }\end{array}$ & $\begin{array}{l}\text { Preenchimento de uma ficha de identificação individual (Apêndice 2). Aplicação } \\
\text { de um questionário diagnóstico (Apêndice 3) para verificar os conhecimentos e } \\
\text { habilidades dos alunos anterior ao início da sequência problematizadora. Para } \\
\text { iniciar a construção de conhecimentos desta etapa da sequência os alunos } \\
\text { realizaram uma atividade experimental. Antes de iniciá-la foi aplicado um } \\
\text { questionário (Apêndice 4) para verificar conhecimentos prévios dos alunos sobre } \\
\text { as transformações químicas. Desenvolvimento de uma atividade experimental }\end{array}$ \\
\hline
\end{tabular}




\begin{tabular}{|l|l|}
\hline (Apêndice 5) envolvendo a transformação da matéria, em que os alunos \\
reconheceram a ocorrência da transformação e as possíveis evidências de \\
transformaçães da matéria. Por meio de exemplos descritos na lousa, os alunos \\
deveriam ser capazes de transformar a representação de uma transformação em \\
linguagem discursiva para a linguagem simbólica. Foram utilizados exemplos da \\
atividade realizada anteriormente (Apêndice 5). Leitura e discussão de um texto \\
(Apêndice 6) em que os alunos verificaram que nem sempre as transformações \\
apresentam evidências de reação. Como síntese, em grupo, elaboraram cartazes \\
que representaram a compreensão das principais ideias contidas no texto. Ao \\
final do módulo foram convidados a elaborar seus próprios conceitos sobre \\
transformações químicas (Apêndice 7).
\end{tabular}

Quadro 9. Descrição das Situações-problema e competências exigidas no segundo módulo.

\begin{tabular}{|c|c|}
\hline \multicolumn{2}{|r|}{$2^{\circ}$ MÓDULO } \\
\hline \multicolumn{2}{|c|}{ Número de aulas: 3 aulas } \\
\hline Competências gerais & $\begin{array}{l}\text { Ao final deste módulo o aluno deverá conhecer diferentes representações a } \\
\text { respeito da transformação química das substâncias e saber utilizá-los em } \\
\text { diferentes contextos. Conhecer a linguagem discursiva e ser capaz de construir } \\
\text { uma linguagem simbólica por meio de equações químicas. Após a transposição da } \\
\text { linguagem o aluno também deverá construir a ideia de conservação das massas } \\
\text { das substâncias. }\end{array}$ \\
\hline $\begin{array}{l}\text { Competências } \\
\text { específicas }\end{array}$ & $\begin{array}{l}\text { Reconhecer a conservação das quantidades em massa dos reagentes e de } \\
\text { produtos envolvidos em uma transformação química. }\end{array}$ \\
\hline Habilidades do ENEM & $\begin{array}{l}\text { H } \mathbf{1 7} \text { = Relacionar informações apresentadas em diferentes formas de linguagem } \\
\text { e representações usadas nas ciências físicas, químicas ou biológicas, como texto } \\
\text { discursivo, gráficos, tabelas, relações matemáticas ou linguagens. } \\
\text { H } \mathbf{2 4}=\text { Utilizar códigos e nomenclatura da química para caracterizar materiais, } \\
\text { substâncias ou transformações químicas. } \\
\text { H } \mathbf{2 5}=\text { Caracterizar materiais ou substâncias, identificando etapas, rendimentos } \\
\text { ou implicações biológicas, sociais, econômicas ou ambientais de sua obtenção ou } \\
\text { produção. }\end{array}$ \\
\hline $\begin{array}{l}\text { Descrição das } \\
\text { atividades }\end{array}$ & $\begin{array}{l}\text { Como forma de verificar o que foi aprendido, a professora juntamente com a } \\
\text { participação dos alunos realiza uma retomada do que foi feito na outra aula por } \\
\text { meio de uma conversa com a sala. } \\
\text { Para iniciar a próxima atividade, a professora colocou em discussão a seguinte } \\
\text { problemática: "Será que ao reagirem certas quantidades de materiais e formarem } \\
\text { novas substâncias, ao verificar no final da reação, é possível dizer que a massa } \\
\text { inicial das substâncias envolvidas são iguais as massas finais das substâncias } \\
\text { formadas?" } \\
\text { Para investigar o problema proposto foi feita uma atividade experimental } \\
\text { demonstrada pela professora com o auxílio de alguns alunos (Apêndice 8), e a } \\
\text { partir dos testes realizados e das discussões estabelecidas, os mesmos deveriam } \\
\text { perceber que a massas dos compostos se conservam. } \\
\text { Como forma de reflexão sobre a lei de conservação das massas estabelecida, os } \\
\text { alunos foram convidados a resolverem dois exercício proposto (Apêndice 9) Para } \\
\text { finalizar as discussões elaboraram um pequeno texto no qual apresentaram suas } \\
\text { impressões e conceitos sobre tudo que foi aprendido até o momento (Apêndice } \\
\text { 10). }\end{array}$ \\
\hline
\end{tabular}

Quadro 10. Descrição das Situações-problema e competências exigidas no terceiro módulo.

\begin{tabular}{|c|l|}
\hline \multicolumn{2}{|c|}{$\mathbf{3}^{\mathbf{0}}$ MÓDULO } \\
\hline Número de aulas: 2 aulas \\
\hline Competências gerais & $\begin{array}{l}\text { Ao final deste módulo o aluno deverá ser capaz de selecionar, organizar, } \\
\text { relacionar, interpretar dados e informações para construir argumentações } \\
\text { consistentes a respeito da ideia de proporção entre o sistema inicial e o final em } \\
\text { uma determinada reação. }\end{array}$ \\
\hline Competências & Reconhecer a proporção fixa entre reagentes e produtos envolvidos em uma \\
\hline
\end{tabular}




\begin{tabular}{|c|c|}
\hline específicas & transformação química. \\
\hline $\begin{array}{c}\text { Habilidades do } \\
\text { ENEM }\end{array}$ & $\begin{array}{l}\text { H } \mathbf{1 7} \text { = Relacionar informações apresentadas em diferentes formas de linguagem } \\
\text { e representaçôes usadas nas ciências físicas, químicas ou biológicas, como texto } \\
\text { discursivo, gráficos, tabelas, relações matemáticas ou linguagens. } \\
\text { H } \mathbf{2 4}=\text { Utilizar códigos e nomenclatura da química para caracterizar materiais, } \\
\text { substâncias ou transformações químicas. } \\
\text { H } \mathbf{2 5}=\text { Caracterizar materiais ou substâncias, identificando etapas, rendimentos } \\
\text { ou implicações biológicas, sociais, econômicas ou ambientais de sua obtenção ou } \\
\text { produção. }\end{array}$ \\
\hline $\begin{array}{c}\text { Descrição das } \\
\text { atividades }\end{array}$ & $\begin{array}{l}\text { Para que os alunos percebessem que em algumas transformações químicas, apesar } \\
\text { de ocorrer a conservação das massas dos reagentes, nem sempre todo reagente é } \\
\text { necessariamente convertido em outro produto, a professora encaminhou o } \\
\text { seguinte questionamento inicial: "Quando se misturam os reagentes, será que tudo } \\
\text { se transforma em produto?". Os alunos realizaram uma atividade experimental } \\
\text { com o objetivo principal de buscar respostas ao questionamento proposto } \\
\text { (Apêndice 11).Ao final da discussão os alunos responderam um questionário } \\
\text { (Apêndice 12) para observar possíveis habilidades construídas. Após a resolução } \\
\text { foi feita uma discussão em sala de aula para verificar as soluções obtidas. }\end{array}$ \\
\hline
\end{tabular}

Quadro 11. Descrição das Situações-problema e competências exigidas no quarto módulo.

\begin{tabular}{|c|c|}
\hline & $4^{\circ}$ MÓDULO \\
\hline Número de aulas: 2 au & \\
\hline Competências gerais & $\begin{array}{l}\text { Ao final deste módulo o aluno deverá ser capaz de selecionar, organizar, } \\
\text { relacionar, interpretar dados e informações para construir argumentações } \\
\text { consistentes a respeito de Situações-problema apresentadas ao longo da aula. }\end{array}$ \\
\hline & $\begin{array}{l}\text { Realizar cálculos para estimar massas, massas molares, quantidade de matéria } \\
\text { (mol) envolvida nas transformações químicas. }\end{array}$ \\
\hline $\begin{array}{l}\text { Habilidades do } \\
\text { ENEM }\end{array}$ & $\begin{array}{l}\text { H } \mathbf{3} \text { = Confrontar interpretações científicas com interpretações baseadas no senso } \\
\text { comum, ao longo do tempo ou em diferentes culturas. } \\
\text { H } \mathbf{8}=\text { Identificar etapas em processos de obtenção, transformação, utilização ou } \\
\text { reciclagem de recursos naturais, energéticos ou matérias-primas, considerando } \\
\text { processos biológicos, químicos ou físicos neles envolvidos. } \\
\text { H } \mathbf{1 7}=\text { Relacionar informações apresentadas em diferentes formas de linguagem e } \\
\text { representações usadas nas ciências físicas, químicas ou biológicas, como texto } \\
\text { discursivo, gráficos, tabelas, relações matemáticas ou linguagens. } \\
\text { H } \mathbf{2 4}=\text { Utilizar códigos e nomenclatura da química para caracterizar materiais, } \\
\text { substâncias ou transformações químicas. } \\
\text { H } \mathbf{2 5}=\text { Caracterizar materiais ou substâncias, identificando etapas, rendimentos ou } \\
\text { implicações biológicas, sociais, econômicas ou ambientais de sua obtenção ou } \\
\text { produção. }\end{array}$ \\
\hline $\begin{array}{l}\text { Descrição das } \\
\text { atividades }\end{array}$ & $\begin{array}{l}\text { Como forma de finalizar a sequência aplicada e verificar conhecimentos e } \\
\text { habilidades constrúdas foi aplicado o instrumento final (Apêndice 13). As } \\
\text { questões propostas retomaram todos os conceitos construídos, e também verificado } \\
\text { possíveis habilidades desenvolvidas pelos alunos na resolução das questões. }\end{array}$ \\
\hline
\end{tabular}

\subsection{Instrumentos de coleta de dados}

O quadro a seguir (Quadro 12) traz um resumo dos diversos instrumentos aplicados, dos conteúdos desenvolvidos e seus principais objetivos.

Quadro 12. Instrumentos aplicados e objetivos pretendidos com as atividades da sequência de ensino. 


\begin{tabular}{|c|c|}
\hline Instrumento & Principais objetivos \\
\hline I1 - Instrumento piloto & $\begin{array}{l}\text { Verificar possíveis dificuldades conceituais e habilidades específicas de } \\
\text { Química através da resolução de questões que abordaram diversos } \\
\text { conteúdos do ensino de Química. }\end{array}$ \\
\hline \multicolumn{2}{|r|}{ Situações problematizadoras } \\
\hline Instrumentos & Principais objetivos \\
\hline $\begin{array}{l}\text { I2 - Ficha de } \\
\text { identificação do aluno }\end{array}$ & $\begin{array}{l}\text { Fornecer um perfil dos alunos em relação a informações como } \\
\text { escolaridade, idade, origem, carreiras de escolha, pretensões em relação } \\
\text { ao cursinho e conhecimentos sobre o ENEM. }\end{array}$ \\
\hline $\begin{array}{l}\text { I3 - Instrumento } \\
\text { diagnóstico }\end{array}$ & $\begin{array}{l}\text { Diagnosticar principais dificuldades conceituais e habilidades específicas } \\
\text { em relação aos temas escolhidos para o desenvolvimento das atividades } \\
\text { da Situação-problematizadora. }\end{array}$ \\
\hline $\begin{array}{l}\text { I4 - Instrumento de } \\
\text { coleta de dados - } \\
\text { concepções prévias }\end{array}$ & $\begin{array}{l}\text { Verificar conhecimentos prévios sobre o conceito de "Transformações } \\
\text { químicas", anterior a realização da atividade experimental, abordando } \\
\text { principalmente aspectos macroscópicos do fenômeno. }\end{array}$ \\
\hline $\begin{array}{l}\text { I5 - Roteiro de atividade } \\
\text { experimental - } \\
\text { evidencias de } \\
\text { transformações químicas }\end{array}$ & $\begin{array}{l}\text { Verificar através de uma atividade experimental como os alunos } \\
\text { reconhecem alguns fenômenos químicos e se conseguem verificar } \\
\text { possíveis evidências das reações químicas. }\end{array}$ \\
\hline $\begin{array}{l}\text { I6 - Texto de apoio } \\
\text { sobre: "Chuva ácida" }\end{array}$ & $\begin{array}{l}\text { Observar a partir da leitura, análise, representações artísticas e discussões } \\
\text { de questões propostas como os alunos verificam que nem todas as } \\
\text { transformações químicas são observadas a partir de evidências de reações. }\end{array}$ \\
\hline $\begin{array}{l}\text { I7 - Síntese dos } \\
\text { conhecimentos }\end{array}$ & $\begin{array}{l}\text { Realizar a síntese de todo conhecimento construído até este momento das } \\
\text { atividades. }\end{array}$ \\
\hline $\begin{array}{l}\text { I8 - Roteiro de atividade } \\
\text { experimental - } \\
\text { conservação da massa }\end{array}$ & $\begin{array}{l}\text { Verificar através de uma atividade experimental o que ocorreu com a } \\
\text { massa total antes e após a reação ocorrer e verificar se ocorreu sua } \\
\text { conservação das quantidades no final da reação. Para estabelecer uma } \\
\text { comparação e melhor compreensão, o fenômeno foi observado em um } \\
\text { sistema aberto e em um sistema fechado. }\end{array}$ \\
\hline $\begin{array}{l}\text { I9 - Reflexões sobre a } \\
\text { Lei de conservação das } \\
\text { massas. }\end{array}$ & $\begin{array}{l}\text { Através de } 2 \text { problemas contendo dados obtidos de forma experimental, } \\
\text { observar possíveis habilidades dos alunos em relacionar a conservação } \\
\text { das massas nas transformações químicas com as situações apresentadas. }\end{array}$ \\
\hline $\begin{array}{l}\text { I10 - Síntese dos } \\
\text { conhecimentos }\end{array}$ & $\begin{array}{l}\text { Realizar a síntese de todo conhecimento construído até este momento das } \\
\text { atividades. Para auxiliar os alunos na construção foram deixados alguns } \\
\text { termos chaves a respeito dos conceitos construídos até o momento. }\end{array}$ \\
\hline $\begin{array}{l}\text { I11 - Roteiro de } \\
\text { atividade experimental - }\end{array}$ & $\begin{array}{l}\text { Realizar e observar a reação que ocorre entre sulfato de cobre e ferro. A } \\
\text { atividade trata da transformação que ocorre entre a palha de aço e a } \\
\text { solução de sulfato de cobre. O aluno deverá perceber que apesar de } \\
\text { ocorrer a conservação das massas dos reagentes, nem sempre todo } \\
\text { reagente é necessariamente convertido em outro produto pois existe uma } \\
\text { relação de proporção entre as quantidades de substâncias que reagem } \\
\text { entre si na formação de uma nova substância. }\end{array}$ \\
\hline $\begin{array}{l}\text { I12 - Reflexões sobre a } \\
\text { Lei de conservação das } \\
\text { massas e da proporção de } \\
\text { Proust }\end{array}$ & $\begin{array}{l}\text { Verificar como os alunos conseguiram articular conceitos, depois de } \\
\text { algumas atividades realizadas e discutidas, sobre a conservação e } \\
\text { proporção das massas em três situações já apresentadas em instrumentos } \\
\text { anteriores. }\end{array}$ \\
\hline $\begin{array}{l}\text { I13 - Verificação final de } \\
\text { conceitos e habilidades }\end{array}$ & $\begin{array}{l}\text { Identificar possíveis construções de conhecimentos e de habilidades } \\
\text { mobilizadas para promover a resolução de questões que abordaram os } \\
\text { conceitos discutidos ao longo de toda a Situação-problema proposta. }\end{array}$ \\
\hline
\end{tabular}

\subsection{Análise dos instrumentos}

Em todos os instrumentos foi aplicada como ferramenta de análise a "Análise de Conteúdo", a qual será brevemente apresentada a seguir. 
Todo ato comunicativo é inaugurado pela emissão de uma mensagem que possui a intenção de um determinado significado. A teoria da linguagem sustenta que este significado receberá um sentido no ato interpretativo. A interpretação, dependendo de condições históricas, sociais e subjetivas diversas de quando, como, onde e por quem é interpretado, pode atribuir um novo significado à mensagem expressa. Desta forma, não existiria um único significado possível, empírico a ser verificado no jogo comunicativo:

O significado de um objeto pode ser absorvido compreendido e generalizado a partir de suas características definidoras e pelo seu corpus de significação. Já o sentido implica a atribuição de um significado pessoal e objetivado que se concretiza na prática social e que se manifesta a partir das Representações Sociais, cognitivas, subjetivas, valorativas e emocionais, necessariamente contextualizadas (FRANCO, 2012, p. 13).

Os recortes das mensagens podem produzir um objeto, independente da objetividade ou subjetividade na produção do conhecimento, e a partir desta produção viabilizar um diálogo com a pesquisa acadêmica (FRANCO, 2012). A Análise de Conteúdo não pretende dar conta de todos os aspectos comunicativos de uma pesquisa, visto que é um processo muito complexo, e sim apenas se firmar como um procedimento de pesquisa, com uma única função: "refletir sobre o sentido da mensagem emitida" (FRANCO, 2012, p. 6).

Portanto, a Análise de Conteúdo estabelece seus limites no "ponto de partida" do processo comunicativo. "Resumindo: o que está escrito, falado, mapeado, figurativamente desenhado, e/ou simbolicamente explicitado sempre será o ponto de partida para a identificação do conteúdo, seja ele explícito e/ou latente.” (Ibdem, p. 17).

O principal trabalho na área da Análise de Conteúdo foi desenvolvido por Laurence Bardin, professora de Psicologia na Universidade de Paris V, que aplicou este método em pesquisas voltadas para a psicossociologia e estudos de comunicação em massa. Sua obra “Análise de Conteúdo", originalmente publicada em 1970, foi reeditada diversas vezes. Segundo a autora, trata-se de um manual de utilização do método oferecido aos leitores de forma a auxiliá-los em seus trabalhos. Pode ser definida pela autora como:

(...) um conjunto de técnicas de análise das comunicações visando obter, por procedimentos, sistemáticos e objetivos de descrição do conteúdo das mensagens, indicadores (quantitativos ou não) que permitam a inferência de conhecimentos relativos às condições de produção/recepção [...] destas mensagens (BARDIN, 1977)

Franco (2012) resume uma forma de estruturação do método em três fases principais que levam a estruturação das categoriais e discussão dos resultados.

1) Pré-análise; 
2) Exploração do material (codificação, decodificação e categorização);

3) Inferência, interpretação e tratamento dos resultados.

A pré-análise é a fase em que se organiza o material objetivando torná-lo operacional. Trata-se da organização propriamente dita por meio de quatro etapas: (a) leitura flutuante, que é o primeiro contato com os dados coletados; (b) escolha dos documentos, que consiste na definição do corpus documental; (c) confirmação ou reformulação das hipóteses e dos objetivos traçados inicialmente e; (d) a elaboração de indicadores que fundamentem a interpretação final (BARDIN, 1977).

De forma detalhada, a Análise de Conteúdo aqui empreendida percorreu o seguinte roteiro:

\section{1) Pré-análise}

(a) Leitura flutuante

A primeira etapa da Pré-análise é a chamada leitura flutuante. Compreendida como o contato inicial com o material a ser analisado conhecendo sua forma de apresentação, impressão, representações, emoções e conhecimentos. No caso do nosso trabalho entendemos como leitura flutuante desde a leitura das respostas dos alunos de cada uma das questões de cada um dos instrumentos aplicados, desde o piloto até o último instrumento da sequência, até as verificações das interações entre os alunos e também entre a professora e os alunos nas filmagens realizadas durante as aplicações de alguns instrumentos.

(b) Escolha dos documentos - definição do corpus documental

A ideia do corpus documental parece ser fundamental já que é preciso escolher com o que se vai trabalhar. Foi possível delimitar o corpus documental desta pesquisa respeitando as quatro regras (exaustividade, representatividade e homogeneidade) de seleção estabelecidas pelo método da Análise de Conteúdo.

No quadro que se segue (Quadro 13) estão organizados os principais conceitos trabalhados em cada Módulo, bem como todos os instrumentos necessários para o desenvolvimento dos mesmos em cada etapa do trabalho.

Quadro 13. Organização dos módulos de acordo com os temas e instrumentos utilizados em cada etapa.

\begin{tabular}{|l|c|c|}
\hline \multicolumn{3}{|c|}{ MÓDULO 1 - Transformações químicas } \\
\hline Conhecimentos & Construção do conhecimento & Verificação do conhecimento \\
\hline
\end{tabular}




\begin{tabular}{|c|c|c|}
\hline prévios & & \\
\hline Instrumentos 3 e 4 & Instrumentos 5 e 6 & Instrumento 7 \\
\hline \multicolumn{3}{|c|}{ MÓDULO 2 - Lei de conservação das massas - "Lei de Lavoisier" } \\
\hline $\begin{array}{c}\text { Conhecimentos } \\
\text { prévios }\end{array}$ & Construção do conhecimento & Verificação do conhecimento \\
\hline Instrumento 3 & Instrumentos 8 e 9 & Instrumento 10 \\
\hline \multicolumn{3}{|c|}{ MÓDULO 3 - Lei das proporções - "Lei de Proust" } \\
\hline $\begin{array}{c}\text { Conhecimentos } \\
\text { prévios }\end{array}$ & Construção do conhecimento & Verificação do conhecimento \\
\hline Instrumento 3 & Instrumento 11 & Instrumento 12 \\
\hline \multicolumn{3}{|c|}{ MÓDULO 4 - Aplicação do conhecimento } \\
\hline \multicolumn{3}{|c|}{ Instrumento 13} \\
\hline
\end{tabular}

Como a proposta foi verificar o desenvolvimento de habilidades específicas dos alunos diante das diversas situações organizadas nos módulos, foi importante analisar materiais de quase todas as atividades. Como critério de escolha dos materiais, a ideia central foi verificar como, conceitual e cognitivamente, os alunos iniciaram a sequência (conhecimentos prévios), quais as formas de construção de tais conhecimentos e habilidades e a verificação da aplicação dos conhecimentos construídos. Em relação à primeira fase da pesquisa, o corpus documental constitui-se como sendo o próprio instrumento piloto, respondido pelos alunos. Já na segunda fase, o corpus documental formou-se de todas as questões que compuseram os instrumentos 3, 4, 7, 9, 10, 12 e 13.

(c) Formulação da hipótese e dos objetivos

A hipótese é a afirmação provisória que nos propomos verificar. Segundo nossa interpretação, tanto a hipótese quanto os objetivos se aproximam dos descritos durante a introdução do trabalho. A hipótese que nasce da problematização do nosso objeto de pesquisa e os objetivos que pretendemos alcançar para contemplação da pesquisa são pontos de convergência da pesquisa com a Análise de Conteúdo:

Torna-se necessário saber a razão porque é que se analisa e explicitá-lo de modo a que se possa saber como analisar. Daqui a necessidade de se precisarem hipóteses e de se enquadrar a técnica dentro de um quadro teórico, tal qual acabamos de ver. (BARDIN,1977, p. 103).

A hipótese principal do nosso trabalho é que uma sequência que problematize através de atividades experimentais, reflexões coletivas $\mathrm{e}$ individuais, relatos escritos do 
conhecimento construído e problemas propostos como reflexão do conhecimento, podem contribuir para o desenvolvimento de competências e habilidades exigidas pelo ENEM na área de ciências da natureza.

Também, conforme descrito na introdução deste trabalho, o objetivo geral desta pesquisa foi verificar se uma sequência de atividades problematizadoras, propostas em um cursinho popular, contribuem para o desenvolvimento de habilidades específicas do ensino de Química, presentes na Matriz de Referência de Ciências da Natureza e suas Tecnologias (INEP, 2009), e de habilidades de alta ordem que se relacionam diretamente com as habilidades do ENEM.

Através da Análise de Conteúdo conseguimos obter categorias de análise que nos mostram um pouco sobre o pensamento do aluno. A partir da relação das categorias construídas com as habilidades cognitivas de alta e baixa ordem (SUART, 2008), conseguimos entender de que forma nossas atividades contribuíram para o desenvolvimento de habilidades específicas do ENEM.

(d) Definição dos indicadores/descritores

Os indicadores ou descritores podem ser caracterizados como a menção a um tema, ou seja, corresponde a frequência observada acerca do tema em questão. O tema passa a ter importância para a análise de dados quanto mais frequente for mencionado (Ibidem, p.60). Em nosso trabalho entendemos como indicadores as respostas dos alunos referentes a cada uma das questões de cada um dos instrumentos, as habilidades escolhidas do ENEM e também as habilidades de alta e baixa ordem de cognição. Com a descrição dos indicadores correspondentes a cada um dos alunos também foi possível observar a frequência de aparecimento de tais indicadores, o que influenciou exponencialmente na criação e contabilização das categorias.

\section{2) Exploração do material}

(a) codificação

Esta etapa pode ser entendida como a fase de preparação do material. A codificação é o momento em que o conteúdo analisado é desmontado, procurando separar suas unidades de significação, “corresponde a uma transformação - efectuada (sic) segundo regras precisas dos dados brutos do texto, transformação esta que, por recorte, agregação e enumeração, 
permite atingir uma representação do conteúdo, ou da sua expressão" (BARDIN, 1977, p. $103)$.

Em relação ao nosso trabalho, fizemos uma leitura ampla de todo o material para adotarmos uma estratégia de como este seria codificado. Dentro de uma única questão realizamos um desmembramento das respostas dos alunos criando blocos de informações conceituais semelhantes. Conforme é mostrado na figura 3, estabelecemos uma sequência de numeração para que pudéssemos organizar as mesmas, as quais foram de grande valia para a etapa seguinte, a decodificação.

Figura 3. Questão 2 retirada do instrumento piloto.

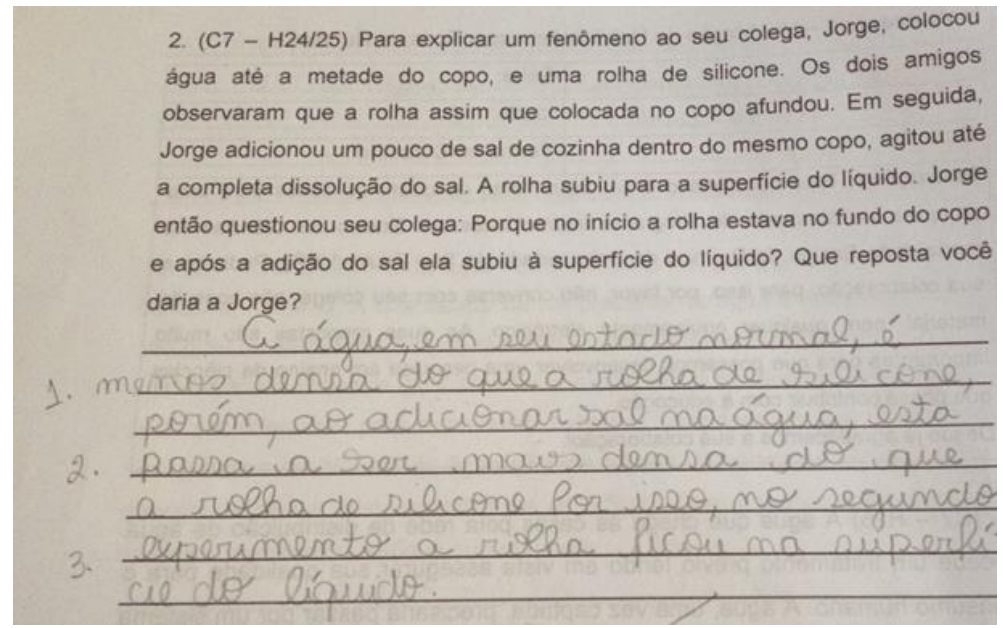

(b) decodificação

Correspondeu à reorganização do material escolhido, não mais respeitando sua organização inicial, mas sim a divisão construída na etapa da codificação. Aproxima-se partes distintas do conteúdo, mas que possuem o mesmo significado. Ao decodificar, ou seja, reunir as diversas partes codificadas que possuem significados próximos segundo a hipótese e objetivo da pesquisa, vai permitir que se construa as categorias:

classificação de elementos constitutivos de um conjunto, por diferenciação e, seguidamente, por reagrupamento segundo o gênero (analogia), com os critérios previamente definidos. As categorias, são rubricas ou classes, as quais reúnem um grupo de elementos ... sob um título genérico, agrupamento esse efectuado em razão dos caracteres comuns destes elementos (BARDIN, 1977, p. 117).

Em nossa pesquisa, decodificar o material inicialmente codificado representou selecionar os blocos criados dentro das respostas das questões de todos os alunos e agrupá-los de acordo com as semelhanças conceituais. Ao nosso entendimento, com a criação das decodificações começamos a diagnosticar algumas das principais dificuldades dos alunos. 
Esta caracteriza-se como uma etapa decisiva de aplicação da ferramenta de "Análise de Conteúdo", visto que as categorias foram organizadas a partir dos resultados da decodificação.

\section{(c) Categorização}

O valor da Análise de Conteúdo é o seu compromisso em criar categorias analíticas a partir do conteúdo estudado. A criação de categorias é compreendida como uma operação de classificação seguida por um agrupamento. É necessário primeiramente utilizar o critério da diferença para poder classificar e posteriormente o da semelhança para poder agrupar, a partir de critérios bem definidos.

Para se realizar a construção das categorias é possível se percorrer dois possíveis caminhos: categorias criadas e categorias não definidas. O primeiro caminho consiste na criação das categorias a priori, ou seja, são predeterminadas para que se possa a partir delas buscar uma resposta específica do investigador.

Já o segundo caminho, optado por nós, consiste na criação de categorias posteriores a análise do material. A escolha em trabalhar com a criação de categorias para analisar os dados das atividades propostas na Situação-problema está fundamentada na Análise de Conteúdo - a preservação e valorização da mensagem- e a codificação, ou seja, organização do mesmo em categorias possibilita esse processo.

Tais categorias emergem do discurso, do conteúdo das respostas no caso de nossa pesquisa - dos alunos. Neste momento torna-se importante realizar uma leitura das respostas dos alunos de forma detalhada, pois quanto maior a clareza conceitual da pesquisadora maior será sua habilidade de fragmentação das respostas dadas e, portanto, melhor será feita a classificação "das convergências e das respectivas divergências das respostas” É criado, um “código para a leitura" (FRANCO, 2012, p. 103). Primeiramente realiza-se a leitura, agrupase as respostas por algum tipo de semelhança, sendo que as categorias somente serão criadas posteriormente aos processos descritos acima, sendo que elas praticamente aparecem nas respostas.

O grande desafio foi não criar uma categoria para cada resposta, e sim não criar uma grande quantidade de categorias, o que fragmenta muito a fala dos alunos e também prejudica a análise dos dados. Nesta etapa de criação de categorias também existem alguns princípios que devem ser seguidos para se tentar garantir a construção de boas categorias, ou seja, aquelas que valorizem o máximo possível o material: 
- A exclusão mútua: depende da "homogeneidade" das categorias, que deve ser orientada por um único princípio de classificação.

- A pertinência: uma categoria só é considerada pertinente quando, segundo Franco, está adaptada ao material de análise escolhido.

- A objetividade e a fidedignidade: muito importante pois com a criação de categorias é muito importante que se siga uma codificação sempre da mesma forma, independente da parte do material que se utiliza e do número de vezes que se analisa.

- A produtividade: por fim, um conjunto de categorias deve ser produtivo se conseguir fornecer dados e resultados relevantes aos objetivos da pesquisa, e também novas hipóteses, possibilidades de críticas construtivas e transformadoras (BARDIN, 1977).

De forma geral, em nossa pesquisa as diversas respostas dadas pelos alunos às situações problematizadoras foram codificadas, posteriormente os diversos trechos das respostas foram decodificados e por fim, quando foram agrupadas de acordo com o sentido que possuíam, resultaram na criação das categorias.

Ao final de todo o processo descrito para cada questão, os dados foram organizados a partir de duas formas distintas. A primeira está representada no quadro 14 organizado em três colunas. A primeira coluna correspondeu as habilidades escolhidas da matriz do ENEM para serem mobilizadas durante a resolução de cada questão. $\mathrm{Na}$ segunda coluna, a da decodificação, utilizamos fragmentos das próprias respostas dos alunos, as quais se originaram dos blocos descritos anteriormente. Talvez esta seja a coluna mais importante da tabela, já que é neste momento em que se utilizamos das respostas dos alunos para a construção da terceira coluna, que foi a categorização propriamente dita.

Quadro 14. Relação das habilidades escolhidas, decodificações e categorias estabelecidas a partir da análise da questão 1 do instrumento piloto.

\section{COMPETÊNCIA DE ÁREA 5/7 (Matriz de referência do ENEM)}

HABILIDADE 17 - Relacionar informações apresentadas em diferentes formas de linguagem e representações usadas nas ciências físicas, químicas ou biológicas, como texto discursivo, gráficos, tabelas, relações matemáticas ou linguagens.

HABILIDADE 25 - Caracterizar materiais ou substâncias, identificando etapas, rendimentos ou implicações biológicas, sociais, econômicas ou ambientais de sua obtenção ou produção.

\begin{tabular}{|c|c|c|}
\hline Habilidades & Decodificação & Categorização \\
\hline $\begin{array}{c}\text { Relacionar } \\
\text { informações } \\
\text { apresentadas em } \\
\text { diferentes formas de } \\
\text { linguagem e } \\
\text { representações usadas } \\
\text { nas ciências físicas, } \\
\text { químicas ou biológicas, }\end{array}$ & $\begin{array}{l}(1) \\
\text { Conseguiu relacionar as informações da figura com } \\
\text { todas as etapas de tratamento da água descritas }\end{array}$ & $\begin{array}{c}\text { CA 1 } \\
\text { Capacidade de } \\
\text { identificar as etapas } \\
\text { do tratamento da } \\
\text { água relacionando } \\
\text { com a figura } \\
\text { proposta } \\
1 \\
\text { CA 2 }\end{array}$ \\
\hline
\end{tabular}




\begin{tabular}{|c|c|c|}
\hline \multirow{3}{*}{$\begin{array}{l}\text { como texto discursivo, } \\
\text { gráficos, tabelas, } \\
\text { relações matemáticas } \\
\text { ou linguagens. }\end{array}$} & Confusão de 1 etapa do tratamento da água & \multirow{4}{*}{$\begin{array}{l}\text { Dificuldade de } \\
\text { relacionar algumas } \\
\text { etapas de } \\
\text { tratamento da água } \\
\text { com a figura } \\
\text { proposta. } \\
\text { 2/3/4/5 } \\
\text { CA } 3 \\
\text { Não possui } \\
\text { habilidades } \\
\text { conceituais para } \\
\text { relacionar a figura } \\
\text { com as etapas de } \\
\text { tratamento da água } \\
\text { de forma correta } \\
6\end{array}$} \\
\hline & $\begin{array}{c}\text { (3) } \\
\text { Confusão entre } 2 \text { etapas do tratamento da água }\end{array}$ & \\
\hline & $\begin{array}{c}\text { (4) } \\
\text { Confusão entre } 3 \text { etapas do tratamento da água }\end{array}$ & \\
\hline \multirow[t]{2}{*}{$\begin{array}{l}\text { Caracterizar materiais } \\
\text { ou substâncias, } \\
\text { identificando etapas, } \\
\text { rendimentos ou } \\
\text { implicações biológicas, } \\
\text { sociais, econômicas ou } \\
\text { ambientais de sua } \\
\text { obtenção ou produção. }\end{array}$} & $\begin{array}{c}\text { (5) } \\
\text { Confusão entre } 4 \text { etapas do tratamento da água }\end{array}$ & \\
\hline & $\begin{array}{c}(6) \\
\text { Confusão entre todas as etapas do tratamento da água }\end{array}$ & \\
\hline
\end{tabular}

Reagrupando as decodificações de cada questão conseguimos obter as categorias, que agrupam desde os alunos que conseguem responder a questão cumprindo todos os prérequisitos esperados como padrão de resposta correta até chegar em uma categoria para o grupo que deixou a questão em branco. O interessante é que para as categorias criadas para agrupar os alunos que conseguiram resolver parcialmente os exercícios, é possível utilizar como identificação da capacidade a habilidade utilizada e da dificuldade aquela que não foi, mas precisaria ser mobilizada.

A segunda forma de organização dos dados obtidos foi expressa através de uma tabela (Tabela 2) organizada a partir de duas informações principais: os alunos e as decodificações, para que pudéssemos organizar nossas marcações. Na medida em que a decodificação criada aparece na resposta, denominamos a numeração 1 como forma de representação, e quando não aparece na resposta denominamos zero. Utilizando cores diversificadas para agrupar resultados semelhantes, ao final do trabalho isso nos ajudou a quantificar as decodificações criadas.

Tabela 2. Decodificações das respostas dos alunos referentes à questão 1 do instrumento piloto.

\begin{tabular}{|r|r|r|r|r|r|r|}
\hline \multicolumn{7}{|c|}{ QUESTÃ O 1 - Turma 1 } \\
\hline Alunos & \multicolumn{5}{|c|}{ Decodificação (DC)* } \\
\hline & 1 & 2 & 3 & 4 & 5 & 6 \\
\hline 1 & 1 & 0 & 0 & 0 & 0 & 0 \\
\hline 2 & 1 & 0 & 0 & 0 & 0 & 0 \\
\hline 3 & 1 & 0 & 0 & 0 & 0 & 0 \\
\hline 4 & 1 & 0 & 0 & 0 & 0 & 0 \\
\hline
\end{tabular}




\begin{tabular}{|r|r|r|r|r|r|r|}
\hline 7 & 1 & 0 & 0 & 0 & 0 & 0 \\
\hline 8 & 1 & 0 & 0 & 0 & 0 & 0 \\
\hline 9 & 1 & 0 & 0 & 0 & 0 & 0 \\
\hline 10 & 1 & 0 & 0 & 0 & 0 & 0 \\
\hline 11 & 1 & 0 & 0 & 0 & 0 & 0 \\
\hline 12 & 1 & 0 & 0 & 0 & 0 & 0 \\
\hline 13 & 1 & 0 & 0 & 0 & 0 & 0 \\
\hline 14 & 1 & 0 & 0 & 0 & 0 & 0 \\
\hline 15 & 1 & 0 & 0 & 0 & 0 & 0 \\
\hline 16 & 1 & 0 & 0 & 0 & 0 & 0 \\
\hline 19 & 1 & 0 & 0 & 0 & 0 & 0 \\
\hline 23 & 1 & 0 & 0 & 0 & 0 & 0 \\
\hline 24 & 1 & 0 & 0 & 0 & 0 & 0 \\
\hline 25 & 1 & 0 & 0 & 0 & 0 & 0 \\
\hline 5 & 0 & 0 & 1 & 0 & 0 & 0 \\
\hline 6 & 0 & 0 & 1 & 0 & 0 & 0 \\
\hline 17 & 0 & 0 & 1 & 0 & 0 & 0 \\
\hline 22 & 0 & 0 & 1 & 0 & 0 & 0 \\
\hline 18 & 0 & 0 & 0 & 1 & 0 & 0 \\
\hline 20 & 0 & 0 & 0 & 0 & 1 & 0 \\
\hline 21 & 0 & 0 & 0 & 0 & 0 & 1 \\
\hline
\end{tabular}

*a numeração corresponde à descrição da decodificação apresentada no quadro anterior

Este tipo de análise nos ajudou a entender até que ponto o aluno conseguiu desenvolver habilidades que o possibilitassem resolver a questão e em que momento ele não conseguiu avançar na resolução de cada problemática proposta.

\section{3) Inferência, interpretação e tratamento dos resultados}

Esta etapa é destinada a interpretação do que significa do todo, quais relações foram passíveis de serem construídas em uma análise reflexiva e crítica do conteúdo agora devidamente codificado, decodificado e categorizado. 
A apresentação dos resultados está organizada em duas partes: uma referente ao instrumento piloto e outra, aos dados obtidos com a aplicação da sequência de ensino.

\subsection{Instrumento piloto}

Foram analisadas todas as questões que compuseram o instrumento piloto aplicado na fase inicial da pesquisa. Assim, estão descritos os resultados obtidos e as análises de cada uma das questões.

\section{QUESTÃO 1}

A água que chega às casas pela rede de distribuição de água recebe um tratamento prévio tendo em vista assegurar sua qualidade para o consumo humano. A água, uma vez captada, precisaria passar por um sistema de purificação, feito nas estações de tratamento, conforme representado no esquema:

\section{Estação de Tratamento de água} Esquema simplificado

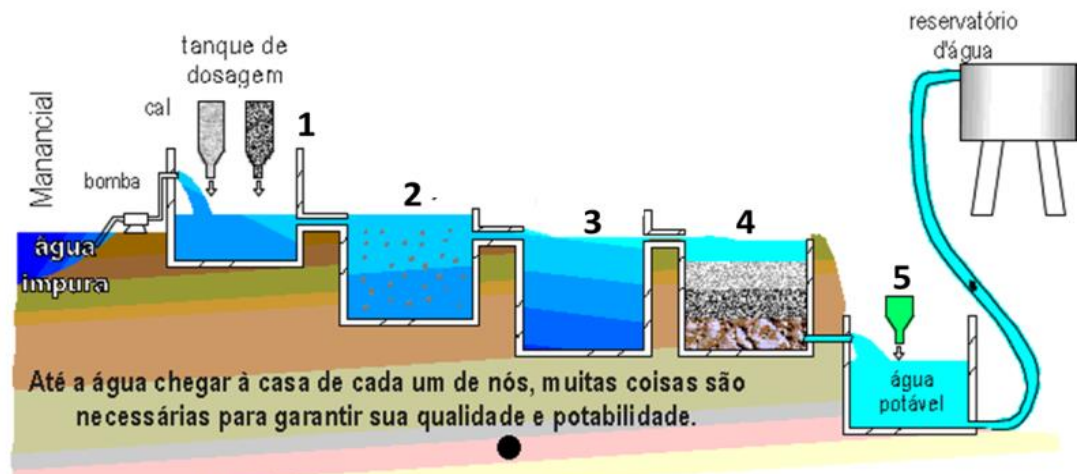

Relacione as etapas descritas com as representadas no esquema acima:

A = Decantação

B = Adição de cloro

C = Floculação

D = Adição de sulfato de alumínio

$\mathbf{E}=$ Filtração
1- $(\quad)$

2- ( )

3- $(\quad)$

4- ( )

5- $(\quad)$

Fonte: Produzida pela autora

Imagem: http://www.uenf.br/uenf/centros/cct/qambiental/ag tratagua.html 
O quadro 15 apresenta, para a Questão 1, as decodificações criadas a partir das respostas dos alunos, as categorias criadas e as habilidades e competências, selecionadas a partir da matriz do ENEM, suscitadas pela questão para serem mobilizadas pelos estudantes.

Quadro 15. Relação das habilidades escolhidas, decodificações e categorias estabelecidas a partir da análise da questão 1 do instrumento piloto.

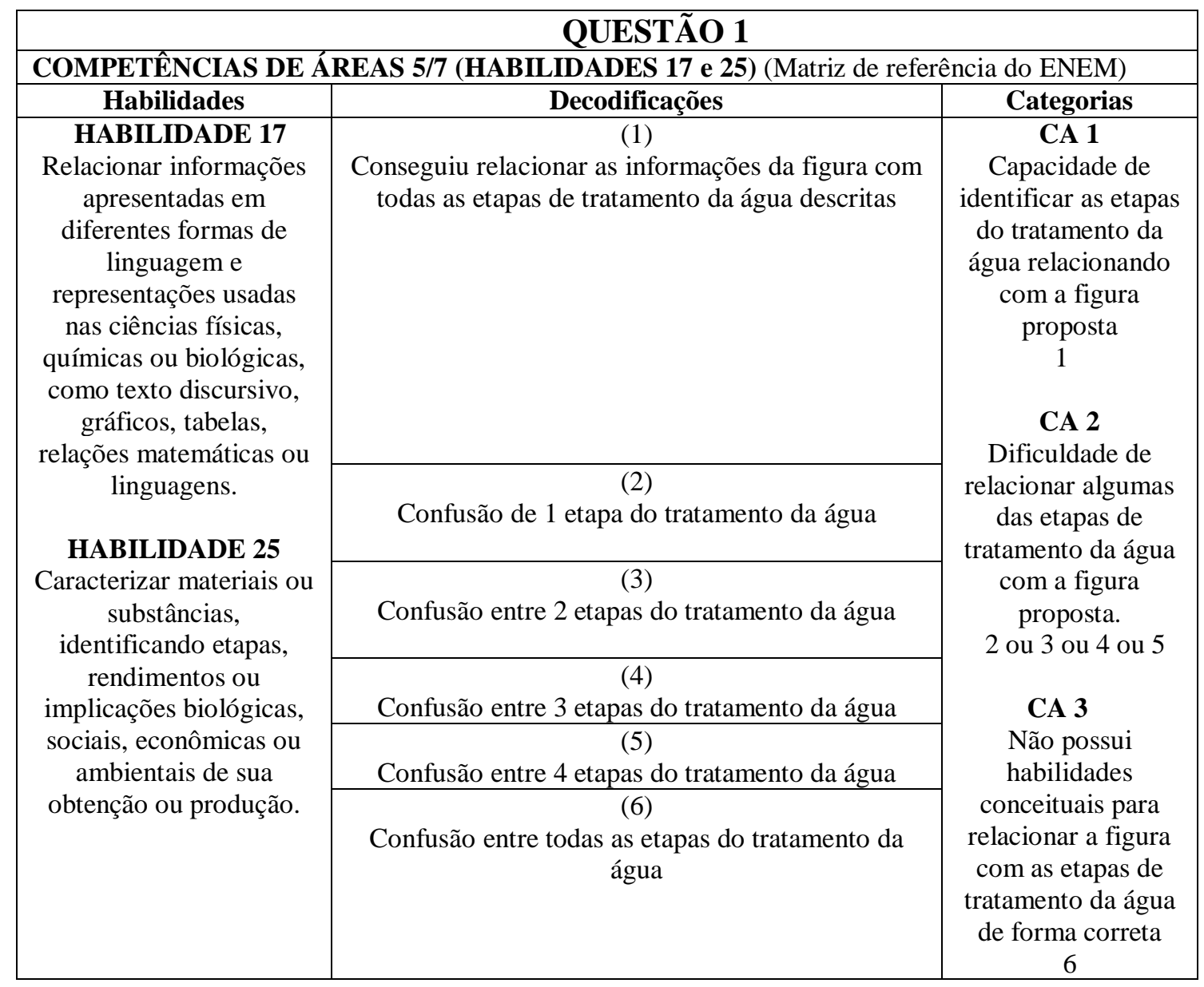

Para melhor visualizarmos as categorias construídas e estabelecermos possíveis comparativos entre elas construímos o gráfico a seguir (Figura 4) em que relacionamos as categorias criadas com as turmas participantes do projeto. 
Figura 4. Número de alunos por categorias referentes à questão 1 do instrumento piloto.

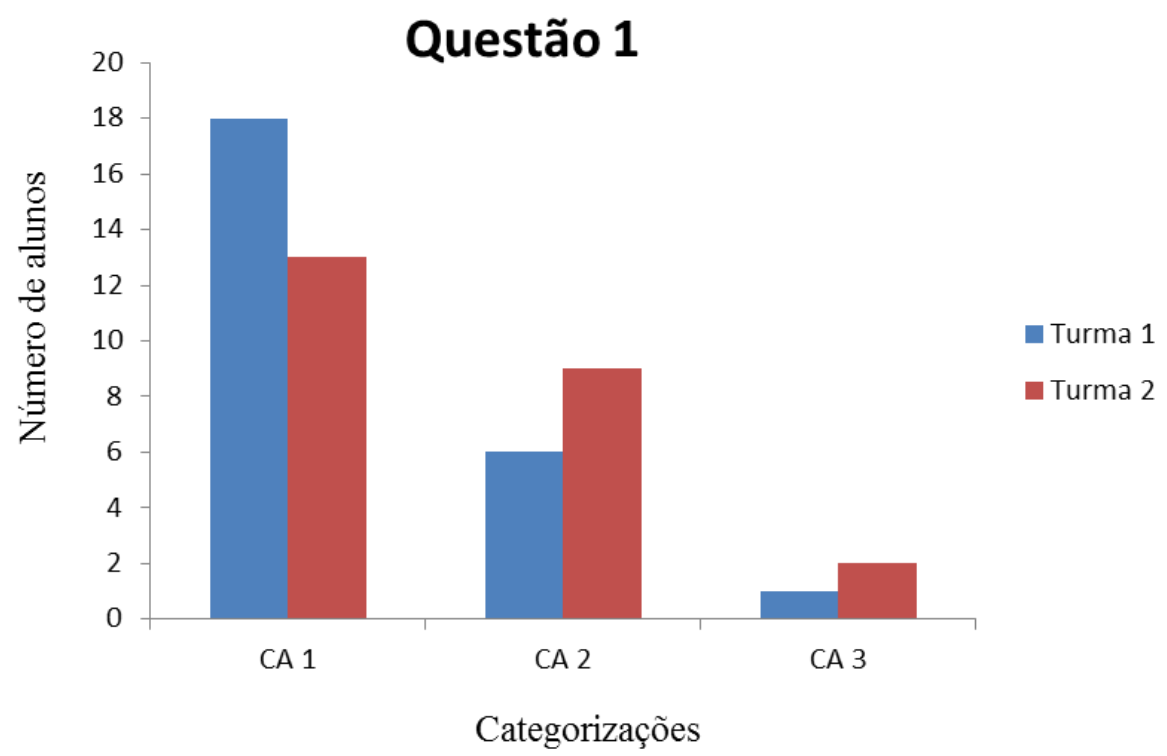

Os resultados dispostos na figura 4 nos permitiram concluir que a maioria dos alunos de ambas as turmas demonstraram a capacidade de identificar todas as etapas de tratamento da água, estabelecendo uma relação com a figura proposta no problema. A pequena diferença entre as turmas se justificou na dificuldade de alguns alunos, principalmente da turma 2, de relacionar todas as etapas ocorrendo certa confusão conceitual conforme observado na categoria 2.

Analisando somente o gráfico das categorizações surgiram dois questionamentos: Qual a quantidade de etapas que foi confundida pelas turmas? É possível identificar quais habilidades não estão sendo mobilizadas pelos alunos? Ou possíveis dificuldades conceituais?

Com o propósito de quantificar os grupos de respostas dadas pelos alunos e investigar possíveis questionamentos levantados a partir da construção do gráfico das categorias, construímos uma tabela em que relacionamos o número de alunos com as decodificações criadas. Nessa tabela (Tabela 3), o número 1 atribuído à resposta do aluno indicou que essa se enquadrava na decodificação, o número zero significou que a decodificação não se aplicava à resposta do aluno.

Tabela 3. Decodificações das respostas dos alunos referentes à questão 1 do instrumento piloto.

\begin{tabular}{|r|r|r|r|r|r|r|}
\hline \multicolumn{7}{|c|}{ QUESTÃO 1 - Turma 1 } \\
\hline Alunos & \multicolumn{7}{|c|}{ Decodificações (DC) } \\
\hline & 1 & 2 & 3 & 4 & 5 & 6 \\
\hline 1 & 1 & 0 & 0 & 0 & 0 & 0 \\
\hline 2 & 1 & 0 & 0 & 0 & 0 & 0 \\
\hline
\end{tabular}




\begin{tabular}{|r|r|r|r|r|r|r|}
\hline 3 & 1 & 0 & 0 & 0 & 0 & 0 \\
\hline 4 & 1 & 0 & 0 & 0 & 0 & 0 \\
\hline 7 & 1 & 0 & 0 & 0 & 0 & 0 \\
\hline 8 & 1 & 0 & 0 & 0 & 0 & 0 \\
\hline 9 & 1 & 0 & 0 & 0 & 0 & 0 \\
\hline 10 & 1 & 0 & 0 & 0 & 0 & 0 \\
\hline 11 & 1 & 0 & 0 & 0 & 0 & 0 \\
\hline 12 & 1 & 0 & 0 & 0 & 0 & 0 \\
\hline 13 & 1 & 0 & 0 & 0 & 0 & 0 \\
\hline 14 & 1 & 0 & 0 & 0 & 0 & 0 \\
\hline 15 & 1 & 0 & 0 & 0 & 0 & 0 \\
\hline 16 & 1 & 0 & 0 & 0 & 0 & 0 \\
\hline 19 & 1 & 0 & 0 & 0 & 0 & 0 \\
\hline 23 & 1 & 0 & 0 & 0 & 0 & 0 \\
\hline 24 & 1 & 0 & 0 & 0 & 0 & 0 \\
\hline 25 & 1 & 0 & 0 & 0 & 0 & 0 \\
\hline 5 & 0 & 0 & 1 & 0 & 0 & 0 \\
\hline 6 & 0 & 0 & 1 & 0 & 0 & 0 \\
\hline 17 & 0 & 0 & 1 & 0 & 0 & 0 \\
\hline 22 & 0 & 0 & 1 & 0 & 0 & 0 \\
\hline 18 & 0 & 0 & 0 & 1 & 0 & 0 \\
\hline 20 & 0 & 0 & 0 & 0 & 1 & 0 \\
\hline 21 & 0 & 0 & 0 & 0 & 0 & 1 \\
\hline 0 & & 0 & & & \\
\hline
\end{tabular}

\section{QUESTÃO 1 - Turma 2}

\begin{tabular}{|r|r|r|r|r|r|r|}
\hline Alunos & \multicolumn{6}{|c|}{ Decodificações (DC) } \\
\hline & 1 & 2 & 3 & 4 & 5 & 6 \\
\hline 1 & 1 & 0 & 0 & 0 & 0 & 0 \\
\hline 2 & 1 & 0 & 0 & 0 & 0 & 0 \\
\hline 6 & 1 & 0 & 0 & 0 & 0 & 0 \\
\hline 8 & 1 & 0 & 0 & 0 & 0 & 0 \\
\hline 9 & 1 & 0 & 0 & 0 & 0 & 0 \\
\hline 12 & 1 & 0 & 0 & 0 & 0 & 0 \\
\hline 13 & 1 & 0 & 0 & 0 & 0 & 0 \\
\hline 14 & 1 & 0 & 0 & 0 & 0 & 0 \\
\hline 15 & 1 & 0 & 0 & 0 & 0 & 0 \\
\hline 17 & 1 & 0 & 0 & 0 & 0 & 0 \\
\hline 18 & 1 & 0 & 0 & 0 & 0 & 0 \\
\hline 19 & 1 & 0 & 0 & 0 & 0 & 0 \\
\hline 22 & 1 & 0 & 0 & 0 & 0 & 0 \\
\hline 7 & 0 & 1 & 0 & 0 & 0 & 0 \\
\hline 5 & 0 & 0 & 1 & 0 & 0 & 0 \\
\hline 11 & 0 & 0 & 1 & 0 & 0 & 0 \\
\hline 20 & 0 & 0 & 1 & 0 & 0 & 0 \\
\hline 21 & 0 & 0 & 1 & 0 & 0 & 0 \\
\hline
\end{tabular}




\begin{tabular}{|r|r|r|r|r|r|r|}
\hline 23 & 0 & 0 & 1 & 0 & 0 & 0 \\
\hline 3 & 0 & 0 & 0 & 1 & 0 & 0 \\
\hline 10 & 0 & 0 & 0 & 0 & 1 & 0 \\
\hline 24 & 0 & 0 & 0 & 0 & 1 & 0 \\
\hline 4 & 0 & 0 & 0 & 0 & 0 & 1 \\
\hline 16 & 0 & 0 & 0 & 0 & 0 & 1 \\
\hline
\end{tabular}

*a numeração corresponde à descrição da decodificação apresentada no quadro anterior

A partir da tabela construiu-se o gráfico (Figura 5) a seguir em que verificamos a relação entre o número de alunos com o tipo de decodificação demonstrada por eles.

Figura 5. Número de alunos por decodificações referentes à questão 1 do instrumento piloto.

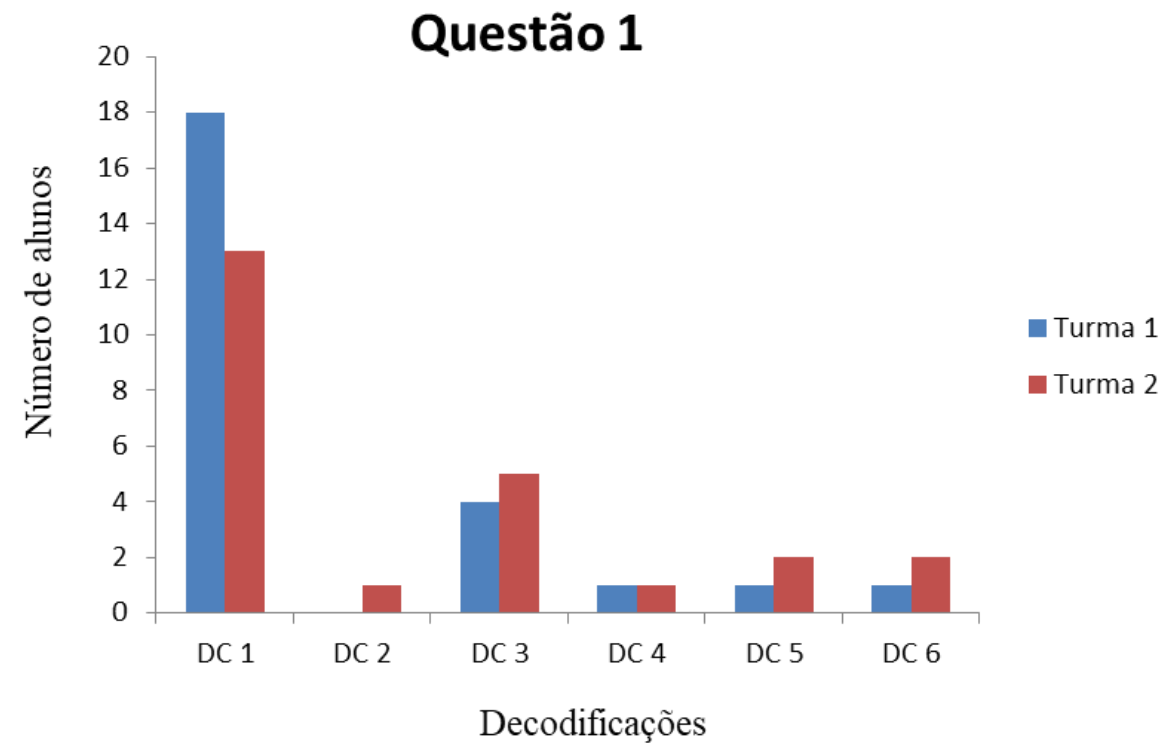

Como já revelado na Figura 5, em ambas as turmas a maior parte dos alunos conseguiu relacionar as informações da figura com todas as etapas de tratamento da água, já que a decodificação 1 aparece em maior proporção. Isto mostra que, ao conseguirem resolver a questão, os alunos mobilizaram inicialmente uma habilidade de mais baixa ordem cognitiva (habilidade 17) e na sequência uma de alta ordem (habilidade 25). A Figura 5 também mostrou que o maior número de confusões apareceu em duas etapas de tratamento da água, já que o maior número de decodificações corresponde a DC 3 para ambas as turmas. Entretanto, ficou um pouco difícil afirmar se a dificuldade estava em relacionar uma informação na linguagem gráfica (habilidade 17) ou caracterizar materiais identificando as etapas de tratamento (habilidade 25) já que as duas habilidades agrupam todos os tipos de confusões conceituais. O perfil das duas turmas foi muito semelhante tanto em relação a habilidade de 
relacionar todas as informações de forma correta quanto na dificuldade em relacionar majoritariamente duas etapas do tratamento de água.

\section{QUESTÃO 2}

Para explicar um fenômeno ao seu colega, Jorge, colocou água até a metade do copo, e uma rolha de silicone. Os dois amigos observaram que a rolha, assim que colocada no copo, afundou. Em seguida, Jorge adicionou um pouco de sal de cozinha dentro do mesmo copo, agitou até a completa dissolução do sal. A rolha subiu para a superfície do líquido. Jorge então questionou seu colega: Por que no início a rolha estava no fundo do copo e após a adição do sal ela subiu à superfície do líquido? Que reposta você daria a Jorge?

Fonte: Produzida pela autora

O quadro 16 apresenta, para a Questão 2, as decodificações criadas a partir das respostas dos alunos, as categorias criadas e as habilidades e competências selecionadas a partir da matriz do ENEM, suscitadas pela questão para serem mobilizadas pelos estudantes.

Quadro 16. Relação das habilidades escolhidas, decodificações e categorias estabelecidas a partir da análise da questão 2 do instrumento piloto.

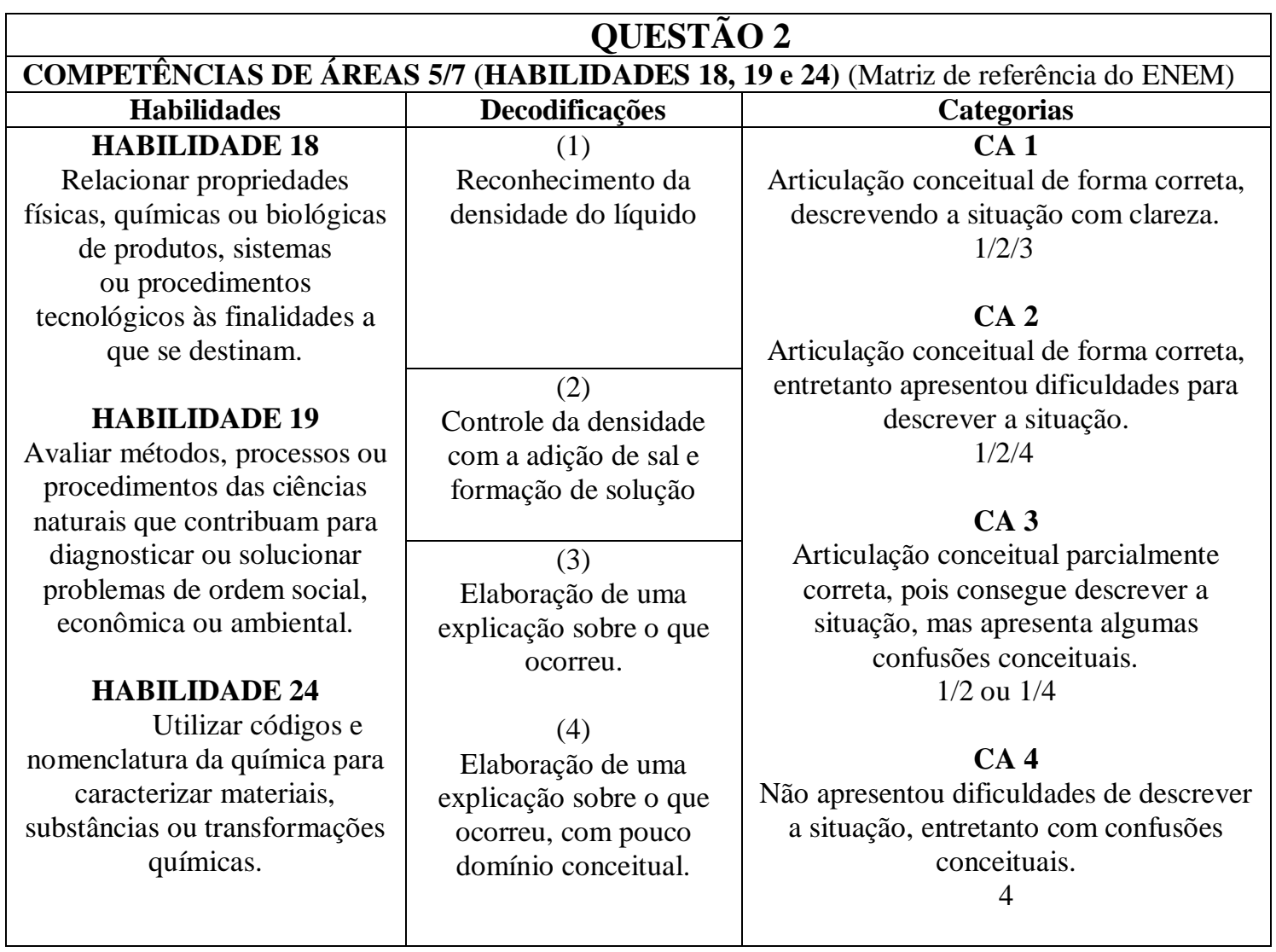


Para melhor visualizarmos as categorias construídas e estabelecermos possíveis comparativos entre elas construímos o gráfico a seguir (Figura 6) em que relacionamos as categorias criadas com as turmas participantes do projeto.

Figura 6. Número de alunos por categorias referentes à questão 2 do instrumento piloto.

\section{Questão 2}

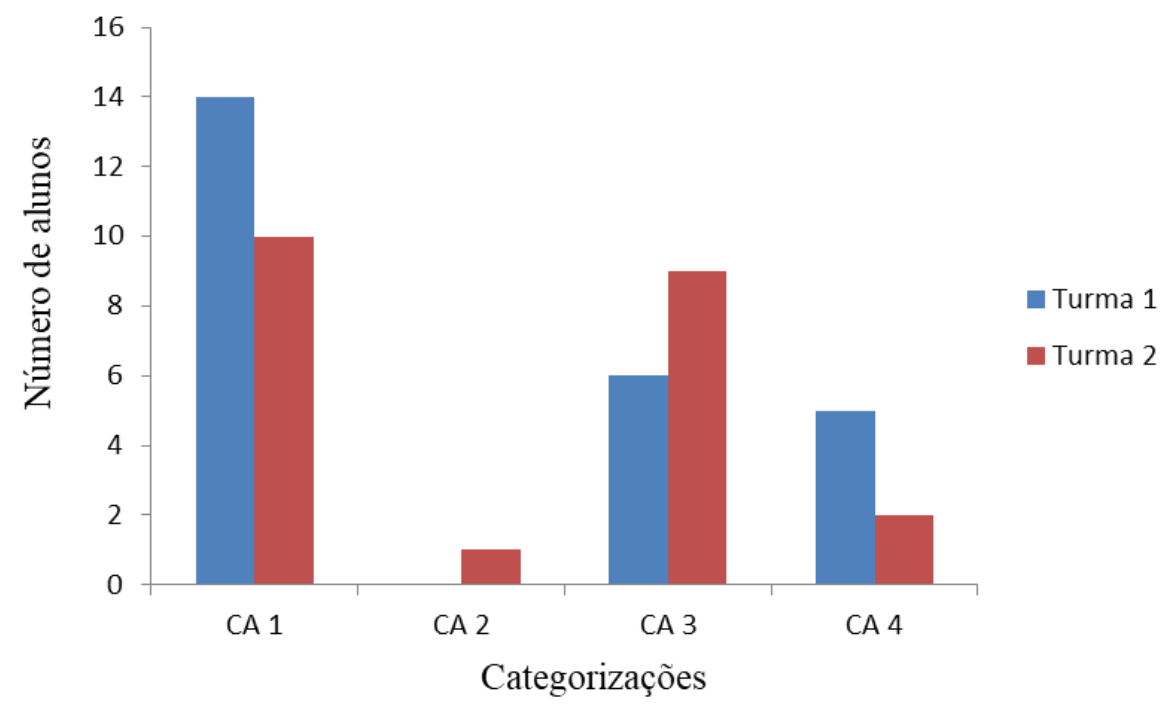

Pode-se perceber um melhor desempenho da turma 1 em conseguir resolver o problema proposto, visto que a metade do número de alunos construíram respostas que revelaram a categoria 1. Esses alunos conseguiram realizar uma articulação conceitual e elaboraram uma explicação coerente sobre a mudança de posição da rolha dentro da solução. A turma 2 ficou dividida em quase sua totalidade entre as categoriais 1 e 3. Diferentemente dos alunos em que suas respostas mostraram a categoria 1, aqueles que mostraram a categoria 3, mesmo conseguindo descrever com clareza a situação observada, apresentaram dificuldades conceituais.

Também, há um grupo de alunos que conseguiu realizar uma articulação conceitual de forma parcialmente correta, entretanto não conseguiu descrever a situação. Por que motivo isso ocorreu? $\mathrm{Na}$ tentativa de responder o questionamento foi construído o gráfico descrito na figura 7 , que relacionou o tipo de resposta com o número de alunos.

Com o propósito de quantificar os grupos de respostas dadas pelos alunos e investigar possíveis questionamentos levantados a partir da construção do gráfico das categorias, construímos uma tabela em que relacionamos o número de alunos com as decodificações criadas. Nessa tabela (Tabela 4), o número 1 atribuído à resposta do aluno 
indicou que essa se enquadrava na decodificação, o número zero significou que a decodificação não se aplicava à resposta do aluno.

Tabela 4. Decodificações das respostas dos alunos referentes a questão 2 do instrumento piloto.

\begin{tabular}{|c|c|c|c|c|}
\hline \multicolumn{5}{|c|}{ QUESTÃO 2 - Turma 1} \\
\hline \multirow[t]{2}{*}{ Alunos } & \multicolumn{4}{|c|}{$\begin{array}{c}\text { Decodificações } \\
\text { (DC)* }\end{array}$} \\
\hline & 1 & 2 & 3 & 4 \\
\hline 1 & 1 & 1 & & 0 \\
\hline 2 & 1 & 1 & 1 & 0 \\
\hline 3 & 1 & 1 & 1 & 0 \\
\hline 4 & 1 & 1 & 1 & 0 \\
\hline 5 & 1 & 1 & 1 & 0 \\
\hline 6 & 1 & 1 & 1 & 0 \\
\hline 7 & 1 & 1 & 1 & 0 \\
\hline 8 & 1 & 1 & 1 & 0 \\
\hline 9 & 1 & 1 & 1 & 0 \\
\hline 10 & 1 & 1 & 1 & 0 \\
\hline 11 & 1 & 1 & 1 & 0 \\
\hline 12 & 1 & 1 & 1 & 0 \\
\hline 13 & 1 & 1 & 1 & 0 \\
\hline 14 & 1 & 1 & 1 & 0 \\
\hline 15 & 1 & 1 & 0 & 0 \\
\hline 16 & 1 & 1 & 0 & 0 \\
\hline 17 & 1 & 1 & 0 & 0 \\
\hline 18 & 1 & 1 & 0 & 0 \\
\hline 19 & 1 & 0 & 0 & 1 \\
\hline 20 & 1 & 0 & 0 & 1 \\
\hline 21 & 0 & 0 & 0 & 1 \\
\hline 22 & 0 & 0 & 0 & 1 \\
\hline 23 & 0 & 0 & 0 & 1 \\
\hline 24 & 0 & 0 & 0 & 1 \\
\hline 25 & 0 & 0 & 0 & 1 \\
\hline \multicolumn{5}{|c|}{ QUESTÃO 2 - Turma 2} \\
\hline \multirow[t]{2}{*}{ Alunos } & \multicolumn{4}{|c|}{$\begin{array}{c}\text { Decodificações } \\
\text { (DC)* }\end{array}$} \\
\hline & 1 & 2 & 3 & 4 \\
\hline 5 & 1 & 1 & 1 & 0 \\
\hline 7 & 1 & 1 & 1 & 0 \\
\hline 8 & 1 & 1 & 1 & 0 \\
\hline 9 & 1 & 1 & 1 & 0 \\
\hline 13 & 1 & 1 & 1 & 0 \\
\hline 14 & 1 & 1 & 1 & 0 \\
\hline
\end{tabular}




\begin{tabular}{|r|r|r|r|r|}
\hline 18 & 1 & 1 & 1 & 0 \\
\hline 20 & 1 & 1 & 1 & 0 \\
\hline 22 & 1 & 1 & 1 & 0 \\
\hline 24 & 1 & 1 & 1 & 0 \\
\hline 6 & 1 & 1 & 0 & 0 \\
\hline 10 & 1 & 1 & 0 & 0 \\
\hline 11 & 1 & 1 & 0 & 0 \\
\hline 12 & 1 & 1 & 0 & 0 \\
\hline 15 & 1 & 1 & 0 & 0 \\
\hline 16 & 1 & 1 & 0 & 0 \\
\hline 17 & 1 & 1 & 0 & 0 \\
\hline 19 & 1 & 1 & 0 & 0 \\
\hline 23 & 1 & 1 & 0 & 0 \\
\hline 21 & 0 & 0 & 0 & 1 \\
\hline 22 & 0 & 0 & 0 & 1 \\
\hline 23 & 0 & 0 & 0 & 0 \\
\hline 24 & 1 & 1 & 0 & 1 \\
\hline & & & \\
\hline
\end{tabular}

*a numeração corresponde à descrição da decodificação apresentada no quadro anterior

A partir da tabela construiu-se o gráfico (Figura 7) a seguir em que verificamos a relação entre o número de alunos com o tipo de decodificação demonstrada por eles.

Figura 7. Número de alunos por decodificações referentes à questão 2 do instrumento piloto.

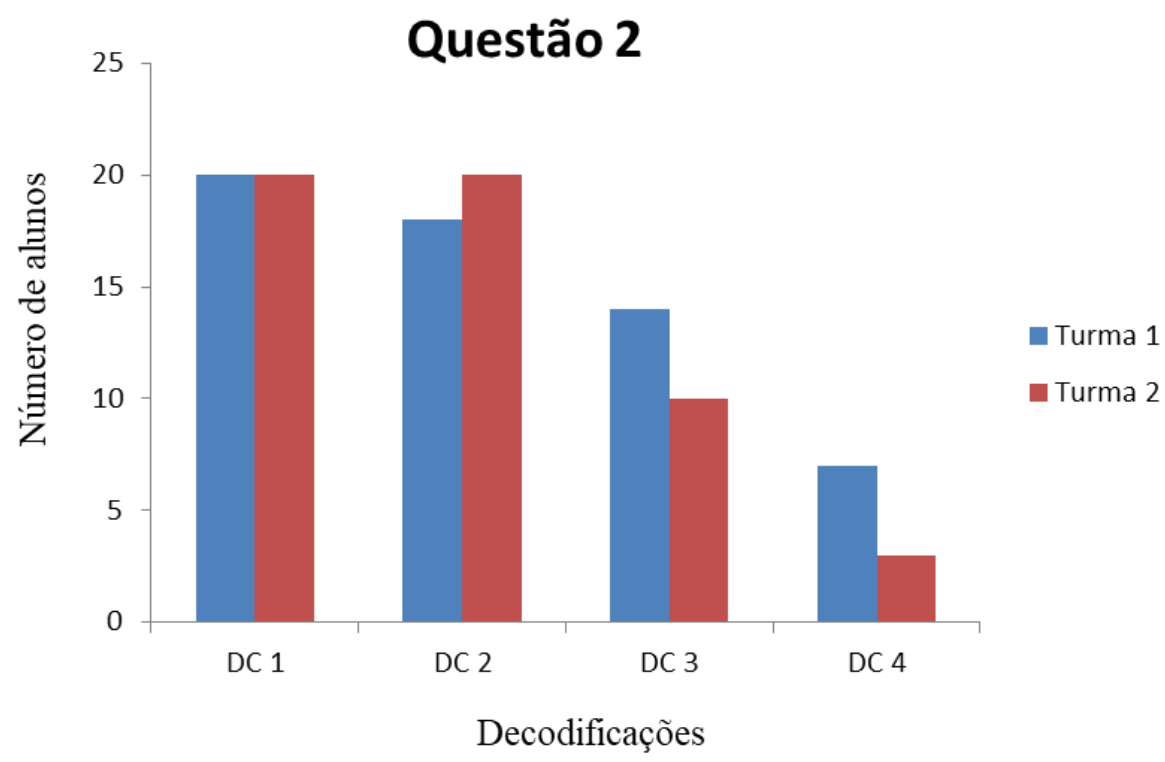

De forma geral, nesta questão, os alunos reconheceram a propriedade física envolvida no fenômeno observado, apresentaram um entendimento das mudanças ocorridas, mas mostraram dificuldades em relatar o que foi observado. 
Como é mostrado na figura 7, há um grupo de alunos, em ambas as turmas, cujas respostas se enquadraram em DC1, que parece dominar uma habilidade de ordem mais baixa, que consistiu em relacionar propriedades físicas de acordo com as finalidades a que se destinam (habilidade 18). Em relação à turma 2, foi possível observar que se manteve o número de alunos que conseguiram avaliar métodos, no caso da adição do sal, que contribuíssem para diagnosticar e solucionar problemas (habilidade 19), diferentemente da turma 1, que apresentou uma pequena redução no número de alunos cujas resposta se enquadraram na decodificação 2. Ao nosso entendimento, neste momento podemos dizer que a diferença entre as turmas se encontrou na mobilização de uma habilidade de alta ordem. Em complemento às nossas ponderações, as análises dos resultados da codificação 3 indicaram dificuldades das turmas na habilidade que envolveu a utilização de códigos e nomenclaturas de química para propor uma saída para a problemática proposta (habilidade 24), sendo esta uma habilidade de ordem mais baixa.

\section{QUESTÃO 3}

Um grande avanço químico se deu com o desenvolvimento da síntese da barrilha ( $\left.\mathrm{Na}_{2} \mathrm{CO}_{3}\right)$, em 1791 por Nicolas Leblanc). A etapa final da síntese da barrilha está descrita a seguir. Considerando que sejam utilizados $200 \mathrm{~g}$ de carbonato de cálcio $\left(\mathrm{CaCO}_{3}\right)$ na reação, quanto deverá ser produzido de barrilha? Justifique sua resposta. Dados: Ca (40 u), C (12 u), O (16 u), Na (23 u).

$$
\mathrm{Na}_{2} \mathrm{SO}_{4}+\mathrm{CaCO}_{3}+2 \mathrm{C} \longrightarrow \mathrm{Na}_{2} \mathrm{CO}_{3}+\mathrm{CaS}+2 \mathrm{CO}_{2}
$$

O quadro 17 apresenta, para a Questão 3, as decodificações criadas a partir das respostas dos alunos, as categorias criadas e as habilidades e competências selecionadas a partir da matriz do ENEM, suscitadas pela questão para serem mobilizadas pelos estudantes.

Quadro 17. Relação das habilidades escolhidas, decodificações e categorias estabelecidas a partir da análise da questão 3 do instrumento piloto.

\begin{tabular}{|c|c|c|}
\hline \multicolumn{2}{|c|}{ QUESTÃO 3} \\
\hline COMPETÊNCIAS DE ÁREAS 5/7 (HABILIDADES 17, 19 e 25) (Matriz de referência do ENEM) \\
\hline Habilidades & Decodificações & Categorias \\
\hline
\end{tabular}




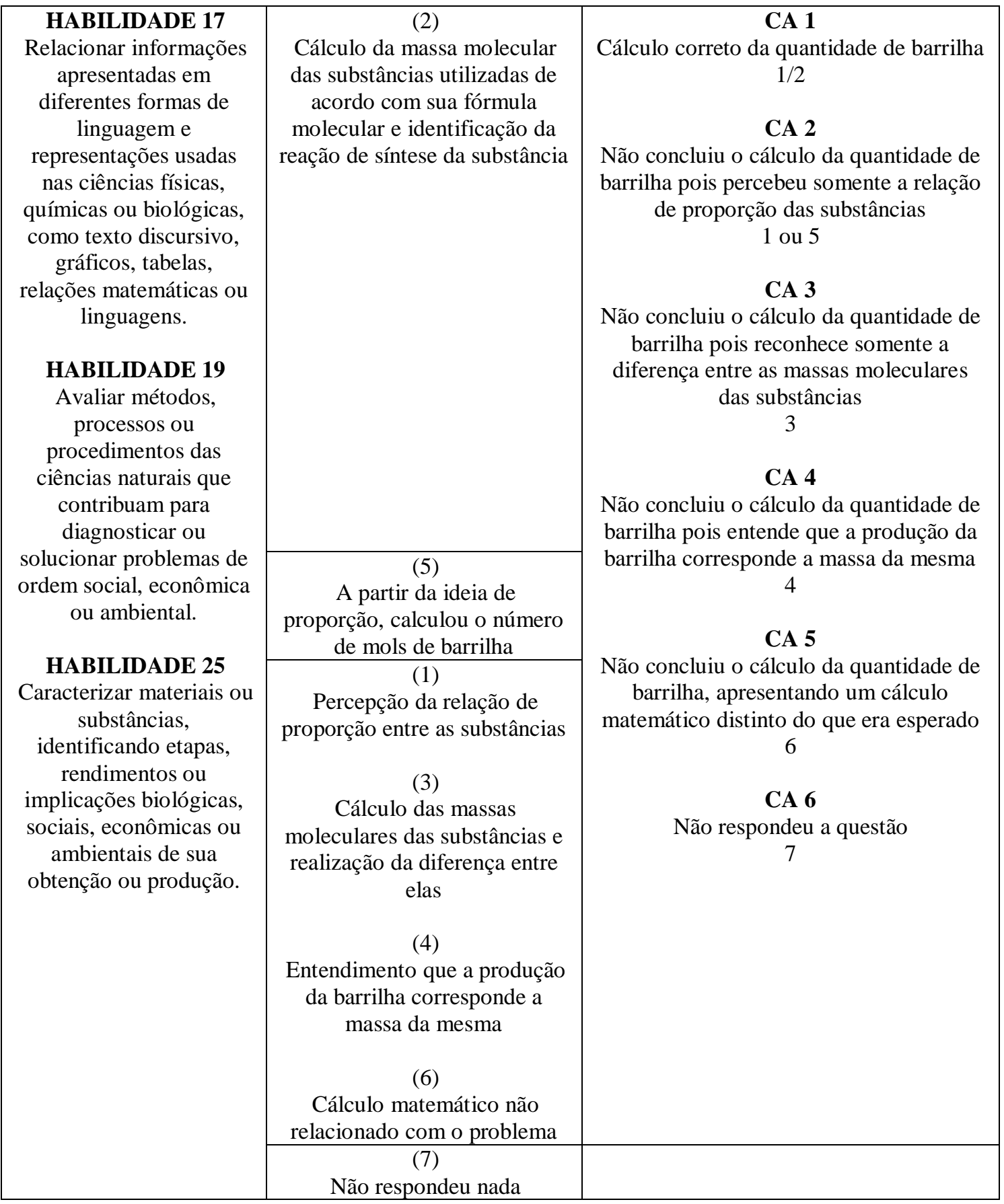

Para melhor visualizarmos as categorias construídas e estabelecermos possíveis comparativos entre elas construímos o gráfico a seguir (Figura 8) em que relacionamos as categorias criadas com as turmas participantes do projeto. 
Figura 8. Número de alunos por categorias referentes à questão 3 do instrumento piloto.

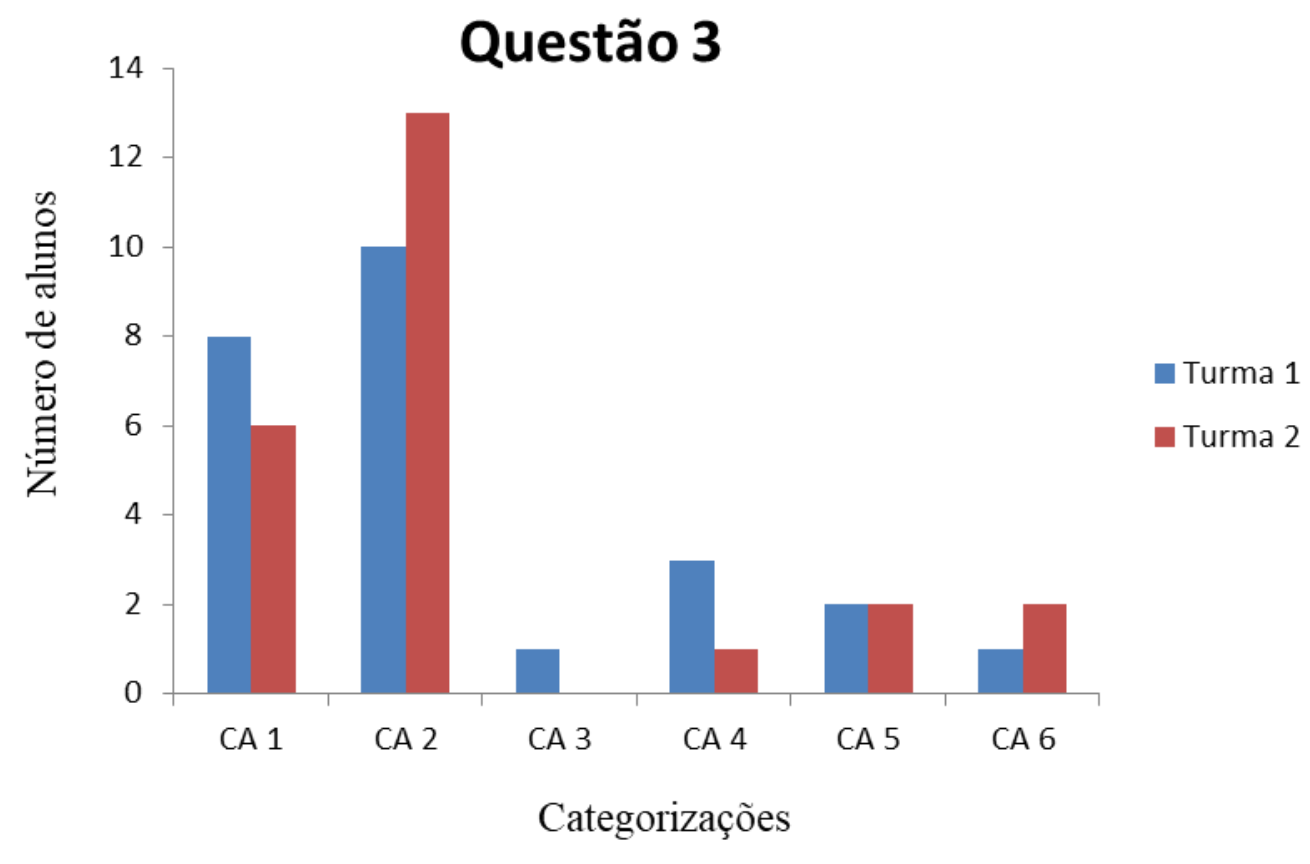

Como foi mostrado na figura 8 , na categoria 1 , tanto em relação à turma 1 quanto à turma 2, aproximadamente um terço do número de alunos conseguiu resolver o problema proposto. Analisando-se as categoriais 2 a 5, pudemos conjecturar algumas razões pelas quais os alunos não conseguiram solucionar o problema proposto, já que cada uma destas categorias foi criada a partir de uma única decodificação.

Entendemos que nesta questão a dificuldade estava na mobilização de uma habilidade de baixa ordem (habilidade 17). Conforme verificado na categoria 2, cerca de metade dos alunos de ambas as turmas não conseguiu determinar a quantidade de barrilha. Nos cálculos mostrados na questão, grande parte dos alunos iniciou a resolução do problema estabelecendo o cálculo da massa molar da barrilha e também do carbonato. Também reconheceram a relação de proporção entre as substâncias, mas não foram capazes de relacionar as informações apresentadas em diferentes linguagens com a representação da reação de síntese da barrilha e com o dado de massa descrito no problema.

Com o propósito de quantificar os grupos de respostas dadas pelos alunos e investigar possíveis questionamentos levantados a partir da construção do gráfico das categorias, construímos uma tabela em que relacionamos o número de alunos com as decodificações criadas. Nessa tabela (Tabela 5), o número 1 atribuído à resposta do aluno indicou que essa se enquadrava na decodificação, o número zero significou que a decodificação não se aplicava à resposta do aluno. 
Tabela 5. Decodificações das respostas dos alunos referentes à questão 3 do instrumento piloto.

\begin{tabular}{|c|c|c|c|c|c|c|c|}
\hline \multicolumn{8}{|c|}{ QUESTÃO 3 - Turma 1} \\
\hline Alunos & \multicolumn{7}{|c|}{ Decodificações (DC)* } \\
\hline & 1 & 2 & 3 & 4 & 5 & 6 & 7 \\
\hline 1 & 1 & 1 & 0 & 0 & 0 & 0 & 0 \\
\hline 2 & 1 & 1 & 0 & 0 & 0 & 0 & 0 \\
\hline 3 & 1 & 1 & 0 & 0 & 0 & 0 & 0 \\
\hline 4 & 1 & 1 & 0 & 0 & 0 & 0 & 0 \\
\hline 6 & 1 & 1 & 0 & 0 & 0 & 0 & 0 \\
\hline 8 & 1 & 1 & 0 & 0 & 0 & 0 & 0 \\
\hline 11 & 1 & 1 & 0 & 0 & 0 & 0 & 0 \\
\hline 14 & 1 & 1 & 0 & 0 & 0 & 0 & 0 \\
\hline 13 & 1 & 0 & 0 & 0 & 0 & 0 & 0 \\
\hline 18 & 1 & 0 & 0 & 0 & 0 & 0 & 0 \\
\hline 19 & 1 & 0 & 0 & 0 & 0 & 0 & 0 \\
\hline 20 & 1 & 0 & 0 & 0 & 0 & 0 & 0 \\
\hline 23 & 1 & 0 & 0 & 0 & 0 & 0 & 0 \\
\hline 25 & 0 & 0 & 1 & 0 & 0 & 0 & 0 \\
\hline 9 & 0 & 0 & 0 & 1 & 0 & 0 & 0 \\
\hline 10 & 0 & 0 & 0 & 1 & 0 & 0 & 0 \\
\hline 15 & 0 & 0 & 0 & 1 & 0 & 0 & 0 \\
\hline 5 & 0 & 0 & 0 & 0 & 1 & 0 & 0 \\
\hline 17 & 0 & 0 & 0 & 0 & 1 & 0 & 0 \\
\hline 21 & 0 & 0 & 0 & 0 & 1 & 0 & 0 \\
\hline 7 & 0 & 0 & 0 & 0 & 1 & 0 & 0 \\
\hline 12 & 0 & 0 & 0 & 0 & 1 & 0 & 0 \\
\hline 16 & 0 & 0 & 0 & 0 & 0 & 1 & 0 \\
\hline 22 & 0 & 0 & 0 & 0 & 0 & 1 & 0 \\
\hline 24 & 0 & 0 & 0 & 0 & 0 & 0 & 1 \\
\hline \multicolumn{8}{|c|}{ QUESTÃO 3 - Turma 2} \\
\hline Alunos & \multicolumn{7}{|c|}{ Decodificações (DC)* } \\
\hline & 1 & 2 & 3 & 4 & 5 & 6 & 7 \\
\hline 6 & 1 & 1 & 0 & 0 & 0 & 0 & 0 \\
\hline 7 & 1 & 1 & 0 & 0 & 0 & 0 & 0 \\
\hline 17 & 1 & 1 & 0 & 0 & 0 & 0 & 0 \\
\hline 13 & 1 & 1 & 0 & 0 & 0 & 0 & 0 \\
\hline 20 & 1 & 1 & 0 & 0 & 0 & 0 & 0 \\
\hline 22 & 1 & 1 & 0 & 0 & 0 & 0 & 0 \\
\hline 14 & 1 & 0 & 0 & 0 & 0 & 0 & 0 \\
\hline 24 & 1 & 0 & 0 & 0 & 0 & 0 & 0 \\
\hline 3 & 0 & 0 & 0 & 1 & 0 & 0 & 0 \\
\hline 4 & 0 & 0 & 0 & 0 & 1 & 0 & 0 \\
\hline 2 & 0 & 0 & 0 & 0 & 1 & 0 & 0 \\
\hline
\end{tabular}




\begin{tabular}{|r|r|r|r|r|r|r|r|}
\hline 15 & 0 & 0 & 0 & 0 & 1 & 0 & 0 \\
\hline 1 & 0 & 0 & 0 & 0 & 1 & 0 & 0 \\
\hline 8 & 0 & 0 & 0 & 0 & 1 & 0 & 0 \\
\hline 9 & 0 & 0 & 0 & 0 & 1 & 0 & 0 \\
\hline 10 & 0 & 0 & 0 & 0 & 1 & 0 & 0 \\
\hline 11 & 0 & 0 & 0 & 0 & 1 & 0 & 0 \\
\hline 12 & 0 & 0 & 0 & 0 & 1 & 0 & 0 \\
\hline 16 & 0 & 0 & 0 & 0 & 1 & 0 & 0 \\
\hline 18 & 0 & 0 & 0 & 0 & 1 & 0 & 0 \\
\hline 19 & 0 & 0 & 0 & 0 & 0 & 1 & 0 \\
\hline 21 & 0 & 0 & 0 & 0 & 0 & 1 & 0 \\
\hline 23 & 0 & 0 & 0 & 0 & 0 & 0 & 1 \\
\hline 5 & 0 & 0 & 0 & 0 & 0 & 0 & 1 \\
\hline
\end{tabular}

*a numeração corresponde à descrição da decodificação apresentada no quadro anterior

A partir da tabela construiu-se o gráfico (Figura 9) a seguir em que verificamos a relação entre o número de alunos com o tipo de decodificação demonstrada por eles.

Figura 9. Número de alunos por decodificações referentes à questão 3 do instrumento piloto.

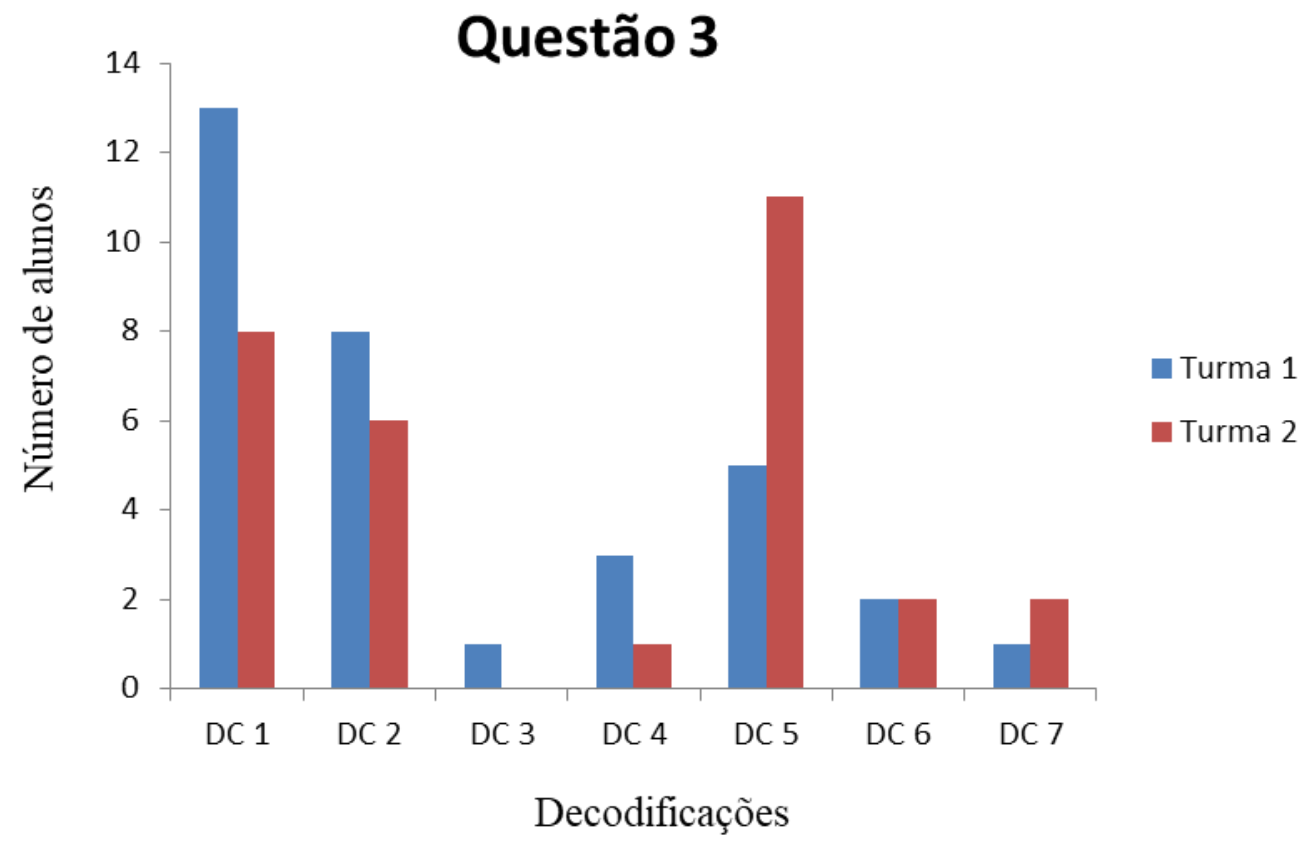

Verificamos, pela leitura da figura 9, que metade dos alunos da turma 1 e um terço da turma 2 expressaram a decodificação 1 . Ou seja, naquele e momento, a habilidade $\mathrm{H} 25$ foi a de maior articulação pelos mesmos, que consistiu na caracterização de materiais identificando etapas ou rendimentos. Para que os alunos finalizassem a resolução da questão 
de forma correta os próximos passos seriam o cálculo da massa molecular da substância e identificação da reação de síntese da barrilha, mobilizando principalmente a H17 e demonstrando a decodificação $2 \mathrm{em}$ suas respostas. Aproximadamente um terço do número total de alunos de ambas as turmas conseguiu expressar a decodificação 2, ou seja, mobilizar a outra habilidade necessária para a completa resolução da questão (habilidade 17). A turma 1 ainda manteve um percentual mais elevado em relação a turma 2. Assim, como muitos não finalizaram a resolução do problema sua respostas passaram a demonstrar a categoria $2 \mathrm{em}$ vez de se manterem na categoria 1.

Por fim, encontramos ainda nessa figura outro dado importante, que complementa as conclusões anteriores a respeito dos alunos somente da turma 2, visto que as respostas referentes aos alunos da turma 1 se dividiram entre as decodificações restantes. A turma 2 não conseguiu resolver a questão pois suas respostas se enquadraram na decodificação 5 , que representa somente o conhecimento da ideia de proporção, não sendo capazes de finalizar a resolução do problema.

\section{QUESTÃO 4}

O debate em torno do uso da energia nuclear para produção de eletricidade permanece atual. Em um encontro internacional para a discussão desse tema, foram colocados os seguintes argumentos:

1. Uma grande vantagem das usinas nucleares é o fato de não contribuírem para o aumento do efeito estufa, uma vez que o urânio, utilizado como "combustivel”, não é queimado, mas sofre fissão.

2. Ainda que sejam raros os acidentes com usinas nucleares, seus efeitos podem ser tão graves que essa alternativa de geração de eletricidade não nos permite ficar tranquilos.

Um pesquisador que estava participando do encontro afirmou que os argumentos colocados acima são irrelevantes. Comente a afirmação do pesquisador. Fonte: adaptação do ENEM 2004

O quadro 18 apresenta, para a Questão 4, as decodificações criadas a partir das respostas dos alunos, as categorias criadas e as habilidades e competências selecionadas a partir da matriz do ENEM, suscitadas pela questão para serem mobilizadas pelos estudantes. 
Quadro 18. Relação das habilidades escolhidas, decodificações e categorias estabelecidas a partir da análise da questão 4 do instrumento piloto.

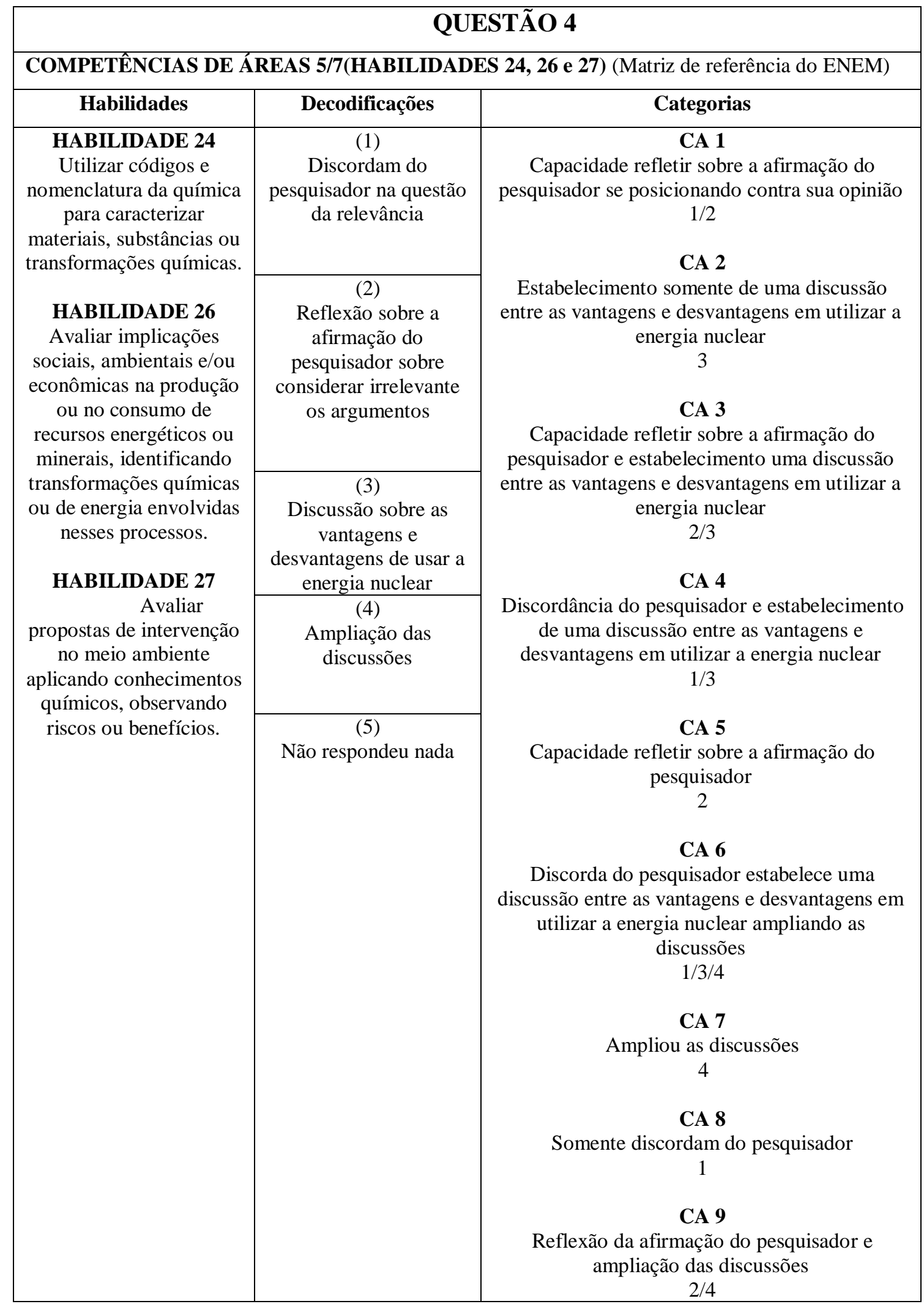


Para melhor visualizarmos as categorias construídas e estabelecermos possíveis comparativos entre elas construímos o gráfico a seguir (Figura 10) em que relacionamos as categorias criadas com as turmas participantes do projeto.

Figura 10. Número de alunos por categorias referentes à questão 4 do instrumento piloto.

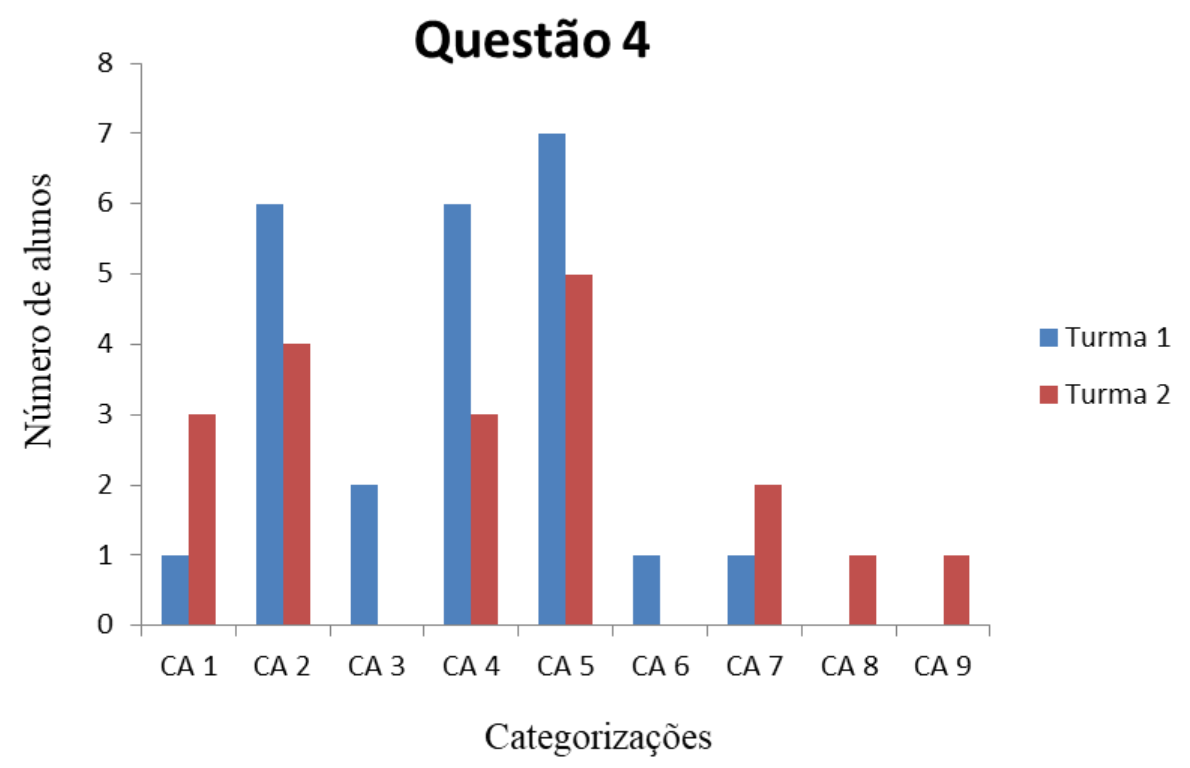

Este foi um dos casos em que o número de categorias ultrapassou o número de decodificações. Isto ocorreu porque a forma com que os alunos organizaram a resolução da questão tornou-se muito distinta, e também pelo fato de que alguns casos de resolução apareceram em somente uma das turmas. Quanto maior a especificação de uma categoria melhor o entendimento dos resultados. Desta forma priorizamos em aumentá-las. Tanto em relação à turma 1 quanto à turma 2, só que em menor número, podemos verificar que os alunos se concentraram especificamente em três categoriais 2, 4 e 5. Tais categorias abrangeram as decodificações 1,2 e 3 .

Em relação à categoria 2, é possível afirmar que foram ampliadas somente discussões sobre o tema, sem que os alunos se posicionassem diante da afirmação do pesquisador. Em relação à categoria 4, podemos afirmar que os alunos somente estabelecem uma discussão entre as vantagens e desvantagens de utilizar a energia nuclear. E por fim, na categoria 5 os alunos foram capazes de refletir sobre a afirmação do pesquisador somente a respeito da relevância dos argumentos.

Com o propósito de quantificar os grupos de respostas dadas pelos alunos e investigar possíveis questionamentos levantados a partir da construção do gráfico das categorias, construímos uma tabela em que relacionamos o número de alunos com as 
decodificações criadas. Nessa tabela (Tabela 6), o número 1 atribuído à resposta do aluno indicou que essa se enquadrava na decodificação, o número zero significou que a decodificação não se aplicava à resposta do aluno.

Tabela 6. Decodificações das respostas dos alunos referentes à questão 4 do instrumento piloto.

\begin{tabular}{|c|c|c|c|c|c|c|}
\hline \multicolumn{7}{|c|}{ QUESTÃO 4 - Turma 1} \\
\hline \multirow[t]{2}{*}{ Alunos } & \multicolumn{6}{|c|}{$\begin{array}{c}\text { Decodificações } \\
\text { (DC)* }\end{array}$} \\
\hline & & 1 & 2 & 3 & & 4 \\
\hline & 3 & 1 & 1 & 0 & & 0 \\
\hline & 2 & 0 & 0 & 1 & & 0 \\
\hline & 5 & 0 & 0 & 1 & & 0 \\
\hline & 5 & 0 & 0 & 1 & & 0 \\
\hline & 4 & 0 & 0 & 1 & & 0 \\
\hline & 0 & 0 & 0 & 1 & & 0 \\
\hline & 9 & 0 & 0 & 1 & & 0 \\
\hline & 6 & 1 & 0 & 1 & & 0 \\
\hline & 4 & 1 & 0 & 1 & & 0 \\
\hline & 7 & 1 & 0 & 1 & & 0 \\
\hline & 2 & 1 & 0 & 1 & & 0 \\
\hline & 2 & 1 & 0 & 1 & & 0 \\
\hline & 6 & 1 & 0 & 1 & & 0 \\
\hline & 4 & 0 & 1 & 1 & & 0 \\
\hline & 8 & 0 & 1 & 1 & & 0 \\
\hline & 9 & 0 & 1 & 0 & & 0 \\
\hline & 8 & 0 & 1 & 0 & & 0 \\
\hline & 0 & 0 & 1 & 0 & & 0 \\
\hline & 3 & 0 & 1 & 0 & & 0 \\
\hline & 1 & 0 & 1 & 0 & & 0 \\
\hline & 5 & 0 & 1 & 0 & & 0 \\
\hline & 7 & 0 & 1 & 0 & & 0 \\
\hline & 1 & 1 & 0 & 1 & & 1 \\
\hline & 3 & 0 & 0 & 0 & & 1 \\
\hline \multicolumn{7}{|c|}{ QUESTÃO 4 - Turma 2} \\
\hline \multirow[t]{2}{*}{ Alunos } & \multicolumn{6}{|c|}{$\begin{array}{c}\text { Decodificações } \\
(\mathrm{DC}) *\end{array}$} \\
\hline & 1 & 2 & 2 & 3 & 4 & 5 \\
\hline 1 & 1 & 1 & 1 & 0 & 0 & 0 \\
\hline 5 & 1 & 1 & 1 & & 0 & 0 \\
\hline 2 & 1 & 1 & 1 & & 0 & 0 \\
\hline 3 & 0 & 0 & 0 & 1 & 0 & 0 \\
\hline 20 & 0 & 0 & 0 & 1 & 0 & 0 \\
\hline
\end{tabular}




\begin{tabular}{|r|r|r|r|r|r|}
\hline 22 & 0 & 0 & 1 & 0 & 0 \\
\hline 6 & 0 & 0 & 1 & 0 & 0 \\
\hline 8 & 1 & 0 & 1 & 0 & 0 \\
\hline 13 & 1 & 0 & 1 & 0 & 0 \\
\hline 14 & 1 & 0 & 1 & 0 & 0 \\
\hline 24 & 0 & 1 & 0 & 0 & 0 \\
\hline 16 & 0 & 1 & 0 & 0 & 0 \\
\hline 10 & 0 & 0 & 0 & 0 & 1 \\
\hline 11 & 0 & 0 & 0 & 0 & 1 \\
\hline 21 & 0 & 1 & 0 & 0 & 0 \\
\hline 12 & 0 & 1 & 0 & 0 & 0 \\
\hline 7 & 0 & 1 & 0 & 0 & 0 \\
\hline 23 & 0 & 1 & 0 & 1 & 0 \\
\hline 15 & 0 & 1 & 0 & 1 & 0 \\
\hline 19 & 1 & 0 & 0 & 0 & 0 \\
\hline
\end{tabular}

*a numeração corresponde à descrição da decodificação apresentada no quadro anterior

A partir da tabela construiu-se o gráfico (Figura 11) a seguir em que verificamos a relação entre o número de alunos com o tipo de decodificação demonstrada por eles.

Figura 11. Número de alunos por decodificações referentes à questão 4 do instrumento piloto.

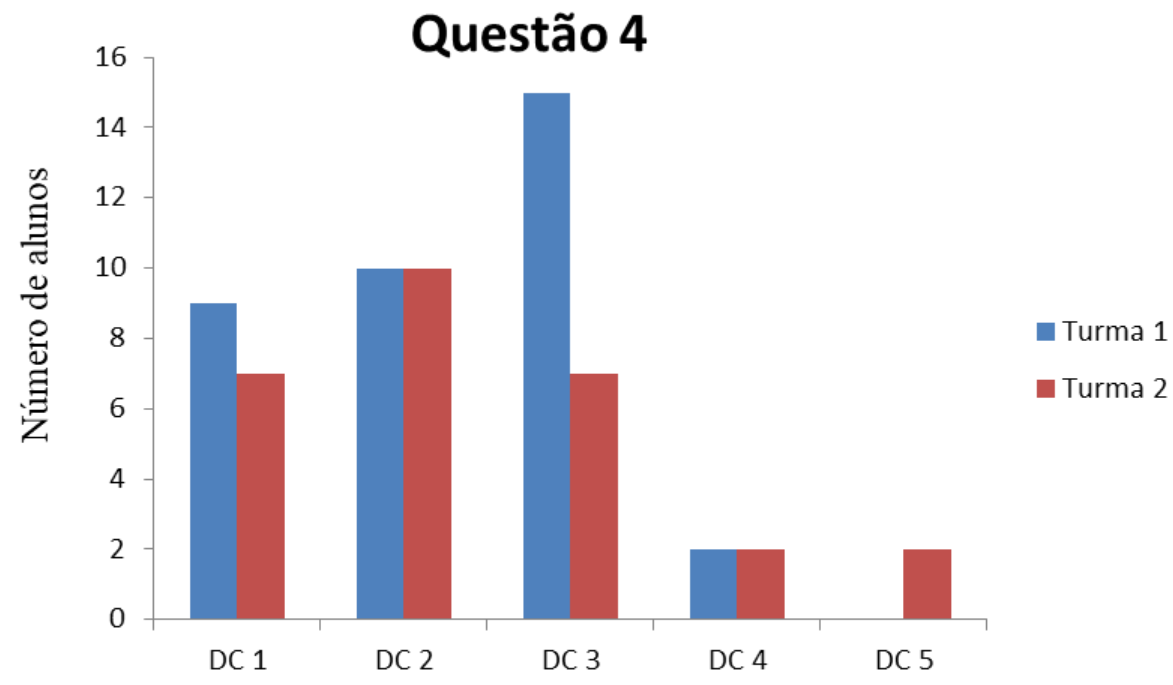

Decodificações

De forma geral as duas turmas expressaram em maiores proporções em decodificações semelhantes (decodificações 1, 2 e 3). As duas primeiras construídas através da mobilização das habilidades 24 e 25 representaram a utilização de códigos e nomenclaturas da química e avaliação da situação proposta sendo construídas respostas em que os alunos 
discordaram da problemática proposta propondo uma reflexão sobre as afirmações contidas na questão. Já com a decodificação 3, através de uma mobilização de ordem mais alta (habilidade 27) ampliaram as discussões refletindo sobre a afirmação do pesquisador e estabelecimento uma discussão entre as vantagens e desvantagens em utilizar a energia nuclear.

\section{QUESTÃO 5}

Muitos professores utilizam a experimentação para enriquecer suas aulas. Uma professora realizou junto com seus alunos as experiências que seguem:

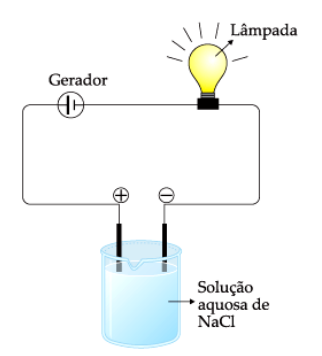

Experiência 1 Experiência 2

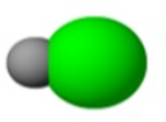

Sal de cozinha $-\mathbf{N a C l}$

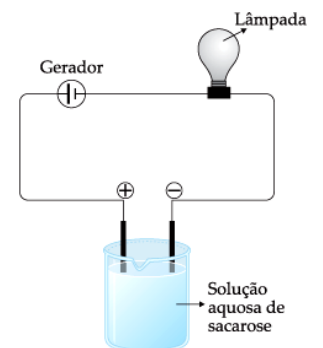

Experiência 3
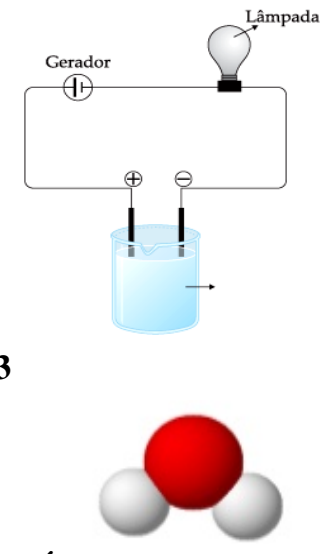

Água $-\mathrm{H}_{2} \mathrm{O}$

Como você explicaria o fato de a lâmpada acender somente na experiência $1 ?$

Fonte: Produzida pela autora

O quadro 19 apresenta, para a Questão 5, as decodificações criadas a partir das respostas dos alunos, as categorias criadas e as habilidades e competências selecionadas a partir da matriz do ENEM, suscitadas pela questão para serem mobilizadas pelos estudantes.

Quadro 19. Relação das habilidades escolhidas, decodificações e categorias estabelecidas a partir da análise da questão 5 do instrumento piloto.

\begin{tabular}{|c|c|c|}
\hline \multicolumn{2}{|c|}{ QUESTÃO 5} \\
\hline COMPETÊNCIAS DE ÁREAS 5/7 (HABILIDADES 17, 18 e 24)(Matriz de referência do ENEM) \\
\hline Habilidades & Decodificações & Categorias \\
\hline $\begin{array}{c}\text { HABILIDADE 17 } \\
\text { Relacionar informações } \\
\text { apresentadas em } \\
\text { diferentes formas de } \\
\text { linguagem e } \\
\text { representações usadas }\end{array}$ & $\begin{array}{c}\text { Reconhecimento que o NaCl } \\
\text { é responsável por acender a } \\
\text { lâmpada }\end{array}$ & $\begin{array}{c}\text { CA 1 } \\
\text { lâmplicação sobre o acendimento da }\end{array}$ \\
\cline { 2 - 3 } & $\begin{array}{c}(2) \\
\text { Compreensão da formação }\end{array}$ & $\begin{array}{c}\text { clareza } \\
1 / 2 / 3\end{array}$ \\
\hline
\end{tabular}




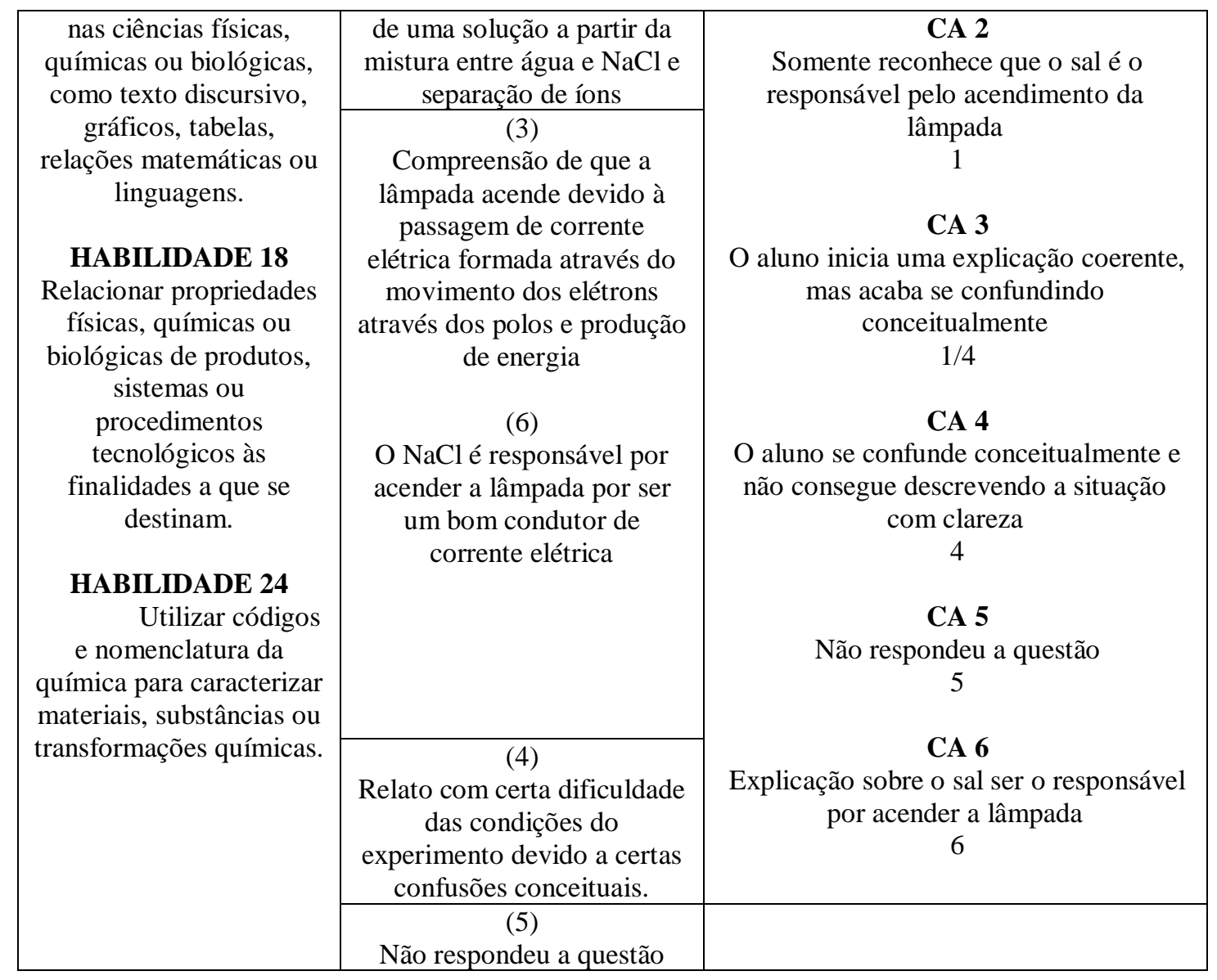

Para melhor visualizarmos as categorias construídas e estabelecermos possíveis comparativos entre elas construímos o gráfico a seguir (Figura 12) em que relacionamos as categorias criadas com as turmas participantes do projeto.

Figura 12. Número de alunos por categorias referentes à questão 5 do instrumento piloto.

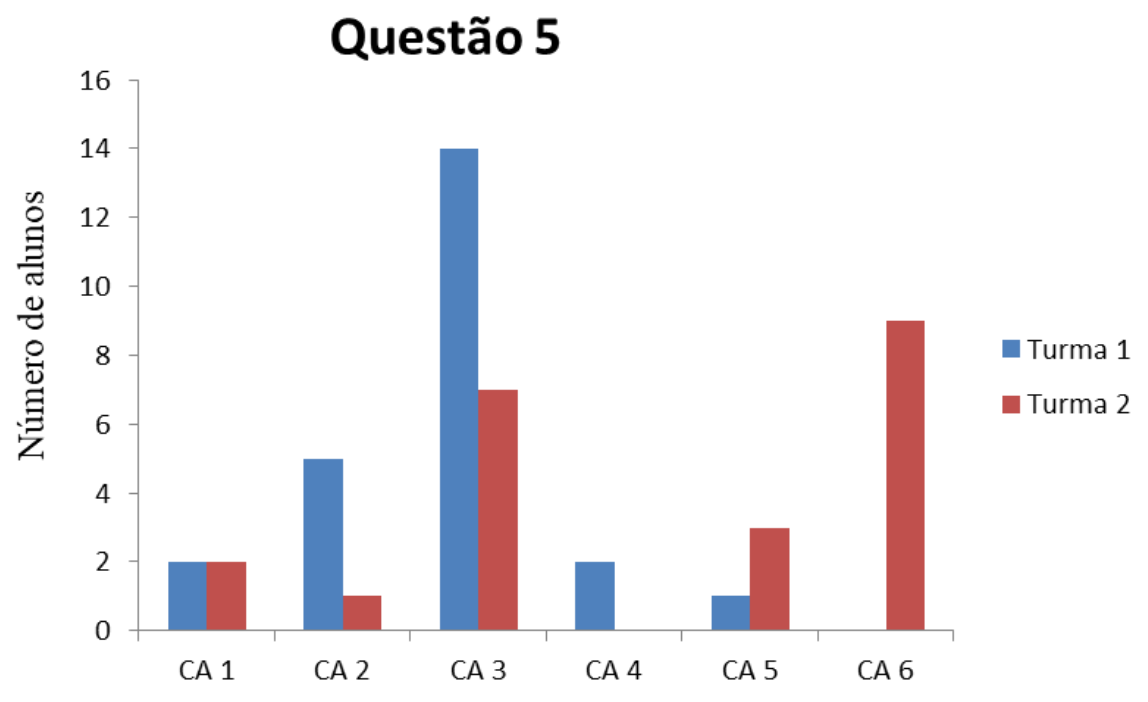

Categorizações 
Esta questão é uma das que apresentam maior nível de dificuldade das propostas no instrumento. Tal fato se justificou pela abordagem em nível microscópico da matéria. O aluno deveria articular conceitos muito abstratos para propor a resolução do problema. E também deveria elaborar textualmente uma explicação para o que ele observou articulando informações apresentadas na figura (Figura 12). Esse conjunto de fatores dificultou a resolução da problemática proposta.

A maior parte da turma 1 manifestou ideias as quais originaram a categoria 3, pois os alunos iniciaram uma explicação coerente para tudo que foi observado, entretanto, apresentaram algumas confusões conceituais. Nesse caso, articularam as habilidades 17 e 24 , embora fique a dúvida de qual dessas habilidades está envolvida na confusão conceitual. Mais da metade da turma 2 apresenta maior expressividade nas categorias 3 e 6 . Aqueles alunos em que suas respostas mostraram a categoria 3 também não conseguiram descrever com clareza tudo que estava sendo observado. Já, os alunos cujas ideias originaram a categoria 6 demonstraram que não aprofundaram seus conhecimentos mesmo entendendo que o sal era o responsável por acender a lâmpada.

Com o propósito de quantificar os grupos de respostas dadas pelos alunos e investigar possíveis questionamentos levantados a partir da construção do gráfico das categorias, construímos uma tabela em que relacionamos o número de alunos com as decodificações criadas. Nessa tabela (Tabela 7), o número 1 atribuído à resposta do aluno indicou que essa se enquadrava na decodificação, o número zero significou que a decodificação não se aplicava à resposta do aluno.

Tabela 7. Decodificações das respostas dos alunos referentes à questão 5 do instrumento piloto.

\begin{tabular}{|r|r|r|r|r|}
\hline \multicolumn{5}{|c|}{ QUESTÃO 5 - Turma 1 } \\
\hline Alunos & \multicolumn{5}{|c|}{$\begin{array}{c}\text { Decodificações } \\
\text { (DC) }\end{array}$} \\
\hline & 1 & 2 & 3 & 4 \\
\hline 3 & 1 & 1 & 1 & 0 \\
\hline 6 & 1 & 1 & 1 & 0 \\
\hline 5 & 1 & 0 & 0 & 0 \\
\hline 15 & 1 & 0 & 0 & 0 \\
\hline 19 & 1 & 0 & 0 & 0 \\
\hline 20 & 1 & 0 & 0 & 0 \\
\hline 23 & 1 & 0 & 0 & 0 \\
\hline 1 & 1 & 0 & 0 & 1 \\
\hline 2 & 1 & 0 & 0 & 1 \\
\hline 7 & 1 & 0 & 0 & 1 \\
\hline
\end{tabular}




\begin{tabular}{|r|r|r|r|r|}
\hline 8 & 1 & 0 & 0 & 1 \\
\hline 9 & 1 & 0 & 0 & 1 \\
\hline 11 & 1 & 0 & 0 & 1 \\
\hline 13 & 1 & 0 & 0 & 1 \\
\hline 14 & 1 & 0 & 0 & 1 \\
\hline 16 & 1 & 0 & 0 & 1 \\
\hline 17 & 1 & 0 & 0 & 1 \\
\hline 21 & 1 & 0 & 0 & 1 \\
\hline 22 & 1 & 0 & 0 & 1 \\
\hline 24 & 1 & 0 & 0 & 1 \\
\hline 25 & 1 & 0 & 0 & 1 \\
\hline 4 & 0 & 0 & 0 & 0 \\
\hline 10 & 0 & 0 & 0 & 1 \\
\hline 18 & 0 & 0 & 0 & 1 \\
\hline 12 & 1 & 0 & 1 & 1 \\
\hline UST & 5 & & \\
\hline
\end{tabular}

QUESTÃO 5 - Turma 2

\begin{tabular}{|c|c|c|c|c|}
\hline \multirow[t]{2}{*}{ Alunos } & \multicolumn{4}{|c|}{$\begin{array}{l}\text { Decodificações } \\
\text { (DC)* }\end{array}$} \\
\hline & 1 & 2 & 3 & 4 \\
\hline 10 & 1 & 1 & 1 & 0 \\
\hline 22 & 1 & 1 & 1 & 0 \\
\hline 4 & 1 & 0 & 0 & 0 \\
\hline 1 & 1 & 0 & 0 & 1 \\
\hline 11 & 1 & 0 & 0 & 1 \\
\hline 14 & 1 & 0 & 0 & 1 \\
\hline 17 & 1 & 0 & 0 & 1 \\
\hline 20 & 1 & 0 & 0 & 1 \\
\hline 21 & 1 & 0 & 0 & 1 \\
\hline 24 & 1 & 0 & 0 & 1 \\
\hline 2 & 0 & 0 & 0 & 0 \\
\hline 6 & 0 & 0 & 0 & 0 \\
\hline 7 & 0 & 0 & 0 & 0 \\
\hline 8 & 0 & 0 & 0 & 0 \\
\hline 9 & 0 & 0 & 0 & 0 \\
\hline 12 & 0 & 0 & 0 & 0 \\
\hline 15 & 0 & 0 & 0 & 0 \\
\hline 18 & 0 & 0 & 0 & 0 \\
\hline 23 & 0 & 0 & 0 & 0 \\
\hline 3 & 0 & 0 & 0 & 0 \\
\hline 16 & 0 & 0 & 0 & 0 \\
\hline 19 & 0 & 0 & 0 & 0 \\
\hline 5 & 1 & 1 & 0 & 1 \\
\hline 13 & 1 & 1 & 0 & 1 \\
\hline
\end{tabular}


*a numeração corresponde à descrição da decodificação apresentada no quadro anterior

A partir da tabela construiu-se o gráfico (Figura 13) a seguir em que verificamos a relação entre o número de alunos com o tipo de decodificação demonstrada por eles.

Figura 13. Número de alunos por decodificações referentes à questão 5 do instrumento piloto.

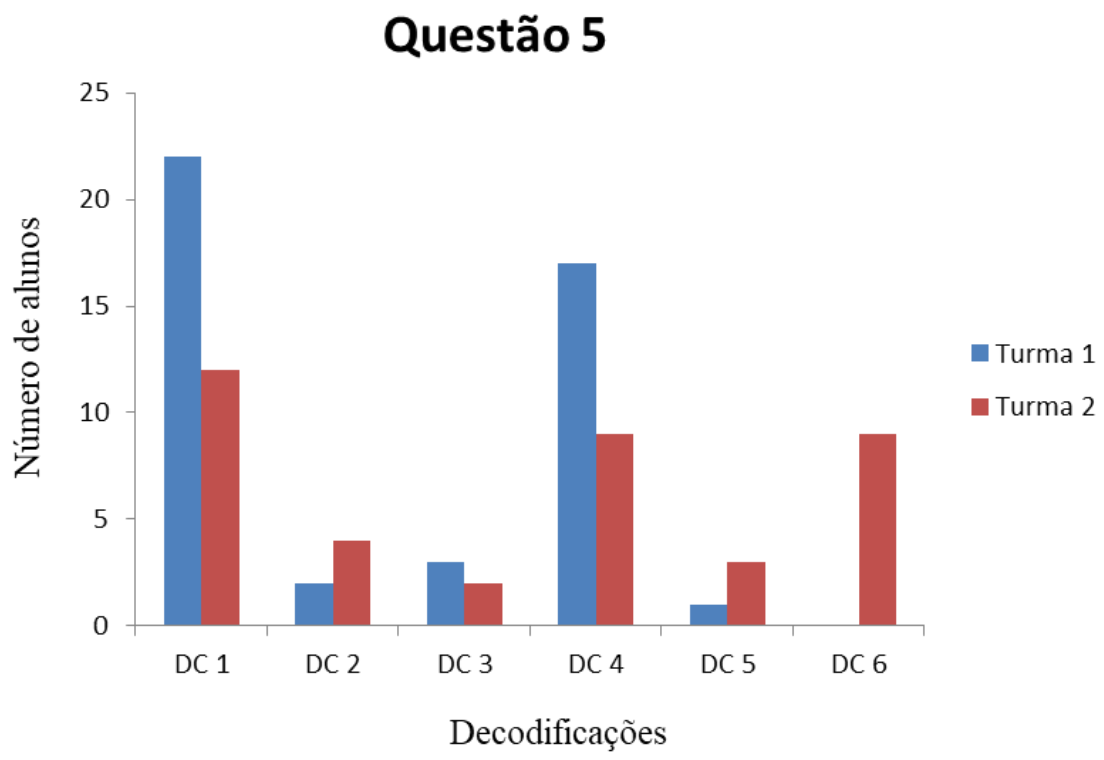

Verificamos igualmente para as duas turmas dois resultados significativos. Ambas possuíram maior número de alunos que se enquadraram nas codificações 1 e 4 , e também na codificação 6 (turma 2). A decodificação 1 significou o reconhecimento do sal como o responsável por acender a lâmpada e a mobilização da habilidade 17. A decodificação 4 representou a dificuldade de compreensão da realização do experimento. Acre ditamos que tal dificuldade certamente se justificou no entendimento da matéria ao nível microscópico.

A turma 2 apresentou uma única distinção em relação à turma 1. Houve um número expressivo de alunos cujas respostas se enquadraram na decodificação 6 , o que pode significar que os alunos também foram capazes de mobilizar a habilidade 18. Ou seja, demonstraram aprofundar seus conhecimentos em relação às propriedades físicas da matéria, com a compreensão de que a lâmpada acende por conta da passagem de corrente elétrica. Mas como os alunos da turma 1 não finalizaram a resolução da questão.

\section{QUESTÃO 6}

Considere duas latas do mesmo refrigerante, uma na versão diet e outra na versão comum. Ambas contêm o mesmo volume de líquido (300 mL) e têm a mesma massa quando 
vazias. A composição do refrigerante é a mesma, exceto por uma diferença: a versão comum contém certa quantidade de açúcar, enquanto a versão diet não contém açúcar (a massa de adoçante artificial contida no refrigerante diet pouco contribui para a massa final, pois é da ordem de miligramas). Pensando-se duas latas fechadas do refrigerante, foram obtidos os seguintes resultados:

\begin{tabular}{|c|c|}
\hline Amostra & Massa (g) \\
\hline Lata com refrigerante comum & 331,2 \\
\hline Lata com refrigerante diet & $\mathbf{3 1 6 , 2}$ \\
\hline
\end{tabular}

Por esses dados, pode-se concluir que a concentração em massa, em g/L, de açúcar no refrigerante comum é de, aproximadamente:
a) 0,020
b) 0,050
c) 1,1
d) 20
e) 50

Fonte: Fuvest(2001)

O quadro 20 apresenta, para a Questão 6, as decodificações criadas a partir das respostas dos alunos, as categorias criadas e as habilidades e competências selecionadas a partir da matriz do ENEM, suscitadas pela questão para serem mobilizadas pelos estudantes.

Quadro 20. Relação das habilidades escolhidas, decodificações e categorias estabelecidas a partir da análise da questão 6 do instrumento piloto.

\begin{tabular}{|c|c|c|}
\hline \multicolumn{2}{|c|}{ QUESTÃO 6} \\
\hline COMPETÊNCIAS DE ÁREAS 7(HABILIDADES 17, 19 e 25) (Matriz de referência do ENEM) \\
\hline Habilidades & Decodificações & Categorias \\
\hline
\end{tabular}




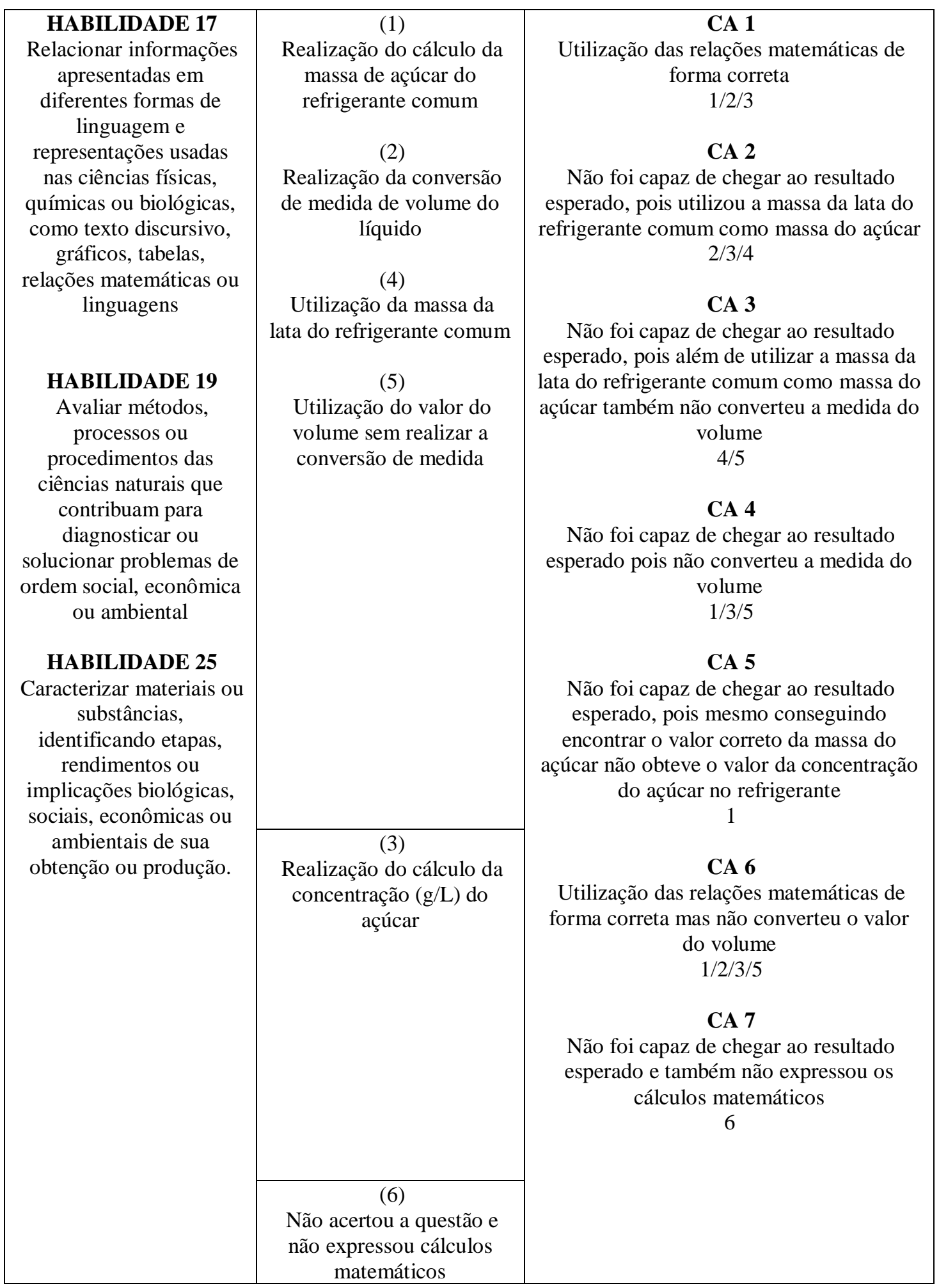

Para melhor visualizarmos as categorias construídas e estabelecermos possíveis comparativos entre elas construímos o gráfico a seguir (Figura 14) em que relacionamos as categorias criadas com as turmas participantes do projeto. 
Figura 14. Número de alunos por categorias referentes à questão 6 do instrumento piloto.

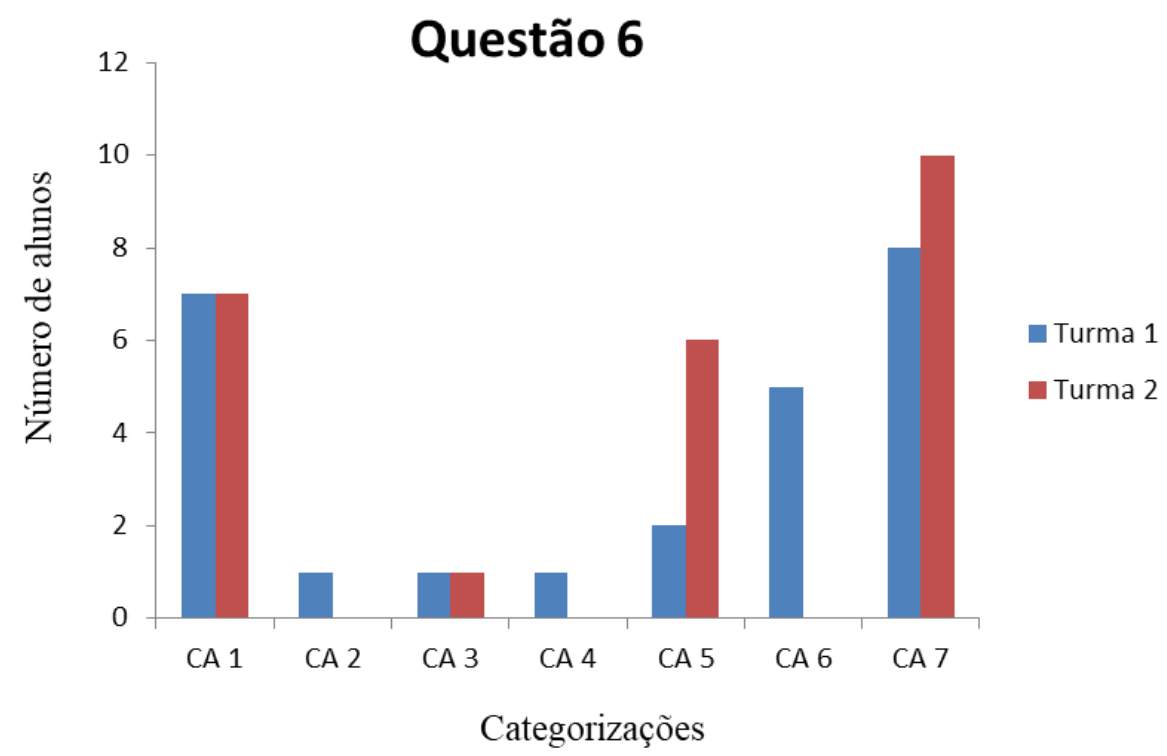

A proposição deste problema trouxe alguns pontos importantes em que o aluno precisou estar atento e mobilizando habilidades distintas. Primeiramente a leitura e relação de informações apresentadas tanto na forma de texto quanto tabela foram fundamentais para a interpretação do problema. Em seguida, o aluno teve de avaliar o que estava sendo pedido para que assim pudesse pensar em possibilidades de resolução.

Observando a figura 14, foi possível verificar que tanto na turma 1 quanto na turma 2, representados pela CA1 existiu uma parcela pequena de alunos que conseguiu resolver o problema por completo. Alguns dos principais motivos das dificuldades dos alunos foram verificados para a turma 1 devido a sua resposta se mostrar, depois da CA1, principalmente na CA 6. E para a turma 2 em virtude de sua resposta refletir em maiores proporções na CA 5.

Para a turma 1 visualizada na categoria 6 significou que os alunos quase conseguiram resolver o problema proposto, exceto pelo fato de que na etapa final de resolução não realizaram a conversão da medida de volume utilizada para uma medida apropriada. Mas ainda sim apresentaram um melhor desempenho do que os alunos da turma 2, que demonstraram como resposta a categoria 5 que significou que conseguiram somente calcular a massa de açúcar do refrigerante comum não avançando nas etapas de resolução da questão.

Por fim, chama a atenção que quase metade do número de alunos de ambas as turmas não conseguiram resolver o problema por completo, não chegando ao resultado esperado. Não foi possível identificar possíveis dificuldades conceituais dos alunos nesta questão, visto que os mesmos não expressaram os cálculos matemáticos. 
Com o propósito de quantificar os grupos de respostas dadas pelos alunos e investigar possíveis questionamentos levantados a partir da construção do gráfico das categorias, construímos uma tabela em que relacionamos o número de alunos com as decodificações criadas. Nessa tabela (Tabela 8), o número 1 atribuído à resposta do aluno indicou que essa se enquadrava na decodificação, o número zero significou que a decodificação não se aplicava à resposta do aluno.

Tabela 8. Decodificações das respostas dos alunos referentes à questão 6 do instrumento piloto.

\begin{tabular}{|c|c|c|c|c|c|c|}
\hline \multicolumn{7}{|c|}{ QUESTÃO 6 - Turma 1} \\
\hline \multirow[t]{2}{*}{ Alunos } & \multicolumn{6}{|c|}{ Decodificações (DC)* } \\
\hline & 1 & 2 & 3 & 4 & 5 & 6 \\
\hline 1 & 1 & 1 & 1 & 0 & 0 & 0 \\
\hline 2 & 1 & 1 & 1 & 0 & 0 & 0 \\
\hline 4 & 1 & 1 & 1 & 0 & 0 & 0 \\
\hline 7 & 1 & 1 & 1 & 0 & 0 & 0 \\
\hline 8 & 1 & 1 & 1 & 0 & 0 & 0 \\
\hline 9 & 1 & 1 & 1 & 0 & 0 & 0 \\
\hline 12 & 1 & 1 & 1 & 0 & 0 & 0 \\
\hline 11 & 1 & 0 & 1 & 0 & 1 & 0 \\
\hline 14 & 0 & 1 & 1 & 1 & 0 & 0 \\
\hline 3 & 1 & 1 & 1 & 0 & 1 & 0 \\
\hline 15 & 1 & 0 & 0 & 0 & 0 & 0 \\
\hline 20 & 1 & 0 & 0 & 0 & 0 & 0 \\
\hline 6 & 0 & 0 & 0 & 1 & 1 & 0 \\
\hline 13 & 0 & 0 & 0 & 1 & 1 & 0 \\
\hline 16 & 0 & 0 & 0 & 1 & 1 & 0 \\
\hline 17 & 0 & 0 & 0 & 1 & 1 & 0 \\
\hline 18 & 0 & 0 & 0 & 1 & 1 & 0 \\
\hline 5 & 0 & 0 & 0 & 0 & 0 & 1 \\
\hline 10 & 0 & 0 & 0 & 0 & 0 & 1 \\
\hline 19 & 0 & 0 & 0 & 0 & 0 & 1 \\
\hline 21 & 0 & 0 & 0 & 0 & 0 & 1 \\
\hline 22 & 0 & 0 & 0 & 0 & 0 & 1 \\
\hline 23 & 0 & 0 & 0 & 0 & 0 & 1 \\
\hline 24 & 0 & 0 & 0 & 0 & 0 & 1 \\
\hline 25 & 0 & 0 & 0 & 0 & 0 & 1 \\
\hline \multicolumn{7}{|c|}{ QUESTÃO 6 - Turma 2} \\
\hline \multirow[t]{2}{*}{ Alunos } & \multicolumn{6}{|c|}{ Decodificações (DC)* } \\
\hline & 1 & 2 & 3 & 4 & 5 & 6 \\
\hline 1 & 1 & 1 & 1 & 0 & 0 & 0 \\
\hline 2 & 1 & 1 & 1 & 0 & 0 & 0 \\
\hline
\end{tabular}




\begin{tabular}{|r|r|r|r|r|r|r|}
\hline 7 & 1 & 1 & 1 & 0 & 0 & 0 \\
\hline 12 & 1 & 1 & 1 & 0 & 0 & 0 \\
\hline 13 & 1 & 1 & 1 & 0 & 0 & 0 \\
\hline 14 & 1 & 1 & 1 & 0 & 0 & 0 \\
\hline 18 & 1 & 1 & 1 & 0 & 0 & 0 \\
\hline 17 & 0 & 1 & 1 & 1 & 0 & 0 \\
\hline 5 & 1 & 0 & 0 & 0 & 0 & 0 \\
\hline 6 & 1 & 0 & 0 & 0 & 0 & 0 \\
\hline 8 & 1 & 0 & 0 & 0 & 0 & 0 \\
\hline 15 & 1 & 0 & 0 & 0 & 0 & 0 \\
\hline 20 & 1 & 0 & 0 & 0 & 0 & 0 \\
\hline 22 & 1 & 0 & 0 & 0 & 0 & 0 \\
\hline 3 & 0 & 0 & 0 & 0 & 0 & 1 \\
\hline 4 & 0 & 0 & 0 & 0 & 0 & 1 \\
\hline 9 & 0 & 0 & 0 & 0 & 0 & 1 \\
\hline 10 & 0 & 0 & 0 & 0 & 0 & 1 \\
\hline 11 & 0 & 0 & 0 & 0 & 0 & 1 \\
\hline 16 & 0 & 0 & 0 & 0 & 0 & 1 \\
\hline 19 & 0 & 0 & 0 & 0 & 0 & 1 \\
\hline 21 & 0 & 0 & 0 & 0 & 0 & 1 \\
\hline 23 & 0 & 0 & 0 & 0 & 0 & 1 \\
\hline 24 & 0 & 0 & 0 & 0 & 0 & 1 \\
\hline
\end{tabular}

*a numeração corresponde à descrição da decodificação apresentada no quadro anterior

A partir da tabela construiu-se o gráfico (Figura 15) a seguir em que verificamos a relação entre o número de alunos com o tipo de decodificação demonstrada por eles. 
Figura 15. Número de alunos por decodificações referentes à questão 6 do instrumento piloto.

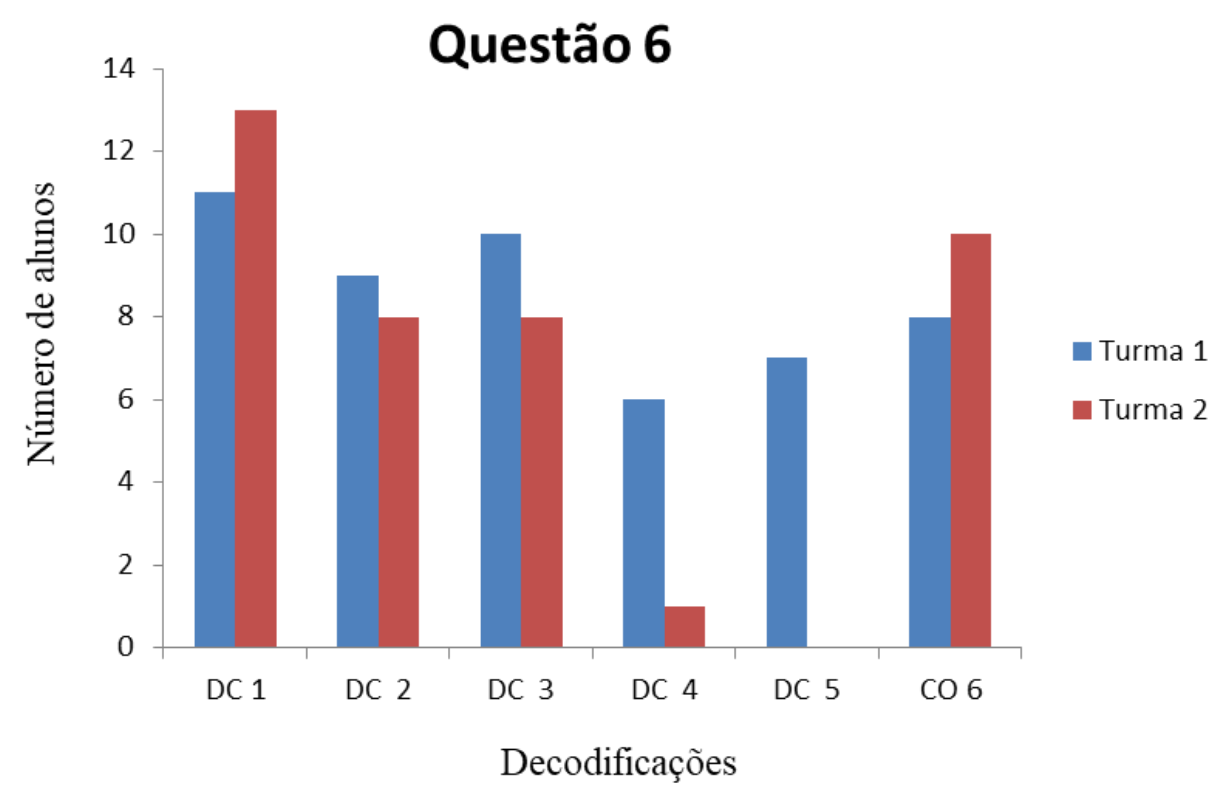

Conforme verificado no gráfico que descreveu as categorias, para resolver por completo a questão, os alunos deveriam expressar a categoria 1 , formada pelas decodificações 1, 2 e 3. Podemos verificar no gráfico acima (Figura 15) que cerca de um terço do total do número de alunos de ambas as turmas apresentaram as DC 1, DC 2 e DC 3, com algumas variações. Outra conexão importante que este gráfico estabeleceu com o gráfico das categorizações também da presente questão (Figura 15) pode ser observada em relação a DC 5 nas respostas dos alunos da turma 1. A formação de tal decodificação nas respostas fez com que os alunos expressassem a categoria 6, conforme já discutida anteriormente, que significou que os alunos quase conseguiram chegar a etapa final de resolução da questão proposta desenvolvendo as habilidades de ordem mais baixa (H18 e H19). E por fim, outro dado de relevância remeteu-se às respostas de também praticamente um terço do total do número de alunos de ambas as turmas mostrarem a decodificação 6 como resposta, a qual significou que os alunos não conseguiram chegar ao resultado esperado e também não expressaram nenhum cálculo matemático na resolução.

\section{QUESTÃO 7}

O dia estava extremamente quente, e para aliviar o calor Miguel e Luíza decidiram preparar uma limonada. No entanto cada um preparou a sua, pois tinham formas diferentes de preparar a bebida. Partindo da ideia de que a solubilidade das substâncias em um mesmo solvente altera-se com a mudança de temperatura do sistema e considerando que os dois utilizaram a mesma quantidade de água, de gelo e de açúcar, 
em qual dos casos você acha que haverá maior quantidade de açúcar dissolvida? Justifique a sua resposta.

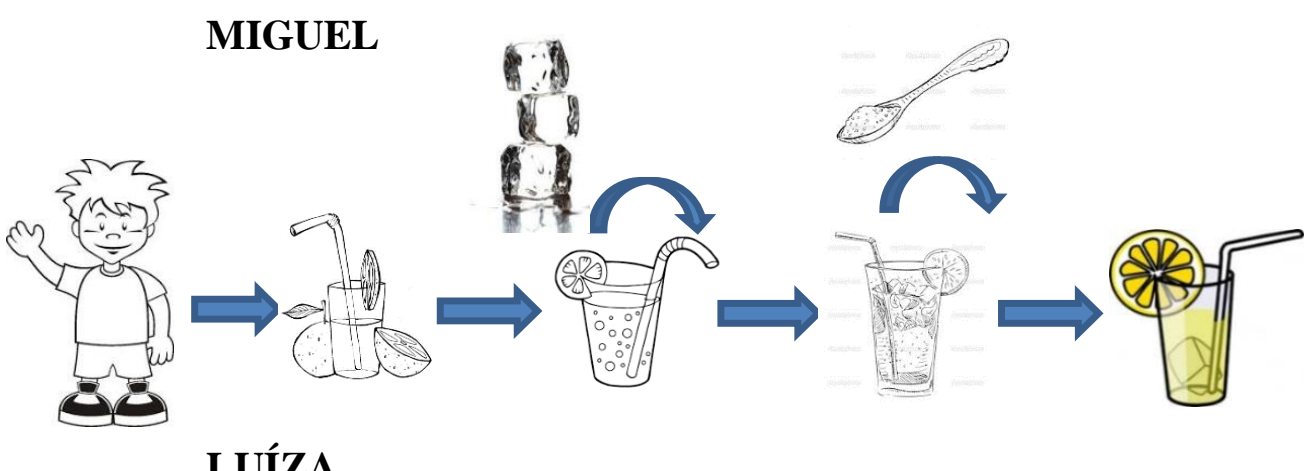

\section{LUÍZA}
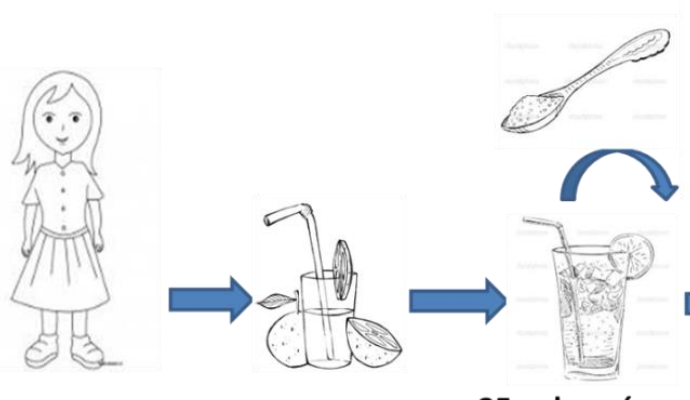

$25 \mathrm{~g}$ de açúcar

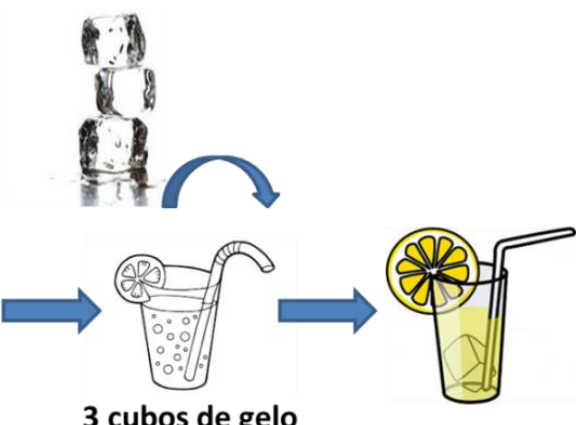

Fonte: Produzida pela autora

O quadro 21 apresenta, para a Questão 7, as decodificações criadas a partir das respostas dos alunos, as categorias criadas e as habilidades e competências selecionadas a partir da matriz do ENEM, suscitadas pela questão para serem mobilizadas pelos estudantes.

Quadro 21. Relação das habilidades escolhidas, decodificações e categorias estabelecidas a partir da análise da questão 7 do instrumento piloto.

\begin{tabular}{|c|c|c|}
\hline \multicolumn{3}{|c|}{ QUESTÃO 7} \\
\hline \multicolumn{3}{|c|}{ COMPETÊNCIAS DE ÁREAS 7 (HABILIDADES 17, 19 e 25) (Matriz de referência do ENEM) } \\
\hline Habilidades & Decodificações & Categorias \\
\hline HABILIDADE 17 & (1) & CA 1 \\
\hline $\begin{array}{l}\text { Relacionar informações } \\
\text { apresentadas em diferentes } \\
\text { formas de linguagem e } \\
\text { representações usadas nas } \\
\text { ciências físicas, químicas }\end{array}$ & $\begin{array}{l}\text { Percepção de que a solubilidade } \\
\text { do açúcar é influenciada pela } \\
\text { temperatura ocorrendo maior } \\
\text { solubilidade com o aumento da } \\
\text { temperatura }\end{array}$ & $\begin{array}{c}\text { Expressou a opinião sustentada em } \\
\text { relações conceituais apresentadas de } \\
\text { forma correta } \\
1 / 2\end{array}$ \\
\hline $\begin{array}{l}\text { ou biológicas, como texto } \\
\text { discursivo, gráficos, } \\
\text { tabelas, relações }\end{array}$ & $\begin{array}{l}\text { (2) } \\
\text { Breve descrição da interferência } \\
\text { da temperatura na solubilidade }\end{array}$ & $\begin{array}{c}\text { CA 2 } \\
\text { Percepção de que a solubilidade do } \\
\text { açúcar é influenciada pela }\end{array}$ \\
\hline
\end{tabular}




\begin{tabular}{|c|c|c|}
\hline $\begin{array}{c}\text { matemáticas ou } \\
\text { linguagens. } \\
\text { HABILIDADE 19 } \\
\text { Avaliar métodos, } \\
\text { processos ou } \\
\text { procedimentos das ciências } \\
\text { naturais que contribuam } \\
\text { para diagnosticar ou } \\
\text { solucionar problemas de } \\
\text { ordem social, econômica } \\
\text { ou ambiental. }\end{array}$ & $\begin{array}{c}(3) \\
\text { Percepção de que a solubilidade } \\
\text { do açúcar é influenciada pela } \\
\text { temperatura ocorrendo maior } \\
\text { solubilidade com a diminuição } \\
\text { da temperatura }\end{array}$ & $\begin{array}{c}\text { temperatura, mas não descreve de que } \\
\text { forma ocorre a situação. } \\
1 \\
\text { CA } 3 \\
\text { Não conseguiu desenvolver uma } \\
\text { explicação para o ocorrido e também } \\
\text { se confundiu conceitualmente } \\
3 \\
\text { CA } 4 \\
\text { Deixou a questão em branco } \\
4\end{array}$ \\
\hline $\begin{array}{c}\text { HABILDADE 25 } \\
\text { Caracterizar } \\
\text { materiais ou substâncias, } \\
\text { identificando etapas, } \\
\text { rendimentos ou } \\
\text { implicações biológicas, } \\
\text { sociais, econômicas ou } \\
\text { ambientais de sua obtenção } \\
\text { ou produção. }\end{array}$ & $\begin{array}{c}\text { (4) } \\
\text { Não respondeu a questão }\end{array}$ & \\
\hline
\end{tabular}

Para melhor visualizarmos as categorias construídas e estabelecermos possíveis comparativos entre elas construímos o gráfico a seguir (Figura 16) em que relacionamos as categorias criadas com as turmas participantes do projeto.

Figura 16. Número de alunos por categorias referentes à questão 7 do instrumento piloto.

\section{Questão 7}

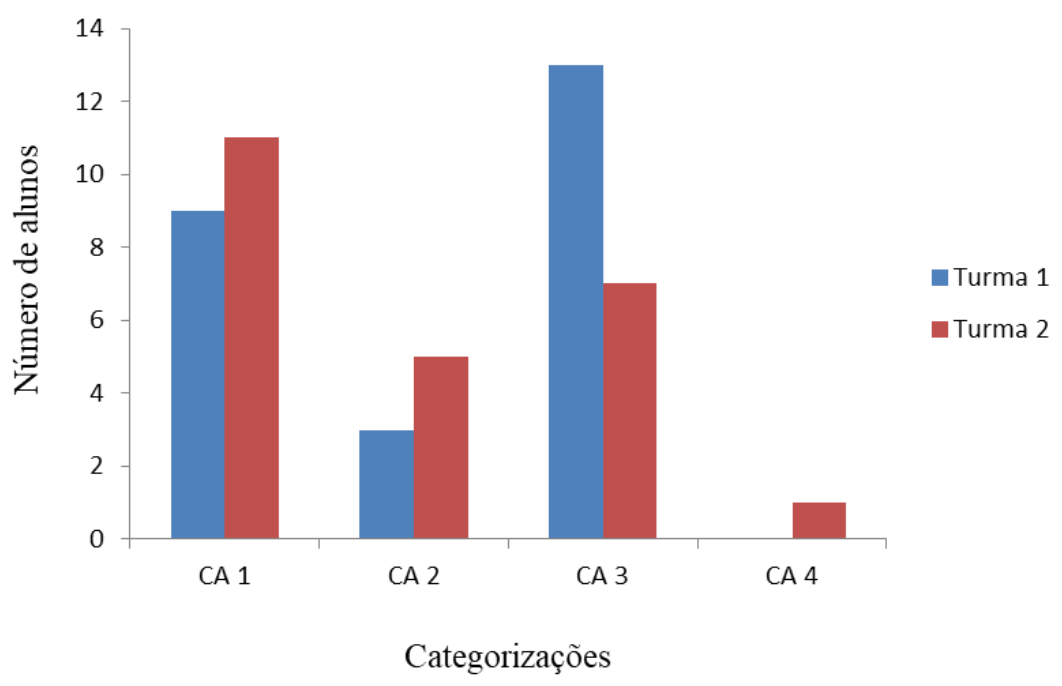

Duas observações importantes foram verificadas a partir da análise do gráfico (Figura 16). As respostas dos alunos se mostraram principalmente a partir de duas categorias: CA1 e CA3. Expressar a categoria 1 em suas respostas representou entender o problema proposto, interpretar as imagens fornecidas, avaliar e propor uma resolução para o problema 
proposto através da caracterização dos materiais. Assim, foi necessária a mobilização das habilidades 17, 19 e 25. A turma 2 (quase metade do número total de alunos) apresentou um melhor desempenho na resolução desta questão comparada a turma 1 em que apenas aproximadamente um terço do total do número de alunos conseguiu resolver a questão.

Em relação à categoria 3, pode-se afirmar que os alunos não conseguiram desenvolver uma explicação para o ocorrido e também confundiram-se conceitualmente no momento de elaborar uma explicação para o fenômeno. Para que as respostas se mostrassem nesta categoria somente foi mobilizada a habilidade 25 como tentativa de solucionar o problema proposto. Neste caso houve uma maior representativa por parte da turma 1 nesta categoria, com aproximadamente metade do número total de alunos representativos da turma 1.

Com o propósito de quantificar os grupos de respostas dadas pelos alunos e investigar possíveis questionamentos levantados a partir da construção do gráfico das categorias, construímos uma tabela em que relacionamos o número de alunos com as decodificações criadas. Nessa tabela (Figura 17), o número 1 atribuído à resposta do aluno indicou que essa se enquadrava na decodificação, o número zero significou que a decodificação não se aplicava à resposta do aluno.

Figura 17. Decodificações das respostas dos alunos referentes à questão 7 do instrumento piloto.

\begin{tabular}{|c|c|c|c|c|}
\hline \multicolumn{5}{|c|}{ QUESTÃO 7 - Turma 1} \\
\hline \multirow[t]{2}{*}{ Alunos } & \multicolumn{4}{|c|}{$\begin{array}{c}\text { Decodificações } \\
\text { (DC)* }\end{array}$} \\
\hline & 1 & 2 & 3 & 4 \\
\hline 23 & 1 & 0 & 0 & 0 \\
\hline 20 & 1 & 0 & 0 & 0 \\
\hline 17 & 1 & 0 & 0 & 0 \\
\hline 14 & 1 & 1 & 0 & 0 \\
\hline 16 & 1 & 1 & 0 & 0 \\
\hline 3 & 1 & 1 & 0 & 0 \\
\hline 4 & 1 & 1 & 0 & 0 \\
\hline 7 & 1 & 1 & 0 & 0 \\
\hline 8 & 1 & 1 & 0 & 0 \\
\hline 10 & 1 & 1 & 0 & 0 \\
\hline 11 & 1 & 1 & 0 & 0 \\
\hline 12 & 1 & 1 & 0 & 0 \\
\hline 1 & 0 & 0 & 1 & 0 \\
\hline 2 & 0 & 0 & 1 & 0 \\
\hline
\end{tabular}




\begin{tabular}{|r|r|r|r|r|}
\hline 5 & 0 & 0 & 1 & 0 \\
\hline 6 & 0 & 0 & 1 & 0 \\
\hline 9 & 0 & 0 & 1 & 0 \\
\hline 13 & 0 & 0 & 1 & 0 \\
\hline 15 & 0 & 0 & 1 & 0 \\
\hline 18 & 0 & 0 & 1 & 0 \\
\hline 19 & 0 & 0 & 1 & 0 \\
\hline 21 & 0 & 0 & 1 & 0 \\
\hline 22 & 0 & 0 & 1 & 0 \\
\hline 24 & 0 & 0 & 1 & 0 \\
\hline 25 & 0 & 0 & 1 & 0 \\
\hline & & &
\end{tabular}

\section{QUESTÃO 7 - Turma 2}

\begin{tabular}{|c|c|c|c|c|}
\hline \multirow[t]{2}{*}{ Alunos } & \multicolumn{4}{|c|}{$\begin{array}{c}\text { Decodificações } \\
(\mathrm{DC}) *\end{array}$} \\
\hline & 1 & 2 & 3 & 4 \\
\hline 2 & 1 & 0 & 0 & 0 \\
\hline 6 & 1 & 0 & 0 & 0 \\
\hline 10 & 1 & 0 & 0 & 0 \\
\hline 17 & 1 & 0 & 0 & 0 \\
\hline 18 & 1 & 0 & 0 & 0 \\
\hline 1 & 1 & 1 & 0 & 0 \\
\hline 5 & 1 & 1 & 0 & 0 \\
\hline 8 & 1 & 1 & 0 & 0 \\
\hline 9 & 1 & 1 & 0 & 0 \\
\hline 11 & 1 & 1 & 0 & 0 \\
\hline 13 & 1 & 1 & 0 & 0 \\
\hline 14 & 1 & 1 & 0 & 0 \\
\hline 16 & 1 & 1 & 0 & 0 \\
\hline 22 & 1 & 1 & 0 & 0 \\
\hline 23 & 1 & 1 & 0 & 0 \\
\hline 24 & 1 & 1 & 0 & 0 \\
\hline 3 & 0 & 0 & 1 & 0 \\
\hline 4 & 0 & 0 & 1 & 0 \\
\hline 7 & 0 & 0 & 1 & 0 \\
\hline 12 & 0 & 0 & 1 & 0 \\
\hline 15 & 0 & 0 & 1 & 0 \\
\hline 20 & 0 & 0 & 1 & 0 \\
\hline 21 & 0 & 0 & 1 & 0 \\
\hline 19 & 0 & 0 & 0 & 1 \\
\hline
\end{tabular}

*a numeração corresponde à descrição da decodificação apresentada no quadro anterior 
A partir da tabela construiu-se o gráfico (Figura 18) a seguir em que verificamos a relação entre o número de alunos com o tipo de decodificação demonstrada por eles.

Figura 18. Número de alunos por decodificações referentes à questão 7 do instrumento piloto.

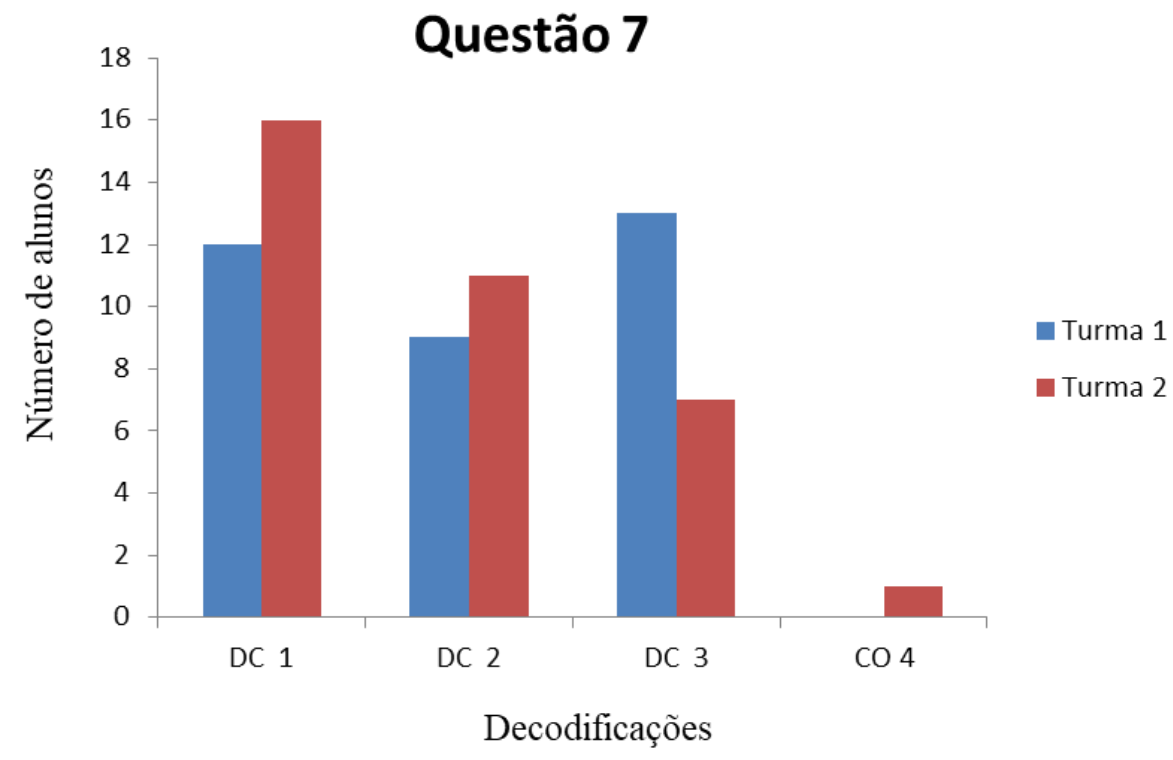

Para que a resposta dada pelo aluno fosse classificada na categoria 1 foi necessário que ele fosse capaz de desenvolver uma explicação para o ocorrido sem se confundir conceitualmente, ou seja, precisava desenvolver juntamente as decodificações 1 e 2 . A expressividade de tais decodificações exigiram a mobilização de uma habilidade de baixa ordem (habilidade 17) na decodificação 1, e uma habilidade de alta ordem cognitiva (habilidade 19) na decodificação 2. Conforme observado no gráfico, comparando-se as turmas, a turma 2 apresentou maior representatividade destas decodificações justamente por apresentarem suas respostas em maior quantidade na categoria 1. Já a turma 1 demonstrou maior expressividade da decodificação 3 justamente por corresponder à categoria 3 , conforme visto no gráfico das categorização (Figura 17), mobilizando somente a habilidade 25 como tentativa de solucionar o problema proposto.

\section{QUESTÃO 8}

Os acidentes de trânsito, no Brasil, em sua maior parte são causados por erro do motorista. Em boa parte deles, o motivo é o fato de dirigir após o consumo de bebida alcoólica. A ingestão de uma lata de cerveja provoca uma concentração de aproximadamente $0,3 \mathrm{~g} / \mathrm{L}$ de álcool no sangue. A tabela mostra os efeitos sobre o corpo humano provocados por bebidas alcoólicas em função de níveis de concentração de álcool no sangue: 


\begin{tabular}{c|l}
\hline $\begin{array}{c}\text { Concentração de } \\
\text { álcool no sangue }(\mathbf{g} / \mathbf{L})\end{array}$ & \multicolumn{1}{c}{ Efeitos } \\
\hline $0,1-0,5$ & Sem influência aparente, ainda que com alterações clínicas \\
\hline $0,3-1,2$ & Euforia suave, sociabilidade acentuada e queda da atenção \\
\hline $0,9-2,5$ & $\begin{array}{l}\text { Excitação, perda de julgamento crítico, queda da sensibilidade e das } \\
\text { reações motoras }\end{array}$ \\
\hline $1,8-3,0$ & Confusão mental e perda da coordenação motora \\
\hline $2,7-4,0$ & Estupor, apatia, vômitos e desequilibrio ao andar \\
\hline $3,5-5,0$ & Coma e morte possível \\
\hline
\end{tabular}

(Revista Pesquisa FAPESP no 57, setembro 2000)

Uma pessoa que tenha tomado três latas de cerveja provavelmente apresenta

a) queda de atenção, de sensibilidade e das reações motoras.

b) aparente normalidade, mas com alterações clínicas.

c) confusão mental e falta de coordenação motora.

d) disfunção digestiva e desequilíbrio ao andar.

e) estupor e risco de parada respiratória.

Fonte: ENEM 2003

O quadro 22 apresenta, para a Questão 8, as decodificações criadas a partir das respostas dos alunos, as categorias criadas e as habilidades e competências selecionadas a partir da matriz do ENEM, suscitadas pela questão para serem mobilizadas pelos estudantes.

Quadro 22. Relação das habilidades escolhidas, decodificações e categorias estabelecidas a partir da análise da questão 8 do instrumento piloto.

\begin{tabular}{|c|c|c|}
\hline \multicolumn{3}{|c|}{ QUESTÃO 8 } \\
\hline \multicolumn{3}{|c|}{ COMPETÊNCIAS DE ÁREAS 7(HABILIDADES 17, 19 e 25)(Matriz de referência do ENEM) } \\
\hline Habilidades & Decodificações & Categorias \\
\hline \multirow{3}{*}{$\begin{array}{l}\text { HABILIDADE } 17 \\
\text { Relacionar informações } \\
\text { apresentadas em diferentes } \\
\text { formas de linguagem e } \\
\text { representações usadas nas } \\
\text { ciências físicas, químicas ou } \\
\text { biológicas, como texto } \\
\text { discursivo, gráficos, tabelas, } \\
\text { relações matemáticas ou }\end{array}$} & $(1)$ & CA 1 \\
\hline & $\begin{array}{l}\text { Leitura, interpretação da } \\
\text { tabela e localização das } \\
\text { informações necessárias. }\end{array}$ & $\begin{array}{c}\text { Capacidade de interpretação das } \\
\text { informações e obtenção do resultado } \\
\text { esperado }\end{array}$ \\
\hline & $\begin{array}{c}\text { (3) } \\
\text { Leitura das alternativas e } \\
\text { localização do efeito } \\
\text { corretamente relacionado } \\
\text { com o enunciado da questão }\end{array}$ & $\begin{array}{c}\text { CA } 2 \\
\text { Não foi capaz de chegar ao resultado }\end{array}$ \\
\hline
\end{tabular}




\begin{tabular}{|c|c|c|}
\hline $\begin{array}{c}\text { linguagens. } \\
\text { HABILIDADE } 19 \\
\text { Avaliar métodos, processos } \\
\text { ou procedimentos das } \\
\text { ciências naturais que } \\
\text { contribuam para diagnosticar } \\
\text { ou solucionar problemas de } \\
\text { ordem social, econômica ou } \\
\text { ambiental. } \\
\text { HABILIDADE } 25 \\
\text { Caracterizar materiais ou } \\
\text { substâncias, identificando } \\
\text { etapas, rendimentos ou } \\
\text { implicações biológicas, } \\
\text { sociais, econômicas ou } \\
\text { ambientais de sua obtenção } \\
\text { ou produção. }\end{array}$ & $\begin{array}{l}\text { (2) } \\
\text { Cálculo da concentração de } \\
\text { álcool de acordo com a } \\
\text { quantidade de latas } \\
\text { (4) } \\
\text { Dificuldade de interpretação } \\
\text { do enunciado da questão }\end{array}$ & $\begin{array}{l}\text { esperado, pois conseguiu interpretar a } \\
\text { tabela, mas obteve dificuldade na } \\
\text { interpretação do enunciado da questão. } \\
2 / 4\end{array}$ \\
\hline
\end{tabular}

Para melhor visualizarmos as categorias construídas e estabelecermos possíveis comparativos entre elas construímos o gráfico a seguir (Figura 19) em que relacionamos as categorias criadas com as turmas participantes do projeto.

Figura 19. Número de alunos por categorias referentes a questão 8 do instrumento piloto.

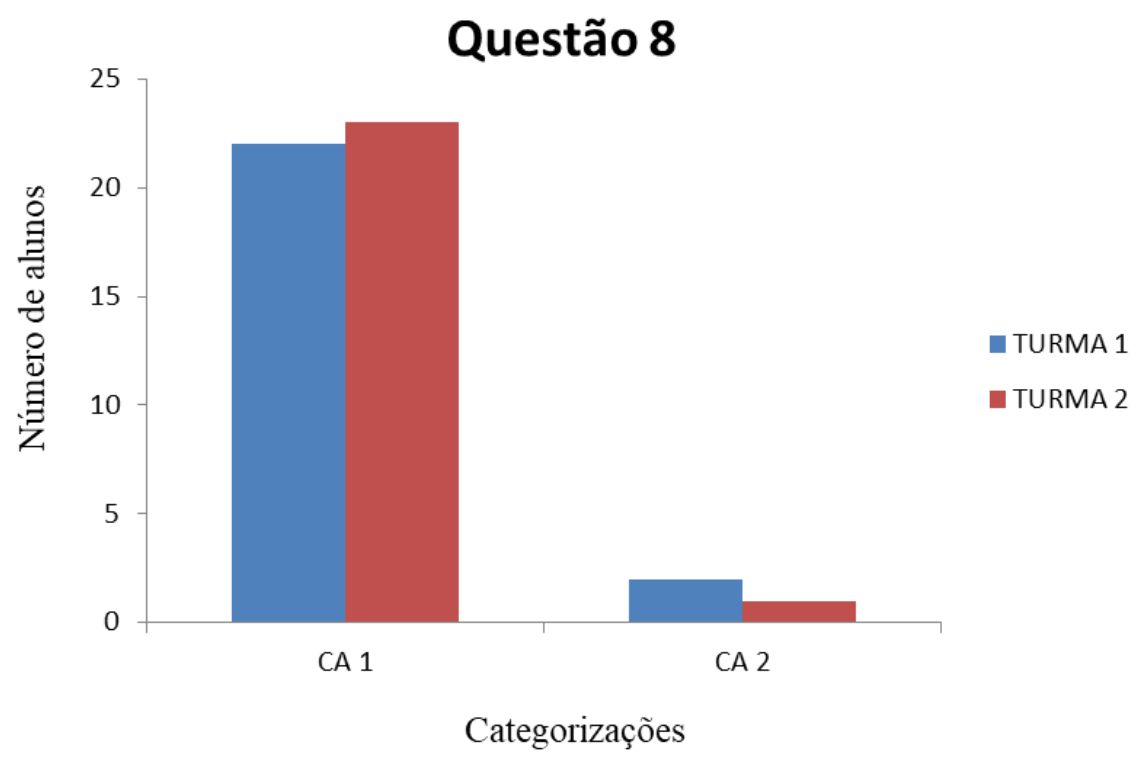

A partir desses resultados podemos considerar que esta talvez seja a questão proposta em que o aluno apresentou maior facilidade de resolução. Tanto a turma 1 quanto a turma 2 deram respostas, em sua grande maioria, apresentadas na forma da categoria 1, o que significa que o aluno apresentou capacidade de interpretação das informações e obtenção do resultado esperado, mobilizando as habilidades cognitivas necessárias (habilidades 17, 19 e 25). Apenas 
dois alunos da turma 1 e um aluno da turma 2 não conseguiram resolver o problema proposto. O gráfico descrito na figura 19 detalhou o tipo de resposta com o número de alunos.

Com o propósito de quantificar os grupos de respostas dadas pelos alunos e investigar possíveis questionamentos levantados a partir da construção do gráfico das categorias, construímos uma tabela em que relacionamos o número de alunos com as decodificações criadas. Nessa tabela (Tabela 9), o número 1 atribuído à resposta do aluno indicou que essa se enquadrava na decodificação, o número zero significou que a decodificação não se aplicava à resposta do aluno.

Tabela 9. Decodificações das respostas dos alunos referentes à questão 8 do instrumento piloto.

\begin{tabular}{|c|c|c|c|c|}
\hline \multicolumn{5}{|c|}{ QUESTÃO 8 - Turma 1} \\
\hline \multirow[t]{2}{*}{ Alunos } & \multicolumn{4}{|c|}{$\begin{array}{l}\text { Decodificações } \\
\text { (DC)* }\end{array}$} \\
\hline & 1 & 2 & 3 & 4 \\
\hline 1 & 1 & 1 & 1 & 0 \\
\hline 2 & 1 & 1 & 1 & 0 \\
\hline 4 & 1 & 1 & 1 & 0 \\
\hline 5 & 1 & 1 & 1 & 0 \\
\hline 6 & 1 & 1 & 1 & 0 \\
\hline 7 & 1 & 1 & 1 & 0 \\
\hline 8 & 1 & 1 & 1 & 0 \\
\hline 9 & 1 & 1 & 1 & 0 \\
\hline 10 & 1 & 1 & 1 & 0 \\
\hline 11 & 1 & 1 & 1 & 0 \\
\hline 12 & 1 & 1 & 1 & 0 \\
\hline 13 & 1 & 1 & 1 & 0 \\
\hline 14 & 1 & 1 & 1 & 0 \\
\hline 15 & 1 & 1 & 1 & 0 \\
\hline 16 & 1 & 1 & 1 & 0 \\
\hline 17 & 1 & 1 & 1 & 0 \\
\hline 18 & 1 & 1 & 1 & 0 \\
\hline 19 & 1 & 1 & 1 & 0 \\
\hline 20 & 1 & 1 & 1 & 0 \\
\hline 22 & 1 & 1 & 1 & 0 \\
\hline 23 & 1 & 1 & 1 & 0 \\
\hline 24 & 1 & 1 & 1 & 0 \\
\hline 3 & 0 & 1 & 0 & 1 \\
\hline 21 & 0 & 1 & 0 & 1 \\
\hline \multicolumn{5}{|c|}{ QUESTÃO 8 - Turma 2} \\
\hline Alunos & De & 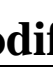 & & \\
\hline
\end{tabular}




\begin{tabular}{|c|c|c|c|c|}
\hline & \multicolumn{4}{|c|}{$(\mathrm{DC}) *$} \\
\hline & 1 & 2 & 3 & 4 \\
\hline 1 & 1 & 1 & 1 & 0 \\
\hline 2 & 1 & 1 & 1 & 0 \\
\hline 3 & 1 & 1 & 1 & 0 \\
\hline 5 & 1 & 1 & 1 & 0 \\
\hline 6 & 1 & 1 & 1 & 0 \\
\hline 7 & 1 & 1 & 1 & 0 \\
\hline 8 & 1 & 1 & 1 & 0 \\
\hline 9 & 1 & 1 & 1 & 0 \\
\hline 10 & 1 & 1 & 1 & 0 \\
\hline 11 & 1 & 1 & 1 & 0 \\
\hline 12 & 1 & 1 & 1 & 0 \\
\hline 13 & 1 & 1 & 1 & 0 \\
\hline 14 & 1 & 1 & 1 & 0 \\
\hline 15 & 1 & 1 & 1 & 0 \\
\hline 16 & 1 & 1 & 1 & 0 \\
\hline 17 & 1 & 1 & 1 & 0 \\
\hline 18 & 1 & 1 & 1 & 0 \\
\hline 19 & 1 & 1 & 1 & 0 \\
\hline 20 & 1 & 1 & 1 & 0 \\
\hline 21 & 1 & 1 & 1 & 0 \\
\hline 22 & 1 & 1 & 1 & 0 \\
\hline 23 & 1 & 1 & 1 & 0 \\
\hline 24 & 1 & 1 & 1 & 0 \\
\hline 4 & 0 & 1 & 0 & 1 \\
\hline
\end{tabular}

*a numeração corresponde à descrição da decodificação apresentada no quadro anterior

A partir da tabela construiu-se o gráfico (Figura 20) a seguir em que verificamos a relação entre o número de alunos com o tipo de decodificação demonstrada por eles. 
Figura 20. Número de alunos por decodificações referentes à questão 8 do instrumento piloto.

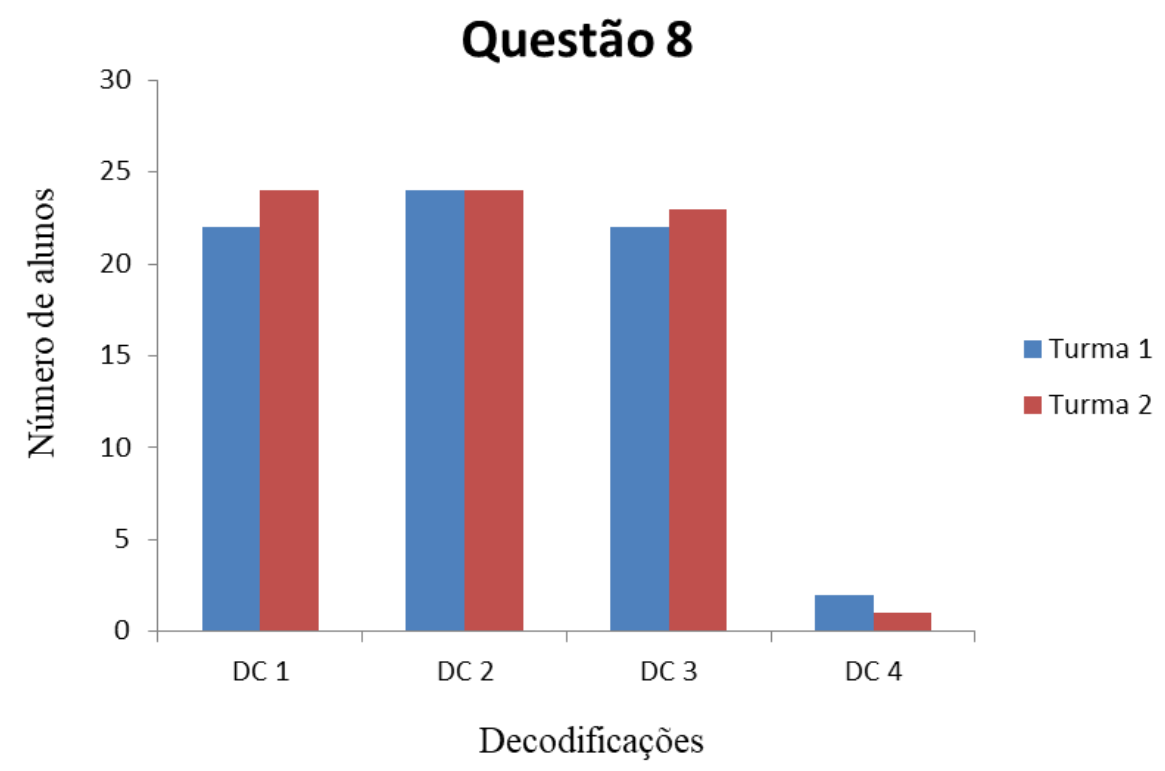

Um aluno, ao resolver adequadamente a problemática proposta, manifestaria ideias representadas pela categoria 1, apresentando, portanto, as codificações 1, 2 e 3. Assim, os alunos deveriam mobilizar as habilidades 17, 19 e 25, as quais representam desde a habilidades de baixa ordem, para as codificação 1 (habilidades 17 e 18), até habilidades de alta ordem cognitiva, para as codificações 2 e 3 (habilidades 19 e 25). Como é mostrado na Figura 20, podemos concluir que todas as etapas de resolução foram contempladas, já que o patamar das três codificações praticamente permaneceu igual.

\section{QUESTÃO 9}

Um escoteiro precisa acender uma fogueira antes que escureça. Para isso foi dar uma caminhada na mata para ver o que encontrava. Ele se deparou com duas situações diferentes:

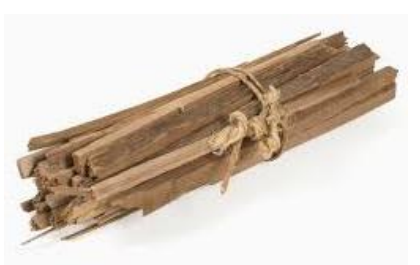

Gravetos de madeira

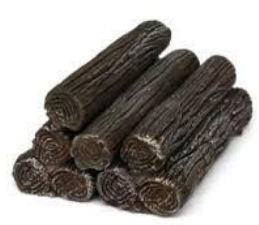

Pedaços de lenha

Considerando a mesma quantidade de madeira (em massa) em cada caso. Em sua opinião, qual foi a opção que o escoteiro escolheu? Explique sua resposta.

Fonte: Produzida pela autora. 
O quadro 23 apresenta, para a Questão 8, as decodificações criadas a partir das respostas dos alunos, as categorias criadas e as habilidades e competências selecionadas a partir da matriz do ENEM, suscitadas pela questão para serem mobilizadas pelos estudantes.

Quadro 23. Relação das habilidades escolhidas, decodificações e categorias estabelecidas a partir da análise da questão 9 do instrumento piloto.

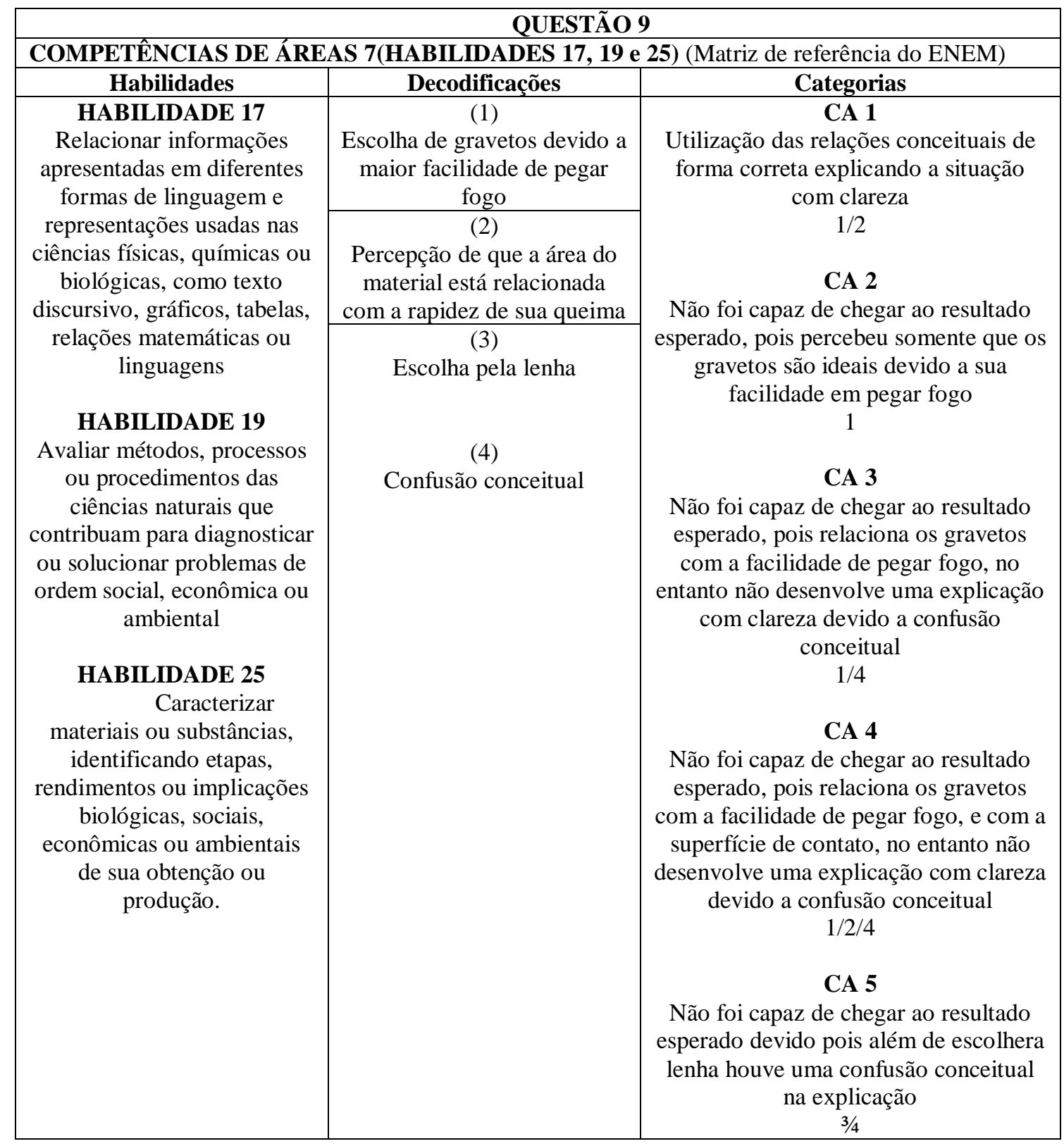

Para melhor visualizarmos as categorias construídas e estabelecermos possíveis comparativos entre elas construímos o gráfico a seguir (Figura 21) em que relacionamos as categorias criadas com as turmas participantes do projeto. 
Figura 21. Número de alunos por categorias referentes à questão 9 do instrumento piloto.

\section{Questão 9}

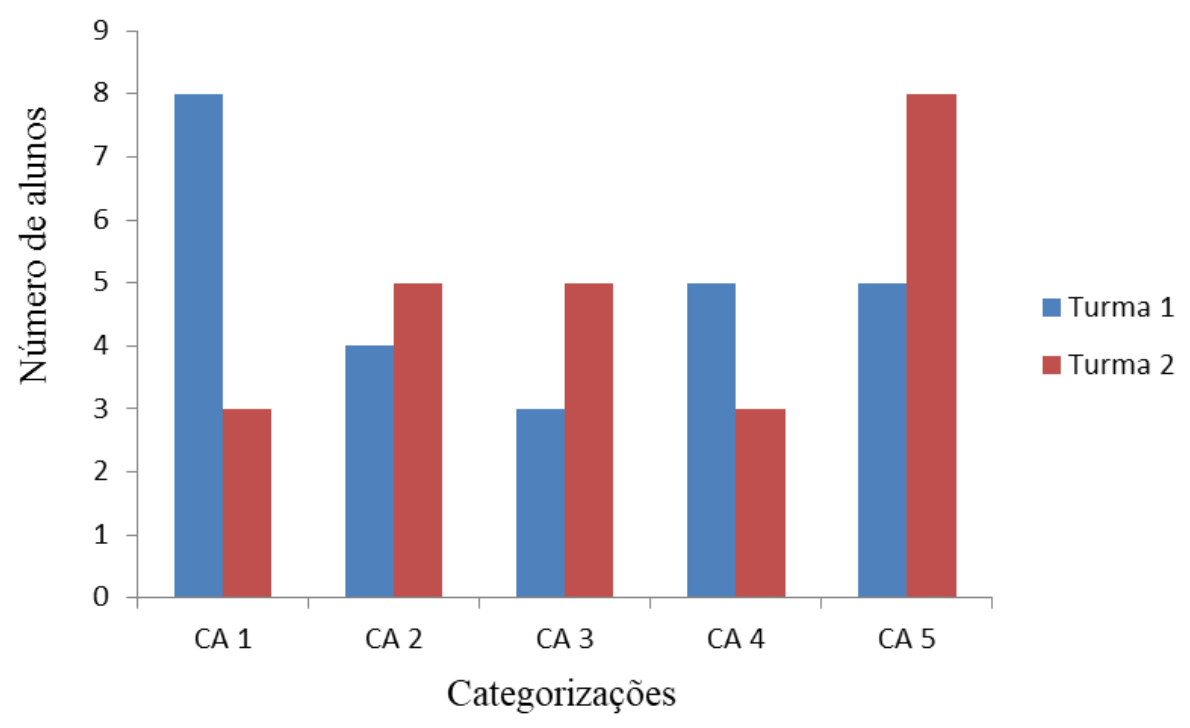

Observando o gráfico, dois resultados nos chamaram atenção. O número de alunos correspondentes a turma 1 que manifestaram respostas classificadas na categoria 1 , correspondeu a igual número de alunos da turma 2 cujas respostas se enquadraram na categoria 5. Ou seja, apesar do baixo o número de alunos da turma 1 cujas respostas foram classificadas na categoria 1, estes apresentam um desempenho superior ao da turma 2. A categoria 1 correspondeu ao grupo de alunos que conseguiram encontrar uma solução para o problema proposto. Em relação à categoria 5, os alunos não foram capazes de chegar ao resultado esperado, pois relacionaram além de relacionarem a lenha como sendo a forma do material de maior facilidade de pegar fogo também não desenvolveram uma explicação com clareza por conta de certa confusão conceitual.

Em relação ao alunos da turma 2 conseguimos perceber através das manifestações das categorias 2 e 3 em suas respostas que a principal dificuldade de não finalizarem a resolução da questão foi devido ao fato de não relacionarem a área do material com a rapidez de sua queima. Já os resultados da turma 1 nas demais categorias foram muito próximos.

Com o propósito de quantificar os grupos de respostas dadas pelos alunos e investigar possíveis questionamentos levantados a partir da construção do gráfico das categorias, construímos uma tabela em que relacionamos o número de alunos com as decodificações criadas. Nessa tabela (Tabela 10), o número 1 atribuído à resposta do aluno indicou que essa se enquadrava na decodificação, o número zero significou que a decodificação não se aplicava à resposta do aluno. 
Tabela 10. Decodificações das respostas dos alunos referentes à questão 9 do instrumento piloto.

\begin{tabular}{|c|c|c|c|c|}
\hline \multicolumn{5}{|c|}{\begin{tabular}{l|c}
\multicolumn{2}{c}{ QUEST T̃O 9 - Turma 1 } \\
Alunos & $\begin{array}{c}\text { Decodificações } \\
\text { (DC)* }\end{array}$ \\
\end{tabular}} \\
\hline & 1 & 2 & 3 & 4 \\
\hline 3 & 1 & 1 & 0 & 1 \\
\hline 10 & 1 & 1 & 0 & 1 \\
\hline 11 & 1 & 1 & 0 & 1 \\
\hline 12 & 1 & 1 & 0 & 1 \\
\hline 13 & 1 & 1 & 0 & 1 \\
\hline 19 & 1 & 0 & 0 & 0 \\
\hline 21 & 1 & 0 & 0 & 0 \\
\hline 22 & 1 & 0 & 0 & 0 \\
\hline 23 & 1 & 0 & 0 & 0 \\
\hline 1 & 1 & 1 & 0 & 0 \\
\hline 4 & 1 & 1 & 0 & 0 \\
\hline 5 & 1 & 1 & 0 & 0 \\
\hline 6 & 1 & 1 & 0 & 0 \\
\hline 16 & 1 & 1 & 0 & 0 \\
\hline 17 & 1 & 1 & 0 & 0 \\
\hline 24 & 1 & 1 & 0 & 0 \\
\hline 25 & 1 & 1 & 0 & 0 \\
\hline 7 & 1 & 0 & 0 & 1 \\
\hline 8 & 1 & 0 & 0 & 1 \\
\hline 9 & 1 & 0 & 0 & 1 \\
\hline 2 & 0 & 0 & 1 & 1 \\
\hline 14 & 0 & 0 & 1 & 1 \\
\hline 15 & 0 & 0 & 1 & 1 \\
\hline 18 & 0 & 0 & 1 & 1 \\
\hline 20 & 0 & 0 & 1 & 1 \\
\hline
\end{tabular}

QUESTÃ̃ 9 - Turma 2

\begin{tabular}{|r|r|r|r|r|}
\hline & \multicolumn{4}{|c|}{$\begin{array}{c}\text { Decodificações } \\
\text { (DC) }\end{array}$} \\
\hline & 1 & 2 & 3 & 4 \\
\hline 3 & 1 & 1 & 0 & 1 \\
\hline 7 & 1 & 1 & 0 & 1 \\
\hline 2 & 1 & 0 & 0 & 0 \\
\hline 16 & 1 & 0 & 0 & 0 \\
\hline 17 & 1 & 0 & 0 & 0 \\
\hline 18 & 1 & 0 & 0 & 0 \\
\hline 19 & 1 & 0 & 0 & 0 \\
\hline 13 & 1 & 1 & 0 & 0 \\
\hline 14 & 1 & 1 & 0 & 0 \\
\hline
\end{tabular}




\begin{tabular}{|r|r|r|r|r|}
\hline 15 & 1 & 1 & 0 & 0 \\
\hline 1 & 1 & 0 & 0 & 1 \\
\hline 9 & 1 & 0 & 0 & 1 \\
\hline 10 & 1 & 0 & 0 & 1 \\
\hline 11 & 1 & 0 & 0 & 1 \\
\hline 4 & 0 & 0 & 1 & 1 \\
\hline 5 & 0 & 0 & 1 & 1 \\
\hline 6 & 0 & 0 & 1 & 1 \\
\hline 20 & 0 & 0 & 1 & 1 \\
\hline 21 & 0 & 0 & 1 & 1 \\
\hline 22 & 0 & 0 & 1 & 1 \\
\hline 23 & 0 & 0 & 1 & 1 \\
\hline 24 & 0 & 0 & 1 & 1 \\
\hline 8 & 1 & 1 & 0 & 1 \\
\hline 12 & 1 & 0 & 0 & 1 \\
\hline
\end{tabular}

*a numeração corresponde à descrição da decodificação apresentada no quadro anterior

A partir da tabela construiu-se o gráfico (Figura 22) a seguir em que verificamos a relação entre o número de alunos com o tipo de decodificação demonstrada por eles.

Figura 22. Número de alunos por decodificações referentes à questão 9 do instrumento piloto.

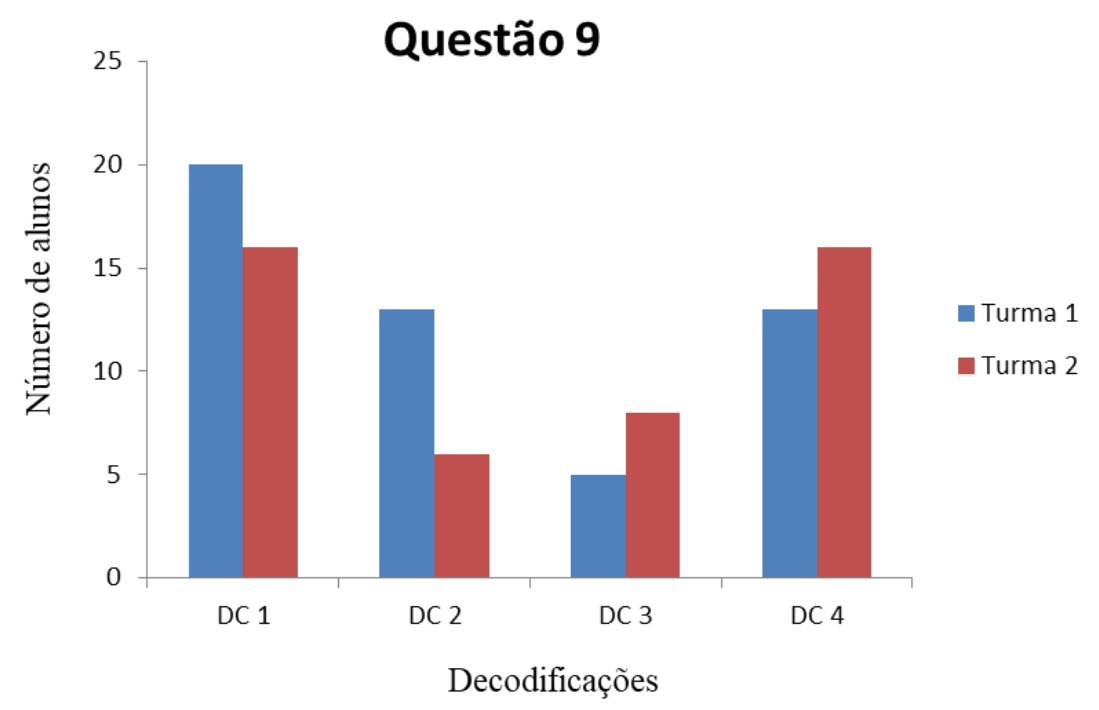

Observando o número de alunos cujas respostas foram agrupadas nas diferentes decodificações, podemos entender alguns resultados de algumas categorizações da mesma questão (Figura 22). Para que o aluno pudesse resolver o problema proposto sua reposta deveria estar contida na categoria 1, em que as decodificações 1 e 2 foram agrupadas. Dessa forma, podemos observar que ambas as turmas iniciaram a resolução, pois as respostas dos 
alunos, em sua maioria, demonstraram a decodificação 1, ou seja, eles foram capazes de mobilizar a habilidade 17, que tratou-se de uma habilidade de baixa ordem. Em menores proporções também demonstraram a decodificação 2, sendo este o motivo pelo qual houve um baixo número de alunos com respostas que puderam ser consideradas na categorização 1 .

Juntamente com as verificações acima pode-se conjecturar que o que impediu que os alunos tivessem um bom desempenho na questão está expresso na decodificação 4, em que tanto os alunos da turma 1 quanto da turma 2 não conseguiram mobilizar a habilidade de alta ordem 25, ou seja, não expressaram entendimento em suas escolhas e também no fato da superfície de contato do material ser um fator que deveria estar envolvido na resolução da questão.

De forma geral ao ser necessário mobilizar habilidades de pensamento de mais alta ordem (habilidades 19 e 25) as duas turmas apresentam grandes dificuldades, sendo o fator contribuinte para que os alunos não conseguissem resolver o problema proposto.

Com a finalidade de estabelecer uma reflexão a respeito do instrumento piloto objetivando perceber possíveis esclarecimentos para os nossos estudos e contribuições do material para as etapas seguintes, que consistiram na elaboração e aplicação de uma sequencia de atividades que problematizaram as maiores dificuldades conceituais dos alunos, estabelecemos um agrupamento das questões de acordo com a resolução das mesmas (tabela 11). Conforme já descrito anteriormente a turma 1 (T1) constitui-se em 25 alunos e a turma 2 (T2) por 24 alunos.

Tabela 11. Rendimentos das questões referentes ao instrumento piloto.

\begin{tabular}{|l|c|c|}
\hline & \multicolumn{3}{|c|}{ QUESTÃO 1 } \\
\hline & T1(\%) & T2 (\%) \\
\hline RC* $^{*}$ & 72 & 54,2 \\
\hline RNC* $^{*}$ & 28 & 45,8 \\
\hline & \multicolumn{3}{|c|}{ QUESTÃO 2 } \\
\hline RC $^{*}$ & 56 & 41,7 \\
\hline RNC* $^{*}$ & 44 & 58,3 \\
\hline & \multicolumn{3}{|c|}{ QUESTÃO 3 } \\
\hline RC $^{*}$ & 32 & 25 \\
\hline RNC* $^{*}$ & 68 & 75 \\
\hline & \multicolumn{3}{|c|}{ QUESTÃO 4** } \\
\hline
\end{tabular}




\begin{tabular}{|c|c|c|}
\hline & \multicolumn{2}{|c|}{ QUESTÃO 5} \\
\hline $\mathrm{RC}^{*}$ & 8 & 8,3 \\
\hline \multirow[t]{2}{*}{$\mathrm{RNC}^{*}$} & 92 & 91,7 \\
\hline & \multicolumn{2}{|c|}{ QUESTÃO 6} \\
\hline $\mathrm{RC}^{*}$ & 28 & 29,2 \\
\hline \multirow[t]{2}{*}{$\mathrm{RNC}^{*}$} & 72 & 70,8 \\
\hline & \multicolumn{2}{|c|}{ QUESTÃO 7} \\
\hline $\mathrm{RC}^{*}$ & 36 & 20,8 \\
\hline \multirow{2}{*}{$\mathrm{RNC}^{*}$} & 64 & 80 \\
\hline & \multicolumn{2}{|c|}{ QUESTÃO 8} \\
\hline $\mathrm{RC}^{*}$ & 92 & 95,8 \\
\hline \multirow[t]{2}{*}{$\mathrm{RNC}^{*}$} & 8 & 4,2 \\
\hline & \multicolumn{2}{|c|}{ QUESTÃO 9} \\
\hline $\mathrm{RC}^{*}$ & 32 & 12,5 \\
\hline RNC* & 68 & 87,5 \\
\hline \multicolumn{3}{|c|}{$\begin{array}{l}\text { A partir das porcentagens referentes ao } \mathrm{RC} \text { de cada } \\
\text { questão, as mesmas foram agrupadas com os seguintes } \\
\text { critérios: }\end{array}$} \\
\hline \multicolumn{3}{|c|}{ Acima de $\mathbf{4 0 \%}=$ Questões 1,2 e 8} \\
\hline \multicolumn{3}{|c|}{ Entre $20 \%$ a $36 \%=$ Questões 3,6 e 7} \\
\hline \multicolumn{3}{|c|}{ Abaixo de $\mathbf{1 0 \%}=$ Questão 5} \\
\hline
\end{tabular}

$\mathrm{RC}^{*}=$ resposta dada pelos alunos de forma coerente com os padrões científicos.

$\mathrm{RNC}^{*}=$ resposta dada pelos alunos de forma NÃO coerente com os padrões científicos.

**Não foram calculadas as porcentagem referentes à questão 4 por se tratar de uma questão de ampla resposta.

Somente em três, das nove questões aplicadas, questões 1 (identificação das etapas de tratamento de água), 2 (alteração da densidade de um material com a adição de um soluto) e 8 (determinação do nível de concentração de álcool no sangue), verificamos um índice de $40 \%$ de respostas dadas pelos alunos de forma coerente com os padrões científicos. Em comparação as demais, os alunos demonstraram um melhor rendimento, sendo que nas questões 1 e 2 quase metade do número de alunos de cada uma das turmas conseguiu resolver totalmente a questão de forma adequada. Já na questão 8, quase todos os alunos encontraram a solução coerente ao problema. 
Os menores rendimentos referiram-se somente a questão 5 (explicação do acendimento de uma lâmpada em um determinado experimento), na qual 2 alunos de cada turma concluíram a resolução da questão com uma explicação coerente para o que foi observado. A questão deveria ser problematizada por meio de uma abordagem microscópica da matéria, em que o aluno precisaria não somente interpretar os esquemas propostos, mas ser capaz de relacionar a ocorrência de interações e modificação das substâncias e utilizar códigos da química para caracterizar os materiais e suas relações. Nenhum estudante reconheceu em suas anotações o fato da lâmpada acender como resultado de uma (modificação na estrutura da molécula) transformação atribuída a interações entre as moléculas. Em relação às dificuldades, existem diversos trabalhos na área de ensino de Química. Segundo Rosa e Schenetzler (1996) uma das dificuldades dos alunos concentra-se em tentar entender aspectos da matéria no nível microscópico através da transferência de aspectos observáveis no nível macroscópico da matéria. Estas reflexões foram observadas na maioria das respostas dos alunos quando os mesmos justificaram ser o sal de cozinha (NACl) o responsável pelo acendimento da lâmpada por conta deste formar íons e produzir corrente elétrica.

Em relação as demais questões, 3 (cálculo em massa da quantidade de barrilha), 6 (cálculo da concentração em massa de açúcar no refrigerante) e 7 (alteração da solubilidade de um material com a adição de um soluto), observamos que o índice de alunos que conseguiram propor uma resolução adequada para os problemas também foi muito abaixo de um resultado satisfatório. Entendemos isto, pois as "Respostas Coerentes" não ultrapassaram $36 \%$ do número total de alunos no caso das três questões, ou seja, um número máximo de 9 alunos, em uma esfera de 25, resolveram integralmente os problemas propostos. Duas das questões (3 e 6) referiram-se à cálculos matemáticos envolvendo a determinação de quantidades de materiais e relações de proporções. Tais assuntos são muito recorrentes em exames classificatórios, sendo que em sua maioria são verificadas grandes dificuldades de resolução por parte dos alunos. Esta problemática é amplamente estudada e discutida na literatura. Para Mortimer e Miranda (1995), “a dificuldade em perceber que as mudanças observadas nas transformações químicas são consequências de rearranjo dos átomos leva estudantes a não usarem o raciocínio de conservação de massa.” sendo este um aspecto fundamental para o entendimento do "balanceamento de equações químicas" e das relações estequiométricas das reações. Veronez e Piazza (2007) realizaram um trabalho de pesquisa com alunos de Ensino Médio no Brasil a respeito de suas ideias sobre relações estequiométricas. A análise dos resultados indicou que apesar de conseguirem realizar o 
balanceamento químico das reações, os alunos demonstraram incompreensões sobre a conservação das massas das substâncias em uma reação química. Também apresentaram dificuldades em cálculos matemáticos de proporções durante a resolução de alguns problemas.

Pensando em todas as questões que compuseram o instrumento piloto, e estabelecendo uma reflexão em relação aos alunos que, por algum motivo não concluíram a resolução dos problemas apresentados, entendemos que, em sua maioria os mesmos começaram a resolver as questões, mas principalmente ou por falta de conhecimento de alguns conceitos ou por apresentarem dificuldades de controle nas variáveis dos problemas e nos raciocínios proporcionais, não conseguiram propor resoluções adequadas para os problemas. Verificando as habilidades relacionadas com tais dificuldades, observamos que de um modo geral as dificuldades apareceram principalmente nas mobilizações das habilidades $17,18,19,24$ e 25 , sendo que a habilidade 25 foi predominante diagnosticada em quase todas as questões. Tais constatações em relação as habilidades complementam as discussões propostas acima, visto que são habilidades específicas da área de Química que envolvem a utilização de códigos e nomenclaturas da Química, a caracterização de materiais ou substâncias identificando etapas e rendimentos e a avaliação e propostas através da aplicação de conhecimentos Químicos. Ou seja, englobam as dificuldades conceituais e de raciocínios matemáticas apresentadas e discutidas anteriormente.

Diante dos resultados encontrados nesta etapa, durante a construção da sequencia de atividades que compuseram as situações problematizadoras, priorizamos desenvolver atividades que pudessem explorar e contribuir com a construção de conhecimentos e habilidades relacionadas aos conteúdos sobre transformação, conservação e proporção das quantidades dos materiais. Assim, gradualmente buscamos desenvolver o controle das variáveis, construir o raciocínio proporcional e reforçar os cálculos matemáticos de forma geral.

\subsection{Situações-problema}

Como já mencionado anteriormente, neste trabalho o tema escolhido, em contribuição às maiores dificuldades dos alunos, para o desenvolvimento das atividades versou sobre as "Grandezas químicas" e as "Relações quantitativas nas transformações químicas da matéria”. As atividades desenvolvidas na forma de Situações-problema foram 
organizadas com o propósito de mobilizar e desenvolver habilidades dos alunos na resolução dos problemas que abrangessem o tema descrito.

Assim como procedemos na análise do instrumento piloto, o primeiro passo nas análises das atividades que compuseram a sequência foi a classificação de todas as questões de todos os instrumentos em relação às habilidades que deveriam ser mobilizadas para sua resolução. Procedeu-se à validação do instrumento diagnóstico, realizada por pesquisadores e estudantes de pós-graduação do nosso grupo (Anexo 3). Participaram da validação 4 alunos de Mestrado e 2 de doutorado, 1 mestre, 2 doutores em ensino de Ciências e 1 aluno de Iniciação científica. $\mathrm{O}$ índice de concordância entre os participantes foi alto, sendo verificados os seguintes resultados (Tabela 12):

Tabela 12. Resultados da validação do Instrumento diagnóstico.

\begin{tabular}{|l|l|}
\hline \multicolumn{2}{|c|}{$\begin{array}{c}\text { INSTRUMENTO DIAGNÓSTICO } \\
\text { (Instrumento 3) }\end{array}$} \\
\hline Questões & Habilidades cognitivas \\
\hline 1 & H3 e H8 \\
\hline 2 & H24 \\
\hline $3,5(\mathrm{a}), 7$ e 9 & H17 e H24 \\
\hline $4,5(\mathrm{~b}), 6,8,10$ e 11 & H17 e H25 \\
\hline
\end{tabular}

Seguindo os critérios estabelecidos no decorrer das validações, foram classificadas as questões dos demais instrumentos (Tabela 13), segundo resultados descritos a seguir,:

Tabela 13. Classificação das questões dos demais instrumentos aplicados na sequência.

\begin{tabular}{|l|l|}
\hline \multicolumn{2}{|c|}{ SEQUENCIA PROBLEMATIZADORA } \\
\hline \multicolumn{2}{|c|}{ INSTRUMENTO 4 } \\
\hline Questões & Habilidades cognitivas \\
\hline 1 & $\mathrm{H} 3$ e H24 \\
\hline 2 & $\mathrm{H} 3$ e H24 \\
\hline 3 & $\mathrm{H} 3$ e H24 \\
\hline \multicolumn{2}{|c|}{ INSTRUMENTO 5 } \\
\hline Questôes & Habilidades cognitivas \\
\hline 1 & H19 e H24 \\
\hline
\end{tabular}




\begin{tabular}{|c|c|}
\hline 2 & H19 e H24 \\
\hline 3 & $\mathrm{H} 18, \mathrm{H} 19$ e $\mathrm{H} 24$ \\
\hline 4 & H18, H19 e H24 \\
\hline \multicolumn{2}{|c|}{ INSTRUMENTO 6} \\
\hline Questões & Habilidades cognitivas \\
\hline 1 & H17 \\
\hline 2 & H17 \\
\hline 3 & H18 e H24 \\
\hline 4 & $\mathrm{H} 18$ e $\mathrm{H} 24$ \\
\hline \multicolumn{2}{|c|}{ INSTRUMENTO 7} \\
\hline \multicolumn{2}{|c|}{$\mathrm{H} 24$} \\
\hline \multicolumn{2}{|c|}{ INSTRUMENTO 8} \\
\hline Questões & Habilidades cognitivas \\
\hline 1 & $\mathrm{H} 8$ e $\mathrm{H} 24$ \\
\hline 2 & $\mathrm{H} 17$ e $\mathrm{H} 25$ \\
\hline 3 & $\mathrm{H} 24$ \\
\hline 4 & $\mathrm{H} 24$ e H25 \\
\hline \multicolumn{2}{|c|}{ INSTRUMENTO 9} \\
\hline Ouestões & Habilidades cognitivas \\
\hline 1 & $\mathrm{H} 8, \mathrm{H} 17$ e $\mathrm{H} 25$ \\
\hline $2(a)$ & H17 e H24 \\
\hline $2(b)$ & $\mathrm{H} 17$ e $\mathrm{H} 24$ \\
\hline $2(c)$ & H17 e H25 \\
\hline \multicolumn{2}{|c|}{ INSTRUMENTO 10} \\
\hline \multicolumn{2}{|c|}{$\mathrm{H} 24$} \\
\hline \multicolumn{2}{|c|}{ INSTRUMENTO 11} \\
\hline Questões & Habilidades cognitivas \\
\hline 1 & $\mathrm{H} 3, \mathrm{H} 8$ e $\mathrm{H} 24$ \\
\hline 2 & $\mathrm{H} 3, \mathrm{H} 8$ e $\mathrm{H} 24$ \\
\hline 3 & $\mathrm{H} 3$ e $\mathrm{H} 24$ \\
\hline 4 & H3, H19 e H24 \\
\hline 5 & $\mathrm{H} 3, \mathrm{H} 19$ e $\mathrm{H} 24$ \\
\hline
\end{tabular}




\begin{tabular}{|c|c|}
\hline \multicolumn{2}{|c|}{ INSTRUMENTO 12} \\
\hline Questões & Habilidades cognitivas \\
\hline $1(a)$ & H17 e H24 \\
\hline $1(b)$ & $\mathrm{H} 17$ e $\mathrm{H} 25$ \\
\hline $2(a)$ & $\mathrm{H} 17$ e $\mathrm{H} 24$ \\
\hline $2(b)$ & H17 e H24 \\
\hline $2(c)$ & $\mathrm{H} 17$ e $\mathrm{H} 25$ \\
\hline $3(a)$ & H17 e H25 \\
\hline $3(b)$ & H17 e H25 \\
\hline $3(c)$ & H17 e H25 \\
\hline \multicolumn{2}{|c|}{ INSTRUMENTO 13} \\
\hline Questões & Habilidades cognitivas \\
\hline 1 & H3 e H8 \\
\hline $2(a / b)$ & H17 e H24 \\
\hline $3(a / b)$ & H17 e H25 \\
\hline $4(a)$ & H17 e H25 \\
\hline $4(b)$ & H17 e H24 \\
\hline 5 & H17 e H24 \\
\hline $6(a)$ & H17 e H24 \\
\hline $6(b / c)$ & H17, H24 e H25 \\
\hline
\end{tabular}

Foi feita a leitura de cada uma das questões de todos os alunos. Cada uma das respostas foram desmembradas em pequenos fragmentos (decodificadores), que, conforme Bardin (1977) apud Franco (2012), representaram as informações conceituais que se assemelhavam dadas nas respostas dos alunos. Em uma etapa seguinte os decodificadores foram reagrupados de acordo com possíveis semelhanças de respostas criando-se finalmente as categorias.

Para cada questão analisada foram construídas duas tabelas. A primeira tabela foi organizada a partir de duas informações principais: os alunos e as decodificações. Na medida em que as decodificações criadas apareceram nas respostas, atribuímos a numeração 1 como forma de representação, e quando não apareceu na resposta atribuímos o zero.

$\mathrm{Na}$ segunda tabela foram relacionadas as categoriais criadas a partir do agrupamento dos decodificadores, o número de alunos constituintes de cada uma das categorias, as 
habilidades desenvolvidas por eles para que suas respostas pudessem ser classificadas em uma categoria e a classificação das habilidades como de mais baixa ou de mais alta ordem cognitiva. Para classificar as habilidades foram utilizados critérios já estabelecidos em trabalhos anteriores de Suart e Marcondes (2008) conforme organizados no quadro 24.

Quadro 24: Descrição dos níveis cognitivos das respostas dos alunos.

\begin{tabular}{|l|ll|}
\hline Nível & \multicolumn{1}{c|}{ Categoria de resposta ALG } \\
\hline N1 & $\bullet$ & $\begin{array}{l}\text { Não reconhece a situação problema. } \\
\text { Limita-se a expor um dado relembrado. } \\
\text { Retêm-se a aplicação de fórmulas ou conceitos. }\end{array}$ \\
\hline Nível & \multicolumn{1}{c|}{ Categoria de resposta LOCS } \\
\hline N2 & $\bullet \quad \begin{array}{l}\text { Reconhece a situação problemática e identifica o que dever ser } \\
\text { buscado. }\end{array}$ & $\begin{array}{l}\text { Não identifica variáveis. } \\
\text { Não estabelece processos de controle para a seleção das informações. }\end{array}$ \\
\hline N3 & $\bullet \quad \begin{array}{l}\text { Explica a resolução do problema utilizando conceitos já conhecidos ou } \\
\text { relembrados (resoluções não fundamentadas, por tentativas e quando } \\
\text { necessário representa o problema com fórmulas ou equações. }\end{array}$ \\
\hline Nível & $\bullet \quad \begin{array}{l}\text { Identifica e estabelece processos de controle para a seleção das } \\
\text { informações. } \\
\text { Identifica as variáveis, podendo não compreender seus significados } \\
\text { conceituais. }\end{array}$ \\
\hline N4 & $\bullet \quad \begin{array}{l}\text { Seleciona as informações relevantes. } \\
\text { Analisa ou avalia as variáveis ou relações causais entre os elementos } \\
\text { do problema. } \\
\text { Sugere as possíveis soluções do problema ou relações causais entre os } \\
\text { elementos do problema. } \\
\text { Exibe capacidade de elaboração de hipóteses. }\end{array}$ \\
\hline N5 & $\bullet \quad \begin{array}{l}\text { Aborda ou generaliza o problema em outros contextos ou condições } \\
\text { iniciais. }\end{array}$ \\
\hline
\end{tabular}

Fonte: Suart e Marcondes (2008).

Nos itens seguintes apresentaremos os resultados das análises dos instrumentos selecionados.

\subsubsection{Resultados das aplicações dos instrumentos}

\subsubsection{Instrumento 3 - Instrumento diagnóstico de verificação de habilidades} específicas. 
O instrumento diagnóstico foi organizado em 11 questões. A ideia principal foi aplicar aos alunos problemas com todos os conceitos que seriam abordados nas aulas seguintes, como transformações químicas, balanceamento de equações químicas e relações quantitativas de conservação e proporção das quantidades de materiais numa transformação química, com a intenção de verificar quais as maiores dificuldades conceituais e cognitivas dos mesmos.

Os resultados obtidos da análise de cada uma das questões constituintes do referido instrumento estão apresentados a seguir.

\section{QUESTÃO 1 - Um estudante listou os seguintes processos como exemplos de fenômenos} que envolvem reações químicas. No entanto o estudante cometeu alguns equívocos. Quais os fenômenos são considerados reações químicas? Justifique sua escolha para cada um deles.

\section{Fermentação da massa na fabricação de pães. Justificativa:}

A tabela 14 apresenta, para a Questão 1(I), as decodificações criadas a partir das respostas dos alunos, as categorias criadas, as habilidades selecionadas a partir da matriz do ENEM, suscitadas pela questão para serem mobilizadas pelos estudantes e as classificações das respostas dos alunos em relação à níveis de cognições das mesmas.

Tabela 14. Categorização das respostas dos alunos referentes à questão 1 (I) do instrumento 3.

\begin{tabular}{|c|c|c|c|c|c|c|}
\hline \multicolumn{7}{|c|}{ QUESTÃO 1 - Fermentação da massa na fabricação de pães } \\
\hline Decodificadores & Categoriais & Alunos & Habilidades & Res & stas do & alunos \\
\hline & \multirow{7}{*}{$\begin{array}{c}\text { Transformação } \\
\text { Biológica }\end{array}$} & \multirow{7}{*}{27} & ENEM & ALG & LOCS & HOCS \\
\hline é uma reação biológica & & & \multirow{6}{*}{ H 3} & \multirow{6}{*}{$\mathrm{N} 1$} & \multirow{6}{*}{$\mathrm{N} 2$} & \multirow[t]{6}{*}{ 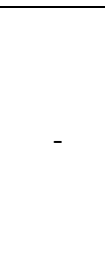 } \\
\hline reação de microrganismos & & & & & & \\
\hline geração de gases pelos fungos & & & & & & \\
\hline por conta do fermento & & & & & & \\
\hline massa cresce mas ainda é massa & & & & & & \\
\hline $\begin{array}{l}\text { por conta dos reagentes químicos } \\
\text { (massa) que geram a fermentação }\end{array}$ & & & & & & \\
\hline reação dos ingredientes & \multirow{5}{*}{$\begin{array}{l}\text { Transformação } \\
\text { Química }\end{array}$} & \multirow{5}{*}{9} & \multirow{5}{*}{ H 3/H8 } & \multirow{5}{*}{-} & \multirow{5}{*}{$\mathrm{N} 2 / \mathrm{N} 3$} & \multirow{5}{*}{-} \\
\hline $\begin{array}{l}\text { gera uma nova composição } \\
\text { (composto) }\end{array}$ & & & & & & \\
\hline ação do oxigênio & & & & & & \\
\hline alteração de fórmulas & & & & & & \\
\hline transformação de estrutura & & & & & & \\
\hline é uma reação física & $\begin{array}{l}\text { Transformação } \\
\text { Física }\end{array}$ & & $\mathrm{H} 3$ & 1 & 2 & \\
\hline deixou em branco & Branco & & - & & & \\
\hline
\end{tabular}


Para melhor visualizarmos as categorias construídas e estabelecermos possíveis comparativos entre elas, construímos o gráfico a seguir (Figura 23), em que relacionamos as categorias criadas com as turmas participantes do projeto.

Figura 23. Número de alunos por categorias referentes à questão (I) do instrumento 3.

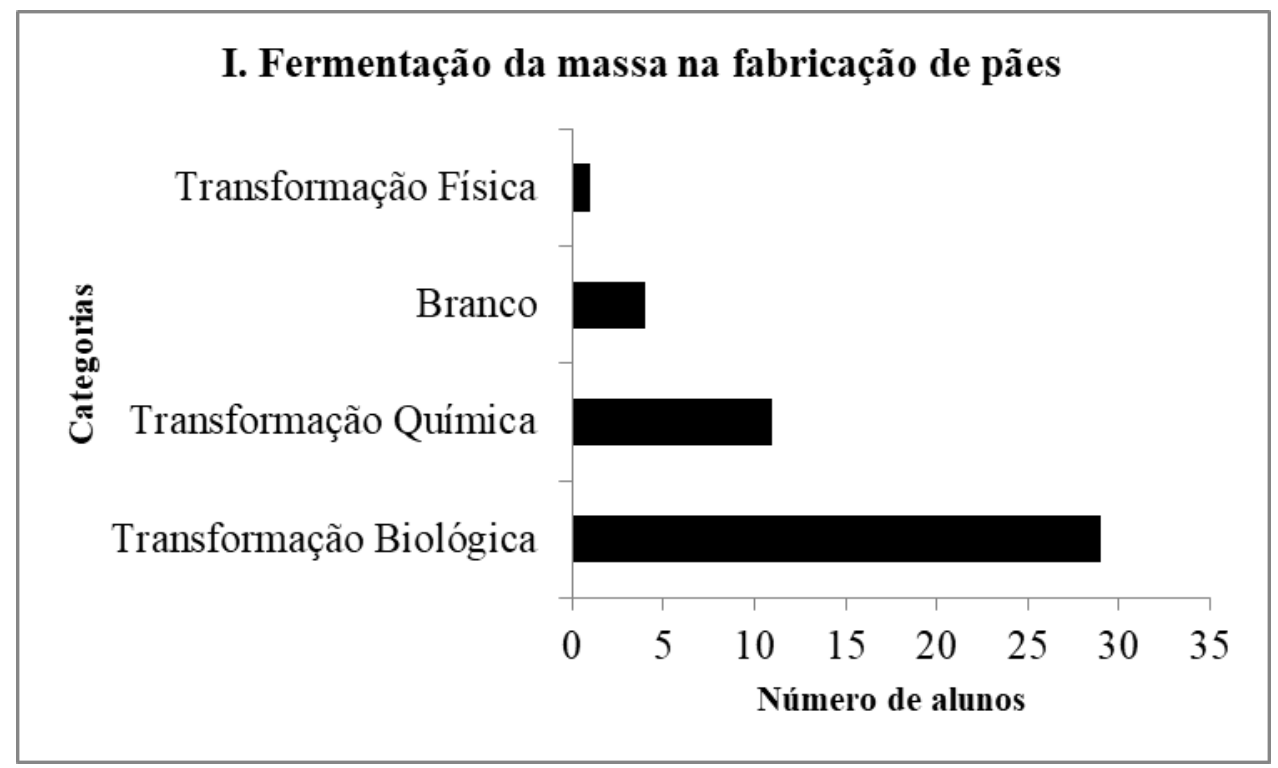

\section{Obtenção de sal por evaporação de água do mar. Justificativa:}

A tabela 15 apresenta, para a Questão 1(II), as decodificações criadas a partir das respostas dos alunos, as categorias criadas, as habilidades selecionadas a partir da matriz do ENEM, suscitadas pela questão para serem mobilizadas pelos estudantes e as classificações das respostas dos alunos em relação à níveis de cognições das mesmas.

Tabela 15. Categorização das respostas dos alunos referentes à questão 1 (II) do instrumento 3.

\begin{tabular}{|c|c|c|c|c|c|c|}
\hline \multicolumn{7}{|c|}{ QUESTÃO 1 - Obtenção de sal por evaporação de água do mar } \\
\hline Decodificadores & Categoriais & Alunos & Habilidades & $\operatorname{Res}$ & stas dos & unos \\
\hline & & & ENEM & ALG & LOCS & HOCS \\
\hline decorrência biológica & Transformação & & & & & \\
\hline fenômeno natural & Biológica/Natural & 3 & H3 & NI & $\mathrm{N} 2$ & - \\
\hline não há alteração química & \multirow{5}{*}{$\begin{array}{l}\text { Transformação } \\
\text { Química }\end{array}$} & \multirow{5}{*}{8} & \multirow{5}{*}{ H 3/H8 } & \multirow{5}{*}{-} & \multirow{5}{*}{$\mathrm{N} 2 / \mathrm{N} 3$} & \multirow{5}{*}{ - } \\
\hline $\begin{array}{l}\text { contato da areia com a água } \\
\text { gera o sal }\end{array}$ & & & & & & \\
\hline não forma nova substância & & & & & & \\
\hline contato com a água & & & & & & \\
\hline somente é uma reação química & & & & & & \\
\hline é uma reação física & \multirow{6}{*}{$\begin{array}{c}\text { Transformação } \\
\text { Física }\end{array}$} & \multirow{6}{*}{23} & \multirow{6}{*}{$\mathrm{H} 3$} & \multirow{6}{*}{ N1 } & \multirow{6}{*}{$\mathrm{N} 2$} & \multirow{6}{*}{ - } \\
\hline é uma reação térmica & & & & & & \\
\hline $\begin{array}{l}\text { explicação do fenômeno } \\
\text { (evaporação) }\end{array}$ & & & & & & \\
\hline ocorre ebulição & & & & & & \\
\hline água volta ao estado líquido & & & & & & \\
\hline separação de substâncias & & & & & & \\
\hline
\end{tabular}


presença de água + sal

deixou em branco

Branco

Para melhor visualizarmos as categorias construídas e estabelecermos possíveis comparativos entre elas, construímos o gráfico a seguir (Figura 24), em que relacionamos as categorias criadas com as turmas participantes do projeto.

Figura 24. Número de alunos por categorias referentes à questão 1 (II) do instrumento 3.

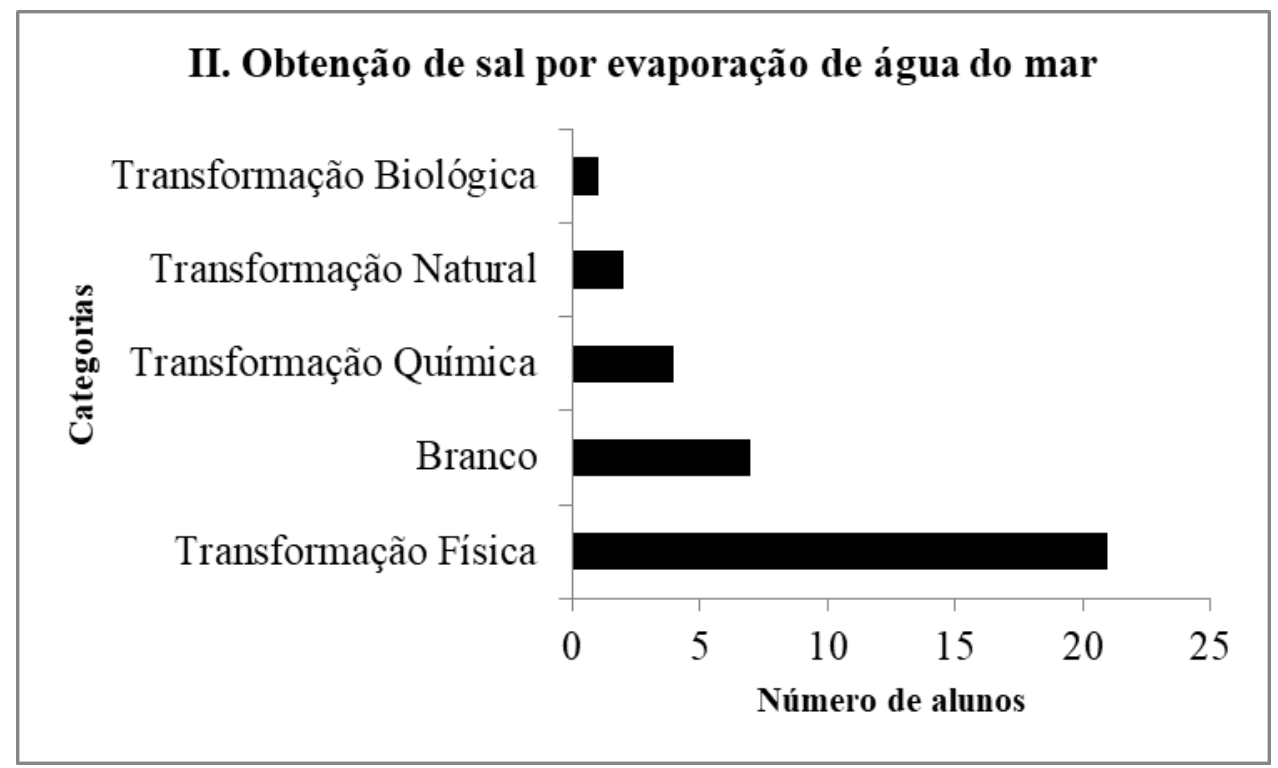

\section{Dissolução de um comprimido efervescente em água. Justificativa:}

A tabela 16 apresenta, para a Questão 1(III), as decodificações criadas a partir das respostas dos alunos, as categorias criadas, as habilidades selecionadas a partir da matriz do ENEM, suscitadas pela questão para serem mobilizadas pelos estudantes e as classificações das respostas dos alunos em relação à níveis de cognições das mesmas.

Tabela 16. Categorização das respostas dos alunos referentes à questão 1 (III) do instrumento 3.

\begin{tabular}{|c|c|c|c|c|c|c|}
\hline \multicolumn{7}{|c|}{ QUESTÃO 1 - Item III - Dissolução de um comprimido efervescente em água } \\
\hline \multirow[t]{2}{*}{ Decodificadores } & \multirow[t]{2}{*}{ Categoriais } & \multirow[t]{2}{*}{ Alunos } & \multirow{2}{*}{$\frac{\text { Habilidades }}{\text { ENEM }}$} & \multicolumn{3}{|c|}{ Respostas dos alunos } \\
\hline & & & & ALG & LOCS & HOCS \\
\hline $\begin{array}{l}\text { contato em os componentes do } \\
\text { comprimido }\end{array}$ & \multirow{9}{*}{$\begin{array}{l}\text { Transformação } \\
\text { Química }\end{array}$} & \multirow{9}{*}{31} & \multirow{9}{*}{ H $3 / \mathrm{H} 8$} & \multirow{9}{*}{-} & \multirow{9}{*}{$\mathrm{N} 2 / \mathrm{N} 3$} & \multirow{9}{*}{ 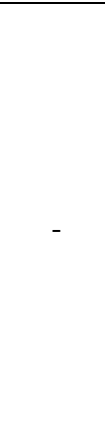 } \\
\hline liberação e dissolução do carbono & & & & & & \\
\hline transformação/reação de substância & & & & & & \\
\hline diluição do comprimido & & & & & & \\
\hline dissolução do comprimido & & & & & & \\
\hline $\begin{array}{llll}\begin{array}{l}\text { formação } \\
\text { gás/bolhas }\end{array} & \text { de } & \text { solução } & \text { com } \\
\end{array}$ & & & & & & \\
\hline efervescência na água & & & & & & \\
\hline $\begin{array}{l}\text { contato com a água que contém } \\
\text { oxigênio }\end{array}$ & & & & & & \\
\hline alteração da propriedade da água & & & & & & \\
\hline
\end{tabular}




\begin{tabular}{|c|c|c|c|c|c|c|}
\hline \multicolumn{5}{|l|}{ junção de substâncias } & & \\
\hline \multicolumn{7}{|l|}{ absorção do comprimido } \\
\hline \multicolumn{7}{|c|}{ liberação de substâncias } \\
\hline \multicolumn{7}{|c|}{ reação de gás carbônico com a água } \\
\hline processo físico & \multirow{2}{*}{$\begin{array}{l}\text { Transformação } \\
\text { Física }\end{array}$} & \multirow{2}{*}{3} & \multirow{2}{*}{ H 3} & \multirow{2}{*}{ N1 } & \multirow{2}{*}{$\mathrm{N} 2$} & \\
\hline não forma nova substância & & & & & & 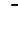 \\
\hline deixou em branco & Branco & 7 & - & - & - & - \\
\hline
\end{tabular}

Para melhor visualizarmos as categorias construídas e estabelecermos possíveis comparativos entre elas, construímos o gráfico a seguir (Figura 25), em que relacionamos as categorias criadas com as turmas participantes do projeto.

Figura 25. Número de alunos por categorias referentes à questão 1(II) do instrumento 3.

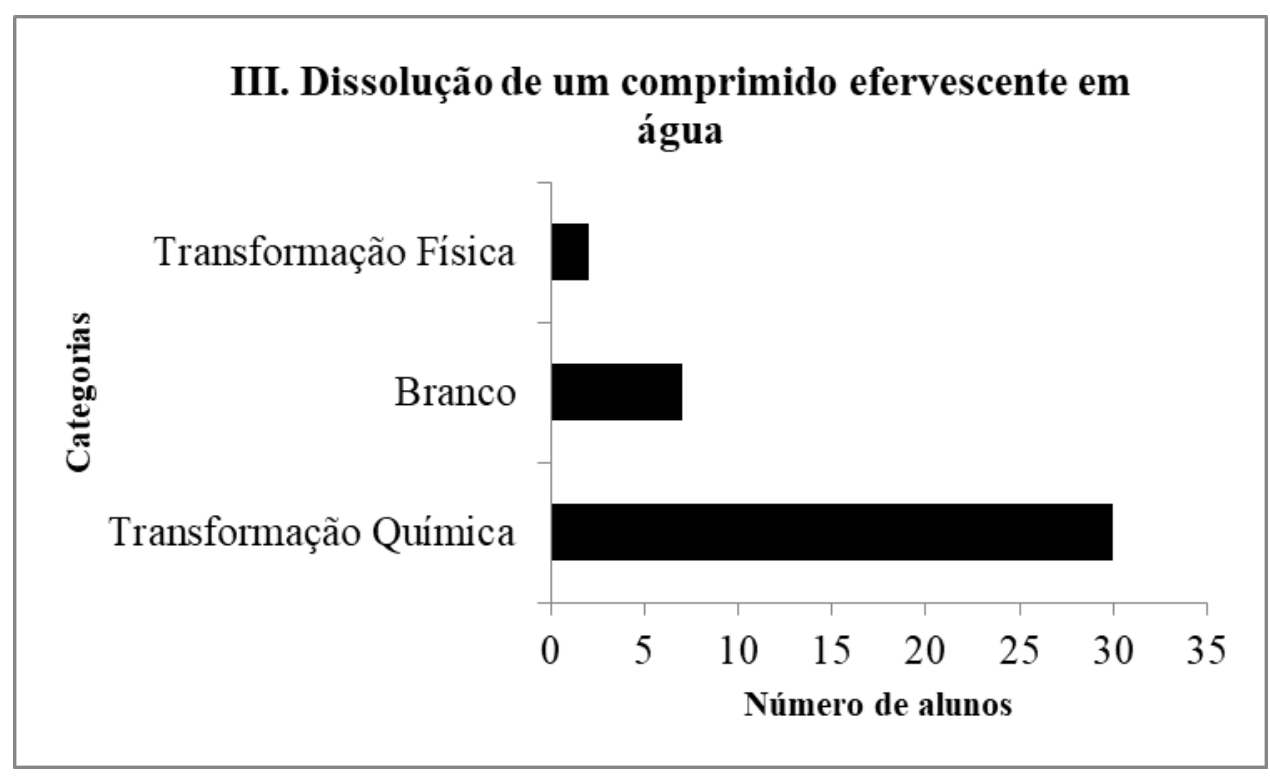

\section{Amadurecimento de uma banana. Justificativa:}

A tabela 17 apresenta, para a Questão 1(IV), as decodificações criadas a partir das respostas dos alunos, as categorias criadas, as habilidades selecionadas a partir da matriz do ENEM, suscitadas pela questão para serem mobilizadas pelos estudantes e as classificações das respostas dos alunos em relação à níveis de cognições das mesmas.

Tabela 17. Categorização das respostas dos alunos referentes à questão 1 (IV) do instrumento 3.

\begin{tabular}{|c|c|c|c|c|c|c|}
\hline \multicolumn{7}{|c|}{ QUESTÃO 1 - Item IV - Amadurecimento de uma banana } \\
\hline Decodificadores & Categoriais & Alunos & Habilidades & Res & stas dos & alunos \\
\hline & & & ENEM & ALG & LOCS & HOCS \\
\hline $\begin{array}{l}\text { acontecimento natural/ciclo das } \\
\text { frutas }\end{array}$ & \multirow{6}{*}{$\begin{array}{c}\text { Transformação } \\
\text { Biológica }\end{array}$} & \multirow{6}{*}{15} & \multirow{6}{*}{ H 3} & \multirow{6}{*}{ N1 } & \multirow{6}{*}{$\mathrm{N} 2$} & \multirow{6}{*}{ - } \\
\hline questões/processo biológicas & & & & & & \\
\hline possui etapas de amadurecimento & & & & & & \\
\hline decomposição da matéria orgânica & & & & & & \\
\hline produção de um hormônio gasoso & & & & & & \\
\hline ação de microrganismos & & & & & & \\
\hline
\end{tabular}




\begin{tabular}{|c|c|c|c|c|c|c|}
\hline mesmo madura ainda é banana & & & & & & \\
\hline reação com oxigênio & \multirow{4}{*}{$\begin{array}{l}\text { Transformação } \\
\text { Química }\end{array}$} & \multirow{4}{*}{5} & \multirow{4}{*}{ H 3/H8 } & \multirow{4}{*}{-} & \multirow{4}{*}{$\mathrm{N} 2 / \mathrm{N} 3$} & \multirow{4}{*}{-} \\
\hline transformação de estrutura & & & & & & \\
\hline $\begin{array}{c}\text { reação da banana com gases da } \\
\text { atmosfera }\end{array}$ & & & & & & \\
\hline alteração de fórmulas & & & & & & \\
\hline não gera nova substância & \multirow{3}{*}{$\begin{array}{l}\text { Transformação } \\
\text { Física }\end{array}$} & \multirow{3}{*}{5} & \multirow{3}{*}{ H 3} & \multirow{3}{*}{ N1 } & \multirow{3}{*}{$\mathrm{N} 2$} & \multirow{3}{*}{-} \\
\hline reação física & & & & & & \\
\hline trocas gasosas & & & & & & \\
\hline não sabe & Não sabe & 1 & H 3 & & & \\
\hline deixou em branco & Branco & 13 & - & - & - & - \\
\hline
\end{tabular}

Para melhor visualizarmos as categorias construídas e estabelecermos possíveis comparativos entre elas, construímos o gráfico a seguir (Figura 26), em que relacionamos as categorias criadas com as turmas participantes do projeto.

Figura 26. Número de alunos por categorias referentes à questão 1 (IV) do instrumento 3.

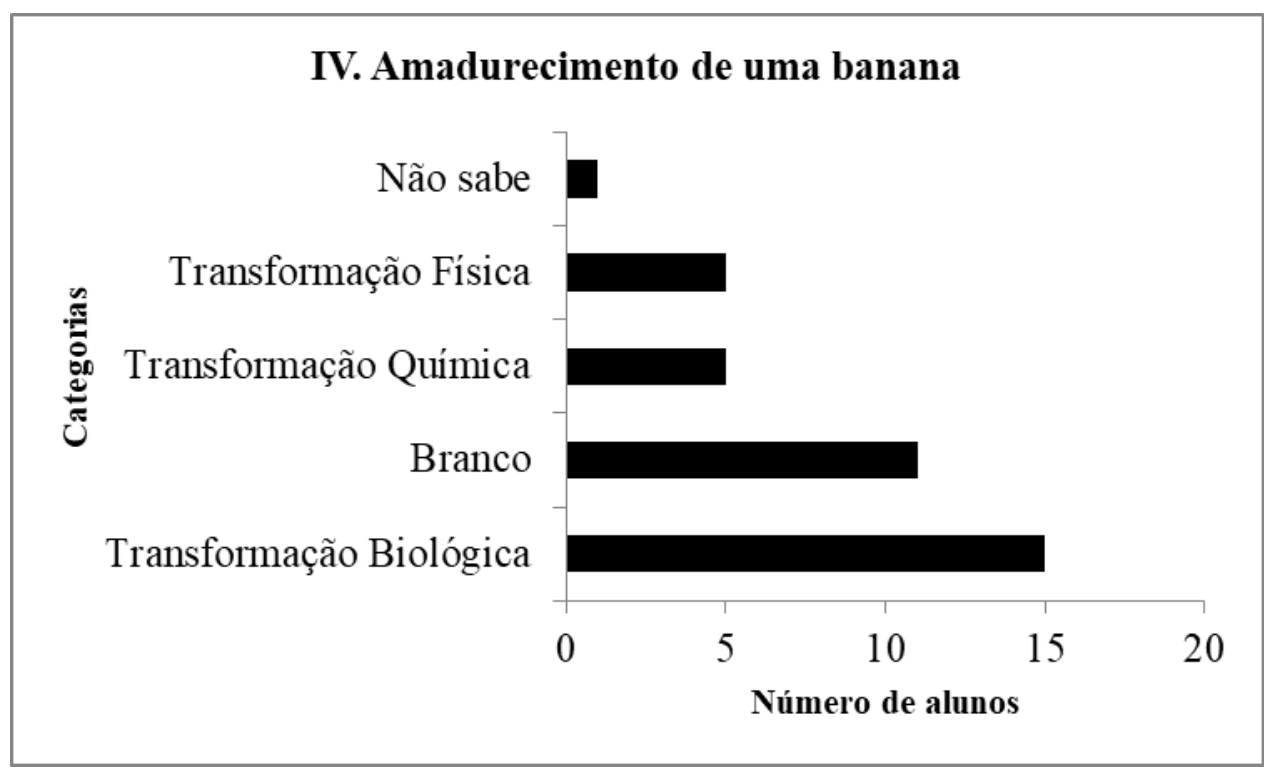

\section{Enferrujamento de um prego. Justificativa:}

A tabela 18 apresenta, para a Questão $1(\mathrm{~V})$, as decodificações criadas a partir das respostas dos alunos, as categorias criadas, as habilidades selecionadas a partir da matriz do ENEM, suscitadas pela questão para serem mobilizadas pelos estudantes e as classificações das respostas dos alunos em relação à níveis de cognições das mesmas.

Tabela 18. Categorização das respostas dos alunos referentes à questão 1 (V) do instrumento 3.

\begin{tabular}{|l|c|c|c|c|c|c|}
\hline \multicolumn{5}{|c|}{ QUESTÃO 1 - Item V - Enferrujamento de um prego } \\
\hline \multicolumn{2}{|c|}{ Decodificadores } & Categoriais & Alunos & Habilidades & \multicolumn{3}{c|}{ Respostas dos alunos } \\
\hline & & & ENEM & ALG & LOCS & HOCS \\
\hline ação de uma bactéria & $\begin{array}{c}\text { Transformação } \\
\text { Biológica }\end{array}$ & 3 & H3 & N1 & N2 & - \\
\hline contato do prego com outra & Transformação & 26 & H3/H8 & - & N2/N3 & - \\
\hline
\end{tabular}




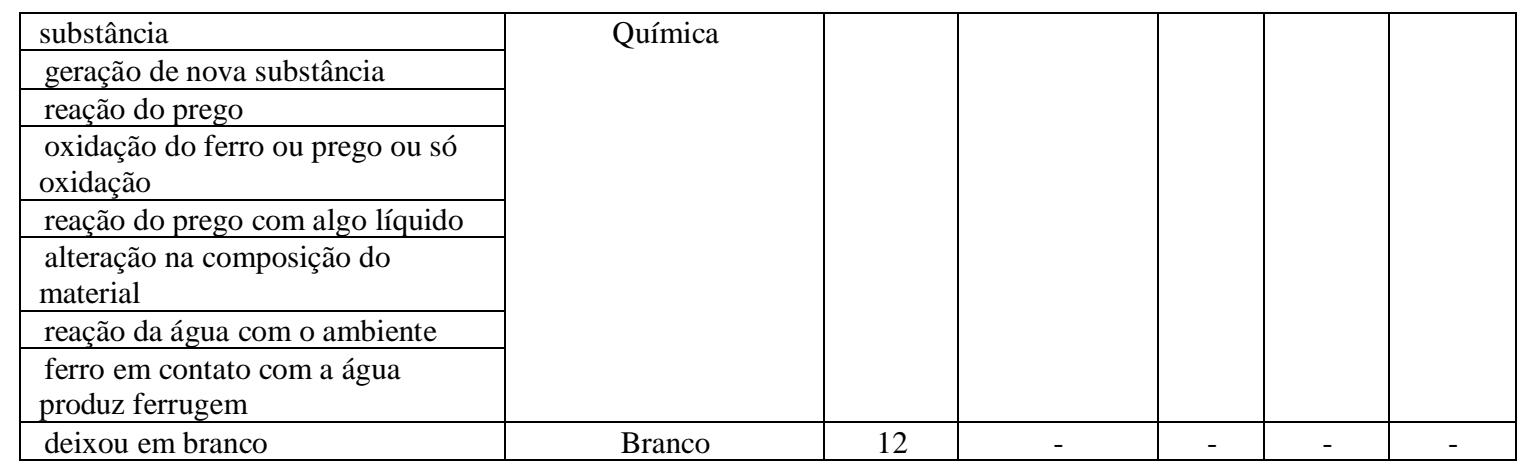

Para melhor visualizarmos as categorias construídas e estabelecermos possíveis comparativos entre elas, construímos o gráfico a seguir (Figura 27), em que relacionamos as categorias criadas com as turmas participantes do projeto.

Figura 27. Número de alunos por categorias referentes à questão 1 (V) do instrumento 3.

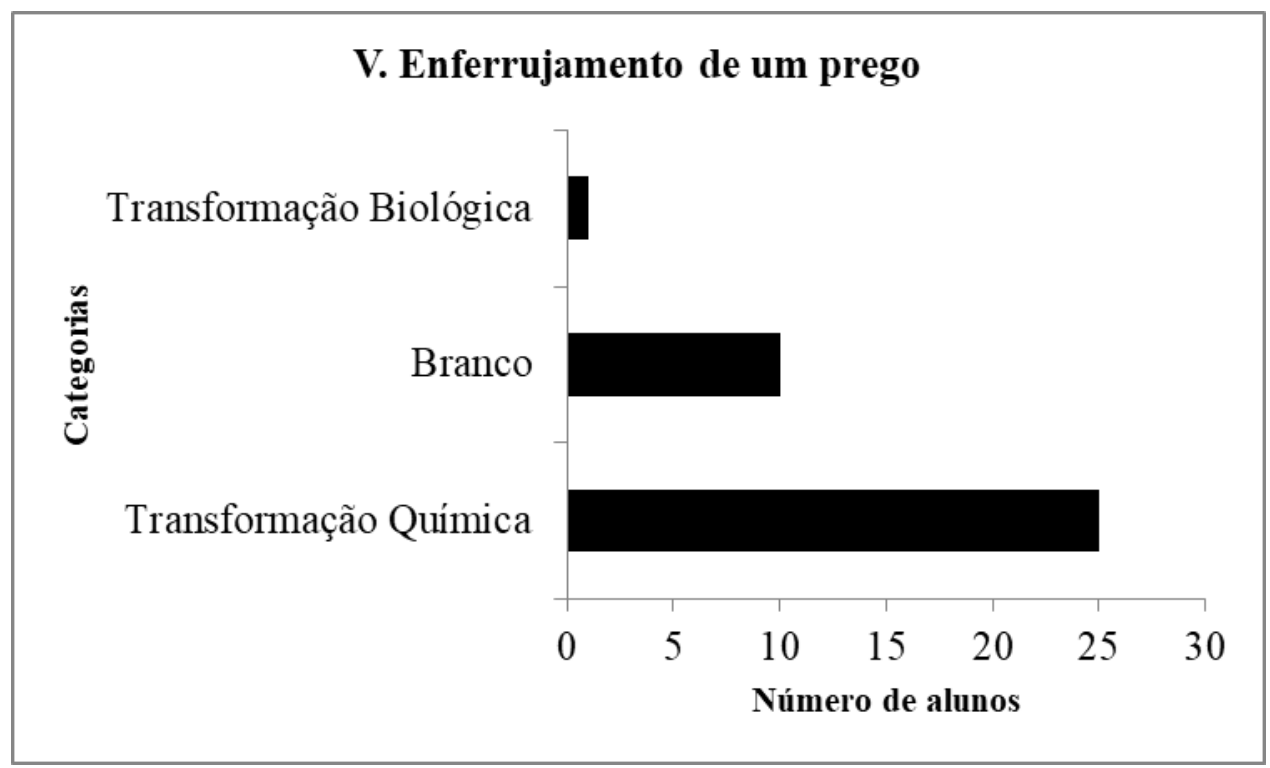

\section{Precipitação da chuva. Justificativa:}

A tabela 19 apresenta, para a Questão 1(VI), as decodificações criadas a partir das respostas dos alunos, as categorias criadas, as habilidades selecionadas a partir da matriz do ENEM, suscitadas pela questão para serem mobilizadas pelos estudantes e as classificações das respostas dos alunos em relação à níveis de cognições das mesmas.

Tabela 19. Categorização das respostas dos alunos referentes à questão 1 (VI) do instrumento 3.

\begin{tabular}{|l|c|c|c|c|c|c|}
\hline \multicolumn{4}{|c|}{ QUESTÃO 1 - Item VI - Precipitação da chuva } \\
\hline Decodificadores & Categoriais & Alunos & Habilidades & \multicolumn{2}{c|}{ Respostas dos alunos } \\
\hline & & & ENEM & ALG & LOCS & HOCS \\
\hline excessos de gases no ambiente & Transformação & 4 & H3 & N1 & N2 & - \\
\hline
\end{tabular}




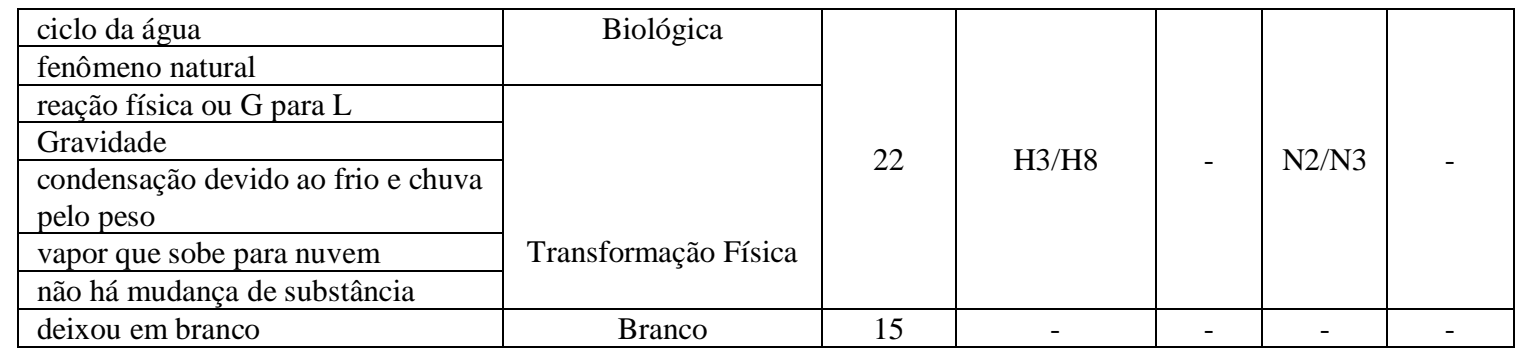

Para melhor visualizarmos as categorias construídas e estabelecermos possíveis comparativos entre elas, construímos o gráfico a seguir (Figura 28), em que relacionamos as categorias criadas com as turmas participantes do projeto.

Figura 28. Número de alunos por categorias referentes à questão 1 (VI) do instrumento 3.

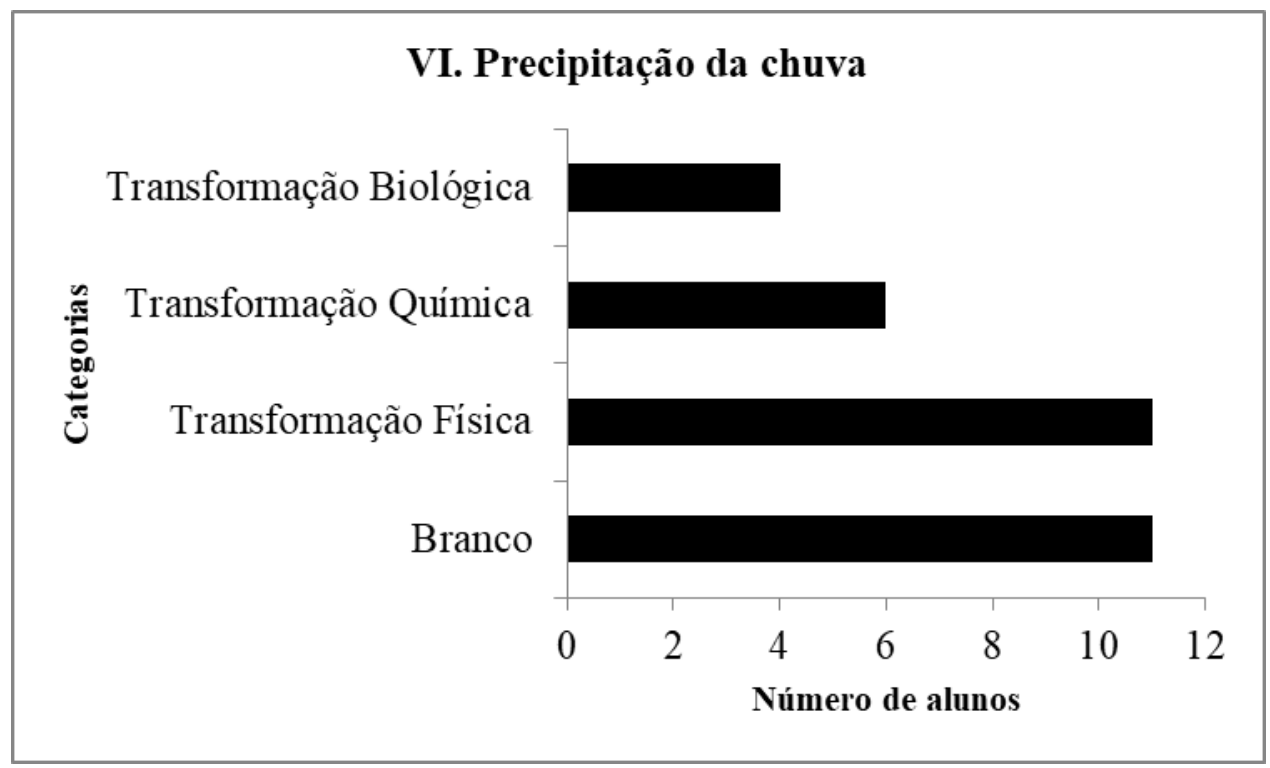

Para que os alunos identificassem os fenômenos químicos e justificassem suas escolhas, os mesmos deveriam reconhecer a situação apresentada, e descrevê-la, utilizando uma associação de conceitos já conhecidos. Nesta primeira questão alguns resultados nos chamaram mais atenção. Observando as categoriais, três tipos dominantes estavam presentes em todos os itens: as transformações químicas, transformações físicas e as transformações biológicas/naturais.

Comparando-se os itens referidos à transformações físicas, foi semelhante a quantidade do número de alunos que reconheceram cada um dos fenômenos. Pouco mais da metade do número total de alunos identificou tanto a "Obtenção do sal por evaporação da água do mar (56,1\%)" quanto a "Precipitação da chuva (53,7\%)" como sendo fenômenos físicos. 
Os menores percentuais de acertos concentraram-se nos itens que envolveram a "fermentação do pão (22\%)" e o "amadurecimento da banana (12\%)". Nos dois casos, a grande maioria dos alunos afirmou tratar-se de fenômenos biológicos/naturais, em que utilizaram como algumas justificativas a presença de microrganismos no processo de transformação, a não alteração do material e simplesmente a classificação como um fenômenos natural.

Verificamos no item que apresentou a situação da "dissolução do comprimido ao ser colocado em água $(75,6 \%)$ " um alto índice de respostas que indicaram o fenômeno como sendo químico. Acreditamos que neste caso a evidência da ocorrência da reação, ou seja a liberação de gás, talvez tenha favorecido o reconhecimento do fenômeno por parte dos alunos. Em menor porcentagem, mas ainda com um resultado favorável, ou seja, mais da metade dos alunos também entendeu o "enferrujamento de um prego $(63,4 \%)$ " como sendo uma transformação química.

Tanto em relação aos fenômenos físicos quanto aos fenômenos químicos, sem o envolvimento de sistemas biológicos, os alunos demonstraram maiores conhecimentos a respeito dos conteúdos. Para as transformações físicas, surgiram explicações do que poderia estar ocorrendo empregando-se os conceitos de "evaporação" e a "não ocorrência de mudança de substâncias, apenas do estado das mesmas".

Em relação as transformações químicas, ideias como a "alteração de propriedades/composição/fórmulas dos materiais, "liberação de novas substâncias" e a "efervescência dos compostos" argumentaram a associação dos fenômenos como sendo químicos.

Segundo Silva, Souza e Marcondes (2008), construir as principais ideias a respeito da transformação química da matéria certamente torna-se complexo quando os alunos necessitam utilizar do conhecimento a respeito das representações simbólicas das transformações, para então serem capazes de transpor seus conhecimentos macroscópicos à modelos explicativos microscópicos. Entretanto, algumas vezes o problema na construção dos conhecimentos ocorre já no reconhecimento de alguns fenômenos, mesmo de forma macroscópica. Consequentemente, reforçam-se as ideias prévias dos alunos que algumas vezes são bem distantes dos conhecimentos científicos e assim surgem as concepções alternativas. Os autores realizaram um trabalho de investigação com 44 alunos do Ensino Médio, com o propósito de conhecer suas concepções sobre reações químicas e como os mesmos classificam algumas reações químicas que ocorrem em organismos vivos. Os estudantes responderam a duas 
questões durante a pesquisa. Na primeira, os mesmos deveriam escrever o que compreenderam sobre transformações químicas. Já na segunda, diante de uma lista de fenômenos deveriam classificá-los como sendo transformações químicas ou não. Os fenômenos selecionados para reconhecimento foram organizados em nove exemplos, divididos igualmente entre "transformações químicas não associadas a sistemas biológicos", "transformações químicas associadas a sistemas biológicos" e "transformações de estados físicos". Os resultados associados a "sistemas biológicos", segundo os autores "foi revelador" pois muitos estudantes classificaram os sistemas como não correspondendo a um processo químico justamente, segundo algumas justificativas, por se tratarem de fenômenos naturais. Comparando os nossos resultados encontrados nesta questão com os resultados do trabalho discutido, verificamos que já foram descritos na literatura resultados semelhantes com complexas discussões sobre o tema.

Os autores ainda argumentaram que o não reconhecimento de um fenômeno natural com uma transformação química pode ter ocorrido por conta de uma visão da química como algo nocivo, danoso ou artificial. Segundo algumas das justificativas dos estudantes que participaram de nossa pesquisa, os fenômenos foram reconhecidos como biológicos/naturais por conta principalmente da ação de microrganismos, por ser um fenômeno natural e da decomposição da material orgânica. Assim, partilhando das conclusões propostas pelos autores, entendemos que em nosso trabalho prevaleceu uma visão da química mais como algo artificial, o que dificultou a associação entre os fenômenos.

\section{QUESTÃO 2 - Você sabe o que significa massa molar? Qual é a diferença entre massa molar de uma substância e a massa de certa amostra da substância?}

A tabela 20 apresenta, para a Questão, as decodificações criadas a partir das respostas dos alunos, as categorias criadas, as habilidades selecionadas a partir da matriz do ENEM, suscitadas pela questão para serem mobilizadas pelos estudantes e as classificações das respostas dos alunos em relação à níveis de cognições das mesmas.

Tabela 20. Categorização das respostas dos alunos referentes à questão 2 do instrumento 3.

\begin{tabular}{|l|c|c|c|c|c|c|}
\hline \multicolumn{7}{|c|}{ QUESTÃO 2 } \\
\hline Decodificadores & Categorias & Alunos & $\begin{array}{c}\text { Habilida } \\
\text { des }\end{array}$ & \multicolumn{2}{|c|}{ Respostas dos alunos } \\
\hline & & & ENEM & ALG & LOCS & HOCS \\
\hline deixou em branco & Branco & 27 & - & - & - & \\
\hline
\end{tabular}




\begin{tabular}{|c|c|c|c|c|c|c|}
\hline & & & & & & - \\
\hline massa molar é medida dela em si & $\begin{array}{l}\text { Definição de massa } \\
\text { molar }\end{array}$ & 1 & H 24 & N1 & - & - \\
\hline $\begin{array}{l}\text { massa da substância é a massa } \\
\text { de um fragmento/parcial }\end{array}$ & \multirow{4}{*}{$\begin{array}{c}\text { Definição de massa da } \\
\text { substância }\end{array}$} & \multirow{4}{*}{7} & \multirow{4}{*}{ H 24} & \multirow{4}{*}{ N1 } & \multirow{4}{*}{-} & \multirow{4}{*}{ - } \\
\hline $\begin{array}{l}\text { massa é a quantidade de uma } \\
\text { substância }\end{array}$ & & & & & & \\
\hline $\begin{array}{l}\text { quantidade de elementos na } \\
\text { substância }\end{array}$ & & & & & & \\
\hline $\begin{array}{l}\text { massa de certa substância é a } \\
\text { soma de todos os elementos }\end{array}$ & & & & & & \\
\hline $\begin{array}{l}\text { massa é o peso e massa molar a } \\
\text { quantidade de moléculas }\end{array}$ & \multirow{3}{*}{$\begin{array}{l}\text { Diferença entre massa } \\
\text { molar e da substância }\end{array}$} & \multirow{3}{*}{3} & \multirow{3}{*}{ H 24} & \multirow{3}{*}{-} & \multirow{3}{*}{$\mathrm{N} 2$} & \multirow{3}{*}{ - } \\
\hline $\begin{array}{l}\text { mede massa de mols e a outra a } \\
\text { da substância }\end{array}$ & & & & & & \\
\hline $\begin{array}{l}\text { quantidade de mols e a massa da } \\
\text { substância mede seu peso }\end{array}$ & & & & & & \\
\hline está na tabela periódica & \multirow{2}{*}{$\begin{array}{l}\text { Resposta sem relação } \\
\text { com a questão }\end{array}$} & \multirow[b]{2}{*}{3} & \multirow[b]{2}{*}{-} & \multirow[b]{2}{*}{ N1 } & \multirow[b]{2}{*}{$\mathrm{X}$} & \multirow[b]{2}{*}{ - } \\
\hline $\begin{array}{l}\text { na amostra há um conjunto de } \\
\text { moléculas e não apenas uma }\end{array}$ & & & & & & \\
\hline
\end{tabular}

Para melhor visualizarmos as categorias construídas e estabelecermos possíveis comparativos entre elas, construímos o gráfico a seguir (Figura 29), em que relacionamos as categorias criadas com as turmas participantes do projeto.

Figura 29. Número de alunos por categorias referentes à questão 2 do instrumento 3.

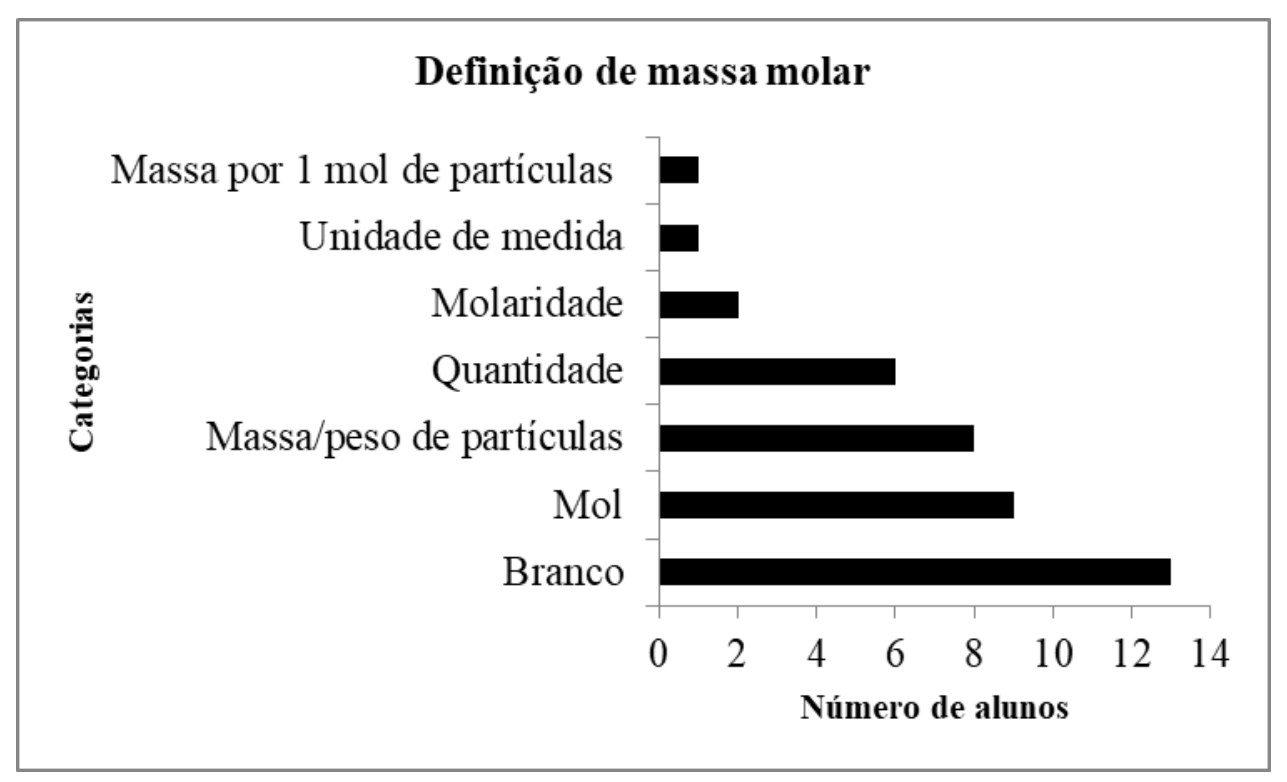

Nesta questão os alunos deveriam reconhecer a situação que, de modo geral reteve-se à aplicação de conceitos teóricos, como Molaridade, Mol e Massa molar, e a exposição de um dado relembrado.

Um número expressivo de 27 alunos, deixou a questão em branco. Certamente esta é uma das questões de maior dificuldade presente no instrumento diagnóstico. De um universo 
de 41 alunos, 3 deles conseguiram responder apenas a segunda parte da questão (que consistiu na diferença entre massa molar de uma substância e a massa de certa amostra da substância) aproximando-se dos conceitos exigidos. Oito alunos demonstraram não compreender integralmente a Situação-problema, visto que simplesmente apresentaram possíveis definições de massa da substância ("representação da quantidade da substância ou da quantidade ou soma de elementos da substância”) e de massa molar ("medida da substância em si”). E por fim, entendemos que 3 alunos não compreenderam o que estava sendo pedido já que suas respostas praticamente não apresentaram relação com o problema proposto.

Ao compararmos esta questão com a questão oito deste mesmo instrumento confirmamos que as maiores dificuldades apresentadas pelos alunos não trataram-se apenas de não relembrarem alguns conceitos, e sim, de não saberem propor uma definição de massa molar de uma substância, tampouco sua diferença em relação à uma certa quantidade da mesma. Construímos tais conclusões pois na oitava questão para calcular a quantidade de barrilha os alunos deveriam estabelecer uma relação de proporção envolvendo as massas molares das substâncias e as quantidades, em massa, das mesmas. Os poucos alunos que iniciaram a resolução da questão somente conseguiram calcular as massas molares das substâncias.

Encontramos na literatura trabalhos que demonstram preocupação em relação ao ensino e a aprendizagem do conceito de "mol" e consequentemente sua aplicação em "massa molar".

Segundo Gil-Pérez (1993), realmente os alunos de Ensino Médio finalizam seus estudos sem conseguirem resolver problemas e com "imagens distorcidas" a respeito de conceitos científicos básicos relacionados a "mol". O autor complementa que não tratam-se de “dúvidas momentâneas" e sim de "ideias muito seguras".

Cruz (1991) discute que as dificuldades dos alunos estão ligadas à própria formação do conceito de quantidade de matéria e sua unidade de medida, o mol. Para os autores associar quantidade de matéria e massa atribui ao aluno certa confusão na construção do conhecimento devido a associação da grandeza cuja unidade é o mol com a massa, visto que são formas de medidas diferentes.

Tanto Furió et al (1993) como Santos (2011) também realizaram pesquisas através da aplicação de questionários, em que o foco era conhecer as ideias dos estudantes sobre mol e os conceitos relacionados. Após a análise dos dados os pesquisadores concluíram que os estudantes não só não compreendiam as relações estabelecidas entre a quantidade de matéria e 
as outras grandezas, como também demonstraram entender que a quantidade de matéria é o mesmo que massa ou volume. Em outro trabalho Furió, Azcona e Guisasola (2002) complementa que as dificuldade em relação ao conceitos discutidos também podem abranger os diversos agentes evolvidos na construção do conhecimento, como por exemplo o professor. $\mathrm{O}$ autor afirma que se o docente não estiver totalmente clareza quanto ao significado deste conceito, isto pode comprometer a relação de ensino e aprendizagem com possíveis incompreensões e erros conceituais.

Em nosso trabalho as conclusões observadas não foram diferentes. A partir de algumas respostas dos alunos tais como, "massa molar é a quantidade de moléculas", "massa molar é a quantidade de mols", "massa molar é medida dela (massa) em si”, percebemos claramente as confusões de mol não somente com sendo a representação da massa de uma substância, como também a quantidade de moléculas.

QUESTÃO 3 - Considere os casos de transformações químicas a seguir:

\begin{tabular}{|l|}
\hline Calcinação do calcário \\
calcário $\longrightarrow$ cal viva + gás carbônico \\
\hline Efervescência da água oxigenada \\
água oxigenada $\longrightarrow$ água + gás oxigênio \\
\hline Formação do gás ozônio \\
gás oxigênio $\longrightarrow$ gás ozônio \\
\hline
\end{tabular}

A análise desses casos confirma ou contraria a ideia de que são necessárias pelo menos duas substâncias para que ocorra uma transformação química? Explique.

A tabela 21 apresenta, para a Questão, as decodificações criadas a partir das respostas dos alunos, as categorias criadas, as habilidades selecionadas a partir da matriz do ENEM, suscitadas pela questão para serem mobilizadas pelos estudantes e as classificações das respostas dos alunos em relação à níveis de cognições das mesmas.

Tabela 21. Categorização das respostas dos alunos referentes à questão 3 do instrumento 3.

\begin{tabular}{|l|l|l|l|l|l|l|l|}
\hline \multicolumn{9}{|c|}{ QUESTÃO 3 } \\
\hline Decodificadores & Categoriais & Alunos & Habilidades & \multicolumn{2}{l|}{ Respostas dos alunos } \\
\hline & & & ENEM & ALG & LOCS & HOCS \\
\hline deixou em branco & & & 2 & - & - & - & - \\
\hline gás ozônio se forma a partir de & & 22 & H17/H24 & - & N2/N3 & - \\
\hline
\end{tabular}




\begin{tabular}{|c|c|c|c|c|c|c|}
\hline $\begin{array}{l}1 \text { substância sem reagir com } \\
\text { outra }\end{array}$ & Apenas 1 substância & & & & & \\
\hline $\begin{array}{l}\text { tem material que se modifica } \\
\text { sozinho, não é necessário outros } \\
\text { materiais }\end{array}$ & & & & & & \\
\hline $\begin{array}{l}\text { reações químicas a partir de } 1 \\
\text { substância }\end{array}$ & & & & & & \\
\hline $\begin{array}{l}\text { elemento precisa estar junto } \\
\text { com outro para ocorrer uma TQ }\end{array}$ & \multirow{3}{*}{2 ou mais substâncias } & \multirow{3}{*}{15} & \multirow{3}{*}{$\mathrm{H} 24$} & \multirow{3}{*}{$\mathrm{N} 1$} & \multirow{3}{*}{-} & \multirow{3}{*}{ 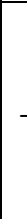 } \\
\hline $\begin{array}{l}\text { necessário } 2 \text { ou mais } \\
\text { substâncias para gerar outra }\end{array}$ & & & & & & \\
\hline $\begin{array}{l}\text { reagente montado com único } \\
\text { produto }\end{array}$ & & & & & & \\
\hline $\begin{array}{l}\text { é necessário o aparecimento de } \\
\text { uma nova substância }\end{array}$ & $\begin{array}{l}\text { Formação de nova } \\
\text { substância }\end{array}$ & 1 & $\mathrm{H} 24$ & N1 & - & - \\
\hline $\begin{array}{l}\text { confusão entre reagente e } \\
\text { produto }\end{array}$ & $\begin{array}{l}\text { Confusão entre } \\
\text { reagente/produto }\end{array}$ & 1 & $\mathrm{H} 24$ & N1 & - & - \\
\hline
\end{tabular}

Para melhor visualizarmos as categorias construídas e estabelecermos possíveis comparativos entre elas, construímos o gráfico a seguir (Figura 30), em que relacionamos as categorias criadas com as turmas participantes do projeto.

Figura 30. Número de alunos por categorias referentes à questão 3 do instrumento 3.

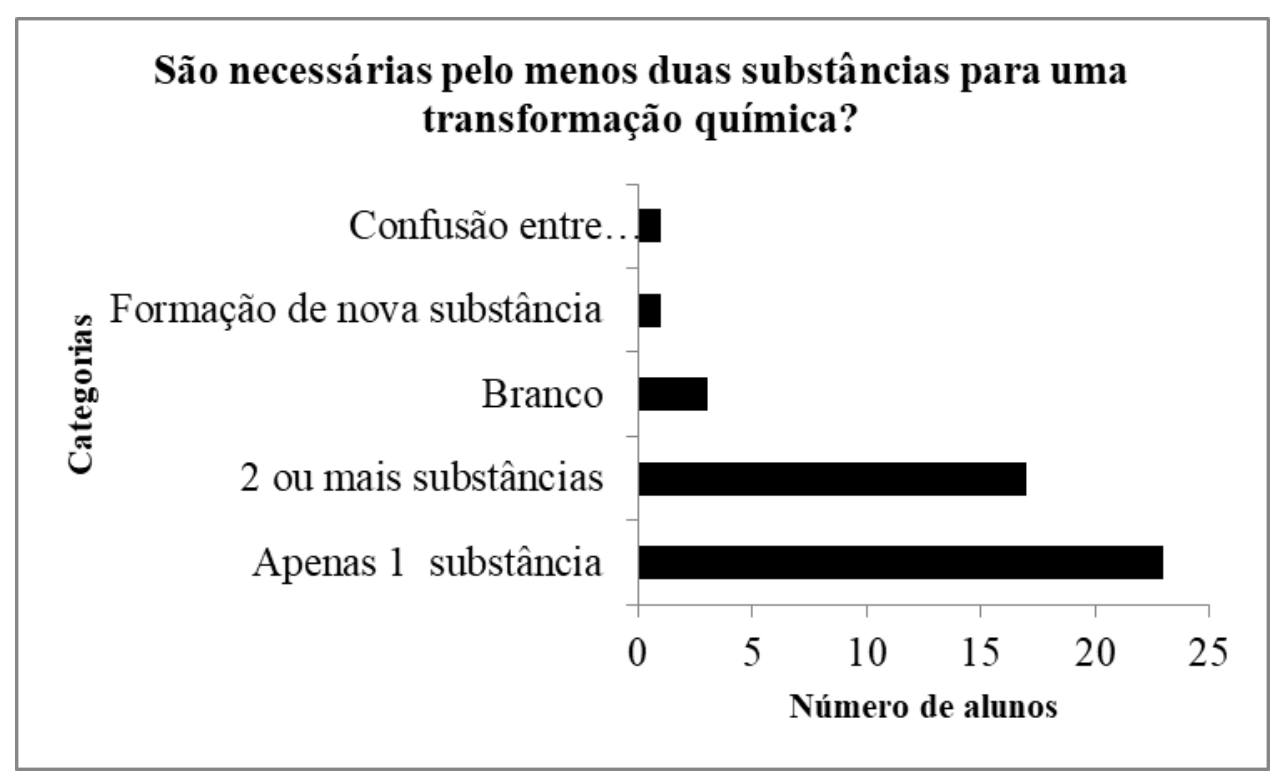

Nesta questão observamos que uma mesma habilidade quando mobilizada a partir de demandas que exigem diferentes níveis cognitivos, pode resultar em respostas de ordem cognitivas diferentes. Metade do total do número de alunos que consideraram como correta a ideia de que é necessária apenas uma substância para que ocorresse uma transformação química, não só foi capaz de utilizar códigos da química para caracterizar a transformação química observada, mas também conseguiu relacionar as informações apresentadas na tabela corretamente, articulando conceitos já conhecidos ou relembrados. Uma parcela também 
significativa (15 alunos) do total do número de alunos não conseguiu resolver o problema. Mesmo sendo capazes de utilizarem códigos para caracterizar uma transformação química, talvez não conseguiram identificar o que deveria ser buscado, ou seja, não perceberam que em nenhum dos casos propostos não havia duas substâncias como reagentes.

Partilhamos de algumas ideias de Diniz, podemos entender que as dificuldades dos alunos na compreensão de alguns conceitos se justificam pela existência de "concepções alternativas/espontâneas" trazidas pelos estudantes. E segundo o autor, "tais concepções podem diferir substancialmente das ideias a serem ensinadas, e estas concepções influenciam a aprendizagem futura" (DINIZ, 1998, p. 28). Assim, é necessário uma compreensão mais aprofundada dos conceitos, de forma que ocorra uma articulação entre os procedimentos didáticos e os alunos, resultando em uma aprendizagem significativa de conceitos (ibdem, p. 31).

QUESTÃO 4 - O responsável técnico de um forno de calcinação de calcário elaborou um relatório sobre as três últimas tiragens da produção de cal. $O$ relatório apresenta a seguinte tabela:

\begin{tabular}{|c|c|c|c|}
\hline Amostras & $\begin{array}{c}\text { Massa de calcário (t) } \\
(\mathbf{C a C O})\end{array}$ & $\begin{array}{c}\text { Massa de cal (t) } \\
(\mathbf{C a O})\end{array}$ & $\begin{array}{c}\text { Massa de dióxido de } \\
\text { carbono (t) } \\
\left(\mathbf{C O}_{2}\right)\end{array}$ \\
\hline I & 10,0 & 5,6 & 4,4 \\
\hline II & 20,0 & 11,2 & 8,8 \\
\hline III & 70,0 & & \\
\hline
\end{tabular}

Determine os valores que faltam na tabela e complete-a. Mostre todos os cálculos realizados.

A tabela 22 apresenta, para a Questão, as decodificações criadas a partir das respostas dos alunos, as categorias criadas, as habilidades selecionadas a partir da matriz do ENEM, suscitadas pela questão para serem mobilizadas pelos estudantes e as classificações das respostas dos alunos em relação à níveis de cognições das mesmas.

Tabela 22. Categorização das respostas dos alunos referentes à questão 4 do instrumento 3.

\begin{tabular}{|l|c|c|c|c|c|c|}
\hline \multicolumn{9}{|c|}{ QUESTÃO 4 } \\
\hline Decodificadores & Categoriais & Alunos & Habilidades & \multicolumn{3}{c|}{ Respostas dos alunos } \\
\hline & & & ENEM & ALG & LOCS & HOCS \\
\hline deixou em branco & Branco & 15 & - & - & - & - \\
\hline
\end{tabular}




\begin{tabular}{|c|c|c|c|c|c|c|}
\hline $\begin{array}{l}\text { proporção entre I e II (x2) e I e } \\
\text { III (x7) }\end{array}$ & \multirow{2}{*}{$\begin{array}{l}\text { Cálculos } \\
\text { corretos }\end{array}$} & \multirow{2}{*}{8} & \multirow{2}{*}{$\mathrm{H} 17 / \mathrm{H} 25$} & \multirow{2}{*}{-} & \multirow{2}{*}{$\mathrm{N} 2 / \mathrm{N} 3$} & \multirow{2}{*}{ N4 } \\
\hline $\begin{array}{l}\text { completou a tabela com } 2 \\
\text { valores corretos }\end{array}$ & & & & & & \\
\hline $\begin{array}{l}\text { completou a tabela com } 1 \\
\text { valor correto }\end{array}$ & \multirow{4}{*}{$\begin{array}{l}\text { Parcialmente } \\
\text { Corretos }\end{array}$} & \multirow{4}{*}{10} & \multirow{4}{*}{$\begin{array}{r}\mathrm{H} 17 / \mathrm{H} 25 \\
\text { (parcial) }\end{array}$} & \multirow{4}{*}{-} & \multirow{4}{*}{$\mathrm{N} 2$} & \multirow{4}{*}{$\mathrm{N} 4$} \\
\hline $\begin{array}{l}\text { proporção somente entre II e } \\
\text { III correta }\end{array}$ & & & & & & \\
\hline $\begin{array}{l}\text { proporção somente entre I e III } \\
\text { (x7) }\end{array}$ & & & & & & \\
\hline $\begin{array}{l}\text { proporção entre II e III } \\
\text { incorreta }\end{array}$ & & & & & & \\
\hline $\begin{array}{l}\text { completou a tabela com } 2 \\
\text { valores incorretos }\end{array}$ & \multirow[b]{2}{*}{$\begin{array}{l}\text { Cálculos } \\
\text { distintos do } \\
\text { esperado }\end{array}$} & \multirow[b]{2}{*}{8} & \multirow[b]{2}{*}{ H17 } & \multirow[b]{2}{*}{-} & \multirow[b]{2}{*}{ N2 } & \multirow[b]{2}{*}{-} \\
\hline $\begin{array}{l}\text { cálculo da \% em massa dos } \\
\text { reagentes e estabelecimento de } \\
\text { igualdade entre as amostras }\end{array}$ & & & & & & \\
\hline
\end{tabular}

Para melhor visualizarmos as categorias construídas e estabelecermos possíveis comparativos entre elas, construímos o gráfico a seguir (Figura 31), em que relacionamos as categorias criadas com as turmas participantes do projeto.

Figura 31. Número de alunos por categorias referentes à questão 4 do instrumento 3.

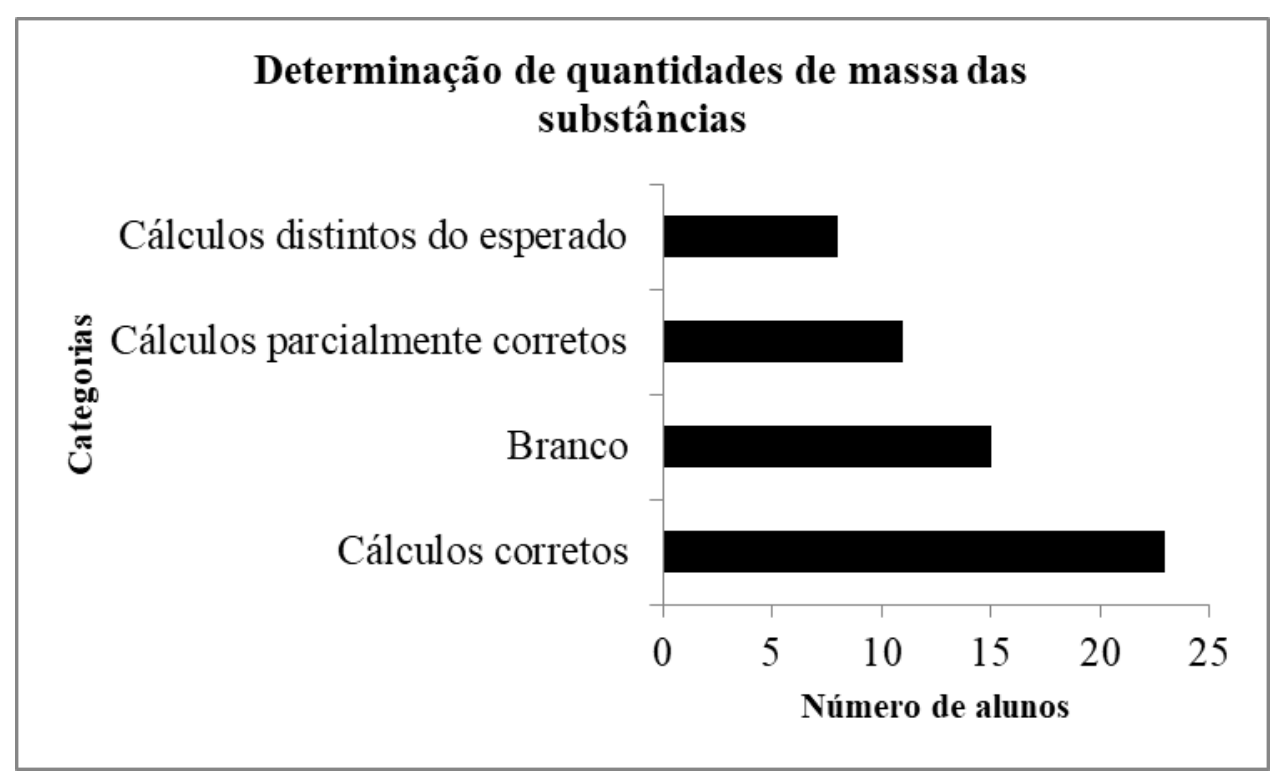

Nesta questão, os alunos não poderiam limitar-se somente a relembrar conceitos. Os mesmos deveriam interpretar informações em outras linguagens, no caso de tabela, e controlar informações relevantes focados na construção de uma possível resolução para o problema apresentado.

Em todas as categoriais de resposta, exceto aquela em que alunos que deixaram a questão em branco, os mesmos manifestaram, a partir de suas anotações, o reconhecimento da situação proposta. De certa forma, todos identificaram o que deveria ser buscado, ou seja, a relação de massas entre os reagentes e os produtos nas diferentes amostras. Aqueles que não 
conseguiram resolver integralmente o problema demonstraram não estabelecer controle de todas as informações. Com o auxílio dos decodificadores criados, foi possível afirmar que a principal dificuldade dos alunos que iniciaram adequadamente uma resolução mas não a finalizaram com sucesso foi na percepção das proporções entre as massas dos materiais.

A nossa grande preocupação se estabeleceu com aqueles que deixaram a questão em branco, que representou uma parcela significativa de respostas $(36,6 \%)$ em relação ao número total de estudantes. Entretanto pontuando quais seriam as principais dificuldades de resolução para este tipo de problema (cálculos numéricos e a percepção e aplicação de relações de proporções entre os materiais), entendemos que se tratavam de dificuldades já diagnosticadas com a aplicação do instrumento piloto (especificamente na questão 3) logo no início da sequência. E também, este foi um momento que ainda não havia se iniciado propriamente a aplicação da sequência de ensino, sendo que os alunos novamente estavam respondendo um questionário de teor investigativo, com um diferencial, agora a respeito de dificuldades conceituais dentro de um mesmo tema.

QUESTÃO 5 - $O$ gás metano $\left(\mathrm{CH}_{4}\right)$ pode ser obtido nos tratamentos de esgoto, por meio de processos biológicos ocorridos em biodigestores. Esse gás, ao reagir com oxigênio $\left(\mathrm{O}_{2}\right)$, formará gás carbônico $\left(\mathrm{CO}_{2}\right)$ e água $\left(\mathrm{H}_{2} \mathrm{O}\right)$.

\section{a) Represente a equação química do processo.}

A tabela 23 apresenta, para a Questão, as decodificações criadas a partir das respostas dos alunos, as categorias criadas, as habilidades selecionadas a partir da matriz do ENEM, suscitadas pela questão para serem mobilizadas pelos estudantes e as classificações das respostas dos alunos em relação à níveis de cognições das mesmas.

Tabela 23. Categorização das respostas dos alunos referentes à questão 5 (A) do instrumento 3.

\begin{tabular}{|c|c|c|c|c|c|c|}
\hline \multicolumn{7}{|c|}{ QUESTÃO 5 - Representação da equação química } \\
\hline Decodificadores & Categoriais & Alunos & Habilidades & Res] & stas dos & lunos \\
\hline & & & ENEM & ALG & LOCS & HOCS \\
\hline deixou em branco & Branco & 6 & - & - & - & - \\
\hline $\begin{array}{c}\text { não separa reagente de } \\
\text { produto }\end{array}$ & \multirow{4}{*}{$\begin{array}{c}\text { Representação parcialmente } \\
\text { esperada (confusões } \\
\text { conceituais) }\end{array}$} & \multirow{4}{*}{6} & \multirow{4}{*}{ H17 } & \multirow{4}{*}{-} & \multirow{4}{*}{$\mathrm{N} 2$} & \multirow{4}{*}{-} \\
\hline $\begin{array}{c}\text { não separa os produtos } \\
\text { entre si }\end{array}$ & & & & & & \\
\hline $\begin{array}{c}\text { representação } \\
\text { parcialmente correta da } \\
\text { equação }\end{array}$ & & & & & & \\
\hline confusão entre reagentes & & & & & & \\
\hline
\end{tabular}




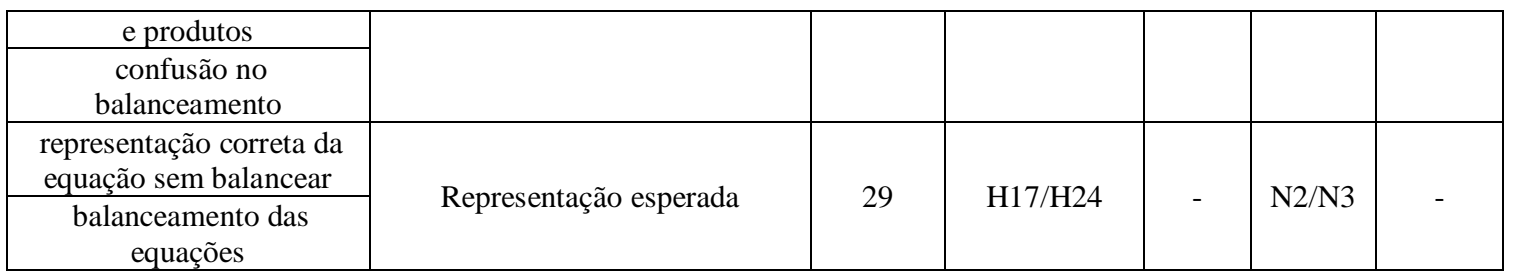

Para melhor visualizarmos as categorias construídas e estabelecermos possíveis comparativos entre elas, construímos o gráfico a seguir (Figura 32), em que relacionamos as categorias criadas com as turmas participantes do projeto.

Figura 32. Número de alunos por categorias referentes à questão 5 (A) do instrumento 3.

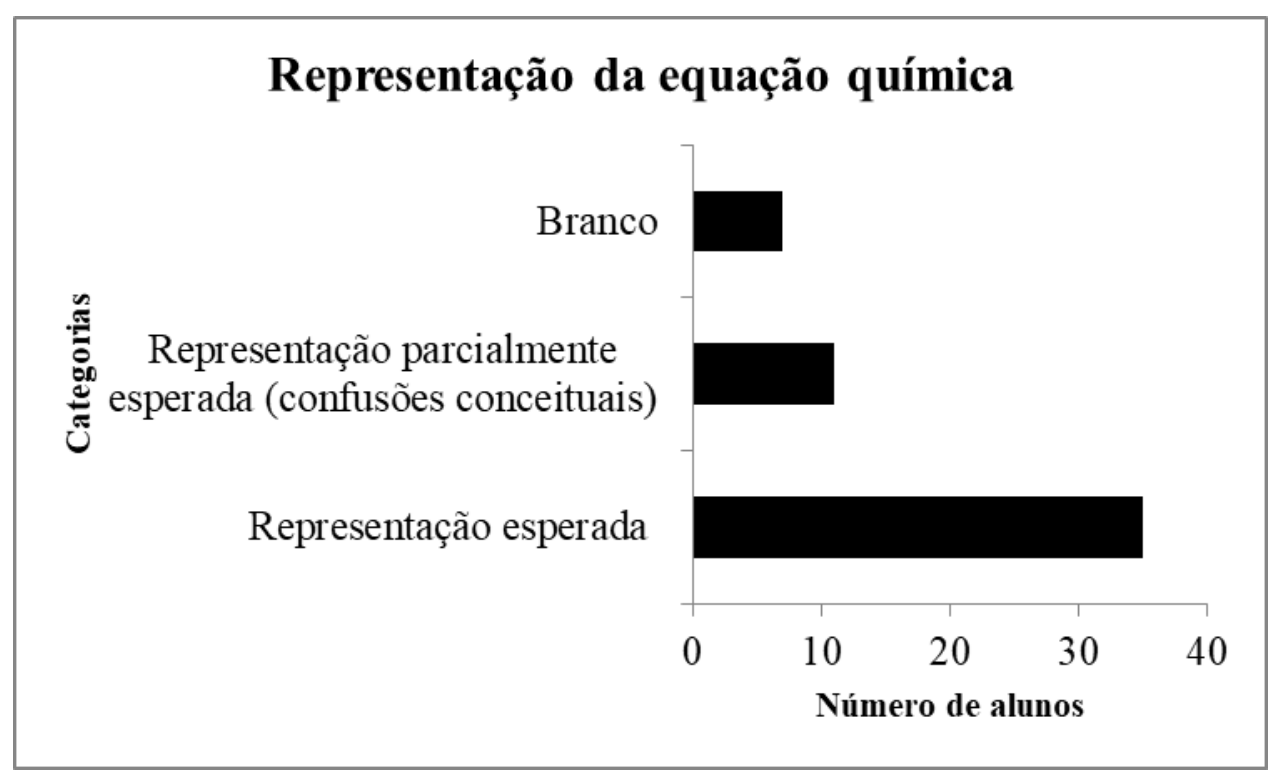

Neste item da questão, a grande maioria dos alunos conseguiu propor uma representação da transformação do gás metano por meio de uma equação química. Eles foram capazes de relacionar informações do texto dispostas em diferentes formas de linguagem e utilizar códigos apropriados da química para representar a reação corretamente. Conforme já verificado em discussões anteriores o conhecimento a respeito das reações químicas é muito importante na proposição de relações entre massas (a nível macroscópico) e quantidades de matéria (a nível microscópico), e também de fundamental relevância para a nossa sequencia de ensino, visto que estão problematizadas em muitas questões aplicadas nos módulos constituintes das Situações-problema.

Uma parcela significativa $(14,6 \%)$ do total de alunos deixou a questão em branco. Embora as informações tenham sido dadas, como as fórmulas e os nomes das substâncias, alguns alunos não tentaram sequer utilizá-las para propor uma resposta para a questão. Nos 
apoiamos na hipótese de não tratar-se de um desconhecimento do que seria uma equação química e como representá-la, mas talvez de não ter o conhecimento de como ela funciona, e também em não ter conhecimento de como fazer o balanceamento químico dos componentes envolvidos.

Aqueles que não concluíram a resolução da questão também encontraram dificuldades na seleção das informações e na representação correta da transformação por meio de uma reação química. Mesmo apresentando habilidade de relacionar informações em diferentes linguagens, ou seja, utilizaram as fórmulas ou nomes de substância corretamente, não apresentaram o domínio da seleção de tais informações, não conseguindo propor uma reação química de forma adequada. Tais conclusões foram observadas a partir da confusão na representação correta de uma equação química, no balanceamento e também na inversão de conceitos como reagentes e produtos.

\section{b) A densidade do gás metano é $0,656 \mathrm{~kg} / \mathrm{m}^{3}$. Qual é a massa de $1000 \mathrm{~L}$ desse} gás?

A tabela 24 apresenta, para a Questão 5, as decodificações criadas a partir das respostas dos alunos, as categorias criadas, as habilidades selecionadas a partir da matriz do ENEM, suscitadas pela questão para serem mobilizadas pelos estudantes e as classificações das respostas dos alunos em relação à níveis de cognições das mesmas.

Tabela 24. Categorização das respostas dos alunos referentes à questão 5 (B) do instrumento 3.

\begin{tabular}{|c|c|c|c|c|c|c|}
\hline \multicolumn{7}{|c|}{ QUESTÃO 5 - Cálculo da massa do gás } \\
\hline \multirow[t]{2}{*}{ Decodificadores } & \multirow{2}{*}{ Categoriais } & \multirow{2}{*}{ Alunos } & \multirow{2}{*}{$\begin{array}{c}\text { Habilidades } \\
\text { ENEM }\end{array}$} & \multicolumn{3}{|c|}{ Respostas dos alunos } \\
\hline & & & & ALG & LOCS & HOCS \\
\hline deixou em branco & Branco & 35 & - & - & - & - \\
\hline $\begin{array}{l}\text { conversão e verificação de } \\
\text { proporção entre a massa e o volume } \\
\text { do gás de } \mathrm{m}^{3} \text { para litros }\end{array}$ & $\begin{array}{l}\text { Cálculo da massa de } \\
\text { gás esperada }\end{array}$ & 4 & $\mathrm{H} 17 / \mathrm{H} 25$ & - & $\mathrm{N} 2 / \mathrm{N} 3$ & N4 \\
\hline $\begin{array}{c}\text { conversão de } \mathrm{m}^{3} \text { para litros } \\
\text { corretamente }\end{array}$ & $\begin{array}{l}\text { Não obteve o valor } \\
\text { de massa esperado }\end{array}$ & 2 & H17 & - & $\mathrm{N} 2$ & - \\
\hline
\end{tabular}

Para melhor visualizarmos as categorias construídas e estabelecermos possíveis comparativos entre elas, construímos o gráfico a seguir (Figura 33), em que relacionamos as categorias criadas com as turmas participantes do projeto. 
Figura 33. Número de alunos por categorias referentes à questão 5 do instrumento 3.

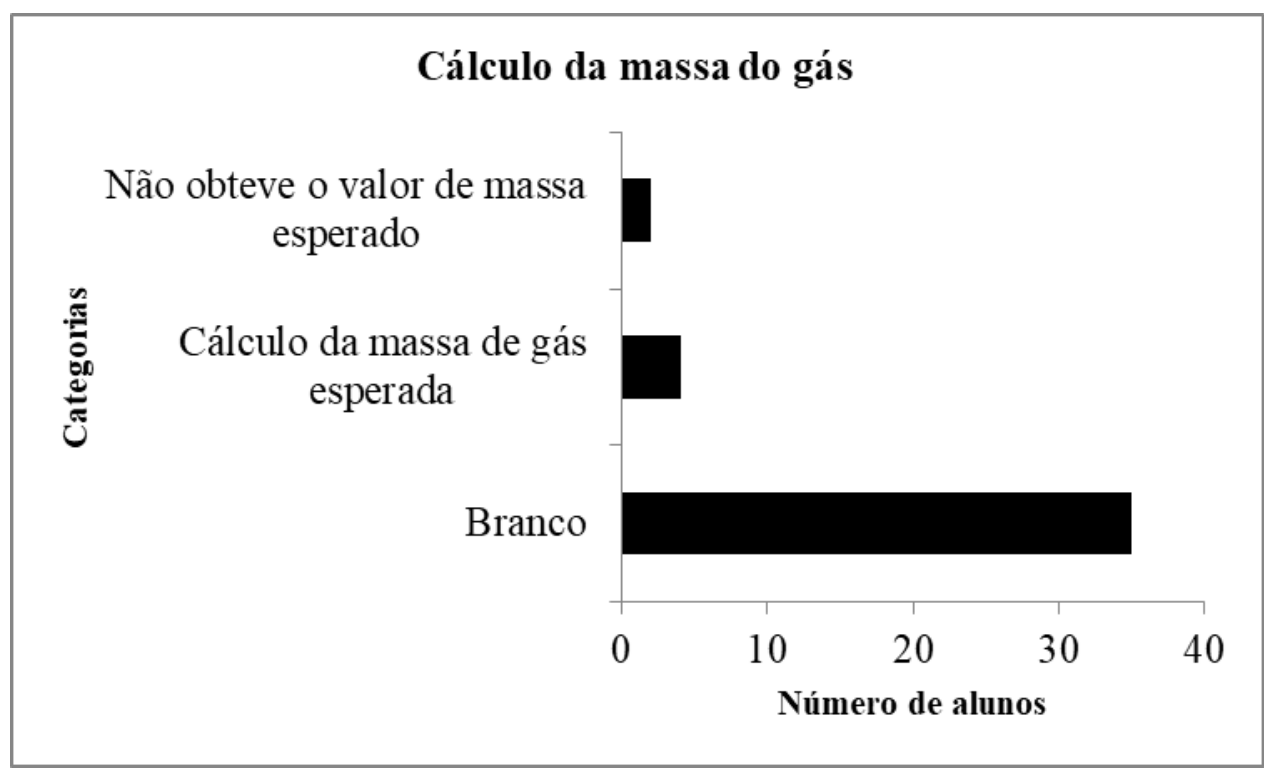

O resultado desta questão foi complementar aos obtidos após análises de algumas questões do instrumento piloto, as quais também abordaram problemas relacionados as "Grandezas químicas e as relações quantitativas da matéria". Verificamos que $85 \%$ do total de alunos deixou a questão em branco, sendo que as principais dificuldades de resolução para este tipo de problema concentraram-se na compreensão dos enunciados, na articulação de conceitos e nos cálculos matemáticos necessários. Também ao deixar a questão em branco, entendemos que os alunos não conseguiram ao menos reconhecer a situação apresentada e identificar o que deveria ser buscado.

QUESTÃO 6 - Aspartame é um adoçante dietético que apresenta potencial adoçante 200 vezes maior que o açúcar comum, permitindo seu uso em pequenas quantidades. O IDA (índice diário aceitável) desse adoçante é $40 \mathrm{mg} / \mathrm{Kg}$ de massa corpórea.

Disponível em: http://boaspraticasfarmaceuticas.com. Acesso em: 27 fev. 201-2.

Com base nas informações do texto, qual a quantidade máxima recomendada de aspartame que uma pessoa de $70 \mathrm{Kg}$ de massa corporal pode ingerir por dia?

A tabela 25 apresenta, para a Questão 6, as decodificações criadas a partir das respostas dos alunos, as categorias criadas, as habilidades selecionadas a partir da matriz do ENEM, suscitadas pela questão para serem mobilizadas pelos estudantes e as classificações das respostas dos alunos em relação à níveis de cognições das mesmas. 
Tabela 25. Categorização das respostas dos alunos referentes à questão 6 do instrumento 3.

\begin{tabular}{|c|c|c|c|c|c|c|}
\hline \multicolumn{7}{|c|}{ QUESTÃO 6} \\
\hline Decodificadores & Categoriais & Alunos & Habilidades & Resp & stas dos & alunos \\
\hline & & & ENEM & ALG & LOCS & HOCS \\
\hline deixou em branco & Branco & 13 & - & - & - & - \\
\hline raciocínio não identificado & \multirow{3}{*}{$\begin{array}{l}\text { Não obteve o } \\
\text { valor esperado }\end{array}$} & \multirow[b]{3}{*}{12} & \multirow[b]{3}{*}{ H17 } & \multirow[b]{3}{*}{-} & \multirow[b]{3}{*}{$\mathrm{N} 2$} & \multirow[b]{3}{*}{-} \\
\hline confusão nos cálculos & & & & & & \\
\hline $\begin{array}{c}\text { não entendimento da relação de } \\
\text { proporção entre o peso e a quantidade } \\
\text { permitida }\end{array}$ & & & & & & \\
\hline $\begin{array}{c}\text { proporção correta entre a quantidade } \\
\text { de adoçante/peso }\end{array}$ & \multirow{2}{*}{$\begin{array}{l}\text { Obteve o } \\
\text { resultado } \\
\text { esperado }\end{array}$} & \multirow{2}{*}{16} & \multirow{2}{*}{$\mathrm{H} 17 / \mathrm{H} 25$} & \multirow{2}{*}{-} & \multirow{2}{*}{$\mathrm{N} 2 / \mathrm{N} 3$} & \multirow{2}{*}{ N4 } \\
\hline cálculos corretos & & & & & & \\
\hline
\end{tabular}

Para melhor visualizarmos as categorias construídas e estabelecermos possíveis comparativos entre elas, construímos o gráfico a seguir (Figura 34), em que relacionamos as categorias criadas com as turmas participantes do projeto.

Figura 34. Número de alunos por categorias referentes à questão 6 do instrumento 3.

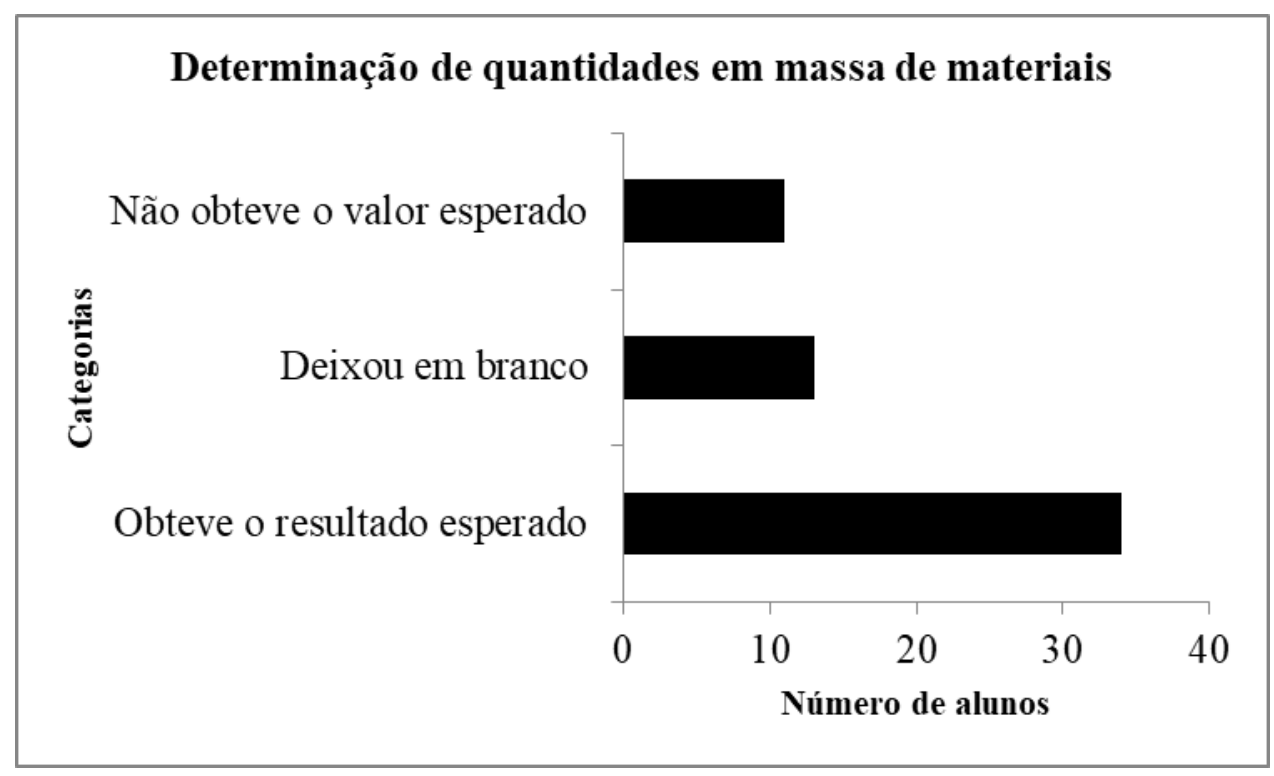

As principais habilidades que deveriam ser mobilizadas durante a resolução da questão relacionavam-se com a interpretação de informações relevantes do texto, especificamente o significado do índice diário aceitável, a relação entre a quantidade de adoçante e a massa corpórea mencionada, e também o cálculo da quantidade de adoçante a partir de uma quantidade de massa corporal específica.

A última categoria descrita na tabela 25 representou uma parcela de $39 \%$ do total de alunos participantes que obtiveram a quantidade esperada de adoçante proporcional a massa 
corporal do indivíduo. O restante de respostas foram expressas igualmente, em relações percentuais, a partir de duas categorias. Dividiram-se entre aqueles que não responderam a questão e aqueles que iniciaram a sua resolução.

Quanto aos alunos que não responderam a questão, considerando os conhecimentos necessário para a resolução do problema, verificamos que ainda pertencem a um grupo que apresentam dificuldades em questões que exigem cálculos e estabelecimentos de proporções. Quanto aqueles descritos na outra categoria demonstram uma tentativa de resolução, isto é, reconheceram as informações relevantes, mas também não conseguiram estabelecer adequadamente a proporção entre as quantidades descritas no problema. Conforme verificado e discutido isto já aconteceu em outras questões (questões 4 e 5 deste mesmo instrumento e questões 3 e 6 do instrumento piloto).

Embora fosse esperado que nessa faixa de escolaridade os alunos já entendessem e soubessem aplicar proporções, a literatura tem mostrado que isto tem sido uma dificuldade entre nossos estudantes. Em um de seus trabalhos Pozo e Crespo (2009) comenta que o grande problema da compreensão e aplicação das relações quantitativas em química inicia-se pela falta de raciocínio proporcional.

Verificamos justamente tais constatações na aplicação desta questão. Tratou-se de uma questão que propunha a elaboração de um problema envolvendo uma razão simples. Ou seja, sem o envolvimento de conceitos como mols, número de partículas, ou cálculos estequiométricos, e também as informações necessárias encontravam-se descritas no enunciado da questão. Segundo Inhelder e Piaget (1955) compreender a ideia de proporção supõe o conhecimento da relação de igualdade entre duas razões e que a mudança de um membro desta igualdade pode ser compensada com a mudança do outro membro, para que seja promovida a manutenção desta relação.

Os alunos que não conseguiram propor uma solução para este problema, representando um percentual de $61 \%$ em relação ao total de alunos demonstraram não entender a relação de igualdade proposta já no enunciado em que descreveu que para cada $1 \mathrm{~kg}$ de massa corpórea é aceitável 40 mg de adoçante por dia. Desta forma, com a mudança de um dos membros desta igualdade não foram capazes de pensar em uma forma de compensação para promover novamente a manutenção desta relação. Em uma listagem de algumas das principais aplicações quantitativas no ensino de Química, descritas pelos autores, encontramse: cálculos com mols, com número de partículas (átomos), ajuste de reações e cálculos estequiométricos. Ou seja, conteúdos relacionados com a nossa sequência de ensino. Assim, 
se ao final de nossas atividades os alunos ainda apresentarem muitas dificuldades em relação à construção dos conhecimentos propostos, certamente tais dificuldades contribuirão ainda mais com a listagem feita pelos autores.

QUESTÃO 7 - Nas indústrias siderúrgicas, o gás monóxido de carbono (CO), formado na combustão incompleta do carvão, reagirá com o óxido de ferro III $\left(\mathrm{Fe}_{2} \mathrm{O}_{3}\right)$ extraído do minério de ferro e terá como produtos o ferro líquido (Fe) e o gás dióxido de carbono $\left(\mathrm{CO}_{2}\right)$. Represente as transformações descritas acima devidamente balanceadas.

A tabela 26 apresenta, para a Questão, as decodificações criadas a partir das respostas dos alunos, as categorias criadas, as habilidades selecionadas a partir da matriz do ENEM, suscitadas pela questão para serem mobilizadas pelos estudantes e as classificações das respostas dos alunos em relação à níveis de cognições das mesmas.

Tabela 26. Categorização das respostas dos alunos referentes à questão 7 do instrumento 3.

\begin{tabular}{|c|c|c|c|c|c|c|}
\hline \multicolumn{7}{|c|}{ QUESTÃO 7} \\
\hline \multirow[t]{2}{*}{ Decodificadores } & \multirow[t]{2}{*}{ Categoriais } & \multirow{2}{*}{ Alunos } & \multirow{2}{*}{$\begin{array}{c}\text { Habilidades } \\
\text { ENEM }\end{array}$} & \multicolumn{3}{|c|}{ Respostas dos alunos } \\
\hline & & & & ALG & LOCS & HOCS \\
\hline deixou em branco & Branco & 13 & - & - & - & - \\
\hline $\begin{array}{c}\text { equação química correta e } \\
\text { balanceada }\end{array}$ & $\begin{array}{l}\text { Representação correta } \\
\text { e balanceada }\end{array}$ & 8 & $\mathrm{H} 17 / \mathrm{H} 24$ & - & $\mathrm{N} 2 / \mathrm{N} 3$ & - \\
\hline $\begin{array}{c}\text { equação química correta e não } \\
\text { balanceada }\end{array}$ & $\begin{array}{l}\text { Representação correta } \\
\text { e não balanceada }\end{array}$ & 3 & H17 & - & $\mathrm{N} 2$ & - \\
\hline $\begin{array}{l}\text { representação da equação química } \\
\text { parcialmente correta e não } \\
\text { balanceada }\end{array}$ & \multirow{5}{*}{ Confusões conceituais } & \multirow{5}{*}{17} & \multirow{5}{*}{ H17 } & \multirow{5}{*}{-} & \multirow{5}{*}{$\mathrm{N} 2$} & \multirow{5}{*}{-} \\
\hline não ocorre separação dos produtos & & & & & & \\
\hline não separa reagentes de produtos & & & & & & \\
\hline confusão no balanceamento & & & & & & \\
\hline $\begin{array}{l}\text { confusão na construção das } \\
\text { moléculas }\end{array}$ & & & & & & \\
\hline
\end{tabular}

Para melhor visualizarmos as categorias construídas e estabelecermos possíveis comparativos entre elas, construímos o gráfico a seguir (Figura 35), em que relacionamos as categorias criadas com as turmas participantes do projeto. 
Figura 35. Número de alunos por categorias referentes à questão 7 do instrumento 3.

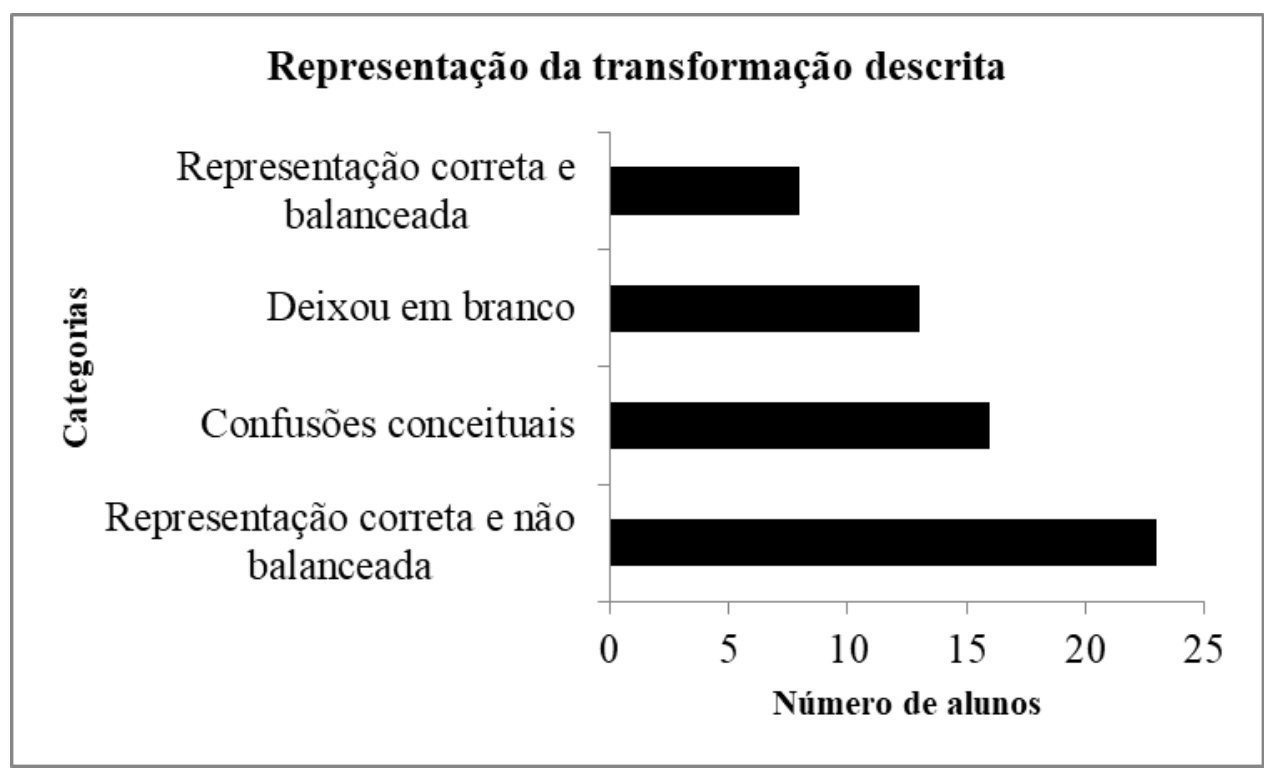

Esta foi uma questão em que os alunos deveriam mobilizar as habilidades 17 e 24 especificamente, em que, através de uma interpretação do enunciado os mesmos deveriam associar informações apresentadas em diferentes linguagens, no caso simbólica, e também utilizando códigos da química descritos na questão, propor a representação da formação do ferro por meio de uma reação química.

Julgamos necessário comparar os dados desta questão com a quinta questão (item a) deste mesmo instrumento. Também por meio de uma reação química e mobilizando os mesmos conhecimentos cognitivos (habilidades 17 e 24), os alunos deveriam representar a combustão do gás metano. Observando os resultados das análises feitas da atual questão em comparação a quinta questão foi possível perceber um acentuado declínio em relação ao número de alunos que responderam corretamente a mesma. Enquanto que 29 alunos representaram corretamente a equação química da combustão do gás metano (questão 5) somente 8 alunos concluíram com sucesso a construção da equação química referente à atual questão. $\mathrm{O}$ que predominou neste momento foram as confusões conceituais por parte dos alunos, ou seja, em relação ao entendimento dos conceitos de reagentes e produtos, na representação das espécies, e no balanceamento das substâncias envolvidas nas reações.

Analisando novamente o enunciado das duas questões construímos como uma possível hipótese a dificuldade na utilização das fórmulas químicas. Ou seja, fórmulas químicas mais complexas como $\mathrm{CO}$ e $\mathrm{Fe}_{2} \mathrm{O}_{3}$, podem dificultar o balanceamento químico da reação. Na combustão do metano $\left(\mathrm{CH}_{4}\right)$ temos 4 hidrogênios formando 2 moléculas de água $\left(\mathrm{H}_{2} \mathrm{O}\right)$. Agora, na formação do ferro $(\mathrm{Fe})$, apesar da relação entre os átomos de ferro ser mais 
facilmente equilibrada do que a relação entre os átomos de carbono, os alunos também tiveram que pensar na relação entre os átomos de oxigênio.

QUESTÃo 8 - Um grande avanço químico se deu com o desenvolvimento da síntese da barrilha ( $\mathrm{Na}_{2} \mathrm{CO}_{3}$ ), em 1791 por Nicolas Leblanc. A etapa final da síntese da barrilha está descrita a seguir. Considerando que sejam utilizados $200 \mathrm{~g}$ de carbonato de cálcio $\left(\mathrm{CaCO}_{3}\right)$ na reação, quanto deverá ser produzido de barrilha? Justifique sua resposta.

Dados: Massas molares (g/mol): Ca: 40, C: 12, O: 16, Na: 23

$$
\mathrm{Na}_{2} \mathrm{SO}_{4}+\mathrm{CaCO}_{3}+2 \mathrm{C} \longrightarrow \mathrm{Na}_{2} \mathrm{CO}_{3}+\mathrm{CaS}+2 \mathrm{CO}_{2}
$$

A tabela 27 apresenta, para a Questão, as decodificações criadas a partir das respostas dos alunos, as categorias criadas, as habilidades selecionadas a partir da matriz do ENEM, suscitadas pela questão para serem mobilizadas pelos estudantes e as classificações das respostas dos alunos em relação à níveis de cognições das mesmas.

Tabela 27. Categorização das respostas dos alunos referentes à questão 8 do instrumento 3.

\begin{tabular}{|c|c|c|c|c|c|c|}
\hline \multicolumn{7}{|c|}{ QUESTÃO 8} \\
\hline \multirow[t]{2}{*}{ Indicadores } & \multirow[t]{2}{*}{ Categoriais } & \multirow[t]{2}{*}{ Alunos } & \multirow{2}{*}{$\begin{array}{c}\text { Habilidades } \\
\text { ENEM }\end{array}$} & \multicolumn{3}{|c|}{ Respostas dos alunos } \\
\hline & & & & ALG & LOCS & HOCS \\
\hline deixou em branco & Branco & 31 & - & - & - & - \\
\hline cálculo de massas das moléculas & $\begin{array}{c}\text { Cálculo de massas das } \\
\text { moléculas }\end{array}$ & 7 & $\mathrm{H} 17$ & - & $\mathrm{N} 2$ & - \\
\hline soma das massas das moléculas & & & & & & \\
\hline $\begin{array}{l}\text { cálculo de massa e verificação do } \\
\text { dobro da quantidade de massa do } \\
\text { carbonato de cálcio }\end{array}$ & $\begin{array}{c}\text { Obtenção da } \\
\text { quantidade de barrilha }\end{array}$ & 3 & $\mathrm{H} 17 / \mathrm{H} 25$ & - & $\mathrm{N} 2 / \mathrm{N} 3$ & N4 \\
\hline
\end{tabular}

Para melhor visualizarmos as categorias construídas e estabelecermos possíveis comparativos entre elas, construímos o gráfico a seguir (Figura 36), em que relacionamos as categorias criadas com as turmas participantes do projeto. 
Figura 36. Número de alunos por categorias referentes à questão 8 do instrumento 3.

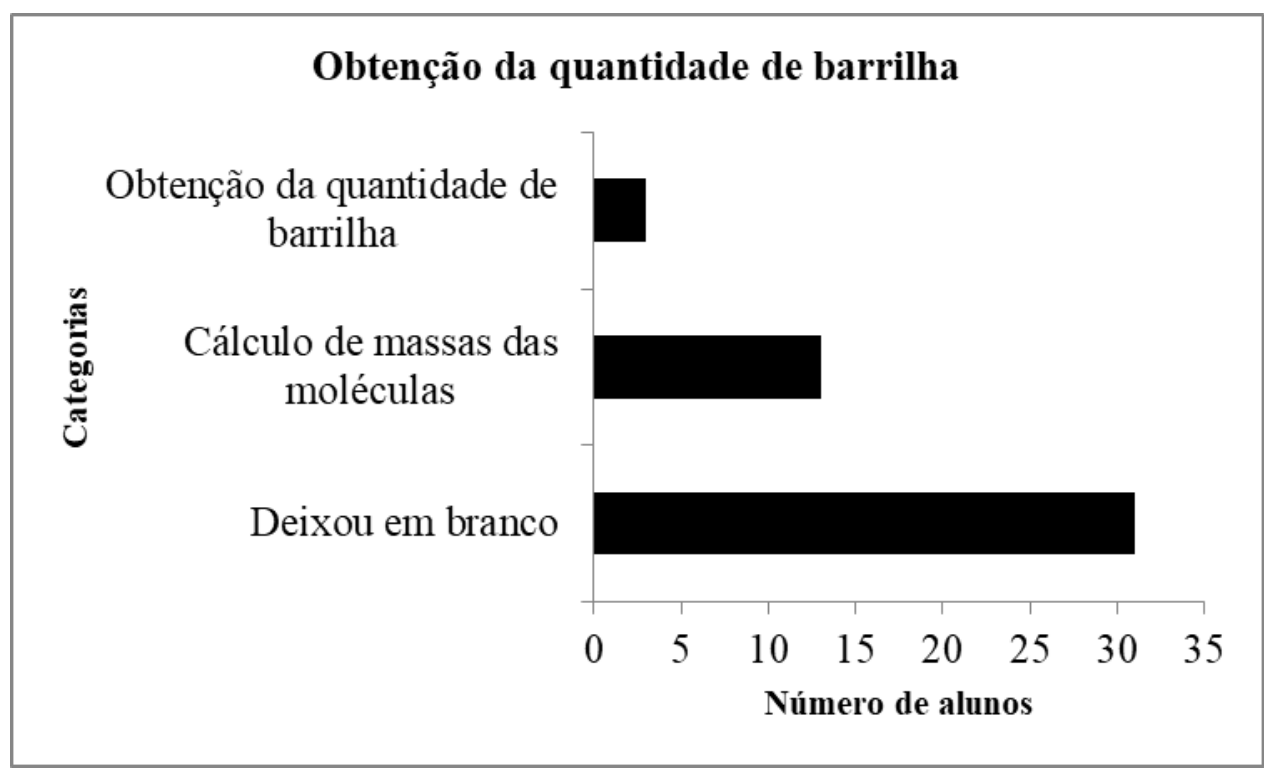

Os dados desta questão podem ser comparados com o item "b" da quinta questão deste mesmo instrumento. De forma geral, ambas empregaram a utilização de cálculos matemáticos, ainda que de formas distintas. Em relação as exigências cognitivas a presente questão é mais complexa do ponto de vista da química, pois não se tratou somente de uma mudança de unidade ( $\mathrm{m}^{3}$ para $\mathrm{L}$ ) ou a mobilização de um conceito (o de densidade). Na presente questão, além do conceito de massa molar, o aluno tem de saber utilizá-lo para transformar massa em quantidade de matéria e também utilizar as relações de proporções para finalizar a resolução do problema.

A grande maioria dos alunos não conseguiu ao menos iniciar a resolução do problema apresentado. Aqueles que reconheceram a situação proposta e conseguiram relacionar as informações descritas no problema também tiveram dificuldades em identificar o que deveria ser buscado, demonstrando a falta de controle das informações já que não concluíram a resolução da questão. Somente três alunos de um total de quarenta e um conseguiram resolver o problema.

Embora as informações tenham sido dadas, de forma semelhante à quinta questão, as principais dificuldades observadas neste tipo de problema concentraram-se na compreensão dos enunciados, na articulação de conceitos e nos cálculos matemáticos. Ao deixar a questão em branco, entendemos que os alunos não conseguiram ao menos reconhecer a situação apresentada e identificar o que deveria ser buscado.

Também podemos estabelecer uma aproximação em relação as conclusões desta questão e da segunda questão aplicada neste instrumento. Em reflexões anteriores verificamos 
e discutimos a respeito das dificuldades dos alunos em diferenciar massa molar de certa quantidade de massa de uma substância. Em relação ao alunos que tentaram propor uma resolução ao problema proposto, observamos que os mesmos calcularam as massas das moléculas, entretanto não iniciaram a etapa seguinte que seria justamente a utilização da quantidade em massa de carbonato de cálcio fornecida na questão e estabelecimento de uma relação de proporção entre as substâncias. As dificuldades no entendimento e verificação das relações de proporções entre componentes foram diagnosticas nas questões 4 e 6 . Agora as dificuldades de associação com as quantidades de massas dos materiais foi verificada também na questão 2, sendo que o foco do problema encontrou-se na diferenciação conceitual entre os termos. Talvez, a dificuldade dos 7 alunos que não finalizaram a resolução desta questão encontre-se justifique-se na dificuldade de entendimento dos mesmos conceitos verificados na questão 2, sendo neste momento ainda relacionados com outros (proporção das substâncias), o que talvez tenha potencializada tais dificuldades.

QUESTÃO 9 - Foram realizadas algumas reações em laboratório sendo que o produto de cada uma delas foi recolhido em diferentes frascos, numerados de 1 a 4 . Considerando os dados abaixo você seria capaz de dizer quais os compostos armazenados em cada frasco?

\section{Dados:}

Bolinhas verdes: átomo de cloro $(\mathrm{Cl})$

Bolinhas cinzas pequenas: átomos de hidrogênio $(\mathrm{H})$

Bolinhas cinzas grandes: átomos de carbono $(\mathrm{C})$

Bolinhas vermelhas: átomos de oxigênio $(O)$
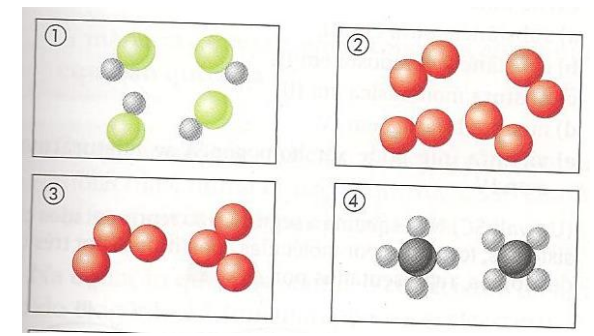

A tabela 28 apresenta, para a Questão, as decodificações criadas a partir das respostas dos alunos, as categorias criadas, as habilidades selecionadas a partir da matriz do ENEM, suscitadas pela questão para serem mobilizadas pelos estudantes e as classificações das respostas dos alunos em relação à níveis de cognições das mesmas.

Tabela 28. Categorização das respostas dos alunos referentes à questão 9 do instrumento 3.

\begin{tabular}{|c|c|c|c|c|c|c|}
\hline \multicolumn{7}{|c|}{ QUESTÃO 9 } \\
\hline Decodificadores & Categoriais & Alunos & Habilidades & \multicolumn{2}{c|}{ Respostas dos alunos } \\
\hline deixou em branco & Branco & 13 & ENEM & ALG & LOCS & HOCS \\
\hline $\begin{array}{c}\text { representação das moléculas } \\
\text { de forma correta }\end{array}$ & $\begin{array}{c}\text { Representação } \\
\text { correta das }\end{array}$ & 9 & H17/H24 & - & N2/N3 & - \\
\hline
\end{tabular}




\begin{tabular}{|c|c|c|c|c|c|c|}
\hline & moléculas & & & & & \\
\hline $\begin{array}{l}\text { não consegue associar todos os } \\
\text { símbolos às representações } \\
\text { (confusão simbólica) }\end{array}$ & \multirow{2}{*}{$\begin{array}{l}\text { Representação } \\
\text { parcialmente } \\
\text { correta das } \\
\text { moléculas }\end{array}$} & \multirow{2}{*}{19} & \multirow{2}{*}{ H17 (parcial) } & \multirow{2}{*}{-} & \multirow{2}{*}{$\mathrm{N} 2$} & \multirow{2}{*}{ - } \\
\hline $\begin{array}{c}\text { confusão entre átomos e } \\
\text { moléculas } \\
\text { reconhece os elementos mas } \\
\text { não forma as moléculas }\end{array}$ & & & & & & \\
\hline
\end{tabular}

Para melhor visualizarmos as categorias construídas e estabelecermos possíveis comparativos entre elas construímos o gráfico a seguir (Figura 37) em que relacionamos as categorias criadas com as turmas participantes do projeto.

Figura 37. Número de alunos por categorias referentes à questão 9 do instrumento 3.

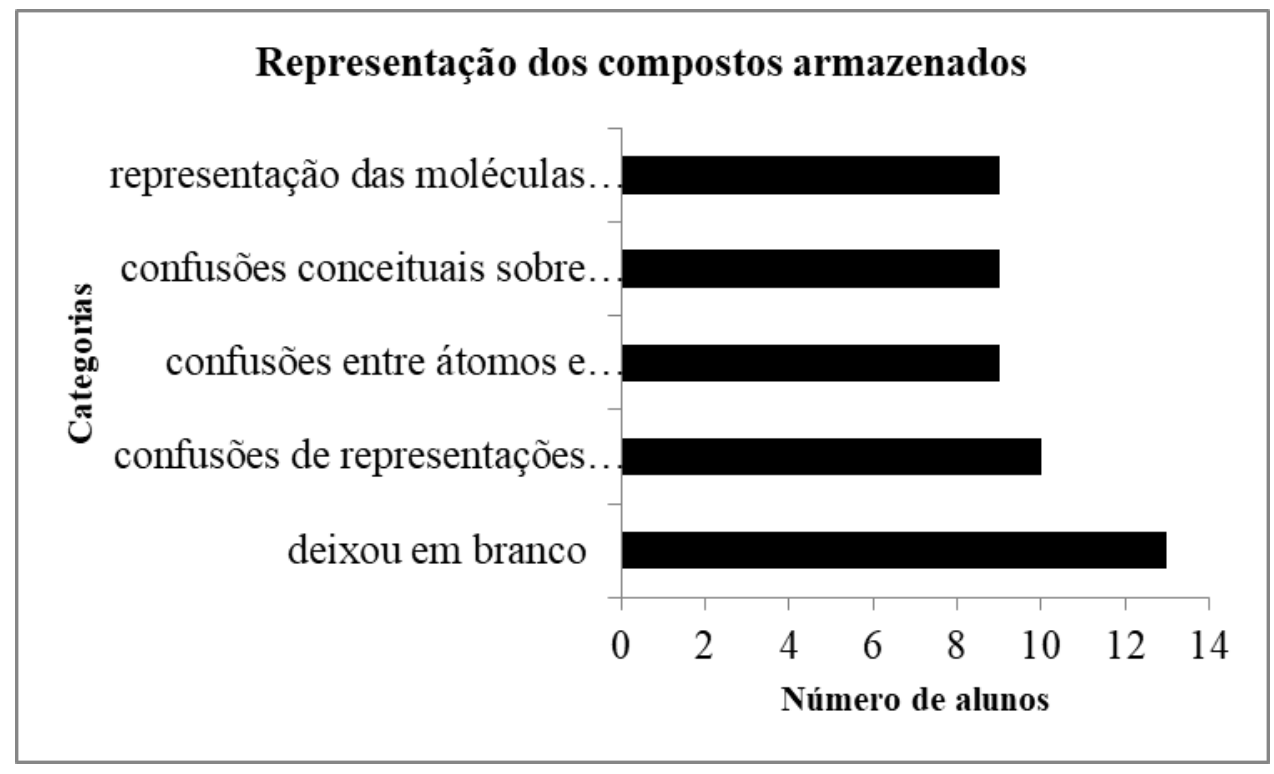

Tratou-se de uma questão que exigiu a aplicação de conceitos os quais deveriam ser relembrados. Os alunos deveriam dominar as habilidades de interpretação de uma linguagem simbólica e a utilização apropriada de códigos da química.

Praticamente um terço do total do número de alunos deixou a questão em branco. $\mathrm{O}$ outro resultado significativo observado na questão foi em relação aos alunos que não conseguiram resolver o problema proposto. De forma geral as principais dificuldades concentraram-se na utilização de forma correta dos códigos químicos e no entendimento dos conceitos de átomos e moléculas. Ou seja, muitos utilizaram símbolos para tentar representar corretamente as moléculas, mas diante das dificuldades de compreensões de conceitos microscópios ocorreram muitas confusões entre representações de átomos e moléculas. E por fim, uma pequena parcela da turma foi capaz de representar integralmente os compostos 
armazenados nos frascos, demonstrando ambas as habilidades de relacionar as informações e empregar os códigos apropriados.

QUESTÃo 10 - Devido à toxicidade do mercúrio, em caso de derramamento desse metal, costuma-se espalhar enxofre no local, para removê-lo. Mercúrio e enxofre reagem, gradativamente, formando sulfeto de mercúrio. Para fins de estudo, a reação pode ocorrer mais rapidamente se as duas substâncias forem misturadas. Usando esse procedimento, foram feitos dois experimentos, observe os dados:

\begin{tabular}{|c|c|c|c|c|}
\hline Experimentos & Mercúrio & Enxofre & $\begin{array}{c}\text { Produto } \\
\text { formado }\end{array}$ & Sobra \\
\hline I & $\mathbf{5 , 0 ~ g}$ & $\mathbf{1 , 0} \mathrm{g}$ & $\mathbf{5 , 8} \mathrm{g}$ & $\mathbf{0 , 2} \mathrm{g}$ de enxofre \\
\hline II & $\mathbf{1 2 , 0} \mathrm{g}$ & $\mathbf{1 , 6} \mathrm{g}$ & $\mathbf{1 1 , 6} \mathrm{g}$ & $\mathbf{2 , 0}$ de mercúrio \\
\hline
\end{tabular}

Mostre que os dois experimentos estão de acordo com a lei de conservação da massa (Lavoisier) e a lei das proporções definidas (Proust).

A tabela 29 apresenta, para a Questão, as decodificações criadas a partir das respostas dos alunos, as categorias criadas, as habilidades selecionadas a partir da matriz do ENEM, suscitadas pela questão para serem mobilizadas pelos estudantes e as classificações das respostas dos alunos em relação à níveis de cognições das mesmas.

Tabela 29. Categorização das respostas dos alunos referentes à questão 10 do instrumento 3.

\begin{tabular}{|c|c|c|c|c|c|c|}
\hline \multicolumn{7}{|c|}{ QUESTÃO 10} \\
\hline \multirow[t]{2}{*}{ Decodificadores } & \multirow[t]{2}{*}{ Categoriais } & \multirow[t]{2}{*}{ Alunos } & \multirow{2}{*}{$\begin{array}{c}\text { Habilidades } \\
\text { ENEM } \\
\end{array}$} & \multicolumn{3}{|c|}{ Respostas dos alunos } \\
\hline & & & & ALG & LOCS & HOCS \\
\hline deixou em branco & Branco & 34 & - & - & - & - \\
\hline $\begin{array}{c}\text { aplicação das leis e } \\
\text { entendimento da sobra do } \\
\text { material }\end{array}$ & $\begin{array}{l}\text { Demonstração esperada } \\
\text { dos experimentos }\end{array}$ & 1 & $\mathrm{H} 17 / \mathrm{H} 25$ & - & $\mathrm{N} 2 / \mathrm{N} 3$ & N4 \\
\hline $\begin{array}{l}\text { escreveu a definição de cada } \\
\text { lei }\end{array}$ & Definição das leis & 1 & H17 (parcial) & - & $\mathrm{N} 2 / \mathrm{N} 3$ & - \\
\hline $\begin{array}{c}\text { classificação de cada } \\
\text { experimento como aplicação } \\
\text { de cada uma das leis }\end{array}$ & $\begin{array}{l}\text { Classificação dos } \\
\text { experimentos como } \\
\text { aplicação das leis }\end{array}$ & 1 & H17 (parcial) & - & $\mathrm{N} 2 / \mathrm{N} 3$ & - \\
\hline $\begin{array}{c}\text { Raciocínio matemático não } \\
\text { identificado }\end{array}$ & $\begin{array}{l}\text { Raciocínio matemático } \\
\text { não identificado }\end{array}$ & 3 & - & N1 & - & - \\
\hline $\begin{array}{l}\text { verificação da proporção entre } \\
\text { os experimentos }\end{array}$ & \multirow{2}{*}{$\begin{array}{l}\text { Verificação de uma das } \\
\text { leis (conservação ou } \\
\text { proporção) }\end{array}$} & \multirow[b]{2}{*}{1} & \multirow{2}{*}{$\begin{array}{l}\mathrm{H} 17 / \mathrm{H} 25 \\
\text { (parcial) }\end{array}$} & \multirow[b]{2}{*}{-} & \multirow{2}{*}{$\mathrm{N} 2$} & \multirow{2}{*}{ N4 } \\
\hline $\begin{array}{l}\text { verificação da conservação das } \\
\text { massas }\end{array}$ & & & & & & \\
\hline
\end{tabular}


Para melhor visualizarmos as categorias construídas e estabelecermos possíveis comparativos entre elas, construímos o gráfico a seguir (Figura 38), em que relacionamos as categorias criadas com as turmas participantes do projeto.

Figura 38. Número de alunos por categorias referentes à questão 10 do instrumento 3.

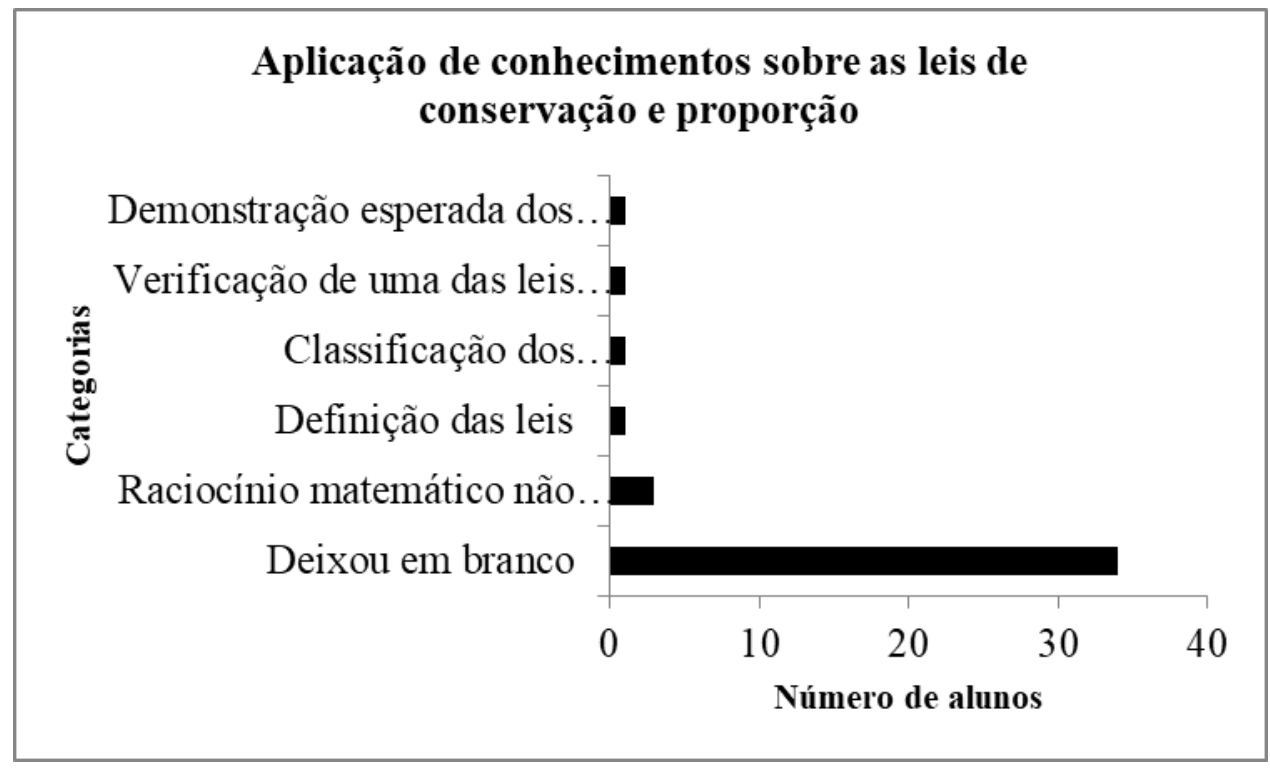

Para propor uma resolução ao problema apresentado, inicialmente os alunos deveriam compreender e relacionar as informações apresentadas na tabela da questão. $\mathrm{Ou}$ seja, precisariam visualizar a ocorrência de uma reação química, e quais as quantidades de materiais realmente envolvidas nas transformações das substâncias. Também precisariam conhecer as leis citadas, e serem capazes de aplicá-las na Situação-problema. A aplicação da lei de Lavoisier parece mais fácil, pois se trata de somar as massas antes e depois da transformação. Já aplicar a lei de Proust, é mais difícil, do ponto de vista de operações mentais, pois tem de descontar a massa em excesso, além de estabelecer a proporção entre as substâncias.

Conforme os dados descritos na figura 37 observamos que apenas um aluno (2,5\% do total do número de alunos participantes das atividades) conseguiu mobilizar todos os conhecimentos e as habilidades necessárias para a resolução do problema. Em um outro extremo visualizamos que um número grande de alunos (34 alunos) deixaram a questão em branco ( $83 \%$ do total de alunos participantes das atividades). Os demais (6 alunos) iniciaram a resolução do problema ou com proposições de definições das leis de conservação e proporção da matéria ou reconhecendo a aplicação de somente uma das leis ponderais. 
Realmente a proporção parece um problema para os alunos, como já verificamos em outras questões presentes neste instrumento (questões 4 e 8). Comparando-se esta com a quarta questão deste mesmo instrumento, em ambos os problemas foram dispostas as informações referentes às quantidades, em massa, dos materiais na forma de tabela. Também, após a leitura dos enunciados das questões os alunos deveriam ser capazes de representar as reações químicas entre os componentes. Entretanto, um diferencial desta para a questão 4, o que provavelmente influenciou de forma decisiva nas porcentagens de questões em branco em cada caso, foi que na questão 10 apareceram sobras de materiais, dificultando a resolução do problema.

QUESTÃO 11 (Fuvest (2014) - adaptada) - Amônia e gás carbônico podem reagir formando ureia e água. $O$ gráfico abaixo mostra as massas de ureia e de água que são produzidas em função da massa de amônia, considerando as reações completas. A partir dos dados do gráfico e dispondo-se de $110 \mathrm{~g}$ de amônia, qual é o valor da massa aproximada, em gramas, de gás carbônico minimamente necessário para reação completa com essa quantidade de amônia?

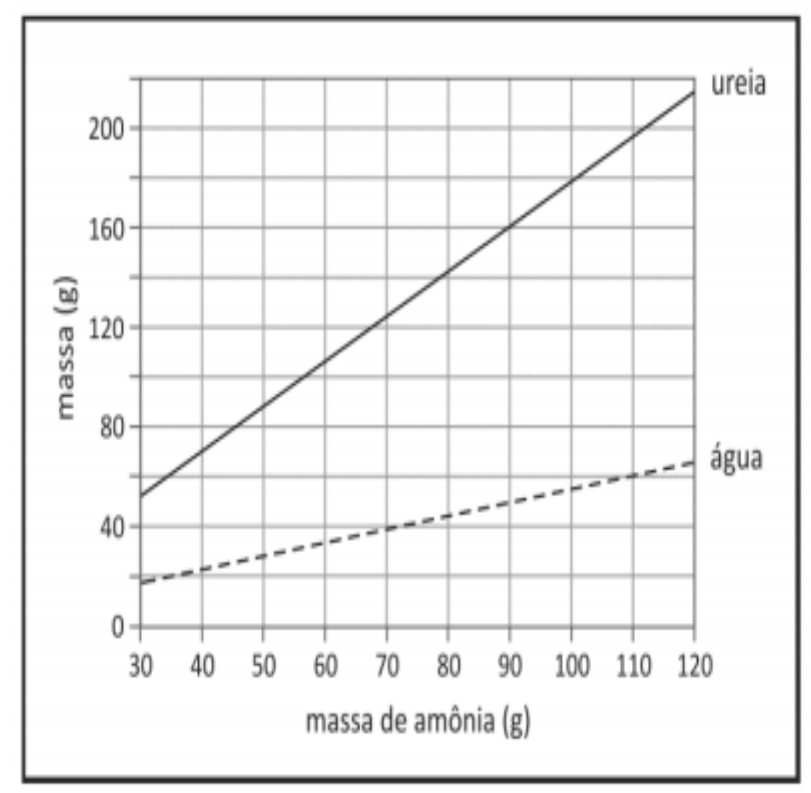

Fonte: estaticog1.globo.com/2014/vestibular/fuvest/oficina/Q75.pdf

\section{Descreva como chegou nos valores de massas.}

A tabela 30 apresenta, para a Questão, as decodificações criadas a partir das respostas dos alunos, as categorias criadas, as habilidades selecionadas a partir da matriz do 
ENEM, suscitadas pela questão para serem mobilizadas pelos estudantes e as classificações das respostas dos alunos em relação à níveis de cognições das mesmas.

Tabela 30. Categorização das respostas dos alunos referentes à questão 11 do instrumento 3.

\begin{tabular}{|l|c|c|c|c|c|c|}
\hline \multicolumn{7}{|c|}{ QUESTÃO 11 } \\
\hline \multicolumn{1}{|c|}{ Decodificadores } & Categoriais & Alunos & Habilidades & \multicolumn{2}{c|}{ Respostas dos alunos } \\
\hline Deixou em branco & Deixou em branco & 35 & - & - & - & - \\
\hline $\begin{array}{l}\text { Raciocínio matemático } \\
\text { não identificado }\end{array}$ & $\begin{array}{c}\text { Raciocínio matemático } \\
\text { não identificado }\end{array}$ & 1 & - & $\mathrm{N} 1$ & - & - \\
\hline $\begin{array}{l}\text { Cálculo das } \\
\text { quantidades de água e } \\
\text { uréia }\end{array}$ & $\begin{array}{c}\text { Cálculo das quantidades } \\
\text { de água e uréia }\end{array}$ & 2 & $\mathrm{H} 17$ & - & $\mathrm{N} 2 / \mathrm{N} 3$ & - \\
\hline $\begin{array}{l}\text { Cálculo da quantidade } \\
\text { de gás carbônico }\end{array}$ & $\begin{array}{c}\text { Cálculo esperado da } \\
\text { quantidade de gás } \\
\text { carbônico }\end{array}$ & 1 & $\mathrm{H} 17 / \mathrm{H} 25$ & - & $\mathrm{N} 2 / \mathrm{N} 3$ & $\mathrm{~N} 4$ \\
\hline $\begin{array}{l}\text { Confusão entre } \\
\text { moléculas }\end{array}$ & Confusão entre moléculas & 2 & $\mathrm{H} 17$ & - & $\mathrm{N} 2$ & - \\
\hline
\end{tabular}

Para melhor visualizarmos as categorias construídas e estabelecermos possíveis comparativos entre elas, construímos o gráfico a seguir (Figura 39), em que relacionamos as categorias criadas com as turmas participantes do projeto.

Figura 39. Número de alunos por categorias referentes à questão 11 do instrumento 3.

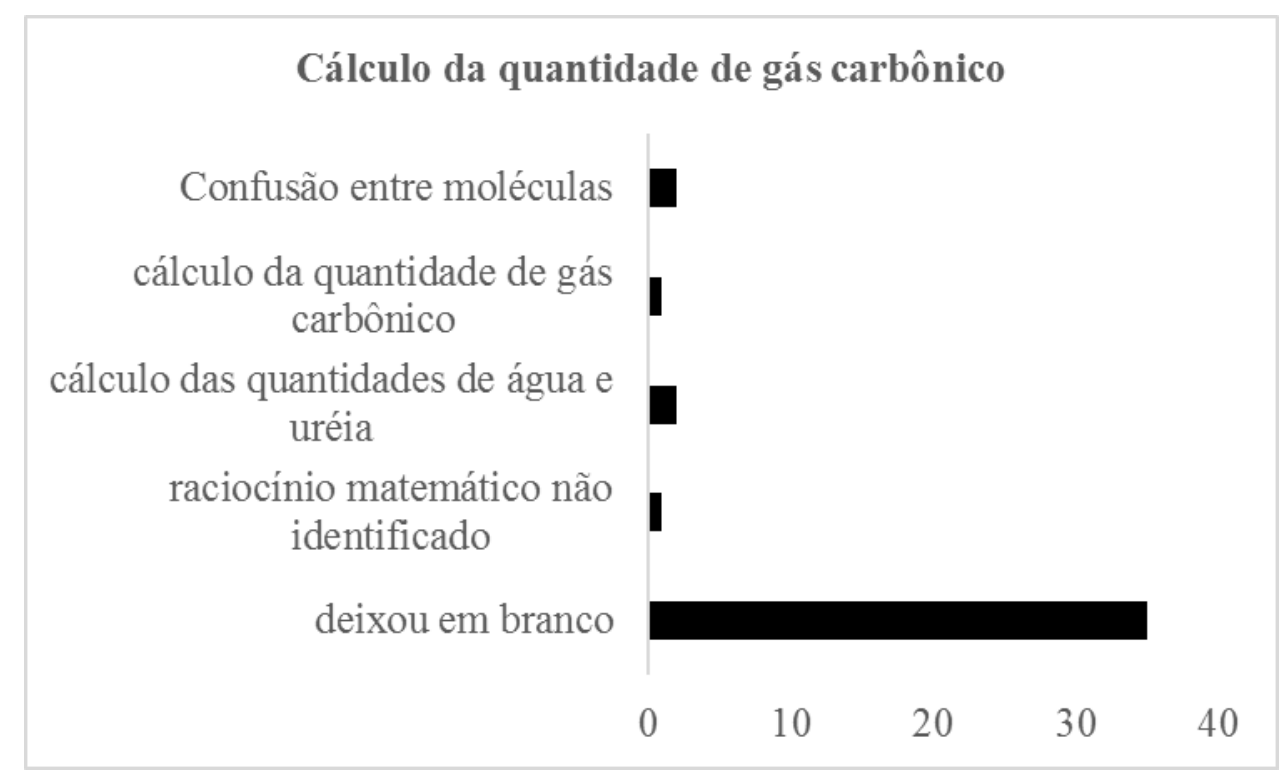

Percebemos novamente a grande dificuldade dos alunos em questões que envolvem raciocínios matemáticos e relações quantitativas da matéria. Em todas as questões do instrumento (questões 4, 6, 8 e 10) em que os alunos deveriam interpretar um gráfico, uma tabela ou descrever através de uma linguagem simbólica o que estava ocorrendo na reação 
para posterior cálculo de quantidades da matéria, foi verificada grande dificuldade por parte dos mesmos, sendo os problemas na maioria dos casos deixados em branco.

Dentre as operações necessárias para a resolução da questão estavam a representação da reação química entre os componentes, a associação e determinação das quantidades das substâncias participantes da reação a partir da quantidade conhecida de amônia (110g) e a aplicação de conhecimentos a respeito da conservação de massa das substâncias em uma transformação química que resultaria na determinação da quantidade de gás carbônico pedida. Entendemos que, nesta questão, assim como na questão 10, as dificuldades dos alunos intensificaram-se devido a associação novamente de conceitos como conservação e proporção de massa com habilidades cognitivas envolvendo a leitura e interpretação de gráficos e tabelas.

3.2.1.2. Instrumento 4 - Instrumento de coleta de dados sobre ideias iniciais a respeito de transformações químicas.

Após a aplicação de um material que serviu como diagnóstico a respeito dos conhecimentos dos alunos sobre os conceitos de transformações químicas e relações entre as quantidades de matéria, a primeira atividade da sequência problematizadora consistiu em um experimento, conforme já mencionado anteriormente e descrito no Anexo 3. Com a atividade experimental os alunos deveriam reconhecer a ocorrência de alterações sofridas pelos materiais e possíveis evidências de transformações dos mesmos. Com o intuito de verificar quais eram as concepções prévias dos alunos a respeito de transformações químicas, antes de iniciar a atividade experimental foram propostos três problemas (Anexo 4) aos mesmos. A seguir, estão descritos os resultados de análise das questões seguindo os mesmos critérios do instrumento diagnóstico. A partir deste instrumento foram selecionados 10 alunos para análise de todos os resultados obtidos, visto que os mesmos tiveram a participação em um mínimo de 11 das 13 atividades proposta em toda a Situação-problematizadora.

\section{QUESTÃo 1 - Com o passar do tempo o homem adquiriu conhecimento para manipular os materiais através de transformações químicas, mas você saberia citar uma transformação química? Justifique sua resposta.}

A tabela 31 apresenta, para a Questão, as decodificações criadas a partir das respostas dos alunos, as categorias criadas, as habilidades selecionadas a partir da matriz do 
ENEM, suscitadas pela questão para serem mobilizadas pelos estudantes e as classificações das respostas dos alunos em relação à níveis de cognições das mesmas.

Tabela 31. Categorização das respostas dos alunos referentes à questão 1 (Exemplos) do instrumento 4.

\begin{tabular}{|c|c|c|c|c|c|c|}
\hline \multicolumn{7}{|c|}{ QUESTÃO 1 - Exemplo de transformação química } \\
\hline Decodificadores & Categoriais & Alunos & Habilidades & Res! & stas dos & lunos \\
\hline & & & ENEM & ALG & LOCS & HOCS \\
\hline preparo de um bolo & \multirow{4}{*}{ Transformação de alimentos } & \multirow{4}{*}{4} & \multirow{4}{*}{$\mathrm{H} 3 / \mathrm{H} 24$} & \multirow{4}{*}{ N1 } & \multirow{4}{*}{ N2 } & \multirow{4}{*}{ - } \\
\hline cozimento de alimento & & & & & & \\
\hline $\begin{array}{l}\text { amadurecimento de uma } \\
\text { fruta }\end{array}$ & & & & & & \\
\hline fritar um ovo & & & & & & \\
\hline Oxidação & \multirow{2}{*}{ Oxidação } & \multirow{2}{*}{2} & \multirow{2}{*}{$\mathrm{H} 3 / \mathrm{H} 24$} & \multirow{2}{*}{ N1 } & \multirow{2}{*}{ N2 } & \multirow{2}{*}{-} \\
\hline enferrujamento de um prego & & & & & & \\
\hline Combustão & \multirow{4}{*}{ Combustão } & \multirow{4}{*}{4} & \multirow{4}{*}{$\mathrm{H} 3 / \mathrm{H} 24$} & \multirow{4}{*}{$\mathrm{N} 1$} & \multirow{4}{*}{$\mathrm{N} 2$} & \multirow{4}{*}{ - } \\
\hline queima em floresta & & & & & & \\
\hline queima de combustíveis & & & & & & \\
\hline $\begin{array}{l}\text { queimar uma folha de } \\
\text { caderno }\end{array}$ & & & & & & \\
\hline
\end{tabular}

Para melhor visualizarmos as categorias construídas e estabelecermos possíveis comparativos entre elas, construímos o gráfico a seguir (Figura 40), em que relacionamos as categorias criadas com as turmas participantes do projeto.

Figura 40. Número de alunos por categorias referentes à questão 1 (Exemplos) do instrumento 4.

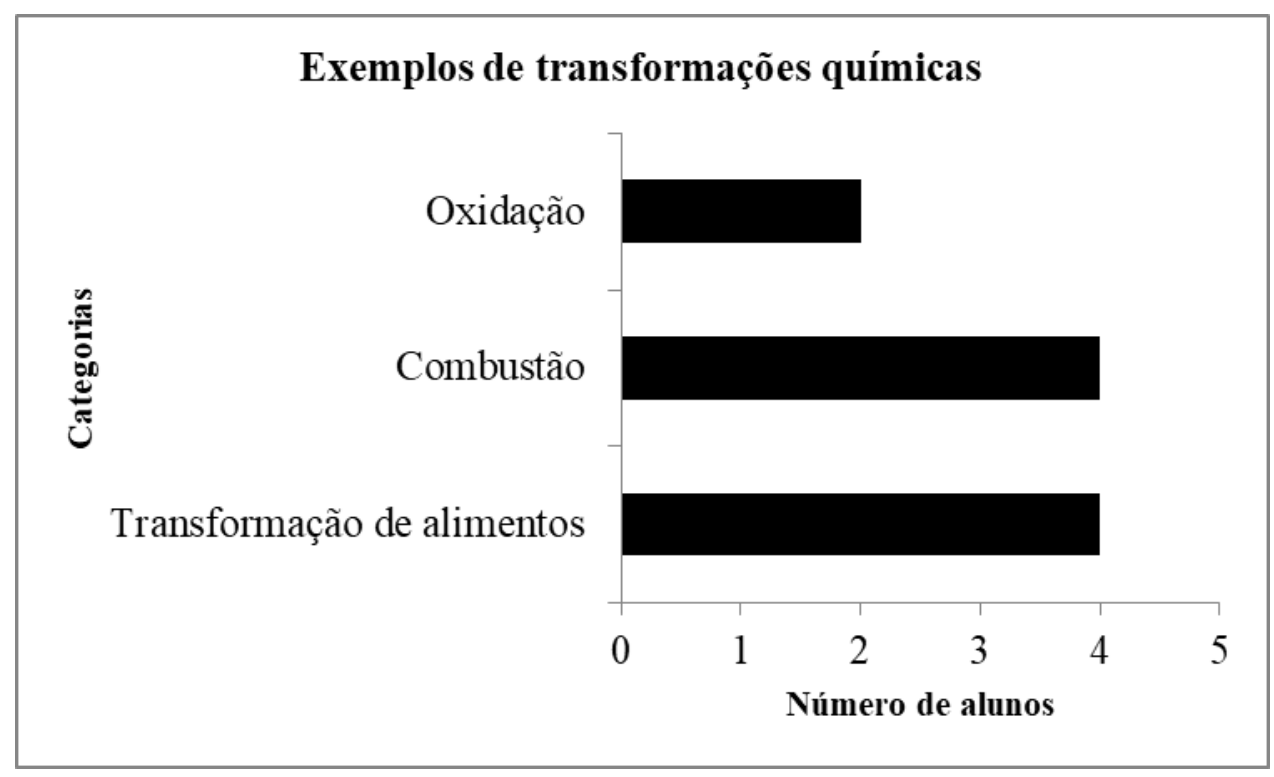


Nesta etapa da questão de certa forma todos os alunos demonstraram conhecer uma transformação química, principalmente por serem capazes de confrontar interpretações científicas com interpretações baseadas no senso comum. Muitos utilizaram os códigos de química, como oxidação e combustão como forma de expressarem seus conhecimentos. Os resultados foram agrupados em três categorias principais: Transformações de alimentos, oxidação e combustão, sendo a primeira e a última representa pela maioria dos alunos.

A tabela 32 apresenta, para a Questão, as decodificações criadas a partir das respostas dos alunos, as categorias criadas, as habilidades selecionadas a partir da matriz do ENEM, suscitadas pela questão para serem mobilizadas pelos estudantes e as classificações das respostas dos alunos em relação à níveis de cognições das mesmas.

Tabela 32. Categorização das respostas dos alunos referentes à questão 1 (Justificativas) do instrumento 4.

\begin{tabular}{|c|c|c|c|c|c|c|}
\hline \multicolumn{7}{|c|}{ QUESTÃO 1 - Justificativas } \\
\hline Decodificadores & Categoriais & Alunos & Habilidades & \multicolumn{3}{|c|}{ Respostas dos alunos } \\
\hline & & & ENEM & ALG & LOCS & HOCS \\
\hline $\begin{array}{c}\text { reação entre } 2 \text { ou }+ \text { substâncias } \\
\text { (reagentes, moléculas) resultando } \\
\text { na transformação dos reagentes em } \\
\text { produto } \\
\end{array}$ & $\begin{array}{l}\text { Transformação de } \\
\text { substâncias }\end{array}$ & 2 & H3 & N1 & - & - \\
\hline $\begin{array}{c}\text { liberação de gás carbônico e o } \\
\text { produto não volta ao seu estado } \\
\text { natural }\end{array}$ & Liberação de gás & 1 & $\mathrm{H} 3 / \mathrm{H} 24$ & N1 & $\mathrm{N} 2$ & - \\
\hline $\begin{array}{l}\text { ocorrência da dissolução de } \\
\text { substâncias }\end{array}$ & Dissolução & 1 & $\mathrm{H} 3 / \mathrm{H} 24$ & N1 & $\mathrm{N} 2$ & - \\
\hline modificação de estrutura da matéria & \multirow{4}{*}{$\begin{array}{l}\text { Reação de } 2 \\
\text { reagentes e formação } \\
\text { de produtos }\end{array}$} & \multirow{4}{*}{5} & \multirow{4}{*}{$\mathrm{H} 3 / \mathrm{H} 24$} & \multirow{4}{*}{-} & \multirow{4}{*}{ N2 } & \multirow{4}{*}{-} \\
\hline mudança nas moléculas & & & & & & \\
\hline reação entre 2 substâncias & & & & & & \\
\hline $\begin{array}{l}\text { mudança de uma ou mais } \\
\text { substâncias }\end{array}$ & & & & & & \\
\hline
\end{tabular}

Para melhor visualizarmos as categorias construídas e estabelecermos possíveis comparativos entre elas, construímos o gráfico a seguir (Figura 41), em que relacionamos as categorias criadas com as turmas participantes do projeto. 
Figura 41. Número de alunos por categorias referentes à questão 1 (Justificativas) do instrumento 4.

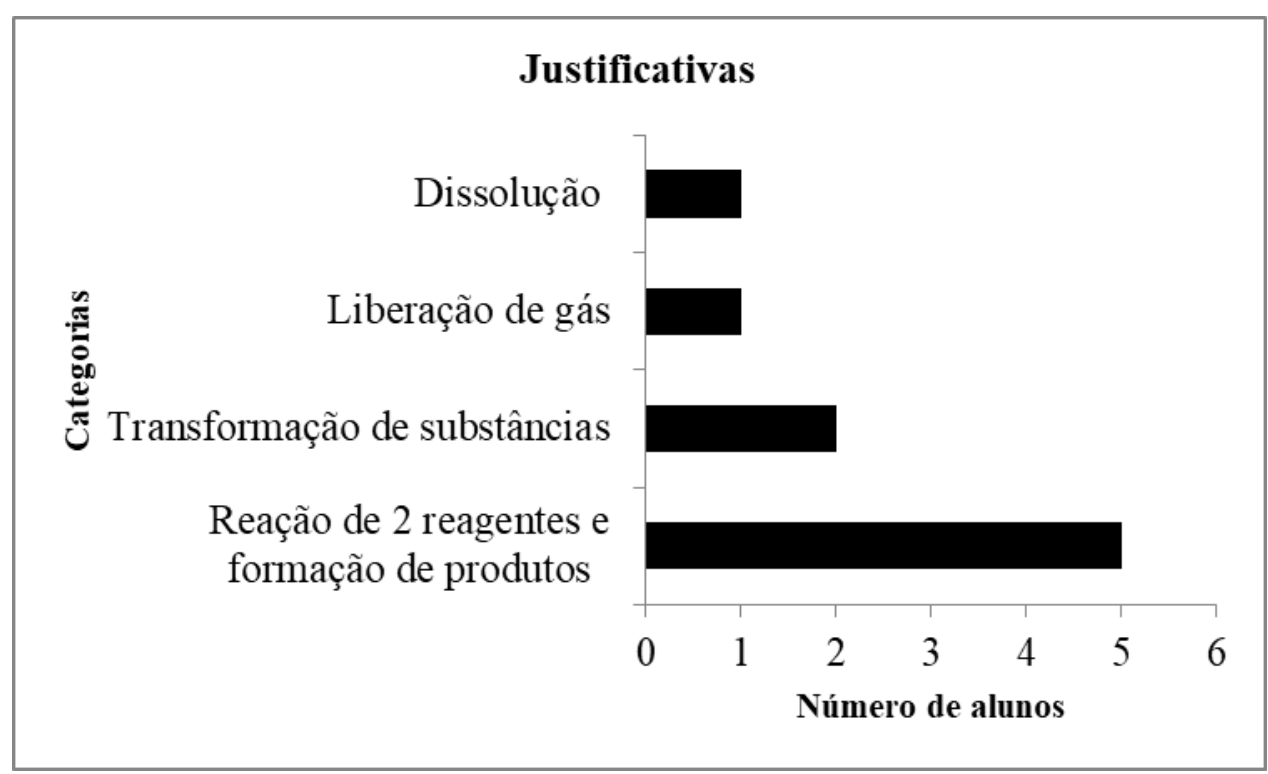

As justificativas se estabeleceram entre a ideia do que seria uma transformação e as evidências de ocorrência de uma transformação. Para maioria dos alunos ocorreu uma transformação por conta da modificação da matéria, que diante dos exemplos certamente foi observada por aspectos visuais.

De forma geral concluímos que a maior parte dos alunos reconheceu a situação apresentada, e limitaram a exposição de conceitos relembrados. Apresentaram certo conhecimento sobre a transformação da matéria, entretanto, este conhecimento se manteve nos aspectos macroscópicos do fenômeno.

QUESTÃo 2 - Num frasco estava um líquido azul identificado como solução de sulfato de cobre. Nele foi colocado um prego em bom estado e previamente lixado. No outro dia o prego foi retirado e estava com uma camada de substância sólida escura ao seu redor enquanto o líquido ficou incolor. Em sua opinião o que aconteceu? Trata-se de uma transformação química? Explique.

A tabela 33 apresenta, para a Questão, as decodificações criadas a partir das respostas dos alunos, as categorias criadas, as habilidades selecionadas a partir da matriz do ENEM, suscitadas pela questão para serem mobilizadas pelos estudantes e as classificações das respostas dos alunos em relação à níveis de cognições das mesmas. 
Tabela 33. Categorização das respostas dos alunos referentes à questão 2 do instrumento 4.

\begin{tabular}{|c|c|c|c|c|c|c|}
\hline \multicolumn{7}{|c|}{ QUESTÃO 2} \\
\hline \multirow[t]{2}{*}{ Decodificadores } & \multirow{2}{*}{ Categoriais } & \multirow{2}{*}{ Alunos } & \multirow{2}{*}{$\begin{array}{c}\text { Habilidades } \\
\text { ENEM }\end{array}$} & \multicolumn{3}{|c|}{ Respostas dos alunos } \\
\hline & & & & ALG & LOCS & HOCS \\
\hline $\begin{array}{l}\text { alteração do pH (reação do } \\
\text { líquido com o prego) }\end{array}$ & Alteração do pH & 1 & $\mathrm{H} 3$ & N1 & - & - \\
\hline $\begin{array}{l}\text { cobre se deposita no prego } \\
\text { (não há reação) }\end{array}$ & \multirow{4}{*}{$\begin{array}{c}\text { Sulfato de cobre } \\
\text { depositado/reage no prego }\end{array}$} & \multirow{4}{*}{6} & \multirow{4}{*}{$\mathrm{H} 3 / \mathrm{H} 24$} & \multirow{4}{*}{ N1 } & \multirow{4}{*}{$\mathrm{N} 2$} & \multirow{4}{*}{-} \\
\hline $\begin{array}{l}\text { líquido ao entrar em contato } \\
\text { com o prego ficou neutro }\end{array}$ & & & & & & \\
\hline $\begin{array}{c}\text { agregação/interação da } \\
\text { substância do líquido no } \\
\text { prego }\end{array}$ & & & & & & \\
\hline $\begin{array}{c}\text { fixação do sulfato de cobre no } \\
\text { prego }\end{array}$ & & & & & & \\
\hline oxidação do prego & \multirow{3}{*}{ Oxidação/Redução } & \multirow{3}{*}{6} & \multirow{3}{*}{$\mathrm{H} 3 / \mathrm{H} 24$} & \multirow{3}{*}{ N1 } & \multirow{3}{*}{$\mathrm{N} 2$} & \multirow{3}{*}{-} \\
\hline $\begin{array}{c}\text { oxidação da substância } \\
\text { líquida } \\
\end{array}$ & & & & & & \\
\hline redução do prego & & & & & & \\
\hline não há reação & Não há reação & 1 & $\mathrm{H} 3$ & N1 & - & - \\
\hline liberação de energia (queima) & Liberação de energia & 1 & $\mathrm{H} 3$ & $\mathrm{~N} 1$ & - & - \\
\hline alteração da cor & Alteração da cor & 1 & H3 & N1 & - & - \\
\hline
\end{tabular}

Para melhor visualizarmos as categorias construídas e estabelecermos possíveis comparativos entre elas, construímos o gráfico a seguir (Figura 42), em que relacionamos as categorias criadas com as turmas participantes do projeto.

Figura 42. Número de alunos por categorias referentes à questão 2 do instrumento 4.

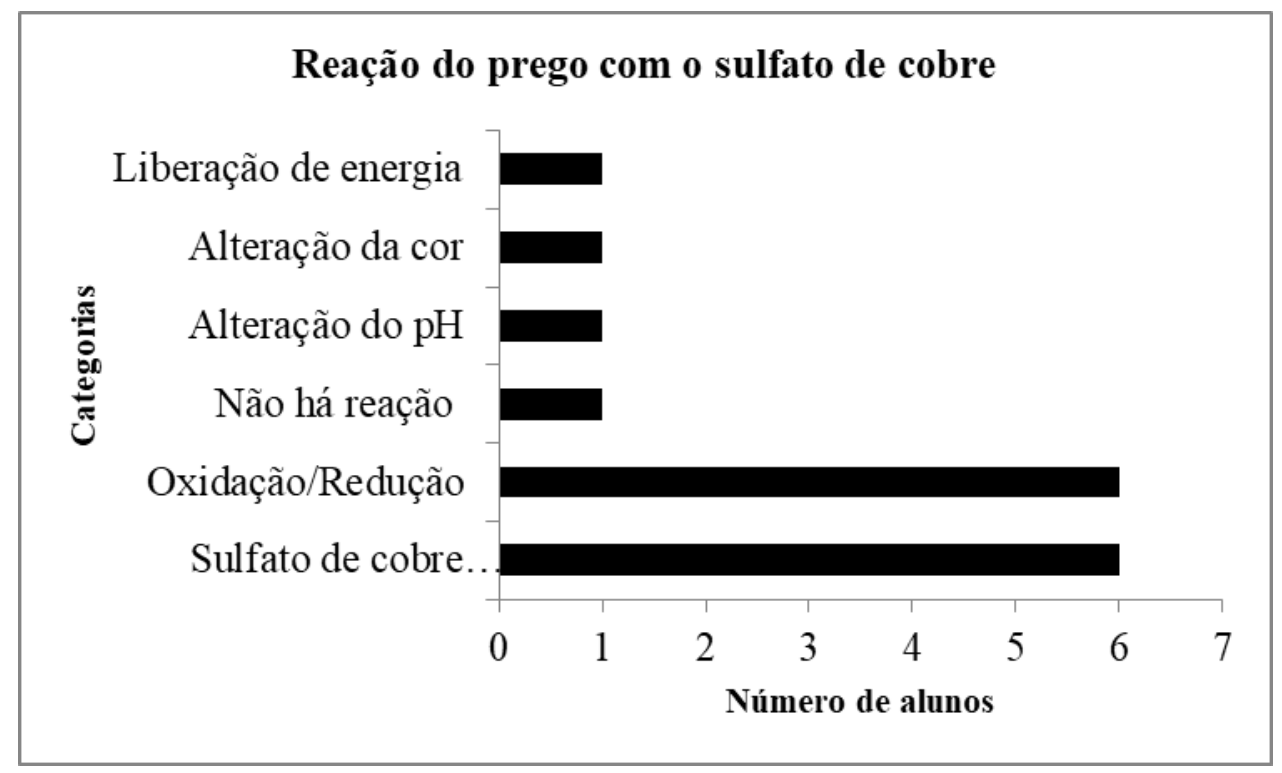

Analisando-se os resultados apresentados no gráfico (Figura 42) verificamos que praticamente todos os alunos tentaram utilizar códigos e nomenclaturas da química para 
explicar o que estava ocorrendo na interação do prego com a solução de sulfato de cobre. As respostas da maioria dos alunos se dividiram em duas categorias. Uma delas diz respeito a utilizar termos como oxidação e redução entretanto sem uma explicação conceitual, o que nos remeteu à ideia de o aluno estar utilizando um conceito apenas relembrado, sem sua compreensão. A outra foi uma justificativa da ocorrência da transformação através do depósito, do contato, da agregação, da fixação ou da interação do sulfato de cobre em relação ao prego, não ocorrendo um aprofundamento das resposta.

Através das categorias formadas verificamos indícios de que os alunos reconhecem a ocorrência da transformação química pelas evidências perceptíveis. Entretanto, não conseguem estabelecer qual o processo que está ocorrendo, isto é, qual é a transformação química, provavelmente devido as dificuldades em relação aos aspectos microscópicos da matéria. Também, a linguagem utilizada muitas vezes não se aproxima de uma linguagem científica, embora pareça uma tentativa de dar explicações ao fenômeno.

\section{QUESTÃo 3 - Com o amadurecimento da fruta vão se desenvolvendo também fatores} internos que a apodrecerão. $O$ calor, a umidade e a luz, aceleram o amadurecimento da fruta e posterior apodrecimento rápido. Ao contrário, o ar seco, a baixa temperatura e a ausência de luz retardam o amadurecimento. $O$ apodrecimento de um fruto pode ser caracterizado como um processo químico? Justifique sua resposta.

A tabela 34 apresenta, para a Questão, as decodificações criadas a partir das respostas dos alunos, as categorias criadas, as habilidades selecionadas a partir da matriz do ENEM, suscitadas pela questão para serem mobilizadas pelos estudantes e as classificações das respostas dos alunos em relação à níveis de cognições das mesmas.

Tabela 34. Categorização das respostas dos alunos referentes à questão 3 do instrumento 4.

\begin{tabular}{|c|c|c|c|c|c|c|}
\hline \multicolumn{7}{|c|}{ QUESTÃO 3} \\
\hline \multirow[t]{2}{*}{ Decodificadores } & \multirow[t]{2}{*}{ Categoriais } & \multirow[t]{2}{*}{ Alunos } & \multirow{2}{*}{$\begin{array}{c}\text { Habilidades } \\
\text { ENEM } \\
\end{array}$} & \multicolumn{3}{|c|}{ Respostas dos alunos } \\
\hline & & & & ALG & LOCS & HOCS \\
\hline alteração enzimática & Alteração enzimática & 1 & $\mathrm{H} 3$ & N1 & - & - \\
\hline $\begin{array}{l}\text { luz e água gera mudança na } \\
\text { estrutura molecular }\end{array}$ & $\begin{array}{c}\text { Alteração da estrutura } \\
\text { molecular }\end{array}$ & 1 & H3/H24 & N1 & $\mathrm{N} 2$ & - \\
\hline $\begin{array}{c}\text { troca gasosa que resulta no } \\
\text { desenvolvimento de } \\
\text { microrganismos }\end{array}$ & Microrganismos & 1 & $\mathrm{H} 3$ & N1 & - & - \\
\hline $\begin{array}{l}\text { reação do ambiente com o fruto } \\
\text { causa amadurecimento }\end{array}$ & $\begin{array}{c}\text { Reação com o } \\
\text { ambiente }\end{array}$ & 1 & $\mathrm{H} 3$ & N1 & $\mathrm{X}$ & - \\
\hline $\begin{array}{l}\text { produção/liberação de gás etileno } \\
\text { responsável pelo amadurecimento }\end{array}$ & $\begin{array}{l}\text { Liberação de gás } \\
\text { (etileno) }\end{array}$ & 4 & $\mathrm{H} 3 / \mathrm{H} 24$ & - & $\mathrm{N} 2$ & - \\
\hline ocorre transformação rápida & Transformação & 2 & H3/H24 & - & N2 & - \\
\hline
\end{tabular}


não volta ao estado inicial

Para melhor visualizarmos as categorias construídas e estabelecermos possíveis comparativos entre elas, construímos o gráfico a seguir (Figura 43), em que relacionamos as categorias criadas com as turmas participantes do projeto.

Figura 43. Número de alunos por categorias referentes à questão 3 do instrumento 4 .

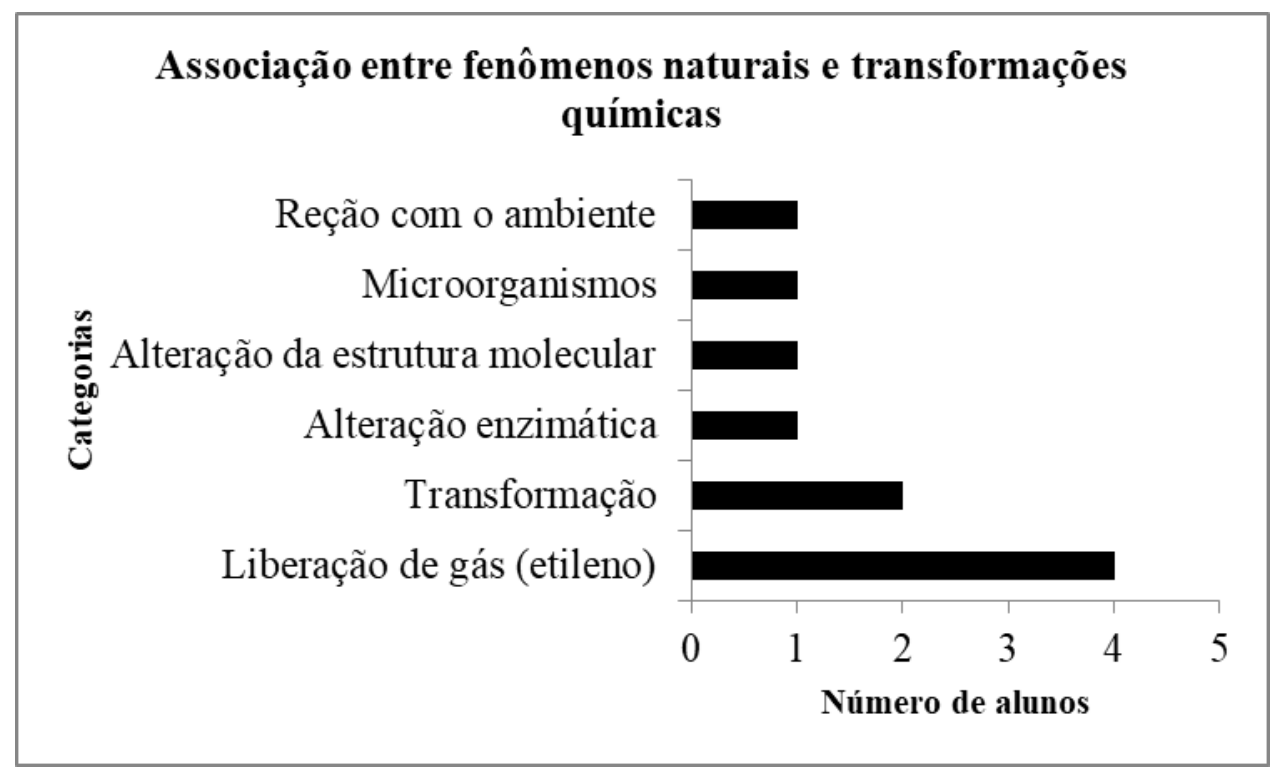

Nesta questão observamos uma evolução no entendimento da transformação química em um processo natural. Após a aplicação do instrumento piloto e antes de iniciar o instrumento seguinte, alguns alunos questionaram em aula sobre o seu desempenho no teste e entre alguns comentários iniciais tratamos sobre os processos naturais também serem entendidos como transformações químicas. Acreditamos que esta discussão inicial pode ter influenciado alguns alunos neste momento. Entretanto, três alunos demonstraram maior controle das informações, utilizando uma nomenclatura química (liberação de gás etileno) para justificar o amadurecimento da fruta. Neste momento os alunos foram capazes de explicar o problema proposto utilizando os conceitos já conhecidos com um controle na seleção de algumas informações importantes como a liberação do gás.

3.2.1.3. Instrumento 7 - Instrumento de coleta de dados sobre a síntese dos alunos a respeito de toda discussão estabelecida. 
O primeiro módulo constituinte das situações problematizadoras organizou-se por meio de um questionário diagnóstico, um instrumento cujo objetivo principal foi verificar os conhecimentos prévios dos alunos a respeitos das transformações dos materiais, da aplicação e discussão de uma atividade experimental e de uma leitura complementar a respeito de transformações químicas em fenômenos cotidianos. Após a realização de todas as atividades descritas e como forma de verificação de possíveis conhecimentos e habilidades construídas foi aplicado o instrumento 7. O objetivo principal da atividade foi verificar a capacidade dos alunos em sintetizar suas ideias a respeito de tudo que foi visto e discutido a respeitos das transformações químicas e possíveis evidências de reações. Entendemos que foi um momento fundamental pois através dos relatos dos alunos verificamos conceitos construídos e possíveis confusões conceituais que ainda prevalecem, habilidades mobilizadas e quais possíveis concepções alternativas que possam existir como dificultadoras da construção do conhecimento científico.

\section{QUESTÃo DE SÍNTESE - Pensando em tudo que foi discutido até agora, se você fosse explicar para um colega o que seria uma transformação química como você descreveria?}

A tabela 35 apresenta, para a Questão, as decodificações criadas a partir das respostas dos alunos, as categorias criadas, as habilidades selecionadas a partir da matriz do ENEM, suscitadas pela questão para serem mobilizadas pelos estudantes e as classificações das respostas dos alunos em relação à níveis de cognições das mesmas.

Tabela 35. Categorização das respostas dos alunos referentes à questão de síntese do instrumento 7.

\begin{tabular}{|c|c|c|c|c|c|c|}
\hline \multicolumn{7}{|c|}{ QUESTÃO DE SÍNTESE } \\
\hline Decodificadores & Categoriais & Alunos & Habilidades & ResI & stas dos & lunos \\
\hline & & & ENEM & ALG & LOCS & HOCS \\
\hline $\begin{array}{c}\text { reação de elementos iguais } \\
\text { e/ou diferentes }\end{array}$ & \multirow{2}{*}{$\begin{array}{c}\text { Reação entre } \\
\text { substâncias/elementos }\end{array}$} & \multirow{2}{*}{4} & \multirow{2}{*}{$\mathrm{H} 24$} & \multirow{2}{*}{-} & \multirow{2}{*}{ N2 } & \multirow{2}{*}{ - } \\
\hline $\begin{array}{l}\text { reação entre duas } \\
\text { substâncias }\end{array}$ & & & & & & \\
\hline $\begin{array}{l}\text { interação de } 1,2 \text { ou mais } \\
\text { elementos }\end{array}$ & Interação entre elementos & 3 & $\mathrm{H} 24$ & - & N2 & - \\
\hline $\begin{array}{l}\text { formação de elementos } \\
\text { diferentes do anterior }\end{array}$ & \multirow{5}{*}{$\begin{array}{c}\text { Formação de nova } \\
\text { substância/elemento }\end{array}$} & \multirow{5}{*}{7} & \multirow{5}{*}{$\mathrm{H} 24$} & \multirow{5}{*}{ - } & \multirow{5}{*}{$\mathrm{N} 2 / \mathrm{N} 3$} & \multirow{5}{*}{ - } \\
\hline $\begin{array}{l}\text { criação de um produto } \\
\text { diferente do reagente }\end{array}$ & & & & & & \\
\hline $\begin{array}{l}\text { substâncias reagem } \\
\text { formando novo produto }\end{array}$ & & & & & & \\
\hline $\begin{array}{l}\text { formação de uma nova } \\
\text { substância }\end{array}$ & & & & & & \\
\hline $\begin{array}{l}\text { produto se torna outro } \\
\text { elemento }\end{array}$ & & & & & & \\
\hline
\end{tabular}




\begin{tabular}{|c|c|c|c|c|c|c|}
\hline $\begin{array}{c}\text { não altera a composição } \\
\text { molecular }\end{array}$ & \multirow{2}{*}{$\begin{array}{l}\text { Alteração da composição } \\
\text { molecular }\end{array}$} & \multirow{2}{*}{2} & \multirow{2}{*}{$\mathrm{H} 24$} & \multirow{2}{*}{-} & \multirow{2}{*}{ N2 } & \multirow{2}{*}{-} \\
\hline $\begin{array}{c}\text { análise da estrutura } \\
\text { molecular }\end{array}$ & & & & & & \\
\hline pode ou não ser visível & \multirow{2}{*}{$\begin{array}{l}\text { Contém ou não evidências de } \\
\text { reação }\end{array}$} & \multirow{2}{*}{4} & \multirow{2}{*}{$\mathrm{H} 24$} & \multirow{2}{*}{-} & \multirow{2}{*}{$\mathrm{N} 2$} & \multirow[b]{2}{*}{-} \\
\hline $\begin{array}{c}\text { pode ou não apresentar } \\
\text { evidências }\end{array}$ & & & & & & \\
\hline
\end{tabular}

Para melhor visualizarmos as categorias construídas e estabelecermos possíveis comparativos entre elas, construímos o gráfico a seguir (Figura 44), em que relacionamos as categorias criadas com as turmas participantes do projeto.

Figura 44. Número de alunos por categorias referentes à questão de síntese do instrumento 7.

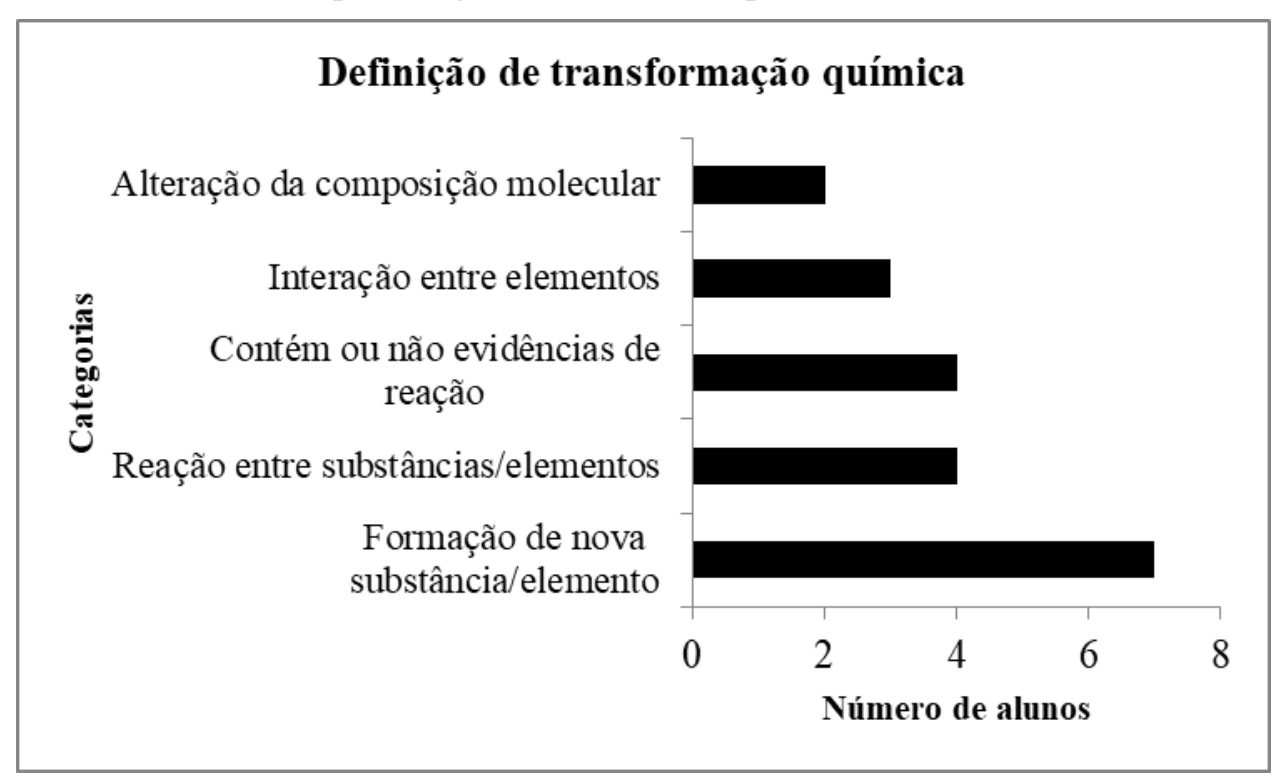

Observando as categorias construídas (figura 44) de maneira geral todos os alunos pareceram compreender o que estava sendo pedido, ou seja, a realização de uma síntese sobre o conceito de transformação química. Os diferentes agrupamentos ocorreram como consequência do nível de aprofundamento nas descrições realizadas pelos alunos.

Em relação a forma como se expressaram, observamos na maior parte das respostas a ocorrência do uso de linguagem de forma inapropriada ou incompleta. Observamos que nas duas primeiras categorias, "Reação entre substâncias/elementos" e "Interação entre elementos", os alunos utilizaram em suas explicações palavras como elementos talvez com a pretensão de dar o significado de substância. Nas demais categorias observamos algumas ideias associadas às transformações, tais como: ter ou não evidência perceptível, mudança na estrutura molecular, formação de nova substância. Tanto na categoria em que houve maior representatividade por parte dos alunos, "formação de nova substância/elemento" (7 alunos) 
quanto na categoria "ter ou não evidência perceptível" (4 alunos) verificamos uma limitação na definição de uma transformação química sob o ponto de vista de aspectos macroscópicos, ou seja, através de evidências da ocorrência da reação que resultou na formação de uma nova substância. Apenas 2 alunos tentaram ampliar as definições do fenômeno para uma reflexão de aspectos microscópicos da matéria entretanto inadequadamente, relando por exemplo que em uma transformação não há alteração na composição da molécula.

Não somente neste momento, assim como de forma geral, conhecer concepções alternativas que podem estar presentes na estrutura cognitiva dos estudantes podem auxiliar o professor no processo de construção de conhecimentos. Especificamente neste momento, ou seja, de encerramento de módulo, entender quais concepções alternativas podem estar influenciando a aprendizagem do aluno deverá ser importante como construção do conceito de transformação química.

Diversas pesquisas relatam concepções alternativas no entendimento de transformações químicas. Em um de seus trabalhos Anderson (1986, p.551-555) apresentou um conjunto de tais concepções:

"É como é": não há interesse em buscar explicações para o fenômeno, aceitando simplesmente que as coisas são, como são.

- Deslocamento: acredita-se que, na transformação química a substância apenas se desloca, mudando de meio ou de sistema, se separando ou se misturando.

- Modificação: segundo essa concepção, a substância produzida é a mesma substância inicial, com alterações em suas propriedades.

- Transmutação: de acordo com essa concepção, ocorre a transformação de matéria em energia ou de energia em matéria. Pode também ocorrer a transformação de um elemento químico em outro.

Encontramos em nossas três primeiras categorias justamente a ideia de transmutação apresentada pelo autor. Como por exemplo, alguns alunos descrevem como transformação a "interação/reação entre elementos iguais ou diferentes", outros relatam que transformações consiste na "formação de elementos diferentes do anterior" e também que "produto se torna outro elemento".

Esta certamente é uma questão em que os alunos deveriam expressar níveis cognitivos de respostas elevados. Trata-se de uma questão em que os alunos deveriam expressar seus conhecimentos construídos após participarem de um módulo inteiro da sequência de ensino (módulo 1). Ou seja, foram construídos conhecimentos sobre Transformação química da matéria” . 
3.2.1.4. Instrumento 9 - Reflexões sobre a Lei de Conservação das massas estabelecida por Lavoisier.

Com a finalização do primeiro módulo da sequência de ensino referente a construção conceitual sobre transformações dos compostos, a etapa seguinte tinha por objetivo principal desenvolver atividades que pudessem contribuir com o desenvolvimento cognitivo e conceitual dos alunos a respeito da conservação dos materiais envolvidos em uma transformação química.

A primeira atividade constituinte do segundo módulo referiu-se a um experimento em que os alunos deveriam investigar o que ocorreu com as massas totais antes e após determinadas reações químicas, sendo que os fenômenos foram observados em sistemas aberto e fechado. Após a finalização da atividade, os grupos se reuniram em um discussão em sala de aula com o propósito de apresentar o que foi observado e possíveis conclusões obtidas. Ao final das discussões, os alunos apresentavam a percepção da conservação das massas dos materiais durante as reações independentemente do tipo de sistema em que as mesmas foram realizadas.

$\mathrm{Na}$ aula seguinte, a professora trouxe para as turmas dois problemas, tratando-se justamente do material organizado no presente questionário (instrumento 9), contendo dados obtidos de forma experimental, sendo o objetivo principal observar possíveis habilidades dos alunos em relacionar a conservação das massas nas transformações químicas das situações apresentadas. E por fim, os alunos deveriam novamente construir a síntese de todo conhecimento construído até este momento das atividades. Para estimular o trabalho dos alunos foram deixados alguns termos chaves a respeito dos conceitos construídos até o momento.

QUESTÃO 1 - O carvão é constituído basicamente de carbono $(C)$, sendo o restante formado por materiais orgânicos não decompostos na carbonização da madeira. Na combustão do carvão, o carbono interage com o oxigênio do ar formando principalmente o gás carbônico. Observe o resultado de três experimentos e combustão do carvão que foram realizados em recipiente fechado e que as massas medidas foram aquelas apresentadas a seguir:

\begin{tabular}{|c|c|c|c|}
\hline Amostra & $\begin{array}{c}\text { Massas iniciais dos } \\
\text { reagentes } \\
\text { (valores em gramas) }\end{array}$ & $\begin{array}{c}\text { Massas iniciais dos } \\
\text { reagentes } \\
\text { (valores em gramas) }\end{array}$ & $\begin{array}{c}\text { Energia } \\
\text { liberada } \\
\text { (Kcal) }\end{array}$ \\
\hline
\end{tabular}




\begin{tabular}{|c|c|c|c|c|c|}
\hline & $\begin{array}{c}\text { Carvão } \\
(\mathbf{C})\end{array}$ & $\begin{array}{c}\text { Gás } \\
\text { oxigênio } \\
\left(\mathbf{O}_{2}\right)\end{array}$ & $\begin{array}{c}\text { Dióxido de } \\
\text { carbono } \\
\left(\mathbf{C O}_{2}\right)\end{array}$ & Cinzas & \\
\hline I & 150 & 320 & 442 & 31 & 1020 \\
\hline II & 60 & 128 & 172 & 12 & 410 \\
\hline III & 23 & 48 & 66 & 5 & 156 \\
\hline
\end{tabular}

Comparando as quantidades dos reagentes em relação às quantidades dos produtos em cada um dos casos, é possível dizer que a massa do sistema inicial permaneceu a mesma depois da combustão do carvão? Se não, a que pode ser atribuída essa diferença?

A tabela 36 apresenta, para a Questão, as decodificações criadas a partir das respostas dos alunos, as categorias criadas, as habilidades selecionadas a partir da matriz do ENEM, suscitadas pela questão para serem mobilizadas pelos estudantes e as classificações das respostas dos alunos em relação à níveis de cognições das mesmas.

Tabela 36. Categorização das respostas dos alunos referentes à questão 1 do instrumento 9.

\begin{tabular}{|c|c|c|c|c|c|c|}
\hline \multicolumn{7}{|c|}{ QUESTÃO 1} \\
\hline Decodificadores & Categoriais & Alunos & Habilidades & & stas do & unos \\
\hline & & & ENEM & ALG & LOCS & HOCS \\
\hline falta de um reagente & \multirow{3}{*}{ Falta de reagentes } & \multirow{3}{*}{4} & \multirow{3}{*}{$\begin{array}{c}\mathrm{H} 8 / \mathrm{H} 17 \mathrm{e} \\
\mathrm{H} 25 \text { (parcial) }\end{array}$} & \multirow{3}{*}{-} & \multirow{3}{*}{$\mathrm{N} 2$} & \multirow{3}{*}{-} \\
\hline $\begin{array}{c}\text { falta de um reagente } \\
\text { limitante }\end{array}$ & & & & & & \\
\hline $\begin{array}{l}\text { diferentes proporções de } \\
\text { reagentes }\end{array}$ & & & & & & \\
\hline formação de produto & $\begin{array}{l}\text { Formação de } \\
\text { produtos }\end{array}$ & 1 & $\begin{array}{c}\mathrm{H} 8 / \mathrm{H} 17 \mathrm{e} \\
\mathrm{H} 25 \text { (parcial) }\end{array}$ & - & N2 & - \\
\hline $\begin{array}{l}\text { oxigênio total não } \\
\text { contabilizado }\end{array}$ & \multirow{4}{*}{$\begin{array}{c}\text { Materiais não foram } \\
\text { totalmente } \\
\text { contabilizados }\end{array}$} & \multirow{4}{*}{4} & \multirow{4}{*}{$\begin{array}{c}\mathrm{H} 8 / \mathrm{H} 17 \mathrm{e} \\
\mathrm{H} 25 \text { (parcial) }\end{array}$} & \multirow{4}{*}{-} & \multirow{4}{*}{$\mathrm{N} 2$} & \multirow{4}{*}{-} \\
\hline $\begin{array}{l}\text { carvão com compostos } \\
\text { não contabilizados }\end{array}$ & & & & & & \\
\hline $\begin{array}{l}\text { cinzas com compostos } \\
\text { não contabilizados }\end{array}$ & & & & & & \\
\hline concentração de gases & & & & & & \\
\hline energia liberada & $\begin{array}{l}\text { Energia liberada } \\
\text { responsável pela } \\
\text { diferença }\end{array}$ & 2 & $\begin{array}{c}\mathrm{H} 8 / \mathrm{H} 17 \mathrm{e} \\
\mathrm{H} 25 \text { (parcial) }\end{array}$ & - & N2 & - \\
\hline
\end{tabular}

Para melhor visualizarmos as categorias construídas e estabelecermos possíveis comparativos entre elas, construímos o gráfico a seguir (Figura 45), em que relacionamos as categorias criadas com as turmas participantes do projeto. 
Figura 45. Número de alunos por categorias referentes à questão 1 do instrumento 9.

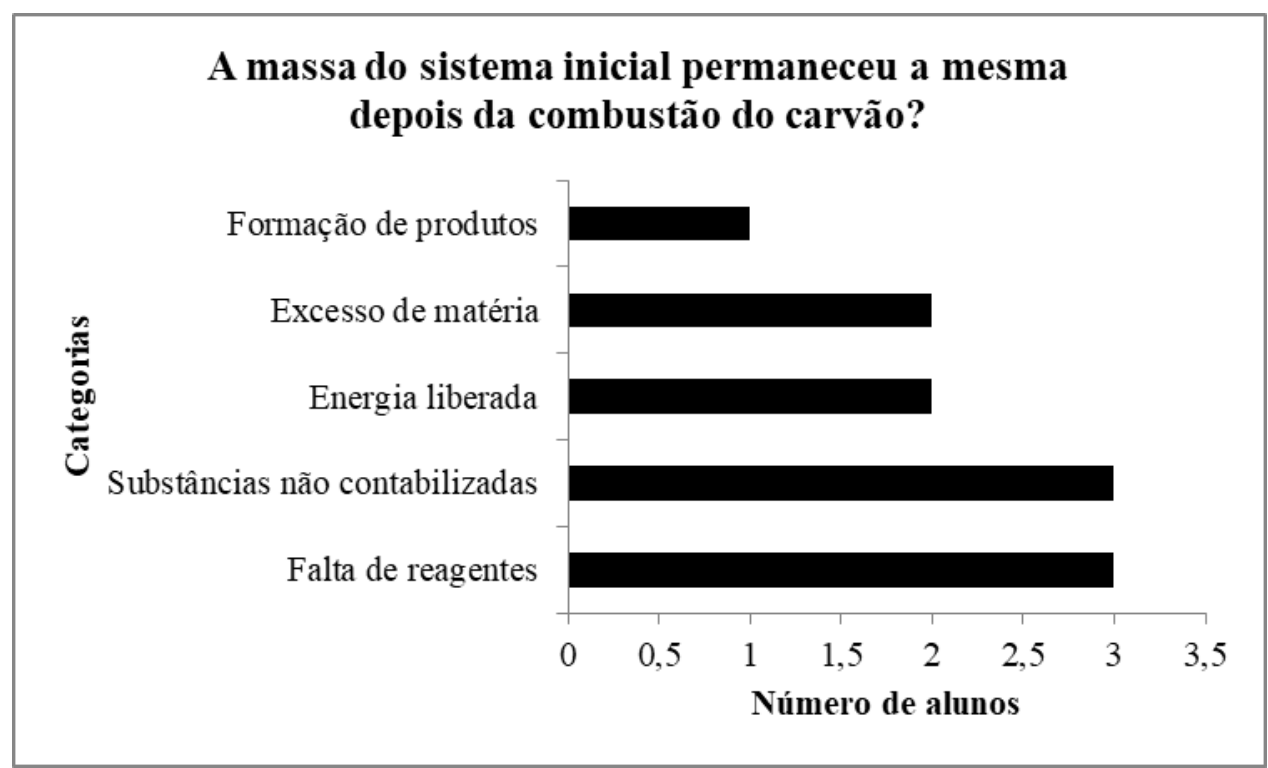

Talvez este tenha sido o momento de toda a sequência de atividades em que os alunos apresentaram maior número de dúvidas e indagações a respeito do problema que lhes foi proposto. Assim que eles receberam a atividade, se organizaram em grupos e tiveram algum tempo para pensar e analisar a questão. Muitos deles demandaram a mediação da professora, tentaram levantar diversas hipóteses e questionamentos. De imediato, ao iniciarem as reflexões de como explicar os possíveis resultados apresentados na tabela, os alunos tentaram verificar se estava ocorrendo a conservação das quantidades dos materiais no decorrer das transformações. Dentro os 9 alunos participantes, 6 deles afirmaram que as massas não permaneceram as mesmas após a combustão e o restante ( 3 alunos) respondeu que em uma delas houve a conservação das massas. Acompanhando as discussões estabelecidas pelos alunos em sala de aula, entendemos que aqueles que reconheceram a conservação das quantidades dos materiais em uma das amostras referiram-se a terceira amostra em que as massa iniciais e finais são idênticas.

Entretanto, observando as justificativas escritas nos materiais de todos os alunos concluímos que, provavelmente, não refletiram a respeito das outras duas amostras que apresentaram uma pequena diferença de massas entre os sistemas. Tais justificativas fundamentam-se nas categorias criadas, ou seja, os alunos mencionam a energia como responsável pela diferença, a falta de reagentes, a formação de produtos e alguns materiais que não foram totalmente contabilizados, como gás oxigênio, carvão ou cinzas (conforme descritos por alguns alunos). 
Diante das dificuldades apresentadas pelos alunos para a resolução desta questão, na aula seguinte a esta, antes de iniciar a atividade de síntese do conteúdo (Instrumento 10), a professora propôs uma discussão e resolução do exercício aplicado na aula anterior. Dentre as dificuldades apresentadas, os alunos não conseguiram resolver o problema principalmente porque não conseguiram perceber que a razão pela qual as massas das substâncias se aproximavam mas tinham uma pequena diferença tratava-se de um erro experimental, ou seja, de medida. Ao longo das discussões a professora primeiramente chamou a atenção dos alunos à conservação das quantidades dos materiais na terceira amostra e a pequena variação de medidas nas outras amostras. A partir desta verificação a professora convida os alunos à uma reflexão a respeito da relação das quantidades dos materiais dentro de uma mesma amostra e em comparação às outras. Por exemplo, como alguns alunos relataram ser a energia a responsável pela não conservação das massas, na discussão a professora comentou que na queima do carvão foi produzida uma quantidade de energia, estabelecendo-se uma relação de proporção em cada um dos testes. Com a comparação entre as relações estabelecidas os alunos encontraram valores de medidas muito próximos. Ao final das discussões os alunos entenderam que existência de tais relações entre os componentes de mantiveram devido a aplicação da lei de conservação da massas descritas por Lavoisier.

QUESTÃO 2 - O responsável técnico de um forno de calcinação de calcário elaborou um relatório sobre as três últimas tiragens da produção de cal. $O$ relatório apresenta a seguinte tabela:

\begin{tabular}{|l|l|l|l|}
\hline Amostras & \multicolumn{1}{|c|}{$\begin{array}{c}\text { Massa de calcário }(\mathrm{t}) \\
\left(\mathrm{CaCO}_{3}\right)\end{array}$} & $\begin{array}{c}\text { Massa de cal }(\mathrm{t}) \\
(\mathrm{CaO})\end{array}$ & $\begin{array}{c}\text { Massa de } \\
\text { dióxido de carbono }(\mathrm{t}) \\
\left(\mathrm{CO}_{2}\right)\end{array}$ \\
\hline $12 / 7$ & 10,0 & 5,6 & 4,4 \\
\hline $15 / 7$ & & 11,2 & \\
\hline $18 / 7$ & 12,0 & 6,7 & \\
\hline
\end{tabular}

Como se pode perceber, faltaram dados da massa de calcário usado no dia 15/7 e da massa de dióxido de carbono formado nos dias 15/7 e 18/7.

a) Identifique quais são os reagentes e produtos nesse processo.

b) Sabendo-se que a calcinação do carbonato de cálcio envolve o consumo de energia, proponha uma equação química que represente a calcinação do calcário e inclua o termo "energia" na equação. 


\section{c) Determine os valores que faltam na tabela e complete-as. Mostre os cálculos realizados.}

A tabela 37 apresenta, para a Questão, as decodificações criadas a partir das respostas dos alunos, as categorias criadas, as habilidades selecionadas a partir da matriz do ENEM, suscitadas pela questão para serem mobilizadas pelos estudantes e as classificações das respostas dos alunos em relação à níveis de cognições das mesmas.

Tabela 37. Categorização das respostas dos alunos referentes à questão 2 (A) do instrumento 9.

\begin{tabular}{|c|c|c|c|c|c|c|}
\hline \multicolumn{7}{|c|}{ QUESTÃO 2 - Identificação de reagentes e produtos } \\
\hline \multirow[t]{2}{*}{ Decodificadores } & Categoriais & Alunos & Habilidades & \multicolumn{3}{|c|}{ Respostas dos alunos } \\
\hline & & & ENEM & ALG & LOCS & HOCS \\
\hline reagente - calcário & \multirow{3}{*}{$\begin{array}{c}\text { representação correta } \\
\text { dos reagentes/produtos }\end{array}$} & \multirow{3}{*}{5} & \multirow{3}{*}{$\mathrm{H} 17 / \mathrm{H} 24$} & \multirow{3}{*}{ - } & \multirow{3}{*}{$\mathrm{N} 2 / \mathrm{N} 3$} & \multirow{3}{*}{-} \\
\hline produto - cal & & & & & & \\
\hline $\begin{array}{l}\text { produto - dióxido de } \\
\text { carbono }\end{array}$ & & & & & & \\
\hline reagente - cal & \multirow{2}{*}{$\begin{array}{l}\text { confusão entre } \\
\text { reagentes/produtos }\end{array}$} & \multirow[b]{2}{*}{2} & \multirow{2}{*}{$\begin{array}{c}\mathrm{H} 17 \text { (parcial) } / \mathrm{H} \\
24\end{array}$} & \multirow[b]{2}{*}{-} & \multirow[b]{2}{*}{$\mathrm{N} 2$} & \multirow[b]{2}{*}{-} \\
\hline $\begin{array}{l}\text { Reconheceu só os } \\
\text { produtos }\end{array}$ & & & & & & \\
\hline $\begin{array}{l}\text { representação da reação } \\
\text { química corretamente }\end{array}$ & $\begin{array}{l}\text { representação da } \\
\text { equação química }\end{array}$ & 2 & H17 & - & $\mathrm{N} 2$ & - \\
\hline deixou em branco & deixou em branco & 1 & - & - & - & - \\
\hline
\end{tabular}

Para melhor visualizarmos as categorias construídas e estabelecermos possíveis comparativos entre elas, construímos o gráfico a seguir (Figura 46), em que relacionamos as categorias criadas com as turmas participantes do projeto.

Figura 46. Número de alunos por categorias referentes à questão 2 (A) do instrumento 9.

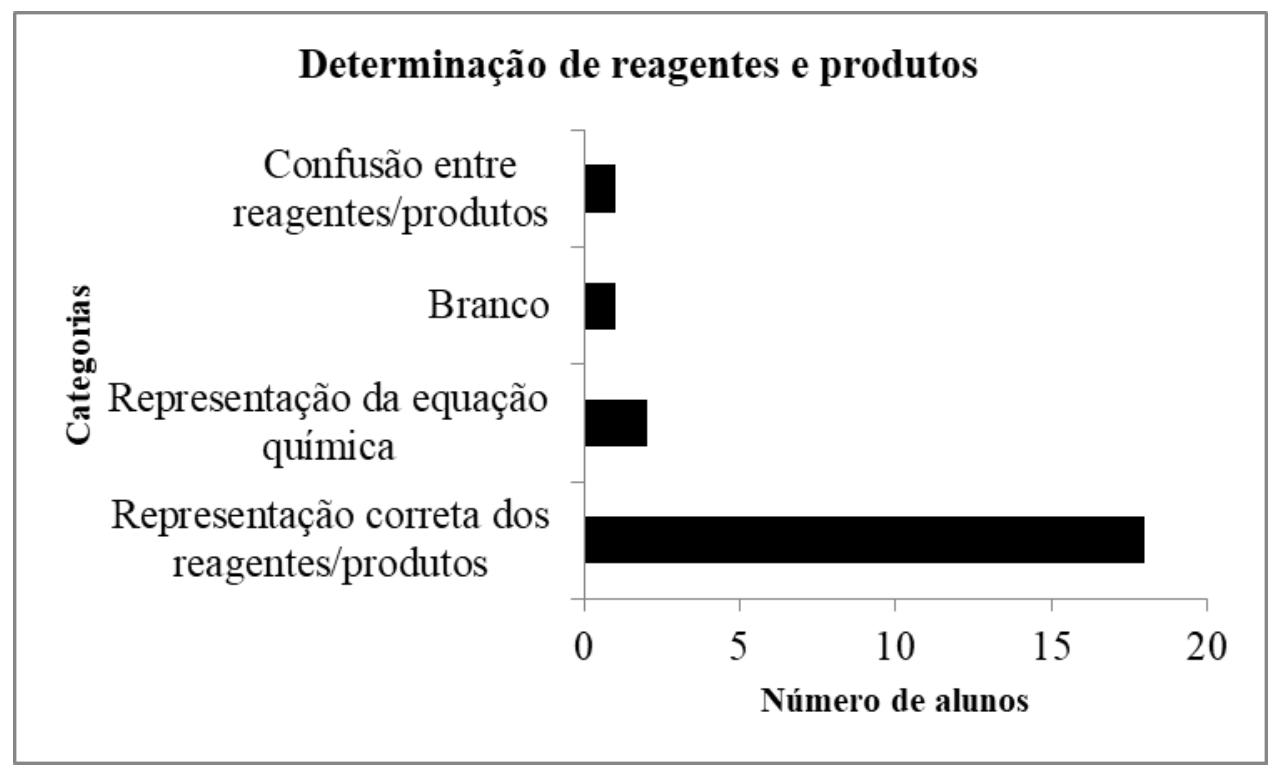


A tabela 38 apresenta, para a Questão 2 (item b), as decodificações criadas a partir das respostas dos alunos, as categorias criadas, as habilidades selecionadas a partir da matriz do ENEM, suscitadas pela questão para serem mobilizadas pelos estudantes e as classificações das respostas dos alunos em relação à níveis de cognições das mesmas.

Tabela 38. Número de alunos categorias referentes à questão 2 (B) do instrumento 9.

\begin{tabular}{|c|c|c|c|c|c|c|}
\hline \multicolumn{7}{|c|}{ QUESTÃO 2 - Representação da equação química } \\
\hline Decodificadores & Categoriais & Alunos & Habilidades & \multicolumn{3}{|c|}{ Respostas dos alunos } \\
\hline & & & ENEM & ALG & LOCS & HOCS \\
\hline $\begin{array}{l}\text { representação correta da } \\
\text { equação química }\end{array}$ & \multirow{2}{*}{$\begin{array}{c}\text { representação } \\
\text { correta da equação } \\
\text { química }\end{array}$} & \multirow{2}{*}{9} & \multirow{2}{*}{$\mathrm{H} 17 / \mathrm{H} 24$} & \multirow{2}{*}{ - } & \multirow{2}{*}{$\mathrm{N} 2 / \mathrm{N} 3$} & \multirow{2}{*}{ - } \\
\hline $\begin{array}{c}\text { representação correta da } \\
\text { energia }\end{array}$ & & & & & & \\
\hline deixou em branco & deixou em branco & 1 & - & - & - & - \\
\hline
\end{tabular}

Para melhor visualizarmos as categorias construídas e estabelecermos possíveis comparativos entre elas construímos o gráfico a seguir (Figura 47) em que relacionamos as categorias criadas com as turmas participantes do projeto.

Figura 47. Número de alunos por categorias referentes à questão 2 (B) do instrumento 9.

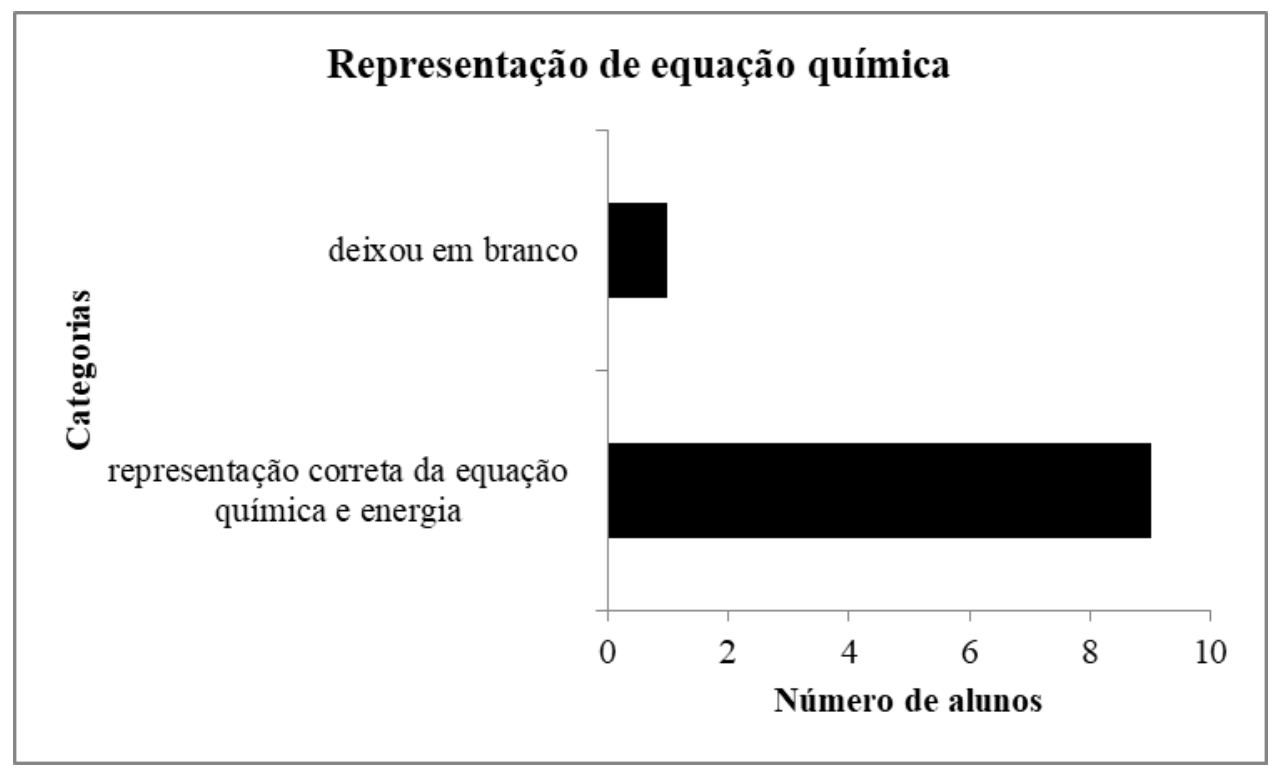

A tabela 39 apresenta, para a Questão, as decodificações criadas a partir das respostas dos alunos, as categorias criadas, as habilidades selecionadas a partir da matriz do ENEM, suscitadas pela questão para serem mobilizadas pelos estudantes e as classificações das respostas dos alunos em relação à níveis de cognições das mesmas. 
Tabela 39. Categorização das respostas dos alunos referentes à questão 2 (C) do instrumento 9.

\begin{tabular}{|c|c|c|c|c|c|c|}
\hline \multicolumn{7}{|c|}{ QUESTÃO 2 - Cálculos de Massa } \\
\hline Decodificadores & Categoriais & Alunos & Habilidades & & stas dos & unos \\
\hline & & & ENEM & ALG & LOCS & HOCS \\
\hline $\begin{array}{c}\text { cálculo correto de todos os } \\
\text { valores }\end{array}$ & \multirow{3}{*}{$\begin{array}{l}\text { Obtenção dos } \\
\text { valores corretos }\end{array}$} & \multirow{3}{*}{5} & \multirow{3}{*}{$\mathrm{H} 17 / \mathrm{H} 25$} & \multirow{3}{*}{-} & \multirow{3}{*}{$\mathrm{N} 2 / \mathrm{N} 3$} & \multirow{3}{*}{ N4 } \\
\hline $\begin{array}{l}\text { verificação da proporção entre } \\
\text { as amostras }\end{array}$ & & & & & & \\
\hline $\begin{array}{l}\text { verificação da conservação } \\
\text { das massas }\end{array}$ & & & & & & \\
\hline $\begin{array}{c}\text { verificação da conservação } \\
\text { das massas }\end{array}$ & \multirow{3}{*}{$\begin{array}{l}\text { Cálculo parcial } \\
\text { dos valores }\end{array}$} & \multirow{3}{*}{5} & \multirow{3}{*}{$\mathrm{H} 17 / \mathrm{H} 25$ (parcial) } & \multirow{3}{*}{-} & \multirow{3}{*}{$\mathrm{N} 2 / \mathrm{N} 3$} & \multirow{3}{*}{-} \\
\hline cálculo parcial dos valores & & & & & & \\
\hline $\begin{array}{l}\text { dificuldades de verificação da } \\
\text { proporção }\end{array}$ & & & & & & \\
\hline
\end{tabular}

Para melhor visualizarmos as categorias construídas e estabelecermos possíveis comparativos entre elas, construímos o gráfico a seguir (Figura 48), em que relacionamos as categorias criadas com as turmas participantes do projeto.

Figura 48. Número de alunos por categorias referentes à questão 2 (C) do instrumento 9.

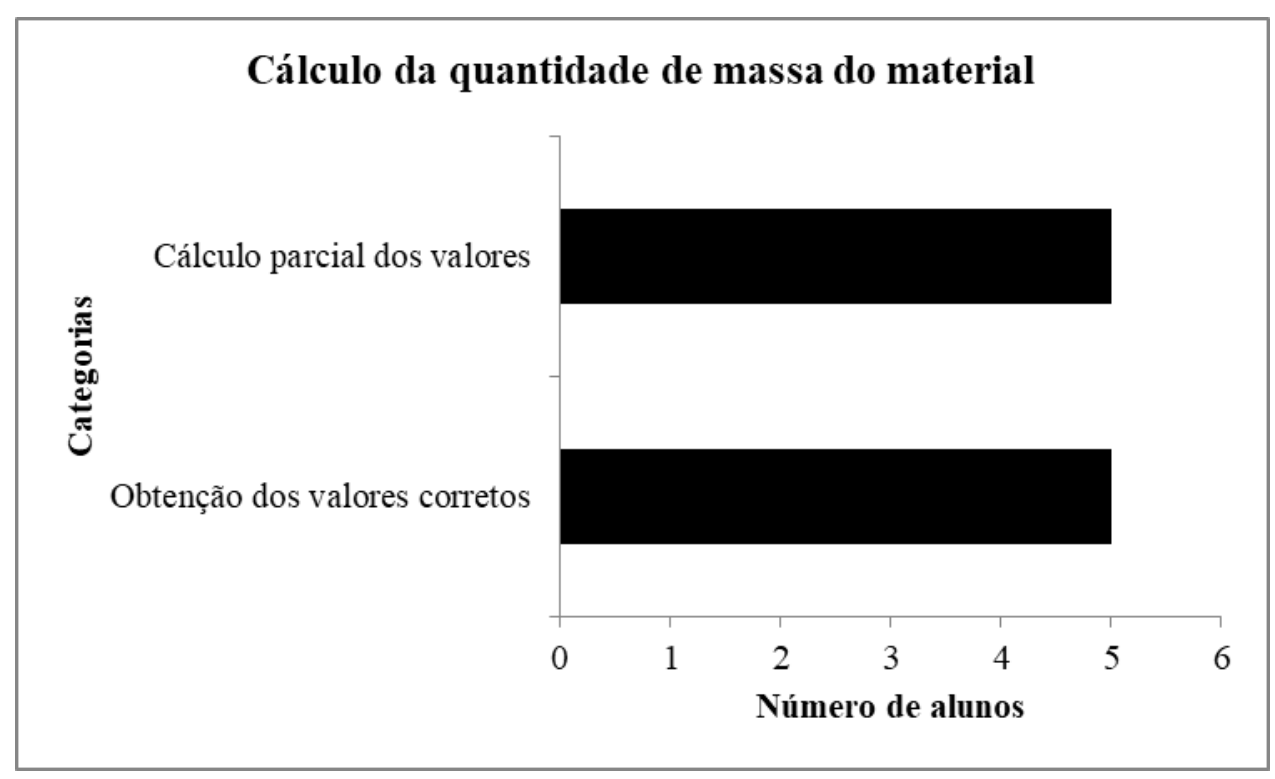

O item a deste exercício demandava a evocação de conhecimentos por parte dos estudantes. Para responder o item b, que solicitava a equação química, o aluno poderia evocar da memória a representação da energia na equação, e mostrar compreensão no que se refere à identificação de reagentes e produtos e à conservação dos átomos na transformação. Tanto em relação ao item a quanto ao b, a maior parte dos alunos demonstraram dominar as habilidades de relacionar as informações apresentadas na forma de tabela e também a utilização de 
códigos e nomenclaturas para representá-las na forma de equação química, caracterizando os materiais enquanto reagentes e produtos.

O item c se tratava de uma verificação de construção de conhecimento. Estes exercícios foram aplicados após a realização e discussão de um experimento em que o aluno deveria verificar a conservação da matéria em diferentes situações e a partir da discussão da atividade experimental construir a ideia de que em qualquer situação a quantidade de material envolvida inicialmente em uma reação se conserva após o término da reação. Assim, após identificar o reagente e os produtos e representar a reação, os alunos deveriam identificar as quantidades de materiais que não foram apresentadas, a partir da ideia da conservação e proporção das quantidades das substâncias. Como alguns não se recordavam de terem tido oportunidade de construção deste conhecimento em sua vida escolar, para esses, tornou-se, ainda, um pouco difícil a compreensão e reflexão do que estava acontecendo. Na mesma proporção percentual de questões certas verificamos um grupo de alunos que conseguiu resolver o problema proposto integralmente. Dentre aqueles que não conseguiram, a maior parte aplicou corretamente o conceito de conservação da matéria mas não finalizou a resolução do problema por apresentar dificuldades de estabelecer a proporção entre as massas das substâncias. Assim, de forma geral entendemos que o nosso objetivo de construção do conhecimento sobre a conservação da matéria foi praticamente atingido até este momento.

\subsubsection{Instrumento 10 - Síntese do conteúdo descrita pelos alunos.}

O objetivo principal do segundo módulo consistiu no reconhecimento e na construção de conhecimento a respeito da conservação das quantidades em massa dos reagentes e de produtos envolvidos em uma transformação química. Foi proposto como primeira atividade do módulo um conjunto de experimentos realizados de forma demonstrativa pela professora e auxiliados pelos próprios alunos. Entretanto o envolvimento da turma foi iniciado através do questionamento proposto: "Será que ao reagirem certas quantidades de materiais e formarem novas substâncias, ao verificar no final da reação, é possível dizer que a massa inicial das substâncias envolvidas são iguais as massas finais das substâncias formadas? Para ampliar as reflexões e conclusões dos mesmos, os experimentos foram observados tanto em um sistema aberto quanto fechado. Após apresentação dos dados obtidos foram realizadas discussões e reflexões a respeito dos conteúdos abordados.

Para verificar construções dos conhecimentos e habilidades desenvolvidas sobre a lei de conservação das massas estabelecidas, os alunos foram convidados a resolverem dois 
exercícios propostos (Apêndice 9). E como última atividade do módulo elaboraram um pequeno texto (instrumento 10) no qual apresentaram suas impressões e conceitos sobre tudo que foi aprendido até o momento. Para auxiliar os alunos na elaboração da atividade foram deixados alguns termos chaves a respeito dos conceitos construídos até o momento.

Conforme verificado no primeiro módulo, reafirmamos que sintetizar tudo que foi aprendido neste segundo módulo também representou um momento muito importante pois através dos relatos dos alunos verificamos conceitos construídos, possíveis confusões conceituais que ainda prevalecem, habilidades mobilizadas e algumas concepções alternativas que possam existir como dificultadoras da construção do conhecimento científico.

A tabela 40 apresenta, para a Questão, as decodificações criadas a partir das respostas dos alunos, as categorias criadas, as habilidades selecionadas a partir da matriz do ENEM, suscitadas pela questão para serem mobilizadas pelos estudantes e as classificações das respostas dos alunos em relação à níveis de cognições das mesmas.

\section{QUESTÃO DE SÍNTESE - UTILIZANDO ALGUMAS DAS PALAVRAS SUGERIDAS ACIMA E TAMBÉM OUTRAS QUE VOCÊ ACHAR NECESSÁRIO, ESCREVA UM TEXTO QUE RESUME TUDO QUE VOCÊ APRENDEU ATÉ AGORA.}

Tabela 40. Categorização das respostas dos alunos referentes à questão de síntese do Instrumento 10.

\begin{tabular}{|c|c|c|c|c|c|c|}
\hline \multicolumn{7}{|c|}{ QUESTÃO DE SÍNTESE } \\
\hline \multirow[t]{2}{*}{ Decodificadores } & \multirow[t]{2}{*}{ Categoriais } & \multirow[t]{2}{*}{ Alunos } & \multirow{2}{*}{$\frac{\text { Habilidades }}{\text { ENEM }}$} & \multicolumn{3}{|c|}{ Respostas dos alunos } \\
\hline & & & & ALG & LOCS & HOCS \\
\hline $\begin{array}{c}\text { compreensão de termos para evitar } \\
\text { confusões }\end{array}$ & \multirow{3}{*}{$\begin{array}{l}\text { Compreensão } \\
\text { significado de } \\
\text { alguns termos }\end{array}$} & \multirow{3}{*}{4} & \multirow{3}{*}{$\mathrm{H} 24$} & \multirow{3}{*}{-} & \multirow{3}{*}{$\mathrm{N} 2$} & \multirow{3}{*}{-} \\
\hline $\begin{array}{l}\text { produtos como sendo o que compõem } \\
\text { os reagentes }\end{array}$ & & & & & & \\
\hline $\begin{array}{c}\text { as equações representam os reagentes } \\
\text { e os produtos }\end{array}$ & & & & & & \\
\hline $\begin{array}{l}\text { conhecimento como compreensão do } \\
\text { cotidiano }\end{array}$ & $\begin{array}{l}\text { compreensão } \\
\text { importância do } \\
\text { cotidiano }\end{array}$ & 1 & $\mathrm{H} 24$ & N1 & - & - \\
\hline $\begin{array}{c}\text { transformação química como } \\
\text { alteração entre estado inicial e final da } \\
\text { estrutura da equação }\end{array}$ & \multirow{6}{*}{$\begin{array}{c}\text { Definição } \\
\text { caracterizações de } \\
\text { transformações } \\
\text { químicas }\end{array}$} & \multirow{6}{*}{12} & \multirow{6}{*}{ H 24} & \multirow{6}{*}{-} & \multirow{6}{*}{$\mathrm{N} 2 / \mathrm{N} 3$} & \multirow{6}{*}{-} \\
\hline $\begin{array}{c}\text { transformação química com } \\
\text { conservação de massa }\end{array}$ & & & & & & \\
\hline $\begin{array}{c}\text { as reações podem ser físicas ou } \\
\text { químicas }\end{array}$ & & & & & & \\
\hline $\begin{array}{c}\text { reações físicas apenas com mudança } \\
\text { de estado físico }\end{array}$ & & & & & & \\
\hline $\begin{array}{c}\text { reações químicas com alterações } \\
\text { moleculares com uma substância se } \\
\text { transformando na outra }\end{array}$ & & & & & & \\
\hline $\begin{array}{c}\text { reagentes como substâncias iniciais } \\
\text { antes de ocorrer a transformação } \\
\text { química }\end{array}$ & & & & & & \\
\hline
\end{tabular}




\begin{tabular}{|c|c|c|c|c|c|c|}
\hline $\begin{array}{l}\text { transformações químicas são baseadas } \\
\text { em evidências }\end{array}$ & & & & & & \\
\hline $\begin{array}{l}\text { entendimento do funcionamento de } \\
\text { uma transformação química }\end{array}$ & & & & & & \\
\hline $\begin{array}{c}\text { produtos como substâncias finais após } \\
\text { ocorrer a transformação química }\end{array}$ & & & & & & \\
\hline $\begin{array}{l}\text { transformação química como criação } \\
\text { de um sistema inicial gerando um } \\
\text { produto }\end{array}$ & & & & & & \\
\hline $\begin{array}{l}\text { existem transformações químicas que } \\
\text { podem ser observadas (efervescência, } \\
\text { decantação, floculação) }\end{array}$ & & & & & & \\
\hline $\begin{array}{l}\text { após a transformação a massa do } \\
\text { reagente é igual a massa do produto }\end{array}$ & & & & & & \\
\hline $\begin{array}{c}\text { a conservação de massa ocorre } \\
\text { dependendo do experimento }\end{array}$ & & & & & & \\
\hline $\begin{array}{c}\text { alterações de massas das substâncias } \\
\text { em um sistema aberto por conta da } \\
\text { alteração do estado da matéria ou } \\
\text { erros experimentais }\end{array}$ & & & & & & \\
\hline relação entre massa inicial e final & & & & & & \\
\hline conservação de massas nas equações & $\begin{array}{l}\text { Entendimento } \\
\text { caracterizacões da }\end{array}$ & & & & & \\
\hline $\begin{array}{l}\text { verificação da conservação de massa } \\
\text { através da comparação das massas das } \\
\text { substâncias do sistema inicial em } \\
\text { comparação com o final }\end{array}$ & $\begin{array}{l}\text { conservação das } \\
\text { massas }\end{array}$ & 13 & H 24 & - & $\mathrm{N} 2 / \mathrm{N} 3$ & - \\
\hline $\begin{array}{c}\text { lei de Lavoisier verificada pela soma } \\
\text { e comparação entre os sistemas } \\
\text { iniciais e finais }\end{array}$ & & & & & & \\
\hline $\begin{array}{l}\text { verificação da conservação de massa } \\
\text { em que todos os reagentes foram } \\
\text { transformados em produtos }\end{array}$ & & & & & & \\
\hline nada se cria nada se transforma & & & & & & \\
\hline
\end{tabular}

Para melhor visualizarmos as categorias construídas e estabelecermos possíveis comparativos entre elas, construímos o gráfico a seguir (Figura 49), em que relacionamos as categorias criadas com as turmas participantes do projeto. 
Figura 49. Número de alunos por categorias referentes à questão de síntese do Instrumento 10.

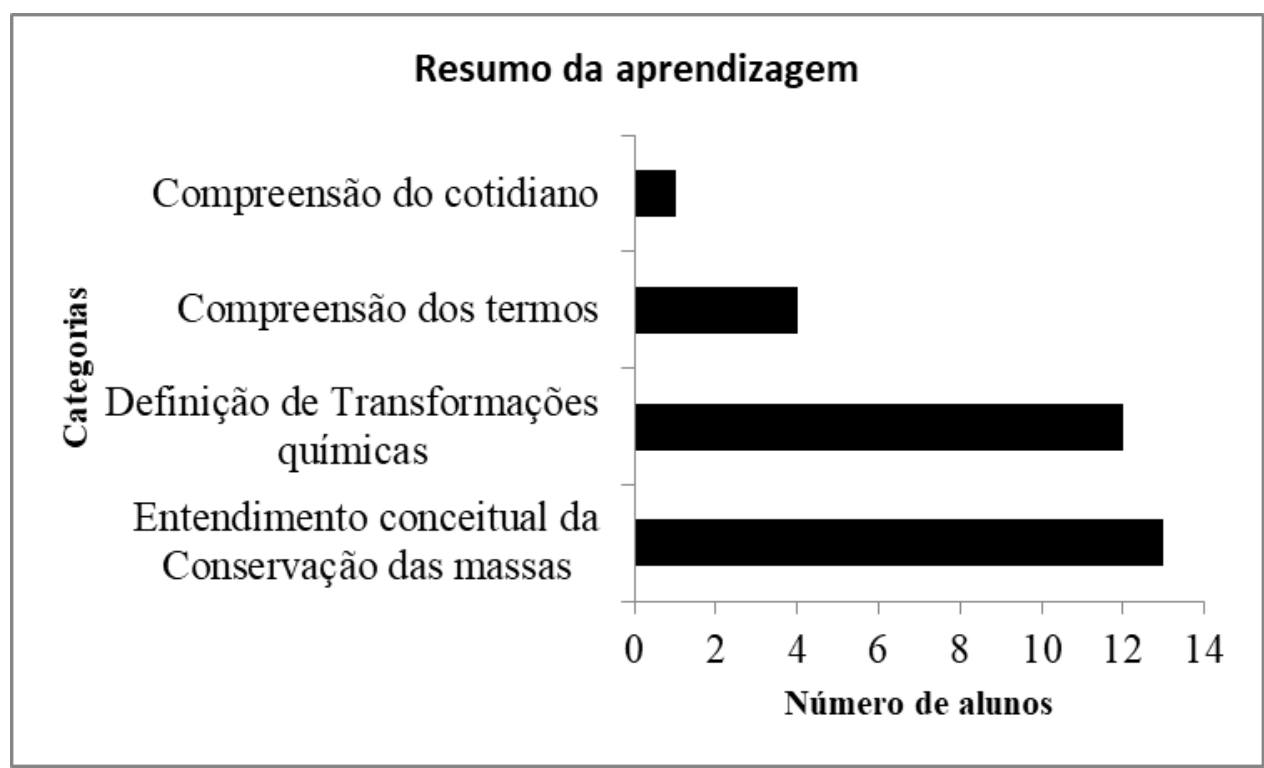

Analisando os resultados deste questionário, verificamos que mesmo com pequenas dificuldades todos os alunos apresentaram diversas ideias na síntese de seus conhecimentos. Um aspecto que nos chamou a atenção foi que, observando as anotações dos estudantes verificamos que praticamente todos conseguiram expressar ideias coerentes sobre o que é a transformação química e a respeito da conservação da massa. Estabelecendo algumas reflexões entendemos que houve um avanço comparado com o que eles sabiam no início do processo.

Em relação às definições a respeito das transformações químicas, trabalhadas no primeiro módulo constituintes das Situações-problema, conseguimos desenvolver atividades (Módulo 1) que contribuíssem com um entendimento macroscópico a respeito das transformações sofridas pelos materiais. Ao final do primeiro módulo, os alunos teriam condições de estabelecer discussões a respeito da ocorrência de transformações principalmente a partir de associações com aspectos visuais verificados nos experimentos. As atividades foram organizadas principalmente através de uma atividade experimental, e da leitura de um texto a respeito da formação da chuva ácida. Ao final de todo o processo, os alunos relataram a respeito das transformações químicas como forma de entendimento de concepções de reagentes e produtos, de evidências de reação, da formação de novas substâncias, representação de reações químicas e o entendimento do uso de símbolos como formação das substâncias. Em relação as atividades organizadas por nós optamos por não ampliar os conhecimentos sobre os aspectos microscópicos, como o rompimento das ligações químicas e o rearranjo de átomos. Ou seja, não foram demandados ao longo a sequência 
problematizadora, conforme discussão a respeito da viabilidade em relação ao tempo para desenvolvimento de atividades.

No segundo módulo ampliamos o entendimento dos alunos a respeito das transformações, ou seja, pensamos em atividades tanto experimental quanto problematizadoras por meio das quais no final do ciclo de atividades os alunos pudessem ser capazes de reconhecer as transformações dos materiais por meio de equações químicas. Desta forma, através de tais representações é possível trabalharmos com os alunos concepções de reagentes, produtos, a respeito da necessidade de balancear uma reação e como esta associada a conservação dos átomos e da massa dos materiais.

Assim quando verificamos os registros dos alunos até a presente atividade observando articulações com a maior parte das concepções trabalhadas adequadamente, ou seja, alinhadas ao parâmetros científicos.

3.2.1.6. Instrumento 12 - Reflexões sobre a Lei de Conservação das massas estabelecida por Lavoisier e a Lei das Proporções de Proust.

Seguindo a mesma proposta do instrumento 9 (Módulo 2), o propósito principal do presente nas questões aplicadas foi a verificação da construção de conhecimentos conceituais e cognitivos sobre os conteúdos desenvolvidos no módulo 3.

Os alunos após sintetizarem ideias a respeito de transformações e conservações dos materiais no instrumento 10 participaram de uma atividade experimental representada pelo instrumento $11 \mathrm{em}$ que deveriam construir e refletir a respeito do conceito de proporções dos materiais. Ao final do módulo, no presente questionário, foram problematizadas 3 questões já aplicadas em questionários anteriores. Todas as questões abordam principalmente conteúdos desenvolvidos no módulo 3.

QUESTÃO 1 - O responsável técnico de um forno de calcinação de calcário elaborou um relatório sobre as três últimas tiragens da produção de cal. $O$ relatório apresenta a seguinte tabela:

\begin{tabular}{|l|l|l|l|}
\hline Amostras & $\begin{array}{c}\text { Massa de calcário }(\mathrm{t}) \\
\left(\mathrm{CaCO}_{3}\right)\end{array}$ & $\begin{array}{c}\text { Massa de cal }(\mathrm{t}) \\
(\mathrm{CaO})\end{array}$ & $\begin{array}{c}\text { Massa de } \\
\text { dióxido de carbono }(\mathrm{t}) \\
\left(\mathrm{CO}_{2}\right)\end{array}$ \\
\hline $12 / 7$ & 10,0 & 5,6 & 4,4 \\
\hline $15 / 7$ & & 11,2 & \\
\hline
\end{tabular}




\begin{tabular}{|l|l|l|l|}
\hline $18 / 7$ & 12,0 & 6,7 & \\
\hline
\end{tabular}

Como se pode perceber, faltaram dados da massa de calcário usado no dia 15/7 e da massa de dióxido de carbono formado nos dia 15/7 e 18/7.

a) Identifique quais são os reagentes e produtos nesse processo.

b) Determine os valores que faltam na tabela e complete-as. Mostre os cálculos realizados.

Esta questão foi aplicada em três momentos ao longo da sequência de atividades. Primeiramente no questionário diagnóstico, sendo utilizada como uma das questões que representaram uma investigação de conhecimentos dos alunos a respeito do conteúdo de proporções dos materiais.

Em um segundo momento, foi proposta no instrumento 9, correspondendo as reflexões conceituais que finalizaram o segundo módulo. Nesta fase de aplicação os alunos tiveram um tempo de reflexão sobre o problema proposto. $\mathrm{Na}$ aula seguinte a professora retomou a questão propondo a participação dos alunos como forma de resolução.

Em relação ao item a, a maior parte dos alunos demonstraram entender que as transformações químicas são representadas por reações químicas, as quais envolvem a transformações de produtos em reagentes, ou seja, cognitivamente mostrar um domínio nas relações das informações apresentadas na tabela e na construção de uma nova linguagem, através das equações químicas. As atividades anteriores, como as discussões dos experimentos e a leitura e discussão do texto certamente contribuíram com o processo de construção de conhecimento. Já em relação ao item b da questão, envolvendo identificação das quantidades de materiais não descritas na tabela, e utilizando conhecimentos como a conservação e proporção das quantidades das substâncias, ainda foram observadas algumas dificuldades de resolução. Entretanto, entendemos que houve uma evolução em relação à construção dos conhecimentos, pois dentre aqueles que não conseguiram, a maior parte aplicou corretamente o conceito de conservação da matéria mas não finalizou a resolução do problema por apresentar dificuldades de estabelecer a proporção entre as massas das substâncias. Ou seja, muitas das dificuldades foram superadas sendo que somente o conceito de proporção ainda prevalecia sem entendimento.

Por fim, a questão foi aplicada novamente no penúltimo instrumento como forma de verificação dos conceitos sobre conservação e proporção dos materiais. Com um sentido também investigativo, mas com um diferencial do segundo momento, nesta fase os alunos 
também já haviam discutido os conceitos de proporções dos componentes de uma reação. Neste momento todos os alunos conseguiram resolver de forma integral o exercício, demonstrando uma evolução na construção de seus conhecimentos.

A tabela 41 apresenta, para a Questão, as decodificações criadas a partir das respostas dos alunos, as categorias criadas, as habilidades selecionadas a partir da matriz do ENEM, suscitadas pela questão para serem mobilizadas pelos estudantes e as classificações das respostas dos alunos em relação à níveis de cognições das mesmas.

Tabela 41. Categorização das respostas dos alunos referentes à questão 1 (A) do Instrumento 12.

\begin{tabular}{|c|c|c|c|c|c|c|}
\hline \multicolumn{7}{|c|}{ QUESTÃO 1 - Identificação de reagentes e produtos } \\
\hline Decodificadores & Categoriais & Alunos & Habilidades & \multicolumn{2}{c|}{ Respostas dos alunos } \\
\hline $\begin{array}{c}\text { representação de uma } \\
\text { equação química } \\
\text { corretamente }\end{array}$ & $\begin{array}{c}\text { representação de uma } \\
\text { equação química } \\
\text { corretamente }\end{array}$ & 6 & $\mathrm{H} 17 / \mathrm{H} 24$ & - & $\mathrm{N} 2 / \mathrm{N} 3$ & - \\
\hline $\begin{array}{c}\text { reagente: calcário e produtos: } \\
\text { cal e dióxido de carbono }\end{array}$ & $\begin{array}{c}\text { reagente: calcário e } \\
\text { produtos: cal e dióxido de } \\
\text { carbono }\end{array}$ & 4 & $\mathrm{H} 17 / \mathrm{H} 24$ & - & $\mathrm{N} 2 / \mathrm{N} 3$ & - \\
\hline
\end{tabular}

Para melhor visualizarmos as categorias construídas e estabelecermos possíveis comparativos entre elas, construímos o gráfico a seguir (Figura 50), em que relacionamos as categorias criadas com as turmas participantes do projeto.

Figura 50. Número de alunos por categorias referentes à questão 1 (A) do Instrumento 12.

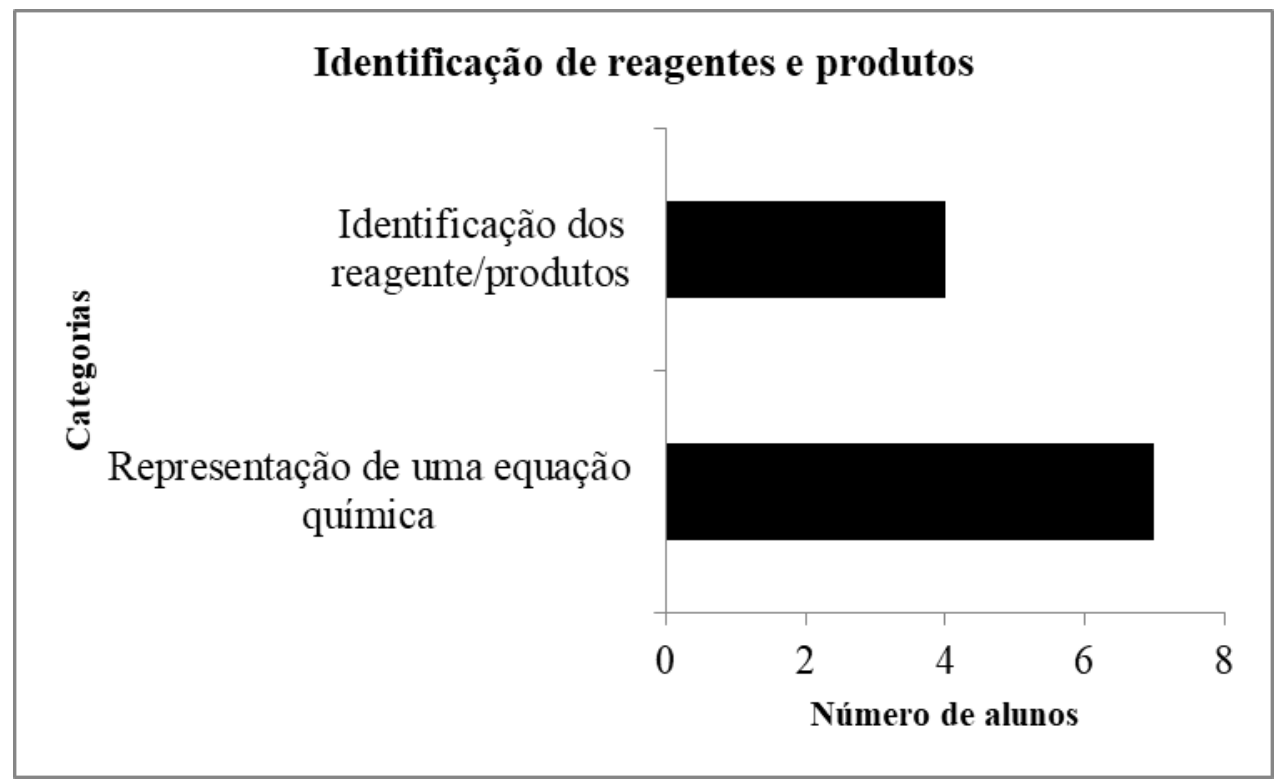

A tabela 42 apresenta, para a Questão, as decodificações criadas a partir das respostas dos alunos, as categorias criadas, as habilidades selecionadas a partir da matriz do 
ENEM, suscitadas pela questão para serem mobilizadas pelos estudantes e as classificações das respostas dos alunos em relação à níveis de cognições das mesmas.

Tabela 42. Categorização das respostas dos alunos referentes à questão 1 (B) do Instrumento 12.

\begin{tabular}{|c|c|c|c|c|c|c|}
\hline \multicolumn{7}{|c|}{ QUESTÃO 1 - Determinação de valores } \\
\hline Decodificadores & Categoriais & Alunos & Habilidades & \multicolumn{3}{|c|}{ Respostas dos alunos } \\
\hline & & & ENEM & ALG & LOCS & HOCS \\
\hline deixou em branco & Branco & 1 & - & - & - & - \\
\hline $\begin{array}{c}\text { aplicação da conservação } \\
\text { das massas em } 18 / 7\end{array}$ & \multirow{2}{*}{$\begin{array}{c}\text { Obtenção dos valores corretos } \\
\text { por proporção e conservação de } \\
\text { massa }\end{array}$} & \multirow{2}{*}{7} & \multirow{2}{*}{$\mathrm{H} 17 / \mathrm{H} 25$} & \multirow{2}{*}{ - } & \multirow{2}{*}{$\mathrm{N} 2 / \mathrm{N} 3$} & \multirow{2}{*}{ N4 } \\
\hline $\begin{array}{c}\text { proporção das amostras } \\
12 / 7 \text { e } 15 / 7(\mathrm{x} 2)\end{array}$ & & & & & & \\
\hline $\begin{array}{c}\text { proporção das amostras } \\
15 / 8 \text { e } 18 / 7 \\
\end{array}$ & \multirow{2}{*}{$\begin{array}{l}\text { Obtenção dos valores corretos } \\
\text { somente por proporção }\end{array}$} & \multirow{2}{*}{2} & \multirow{2}{*}{$\mathrm{H} 17 / \mathrm{H} 25$} & \multirow{2}{*}{ - } & \multirow{2}{*}{$\mathrm{N} 2 / \mathrm{N} 3$} & \multirow{2}{*}{ N4 } \\
\hline $\begin{array}{c}\text { proporção das amostras } \\
12 / 7 \text { e } 18 / 7\end{array}$ & & & & & & \\
\hline
\end{tabular}

Para melhor visualizarmos as categorias construídas e estabelecermos possíveis comparativos entre elas, construímos o gráfico a seguir (Figura 51), em que relacionamos as categorias criadas com as turmas participantes do projeto.

Figura 51. Número de alunos por categorias referentes à questão 1(B) do Instrumento 12.

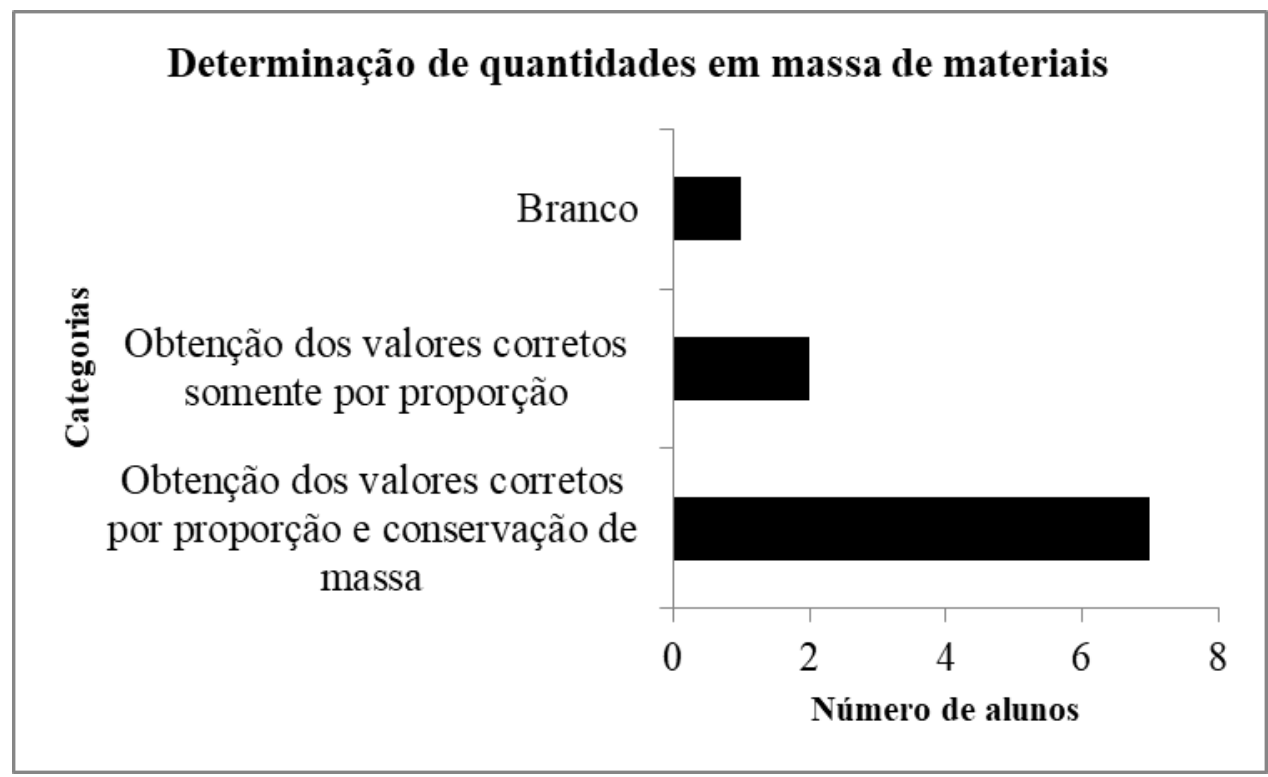

Conforme já discutido no início da apresentação da questão, e agora observando os gráficos correspondentes aos resultados de cada um dos itens, entendemos que nesta etapa de aplicação da pesquisa os alunos já demonstraram uma evolução significativa em relação à construção de conhecimentos e de habilidades cognitivas. Pensando em uma parte dos conceitos necessários para o entendimento do primeiro módulo que seria ideia de reagentes, 
produtos e a representação de uma equação química, verificamos através desta questão que todos os alunos são capazes de solucionar problemas com esta necessidade de conhecimentos teóricos e cognitivos. Em relação às demandas relacionadas à relações quantitativas da matéria, verificamos nos dados representados na figura 50 que $70 \%$ dos alunos conseguiram obter os valores esperados referentes às quantidades dos materiais através da aplicação de conhecimentos sobre proporção e conservação de massas das substâncias. O representativo de $20 \%$ do total de alunos que não finalizaram a resolução da questão indicou dificuldade na associação do problema à proporção em massa dos compostos.

QUESTÃO 2 - Devido à toxicidade do mercúrio, em caso de derramamento desse metal, costuma-se espalhar enxofre no local, para removê-lo. Mercúrio e enxofre reagem, gradativamente, formando sulfeto de mercúrio. Para fins de estudo, a reação pode ocorrer mais rapidamente se as duas substâncias forem misturadas. Usando esse procedimento, foram feitos dois experimentos, observe os dados:

\begin{tabular}{|l|l|l|l|l|}
\hline Experimentos & Mercúrio & Enxofre & $\begin{array}{l}\text { Produto } \\
\text { formado }\end{array}$ & Sobra \\
\hline I & $5,0 \mathrm{~g}$ & $1,0 \mathrm{~g}$ & $5,8 \mathrm{~g}$ & $\mathbf{0 , 2} \mathrm{g}$ de enxofre \\
\hline II & $12,0 \mathrm{~g}$ & $1,6 \mathrm{~g}$ & $11,6 \mathrm{~g}$ & 2,0 de mercúrio \\
\hline
\end{tabular}

a) Represente essa transformação, por meio de uma equação química, a partir das informações do texto, mesmo sem utilizar as fórmulas químicas.

b) Para cada um desses experimentos, a massa inicial do sistema é a mesma que a massa final? Você pode dizer que houve conservação da massa do sistema nessa transformação.

c) Pode-se afirmar que há uma proporção entre a massa do produto formado e as massas dos reagentes que efetivamente reagem. Como você poderia verificar essa proporção? Descreva seu raciocínio.

A tabela 43 apresenta, para a Questão, as decodificações criadas a partir das respostas dos alunos, as categorias criadas, as habilidades selecionadas a partir da matriz do ENEM, suscitadas pela questão para serem mobilizadas pelos estudantes e as classificações das respostas dos alunos em relação à níveis de cognições das mesmas. 
Tabela 43. Categorização das respostas dos alunos referentes à questão 2 (A) do Instrumento 12.

\begin{tabular}{|c|c|c|c|c|c|c|}
\hline \multicolumn{7}{|c|}{ QUESTÃO 2 - Representação da equação química } \\
\hline Decodificadores & Categoriais & Alunos & Habilidades & \multicolumn{2}{c|}{ Respostas dos alunos } \\
\hline $\begin{array}{c}\text { representação correta da } \\
\text { equação química }\end{array}$ & $\begin{array}{c}\text { Representação correta da } \\
\text { equação química }\end{array}$ & 5 & H17/H24 & - & N2/N3 & - \\
\hline $\begin{array}{c}\text { equação química com } \\
\text { reconhecimento de enxofre } \\
\text { como reagente e produto }\end{array}$ & $\begin{array}{c}\text { Equação química com } \\
\text { reconhecimento de enxofre } \\
\text { como reagente e produto }\end{array}$ & 1 & $\mathrm{H} 17$ & - & $\mathrm{N} 2$ & - \\
\hline $\begin{array}{c}\text { equação química com } \\
\text { reconhecimento de ambas } \\
\text { as sobras como produto }\end{array}$ & $\begin{array}{c}\text { Equação química com } \\
\text { reconhecimento de ambas as } \\
\text { sobras como produto }\end{array}$ & 4 & $\mathrm{H} 17 / \mathrm{H} 24$ & - & $\mathrm{N} 2 / \mathrm{N} 3$ & - \\
\hline
\end{tabular}

Para melhor visualizarmos as categorias construídas e estabelecermos possíveis comparativos entre elas construímos o gráfico a seguir (Figura 52) em que relacionamos as categorias criadas com as turmas participantes do projeto.

Figura 52. Número de alunos por categorias referentes à questão 2 (A) do Instrumento 12.

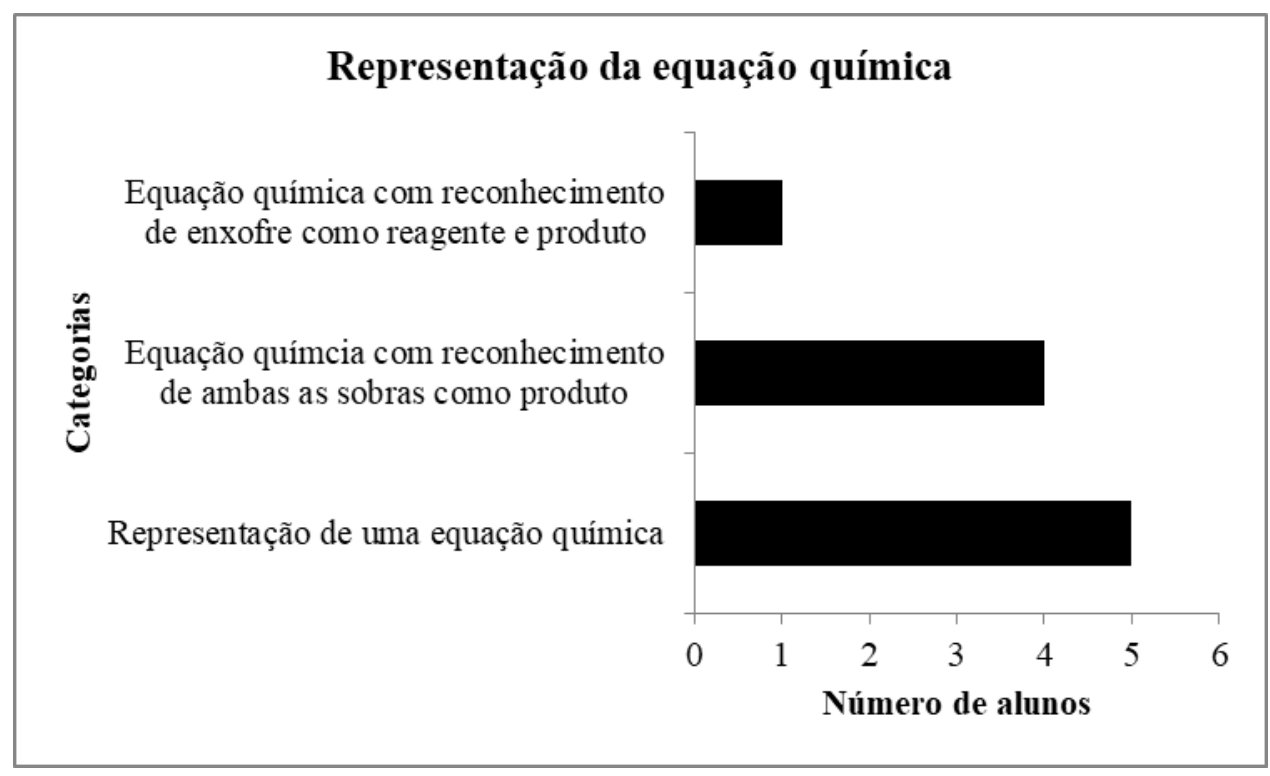

A tabela 44 apresenta, para a Questão, as decodificações criadas a partir das respostas dos alunos, as categorias criadas, as habilidades selecionadas a partir da matriz do ENEM, suscitadas pela questão para serem mobilizadas pelos estudantes e as classificações das respostas dos alunos em relação à níveis de cognições das mesmas.

Tabela 44. Categorização das respostas dos alunos referentes à questão 2 (B) do Instrumento 12.

\begin{tabular}{|l|c|c|c|c|}
\hline \multicolumn{5}{|c|}{ QUESTÃO 2- As massas iniciais e finais são iguais? Conservação das } \\
massas? \\
\hline Decodificadores & Categoriais & Alunos & Habilidades & Respostas dos alunos \\
\hline
\end{tabular}




\begin{tabular}{|c|c|c|c|c|c|c|}
\hline & & & ENEM & ALG & LOCS & HOCS \\
\hline $\begin{array}{l}\text { as massas iniciais e finais não } \\
\text { são iguais } \\
\text { cálculo da massa de enxofre que } \\
\text { reagiu no experimento I }\end{array}$ & \multirow[b]{2}{*}{$\begin{array}{l}\text { Massas diferentes } \\
\text { com justificativas }\end{array}$} & \multirow[b]{2}{*}{6} & \multirow[b]{2}{*}{$\mathrm{H} 17$ (parcial)/H24 } & \multirow[b]{2}{*}{-} & \multirow[b]{2}{*}{$\mathrm{N} 2$} & \multirow[b]{2}{*}{-} \\
\hline $\begin{array}{l}\text { nem todo reagente se } \\
\text { transformou em produto } \\
\text { a massa de sobra também } \\
\text { representa o produto formado } \\
\text { houve formação de sobra }\end{array}$ & & & & & & \\
\hline $\begin{array}{l}\text { soma das massas dos reagentes } \\
\text { são iguais a dos produtos junto } \\
\text { com as sobras } \\
\text { devido à existência da sobra }\end{array}$ & $\begin{array}{l}\text { Massas iguais } \\
\text { considerando as } \\
\text { sobras }\end{array}$ & 2 & $\mathrm{H} 17 / \mathrm{H} 24$ (parcial) & - & $\mathrm{N} 2 / \mathrm{N} 3$ & - \\
\hline houve conservação de massas & \multirow{2}{*}{$\begin{array}{l}\text { Houve conservação } \\
\text { de massas }\end{array}$} & \multirow{2}{*}{2} & \multirow{2}{*}{$\mathrm{H} 17 / \mathrm{H} 24$} & \multirow{2}{*}{-} & \multirow{2}{*}{$\mathrm{N} 2 / \mathrm{N} 3$} & \multirow[b]{2}{*}{-} \\
\hline $\begin{array}{l}\text { houve conservação de massas, só } \\
\text { não virou produto }\end{array}$ & & & & & & \\
\hline
\end{tabular}

Para melhor visualizarmos as categorias construídas e estabelecermos possíveis comparativos entre elas, construímos o gráfico a seguir (Figura 53), em que relacionamos as categorias criadas com as turmas participantes do projeto.

Figura 53. Número de alunos por categorias referentes à questão 2 (B) do Instrumento 12.

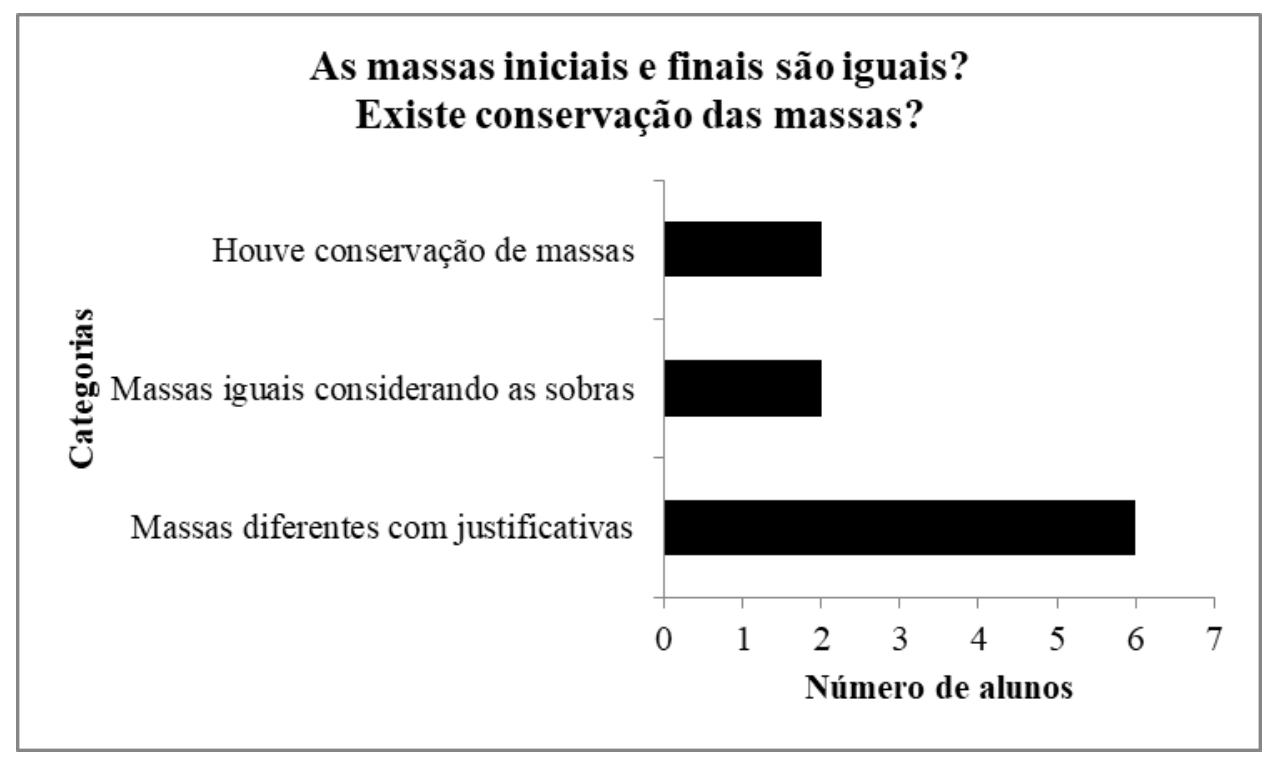

A tabela 45 apresenta, para a Questão, as decodificações criadas a partir das respostas dos alunos, as categorias criadas, as habilidades selecionadas a partir da matriz do ENEM, suscitadas pela questão para serem mobilizadas pelos estudantes e as classificações das respostas dos alunos em relação à níveis de cognições das mesmas. 
Tabela 45. Categorização das respostas dos alunos referentes à questão 2 (C) do Instrumento 12.

\begin{tabular}{|c|c|c|c|c|c|c|}
\hline \multicolumn{7}{|c|}{$\begin{array}{c}\text { QUESTÃO } 2 \text { - Há proporção entre os produtos formados e os reagentes que } \\
\text { reagem? Descreva }\end{array}$} \\
\hline Indicadores & CATEGORIAIS & Alunos & Habilidades & Resp & stas dos & lunos \\
\hline & & & ENEM & ALG & LOCS & HOCS \\
\hline $\begin{array}{l}\text { cálculo do enxofre } \\
\text { realmente utilizado na } \\
\text { reação no experimento I }\end{array}$ & \multirow{2}{*}{$\begin{array}{c}\text { Verificação das proporções } \\
\text { corretas }\end{array}$} & \multirow{2}{*}{3} & \multirow{2}{*}{$\mathrm{H} 17 / \mathrm{H} 25$} & \multirow{2}{*}{-} & \multirow{2}{*}{$\mathrm{N} 2 / \mathrm{N} 3$} & \multirow{2}{*}{ N4 } \\
\hline $\begin{array}{l}\text { verificação da proporção } \\
\text { entre os experimentos I e } \\
\text { II }\end{array}$ & & & & & & \\
\hline $\begin{array}{l}\text { soma dos reagentes menos } \\
\text { a sobra }\end{array}$ & $\begin{array}{l}\text { Verificação da conservação } \\
\text { das massas desconsiderando } \\
\text { as sobras }\end{array}$ & 2 & H17 & - & $\mathrm{N} 2$ & - \\
\hline $\begin{array}{l}\text { verificação da proporção } \\
\text { através do cálculo } \\
\text { excessivo de substâncias }\end{array}$ & $\begin{array}{l}\text { Verificação de proporção } \\
\text { considerando as sobras }\end{array}$ & 1 & $\begin{array}{c}\mathrm{H} 17 / \mathrm{H} 25 \\
\text { (parcial) }\end{array}$ & - & $\mathrm{N} 2 / \mathrm{N} 3$ & - \\
\hline $\begin{array}{l}\text { verificação da proporção } \\
\text { somente entre os produtos } \\
\text { dos experimentos I e II }\end{array}$ & $\begin{array}{l}\text { Verificação de proporção das } \\
\text { substâncias desconsiderando } \\
\text { as sobras }\end{array}$ & 1 & H17 & - & $\mathrm{N} 2$ & - \\
\hline $\begin{array}{l}\text { quanto maior a } \\
\text { desproporção maior a } \\
\text { sobra }\end{array}$ & \multirow{3}{*}{ Respostas não conclusivas } & \multirow{3}{*}{3} & \multirow{3}{*}{ H17 } & \multirow{3}{*}{ N1 } & \multirow{3}{*}{-} & \multirow{3}{*}{-} \\
\hline $\begin{array}{l}\text { raciocínio matemático não } \\
\text { identificado }\end{array}$ & & & & & & \\
\hline $\begin{array}{c}\text { a sobra de mercúrio } \\
\text { dependerá da quantidade } \\
\text { de enxofre }\end{array}$ & & & & & & \\
\hline
\end{tabular}

Para melhor visualizarmos as categorias construídas e estabelecermos possíveis comparativos entre elas, construímos o gráfico a seguir (Figura 54), em que relacionamos as categorias criadas com as turmas participantes do projeto.

Figura 54. Número de alunos por categorias referentes à questão 2 (C) do Instrumento 12.

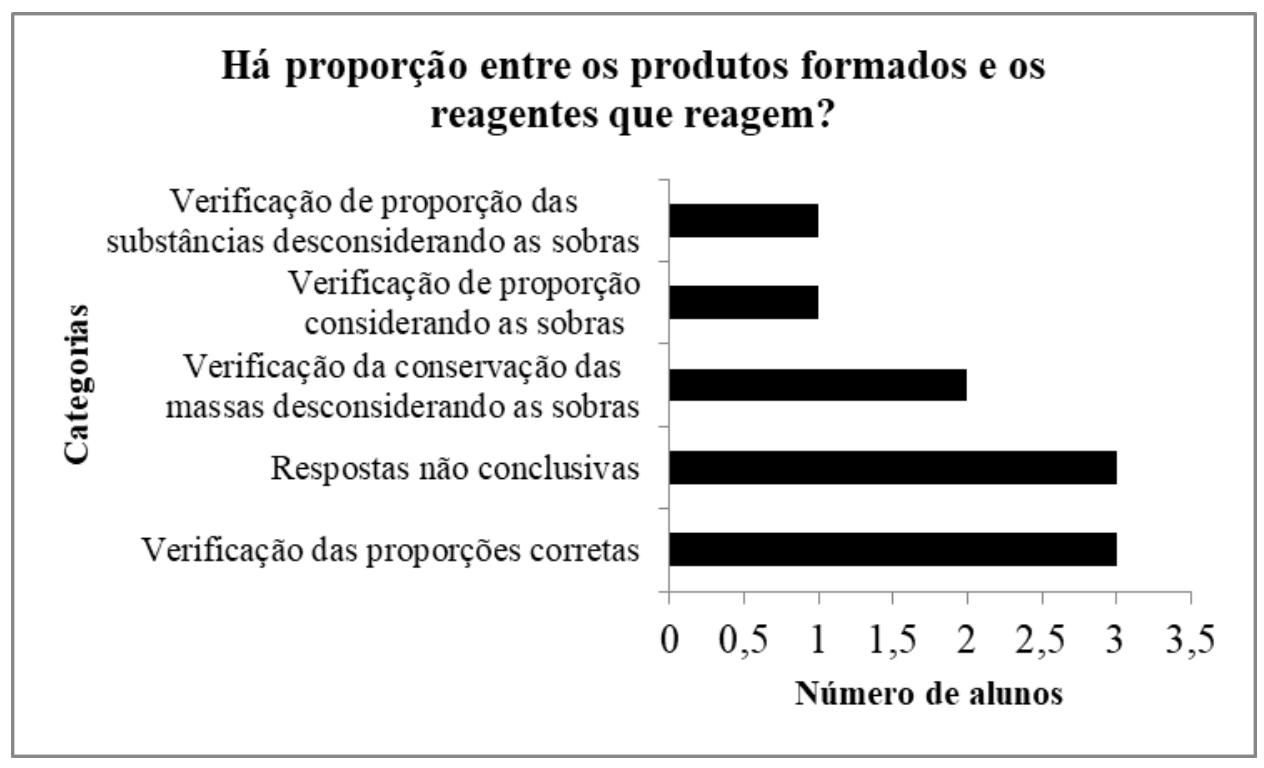


Esta foi uma questão que também foi aplicada no questionário diagnóstico (instrumento 3). Em comparação aos dois questionários, houve uma mudança significativa no que se referiu aos conhecimentos construídos.

Em relação ao questionário diagnóstico $83 \%$ do total de alunos deixaram em branco a questão. Neste momento este percentual foi revertido significativamente. Em relação ao item a da atual questão os alunos demonstram serem capazes de realizar a interpretação do enunciado (90\% dos alunos representaram adequadamente a transformação) mesmo descrito em diferentes formas de linguagem, como por exemplo a proposição de uma tabela como organização dos dados. Já nos itens b e c, as porcentagem de acertos mantiveram-se em 30\% e $40 \%$ em relação ao total de alunos, respetivamente. Porém, neste momento foram exigidas mobilizações de maior complexidade, principalmente no último item da questão. Para verificarem a existência da conservação das massas dos componentes envolvidos teriam que entender que a sobra de uma quantidade de reagente não deveria ser contabilizada como produto da reação, e sim como uma quantidade de reagente que não se transformou em produto e portanto permaneceu no sistema sem envolvimento com a reação química ocorrida. Desta forma, quando o aluno reconhece o significado do excesso de um material durante a ocorrência de uma reação significa entender quimicamente o que está acontecendo e compreender o conceito de proporção das massas em uma transformação química. Os alunos que conseguiram finalizar a resolução adequada da questão representam uma evolução em relação à construção de conceitos e habilidades.

QUESTÃo 3 - Amônia e gás carbônico podem reagir formando ureia e água. O gráfico abaixo mostra as massas de ureia e de água que são produzidas em função da massa de amônia, considerando as reações completas. A partir dos dados do gráfico e dispondo-se de $110 \mathrm{~g}$ de amônia, qual é o valor da massa aproximada, em gramas, de gás carbônico minimamente necessário para reação completa com essa quantidade de amônia? Por que essa massa é mínima? Se tivesse uma massa maior de $\mathrm{CO}_{2}$ seria produzida mais água e ureia? Justifique

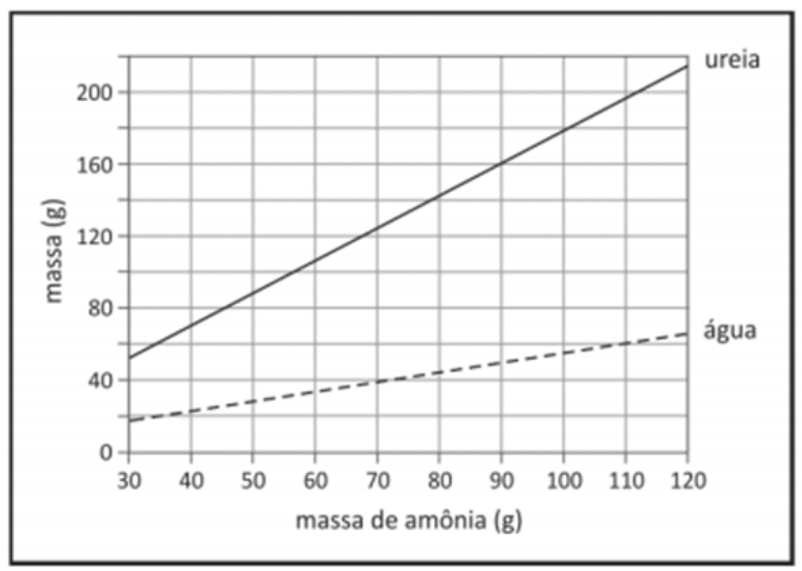


Algumas reflexões que podem auxiliar na resolução do problema...

- Como podemos representar essa transformação, por meio de uma equação química, a partir das informações do texto, mesmo sem utilizar as fórmulas químicas?

- Leia o texto novamente e procure entender quais as relações estabelecidas no gráfico com cada uma das substâncias

A tabela 46 apresenta, para a Questão, as decodificações criadas a partir das respostas dos alunos, as categorias criadas, as habilidades selecionadas a partir da matriz do ENEM, suscitadas pela questão para serem mobilizadas pelos estudantes e as classificações das respostas dos alunos em relação à níveis de cognições das mesmas.

Tabela 46. Categorização das respostas dos alunos referentes à questão 3 (I) do Instrumento 12.

\begin{tabular}{|c|c|c|c|c|c|c|}
\hline \multicolumn{7}{|c|}{ QUESTÃO 3 - Cálculo da massa de gás carbônico } \\
\hline Decodificadores & CATEGORIAS & Alunos & Habilidades & Res & stas dos & lunos \\
\hline & & & ENEM & ALG & LOCS & HOCS \\
\hline $\begin{array}{l}\text { representação da equação } \\
\text { química corretamente }\end{array}$ & \multirow{3}{*}{$\begin{array}{l}\text { Obtenção da massa } \\
\text { esperada de gás } \\
\text { carbônico }\end{array}$} & \multirow{3}{*}{8} & \multirow{3}{*}{$\mathrm{H} 17 / \mathrm{H} 25$} & \multirow{3}{*}{-} & \multirow{3}{*}{ N2/N3 } & \multirow{3}{*}{ N4 } \\
\hline $\begin{array}{l}\text { representação das quantidades } \\
\text { mínimas de cada substância a } \\
\text { partir de } 110 \mathrm{~g} \text { de amônia }\end{array}$ & & & & & & \\
\hline $\begin{array}{l}\text { verificação da quantidade de gás } \\
\text { carbônico pela Lei de } \\
\text { conservação das massa }\end{array}$ & & & & & & \\
\hline $\begin{array}{c}\text { cálculos parcialmente corretos } \\
\text { devido aos valores numéricos } \\
\text { adotados }\end{array}$ & $\begin{array}{c}\text { Erros de aproximação } \\
\text { numérica }\end{array}$ & 2 & $\mathrm{H} 17$ & - & N2 & - \\
\hline
\end{tabular}

Para melhor visualizarmos as categorias construídas e estabelecermos possíveis comparativos entre elas, construímos o gráfico a seguir (Figura 55), em que relacionamos as categorias criadas com as turmas participantes do projeto. 
Figura 55. Número de alunos por categorias referentes à questão 3 (I) do Instrumento 12.

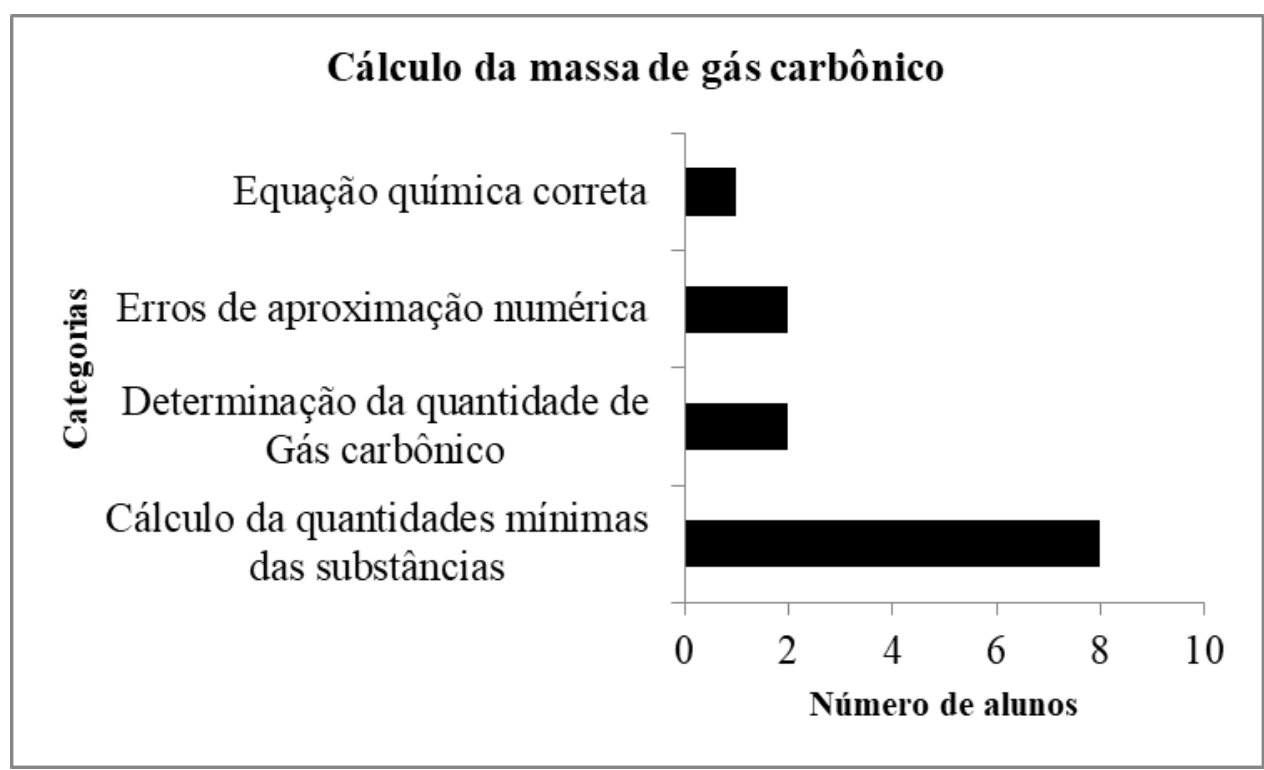

A tabela 47 apresenta, para a Questão, as decodificações criadas a partir das respostas dos alunos, as categorias criadas, as habilidades selecionadas a partir da matriz do ENEM, suscitadas pela questão para serem mobilizadas pelos estudantes e as classificações das respostas dos alunos em relação à níveis de cognições das mesmas.

Tabela 47. Categorização das respostas dos alunos referentes à questão 3 (II) do Instrumento 12.

\begin{tabular}{|c|c|c|c|c|c|c|}
\hline \multicolumn{7}{|c|}{ QUESTÃO 3 - Porque a massa é mínima? } \\
\hline \multirow[t]{2}{*}{ Decodificadores } & \multirow[t]{2}{*}{ Categoriais } & \multirow[t]{2}{*}{ Alunos } & \multirow{2}{*}{$\begin{array}{c}\text { Habilidades } \\
\text { ENEM }\end{array}$} & \multicolumn{3}{|c|}{ Respostas dos alunos } \\
\hline & & & & ALG & LOCS & HOCS \\
\hline $\begin{array}{c}\text { é o valor que falta para } \\
\text { completar a massa dos produtos }\end{array}$ & $\begin{array}{c}\text { Quantidades necessárias } \\
\text { das substâncias }\end{array}$ & 4 & $\mathrm{H} 17$ & - & $\mathrm{N} 2$ & - \\
\hline alteraria a massa dos produtos & \multirow{2}{*}{$\begin{array}{l}\text { Verificação de } \\
\text { proporção entre as } \\
\text { substâncias }\end{array}$} & \multirow{2}{*}{2} & \multirow{2}{*}{$\mathrm{H} 17 / \mathrm{H} 25$} & \multirow{2}{*}{-} & \multirow{2}{*}{$\mathrm{N} 2 / \mathrm{N} 3$} & \multirow{2}{*}{ N4 } \\
\hline toda a amônia foi consumida & & & & & & \\
\hline somente é mínima & $\begin{array}{c}\text { Afirmações não } \\
\text { conclusivas }\end{array}$ & 1 & H17 (parcial) & N1 & - & - \\
\hline
\end{tabular}

Para melhor visualizarmos as categorias construídas e estabelecermos possíveis comparativos entre elas, construímos o gráfico a seguir (Figura 56), em que relacionamos as categorias criadas com as turmas participantes do projeto. 
Figura 56. Número de alunos por categorias referentes à questão 3 (II) do Instrumento 12.

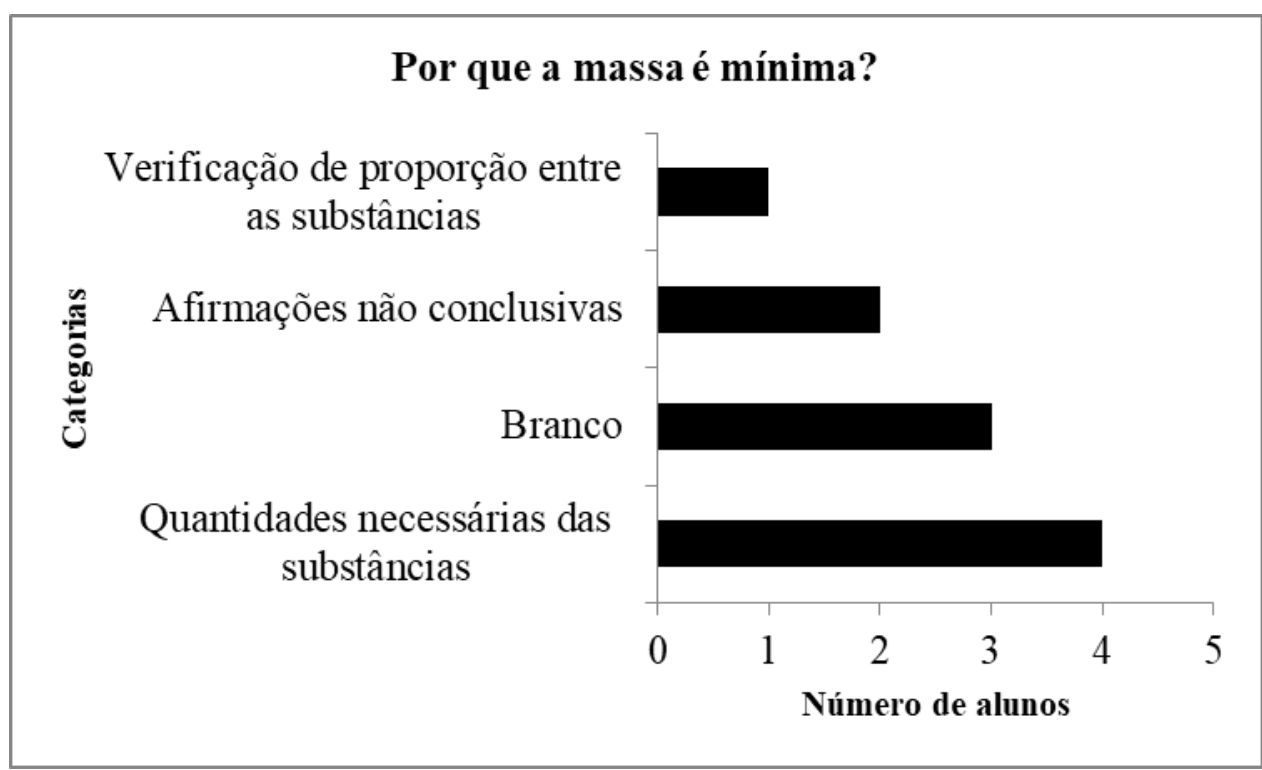

A tabela 48 apresenta, para a Questão, as decodificações criadas a partir das respostas dos alunos, as categorias criadas, as habilidades selecionadas a partir da matriz do ENEM, suscitadas pela questão para serem mobilizadas pelos estudantes e as classificações das respostas dos alunos em relação à níveis de cognições das mesmas.

Tabela 48. Categorização das respostas dos alunos referentes à questão 3 (III) do Instrumento 12.

\begin{tabular}{|c|c|c|c|c|c|c|}
\hline \multicolumn{7}{|c|}{ QUESTÃO 3 - E para uma massa maior de gás carbônico? } \\
\hline \multirow{2}{*}{ Decodificadores } & \multirow[t]{2}{*}{ Categoriais } & \multirow[t]{2}{*}{ Alunos } & \multirow{2}{*}{$\begin{array}{c}\text { Habilidades } \\
\text { ENEM } \\
\end{array}$} & \multicolumn{3}{|c|}{ Respostas dos alunos } \\
\hline & & & & ALG & LOCS & HOCS \\
\hline $\begin{array}{l}\text { deveria ser aumentada as } \\
\text { quantidades de amônia e gás } \\
\text { carbônico proporcionalmente }\end{array}$ & \multirow{5}{*}{$\begin{array}{l}\text { Percepção parcial } \\
\text { da proporção entre } \\
\text { as substâncias }\end{array}$} & \multirow{5}{*}{7} & \multirow{5}{*}{$\mathrm{H} 17 / \mathrm{H} 25$ (parcial) } & \multirow{5}{*}{ - } & \multirow{5}{*}{$\mathrm{N} 2 / \mathrm{N} 3$} & \multirow{5}{*}{ - } \\
\hline ocorreria sobra de gás carbônico & & & & & & \\
\hline $\begin{array}{c}\text { seria necessária maior quantidade } \\
\text { de amônia }\end{array}$ & & & & & & \\
\hline $\begin{array}{l}\text { aumentariam a massa dos } \\
\text { produtos }\end{array}$ & & & & & & \\
\hline $\begin{array}{c}\text { não teria amônia para produzir } \\
\text { nada }\end{array}$ & & & & & & \\
\hline $\begin{array}{c}\text { Não haveria proporcionalidade } \\
\text { pois haveria sobra de gás } \\
\text { carbônico }\end{array}$ & $\begin{array}{l}\text { Não identifica a } \\
\text { proporção entre as } \\
\text { substâncias } \\
\end{array}$ & 1 & H17(parcial) & $\mathrm{N} 1$ & - & - \\
\hline não respondeu & Branco & 2 & - & - & - & - \\
\hline
\end{tabular}

Para melhor visualizarmos as categorias construídas e estabelecermos possíveis comparativos entre elas, construímos o gráfico a seguir (Figura 57), em que relacionamos as categorias criadas com as turmas participantes do projeto. 
Figura 57. Número de alunos por categorias referentes à questão 2 (III) do Instrumento 12.

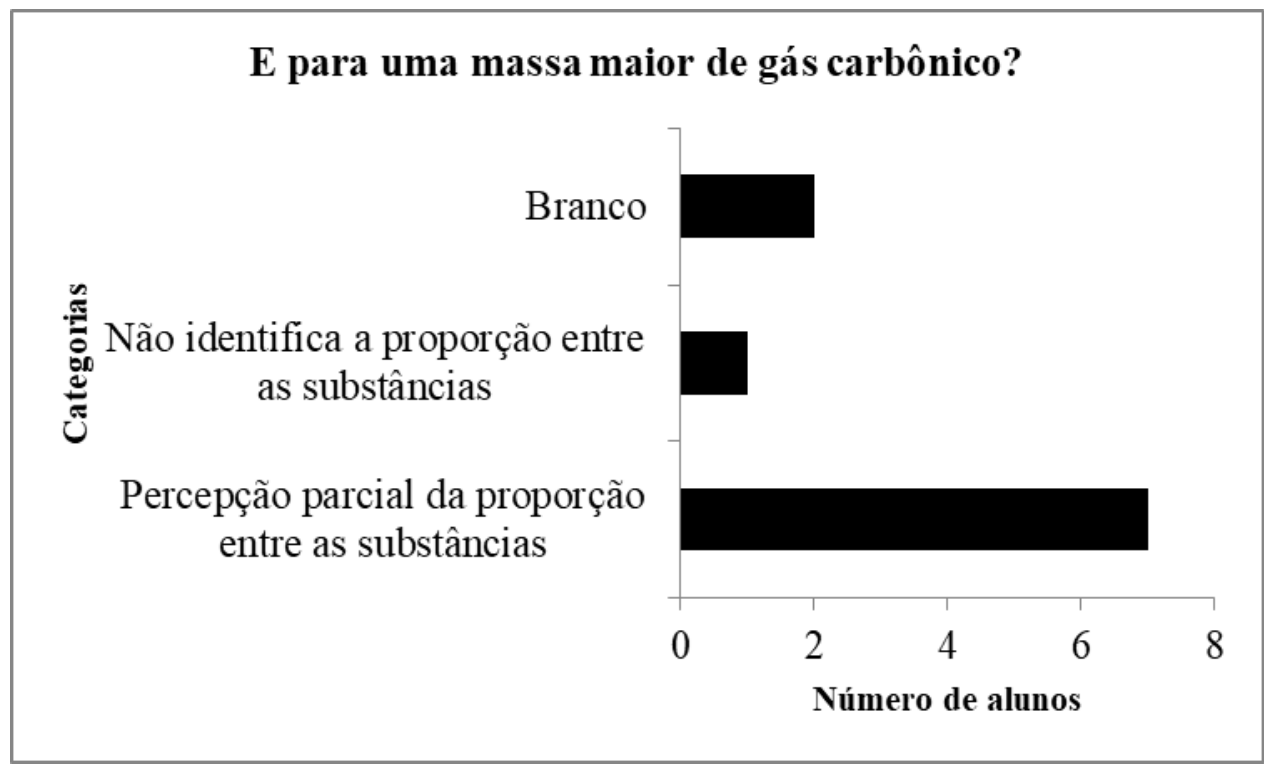

Assim como as outras questões deste instrumento, esta já havia sido aplicada no questionário diagnóstico. Com um índice de respostas em branco muito grande, ou seja, 83\% dos alunos não responderam a questão, neste momento julgamos fundamental uma reaplicação do problema para verificar possíveis evoluções dos mesmos em relação a construção de conhecimentos. Entretanto, o problema sofreu pequenos ajustes em seu enunciado. Em sua primeira versão, ao final do problema foi pedido aos alunos de forma direta que eles descrevessem como chegaram nos valores de massas pedidos na questão. Entendemos este questionamento muito objetivo, tornando-se um dos obstáculo de resolução, visto que certamente suas dificuldades iniciaram-se já na leitura do texto e na interpretação do gráfico. Assim, pensamos em aplicar novamente a questão com algumas dicas que promovessem reflexões por parte dos alunos no momento da resolução. Na primeira reflexão descrita seria proposto ao aluno pensar primeiramente na construção de uma equação química que pudesse representar tudo que estava sendo descrito no início da questão. Então, somente em uma próxima etapa de resolução os alunos deveriam interpretar o gráfico proposto. Esta sequência de pensamentos deveria auxiliar os alunos a perceberem que as informações gráficas representam somente a quantidade de três dos quatro compostos participantes da reação química. Após estas etapas de reflexões é que os alunos precisariam de informações conceituais sobre a conservação das quantidades dos materiais para finalizarem a resolução do problema.

Após a análise dos dados verificamos uma evolução dos alunos em relação a resolução da questão. A grande maioria dos alunos conseguiu calcular a quantidade de gás 
carbônico por meio da mobilização de duas habilidades importantes: eles conseguiram relacionar as informações descritas na tabela e identificaram as etapas e quantidades dos materiais necessários. Ao serem questionados sobre a massa de gás carbônico ser mínima, aproximadamente metade do número de alunos demonstrou entender a necessidade de somente certa massa de material para ocorrência da reação. No terceiro item da questão, em que foi questionada a hipótese de aumento da massa de gás carbônico, poucos alunos afirmaram a necessidade de aumento da quantidade das outras substâncias seguindo uma proporcionalidade. Afirmamos que, de fato, houve uma evolução na construção do conhecimento. Os alunos, que deixaram em branco a questão passaram a resolvê-la quase que de forma integral.

3.2.1.7 Instrumento 13 - instrumento de verificação de conhecimentos e habilidades construídas.

Este foi o único questionário i constituinte do quarto e último módulo da sequência de atividades. Sua principal finalidade foi semelhante a do questionário diagnóstico, entretanto, com um diferencial, a participação dos alunos, anterior a aplicação do questionário em atividades que problematizaram o ensino e a aprendizagem dos conceitos químicos presentes nas questões. O questionário foi organizado a partir de 6 questões, as quais tiveram como principal objetivo criações de Situações-problema aos alunos envolvendo conhecimentos sobre as transformações químicas dos materiais, formas de representação do processo, e a verificação de quantidades de materiais envolvidos nas reações considerando a conservação e a proporção em massa dos mesmos.

\section{QUESTÃO 1 - A seguir estão relacionados vários fenômenos. Assinale aqueles que você considera que são transformações químicas e justifique a resposta dada a cada um deles.}

\section{Enferrujamento de um carro}

A tabela 49 apresenta, para a Questão, as decodificações criadas a partir das respostas dos alunos, as categorias criadas, as habilidades selecionadas a partir da matriz do ENEM, suscitadas pela questão para serem mobilizadas pelos estudantes e as classificações das respostas dos alunos em relação à níveis de cognições das mesmas. 
Tabela 49. Categorização das respostas dos alunos referentes à questão 1 (I) do Instrumento 13.

\begin{tabular}{|c|c|c|c|c|c|c|}
\hline \multicolumn{7}{|c|}{ QUESTÃO 1 - Enferrujamento de um carro } \\
\hline Decodificadores & Categoriais & Alunos & Habilidades & \multicolumn{3}{|c|}{ Respostas dos alunos } \\
\hline & & & ENEM & ALG & LOCS & HOCS \\
\hline $\begin{array}{c}\text { reação entre } \\
\text { ambiente e } \\
\text { substâncias do carro }\end{array}$ & $\begin{array}{l}\text { Sim, reação entre o carro e o } \\
\text { ambiente }\end{array}$ & 1 & $\mathrm{H} 3 / \mathrm{H} 8$ & - & $\mathrm{N} 2 / \mathrm{N} 3$ & - \\
\hline $\begin{array}{l}\text { corrosão transforma } \\
\text { as moléculas }\end{array}$ & \multirow{2}{*}{$\begin{array}{c}\text { Sim, } \\
\text { oxidação/corrosão/enferrujamento }\end{array}$} & \multirow{2}{*}{6} & \multirow{2}{*}{$\mathrm{H} 3 / \mathrm{H} 8$} & \multirow{2}{*}{-} & \multirow{2}{*}{$\mathrm{N} 2 / \mathrm{N} 3$} & \multirow{2}{*}{ - } \\
\hline Enferrujamento & & & & & & \\
\hline $\begin{array}{l}\text { Mudança na } \\
\text { coloração }\end{array}$ & Sim, mudança na coloração & 1 & $\mathrm{H} 3 / \mathrm{H} 8$ & - & $\mathrm{N} 2$ & - \\
\hline mudança no metal & Sim, mudança no metal & 1 & H3/H8(parcial) & - & $\mathrm{N} 2$ & - \\
\hline
\end{tabular}

Para melhor visualizarmos as categorias construídas e estabelecermos possíveis comparativos entre elas, construímos o gráfico a seguir (Figura 58), em que relacionamos as categorias criadas com as turmas participantes do projeto.

Figura 58. Número de alunos por categorias referentes à questão 1 (I) do Instrumento 13.

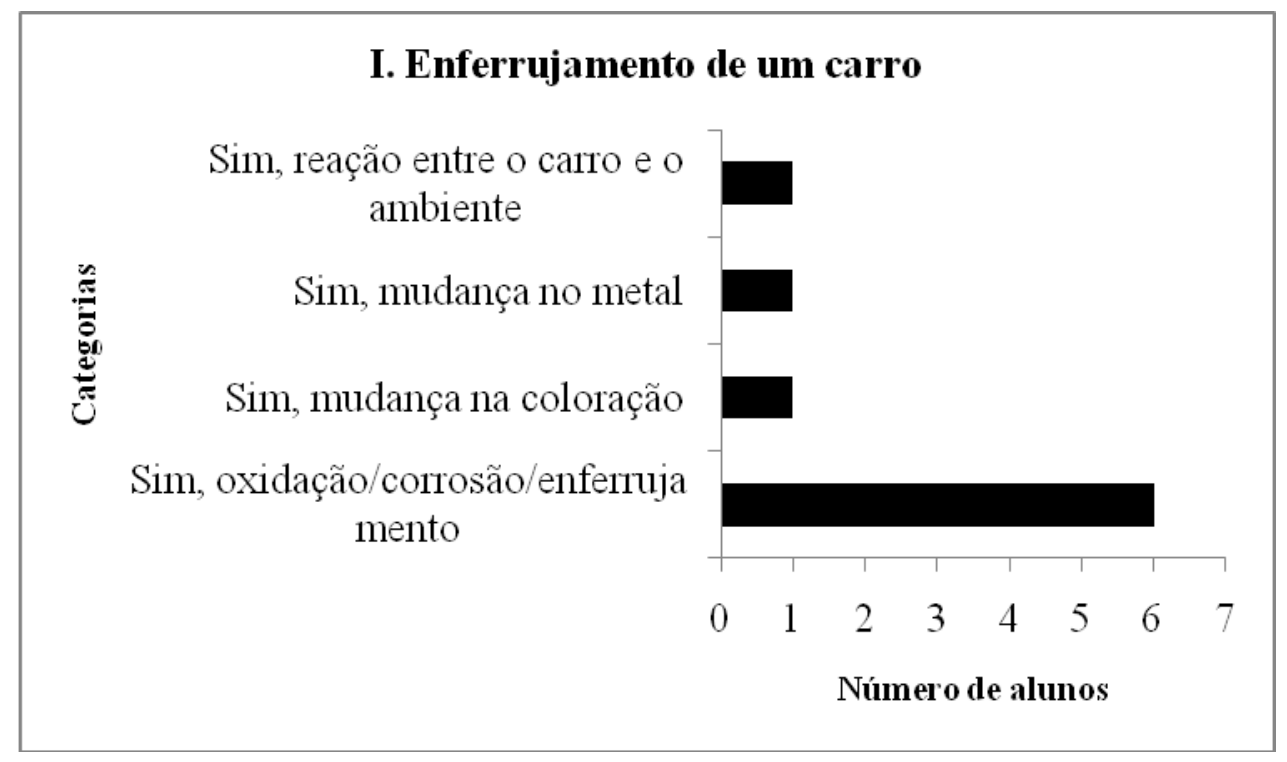

\section{Formação de bolor em alimentos}

A tabela 50 apresenta, para a Questão, as decodificações criadas a partir das respostas dos alunos, as categorias criadas, as habilidades selecionadas a partir da matriz do ENEM, suscitadas pela questão para serem mobilizadas pelos estudantes e as classificações das respostas dos alunos em relação à níveis de cognições das mesmas.

Tabela 50. Categorização das respostas dos alunos referentes à questão 1 (II) do Instrumento 13.

\begin{tabular}{|c|c|c|c|c|}
\hline \multicolumn{4}{|c|}{ QUESTÃO 1 - Formação de bolor em alimentos } \\
\hline Decodificadores & Categoriais & Aluno & Habilidades & Respostas dos alunos \\
\hline
\end{tabular}




\begin{tabular}{|c|c|c|c|c|c|c|}
\hline & & $\mathbf{s}$ & & & & \\
\hline & & & ENEM & ALG & LOCS & HOCS \\
\hline $\begin{array}{l}\text { formação do bolor é mas o } \\
\text { bolor não é um TQ }\end{array}$ & Não, só formou bolor & 1 & H3 & - & $\mathrm{N} 2$ & - \\
\hline liberação de substâncias & $\begin{array}{c}\text { Sim, liberação de } \\
\text { substâncias }\end{array}$ & 1 & $\begin{array}{c}\mathrm{H} 3 / \mathrm{H} 8 \\
\text { (parcial) }\end{array}$ & - & $\mathrm{N} 2$ & - \\
\hline $\begin{array}{l}\text { diferente aparência com } \\
\text { alteração na estrutura química }\end{array}$ & \multirow{3}{*}{$\begin{array}{c}\text { Sim, com alteração } \\
\text { visível da substância }\end{array}$} & \multirow{3}{*}{5} & \multirow{3}{*}{$\mathrm{H} 3 / \mathrm{H} 8$} & \multirow{3}{*}{-} & \multirow{3}{*}{$\mathrm{N} 2 / \mathrm{N} 3$} & \multirow{3}{*}{-} \\
\hline alteração na composição & & & & & & \\
\hline alteração de cor e cheiro & & & & & & \\
\hline $\begin{array}{c}\text { é uma transformação } \\
\text { biológica }\end{array}$ & \multirow{2}{*}{$\begin{array}{l}\text { Não, transformação } \\
\text { biológica }\end{array}$} & \multirow[t]{2}{*}{1} & \multirow[t]{2}{*}{$\mathrm{H} 3$} & \multirow[t]{2}{*}{-} & \multirow[t]{2}{*}{$\mathrm{N} 2$} & \multirow[t]{2}{*}{-} \\
\hline microrganismos amontoados & & & & & & \\
\hline surgimento de fungo & $\begin{array}{l}\text { Sim, transformação } \\
\text { biológica }\end{array}$ & 1 & H3 & - & $\mathrm{N} 2$ & - \\
\hline
\end{tabular}

Para melhor visualizarmos as categorias construídas e estabelecermos possíveis comparativos entre elas, construímos o gráfico a seguir (Figura 59), em que relacionamos as categorias criadas com as turmas participantes do projeto.

Figura 59. Número de alunos por categorias referentes à questão 1 (II) do Instrumento 13.

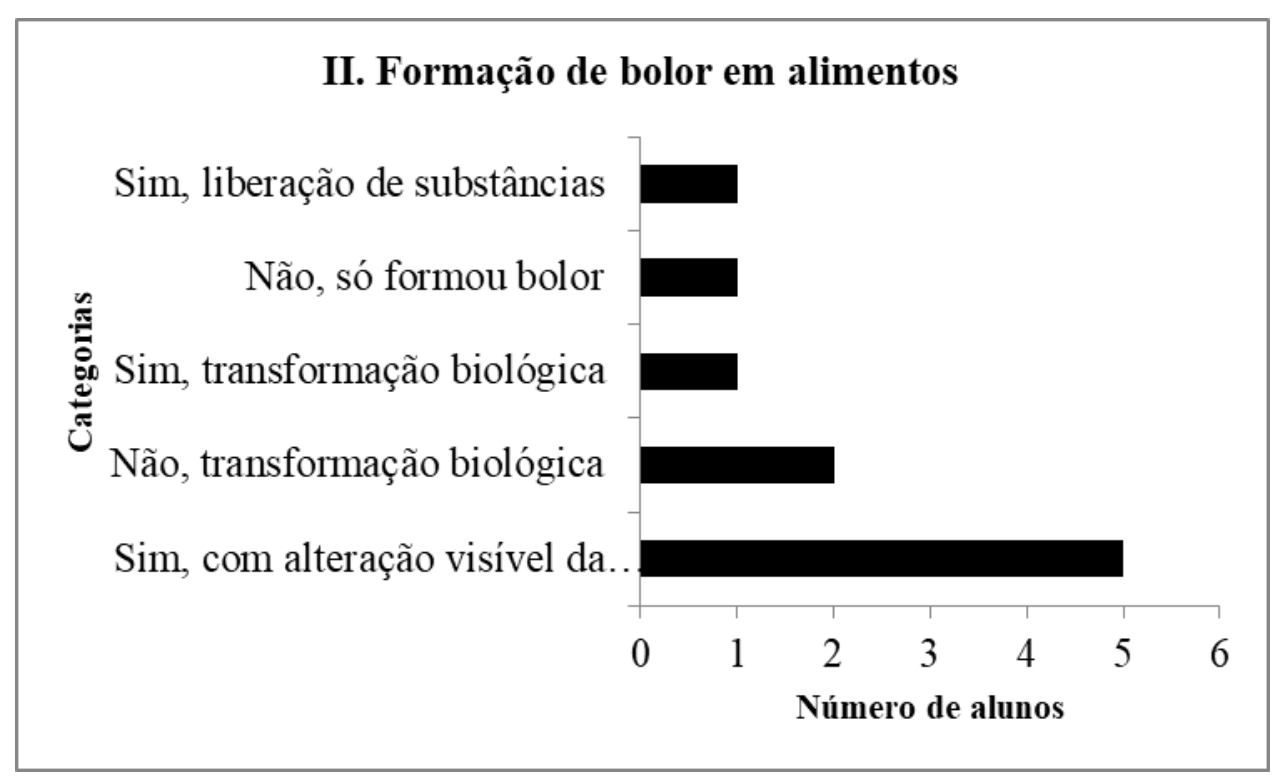

\section{Desgaste de uma construção pela chuva ácida.}

A tabela 51 apresenta, para a Questão, as decodificações criadas a partir das respostas dos alunos, as categorias criadas, as habilidades selecionadas a partir da matriz do ENEM, suscitadas pela questão para serem mobilizadas pelos estudantes e as classificações das respostas dos alunos em relação à níveis de cognições das mesmas. 
Tabela 51. Categorização das respostas dos alunos referentes à questão 1 (III) do Instrumento 13.

\begin{tabular}{|c|c|c|c|c|c|c|}
\hline \multicolumn{7}{|c|}{ QUESTÃO 1 - Desgaste de uma construção pela chuva ácida } \\
\hline \multirow[t]{2}{*}{ Decodificadores } & \multirow[t]{2}{*}{ Categoriais } & \multirow[t]{2}{*}{ Alunos } & \multirow{2}{*}{$\begin{array}{c}\text { Habilidades } \\
\text { ENEM } \\
\end{array}$} & \multicolumn{3}{|c|}{ Respostas dos alunos } \\
\hline & & & & ALG & LOCS & HOCS \\
\hline interação das substâncias & & & & & & \\
\hline reação ácida com o material & substâncias & 2 & $115 / 110$ & - & N2 & - \\
\hline corrosão na construção & $\begin{array}{l}\text { Sim, corrosão na } \\
\text { construção }\end{array}$ & 4 & $\mathrm{H} 3 / \mathrm{H} 8$ & - & $\mathrm{N} 2 / \mathrm{N} 3$ & - \\
\hline $\begin{array}{c}\text { as moléculas se quebram } \\
\text { retornando a sua forma } \\
\text { antiga }\end{array}$ & $\begin{array}{l}\text { Sim, moléculas se } \\
\text { quebram e voltam a } \\
\text { forma antiga }\end{array}$ & 1 & $\mathrm{H} 3 / \mathrm{H} 8$ (parcial) & - & $\mathrm{N} 2$ & - \\
\hline $\begin{array}{c}\text { alteração da composição dos } \\
\text { materiais }\end{array}$ & $\begin{array}{c}\text { Sim, alteração da } \\
\text { composição do } \\
\text { material }\end{array}$ & 1 & $\mathrm{H} 3 / \mathrm{H} 8$ (parcial) & - & $\mathrm{N} 2$ & - \\
\hline Sim & Sim & 1 & H3 & N1 & - & - \\
\hline
\end{tabular}

Para melhor visualizarmos as categorias construídas e estabelecermos possíveis comparativos entre elas, construímos o gráfico a seguir (Figura 60), em que relacionamos as categorias criadas com as turmas participantes do projeto.

Figura 60. Número de alunos por categorias referentes à questão 1 (III) do Instrumento 13.

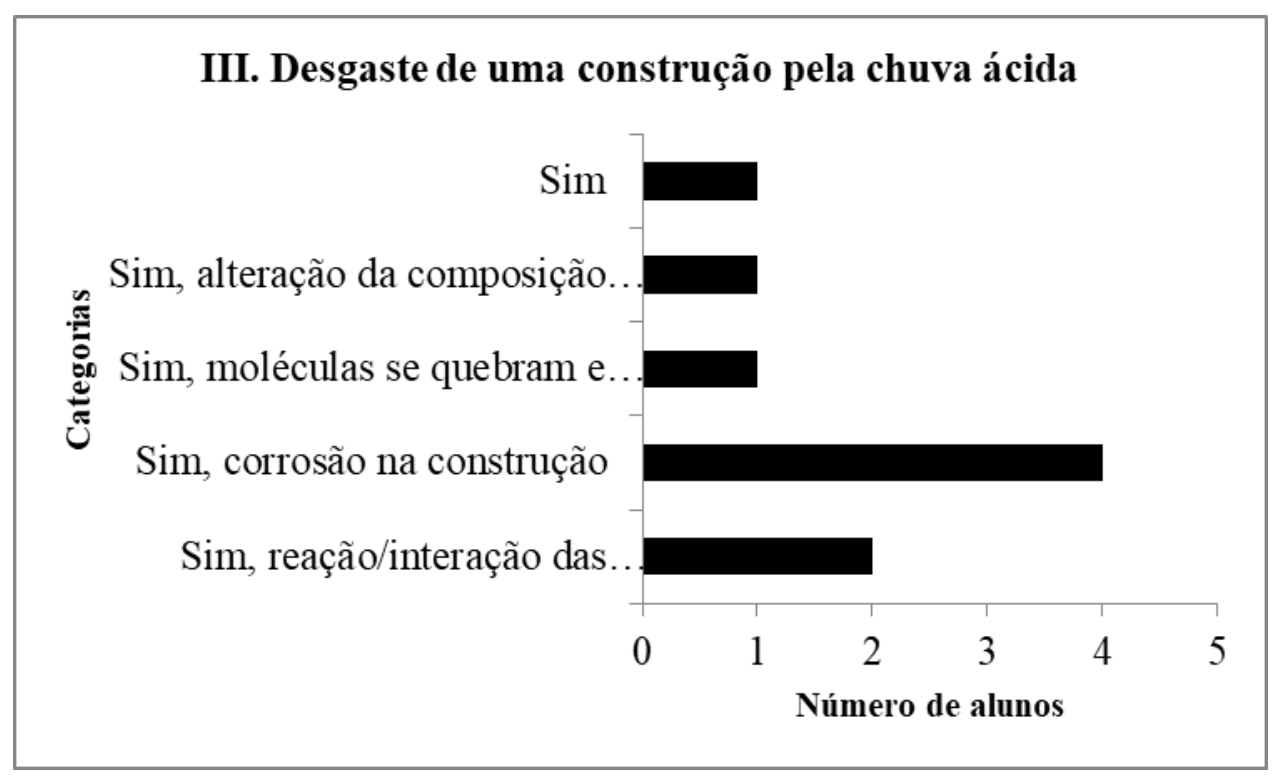

\section{Queima de Biocombustível}

A tabela 52 apresenta, para a Questão, as decodificações criadas a partir das respostas dos alunos, as categorias criadas, as habilidades selecionadas a partir da matriz do ENEM, suscitadas pela questão para serem mobilizadas pelos estudantes e as classificações das respostas dos alunos em relação à níveis de cognições das mesmas. 
Tabela 52. Categorização das respostas dos alunos referentes à questão 1 (IV) do Instrumento 13.

\begin{tabular}{|l|c|c|c|c|c|c|}
\hline \multicolumn{7}{|c|}{ QUESTÃO 1- Queima de Biocombustível } \\
\hline \multicolumn{1}{|c|}{ Decodificadores } & Categoriais & Alunos & Habilidades & \multicolumn{2}{c|}{ Respostas dos alunos } \\
\hline $\begin{array}{l}\text { formação de novo } \\
\text { produto/substância }\end{array}$ & $\begin{array}{c}\text { Sim, formação de } \\
\text { um novo produto }\end{array}$ & 3 & $\mathrm{H} 3 / \mathrm{H} 8$ & - & $\mathrm{N} 2 / \mathrm{N} 3$ & - \\
\hline $\begin{array}{l}\text { produção de } \mathrm{CO}_{2} \mathrm{e} \\
\text { mudança nos elementos }\end{array}$ & $\begin{array}{c}\text { Sim, produção de } \\
\text { CO2 e mudança nos } \\
\text { elementos }\end{array}$ & 3 & $\mathrm{H} 3 / \mathrm{H} 8$ & - & $\mathrm{N} 2$ & - \\
\hline $\begin{array}{l}\text { transformação de } \\
\text { substância em energia }\end{array}$ & $\begin{array}{c}\text { Sim, transformação } \\
\text { de substância em } \\
\text { energia }\end{array}$ & 2 & $\mathrm{H} 3 / \mathrm{H} 8($ parcial) & - & $\mathrm{N} 2$ & - \\
\hline combustão é TQ & $\begin{array}{c}\text { Sim, combustão é } \\
\text { transformação } \\
\text { química }\end{array}$ & 1 & $\mathrm{H} 3 / \mathrm{H} 8$ (parcial) & - & $\mathrm{N} 2$ & - \\
\hline
\end{tabular}

Pa Para melhor visualizarmos as categorias construídas e estabelecermos possíveis comparativos entre elas, construímos o gráfico a seguir (Figura 61), em que relacionamos as categorias criadas com as turmas participantes do projeto.

Figura 61. Número de alunos por categorias referentes à questão 1 (IV) do Instrumento 13.

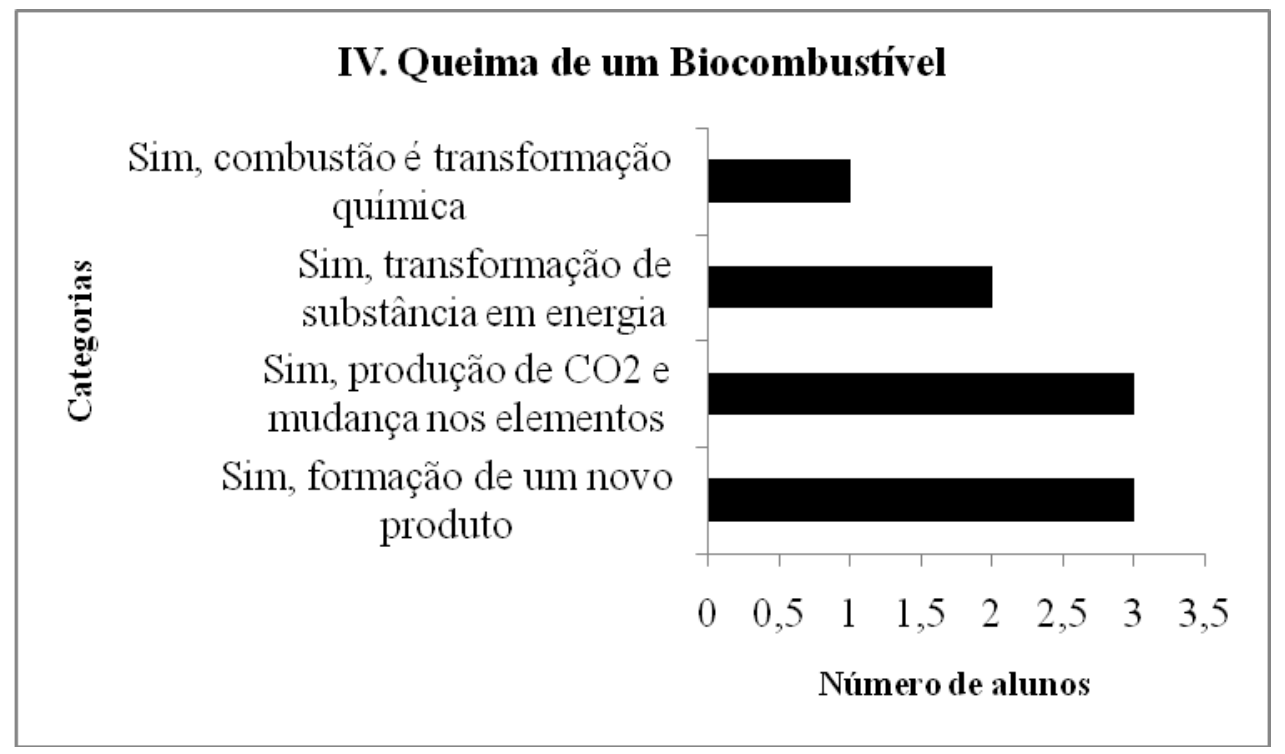

\section{Respiração humana}

A tabela 53 apresenta, para a Questão, as decodificações criadas a partir das respostas dos alunos, as categorias criadas, as habilidades selecionadas a partir da matriz do ENEM, suscitadas pela questão para serem mobilizadas pelos estudantes e as classificações das respostas dos alunos em relação à níveis de cognições das mesmas. 
Tabela 53. Número de alunos por categorias referentes à questão 1 (V) do Instrumento 13.

\begin{tabular}{|c|c|c|c|c|c|c|}
\hline \multicolumn{7}{|c|}{ QUESTÃO 1 - Respiração humana } \\
\hline \multirow[t]{2}{*}{ Decodificadores } & \multirow{2}{*}{ Categoriais } & \multirow[t]{2}{*}{ Alunos } & \multirow{2}{*}{$\begin{array}{c}\text { Habilidades } \\
\text { ENEM } \\
\end{array}$} & \multicolumn{3}{|c|}{ Respostas dos alunos } \\
\hline & & & & ALG & LOCS & HOCS \\
\hline $\begin{array}{c}\text { Sim, formação de nova } \\
\text { substância }\end{array}$ & $\begin{array}{l}\text { Sim, formação de } \\
\text { nova substância }\end{array}$ & 3 & $\mathrm{H} 3 / \mathrm{H} 8$ & - & $\mathrm{N} 2$ & - \\
\hline $\begin{array}{l}\text { Sim, entrada e saída de gases } \\
\text { distintos }\end{array}$ & $\begin{array}{l}\text { Sim, entrada e saída } \\
\text { de gases distintos }\end{array}$ & 3 & $\mathrm{H} 3 / \mathrm{H} 8$ & - & $\mathrm{N} 2$ & - \\
\hline Sim, liberação de gases & $\begin{array}{c}\text { Sim, liberação de } \\
\text { gases }\end{array}$ & 1 & H3/H8(parcial) & - & $\mathrm{N} 2$ & - \\
\hline $\begin{array}{l}\text { Não, entrada e saída de gases } \\
\text { distintos }\end{array}$ & $\begin{array}{l}\text { Não, entrada e } \\
\text { saída de gases } \\
\text { distintos }\end{array}$ & 1 & H3/H8(parcial) & - & N2 & - \\
\hline $\begin{array}{l}\text { Não, não há alteração na } \\
\text { composição }\end{array}$ & $\begin{array}{l}\text { Não, não há } \\
\text { alteração na } \\
\text { composição }\end{array}$ & 1 & H3 & N1 & ‘ & $\mathrm{X}$ \\
\hline
\end{tabular}

Para melhor visualizarmos as categorias construídas e estabelecermos possíveis comparativos entre elas, construímos o gráfico a seguir (Figura 62), em que relacionamos as categorias criadas com as turmas participantes do projeto.

Figura 62. Número de alunos por categorias referentes à questão 1 (V) do Instrumento 13.

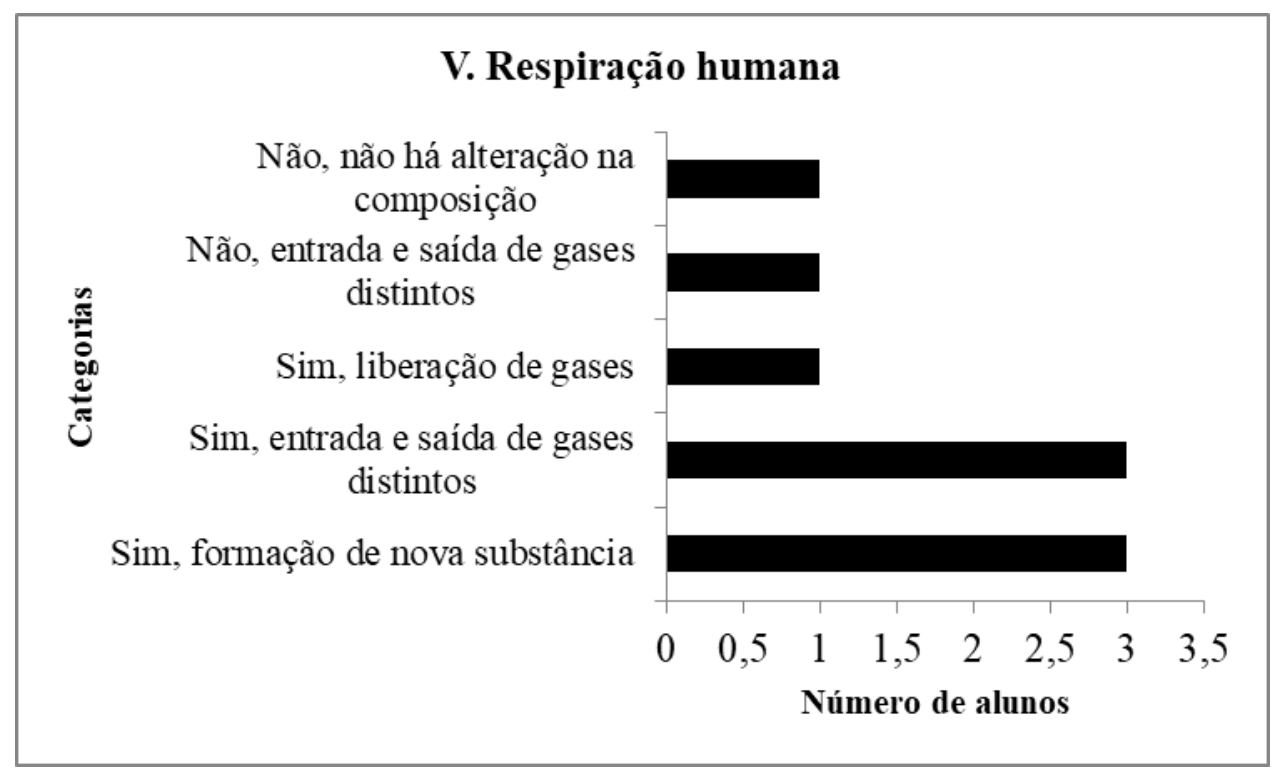

\section{Digestão de alimentos}

A tabela 54 apresenta, para a Questão, as decodificações criadas a partir das respostas dos alunos, as categorias criadas, as habilidades selecionadas a partir da matriz do ENEM, suscitadas pela questão para serem mobilizadas pelos estudantes e as classificações das respostas dos alunos em relação à níveis de cognições das mesmas. 
Tabela 54. Categorização das respostas dos alunos referentes à questão 1 (VI) do Instrumento 13.

\begin{tabular}{|c|c|c|c|c|c|c|}
\hline \multicolumn{7}{|c|}{ QUESTÃO 1 - Digestão de alimentos } \\
\hline Decodificadores & Categoriais & Alunos & Habilidades & & stas dos & unos \\
\hline & & & ENEM & ALG & LOCS & HOCS \\
\hline $\begin{array}{c}\text { transformação em } \\
\text { moléculas/partículas } \\
\text { menores }\end{array}$ & \multirow{3}{*}{$\begin{array}{l}\text { Sim, } \\
\text { transformação/altera } \\
\text { ção da molécula }\end{array}$} & \multirow{3}{*}{5} & \multirow{3}{*}{ H3/H8 } & \multirow{3}{*}{-} & \multirow{3}{*}{$\mathrm{N} 2 / \mathrm{N} 3$} & \multirow{3}{*}{ - } \\
\hline $\begin{array}{c}\text { alteração das moléculas } \\
\text { que são perdidas para o } \\
\text { organismo }\end{array}$ & & & & & & \\
\hline $\begin{array}{c}\text { quebra de carboidrato e } \\
\text { formação de dissacarídeo } \\
\text { alimentos são } \\
\text { processados e } \\
\text { transformados em } \\
\text { excrementos } \\
\end{array}$ & & & & & & \\
\hline $\begin{array}{c}\text { interação e quebra de } \\
\text { moléculas }\end{array}$ & $\begin{array}{c}\text { Sim, interação e } \\
\text { quebra de moléculas }\end{array}$ & 1 & $\mathrm{H} 3 / \mathrm{H} 8$ & - & $\mathrm{N} 2 / \mathrm{N} 3$ & - \\
\hline produção de energia & $\begin{array}{l}\text { Sim, produção de } \\
\text { energia }\end{array}$ & 1 & $\mathrm{H} 3 / \mathrm{H} 8$ (parcial) & - & $\mathrm{N} 2$ & - \\
\hline $\begin{array}{l}\text { derretimento e absorção } \\
\text { do alimento }\end{array}$ & $\begin{array}{l}\text { Sim, derretimento e } \\
\text { absorção do } \\
\text { alimento }\end{array}$ & 1 & H3/H8(parcial) & - & $\mathrm{N} 2$ & - \\
\hline Sim & Sim & 1 & $\mathrm{H} 3$ & N1 & - & - \\
\hline
\end{tabular}

Para melhor visualizarmos as categorias construídas e estabelecermos possíveis comparativos entre elas, construímos o gráfico a seguir (Figura 58), em que relacionamos as categorias criadas com as turmas participantes do projeto.

Figura 63. Número de alunos por categorias referentes à questão 1 (VI) do Instrumento 13.

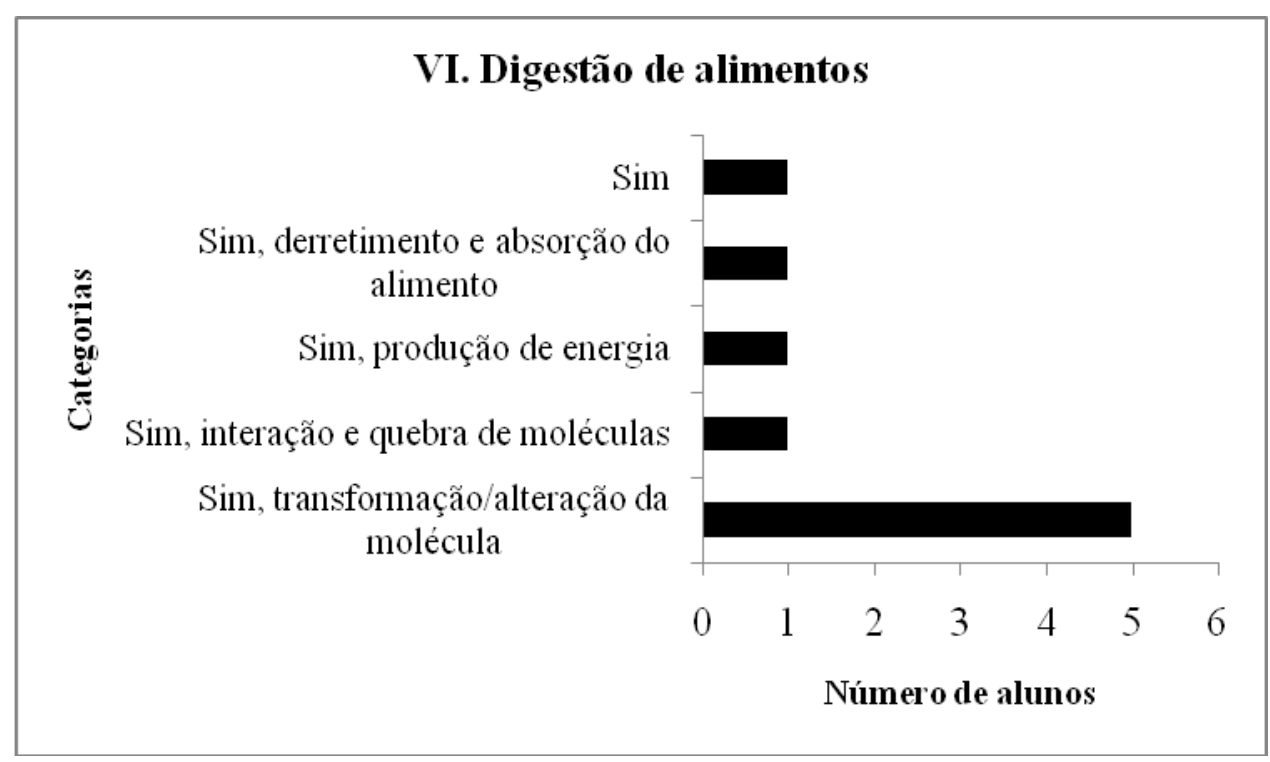

\section{Coagulação do Sangue}

A tabela 55 apresenta, para a Questão, as decodificações criadas a partir das respostas dos alunos, as categorias criadas, as habilidades selecionadas a partir da matriz do 
ENEM, suscitadas pela questão para serem mobilizadas pelos estudantes e as classificações das respostas dos alunos em relação à níveis de cognições das mesmas.

Tabela 55. Categorização das respostas dos alunos referentes à questão 1 (VII) do Instrumento 13.

\begin{tabular}{|c|c|c|c|c|c|c|}
\hline \multicolumn{7}{|c|}{ QUESTÃO 1 - Coagulação do Sangue } \\
\hline Decodificadores & Categoriais & Alunos & Habilidades & \multicolumn{3}{|c|}{ Respostas dos alunos } \\
\hline & & & ENEM & ALG & LOCS & HOCS \\
\hline Depende & Depende & 1 & $\mathrm{H} 3$ & N1 & - & - \\
\hline $\begin{array}{c}\text { altera a composição do } \\
\text { sangue }\end{array}$ & $\begin{array}{c}\text { Sim, alteração da } \\
\text { composição do sangue }\end{array}$ & 1 & $\mathrm{H} 3 / \mathrm{H} 8$ & - & $\mathrm{N} 2$ & - \\
\hline transformação física & Não, transformação física & 1 & $\mathrm{H} 3$ & N1 & - & - \\
\hline $\begin{array}{c}\text { reação do sangue com o } \\
\text { meio }\end{array}$ & $\begin{array}{c}\text { Não, reação do sangue } \\
\text { com o meio }\end{array}$ & 1 & $\mathrm{H} 3$ & $\mathrm{~N} 1$ & - & - \\
\hline não tem evidência de reação & $\begin{array}{l}\text { Não, pois não tem } \\
\text { evidência de reação }\end{array}$ & 1 & H3/H8(parcial) & - & $\mathrm{N} 2$ & - \\
\hline aglutinação de hemácias & \multirow{2}{*}{$\begin{array}{l}\text { Não, ocorreu uma } \\
\text { aglutinação de hemácias }\end{array}$} & \multirow{2}{*}{2} & \multirow{2}{*}{ H3/H8(parcial) } & \multirow{2}{*}{ - } & \multirow{2}{*}{$\mathrm{N} 2$} & \multirow{2}{*}{-} \\
\hline & & & & & & \\
\hline Não & Não & 2 & $\mathrm{H} 3$ & N1 & - & - \\
\hline
\end{tabular}

Para melhor visualizarmos as categorias construídas e estabelecermos possíveis comparativos entre elas, construímos o gráfico a seguir (Figura 64), em que relacionamos as categorias criadas com as turmas participantes do projeto.

Figura 64. Número de alunos por categorias referentes à questão 1 (VII) do Instrumento 13.

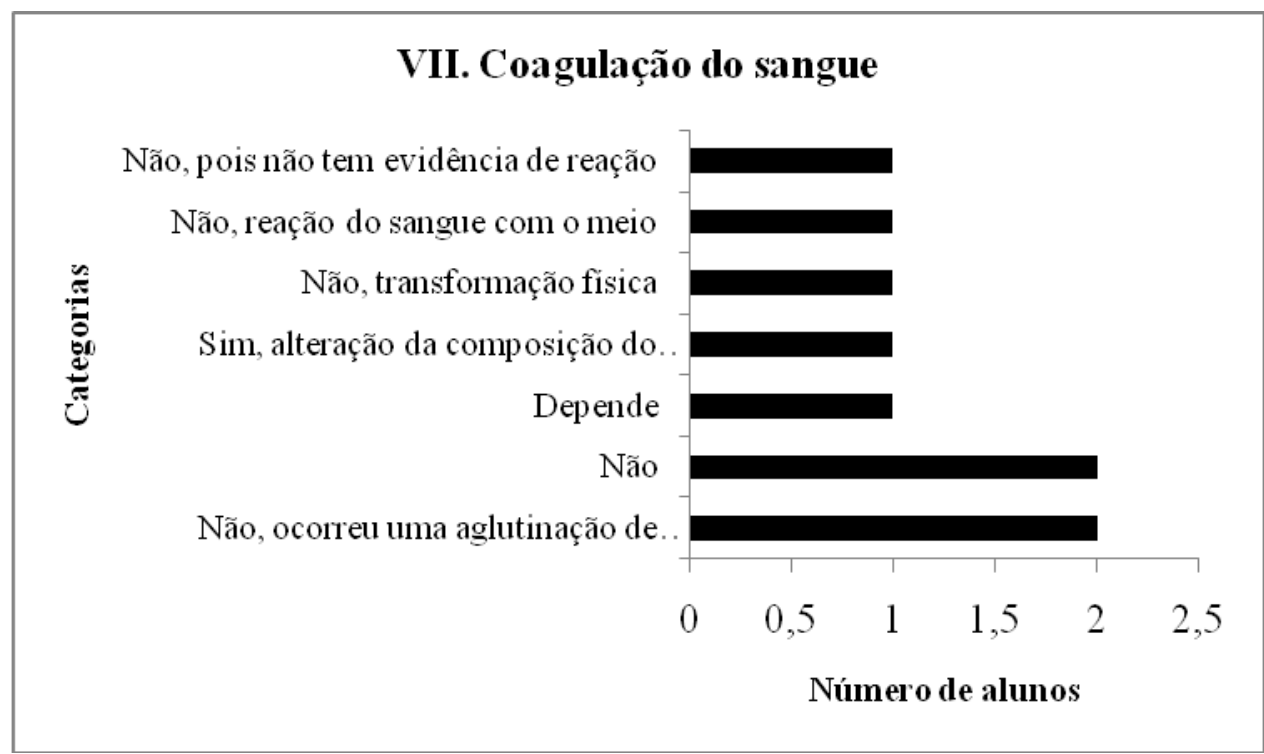

\section{Cozimento de um ovo}

A tabela 56 apresenta, para a Questão, as decodificações criadas a partir das respostas dos alunos, as categorias criadas, as habilidades selecionadas a partir da matriz do 
ENEM, suscitadas pela questão para serem mobilizadas pelos estudantes e as classificações das respostas dos alunos em relação à níveis de cognições das mesmas.

Tabela 56. Categorização das respostas dos alunos referentes à questão 1 (VIII) do Instrumento 13.

\begin{tabular}{|c|c|c|c|c|c|c|}
\hline \multicolumn{7}{|c|}{ QUESTÃO 1 - Cozimento de um ovo } \\
\hline Decodificadores & Categoriais & Alunos & Habilidades & $\operatorname{Res}$ & stas dos & lunos \\
\hline & & & ENEM & ALG & LOCS & HOCS \\
\hline $\begin{array}{c}\text { mudança nas proteínas da } \\
\text { clara mudança de cor e } \\
\text { textura }\end{array}$ & Sim, alteração das proteínas & 3 & $\mathrm{H} 3 / \mathrm{H} 8$ & - & $\mathrm{N} 2 / \mathrm{N} 3$ & - \\
\hline mudança de estado físico & $\begin{array}{c}\text { Sim, mudanças visíveis da } \\
\text { substância }\end{array}$ & 3 & $\mathrm{H} 3 / \mathrm{H} 8$ & - & $\mathrm{N} 2 / \mathrm{N} 3$ & - \\
\hline alteração da composição & $\begin{array}{l}\text { Sim, alteração na } \\
\text { composição }\end{array}$ & 1 & $\mathrm{H} 3 / \mathrm{H} 8$ & - & $\mathrm{N} 2 / \mathrm{N} 3$ & - \\
\hline $\begin{array}{l}\text { mudança de temperatura no } \\
\text { interior do alimento }\end{array}$ & $\begin{array}{l}\text { Não, alteração somente na } \\
\text { temperatura no interior do } \\
\text { alimento }\end{array}$ & 1 & $\mathrm{H} 3 / \mathrm{H} 8$ (parcial) & - & $\mathrm{N} 2$ & - \\
\hline Não & Não & 1 & H3 & N1 & - & - \\
\hline
\end{tabular}

Para melhor visualizarmos as categorias construídas e estabelecermos possíveis comparativos entre elas, construímos o gráfico a seguir (Figura 65), em que relacionamos as categorias criadas com as turmas participantes do projeto.

Figura 65. Número de alunos por categorias referentes à questão 1 (VIII) do Instrumento 13.

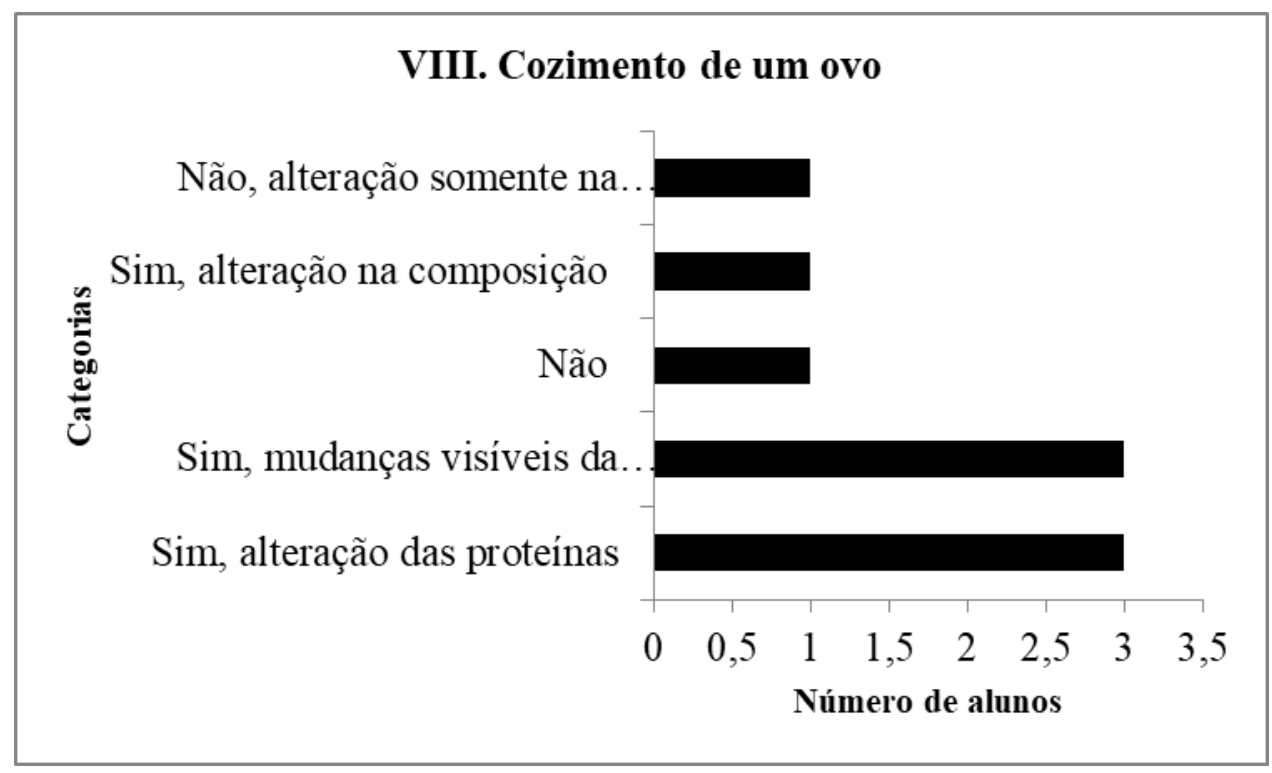

Nesta questão, assim como na primeira do questionário diagnóstico aplicado, os alunos deveriam identificar os fenômenos químicos justificando suas escolhas. Seria necessário reconhecer a situação apresentada identificando o que deveria ser buscado por meio da utilização de conceitos já conhecidos e relembrados. Os resultados da questão 
aplicada no questionário diagnóstico, de forma geral, já demonstraram que os alunos conseguiram reconhecer na maioria das situações cotidianas propostas as transformações químicas da matéria, sendo suas principais dificuldades os fenômenos naturais.

Após a análise da atual questão, os resultados foram ainda mais significativos. Quase que em sua totalidade, os alunos identificaram corretamente as transformações químicas. Talvez possamos afirmar que as justificativas ainda permaneceram em observações macroscópicas, como as evidências de reações, não havendo um aprofundamento de respostas. Também, os alunos utilizaram de alguns conceitos químicos, por exemplo oxidação e redução, mas que não podemos afirmar qual o nível de entendimento desses conceitos utilizados por eles. Outro ponto importante foi um aumento do número de alunos que passaram a entender as transformações naturais como químicas. De 9 alunos participantes das atividades, somente 3 deles ainda apresentam dificuldade no reconhecimento de processos naturais também como sendo transformações químicas. No início das atividades (instrumento 3) da sequência aproximadamente $80 \%$ dos alunos não reconheciam os fenômenos naturais como químicos. As discussões após a atividade experimental (instrumento 5) e leitura de um texto que complementava a formação de conceitos (instrumento 6) certamente auxiliaram no entendimento e construção conceitual e cognitiva.

QUESTÃo 2 - Um professor de Química em uma de suas aulas colocou um pouco de vinagre dentro de uma garrafa e prendeu uma bexiga contendo bicarbonato de sódio no gargalo da garrafa, conforme representado no esquema (Figura 1):

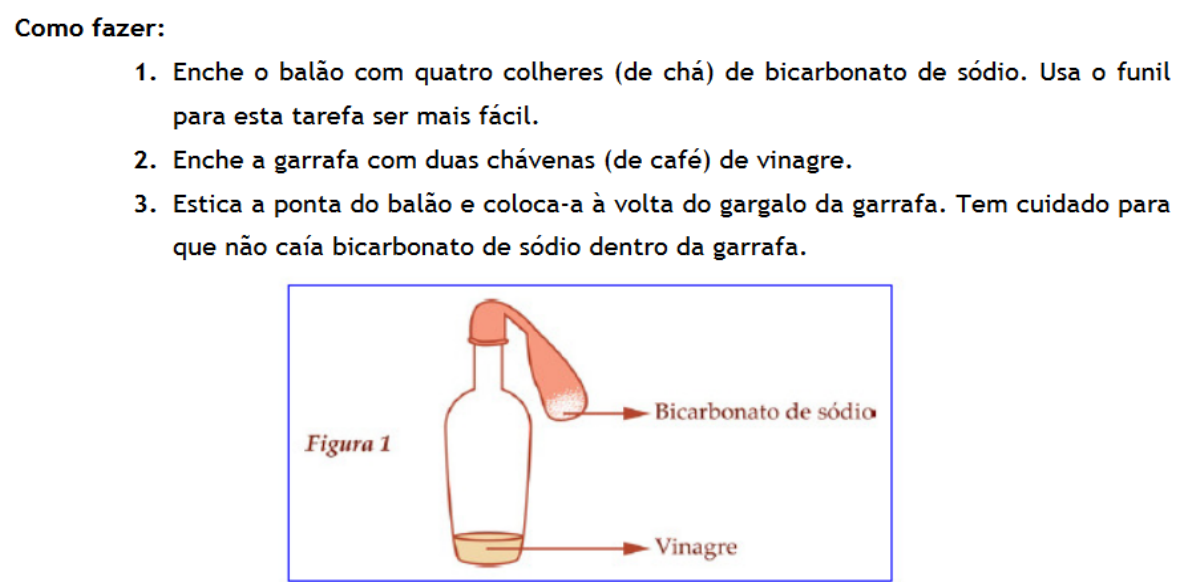

4. Endireita o balão rapidamente, de modo a que o bicarbonato caia no vinagre. Observa o que acontece.

Fonte: https://www.pavconhecimento.pt/media/media/801_quimica-1e2ciclo-encher-um-balao.pdf 
Em seguida, o professor esticou a ponta da bexiga de modo que todo o bicarbonato de sódio entrasse em contato com o vinagre contido na garrafa. Os alunos observaram a formação de uma efervescência e o enchimento do balão. Durante as discussões com seus alunos, chegou-se a conclusão que se tratava de uma transformação química que envolvia a reação entre o bicarbonato de sódio e o vinagre com formação do acetato de sódio, água e gás carbônico.

a) Indique quais são os reagentes e os produtos envolvidos nesta reação.

b) Represente essa transformação por meio de uma equação química (não é necessário o uso de fórmulas químicas).

A tabela 57 apresenta, para a Questão, as decodificações criadas a partir das respostas dos alunos, as categorias criadas, as habilidades selecionadas a partir da matriz do ENEM, suscitadas pela questão para serem mobilizadas pelos estudantes e as classificações das respostas dos alunos em relação à níveis de cognições das mesmas.

Tabela 57. Categorização das respostas dos alunos referentes à questão 2 (A) do Instrumento 13.

\begin{tabular}{|c|c|c|c|c|c|c|}
\hline \multicolumn{7}{|c|}{ QUESTÃO 2 - Indicação dos reagentes/produtos } \\
\hline Indicadores & Categoriais & Alunos & Habilidades & \multicolumn{2}{c|}{ Respostas dos alunos } \\
\hline $\begin{array}{c}\text { Indicação dos } \\
\text { reagentes/produtos }\end{array}$ & $\begin{array}{c}\text { Identificação dos } \\
\text { reagente/produtos }\end{array}$ & 4 & $\mathrm{H} 17 / \mathrm{H} 24$ & - & $\mathrm{N} 2 / \mathrm{N} 3$ & - \\
\hline $\begin{array}{c}\text { Representação correta da } \\
\text { equação química }\end{array}$ & $\begin{array}{c}\text { Representação de } \\
\text { uma equação } \\
\text { química }\end{array}$ & 7 & $\mathrm{H} 17 / \mathrm{H} 24$ & - & $\mathrm{N} 2 / \mathrm{N} 3$ & - \\
\hline
\end{tabular}

Para melhor visualizarmos as categorias construídas e estabelecermos possíveis comparativos entre elas, construímos o gráfico a seguir (Figura 66), em que relacionamos as categorias criadas com as turmas participantes do projeto. 
Figura 66. Número de alunos por categorias referentes à questão 2(A) do Instrumento 13.

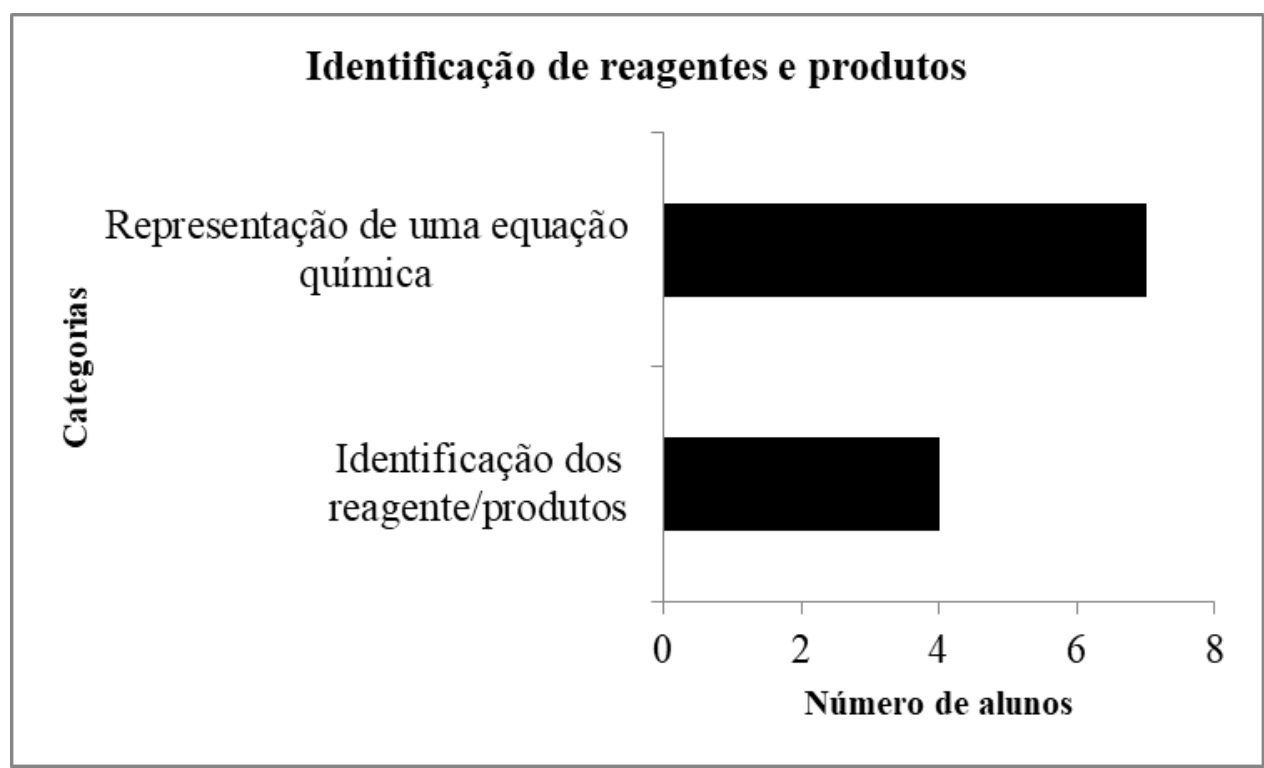

A tabela 58 apresenta, para a Questão, as decodificações criadas a partir das respostas dos alunos, as categorias criadas, as habilidades selecionadas a partir da matriz do ENEM, suscitadas pela questão para serem mobilizadas pelos estudantes e as classificações das respostas dos alunos em relação à níveis de cognições das mesmas.

Tabela 58. Categorização das respostas dos alunos referentes à questão 2 (B) do instrumento 13.

\begin{tabular}{|c|c|c|c|c|c|c|}
\hline \multicolumn{6}{|c|}{ QUESTÃO 2 - Representação da transformação por equação química } \\
\hline Indicadores & Categoriais & Alunos & Habilidades & \multicolumn{3}{c|}{ Respostas dos alunos } \\
\hline $\begin{array}{c}\text { Representação correta da } \\
\text { equação química }\end{array}$ & $\begin{array}{c}\text { Representação } \\
\text { correta da equação } \\
\text { química }\end{array}$ & 9 & H17/H24 & - & N2/N3 & - \\
\hline
\end{tabular}

Conforme já relatado, que o propósito central deste instrumento foi verificar todos os conhecimentos construídos ao longo de todas as atividades aplicadas, a abordagem tanto do item a quanto do b permearam questionamentos que já apareceram por diversas vezes em instrumentos anteriores. A partir dos resultados obtidos nos dois itens, concluímos que para este tipo de abordagem, os alunos são totalmente capazes de reconhecer a situação sem qualquer dificuldade na verificação de transformações dos materiais à nível macroscópico e também representacional (descrição dos componentes de uma reação).

QUESTÃO 3 - Nas indústrias siderúrgicas o gás monóxido de carbono (CO), formado na combustão incompleta do carvão, reagirá com o óxido de ferro III $\left(\mathrm{Fe}_{2} \mathrm{O}_{3}\right)$ extraído do minério de ferro, ocorrendo a formação de ferro líquido (Fe) e o gás dióxido de carbono 
$\left(\mathrm{CO}_{2}\right)$. $\mathrm{O}$ responsável técnico pelo monitoramento da reação elaborou um relatório sobre as três últimas tiragens da produção do ferro líquido. $O$ relatório apresenta a seguinte tabela:

\begin{tabular}{|c|c|c|c|c|}
\hline Tiragem & $\begin{array}{c}\text { Massa do óxido } \\
\text { de ferro III (g) } \\
\left(\mathrm{Fe}_{2} \mathrm{O}_{3}\right)\end{array}$ & $\begin{array}{c}\text { Massa do } \\
\text { monóxido de } \\
\text { carbono }(\mathrm{g})\end{array}$ & Massa do ferro $(\mathrm{g})$ & $\begin{array}{c}\text { Massa do dióxido } \\
\text { de carbono }(\mathrm{g}) \\
(\mathrm{CO})\end{array}$ \\
\hline 1 & 320 & 168 & 224 & $\mathrm{X}$ \\
\hline 2 & 800 & $\left.\mathrm{CO})_{2}\right)$ & 660 \\
\hline 3 & $\mathrm{Z}$ & 672 & 560 & 1056 \\
\hline
\end{tabular}

Considerando que não há excesso de reagentes, e que toda a quantidade de reagentes se transformou em produtos em uma reação completa, responda os itens que se seguem:

a) Observe as tiragens 1 e 2. Determine as quantidades de dióxido de carbono $\left(\mathrm{CO}_{2}(\mathrm{~g})\right)$ produzido na primeira tiragem e de monóxido de carbono $\left(\mathrm{CO}_{(\mathrm{g})}\right)$ consumido na segunda tiragem.

b) Comparando as medidas obtidas da tiragem $1 \mathrm{com}$ a tiragem 3 é possível estabelecer uma relação entre elas? Determine os valores das medidas que estão faltando da tiragem 3.

A tabela 59 apresenta, para a Questão, as decodificações criadas a partir das respostas dos alunos, as categorias criadas, as habilidades selecionadas a partir da matriz do ENEM, suscitadas pela questão para serem mobilizadas pelos estudantes e as classificações das respostas dos alunos em relação à níveis de cognições das mesmas.

Tabela 59. Categorização das respostas dos alunos referentes à questão 3 (A) do Instrumento 13.

\begin{tabular}{|c|c|c|c|c|c|c|}
\hline \multicolumn{7}{|c|}{ QUESTÃO 3 - Determinação das quantidades de $\mathrm{CO}_{2}$ e $\mathrm{CO}$} \\
\hline \multirow[t]{2}{*}{ Indicadores } & \multirow{2}{*}{ Categoriais } & \multirow{2}{*}{ Alunos } & \multirow{2}{*}{$\begin{array}{c}\text { Habilidades } \\
\text { ENEM } \\
\end{array}$} & \multicolumn{3}{|c|}{ Respostas dos alunos } \\
\hline & & & & ALG & LOCS & HOCS \\
\hline $\begin{array}{l}\text { Obtenção das quantidades } \\
\text { corretas de ambas as } \\
\text { substâncias }\end{array}$ & \multirow{2}{*}{$\begin{array}{l}\text { Quantidades } \\
\text { corretas e } \\
\text { verificação de } \\
\text { proporção }\end{array}$} & \multirow{2}{*}{8} & \multirow{2}{*}{$\mathrm{H} 17 / \mathrm{H} 25$} & \multirow{2}{*}{-} & \multirow{2}{*}{$\mathrm{N} 2 / \mathrm{N} 3$} & \multirow{2}{*}{ N4 } \\
\hline $\begin{array}{l}\text { Verificação de proporção } \\
\text { entre as substâncias de uma } \\
\text { tiragem }\end{array}$ & & & & & & \\
\hline $\begin{array}{l}\text { Obtenção de quantidades } \\
\text { diferentes das esperadas }\end{array}$ & $\begin{array}{l}\text { Quantidades } \\
\text { diferentes do } \\
\text { esperado e }\end{array}$ & 1 & $\mathrm{H} 17 / \mathrm{H} 25$ (parcial) & - & $\mathrm{N} 2 / \mathrm{N} 3$ & - \\
\hline
\end{tabular}




\begin{tabular}{|l|l|l|l|l|l|l|}
\hline & $\begin{array}{c}\text { verificação de } \\
\text { proporção }\end{array}$ & & & & & \\
\hline
\end{tabular}

Para melhor visualizarmos as categorias construídas e estabelecermos possíveis comparativos entre elas, construímos o gráfico a seguir (Figura 67), em que relacionamos as categorias criadas com as turmas participantes do projeto.

Figura 67. Número de alunos por categorias referentes à questão 3 (A) do Instrumento 13.

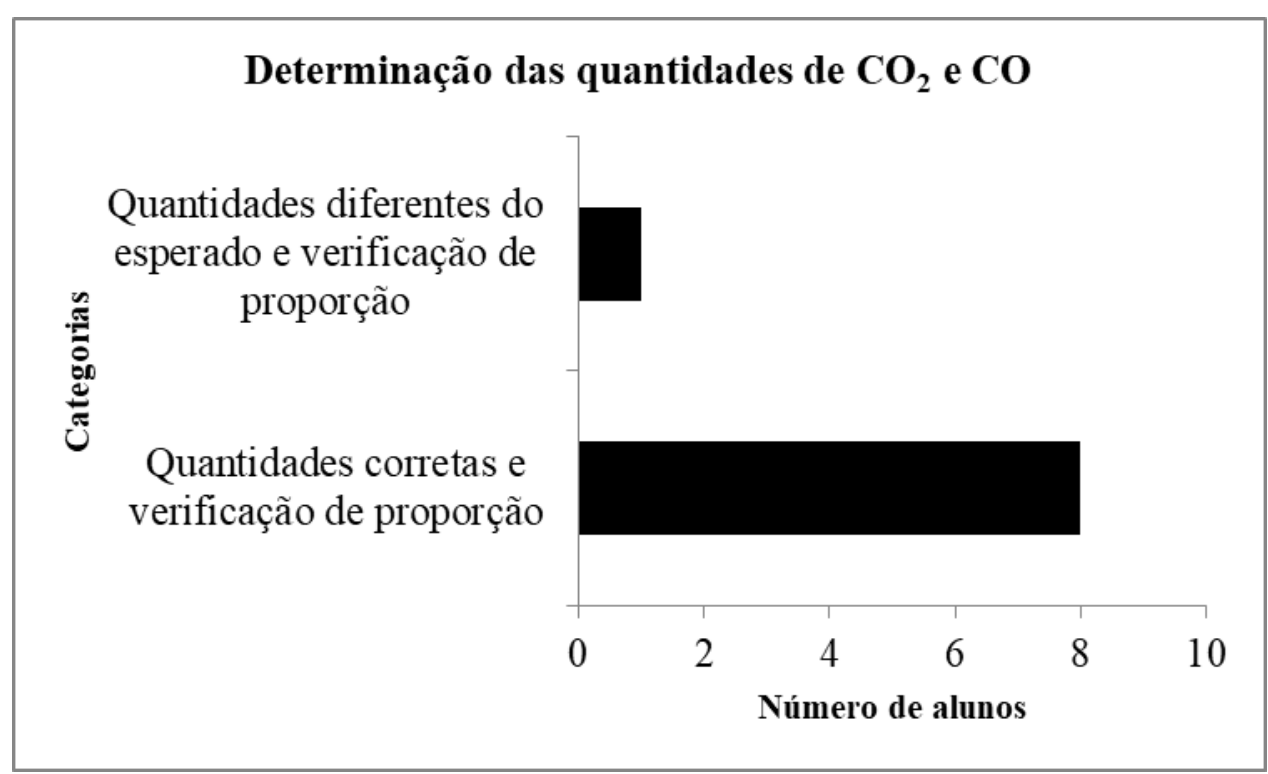

A tabela 60 apresenta, para a Questão, as decodificações criadas a partir das respostas dos alunos, as categorias criadas, as habilidades selecionadas a partir da matriz do ENEM, suscitadas pela questão para serem mobilizadas pelos estudantes e as classificações das respostas dos alunos em relação à níveis de cognições das mesmas.

Tabela 60. Categorização das respostas dos alunos referentes à questão 3 (B) do Instrumento 13.

\begin{tabular}{|c|c|c|c|c|c|c|}
\hline \multicolumn{7}{|c|}{ QUESTÃO 3 - Relação entre as tiragens? Cálculo das quantidades } \\
\hline Indicadores & Categoriais & Alunos & Habilidades & & stas dos & unos \\
\hline & & & ENEM & ALG & LOCS & HOCS \\
\hline $\begin{array}{l}\text { Verificação de proporção } \\
\text { entre as tiragens }\end{array}$ & \multirow{2}{*}{$\begin{array}{l}\text { Quantidades } \\
\text { corretas e } \\
\text { verificação de } \\
\text { proporção }\end{array}$} & \multirow[b]{2}{*}{7} & \multirow[b]{2}{*}{$\mathrm{H} 17 / \mathrm{H} 25$} & \multirow[b]{2}{*}{ - } & \multirow[b]{2}{*}{$\mathrm{N} 2 / \mathrm{N} 3$} & \multirow[b]{2}{*}{ N4 } \\
\hline $\begin{array}{c}\text { Obtenção das quantidades } \\
\text { esperadas para todas as } \\
\text { substâncias }\end{array}$ & & & & & & \\
\hline $\begin{array}{c}\text { Verificação de proporção em } \\
\text { uma única tiragem }\end{array}$ & \multirow{2}{*}{$\begin{array}{l}\text { Valores encontrados } \\
\text { distintos do } \\
\text { esperado }\end{array}$} & \multirow[b]{2}{*}{1} & \multirow{2}{*}{$\begin{array}{l}\mathrm{H} 17 / \mathrm{H} 25 \\
\text { (parcial) }\end{array}$} & \multirow[b]{2}{*}{-} & \multirow[b]{2}{*}{$\mathrm{N} 2 / \mathrm{N} 3$} & \multirow[b]{2}{*}{-} \\
\hline $\begin{array}{l}\text { Obtenção de quantidades } \\
\text { diferentes das esperadas para } \\
\text { todas as substâncias }\end{array}$ & & & & & & \\
\hline
\end{tabular}


Verificação de proporção, mas obtenção das quantidades esperadas para 3 substâncias
Valores encontrados
parcialmente

\begin{tabular}{|c|c|c|c|}
\hline $\begin{array}{c}\mathrm{H} 17 / \mathrm{H} 25 \\
\text { (parcial) }\end{array}$ & - & $\mathrm{N} 2 / \mathrm{N} 3$ & - \\
\hline
\end{tabular}

Para melhor visualizarmos as categorias construídas e estabelecermos possíveis comparativos entre elas, construímos o gráfico a seguir (Figura 68), em que relacionamos as categorias criadas com as turmas participantes do projeto.

Figura 68. Número de alunos por categorias referentes à questão 3 (B) do Instrumento 13.

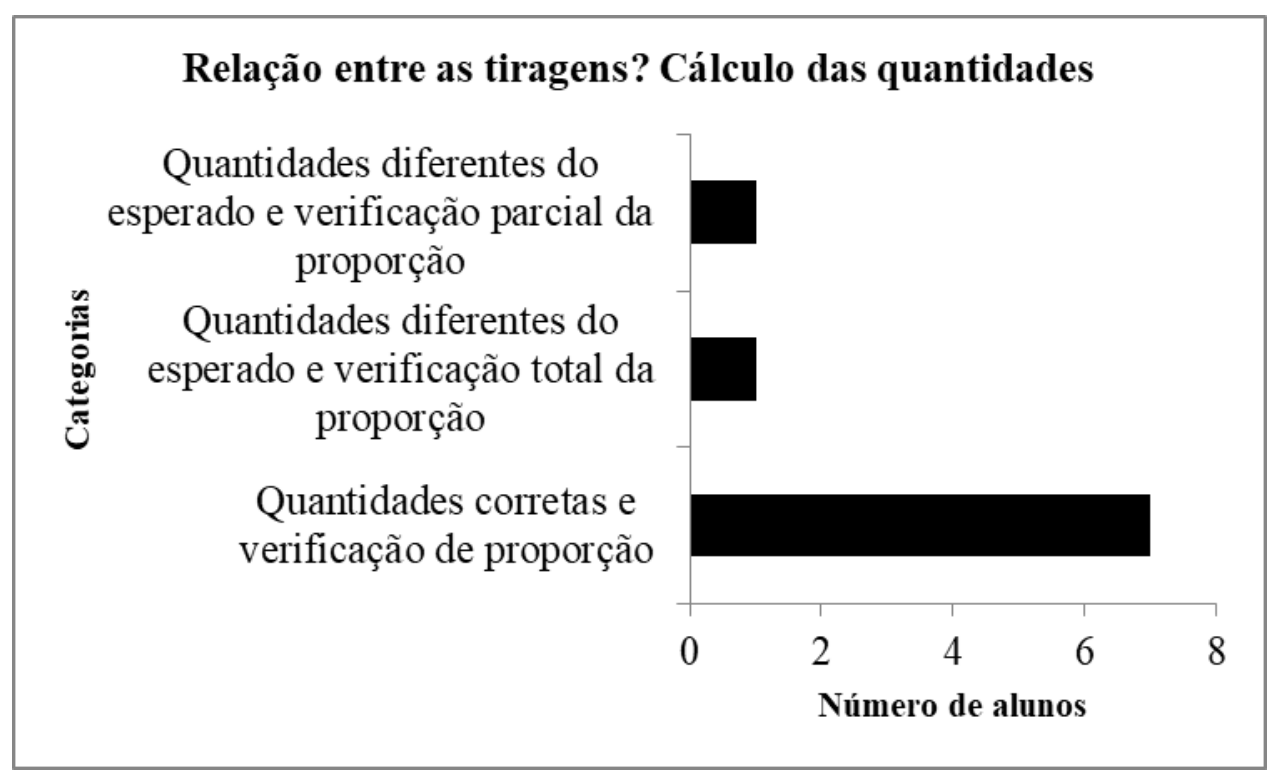

Esta questão trouxe novamente situações envolvendo conceitos referentes às “Grandezas Químicas” e as "Relações quantitativas". Verificamos ao longo das atividades que desenvolver habilidades para a resolução deste tipo de problema foram as maiores dificuldades enfrentadas pelos alunos, sendo que diversas vezes as resoluções dos problemas não foram concluídas.

Após as análises dos dados, os resultados atuais nos mostraram uma mudança significativa. Entre 7 a 8 alunos de um total de 10 conseguiram resolver esta questão. Estes resultados nos mostraram que para encontrarem as resoluções apropriadas os alunos reconheceram as Situações-problema, identificaram o que deveria ser buscado, identificaram as variáveis envolvidas e o mais importante, foram capazes de estabelecer processos de controle diante das informações selecionadas. Esses resultados apontam que foram superadas dificuldades de raciocínio matemático, e também no estabelecimento de proporção entre as massas de reagentes e produtos. 
QUESTÃO 4 - (Questão 59 - ENEM 2012 - adaptado)

No Japão, um movimento nacional para a promoção da luta contra o aquecimento global leva o slogan: 1 pessoa, 1 dia, $1 \mathrm{~kg}$ de $\mathrm{CO}_{2}$ a menos! A ideia é cada pessoa reduzir em $1 \mathrm{~kg}$ a quantidade de $\mathrm{CO}_{2}$ emitida todo dia, por meio de pequenos gestos ecológicos como diminuir a queima de gás de cozinha. Um hambúrguer ecológico? É pra já!

Disponível em: http://lqes.iqm.unicamp.br. Acesso em: 24 fev. 2012 (adaptado).

A reação abaixo representa o processo de queima do gás de cozinha bem como quantidades, em gramas, das substâncias envolvidas na reação.

\begin{tabular}{|c|c|}
\hline & $8 \mathrm{CO}_{2}+10 \mathrm{H}_{2} \mathrm{O}$ \\
\hline $\mathrm{C}_{4} \mathrm{H}_{10}$ & $\mathrm{CO}_{2}$ \\
\hline $116 \mathrm{~g}$ & $352 \mathrm{~g}$ \\
\hline
\end{tabular}

a) Qual a quantidade mínima, em gramas, desse gás que um japonês deve deixar de queimar para atender à meta diária?

b) No quadro foi representada a equação da reação de combustão do gás de cozinha (supondo que este gás seja formado apenas de butano). A equação foi balanceada adequadamente? Como você chegou a essa resposta?

A tabela 61 apresenta, para a Questão, as decodificações criadas a partir das respostas dos alunos, as categorias criadas, as habilidades selecionadas a partir da matriz do ENEM, suscitadas pela questão para serem mobilizadas pelos estudantes e as classificações das respostas dos alunos em relação à níveis de cognições das mesmas.

Tabela 61. Categorização das respostas dos alunos referentes à questão 4 (A) do Instrumento 13.

\begin{tabular}{|c|c|c|c|c|c|c|}
\hline \multicolumn{7}{|c|}{ QUESTÃO 4 - Determinação do gás } \\
\hline Indicadores & Categoriais & Alunos & Habilidades & \multicolumn{2}{c|}{ Respostas dos alunos } \\
\hline branco & Branco & 2 & - & - & - & ENEM \\
\hline $\begin{array}{c}\text { Quantidade correta do } \\
\text { gás }\end{array}$ & $\begin{array}{c}\text { Quantidade correta do } \\
\text { gás }\end{array}$ & 3 & H17/H25 & - & N2/N3 & N4 \\
\hline $\begin{array}{c}\text { Quantidade incorreta } \\
\text { pois considera } \\
\text { novamente a proporção } \\
\text { das substâncias }\end{array}$ & $\begin{array}{c}\text { Quantidade incorreta pois } \\
\text { considera novamente a } \\
\text { proporção das substâncias }\end{array}$ & 2 & $\begin{array}{c}\text { H17/H25 } \\
\text { (parcial) }\end{array}$ & - & N2/N3 & - \\
\hline $\begin{array}{c}\text { Quantidade incorreta } \\
\text { com raciocínio } \\
\text { matemático não } \\
\text { identificado }\end{array}$ & $\begin{array}{c}\text { Quantidade incorreta com } \\
\text { raciocínio matemático não } \\
\text { identificado }\end{array}$ & 1 & H17 & N1 & - & - \\
\hline $\begin{array}{c}\text { Quantidade incorreta } \\
\text { devido ao erro em }\end{array}$ & $\begin{array}{c}\text { Quantidade incorreta } \\
\text { devido ao erro em }\end{array}$ & 1 & $\begin{array}{c}\text { H17/H25 } \\
\text { (parcial) }\end{array}$ & - & N2/N3 & - \\
\hline
\end{tabular}




\begin{tabular}{|l|l|l|l|l|l|l|}
\hline operações matemáticas & operações matemáticas & & & & & \\
\hline
\end{tabular}

Para melhor visualizarmos as categorias construídas e estabelecermos possíveis comparativos entre elas, construímos o gráfico a seguir (Figura 69), em que relacionamos as categorias criadas com as turmas participantes do projeto.

Figura 69. Número de alunos por categorias referentes à questão 4 (A) do Instrumento 13.

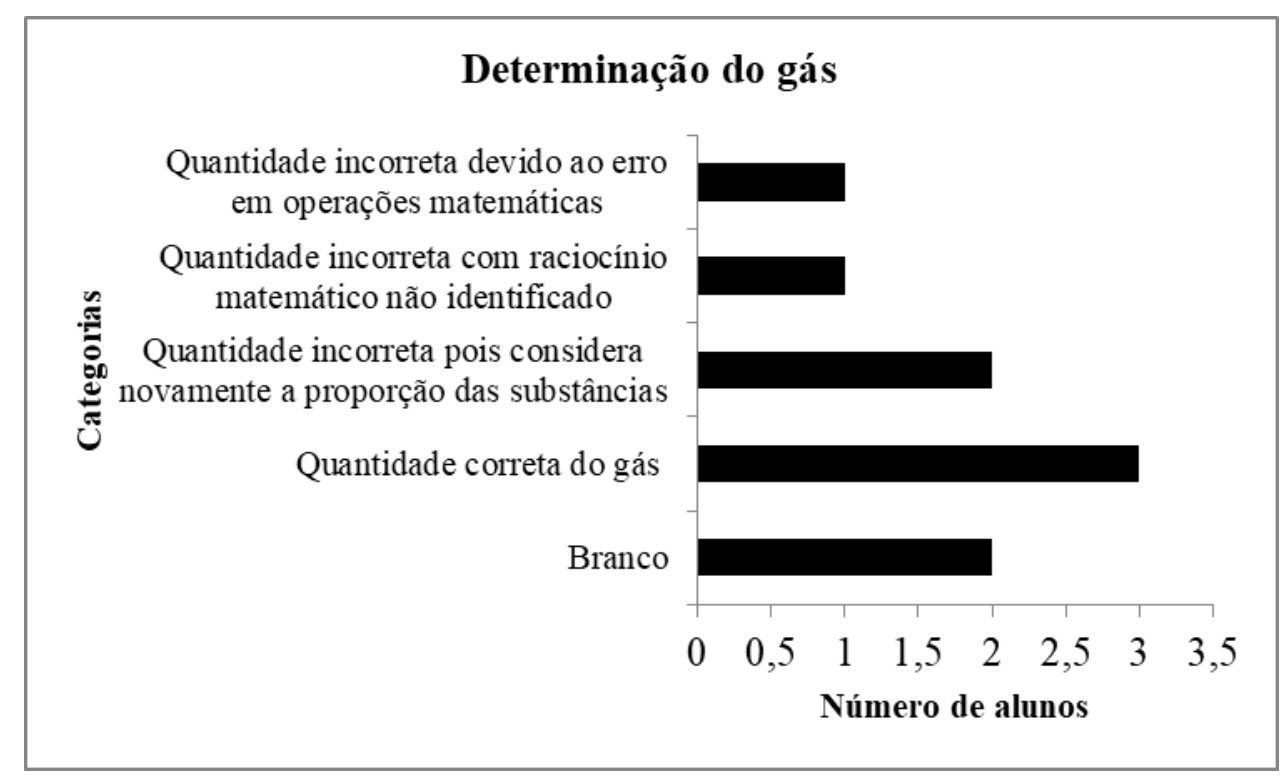

A tabela 62 apresenta, para a Questão, as decodificações criadas a partir das respostas dos alunos, as categorias criadas, as habilidades selecionadas a partir da matriz do ENEM, suscitadas pela questão para serem mobilizadas pelos estudantes e as classificações das respostas dos alunos em relação à níveis de cognições das mesmas.

Tabela 62. Categorização das respostas dos alunos referentes à questão 4 (B) do Instrumento 13.

\begin{tabular}{|c|c|c|c|c|c|c|}
\hline \multicolumn{7}{|c|}{ QUESTÃO 4-Equaço balanceada adequadamente? } \\
\hline Indicadores & Categoriais & Alunos & Habilidades & \multicolumn{2}{c|}{ Respostas dos alunos } \\
\hline $\begin{array}{c}\text { Sim, contagem da quantidade } \\
\text { de átomos no início e no final } \\
\text { da reação }\end{array}$ & $\begin{array}{c}\text { Sim. Verificação da } \\
\text { quantidade de } \\
\text { átomos iniciais e } \\
\text { finais }\end{array}$ & 8 & $\mathrm{H} 17 / \mathrm{H} 24$ & - & $\mathrm{N} 2 / \mathrm{N} 3$ & - \\
\hline $\begin{array}{c}\text { Não, diferentes valores de } \\
\text { átomos das substâncias }\end{array}$ & $\begin{array}{c}\text { Não. Diferença nas } \\
\text { quantidades de } \\
\text { átomos das } \\
\text { substâncias }\end{array}$ & 1 & $\begin{array}{c}\mathrm{H} 17 / \mathrm{H} 24 \\
\text { (parcial) }\end{array}$ & - & $\mathrm{N} 2$ & - \\
\hline
\end{tabular}


Para melhor visualizarmos as categorias construídas e estabelecermos possíveis comparativos entre elas, construímos o gráfico a seguir (Figura 70), em que relacionamos as categorias criadas com as turmas participantes do projeto.

Figura 70. Número de alunos por categorias referentes à questão 4 (B) do Instrumento 13.

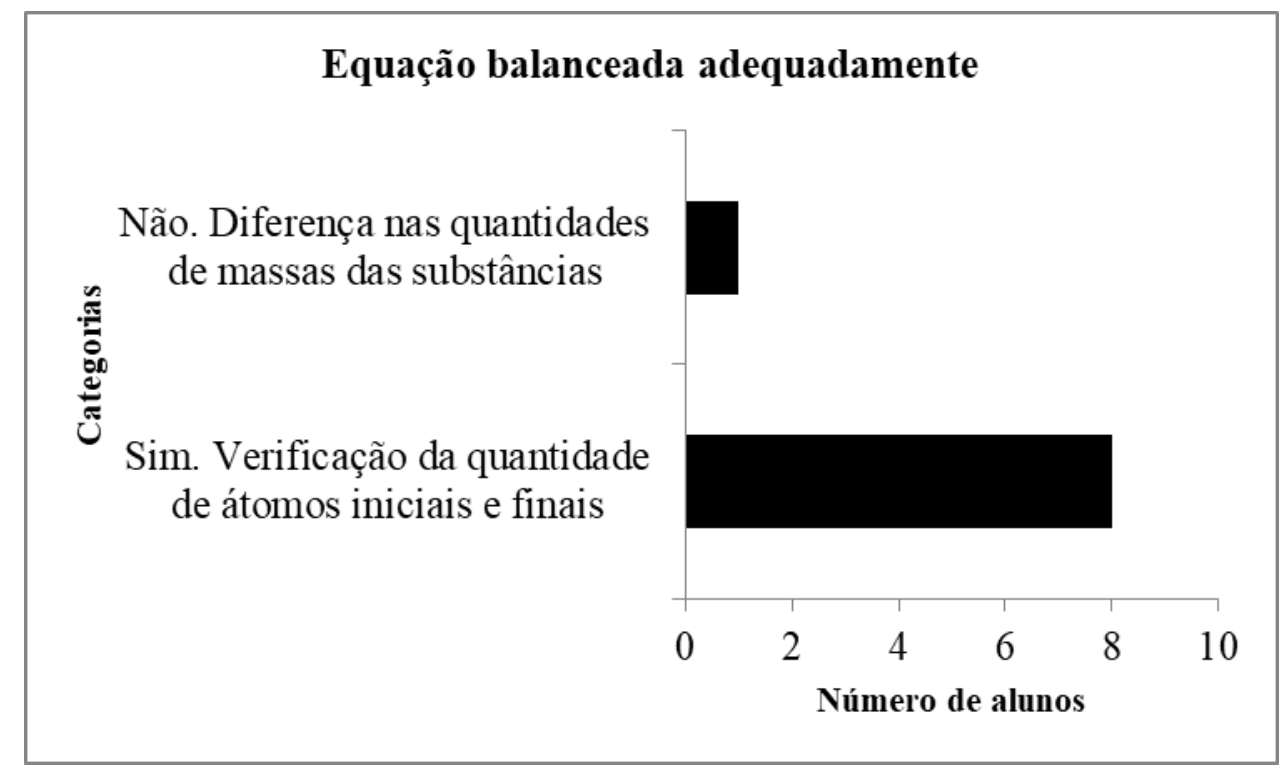

Nesta questão foi observada a construção de dois conceitos principais: as relações quantitativas da matéria (item a) e balanceamento de equações químicas (item b). Em relação ao primeiro item, os resultados indicaram que 33,3\% dos alunos resolveram integralmente a questão. Os demais se dividiram em quatro grupos, sendo que em dois deles observamos alguns aspectos positivos em relação ao entendimento de conceitos. Um dos grupos representa o número de alunos que apresentaram conhecimentos a respeito da proporção de materiais, porém não souberam utilizá-los adequadamente, visto que empregaram a ideia de proporção duas vezes para a mesma situação.

Em relação aos outros dois grupos, um deles representado por 2 alunos que deixaram a questão em branco $(22,2 \%)$ e o outro constituído somente por 1 aluno $(11,1 \%)$ que iniciou a resolução do problema mas não finalizou pois apresentou raciocínios matemáticos os quais consideramos como "não identificados" pois expressaram operações matemáticas que resultaram em soluções sem qualquer relação com os valores esperados como respostas.

QUESTÃO 5 - Observe a imagem, que apresenta uma situação de intensa poluição do ar que danifica veículos, edifícios, monumentos, vegetação e acarreta transtornos ainda maiores para a população. Trata-se de chuvas com poluentes ácidos ou corrosivos produzidos por reações químicas na atmosfera. 
Em A está destacado a presença de dois óxidos que participam do processo de reação química que resultará na acidez da chuva. Em B ocorrerão transformações químicas desses óxidos que resultarão na formação de ácidos que contribuirão para a geração da chuva ácida, como por exemplo, o ácido sulfúrico $\left(\mathrm{H}_{2} \mathrm{SO}_{4}\right)$.

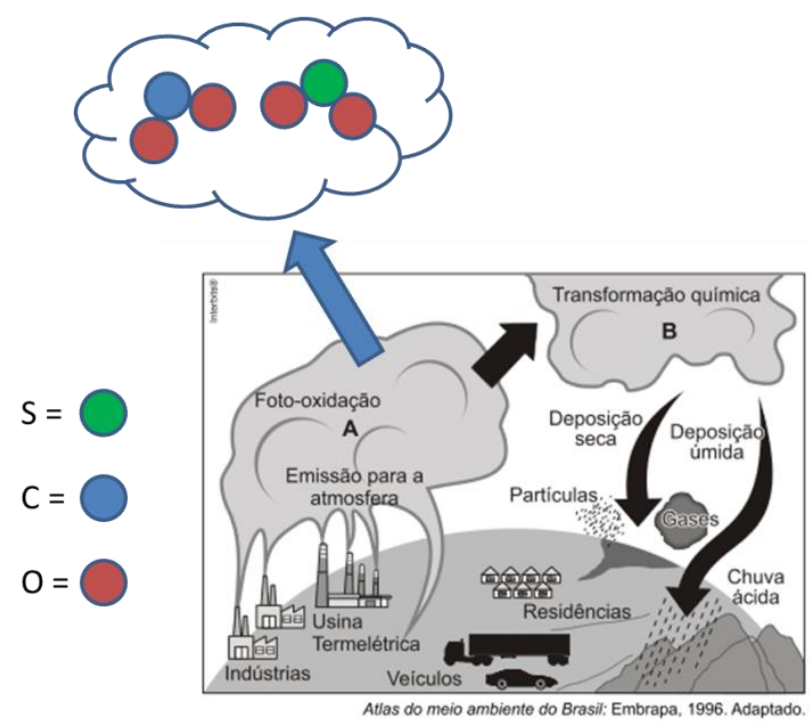

Considerando os dados descritos acima você seria capaz de dizer quais os óxidos descritos em A?

A tabela 63 apresenta, para a Questão, as decodificações criadas a partir das respostas dos alunos, as categorias criadas, as habilidades selecionadas a partir da matriz do ENEM, suscitadas pela questão para serem mobilizadas pelos estudantes e as classificações das respostas dos alunos em relação à níveis de cognições das mesmas.

Tabela 63. Categorização das respostas dos alunos referentes à questão 5 do Instrumento 13.

\begin{tabular}{|c|c|c|c|c|c|c|}
\hline \multicolumn{5}{|c|}{ QUESTÃO 5 -Reconhecimento de transformação química e explicação } \\
\hline Indicadores & Categoriais & Alunos & Habilidades & \multicolumn{2}{c|}{ Respostas dos alunos } \\
\hline $\begin{array}{c}\text { Representação correta das } \\
\text { moléculas }\end{array}$ & $\begin{array}{c}\text { Representação } \\
\text { correta das } \\
\text { moléculas }\end{array}$ & 5 & $\mathrm{H} 17 / \mathrm{H} 24$ & - & $\mathrm{N} 2 / \mathrm{N} 3$ & - \\
\hline $\begin{array}{c}\text { Somente a descrição correta } \\
\text { da nomenclatura dos óxidos }\end{array}$ & $\begin{array}{c}\text { Somente a descrição } \\
\text { correta da } \\
\text { nomenclatura dos } \\
\text { óxidos }\end{array}$ & 1 & $\mathrm{H} 17 / \mathrm{H} 24$ & - & $\mathrm{N} 2 / \mathrm{N} 3$ & - \\
\hline $\begin{array}{c}\text { Representação } \\
\text { correta das } \\
\text { moléculáculas com } \\
\text { dos óxidos }\end{array}$ & 3 & $\mathrm{H} 17 / \mathrm{H} 24$ & - & $\mathrm{N} 2 / \mathrm{N} 3$ & - \\
\hline
\end{tabular}


Para melhor visualizarmos as categorias construídas e estabelecermos possíveis comparativos entre elas, construímos o gráfico a seguir (Figura 71), em que relacionamos as categorias criadas com as turmas participantes do projeto.

Figura 71. Número de alunos por categorias referentes à questão 5 do Instrumento 13.

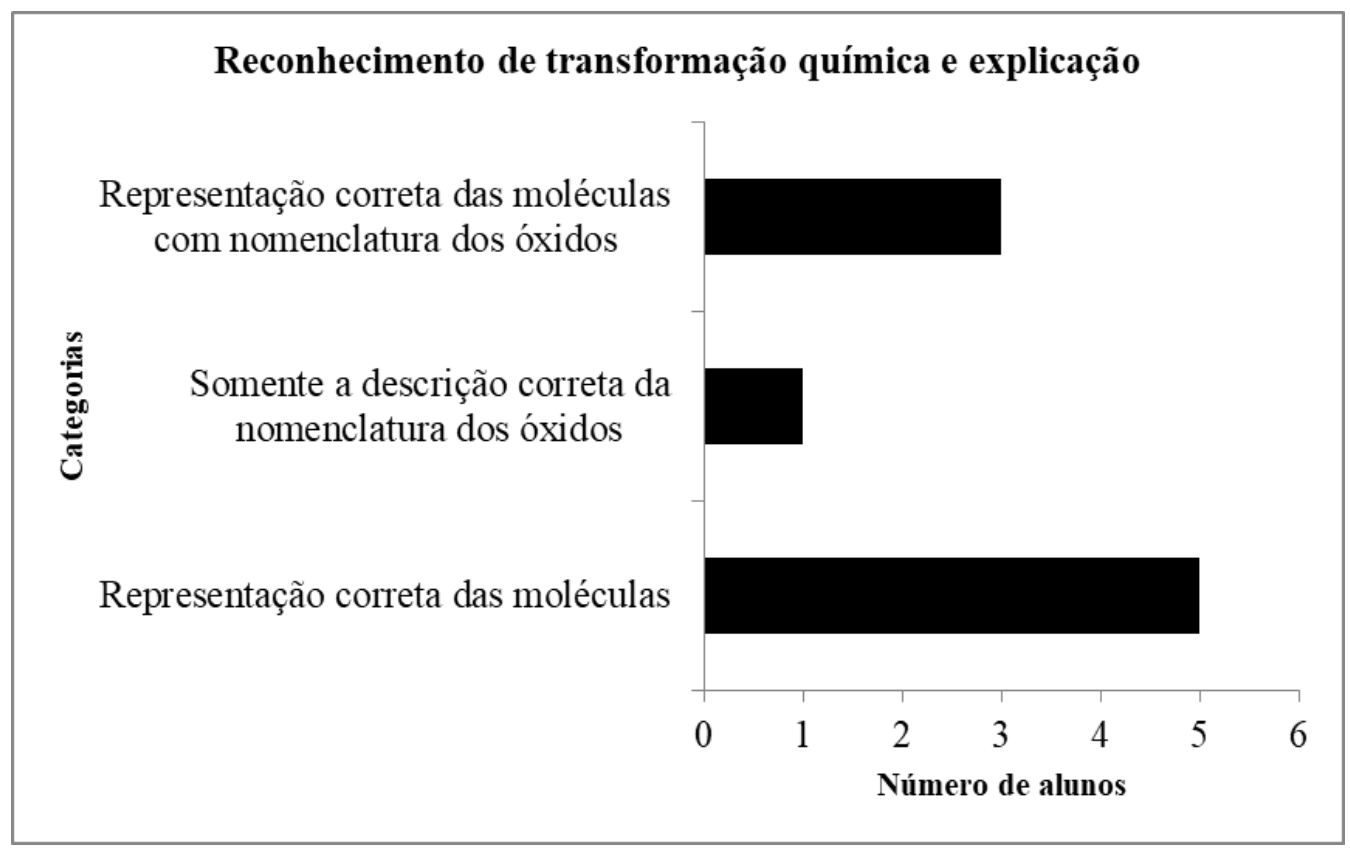

Nesta questão, os alunos deveriam recordar conceitos de átomos e moléculas, sendo necessária a construção de representações das mesmas a partir de figuras ilustrativas. Os alunos praticamente não apresentarem grandes dificuldades nas construções das moléculas. Muito diferente do que ocorreu na questão nove do questionário diagnóstico. Em ambas as questões foram trazidas figuras que pudessem auxiliar os alunos na construção das moléculas. $\mathrm{Na}$ questão do questionário diagnóstico pouquíssimos alunos conseguiram construir as representações das moléculas corretamente, no entanto, neste momento praticamente todos os alunos realizaram com sucesso a atividade proposta. Alguns somente construíram as moléculas pedidas, já outras além da construção também deram a nomenclaturas dos compostos obtidos.

QUESTÃo 6 - Adicionando-se solução aquosa de sal A a uma solução aquosa de sal B, forma-se um precipitado em uma reação completa. Para se determinar a proporção entre os reagentes e produto envolvido na transformação, fez uma série de 4 experimentos. As quantidades dos reagentes utilizadas foram descritas na seguinte tabela: 


\begin{tabular}{|r|c|c|c|c|}
\hline Experimentos & 1 & 2 & 3 & 4 \\
\hline Massa do Sal A (g) & 1,20 & 2,40 & 3,60 & 4,80 \\
\hline Massa do Sal B (g) & $\mathbf{0 , 6 0}$ & 1,20 & 1,80 & 2,40 \\
\hline
\end{tabular}

Após a realização de cada experimento foi construído um gráfico que relaciona as massas de um dos sais envolvidos na reação e do precipitado produzido.

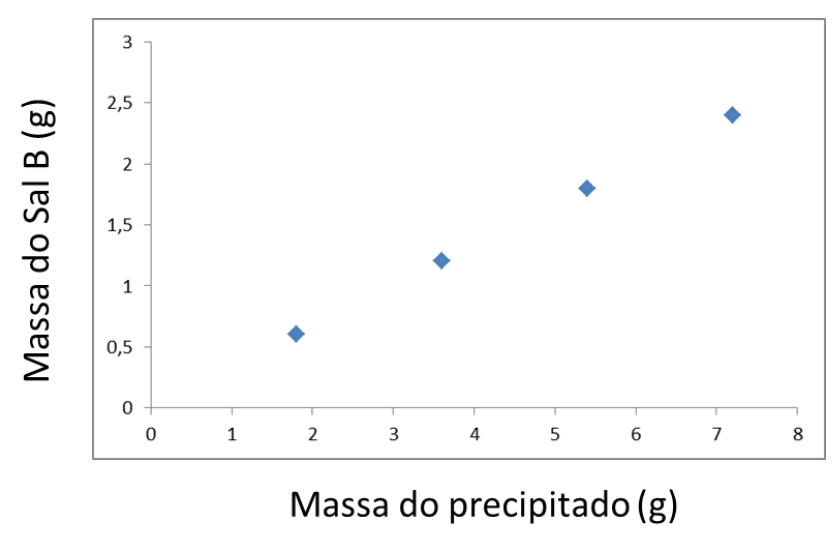

A partir da análise dos dados descritos:

a) Represente essa transformação por meio de uma equação química (não é necessário o uso de fórmulas químicas).

b) Você acha que existe alguma relação de proporção entre as massas de reagentes as massas de produtos? Apresente alguns argumentos para a sua resposta.

c) Se você tivesse realizado um $5^{\circ}$ experimento utilizando $3,0 \mathrm{~g}$ do Sal $\mathrm{B}$, seria possível determinar a quantidade necessária de Sal A e também a quantidade produzida do precipitado?

A tabela 64 apresenta, para a Questão, as decodificações criadas a partir das respostas dos alunos, as categorias criadas, as habilidades selecionadas a partir da matriz do ENEM, suscitadas pela questão para serem mobilizadas pelos estudantes e as classificações das respostas dos alunos em relação à níveis de cognições das mesmas.

Tabela 64. Categorização das respostas dos alunos referentes à questão 6 (A) do Instrumento 13.

\begin{tabular}{|c|c|c|c|c|c|c|}
\hline \multicolumn{2}{|c|}{ QUESTÃO 6 - Representação da transformação por equação química } \\
\hline Indicadores & Categoriais & Alunos & Habilidades & \multicolumn{3}{c|}{ Respostas dos alunos } \\
\hline $\begin{array}{c}\text { Representação correta da } \\
\text { equação }\end{array}$ & $\begin{array}{c}\text { Representação } \\
\text { correta da equação }\end{array}$ & 9 & ENEM & ALG & LOCS & HOCS \\
\hline
\end{tabular}

A tabela 65 apresenta, para a Questão, as decodificações criadas a partir das respostas dos alunos, as categorias criadas, as habilidades selecionadas a partir da matriz do 
ENEM, suscitadas pela questão para serem mobilizadas pelos estudantes e as classificações das respostas dos alunos em relação à níveis de cognições das mesmas.

Tabela 65. Categorização das respostas dos alunos referentes à questão 6 (B) do Instrumento 13.

\begin{tabular}{|c|c|c|c|c|c|c|}
\hline \multicolumn{7}{|c|}{ QUESTÃO 6 - Relação de proporção entre reagentes e produtos? Argumente } \\
\hline \multirow[t]{2}{*}{ Indicadores } & \multirow[t]{2}{*}{ Categoriais } & \multirow[t]{2}{*}{ Alunos } & \multirow{2}{*}{$\begin{array}{c}\text { Habilidades } \\
\text { ENEM }\end{array}$} & \multicolumn{3}{|c|}{ Respostas dos alunos } \\
\hline & & & & ALG & LOCS & HOCS \\
\hline $\begin{array}{c}\text { Sim. Verificação da } \\
\text { Conservação das Massas em } \\
\text { um único experimento e } \\
\text { proporção }\end{array}$ & $\begin{array}{l}\text { Sim. Verificação da } \\
\text { Conservação das } \\
\text { Massas em um } \\
\text { único experimento e } \\
\text { proporção }\end{array}$ & 4 & $\mathrm{H} 17 / \mathrm{H} 24 / \mathrm{H} 25$ & - & $\mathrm{N} 2 / \mathrm{N} 3$ & N4 \\
\hline $\begin{array}{l}\text { Sim. Verificação da } \\
\text { proporção somente entre os } \\
\text { reagentes }\end{array}$ & $\begin{array}{l}\text { Sim. Verificação da } \\
\text { proporção somente } \\
\text { entre os reagentes }\end{array}$ & 3 & $\begin{array}{c}\mathrm{H} 17 / \mathrm{H} 24 / \mathrm{H} 25 \\
\text { (parcial) }\end{array}$ & - & $\mathrm{N} 2 / \mathrm{N} 3$ & - \\
\hline $\begin{array}{l}\text { Sim. Definição da Lei de } \\
\text { Conservação das Massas sem } \\
\text { relação com os dados }\end{array}$ & $\begin{array}{l}\text { Sim. Definição da } \\
\text { Lei de Conservação } \\
\text { das Massas sem } \\
\text { relação com os } \\
\text { dados }\end{array}$ & 1 & $\mathrm{H} 17 / \mathrm{H} 24$ & - & $\mathrm{N} 2 / \mathrm{N} 3$ & - \\
\hline $\begin{array}{c}\text { Sim. Verificação da } \\
\text { proporção entre os reagentes e } \\
\text { o precipitado }\end{array}$ & $\begin{array}{l}\text { Sim. Verificação da } \\
\text { proporção entre os } \\
\text { reagentes e o } \\
\text { precipitado }\end{array}$ & 1 & $\mathrm{H} 17 / \mathrm{H} 24 / \mathrm{H} 25$ & - & $\mathrm{N} 2 / \mathrm{N} 3$ & N4 \\
\hline
\end{tabular}

Para melhor visualizarmos as categorias construídas e estabelecermos possíveis comparativos entre elas, construímos o gráfico a seguir (Figura 72), em que relacionamos as categorias criadas com as turmas participantes do projeto.

Figura 72. Número de alunos por categorias referentes à questão 6 (B) do Instrumento 13.

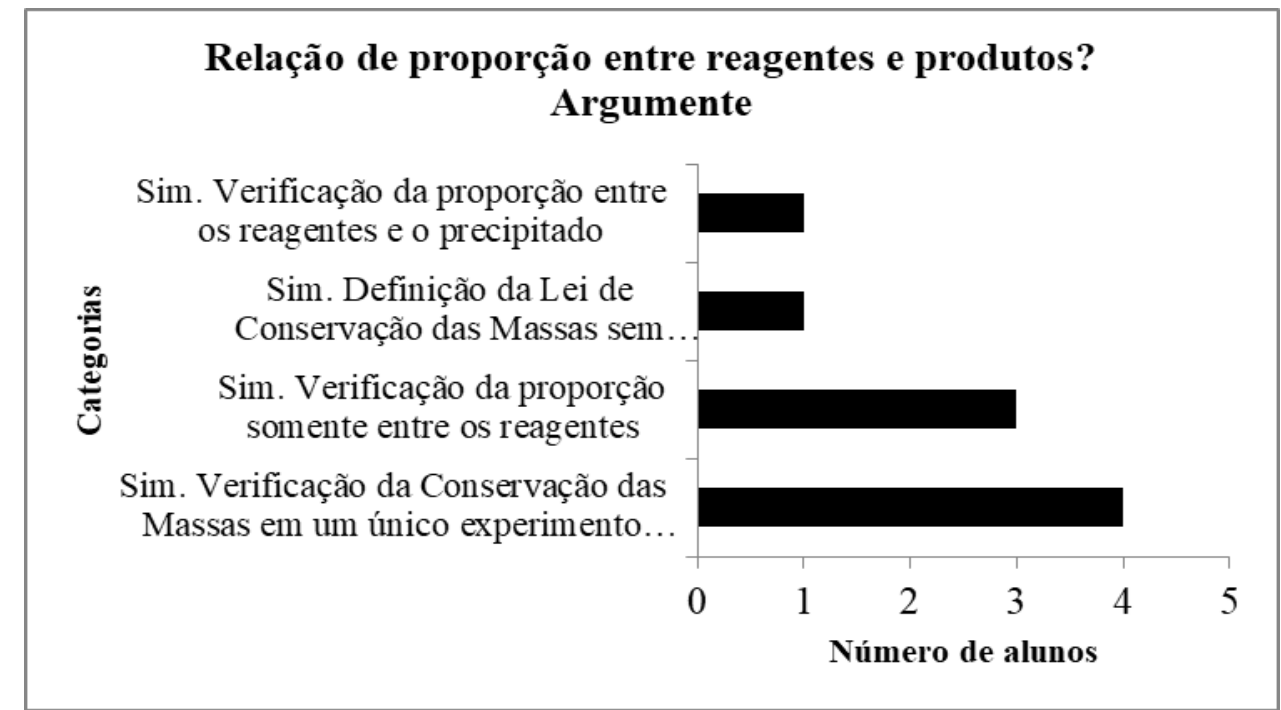

A tabela 66 apresenta, para a Questão, as decodificações criadas a partir das respostas dos alunos, as categorias criadas, as habilidades selecionadas a partir da matriz do 
ENEM, suscitadas pela questão para serem mobilizadas pelos estudantes e as classificações das respostas dos alunos em relação à níveis de cognições das mesmas.

Tabela 66. Categorização das respostas dos alunos referentes à questão $6(C)$ do Instrumento 13.

\begin{tabular}{|c|c|c|c|c|c|c|}
\hline \multicolumn{7}{|c|}{ QUESTÃO 6 - Determinação do sal A e do precipitado } \\
\hline Indicadores & Categoriais & Alunos & Habilidades & \multicolumn{3}{|c|}{ Respostas dos alunos } \\
\hline & & & ENEM & ALG & LOCS & HOCS \\
\hline $\begin{array}{l}\text { Determinação da quantidade } \\
\text { do Sal A e do precipitado } \\
\text { produzido corretamente }\end{array}$ & \multirow{2}{*}{$\begin{array}{l}\text { Determinação da } \\
\text { quantidade do Sal A } \\
\text { e do precipitado } \\
\text { produzido } \\
\text { corretamente }\end{array}$} & \multirow{2}{*}{5} & \multirow{2}{*}{$\begin{array}{c}\mathrm{H} 17 / \mathrm{H} 24 / \mathrm{H} 2 \\
5\end{array}$} & \multirow{2}{*}{ - } & \multirow{2}{*}{$\mathrm{N} 2 / \mathrm{N} 3$} & \multirow{2}{*}{ N4 } \\
\hline $\begin{array}{l}\text { Aplicação da proporção entre } \\
\text { as quantidades dos sais e } \\
\text { precipitado corretamente }\end{array}$ & & & & & & \\
\hline $\begin{array}{l}\text { Determinação da quantidade } \\
\text { do Sal A corretamente e } \\
\text { precipitado incorreto }\end{array}$ & $\begin{array}{l}\text { Determinação da } \\
\text { quantidade do Sal A } \\
\text { corretamente e } \\
\text { precipitado } \\
\text { incorreto }\end{array}$ & 1 & $\begin{array}{l}\mathrm{H} 17 / \mathrm{H} 24 / \mathrm{H} 2 \\
5 \text { (parcial) }\end{array}$ & - & $\mathrm{N} 2 / \mathrm{N} 3$ & - \\
\hline $\begin{array}{l}\text { Determinação somente da } \\
\text { quantidade do Sal A }\end{array}$ & $\begin{array}{c}\text { Determinação } \\
\text { somente da } \\
\text { quantidade do Sal A }\end{array}$ & 3 & $\begin{array}{l}\mathrm{H} 17 / \mathrm{H} 24 / \mathrm{H} 2 \\
5 \text { (parcial) }\end{array}$ & - & $\mathrm{N} 2 / \mathrm{N} 3$ & - \\
\hline
\end{tabular}

Para melhor visualizarmos as categorias construídas e estabelecermos possíveis comparativos entre elas, construímos o gráfico a seguir (Figura 73), em que relacionamos as categorias criadas com as turmas participantes do projeto.

Figura 73. Número de alunos por categorias referentes à questão 6 (C) do Instrumento 13.

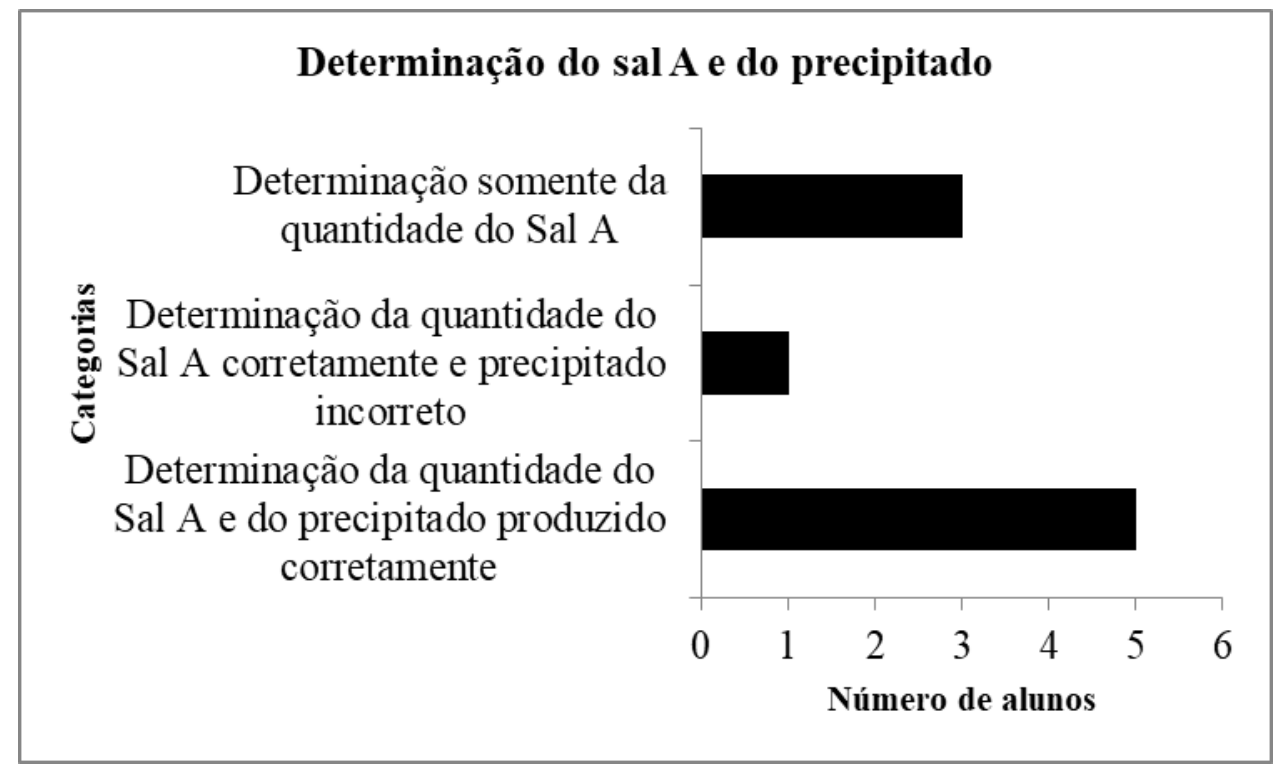

Confirmando alguns resultados obtidos anteriormente, todos os alunos representaram corretamente as transformações químicas, demonstrando domínio de habilidades tais como, a 
interpretação de linguagens e a utilização de códigos apropriados da química para descrever a equação química neste problema.

Em relação ao item b, existem dois caminhos a serem seguidos pelos alunos como tentativa de resolução. Como uma alternativa poderiam aplicar o conceito de conservação das massas dos materiais para obterem as quantidades de precipitados em cada um dos experimentos. Então, a partir dos resultados deveriam verificar a existência de proporção entre as substâncias envolvidas na reação. A primeira categoria descrita na tabela 66 representa os alunos $(44,5 \%)$ que articularam conhecimentos conceituais e cognitivos nesta sentido de resolução. Outra forma de pensamento seria a mobilização de habilidades de leitura e interpretação gráfica, em que os alunos deveriam encontrar quantidades formadas de precipitado em cada experimento a partir da relação deste com quantidades do sal B também descritas no gráfico. Observamos que apenas um aluno foi capaz de demonstrar tais habilidades como forma de resolução. Ou seja, um pouco mais da metade do número total de alunos $(55,6 \%)$ conseguiu propor uma resolução adequada para este item do problema. Comparando esta questão com a questão 3 deste mesmo instrumento, na qual, aproximadamente $80 \%$ dos alunos propuseram resoluções adequadas ao problema, entendemos que houve uma superação de dificuldades conceituais e cognitivas por parte dos alunos. Na questão 3 foi proposta uma situação muito semelhante à diversas outras já descritas nesta sequência de atividades. Já neste problema, os alunos deveriam relacionar informações descritas em tabela e gráfico, sendo que algumas delas não estavam sendo apresentadas de forma direta, ou seja, os alunos deveriam no decorrer da resolução do problema utilizar conhecimentos teóricos, habilidades específicas e reflexões sobre tudo que estava sendo proposto para dar finalizar as atividades propostas. Ainda para aqueles alunos que não concluíram a resolução do problema observamos em uma das categorias, que três alunos reconheceram somente a proporção entre os reagentes e na outra um aluno apenas descreveu a lei de conservação dos materiais sem qualquer relação com as quantidades das substâncias descritas na questão. Todas estas reflexões nos mostram que todos os alunos foram capazes de interpretar inicialmente o que estava sendo proposto, entretanto, aqueles que não concluíram a questão apresentaram problemas principalmente na habilidade 25 , ou seja, no cálculo das quantidades dos materiais, visto que não foram capazes de realizar interpretações e reflexões mais específicas neste item da questão.

Verificamos que no item c foi mantida a mesma porcentagem do b em relação aos alunos que propuseram resoluções adequadas à questão. Entendemos que para que os alunos 
conseguissem encontrar a massa do precipitado neste item os mesmos deveriam apresentar praticamente todos os conhecimentos e habilidades exigidas no item b. Como no encontramos no enunciado do item somente uma quantidade expressa em massa para o sal $\mathrm{B}$, os alunos teriam que estabelecer relações deste com o sal A, através da aplicação de proporcionalidade entre os reagentes, e consequentemente com o precipitado por meio da verificação da conservação ou da proporção de massa dos materiais. Todas estas descrições têm uma demanda cognitiva mais alta do que somente a realização de cálculos matemáticos a partir de informações descritas.

Zoller, Dori e Lubezky (2002) afirmam que o processo de ensino e aprendizagem está diretamente relacionado ao desempenho de habilidades cognitivas. Assim, realizar um estudo de todas as habilidades mobilizadas em nossa sequência de atividades torna-se o início de uma jornada para a realização da proposta do autor. Como forma de investigação de tais relações cognitivas construímos duas tabelas (Tabelas 67 e 68).

Ao analisarmos todas as questões, percebemos relações entre as habilidades e os níveis cognitivos das respostas dos alunos, as quais mantiveram-se até o final da sequência. Assim, a tabela 67 apresenta as habilidades demandadas no ENEM, utilizadas nas soluções das respostas consideradas totalmente corretas, os níveis cognitivos manifestados pelos alunos e as categorias de respostas elaboradas por Suart e Marcondes (2008).

Tabela 67. Relações cognitivas entre os níveis das respostas dos alunos e as habilidades mobilizadas na resolução dos problemas propostos.

\begin{tabular}{|c|c|c|}
\hline \multicolumn{3}{|c|}{ RELAÇÕES COGNITIVAS } \\
\hline Categorias de respostas* & $\begin{array}{l}\text { Nível cognitivo do aluno* } \\
\text { (Suart e Marcondes, 2008) }\end{array}$ & Habilidades do ENEM \\
\hline \multirow{5}{*}{ ALG e LOCS } & $\mathrm{N} 1$ e N 2 & \multirow{2}{*}{ H 3 e H 24} \\
\hline & N 2 & \\
\hline & \multirow{3}{*}{$\mathrm{N} 2$ e $\mathrm{N} 3$} & $\mathrm{H} 3$ e H 8 \\
\hline & & $\mathrm{H} 24$ \\
\hline & & $\mathrm{H} 17$ e H 24 \\
\hline LOCS e HOCS & $\mathrm{N} 2, \mathrm{~N} 3$ e $\mathrm{N} 4$ & H 17 e H 25 \\
\hline
\end{tabular}

Categorias de respostas* ${ }^{*}$ representa a classificação das habilidades cognitivas, como habilidades cognitivas de ordem baixa (ALG e LOCS) e de ordem mais alta (HOCS) (Zoller, Dori e Lubezky (2002).

Nível cognitivo do aluno $*$ representa o nível cognitivo das respostas dos alunos durante a resolução de problemas (Suart e Marcondes, 2008). 
Os problemas em que foram mobilizadas, de forma combinada, as habilidades 3 e 24 , exigiram um o nível cognitivo das respostas fornecidas pelos alunos que permearam entre a combinação de N 1 e N 2 ou somente N 2. Entretanto, ao alterar a combinação das habilidades 3 e 24 para uma nova combinação entre as habilidades 3 e 8 , ou entre 17 e 24, ou somente 24, verificamos um aumento do nível cognitivo das respostas dos alunos, de N1 e N2 para N2 e N3. Quando a combinação necessária para a resolução de um determinado problema ocorreu entre as habilidades 17 e 25, o nível de cognição das respostas dadas foi ainda maior, constituindo-se em um conjunto de N2, N3 e N4.

Segundo conclusões estabelecidas por Suart e Marcondes (2008), entender o nível de cognição dos alunos representa diagnosticar possíveis dificuldades e evoluções em relação aos seus desenvolvimentos cognitivos. Ou seja, para as autoras, os alunos que apresentam dificuldades de compreensão do problema proposto e simplesmente utilizam dados algorítmicos e memorização, demonstram um nível N1 de cognição. Agora, mesmo com dificuldades de identificar as variáveis dos problemas, mas demonstrando entendimento na compreensão dos mesmos, conseguem evoluir para o nível N2 de cognição. Expressar respostas pertencentes a um nível N3 de cognição significa que os alunos propuseram explicações para um determinado problema utilizando conceitos já conhecidos e foram capazes de controlar algumas informações apresentadas na questão. Todas estas características, para as autoras, significam uma possível evolução para o nível N4, em que os alunos deverão desenvolver um pensamento mais complexo durante a proposição de resolução de um problema como a elaboração de hipóteses e a análise de variáveis.

Assim, se as alterações dos níveis cognitivos das respostas dos alunos são resultados das mobilizações de diferentes habilidades cognitivas, concluímos que a medida que ocorreu um aumento na cognição das respostas, estas ocorreram por conta de uma maior demanda cognitiva de habilidades de ordem mais elevadas, ou seja, conseguimos classificar as habilidades 17 e 25 como habilidades de alta ordem cognitiva.

Compreender a relação de cada uma das habilidades com o nível cognitivo das respostas também foi importante para avaliarmos se as atividades problematizadoras realmente contribuíram com uma evolução cognitiva dos alunos, que momento da sequência e quais instrumentos contribuíram significativamente no desenvolvimento das habilidades descritas.

Em complemento as análises descritas, na tabela 68 quantificamos os alunos que responderam adequadamente as questões segundo parâmetros científicos. Também 
descrevemos os níveis cognitivos e as habilidades que foram mobilizadas somente referentes às respostas adequadas.

Tabela 68. Habilidades, níveis cognitivos e rendimento dos alunos nas Situações-problema.

\begin{tabular}{|c|c|c|c|c|c|}
\hline \multicolumn{6}{|c|}{ ESTUDO DAS HABILIDADES DESENVOLVIDAS } \\
\hline \multicolumn{6}{|c|}{ MÓDULO 1 - Transformações Químicas } \\
\hline \multicolumn{6}{|c|}{ INSTRUMENTO 3 (10 alunos responderam a questão) } \\
\hline QUESTÕES & HN* & $\mathbf{N C}^{*}$ & $\mathrm{CR}^{*}$ & $\begin{array}{c}\text { RA* }^{*} \\
\text { (ALUNOS) }\end{array}$ & $\begin{array}{l}\text { RA* } \\
(\%)\end{array}$ \\
\hline $\mathrm{Q} 1(\mathrm{I})$ & $\mathrm{H} 3 / \mathrm{H} 8$ & $\mathrm{~N} 2 / \mathrm{N} 3$ & LOCS & 7 & 70 \\
\hline Q1(II) & $\mathrm{H} 3 / \mathrm{H} 8$ & $\mathrm{~N} 2 / \mathrm{N} 3$ & LOCS & 6 & 60 \\
\hline Q1(III) & $\mathrm{H} 3 / \mathrm{H} 8$ & $\mathrm{~N} 2 / \mathrm{N} 3$ & LOCS & 6 & 60 \\
\hline Q1(IV) & $\mathrm{H} 3 / \mathrm{H} 8$ & $\mathrm{~N} 2 / \mathrm{N} 3$ & LOCS & 4 & 40 \\
\hline Q1(V) & $\mathrm{H} 3 / \mathrm{H} 8$ & $\mathrm{~N} 2 / \mathrm{N} 3$ & LOCS & 7 & 70 \\
\hline Q1(VI) & $\mathrm{H} 3 / \mathrm{H} 8$ & $\mathrm{~N} 2 / \mathrm{N} 3$ & LOCS & 8 & 80 \\
\hline Q 3 & $\mathrm{H} 17 / \mathrm{H} 24$ & $\mathrm{~N} 2 / \mathrm{N} 3$ & LOCS & 6 & 60 \\
\hline Q 5(a) & $\mathrm{H} 17 / \mathrm{H} 24$ & $\mathrm{~N} 2 / \mathrm{N} 3$ & LOCS & 9 & 90 \\
\hline Q 7 & $\mathrm{H} 17 / \mathrm{H} 24$ & $\mathrm{~N} 2 / \mathrm{N} 3$ & LOCS & 8 & 70 \\
\hline \multicolumn{6}{|c|}{ INSTRUMENTO 4 (10 alunos responderam a questão) } \\
\hline QUESTÕES & HN* & NC* & $\mathrm{CR}^{*}$ & $\begin{array}{c}\text { RA* } \\
\text { (ALUNOS) }\end{array}$ & $\begin{array}{l}\text { RA* } \\
(\%)\end{array}$ \\
\hline Q 1 (i) & $\mathrm{H} 3 / \mathrm{H} 24$ & $\mathrm{~N} 1 / \mathrm{N} 2$ & ALG/LOCS & 10 & 100 \\
\hline Q 1 (ii) & $\mathrm{H} 3 / \mathrm{H} 24$ & $\mathrm{~N} 1 / \mathrm{N} 2$ & ALG/LOCS & 9 & 90 \\
\hline Q 2 & $\mathrm{H} 3 / \mathrm{H} 24$ & $\mathrm{~N} 1 / \mathrm{N} 2$ & ALG/LOCS & 6 & 60 \\
\hline Q 3 & $\mathrm{H} 3 / \mathrm{H} 24$ & $\mathrm{~N} 1 / \mathrm{N} 2$ & ALG/LOCS & 7 & 70 \\
\hline \multicolumn{6}{|c|}{ INSTRUMENTO 9 (10 alunos responderam a questão) } \\
\hline QUESTÕES & HN* & $\mathrm{NC}^{*}$ & $\mathrm{CR}^{*}$ & $\begin{array}{c}\text { RA* } \\
\text { (ALUNOS) }\end{array}$ & $\begin{array}{l}\mathbf{R A}^{*} \\
(\%)\end{array}$ \\
\hline Q 2(a) & $\mathrm{H} 17 / \mathrm{H} 24$ & $\mathrm{~N} 2 / \mathrm{N} 3$ & LOCS & 5 & 50 \\
\hline Q 2(b) & $\mathrm{H} 17 / \mathrm{H} 24$ & $\mathrm{~N} 2 / \mathrm{N} 3$ & LOCS & 9 & 90 \\
\hline \multicolumn{6}{|c|}{ INSTRUMENTO 12 (10 alunos responderam a questão) } \\
\hline QUESTÕES & HN* & $\mathbf{N C}^{*}$ & $\mathbf{C R}^{*}$ & $\begin{array}{c}\text { RA* } \\
\text { (ALUNOS) }\end{array}$ & $\begin{array}{l}\text { RA* } \\
(\%)\end{array}$ \\
\hline Q 1(a) & $\mathrm{H} 17 / \mathrm{H} 24$ & $\mathrm{~N} 2 / \mathrm{N} 3$ & LOCS & 10 & 100 \\
\hline Q 2(a) & $\mathrm{H} 17 / \mathrm{H} 24$ & $\mathrm{~N} 2 / \mathrm{N} 3$ & LOCS & 9 & 90 \\
\hline \multicolumn{6}{|c|}{ INSTRUMENTO 13 (9 alunos responderam a questão) } \\
\hline QUESTÕES & $\mathbf{H N}^{*}$ & NC* & $\mathbf{C R}^{*}$ & $\begin{array}{c}\text { RA* }^{*} \\
\text { (ALUNOS) }\end{array}$ & $\begin{array}{l}\text { RA* } \\
(\%)\end{array}$ \\
\hline Q $1(I)$ & $\mathrm{H} 3 / \mathrm{H} 8$ & $\mathrm{~N} 2 / \mathrm{N} 3$ & LOCS & 8 & 88,9 \\
\hline $\mathrm{Q} 1(I I)$ & $\mathrm{H} 3 / \mathrm{H} 8$ & $\mathrm{~N} 2 / \mathrm{N} 3$ & LOCS & 5 & 55,6 \\
\hline Q 1(III) & $\mathrm{H} 3 / \mathrm{H} 8$ & $\mathrm{~N} 2 / \mathrm{N} 3$ & LOCS & 6 & 66,7 \\
\hline $\mathrm{Q} 1(I V)$ & $\mathrm{H} 3 / \mathrm{H} 8$ & $\mathrm{~N} 2 / \mathrm{N} 3$ & LOCS & 6 & 66,7 \\
\hline $\mathrm{Q} 1(V)$ & $\mathrm{H} 3 / \mathrm{H} 8$ & $\mathrm{~N} 2 / \mathrm{N} 3$ & LOCS & 6 & 66,7 \\
\hline Q 1(VI) & $\mathrm{H} 3 / \mathrm{H} 8$ & $\mathrm{~N} 2 / \mathrm{N} 3$ & LOCS & 6 & 66,7 \\
\hline Q 1(VII) & $\mathrm{H} 3 / \mathrm{H} 8$ & $\mathrm{~N} 2 / \mathrm{N} 3$ & LOCS & 1 & 11,2 \\
\hline Q 1(VIII) & H3/H8 & $\mathrm{N} 2 / \mathrm{N} 3$ & LOCS & 7 & 77,8 \\
\hline Q 2(a) & $\mathrm{H} 17 / \mathrm{H} 24$ & $\mathrm{~N} 2 / \mathrm{N} 3$ & LOCS & 9 & 100 \\
\hline Q 2 (b) & $\mathrm{H} 17 / \mathrm{H} 24$ & $\mathrm{~N} 2 / \mathrm{N} 3$ & LOCS & 9 & 100 \\
\hline
\end{tabular}




\begin{tabular}{|c|c|c|c|c|c|}
\hline Q 4 (b) & $\mathrm{H} 17 / \mathrm{H} 24$ & $\mathrm{~N} 2 / \mathrm{N} 3$ & LOCS & 8 & 88,9 \\
\hline Q 6 (a) & $\mathrm{H} 17 / \mathrm{H} 24$ & $\mathrm{~N} 2 / \mathrm{N} 3$ & LOCS & 9 & 100 \\
\hline \multicolumn{6}{|c|}{ MÓDULO 2 - Conservação das massas dos materiais } \\
\hline \multicolumn{6}{|c|}{ INSTRUMENTO 3 (10 alunos responderam a questão) } \\
\hline QUESTÕES & $\mathbf{H N}^{*}$ & $\mathrm{NC}^{*}$ & $\mathbf{C R}^{*}$ & $\begin{array}{c}\text { RA* }^{*} \\
\text { (ALUNOS) }\end{array}$ & $\begin{array}{l}\mathbf{R A}^{*} \\
(\%)\end{array}$ \\
\hline Q 4 & $\mathrm{H} 17 / \mathrm{H} 25$ & $\mathrm{~N} 2 / \mathrm{N} 3 / \mathrm{N} 4$ & LOCS/HOCS & 5 & 50 \\
\hline Q 10 & $\mathrm{H} 17 / \mathrm{H} 25$ & $\mathrm{~N} 2 / \mathrm{N} 3 / \mathrm{N} 4$ & LOCS/HOCS & 1 & 10 \\
\hline Q 11 & $\mathrm{H} 17 / \mathrm{H} 25$ & $\mathrm{~N} 2 / \mathrm{N} 3 / \mathrm{N} 4$ & LOCS/HOCS & 0 & 0 \\
\hline \multicolumn{6}{|c|}{ INSTRUMENTO 9 (10 alunos responderam a questão) } \\
\hline QUESTÕES & HN* & NC* & $\mathbf{C R}^{*}$ & $\begin{array}{c}\text { RA* }^{*} \\
\text { (ALUNOS) }\end{array}$ & $\begin{array}{l}\text { RA* } \\
(\%)\end{array}$ \\
\hline Q 1 & $\mathrm{H} 17 / \mathrm{H} 24$ & $\mathrm{~N} 2$ & LOCS & 0 & 0 \\
\hline Q 2(c) & $\mathrm{H} 17 / \mathrm{H} 25$ & $\mathrm{~N} 2 / \mathrm{N} 3 / \mathrm{N} 4$ & LOCS/HOCS & 5 & 50 \\
\hline \multicolumn{6}{|c|}{ INSTRUMENTO 12 (10 alunos responderam a questão) } \\
\hline QUESTÕES & HN* & $\mathrm{NC}^{*}$ & $\mathbf{C R}^{*}$ & $\begin{array}{c}\text { RA* }^{*} \\
\text { (ALUNOS) }\end{array}$ & $\begin{array}{l}\text { RA* } \\
(\%)\end{array}$ \\
\hline Q 1(b) & $\mathrm{H} 17 / \mathrm{H} 25$ & $\mathrm{~N} 2 / \mathrm{N} 3 / \mathrm{N} 4$ & LOCS/HOCS & 9 & 90 \\
\hline Q 2(b) & $\mathrm{H} 17 / \mathrm{H} 24$ & $\mathrm{~N} 2 / \mathrm{N} 3$ & LOCS & 4 & 40 \\
\hline Q 3(a) & $\mathrm{H} 17 / \mathrm{H} 25$ & $\mathrm{~N} 2 / \mathrm{N} 3 / \mathrm{N} 4$ & LOCS/HOCS & 8 & 80 \\
\hline \multicolumn{6}{|c|}{ INSTRUMENTO 13 ( 9 alunos responderam a questão) } \\
\hline QUESTÕES & $\mathbf{H N}^{*}$ & NC* & $\mathbf{C R}^{*}$ & $\begin{array}{c}\text { RA* }^{*} \\
\text { (ALUNOS) }\end{array}$ & $\begin{array}{l}\text { RA* } \\
(\%)\end{array}$ \\
\hline Q 3(a) & $\mathrm{H} 17 / \mathrm{H} 25$ & $\mathrm{~N} 2 / \mathrm{N} 3 / \mathrm{N} 4$ & LOCS/HOCS & 8 & 77,9 \\
\hline Q $6(\mathrm{~b})$ & $\mathrm{H} 17 / \mathrm{H} 24 / \mathrm{H} 25$ & $\mathrm{~N} 2 / \mathrm{N} 3 / \mathrm{N} 4$ & LOCS/HOCS & 5 & 55,6 \\
\hline \multicolumn{6}{|c|}{ MÓDULO 3 - Proporções das massas dos materiais } \\
\hline \multicolumn{6}{|c|}{ INSTRUMENTO 3 (10 alunos responderam a questão) } \\
\hline QUESTÕES & HN* & $\mathrm{NC}^{*}$ & $\mathbf{C R}^{*}$ & $\begin{array}{c}\text { RA* }^{*} \\
\text { (ALUNOS) }\end{array}$ & $\begin{array}{l}\text { RA* } \\
(\%)\end{array}$ \\
\hline Q 4 & $\mathrm{H} 17 / \mathrm{H} 25$ & $\mathrm{~N} 2 / \mathrm{N} 3 / \mathrm{N} 4$ & LOCS/HOCS & 5 & 50 \\
\hline Q 6 & $\mathrm{H} 17 / \mathrm{H} 25$ & $\mathrm{~N} 2 / \mathrm{N} 3 / \mathrm{N} 4$ & LOCS/HOCS & 6 & 60 \\
\hline Q 8 & $\mathrm{H} 17 / \mathrm{H} 25$ & $\mathrm{~N} 2 / \mathrm{N} 3 / \mathrm{N} 4$ & LOCS/HOCS & 2 & 20 \\
\hline Q 10 & $\mathrm{H} 17 / \mathrm{H} 25$ & $\mathrm{~N} 2 / \mathrm{N} 3 / \mathrm{N} 4$ & LOCS/HOCS & 1 & 10 \\
\hline Q 11 & $\mathrm{H} 17 / \mathrm{H} 25$ & $\mathrm{~N} 2 / \mathrm{N} 3 / \mathrm{N} 4$ & LOCS/HOCS & 0 & 0 \\
\hline \multicolumn{6}{|c|}{ INSTRUMENTO 12 (10 alunos responderam a questão) } \\
\hline QUESTÕES & HN* & $\mathrm{NC}^{*}$ & $\mathbf{C R}^{*}$ & $\begin{array}{c}\text { RA* }^{*} \\
\text { (ALUNOS) }\end{array}$ & $\begin{array}{l}\text { RA* } \\
\text { (\%) }\end{array}$ \\
\hline Q 1(b) & $\mathrm{H} 17 / \mathrm{H} 25$ & $\mathrm{~N} 2 / \mathrm{N} 3 / \mathrm{N} 4$ & LOCS/HOCS & 9 & 90 \\
\hline Q 2(c) & $\mathrm{H} 17 / \mathrm{H} 25$ & $\mathrm{~N} 2 / \mathrm{N} 3 / \mathrm{N} 4$ & LOCS/HOCS & 3 & 30 \\
\hline Q 3(b) & $\mathrm{H} 17 / \mathrm{H} 25$ & $\mathrm{~N} 2 / \mathrm{N} 3 / \mathrm{N} 4$ & LOCS/HOCS & 2 & 20 \\
\hline Q 3(c) & $\mathrm{H} 17 / \mathrm{H} 25$ & $\mathrm{~N} 2 / \mathrm{N} 3 / \mathrm{N} 4$ & LOCS/HOCS & 0 & 0 \\
\hline \multicolumn{6}{|c|}{ INSTRUMENTO 13 (9 alunos responderam a questão) } \\
\hline QUESTÕES & $\mathbf{H N}^{*}$ & $\mathrm{NC}^{*}$ & $\mathbf{C R} *$ & $\begin{array}{c}\text { RA* }^{*} \\
\text { (ALUNOS) }\end{array}$ & $\begin{array}{l}\text { RA* } \\
(\%)\end{array}$ \\
\hline Q 3(b) & $\mathrm{H} 17 / \mathrm{H} 25$ & $\mathrm{~N} 2 / \mathrm{N} 3 / \mathrm{N} 4$ & LOCS/HOCS & 7 & 77,8 \\
\hline Q 4(a) & $\mathrm{H} 17 / \mathrm{H} 25$ & $\mathrm{~N} 2 / \mathrm{N} 3 / \mathrm{N} 4$ & LOCS/HOCS & 3 & 33,4 \\
\hline Q 6(b) & $\mathrm{H} 17 / \mathrm{H} 24 / \mathrm{H} 25$ & $\mathrm{~N} 2 / \mathrm{N} 3 / \mathrm{N} 4$ & LOCS/HOCS & 5 & 55,6 \\
\hline Q6 (c) & $\mathrm{H} 17 / \mathrm{H} 24 / \mathrm{H} 25$ & $\mathrm{~N} 2 / \mathrm{N} 3 / \mathrm{N} 4$ & LOCS/HOCS & 5 & 55,6 \\
\hline
\end{tabular}


RA $*$ (alunos $)=$ Respostas adequadas dadas pelos alunos segundo os padrões científicos. Neste caso representa o número de alunos.

RA $*(\%)=$ Respostas adequadas dadas pelos alunos segundo os padrões científicos. Neste caso o número de alunos foi transformado em porcentagem.

Observando a tabela 68 , verificamos no primeiro módulo da sequência de atividades a necessidade de mobilização somente de habilidades de baixa ordem cognitiva para a resolução dos problemas. Habilidades de menores complexidades (habilidades 3 e 8), apareceram nos instrumentos iniciais (instrumentos 3 e 4) da sequência voltando a aparecer somente nas atividades finais (instrumento 13). A proposta dos instrumentos 3 e 4 foi a verificação de conhecimentos prévios dos alunos a partir de problemas que envolveram o reconhecimento de fenômenos químicos em situações do senso comum. Ou seja, justamente o esperado na proposta de mobilização das habilidades mencionadas. No instrumento 13 foram averiguados os conhecimentos construídos após a aplicação de todas as atividades. Comparando-se os percentuais de respostas adequadas dadas pelos alunos ( $\mathrm{RC} \%$ ) entre a primeira questão tanto do instrumento 3 quanto do instrumento 13, observamos no instrumento 13 um aumento na porcentagem de respostas adequadas. Desde a primeira atividade, os alunos já demonstravam elevada habilidade no reconhecimento das transformações químicas em situações diversas, entretanto, podemos afirmar que houve superação de algumas dificuldades, como no caso do reconhecimento das transformações naturais como sendo fenômenos químicos.

Comparadas as habilidades descritas acima, habilidades de maior complexidade foram utilizadas no decorrer da sequência, sendo observadas já o instrumento 3 (habilidades 17 e 24). A habilidade 17 voltou a ser desenvolvida a partir do instrumento 9, diferentemente da 24, que apareceu em todos os instrumentos do módulo. De forma geral, desde o início, os alunos também conseguiram apresentar certa facilidade na mobilização de ambas habilidades, mas verificamos que ao final do módulo, praticamente, os resultados percentuais atingiram valores máximos. Ou seja, após participarem da sequência de ensino a grande maioria dos alunos participantes foi capaz de utilizar códigos e nomenclaturas da química corretamente para identificar reagentes e produtos envolvidos em uma transformação química. E, também, de relacionar informações em diferentes linguagens que exigissem conhecimentos relacionados as transformações químicas e a representação das mesmas na forma de reações.

Considerações importantes podem ser feitas na comparação entre o item a da segunda questão do instrumento 9 e o item a da primeira questão do instrumento 12 . Trata-se do mesmo problema sendo aplicado em etapas distintas da sequencia. O rendimento no 
instrumento 9 foi de $50 \%$ em relação ao número de respostas adequadas fornecidas pelos estudantes, enquanto que no instrumento 12 foi de $100 \%$. Para responder ao instrumento 12 , o aluno já havia passado por todas as etapas de construção de conhecimentos químicos a partir das situações que problematizaram o ensino. E, também, na aula seguinte à finalização do instrumento 9, houve uma resolução em grupo dos exercícios propostos, o que certamente contribuiu com a evolução no entendimento conceitual dos alunos.

Em comparação com o módulo 1, os resultados da tabela referentes ao módulo 2 representaram uma mudança na complexidade das habilidades exigidas. Observamos no decorrer do segundo módulo a predominância nas mobilizações das habilidades 17, 24 e 25 . De um total de 10 questões descritas na tabela 68 referentes ao segundo módulo, em 8 delas os alunos mobilizaram habilidades de ordens mais elevadas (habilidades 17 e 25), em relação a 2 questões que exigiram habilidades de ordem mais baixa (Habilidades 17 e 24) na proposição de soluções. Utilizando as relações entre os níveis cognitivos e as categorias de respostas já descritas nos trabalhos de Suart e Marcondes (2008), e a partir de nossas classificações, entendemos que os alunos ao mobilizarem as habilidades 17 e 25 de forma conjunta passam por uma transição dos níveis cognitivos mais baixos (LOCS) para níveis mais elevados (HOCS) de cognição, justamente por apresentarem respostas pertencentes ao o nível 4 (N4) de respostas. Este perfil também se repetiu no último módulo da sequência. Diferente do módulo 1, observamos mudanças significativas em relação aos percentuais de acertos de algumas questões.

Nos instrumentos 3 e 9 as porcentagens de acerto não ultrapassaram 50\% em relação ao número total de alunos. Mas, a partir do módulo 12 já no final da sequência proposta, observamos até $90 \%$ de acertos, principalmente quando combinadas as habilidades 17 e 25 . Acreditamos que a forma como organizamos nossas atividades, em relação à disposição dos problemas propostos e dos tipos de atividades que constituíram as situações de ensino, contribuíram de forma efetiva na mobilização gradual das habilidades. Ou seja, percebemos que os alunos conseguem apresentar soluções para os problemas agrupadas em categorias de respostas de baixa à alta ordem cognitiva $(\mathrm{CR})$ e de menores à maiores níveis cognitivos de respostas (NC).

Comparando-se as questões 11 e 3 (itens a, b e c) presentes nos instrumentos 3 e 12, nesta ordem, ambas referentes ao mesmo problema, verificamos uma melhora significativa em relação ao número de alunos que acertaram parte da questão em seu segundo momento de 
aplicação. Em sua primeira versão, apresentada no instrumento 3, a questão foi problematizada a partir de um texto que descrevia a reação entre amônia e gás carbônico produzindo ureia e água. Partindo de $110 \mathrm{~g}$ de amônia, o aluno deveria calcular a quantidade de gás carbônico produzido na reação. Para auxiliar os alunos me suas reflexões, no final da questão foi apresentado um gráfico que relacionava quantidades de ureia, água e amônia. Os alunos deveriam obter a quantidade de gás carbônico a partir de considerações sobre a conservação e proporção das substâncias envolvidas e das relações entre as quantidades em massa das substâncias descritas no gráfico. Nenhum dos alunos presentes neste momento foi capaz de responder de forma correta a questão, sendo que a maioria deles deixou a mesma em branco. A partir de uma reformulação, a questão foi novamente aplicada, contendo informações abaixo do gráfico, as quais deveriam ser utilizadas como reflexões que pudessem auxiliar os estudantes na resolução do problema. Em vez de um único questionamento a respeito da determinação da quantidade em massa de gás carbônico obtida a partir de $110 \mathrm{~g}$ de amônia, também foram propostas investigações sobre o motivo de a massa do gás ser mínima, conforme relatado no problema e qual deveria ser a quantidade produzida de água e ureia se a quantidade em massa de gás carbônico fosse maior do que a obtida na relação descrita inicialmente na questão. Em relação ao cálculo da quantidade de gás carbônico, observamos um aumento significativo do número de alunos que acertaram a questão, passando de $0 \%$ para $80 \%$ do total de alunos participantes. Os resultados indicaram que ao participarem de todas as etapas da sequência, os alunos passaram e mobilizar habilidades relacionadas aos cálculos matemáticos e às relações de proporção com maior entendimento. Entretanto, ainda foram percebidas muitas dificuldades em responder os demais itens. Talvez pela forma como foi apresentada a informação e pelo tipo de questionamento realizado, ou seja, entendemos que o aluno não conseguiu estabelecer conexões por exemplo com a ideia de uma massa ser mínima devido a proporção entre as substâncias em uma reação. Desta forma, ele não foi capaz de desenvolver reflexões sobre as proporções dos materiais, não conseguiu pensar em soluções para o que aconteceria se a massa de gás carbônico fosse ainda maior.

No módulo 3 também predominou a utilização de habilidades de ordem mais complexas. A habilidade 24 somente foi mobilizada no último questionário da sequência, em uma única questão. Nas demais questões predominaram a utilização conjunta das habilidades 17 e 25. Assim como no módulo anterior, as situações que problematizaram o ensino envolveram conhecimentos relacionados aos cálculos matemáticos, as relações de proporções 
e as conservações das quantidades dos materiais em uma reação química. Desta forma, não poderia ser diferente a demanda cognitiva em caracterizar os materiais a partir da identificação de seus rendimentos (habilidade 25).

A partir dos dados descritos na tabela 68 verificamos um aumento do número de alunos que passaram a responder adequadamente às questões que envolveram conhecimentos conceituais a respeito da conservação e proporção dos materiais, entretanto, o desempenho dos mesmos foram determinados pelo tipo de questão.

Por exemplo, comparando os resultados da questão 4 do instrumento 3 com a questão 1(b) do instrumento 12 , verificamos um aumento significativo na porcentagem de acertos dos alunos, de $50 \%$ para 90\%. Também tratou-se de uma mesma questão aplicada em dois momentos da sequência em que os alunos deveriam calcular a massa dos componentes envolvidos na reação. Entendemos que os mesmos apresentaram maior domínio de alguns conhecimentos e também foram capaz de articular algumas habilidades com maior facilidade ao final das atividades (instrumento 12), como a percepção da proporção entre as amostras na produção de cal e a conservação entre as quantidades em massas dos componentes envolvidos inicialmente e no término das reações. Talvez, neste momento das atividades, os alunos já tivessem mais familiarizados com a forma como foi proposto o problema, ou seja, com os dados organizados em uma tabela. A partir de algumas informações, geralmente descritas na forma de quantidade em massa das substâncias, os alunos deveriam encontrar as quantidades em massa de substâncias que não foram calculadas, sendo que a ordem das substâncias descritas nas tabelas representavam a mesma ordem de uma reação química, o que facilitava na reflexão do problema. Tais constatações também foram verificadas na questão 3 (item b) do instrumento 13 , sendo que o rendimento foi ainda maior, cerca de $78 \%$ dos alunos resolveram de forma correta o problema. E também nos itens b e c da questão 6 do mesmo instrumento, sendo que o percentual de acerto foi de 55\%, sendo um pouco menor talvez por relacionar informações em tabela e também em gráfico, o que ainda entendemos serem habilidades que devem ser aprimoradas visto a quantidade de relações a serem feitas no momento da resolução do problema.

Já, em relação às questões 10 , do instrumento 3 , e 2, do instrumento 12 , os rendimentos não foram tão significativos. Ou seja, neste caso ocorreu uma aumento de apenas $20 \%$ do número de alunos que passaram a acertar a questão, variando de $10 \%$ (instrumento 3) para $30 \%$ (instrumento 2) do total de alunos que resolveram adequadamente a questão. Mesmo sendo um problema em que as informações também estavam dispostas em forma de 
tabela, no caso desta questão, o relato da sobra de materiais envolvidos na reação dificultou o pensamento dos alunos na proposição de uma solução para o problema. Alguns alunos ficaram com uma preocupação em utilizar a quantidade de material que sobrou na comprovação da lei de conservação das massas envolvidas na reação, somando a sobra de materiais a quantidade de produto formado e assim afirmando que havia conservação das massas dos materiais. Também, interpretaram a sobra de material como um dos produtos formados na reação, talvez pela informação referente à quantidade da sobra aparecer logo após a quantidade do produto da reação. E por fim, outros entenderam que sobrar material em uma reação significa a não conservação das quantidades em massas das substâncias envolvida no início e no final da reação. Ou seja, entendemos que para eles a conservação das massas das substâncias envolvidas em qualquer reação química somente ocorre quando a quantidade total de reagentes se transforma em produto.

Segundo Zoller (1993), questões de baixa ordem cognitiva (LOCS) e algorítmicas (ALG) demandam dos estudantes relembrar informações ou aplicar conhecimentos muitas vezes sem entenderem os conceitos químicos. Já as habilidades de alta ordem cognitiva (HOCS) exigem dos estudantes a reflexão a partir de problemas não familiares para os alunos, sendo necessária a aplicação de outros conhecimentos, estabelecimento de conexões, investigações e desenvolvimento de pensamento crítico.

Assim, como foi verificado no trabalho de Zoller, Dori e Lubezky (2002), em nossa pesquisa também observamos bons rendimentos em questões algorítmicas. Tais questões foram aplicadas no primeiro módulo da sequência de ensino, sendo observados altos índices de acertos desde a primeira questão até questões presentes no final do módulo. Segundo os autores, tais resultados se justificam em decorrência da facilidade dos estudantes em reproduzirem questões algorítmicas. Quanto aos rendimentos de questões que demandaram alta cognição, observamos um aumento gradual e significativo. Tais observações decorreram de momentos das atividades em que os alunos articularam conhecimentos sobre a conservação e proporção dos materiais, mesmo sendo mais difíceis para os estudantes aplicarem seus conhecimentos em novas situações.

De forma geral, contribuímos no desenvolvimento tanto de habilidades de baixa quanto de alta ordem cognitivas. Ao final da sequência de ensino, os alunos ampliaram seus conhecimentos e também passaram a articular com maior facilidade a aplicação de conceitos, a reflexão, a articulação de novas informações e a investigação de situações propostas. 


\subsubsection{Resultados das aplicações por aluno}

Analisar as atividades que compuseram as Situações-problema foi muito importante na percepção de uma evolução na construção dos conhecimentos e no desenvolvimento de habilidades cognitivas. Diagnosticamos dificuldades conceituais durante a resolução dos problemas, e também quais habilidades foram aprimoradas ao longo de toda a sequência. Entretanto, em uma avaliação geral dos instrumentos não pudemos acompanhar a evolução individual dos alunos. Com o propósito de realizar um acompanhamento específico escolhemos três alunos que participaram de no mínimo de 11 das 13 atividades, para realizar uma análise de seus dados e descrever como decorreram as principais construções de conhecimentos e de habilidades ao longo de cada uma das atividades. Acreditamos ter mapeado alguns momentos importantes das atividades em que alguns conceitos foram reformulados e habilidades aperfeiçoadas.

Optamos por reproduzir os registros escritos dos alunos em três quadros, sendo cada um deles organizado de acordo com os módulos da sequência de atividades. Como forma de acompanhamento dos alunos por módulo, os relatos das informações são descritas nos quadros de acordo com as seguintes categorias: Ideias prévias (conhecimentos trazidos pelos alunos anteriormente à realização das atividades), Construção de conhecimentos teórico e Habilidades Cognitivas (de que forma no decorrer das atividades ocorreram evoluções dos conhecimentos conceituais e cognitivos), Síntese da construção (demonstração, por parte dos alunos, de como estão organizados os conceitos construídos) e as Aplicação de conhecimentos (Aplicação dos conhecimentos em outras situações propostas, distintas ou semelhantes da anteriores).

Como forma de comunicação utilizamos duas marcações para facilitar a identificação das ideias apresentadas. Palavras "sublinhadas e em negrito", retiradas das resoluções, expressaram a construção de conhecimentos, ao longo da aplicação dos módulos, adequadamente e com mudanças significativas. Já as palavras em "itálico e negrito" indicaram respostas que não utilizaram os conceitos corretos, a partir dos padrões científicos.

Os estudantes analisados já apresentavam algumas concepções prévias a respeito dos conteúdos tratado, sendo algumas modificadas e outras conservadas no decorrer dos módulos. A seguir estão descritos os quadros (Quadros 23, 24 e 25) representativos dos três módulos referentes às análises de cada um deles. 


\section{ALUNO 1}

Nos quadros 25, 26 e 27 estão apresentadas as respostas dada pelo aluno 1, bem como alguns comentários de análise, nas quatro categorias mencionadas anteriormente, em relação às questões específicas dos questionários.

Quadro 25. Acompanhamento individual na construção de conhecimentos conceituais e cognitivos do Aluno 1 referentes ao módulo 1. (Palavras "sublinhadas e em negrito", expressaram a construção de conhecimentos adequadamente e com mudanças significativas; palavras em itálico e negrito" indicaram respostas que não utilizaram os conceitos corretos, a partir dos padrões científicos). "

\begin{tabular}{|c|c|}
\hline \multicolumn{2}{|c|}{ Módulo 1: Transformações Químicas - reconhecimento e conceituação } \\
\hline \multicolumn{2}{|r|}{ IDEIAS PRÉVIAS } \\
\hline \multicolumn{2}{|r|}{ INSTRUMENTO 2} \\
\hline $\begin{array}{c}\text { QUESTÃO } 1 \\
\text { Classificar os fenômenos químicos }\end{array}$ & $\begin{array}{l}\text { Fenômenos Químicos } \\
\text { • Dissolução de um comprimido efervescente em } \\
\text { água; } \\
\text { - Enferrujamento de um prego. } \\
\text { Fenômenos Biológicos/Naturais } \\
\text { - Fermentação da massa na fabricação de pães; } \\
\text { - Amadurecimento de uma banana } \\
\text { Fenômenos Físicos } \\
\text { - Obtenção de sal por evaporação da água do mar; } \\
\text { - Precipitação da chuva. }\end{array}$ \\
\hline $\begin{array}{c}\text { QUESTÃO 3 } \\
\text { Analisar os casos e verificação de } \\
\text { ideias que contrariam ou confirmam a } \\
\text { necessidade de pelo menos duas } \\
\text { substâncias para que ocorra uma } \\
\text { transformação química } \\
\end{array}$ & ...é necessário 2 ou mais substâncias para gerar outra. \\
\hline $\begin{array}{c}\text { QUESTÃ̃ O 5 } \\
\text { Item a - Representar a equação } \\
\text { química }\end{array}$ & $\begin{array}{l}\text { Representação correta da equação química do processo } \\
\text { sem balancear }\end{array}$ \\
\hline $\begin{array}{c}\text { QUESTÃO } 5 \\
\text { Item b- calcular a massa }\end{array}$ & Cálculo correto da massa do gás metano. \\
\hline $\begin{array}{c}\text { QUESTÃO 7 } \\
\begin{array}{c}\text { Representar a equação química } \\
\text { balanceada }\end{array}\end{array}$ & $\begin{array}{l}\text { Representação correta e balanceada da equação química } \\
\text { do processo. }\end{array}$ \\
\hline $\begin{array}{c}\text { QUESTÃO 9 } \\
\text { Associar as imagens representativas das } \\
\text { moléculas com a linguagem simbólica }\end{array}$ & $\begin{array}{l}\text { - Não consegue associar todos os símbolos às } \\
\text { representações (confusão simbólica). } \\
\text { - Reconhece os elementos, mas não forma as } \\
\text { moléculas. }\end{array}$ \\
\hline & INSTRUMENTO 3 \\
\hline
\end{tabular}




\begin{tabular}{|c|c|}
\hline $\begin{array}{l}\text { QUESTÃ O 1 } \\
\text { Fornecer exemplos de transformações } \\
\text { Químicas com justificativas }\end{array}$ & $\begin{array}{l}\text { Oxidação e Combustão pois ocorre a reação entre } 2 \\
\text { substâncias ocorrendo a transformação dos reagentes } \\
\text { em produto. }\end{array}$ \\
\hline $\begin{array}{c}\text { QUESTÃO } 2 \\
\text { Relatar se a reação entre solução de } \\
\text { sulfato de cobre e um prego é uma } \\
\text { reação química }\end{array}$ & $\begin{array}{l}\text { Não é uma reação química } \\
\text { O cobre se depositou na superfície do prego e não é } \\
\text { uma transformação pois não há reação. }\end{array}$ \\
\hline $\begin{array}{l}\text { QUESTÃO 3 } \\
\text { Responder se o apodrecimento de um } \\
\text { fruto é um processo químico }\end{array}$ & $\begin{array}{l}\text { Sim. Produção/liberação de gás etileno responsável } \\
\text { pelo amadurecimento }\end{array}$ \\
\hline \multicolumn{2}{|c|}{$\begin{array}{c}\text { CONSTRUÇÃO DE CONHECIMENTOS } \\
\text { E HABILIDADES COGNITIVAS }\end{array}$} \\
\hline \multicolumn{2}{|c|}{ INSTRUMENTO 4 (EM GRUPO) } \\
\hline $\begin{array}{c}\text { QUESTÃO 2 } \\
\begin{array}{c}\text { Verificar se ocorreu a formação de um } \\
\text { novo material nos testes }\end{array} \\
\end{array}$ & $\begin{array}{l}\text { Não, eles não se dissolvem, não se misturam, assim } \\
\text { não formando um novo material. Ex: Teste } 1 \text { - tubo } 1- \\
\text { água e óleo. }\end{array}$ \\
\hline $\begin{array}{l}\text { QUESTÃO 3 } \\
\text { Verificar se a adição de sal de frutas em } \\
\text { água trata-se de uma transformação da } \\
\text { matéria. Descrever possíveis evidências }\end{array}$ & Sim, a dissolução e a formação de gases formados. \\
\hline \multicolumn{2}{|r|}{ INSTRUMENTO 5} \\
\hline $\begin{array}{c}\text { QUESTÃO 3 } \\
\text { Relatar e justificar se a formação de } \\
\text { chuva ácida é uma transformação } \\
\text { química }\end{array}$ & $\begin{array}{l}\text { Sim, pois houve uma combinação dos elementos } \\
\text { químicos (gás carbônico e vapor d'água) formando a } \\
\text { chuva ácida. }\end{array}$ \\
\hline $\begin{array}{c}\text { QUEST T̃O 4 } \\
\text { Relatar e justificar se existe evidência } \\
\text { de que a chuva está ácida }\end{array}$ & $\begin{array}{l}\text { Não apresenta evidência visível, mas pode ser } \\
\text { observado com análises de pH em corpos hídricos ou } \\
\text { em solos. }\end{array}$ \\
\hline \multicolumn{2}{|r|}{ SÍNTESE DA CONSTRUÇÃO } \\
\hline \multicolumn{2}{|r|}{ INSTRUMENTO 6} \\
\hline $\begin{array}{l}\text { SÍNTESE DE CONTEÚDOS } \\
\text { Sintetizar os principais conteúdos } \\
\text { construídos após realização do primeiro } \\
\text { módulo }\end{array}$ & $\begin{array}{l}\text { - Reação de elementos iguais e/ou diferentes; } \\
\text { - Formação de elementos diferentes do anterior; } \\
\text { - Criação de um produto diferente do reagente; } \\
\text { - Não altera a composição molecular; }\end{array}$ \\
\hline \multicolumn{2}{|c|}{ APLICAÇÃO DE CONHECIMENTOS } \\
\hline \multicolumn{2}{|r|}{ INSTRUMENTO 12} \\
\hline $\begin{array}{c}\text { QUESTÃO O 1 } \\
\text { Classificar os fenômenos químicos }\end{array}$ & 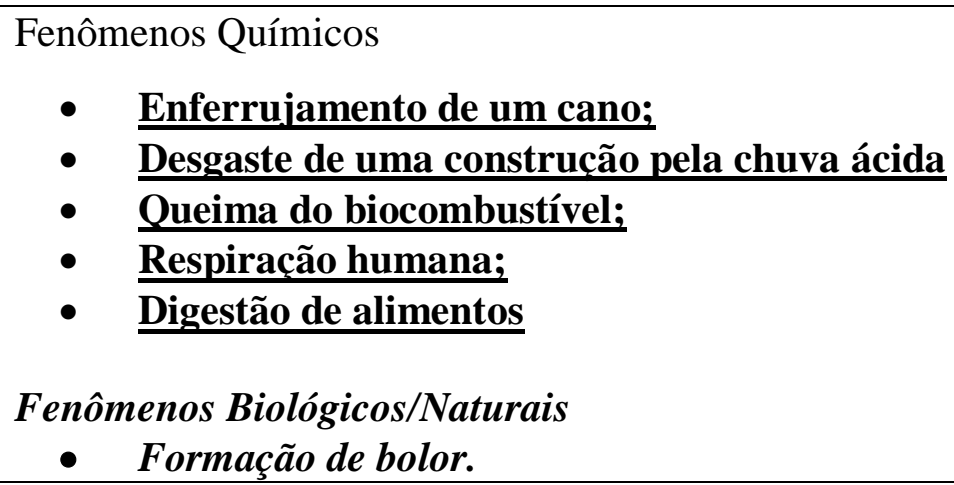 \\
\hline
\end{tabular}




\begin{tabular}{|c|l|}
\hline $\begin{array}{c}\text { QUESTÃO 2 } \\
\text { Reconhecer reagentes/produtos e } \\
\text { representar a equação química }\end{array}$ & $\begin{array}{l}\text { Indicação correta de reagentes e produtos; } \\
\text { Representação correta da reação química. }\end{array}$ \\
\hline $\begin{array}{c}\text { QUESTÃO 4 } \\
\text { Item b: representar a reação química } \\
\text { balanceada }\end{array}$ & Equação química balanceada corretamente. \\
\hline $\begin{array}{c}\text { QUESTÃO 5 } \\
\text { Representar a reação química }\end{array}$ & Representação correta das moléculas. \\
\hline $\begin{array}{c}\text { QUESTÃO 6 } \\
\text { Item a: representar a reação química }\end{array}$ & Representação correta da reação química. \\
\hline
\end{tabular}

Quadro 26. Acompanhamento individual na construção de conhecimentos conceituais e cognitivos do Aluno 1 referentes ao módulo 2. (Palavras "sublinhadas e em negrito", expressaram a construção de conhecimentos adequadamente e com mudanças significativas; palavras em itálico e negrito" indicaram respostas que não utilizaram os conceitos corretos, a partir dos padrões científicos). “

\begin{tabular}{|c|c|}
\hline \multicolumn{2}{|c|}{ Módulo 2: Conservação das massas numa transformação química } \\
\hline \multicolumn{2}{|r|}{ IDEIAS PRÉVIAS } \\
\hline \multicolumn{2}{|r|}{ INSTRUMENTO 2} \\
\hline $\begin{array}{l}\text { QUESTÃO 4 } \\
\text { calcular a massa }\end{array}$ & Completou a tabela com os dois valores corretos. \\
\hline $\begin{array}{c}\text { QUESTÃO } \mathbf{1 0} \\
\text { Aplicar conhecimentos sobre as leis de } \\
\text { conservação e proporção }\end{array}$ & $\begin{array}{l}\text { Verificação da conservação e proporção das } \\
\text { substâncias; relato sobre a existência de sobra de } \\
\text { materiais. }\end{array}$ \\
\hline $\begin{array}{c}\text { QUESTÃO } 11 \\
\text { calcular a massa }\end{array}$ & Deixou a questão em branco. \\
\hline \multicolumn{2}{|c|}{$\begin{array}{c}\text { CONSTRUÇÃO DE CONHECIMENTOS } \\
\text { E HABILIDADES COGNITIVAS }\end{array}$} \\
\hline \multicolumn{2}{|c|}{ INSTRUMENTO 7} \\
\hline $\begin{array}{c}\text { QUESTÃO } 1 \\
\text { Reconhecer uma transformação } \\
\text { química }\end{array}$ & $\begin{array}{l}\text { Teste } 1 \text { - sistema fechado - SIM } \\
\text { Teste } 1 \text { - sistema aberto - NÃO } \\
\text { Teste } 2 \text { - sistema aberto - SIM }\end{array}$ \\
\hline $\begin{array}{c}\text { QUESTÃO } 2 \\
\text { Comparar os valores obtidos para as } \\
\text { massas do sistema antes e depois da } \\
\text { reação }\end{array}$ & $\begin{array}{l}\text { Teste } 1 \text { - sistema fechado - nenhum comentário } \\
\text { Teste } 1 \text { - sistema aberto perde massa - liberação de } \\
\text { gás } \\
\text { Teste } 2 \text { - sistema aberto - não houve efervescência } \\
\text { nem liberação de gás }\end{array}$ \\
\hline $\begin{array}{c}\text { QUESTÃO 3 } \\
\text { Atribuir as diferenças de massas }\end{array}$ & $\begin{array}{l}\text { Liberação de gás - efervescência - mudança de estado } \\
\text { físico }\end{array}$ \\
\hline $\begin{array}{l}\text { QUESTÃO } 4 \\
\text { Justificar o motivo de não haver } \\
\text { alteração de massa }\end{array}$ & $\begin{array}{l}\text { Apesar da mudança de estado físico, não houve } \\
\text { liberação de gás }\end{array}$ \\
\hline & INSTRUMENTO 8 \\
\hline
\end{tabular}




\begin{tabular}{|c|c|}
\hline $\begin{array}{c}\text { QUESTÃO } 1 \\
\text { Verificar se houve conservação de } \\
\text { massa }\end{array}$ & $\begin{array}{l}\text { Não. Quantidades pequenas e insignificantes } \\
\text { Falta de um reagente } \\
\text { Oxigênio total não contabilizado }\end{array}$ \\
\hline \multicolumn{2}{|c|}{ SÍNTESE DA CONSTRUÇÃO } \\
\hline \multicolumn{2}{|c|}{ INSTRUMENTO 8} \\
\hline $\begin{array}{c}\text { QUESTÃO 2 } \\
\text { Itens a/b: Determinar equação e reação } \\
\text { química e cálculo de massa do material }\end{array}$ & $\begin{array}{l}\text { Determinação de reagente, produto, equação química e } \\
\text { cálculo de massa corretamente. }\end{array}$ \\
\hline \multicolumn{2}{|r|}{ INSTRUMENTO 9} \\
\hline SÍNTESE DE CONTEÚDOS & Compreensão de termos para evitar confusões. \\
\hline \multicolumn{2}{|r|}{ INSTRUMENTO 11} \\
\hline $\begin{array}{c}\text { QUESTÃO 1 } \\
\text { Item b: Determinar de valores de } \\
\text { massas das substâncias }\end{array}$ & $\begin{array}{l}\text { Obtencão das quantidades corretas de ambas as } \\
\text { substâncias. }\end{array}$ \\
\hline $\begin{array}{c}\text { QUESTÃO 2 } \\
\text { Item b: Refletir se a massa inicial do } \\
\text { sistema é a mesma que a massa final?... }\end{array}$ & $\begin{array}{l}\text { A massa foi conservada } \\
\text { As massas iniciais e finais não são iguais pois } \\
\text { só não virou produto. }\end{array}$ \\
\hline \multicolumn{2}{|c|}{ APLICAÇÃO DE CONHECIMENTOS } \\
\hline \multicolumn{2}{|c|}{ INSTRUMENTO 12} \\
\hline $\begin{array}{c}\text { QUESTÃO 3 } \\
\text { Itens a/b: Determinar os valores de } \\
\text { massa de } \mathrm{CO}_{2} \text { e CO }\end{array}$ & $\begin{array}{l}\text { Obtencão das quantidades corretas de ambas as } \\
\text { substâncias. }\end{array}$ \\
\hline $\begin{array}{c}\text { QUESTÃO 4 } \\
\text { Item a: Verificar a relação entre as } \\
\text { tiragens? cálculo das quantidades }\end{array}$ & $\begin{array}{l}\text { Obtencão das quantidades esperadas para todas as } \\
\text { substâncias. }\end{array}$ \\
\hline
\end{tabular}

Quadro 27. Acompanhamento individual na construção de conhecimentos conceituais e cognitivos do Aluno 1 referentes ao módulo 3. (Palavras "sublinhadas e em negrito", expressaram a construção de conhecimentos adequadamente e com mudanças significativas; palavras em itálico e negrito" indicaram respostas que não utilizaram os conceitos corretos, a partir dos padrões científicos). "

\begin{tabular}{|c|c|}
\hline \multicolumn{2}{|c|}{ Módulo 3: Proporções entre as massas numa transformação química } \\
\hline \multicolumn{2}{|r|}{ IDEIAS PRÉVIAS } \\
\hline \multicolumn{2}{|r|}{ INSTRUMENTO 2} \\
\hline $\begin{array}{c}\text { QUESTÃO 4 } \\
\text { Calcular as massas }\end{array}$ & Completou a tabela com os dois valores corretos. \\
\hline $\begin{array}{c}\text { QUESTÃO 8 } \\
\text { Calcular as produção de barrilha a } \\
\text { partir de } 200 \mathrm{~g} \text { de carbonato de cálcio } \\
\left(\mathrm{CaCO}_{3}\right) \text { na reação }\end{array}$ & $\begin{array}{l}\text { - } \quad \text { cálculo da massa da molécula; } \\
\text { - } \quad \text { soma das massas das moléculas; } \\
\text { carbonato de cálcio. }\end{array}$ \\
\hline $\begin{array}{c}\text { QUESTÃO } \mathbf{1 0} \\
\begin{array}{c}\text { Aplicar conhecimentos sobre as leis de } \\
\text { conservação e proporção }\end{array}\end{array}$ & $\begin{array}{l}\text { Verificação da conservação e proporção das } \\
\text { substâncias; relato sobre a existência de sobra de } \\
\text { materiais. }\end{array}$ \\
\hline $\begin{array}{c}\text { QUESTÃ̃O 11 } \\
\text { Calcular o valor de massa de gás } \\
\text { carbônico }\end{array}$ & Deixou a questão em branco. \\
\hline \multicolumn{2}{|c|}{$\begin{array}{c}\text { CONSTRUÇÃO DE CONHECIMENTOS } \\
\text { E HABILIDADES COGNITIVAS }\end{array}$} \\
\hline
\end{tabular}




\begin{tabular}{|c|c|}
\hline \multicolumn{2}{|r|}{ INSTRUMENTO 10} \\
\hline $\begin{array}{c}\text { QUESTÃO } 4 \\
\text { Refletir sobre o que aconteceria se } \\
\text { fosse colocado mais bolinhas nos tubos } \\
1 \text { e } 2 ?\end{array}$ & $\begin{array}{l}\text { Nada, os testes realizados mostram que o cobre do } \\
\text { líquido reage com a bolinha. Por isso a mudança de } \\
\text { coloração. }\end{array}$ \\
\hline $\begin{array}{l}\text { QUESTÃO 5 } \\
\text { Refletir sobre quando se misturam } \\
\text { reagentes, será que tudo se transforma } \\
\text { em produtos. }\end{array}$ & $\begin{array}{l}\text { Não, pois se houver um reagente limitante não há } \\
\text { um produto final dependendo de um resultado } \\
\text { esperado. }\end{array}$ \\
\hline \multicolumn{2}{|c|}{ SÍNTESE DA CONSTRUÇÃO } \\
\hline \multicolumn{2}{|c|}{ INSTRUMENTO 11} \\
\hline $\begin{array}{c}\text { QUESTÃO } 2 \\
\text { Item c: Verificar a proporção de } \\
\text { massas das substâncias }\end{array}$ & $\begin{array}{l}\text { Sim. Cálculo do enxofre realmente utilizado na } \\
\text { reacão no experimento I; } \\
\text { Verificacãa da proporção entre os experimentos I e } \\
\text { II. }\end{array}$ \\
\hline $\begin{array}{c}\text { QUESTÃO 3 } \\
\text { Item a: calcular a massa de gás } \\
\text { carbônico }\end{array}$ & $\begin{array}{l}\text { Representação da equação química corretamente; } \\
\text { Representacão das quantidades mínimas de cada } \\
\text { substância a partir de } 110 \text { g de amônia; } \\
\text { Verificacãa da quantidade de gás carbônico pela Lei } \\
\text { de conservação das massas. }\end{array}$ \\
\hline $\begin{array}{l}\text { QUESTÃO 3 } \\
\text { Item b: Responder o porque que a } \\
\text { massa é mínima }\end{array}$ & Não pode ser feito com menos. \\
\hline $\begin{array}{l}\text { QUEST } \tilde{\mathbf{A O} 3} \\
\text { Item c: Refletir o que acontece para } \\
\text { uma massa maior de gás carbônico? }\end{array}$ & $\begin{array}{l}\text { Deveria ser aumentada as quantidades de amônia e } \\
\text { gás carbônico proporcionalmente }\end{array}$ \\
\hline \multicolumn{2}{|c|}{ APLICAÇÃO DE CONHECIMENTOS } \\
\hline \multicolumn{2}{|c|}{ INSTRUMENTO 12} \\
\hline $\begin{array}{c}\text { QUESTÃO 6 } \\
\text { Item b: Argumentar sobre relação de } \\
\text { proporção entre reagentes e produtos }\end{array}$ & $\begin{array}{l}\text { Sim. Verificação da Conservação das Massas em um } \\
\text { único experimento e proporção. }\end{array}$ \\
\hline $\begin{array}{c}\text { QUESTÃO 6 } \\
\text { Item c: } \text { Determinar a quantidade do } \\
\text { Sal A e do precipitado produzido }\end{array}$ & $\begin{array}{l}\text { Determinacão da quantidade do Sal A e do } \\
\text { precipitado produzido corretamente; } \\
\text { Aplicacão da proporcão entre as quantidades dos } \\
\text { sais e precipitado corretamente. }\end{array}$ \\
\hline
\end{tabular}

Em relação ao primeiro módulo, as respostas do estudante 1 evidenciaram algumas dificuldades: a não associação de fenômenos naturais como representações de uma reação química, confusões conceituais entre elementos e moléculas, o entendimento da ocorrência de uma reação química somente a partir de duas substâncias, a verificação de um fenômeno químico sempre por meio de uma evidência visível da reação e por fim, a dificuldade em balancear uma equação química. Ao final da aplicação do módulo o aluno demonstrou superação de algumas dificuldades. Durante a etapa de construção de conhecimentos 
reconheceu que apesar de não haver evidência visível na formação da chuva ácida estava ocorrendo uma transformação, no último instrumento representou uma equação química balanceada corretamente e conseguiu associar quase todos os fenômenos naturais como químicos. Entretanto, persistiram em todas as situações recorrentes as dificuldades em conceituar corretamente os elementos químicos e as moléculas. A sequência desenvolvida neste primeiro módulo contribuiu principalmente para o desenvolvimento das habilidades 17 (Relacionar informações apresentadas em diferentes formas de linguagem e representação usadas nas ciências físicas, químicas ou biológicas, como texto discursivo, gráficos, tabelas, relações matemáticas ou linguagem simbólica) e 24 (Utilizar códigos e nomenclatura da química para caracterizar materiais, substâncias ou transformações químicas), visto a evolução em conceituar as transformações químicas e a representação correta das moléculas.

Quanto ao segundo módulo, juntamente com as dificuldades de leitura e interpretação gráfica, estão o cálculo de massa dos materiais e o não reconhecimento da conservação da massa do sistema quando uma reação ocorre em um sistema aberto. Especificamente, a formação de gás, em um sistema aberto significou perda de material não sendo medida a massa dissipada da substância, logo para o aluno a massa inicial e a final dos materiais não se conservaram. Também, para ele, a massa se conserva em uma reação química desde que as quantidades em massa dos reagentes de uma reação seja igual a quantidade dos produtos. Ao final da aplicação das atividades houve uma evolução de conhecimentos e habilidades, o aluno foi capaz de encontrar valores corretos de massas das substâncias aplicando o conceito de conservação da massa do sistema reacional. Entretanto, ele ainda apresentou a ideia da necessidade de transformação total dos reagentes em produtos para que ocorra a conservação em massa dos materiais. A sequência apresentada neste segundo módulo contribuiu principalmente para o desenvolvimento das habilidades 25 (Caracterizar materiais ou substâncias, identificando etapas, rendimentos ou implicações biológicas, sociais, econômicas ou ambientais de sua obtenção ou produção), uma habilidade empregada no ensino de Química, considerada pelo fato de caracterizar as substâncias e rendimentos através da aplicação da lei de Conservação das Massas).

Por fim, no terceiro módulo o estudante apresentou dificuldade no cálculo da massa de gás carbônico envolvida em uma reação com a amônia resultando na produção da ureia e água. Certamente, a forma gráfica foi um obstáculo na verificação das quantidades das substâncias envolvidas na reação. No decorrer das atividades percebemos que o aluno praticamente não apresentou outras dificuldades de entendimento, sendo capaz de propor 
soluções para todos os problemas que envolveram os conceitos de conservação e proporção dos matérias. Ao final da sequência de atividades o problema envolvendo o cálculo da quantidade em massa de gás carbônico foi reaplicado sendo resolvido sem qualquer dificuldade. A sequência desenvolvida neste terceiro módulo contribuiu principalmente para o desenvolvimento das habilidades 17 (Relacionar informações apresentadas em diferentes formas de linguagem e representação usadas nas ciências físicas, químicas ou biológicas, como texto discursivo, gráficos, tabelas, relações matemáticas ou linguagem simbólica) devido à decodificação da linguagem utilizada a partir de tabelas e gráficos.

\section{ALUNO 2}

Nos quadros 28, 29 e 30 estão apresentadas as respostas dada pelo aluno 2, bem como alguns comentários de análise, nas quatro categorias mencionadas anteriormente, em relação às questões específicas dos instrumentos.

Quadro 28. Acompanhamento individual na construção de conhecimentos conceituais e cognitivos do Aluno 2 referentes ao módulo 1. (Palavras "sublinhadas e em negrito", expressaram a construção de conhecimentos adequadamente e com mudanças significativas; palavras em "itálico e negrito" indicaram respostas que não utilizaram os conceitos corretos, a partir dos padrões científicos).

\begin{tabular}{|c|c|}
\hline \multicolumn{2}{|c|}{ Módulo 1: Transformações Químicas - reconhecimento e conceituação } \\
\hline \multicolumn{2}{|r|}{ IDEIAS PRÉVIAS } \\
\hline \multicolumn{2}{|r|}{ INSTRUMENTO 2} \\
\hline \multirow{4}{*}{$\begin{array}{c}\text { QUESTÃO } 1 \\
\text { Classificar os fenômenos químicos }\end{array}$} & Fenômenos Químicos \\
\hline & $\begin{array}{l}\text { - Dissolução de um comprimido efervescente em } \\
\text { água }\end{array}$ \\
\hline & $\begin{array}{l}\text { Fenômenos Físicos } \\
\text { • Obtenção de sal por evaporação da água do mar }\end{array}$ \\
\hline & $\begin{array}{l}\text { Deixou em branco } \\
\text { - Fermentação da massa na fabricação de pão } \\
\text { - } \quad \text { Amadurecimento da banana } \\
\text { - } \quad \text { Enferrujamento de um prego } \\
\text { - } \quad \text { Precipitação da chuva }\end{array}$ \\
\hline $\begin{array}{c}\text { QUESTÃO 3 } \\
\text { Analisar os casos e verificação de } \\
\text { ideias que contrariam ou confirmam a } \\
\text { necessidade de pelo menos duas } \\
\text { substâncias para que ocorra uma } \\
\text { transformação química }\end{array}$ & $\begin{array}{l}\text {...gás ozônio se forma a partir de } 1 \text { substância sem } \\
\text { reagir com outra }\end{array}$ \\
\hline $\begin{array}{c}\text { QUESTÃ̃O 5 } \\
\text { Item a - Representar a equação }\end{array}$ & $\begin{array}{l}\text { Representação correta da equação química do processo } \\
\text { sem balancear }\end{array}$ \\
\hline
\end{tabular}




\begin{tabular}{|c|c|}
\hline química & \\
\hline $\begin{array}{c}\text { QUEST ̃̃O } 5 \\
\text { Item b- calcular a massa }\end{array}$ & $\begin{array}{l}\text { conversão e verificação de proporção entre a massa e o } \\
\text { volume do gás }\end{array}$ \\
\hline $\begin{array}{c}\text { QUESTÃOO 7 } \\
\text { Representar a equação química } \\
\text { balanceada }\end{array}$ & $\begin{array}{l}\text { Representação correta e confusão no balanceamento } \\
\text { da equação química do processo. }\end{array}$ \\
\hline $\begin{array}{l}\text { QUEST ÃO 9 } \\
\text { Associar as imagens representativas das } \\
\text { moléculas com a linguagem simbólica }\end{array}$ & Representação das moléculas de forma correta. \\
\hline & INSTRUMENTO 3 \\
\hline $\begin{array}{c}\text { QUESTÃO 1 } \\
\text { Fornecer exemplos de transformações } \\
\text { Químicas com justificativas }\end{array}$ & Preparo de um bolo sem justificativas \\
\hline $\begin{array}{c}\text { QUESTÃO } 2 \\
\text { Relatar se a reação entre solução de } \\
\text { sulfato de cobre e um prego é uma } \\
\text { reação química }\end{array}$ & $\begin{array}{l}\text { Sim. Alteração do pH (reação do líquido com o } \\
\text { prego), agregaçấo/interação da substância do líquido } \\
\text { no prego e líquido ao entrar em contato com o prego } \\
\text { ficou neutro; }\end{array}$ \\
\hline $\begin{array}{l}\text { QUESTÃO 3 } \\
\text { Responder se o apodrecimento de um } \\
\text { fruto é um processo químico }\end{array}$ & $\begin{array}{l}\text { Sim. Ocorre a troca gasosa que resulta no } \\
\text { desenvolvimento de microrganismos }\end{array}$ \\
\hline \multicolumn{2}{|c|}{$\begin{array}{c}\text { CONSTRUÇÃO DE CONHECIMENTOS } \\
\text { E HABILIDADES COGNITIVAS }\end{array}$} \\
\hline \multicolumn{2}{|c|}{ INSTRUMENTO 4 (EM GRUPO) } \\
\hline $\begin{array}{c}\text { QUESTÃO 2 } \\
\begin{array}{c}\text { Verificar se ocorreu a formação de um } \\
\text { novo material nos testes }\end{array} \\
\end{array}$ & Devido a liberação de energia ou mudança de cor \\
\hline $\begin{array}{l}\text { QUESTÃO 3 } \\
\text { Verificar se a adição de sal de frutas em } \\
\text { agua trata-se de uma transformação da } \\
\text { matéria. Descrever possíveis evidências }\end{array}$ & $\begin{array}{l}\text { Sim, o sal de frutas passou do estado sólido para o } \\
\text { gasoso. Pode ser comprovado devido as bolhas } \\
\text { formadas no recipiente. }\end{array}$ \\
\hline \multicolumn{2}{|r|}{ INSTRUMENTO 5} \\
\hline $\begin{array}{c}\text { QUESTÃO 3 } \\
\text { Relatar e justificar se a formação de } \\
\text { chuva ácida é uma transformação } \\
\text { química }\end{array}$ & $\begin{array}{l}\text { Sim, pois houve uma combinação dos elementos } \\
\text { químicos }\left(\mathrm{CO}_{2}+\text { vapor d'água), formando a chuva }\right. \\
\text { ácida. }\end{array}$ \\
\hline $\begin{array}{c}\text { QUESTÃO } 4 \\
\text { Relatar e justificar se existe evidência } \\
\text { de que a chuva está ácida }\end{array}$ & $\begin{array}{l}\text { Não apresenta evidências visível, mas pode ser } \\
\text { observado com análises de } \mathrm{pH} \text { em corpos hídricos ou } \\
\text { solos. }\end{array}$ \\
\hline \multicolumn{2}{|r|}{ SÍNTESE DA CONSTRUÇÃO } \\
\hline \multicolumn{2}{|r|}{ INSTRUMENTO 6} \\
\hline $\begin{array}{l}\text { SÍNTESE DE CONTEÚDOS } \\
\text { Sintetizar os principais conteúdos } \\
\text { construídos após realização do primeiro } \\
\text { módulo } \\
\end{array}$ & $\begin{array}{l}\text { - } \quad \text { Formação de elementos diferentes do anterior } \\
\text { - } \quad \text { Interação de } 1,2 \text { ou mais elementos }\end{array}$ \\
\hline \multicolumn{2}{|c|}{ APLICAÇÃO DE CONHECIMENTOS } \\
\hline \multicolumn{2}{|r|}{ INSTRUMENTO 12} \\
\hline $\begin{array}{c}\text { QUESTÃO O 1 } \\
\text { Classificar os fenômenos químicos }\end{array}$ & Fenômenos Químicos \\
\hline
\end{tabular}




\begin{tabular}{|c|c|}
\hline & $\begin{array}{ll}\text { - } & \text { Enferrujamento de um cano; } \\
\text { - } & \text { Formação de bolor. } \\
\text { - } & \text { Desgaste de uma construcão pela chuva ácida } \\
\text { - } & \text { Queima do biocombustível; } \\
\text { - } & \text { Respiração humana; } \\
\text { - } & \text { Digestão de alimentos; } \\
\text { - } & \text { Liberação de gás do refrigerante (não); } \\
\text { - } & \text { Coagulação do sangue (não) } \\
\text { - } & \text { Cozimento de um ovo. }\end{array}$ \\
\hline $\begin{array}{c}\text { QUESTÃO 2 } \\
\text { Reconhecer reagentes/produtos e } \\
\text { representar a equação química }\end{array}$ & Indicação correta de reagentes e produtos; \\
\hline $\begin{array}{c}\text { QUEST } \tilde{A} \mathbf{O} 4 \\
\text { Item b: representar a reação química } \\
\text { balanceada }\end{array}$ & Deixou em branco \\
\hline $\begin{array}{c}\text { QUESTÃ̃O 5 } \\
\text { Representar a reação química }\end{array}$ & Representação correta das moléculas. \\
\hline $\begin{array}{c}\text { QUEST T̃̃O 6 } \\
\text { Item a: representar a reação química }\end{array}$ & Representação correta da reação química. \\
\hline
\end{tabular}

Quadro 29. Acompanhamento individual na construção de conhecimentos conceituais e cognitivos do Aluno 2 referentes ao módulo 2. (Palavras "sublinhadas e em negrito", , expressaram a construção de conhecimentos adequadamente e com mudanças significativas; palavras em "itálico e negrito" indicaram respostas que não utilizaram os conceitos corretos, a partir dos padrões científicos).

\begin{tabular}{|c|c|}
\hline \multicolumn{2}{|c|}{ Módulo 2: Conservação das massas numa transformação química } \\
\hline \multicolumn{2}{|r|}{ IDEIAS PRÉVIAS } \\
\hline \multicolumn{2}{|r|}{ INSTRUMENTO 2} \\
\hline $\begin{array}{c}\text { QUESTÃO } 4 \\
\text { calcular a massa }\end{array}$ & Completou a tabela com os dois valores incorretos. \\
\hline $\begin{array}{l}\text { QUEST ÃO 10 } \\
\text { Aplicar conhecimentos sobre as leis de } \\
\text { conservação e proporção }\end{array}$ & Raciocínio matemático não identificado \\
\hline $\begin{array}{c}\text { QUEST ÃO 11 } \\
\text { calcular a massa }\end{array}$ & Deixou a questão em branco. \\
\hline \multicolumn{2}{|c|}{$\begin{array}{c}\text { CONSTRUÇÃO DE CONHECIMENTOS } \\
\text { E HABILIDADES COGNITIVAS }\end{array}$} \\
\hline \multicolumn{2}{|c|}{ INSTRUMENTO 7} \\
\hline $\begin{array}{c}\text { QUESTÃO 1 } \\
\text { Reconhecer uma transformação } \\
\text { química }\end{array}$ & $\begin{array}{l}\text { Teste } 1 \text { - sistema fechado - SIM } \\
\text { Teste } 1 \text { - sistema aberto - N } \tilde{O} \boldsymbol{O} \\
\text { Teste } 2 \text { - sistema aberto - SIM }\end{array}$ \\
\hline $\begin{array}{c}\text { QUESTÃO 2 } \\
\text { Comparar os valores obtidos para as } \\
\text { massas do sistema antes e depois da } \\
\text { reação }\end{array}$ & $\begin{array}{l}\text { Teste } 1 \text { - sistema aberto - não há conservação de } \\
\text { massa } \\
\text { Teste } 1 \text { - sistema fechado - conservação da massa } \\
\text { Teste } 2 \text { - sistema aberto - conservação da massa }\end{array}$ \\
\hline $\begin{array}{c}\text { QUESTÃOO 3 } \\
\text { Atribuir as diferenças de massas }\end{array}$ & Liberação de gás \\
\hline
\end{tabular}




\begin{tabular}{|c|c|}
\hline $\begin{array}{c}\text { QUESTÃO } 4 \\
\text { Justificar o motivo de não haver } \\
\text { alteração de massa }\end{array}$ & $\begin{array}{l}\text { Transformação não gerou gás } \\
\text { Não há efervescência }\end{array}$ \\
\hline & INSTRUMENTO 8 \\
\hline $\begin{array}{c}\text { QUESTÃOO 1 } \\
\text { Verificar se houve conservação de } \\
\text { massa }\end{array}$ & Faltou na aula \\
\hline \multicolumn{2}{|c|}{ SÍNTESE DA CONSTRUCÃO } \\
\hline \multicolumn{2}{|c|}{ INSTRUMENTO 8} \\
\hline $\begin{array}{c}\text { QUESTÃO 2 } \\
\text { Itens a/b: Determinar equação e reação } \\
\text { química } \\
\end{array}$ & Faltou na aula \\
\hline $\begin{array}{c}\text { QUESTÃO 2 } \\
\text { Itens c: Determinar as quantidades de } \\
\text { substâncias envolvendo a proporção } \\
\text { dos materiais }\end{array}$ & Faltou na aula \\
\hline \multicolumn{2}{|r|}{ INSTRUMENTO 9} \\
\hline SÍNTESE DE CONTEÚDOS & $\begin{array}{l}\text { - compreensão de termos para evitar confusões; } \\
\text { - transformação química com conservação de } \\
\text { massa; } \\
\text { - verificação da conservação de massa em que } \\
\text { todos os reagentes foram transformados em } \\
\text { produtos; }\end{array}$ \\
\hline \multicolumn{2}{|r|}{ INSTRUMENTO 11} \\
\hline $\begin{array}{c}\text { QUESTÃ̃ 1 } \\
\text { Item b: Determinar de valores de } \\
\text { massas das substâncias }\end{array}$ & $\begin{array}{l}\text { Proporção das amostras 12/7 e 15/7 (x2) } \\
\text { Proporção das amostras 12/7 e 18/7 }\end{array}$ \\
\hline $\begin{array}{c}\text { QUESTÃO 2 } \\
\text { Item b: Refletir se a massa inicial do } \\
\text { sistema é a mesma que a massa final?... }\end{array}$ & $\begin{array}{l}\text { Houve conservação de massas } \\
\text { Cálculo da massa de enxofre que reagiu no experimento } \\
\text { I }\end{array}$ \\
\hline \multicolumn{2}{|c|}{ APLICAÇÃ̃ DE CONHECIMENTOS } \\
\hline \multicolumn{2}{|c|}{ INSTRUMENTO 12} \\
\hline $\begin{array}{c}\text { QUESTÃO 3 } \\
\text { Itens a/b: Determinar os valores de } \\
\text { massa de } \mathrm{CO}_{2} \text { e } \mathrm{CO}\end{array}$ & $\begin{array}{l}\text { Obtencão das quantidades corretas de ambas as } \\
\text { substâncias } \\
\text { Verificação de proporção entre as substâncias de } \\
\text { uma tiragem }\end{array}$ \\
\hline $\begin{array}{c}\text { QUESTÃO } 4 \\
\text { Item a: Verificar a relação entre as } \\
\text { tiragens? cálculo das quantidades }\end{array}$ & Deixou em branco \\
\hline
\end{tabular}

Quadro 30. Acompanhamento individual na construção de conhecimentos conceituais e cognitivos do Aluno 2 referentes ao módulo 3. (Palavras "sublinhadas e em negrito", expressaram a construção de conhecimentos adequadamente e com mudanças significativas; palavras em "itálico e negrito" indicaram respostas que não utilizaram os conceitos corretos, a partir dos padrões científicos).

Módulo 3: Proporções entre as massas numa transformação química

\begin{tabular}{|c|c|}
\hline & IDEIAS PRÉVIAS \\
\hline & INSTRUMENTO 2 \\
\hline QUESTÃO 4 & Apresentou os cálculos; \\
\hline
\end{tabular}




\begin{tabular}{|c|c|}
\hline Calcular as massas & Proporção entre I e II (x2) e I e III (x7) \\
\hline $\begin{array}{c}\text { QUESTÃO 8 } \\
\text { Calcular as produção de barrilha a } \\
\text { partir de } 200 \mathrm{~g} \text { de carbonato de cálcio } \\
\left(\mathrm{CaCO}_{3}\right) \text { na reação }\end{array}$ & Deixou a questão em branco. \\
\hline $\begin{array}{l}\text { QUESTÃ̃ } \mathbf{1 0} \\
\text { Aplicar conhecimentos sobre as leis de } \\
\text { conservação e proporção }\end{array}$ & Raciocínio matemático não identificado \\
\hline $\begin{array}{l}\text { QUEST ÃO 11 } \\
\text { Calcular o valor de massa de gás } \\
\text { carbônico }\end{array}$ & Deixou a questão em branco. \\
\hline \multicolumn{2}{|c|}{$\begin{array}{c}\text { CONSTRUÇÃO DE CONHECIMENTOS } \\
\text { E HABILIDADES COGNITIVAS }\end{array}$} \\
\hline \multicolumn{2}{|c|}{ INSTRUMENTO 10 (EM GRUPO) } \\
\hline $\begin{array}{c}\text { QUESTÃO 4 } \\
\text { Refletir sobre o que aconteceria se } \\
\text { fosse colocado mais bolinhas nos tubos } \\
1 \text { e } 2 ?\end{array}$ & $\begin{array}{l}\text { Nada, os testes realizados mostram que o cobre do } \\
\text { líquido reage com a bolinha. Por isso a mudança de } \\
\text { coloração. }\end{array}$ \\
\hline $\begin{array}{c}\text { QUESTÃO 5 } \\
\text { Refletir sobre quando se misturam } \\
\text { reagentes, será que tudo se transforma } \\
\text { em produtos? }\end{array}$ & $\begin{array}{l}\text { Não, pois se houver um reagente limitante não há um } \\
\text { produto final dependendo de um resultado esperado. }\end{array}$ \\
\hline \multicolumn{2}{|c|}{ SÍNTESE DA CONSTRUÇÃO } \\
\hline \multicolumn{2}{|c|}{ INSTRUMENTO 11} \\
\hline $\begin{array}{c}\text { QUESTÃO 2 } \\
\begin{array}{c}\text { Item c: Verificar da proporção de } \\
\text { massas das substâncias) }\end{array}\end{array}$ & $\begin{array}{l}\text { Sim. Cálculo do enxofre realmente utilizado na } \\
\text { reacão no experimento I; Verificacão da proporcão } \\
\text { entre os experimentos I e II. }\end{array}$ \\
\hline $\begin{array}{c}\text { QUESTÃO } 3 \\
\text { Item a: cálculo da massa de gás } \\
\text { carbônico) }\end{array}$ & $\begin{array}{l}\text { Representação da equação química corretamente; } \\
\text { Representação das quantidades mínimas de cada } \\
\text { substância a partir de } 110 \text { g de amônia; } \\
\text { Verificação da quantidade de gás carbônico pela Lei } \\
\text { de conservação das massas. }\end{array}$ \\
\hline $\begin{array}{c}\text { QUESTÃO 3 } \\
\text { Item b: Responder o porque que a } \\
\text { massa é mínima }\end{array}$ & Deixou em branco. \\
\hline $\begin{array}{l}\text { QUESTÃO 3 } \\
\text { Item c: Refletir o que acontece para } \\
\text { uma massa maior de gás carbônico? }\end{array}$ & Deixou em branco. \\
\hline \multicolumn{2}{|c|}{ APLICAÇÃ̃ DE CONHECIMENTOS } \\
\hline \multicolumn{2}{|c|}{ INSTRUMENTO 12} \\
\hline $\begin{array}{l}\text { QUESTÃO } 6 \\
\text { Item b: Argumentar sobre relação de } \\
\text { proporção entre reagentes e produtos }\end{array}$ & $\begin{array}{l}\text { Sim. Verificação da proporção somente entre os } \\
\text { reagentes. }\end{array}$ \\
\hline $\begin{array}{c}\text { QUESTÃO 6 } \\
\text { Item c: Determinar a quantidade do } \\
\text { Sal A e do precipitado produzido }\end{array}$ & $\begin{array}{l}\text { Determinação da quantidade do Sal A corretamente } \\
\text { e precipitado incorreto. }\end{array}$ \\
\hline
\end{tabular}

No primeiro módulo, o segundo estudante também apresentou dificuldade na associação de fenômenos naturais como representação de reações químicas, além de não 
classificar alguns dos demais fenômenos como químicos. O aluno foi capaz de representar uma reação, porém com dificuldades no balanceamento da equação química e, ao sintetizar os conteúdos, confundiu conceitos, utilizando a ideia de elemento químico para conceituar moléculas. Ao final da aplicação do módulo o aluno demonstrou evolução na classificação dos fenômenos químicos, entretanto persistiram as dificuldades em balancear uma equação química e conceituar elementos e moléculas. A sequência desenvolvida neste primeiro módulo contribuiu principalmente para o desenvolvimento das habilidades 17 (Relacionar informações apresentadas em diferentes formas de linguagem e representação usadas nas ciências físicas, químicas ou biológicas, como texto discursivo, gráficos, tabelas, relações matemáticas ou linguagem simbólica) e 24 (Utilizar códigos e nomenclatura da química para caracterizar materiais, substâncias ou transformações químicas), visto a evolução em conceituar as transformações químicas e a representação correta das moléculas.

Ao final do módulo 2 observamos confusões de conhecimentos sobre as leis de conservação das massas das substâncias, pois verificamos que o aluno somente descreve que houve conservação das quantidades das substâncias sem relacionar com os valores referentes às massas das mesmas. $\mathrm{O}$ aluno apresentou dificuldades de compreender que em um sistema aberto com formação de gases também se aplica a lei de conservação das massas das substâncias. Também, na conservação da massa do sistema em uma reação química, todas as quantidades de reagentes devem ser transformados em produtos. O estudante não esteve presente em uma atividade de síntese da construção, o que dificultou o processo de aprendizagem do mesmo. Entretanto, ao final das atividades demonstrou evolução de compreensão dos conhecimentos. Não somente foi capaz de determinar as quantidades em massa de algumas substâncias, como também foi capaz de verificar corretamente a conservação e proporção em massas de alguns materiais.

Apesar de o estudante, ao final do módulo 3, ter deixado em branco uma questão discursiva envolvendo o conceito de proporção, ele demonstrou evolução na construção do conhecimento, já que resolve adequadamente questões envolvendo a conservação e a proporção das substâncias. No início da sequência de atividades o aluno demonstrou muitas dificuldades no entendimento e aplicação do conceito de proporções químicas, visto que no instrumento 2 praticamente todas as questões que demandaram conhecimento sobre a proporção dos materiais foram deixadas em branco. No decorrer das atividades, especificamente após atividade experimental que abordou o conteúdo, o aluno passou a 
responder algumas questões, como exemplo a questão 3 do instrumento 11, a qual tinha sido aplicada como questão 11 do instrumento 2 em que o aluno deixou em branco.

\section{ALUNO 3}

Nos quadros 31, 32 e 33 estão apresentadas as respostas dada pelo aluno 3, bem como alguns comentários de análise, nas quatro categorias mencionadas anteriormente, em relação às questões específicas dos instrumentos.

Quadro 31. Acompanhamento individual na construção de conhecimentos conceituais e cognitivos do Aluno 3 referentes ao módulo 1. (Palavras "sublinhadas e em negrito", expressaram a construção de conhecimentos adequadamente e com mudanças significativas; palavras em "itálico e negrito" indicaram respostas que não utilizaram os conceitos corretos, a partir dos padrões científicos).

\begin{tabular}{|c|c|}
\hline \multicolumn{2}{|c|}{ Módulo 1: Transformações Químicas - reconhecimento e conceituação } \\
\hline \multicolumn{2}{|r|}{ IDEIAS PRÉVIAS } \\
\hline \multicolumn{2}{|r|}{ INSTRUMENTO 2} \\
\hline $\begin{array}{c}\text { QUESTÃO } 1 \\
\text { Classificar os fenômenos químicos }\end{array}$ & $\begin{array}{l}\text { Fenômenos Químicos } \\
\text { • Dissolução de um comprimido efervescente em } \\
\text { água; } \\
\text { • Enferrujamento de um prego. } \\
\text { Fenômenos Biológicos/Naturais } \\
\text { - Fermentação da massa na fabricação de pães; } \\
\text { - Amadurecimento de uma banana. } \\
\text { Fenômenos Físicos } \\
\text { - Obtenção de sal por evaporação da água do mar; } \\
\text { - Precipitação da chuva. }\end{array}$ \\
\hline $\begin{array}{c}\text { QUESTÃO 3 } \\
\text { Analisar os casos e verificação de } \\
\text { ideias que contrariam ou confirmam a } \\
\text { necessidade de pelo menos duas } \\
\text { substâncias para que ocorra uma } \\
\text { transformação química } \\
\end{array}$ & $\begin{array}{l}\text {...gás ozônio se forma a partir de } 1 \text { substância sem } \\
\text { reagir com outra. }\end{array}$ \\
\hline $\begin{array}{c}\text { QUESTÃO } 5 \\
\text { Item a - Representar a equação } \\
\text { química }\end{array}$ & $\begin{array}{l}\text { Representação correta e balanceada da equação química } \\
\text { do processo. }\end{array}$ \\
\hline $\begin{array}{c}\text { QUESTÃO 5 } \\
\text { Item b- calcular a massa }\end{array}$ & $\begin{array}{l}\text { Conversão e verificação de proporção entre a massa e o } \\
\text { volume do gás. }\end{array}$ \\
\hline $\begin{array}{c}\text { QUESTÃO 7 } \\
\begin{array}{c}\text { Representar a equação química } \\
\text { balanceada }\end{array}\end{array}$ & Representação correta e balanceada. \\
\hline $\begin{array}{l}\text { QUEST T̃O 9 } \\
\text { Associar as imagens representativas das } \\
\text { moléculas com a linguagem simbólica }\end{array}$ & Deixou em branco \\
\hline & INSTRUMENTO 3 \\
\hline
\end{tabular}




\begin{tabular}{|c|c|}
\hline $\begin{array}{c}\text { QUESTÃO 1 } \\
\text { Fornecer exemplos de transformações } \\
\text { Químicas com justificativas }\end{array}$ & Deixou em branco \\
\hline $\begin{array}{c}\text { QUESTÃO } 2 \\
\text { Relatar se a reação entre solução de } \\
\text { sulfato de cobre e um prego é uma } \\
\text { reação química }\end{array}$ & Deixou em branco \\
\hline $\begin{array}{l}\text { QUESTÃO 3 } \\
\text { Responder se o apodrecimento de um } \\
\text { fruto é um processo químico }\end{array}$ & Deixou em branco \\
\hline \multicolumn{2}{|c|}{$\begin{array}{c}\text { CONSTRUÇÃO DE CONHECIMENTOS } \\
\text { E HABILIDADES COGNITIVAS }\end{array}$} \\
\hline \multicolumn{2}{|c|}{ INSTRUMENTO 4 (EM GRUPO) } \\
\hline $\begin{array}{c}\text { QUESTÃO 2 } \\
\begin{array}{c}\text { Verificar se ocorreu a formação de um } \\
\text { novo material nos testes }\end{array}\end{array}$ & Devido a liberação de energia ou mudança de cor. \\
\hline $\begin{array}{l}\text { QUESTÃO 3 } \\
\text { Verificar se a adição de sal de frutas em } \\
\text { água trata-se de uma transformação da } \\
\text { matéria. Descrever possíveis evidências }\end{array}$ & $\begin{array}{l}\text { Sim, o sal de frutas passou do estado sólido para o } \\
\text { gasoso. Pode ser comprovado devido as bolhas } \\
\text { formadas no recipiente. }\end{array}$ \\
\hline \multicolumn{2}{|r|}{ INSTRUMENTO 5} \\
\hline $\begin{array}{c}\text { QUESTÃO 3 } \\
\text { Relatar e justificar se a formação de } \\
\text { chuva ácida é uma transformação } \\
\text { química } \\
\end{array}$ & Faltou da atividade \\
\hline $\begin{array}{c}\text { QUESTÃO } 4 \\
\text { Relatar e justificar se existe evidência } \\
\text { de que a chuva está ácida }\end{array}$ & Faltou da atividade \\
\hline \multicolumn{2}{|c|}{ SÍNTESE DA CONSTRUÇÃO } \\
\hline \multicolumn{2}{|r|}{ INSTRUMENTO 6} \\
\hline $\begin{array}{l}\text { SÍNTESE DE CONTEÚDOS } \\
\text { Sintetizar os principais conteúdos } \\
\text { construídos após realização do primeiro } \\
\text { módulo }\end{array}$ & $\begin{array}{l}\text { - reação de elementos iguais e/ou diferentes; } \\
\text { - } \quad \text { formação de elementos diferentes do anterior; } \\
\text { - interação de } 1,2 \text { ou mais elementos; } \\
\text { - } \quad \text { produto se torna outro elementos. }\end{array}$ \\
\hline \multicolumn{2}{|c|}{ APLICAÇÃO DE CONHECIMENTOS } \\
\hline \multicolumn{2}{|r|}{ INSTRUMENTO 12} \\
\hline $\begin{array}{c}\text { QUESTÃO } 1 \\
\text { Classificar os fenômenos químicos }\end{array}$ & $\begin{array}{l}\text { Fenômenos Químicos } \\
\text { - } \quad \text { Enferrujamento de um cano; } \\
\text { - } \text { Formação de bolor. } \\
\text { - } \quad \text { Desgaste de uma construção pela chuva ácida } \\
\text { - } \\
\text { - } \\
\text { - } \\
\text { Respima do biocombuãão humana; } \\
\end{array}$ \\
\hline $\begin{array}{c}\text { QUESTÃO 2 } \\
\text { Reconhecer reagentes/produtos e } \\
\text { representar a equação química }\end{array}$ & $\begin{array}{l}\text { Indicação correta de reagentes e produtos e } \\
\text { representação da reação química; }\end{array}$ \\
\hline
\end{tabular}




\begin{tabular}{|c|l|}
\hline $\begin{array}{c}\text { QUESTÃO 4 } \\
\text { Item b: representar a reação química } \\
\text { balanceada }\end{array}$ & $\begin{array}{l}\text { Quantidade incorreta pois considera novamente a } \\
\text { proporção das substâncias }\end{array}$ \\
\hline $\begin{array}{c}\text { QUESTÃO 5 } \\
\text { Representar a reação química }\end{array}$ & Representação correta das moléculas. \\
\hline $\begin{array}{c}\text { QUESTÃO 6 } \\
\text { Item a: representar a reação química }\end{array}$ & Representação correta da reação química. \\
\hline
\end{tabular}

Quadro 32. Acompanhamento individual na construção de conhecimentos conceituais e cognitivos do Aluno 3 referentes ao módulo 2. (Palavras "sublinhadas e em negrito", expressaram a construção de conhecimentos adequadamente e com mudanças significativas; palavras em "itálico e negrito" indicaram respostas que não utilizaram os conceitos corretos, a partir dos padrões científicos).

\begin{tabular}{|c|c|}
\hline \multicolumn{2}{|c|}{ Módulo 2: Conservação das massas numa transformação química } \\
\hline \multicolumn{2}{|r|}{ IDEIAS PRÉVIAS } \\
\hline \multicolumn{2}{|r|}{ INSTRUMENTO 2} \\
\hline $\begin{array}{l}\text { QUESTÃO } 4 \\
\text { calcular a massa }\end{array}$ & $\begin{array}{l}\text { Completou a tabela com os dois valores corretos. } \\
\text { apresentou os cálculos } \\
\text { proporção entre I e II (x2) e I e III (x7) }\end{array}$ \\
\hline $\begin{array}{l}\text { QUEST } \tilde{A} \mathbf{O} \mathbf{1 0} \\
\text { Aplicar conhecimentos sobre as leis de } \\
\text { conservacão e proporção }\end{array}$ & Deixou a questão em branco. \\
\hline $\begin{array}{c}\text { QUEST ̃̃̃ 11 } \\
\text { calcular a massa }\end{array}$ & Deixou a questão em branco. \\
\hline \multicolumn{2}{|c|}{$\begin{array}{c}\text { CONSTRUÇÃA DE CONHECIMENTOS } \\
\text { E HABILIDADES COGNITIVAS }\end{array}$} \\
\hline \multicolumn{2}{|c|}{ INSTRUMENTO 7} \\
\hline $\begin{array}{c}\text { QUESTÃO } 1 \\
\text { Reconhecer uma transformação } \\
\text { química }\end{array}$ & $\begin{array}{l}\text { Teste } 1 \text { - sistema fechado - SIM } \\
\text { Teste } 1 \text { - sistema aberto - SIM } \\
\text { Teste } 2 \text { - sistema aberto - SIM }\end{array}$ \\
\hline $\begin{array}{c}\text { QUESTÃO 2 } \\
\text { Comparar os valores obtidos para as } \\
\text { massas do sistema antes e depois da } \\
\text { reação }\end{array}$ & $\begin{array}{l}\text { Teste } 1 \text { - sistema aberto - liberação de gás e alteração } \\
\text { da massa } \\
\text { Teste } 1 \text { - sistema fechado - aumento da massa } \\
\text { Teste } 2 \text { - sistema aberto - nenhum comentário }\end{array}$ \\
\hline $\begin{array}{c}\text { QUESTÃO 3 } \\
\text { Atribuir as diferenças de massas }\end{array}$ & Liberação de gás \\
\hline $\begin{array}{l}\text { QUESTÃO } 4 \\
\text { Justificar o motivo de não haver } \\
\text { alteração de massa }\end{array}$ & Transformação não gerou gás \\
\hline \multicolumn{2}{|r|}{ INSTRUMENTO 8} \\
\hline $\begin{array}{l}\text { QUESTÃO } 1 \\
\text { Verificar se houve conservação de } \\
\text { massa }\end{array}$ & Não \\
\hline \multicolumn{2}{|c|}{ SÍNTESE DA CONSTRUÇÃO } \\
\hline \multicolumn{2}{|c|}{ INSTRUMENTO 8} \\
\hline $\begin{array}{c}\text { QUESTÃO 2 } \\
\text { Itens a/b: Determinar equação e reação } \\
\text { química } \\
\end{array}$ & Determinação de reagente, produto, equação química \\
\hline
\end{tabular}




\begin{tabular}{|c|c|}
\hline $\begin{array}{c}\text { QUESTÃO 2 } \\
\text { Itens c: Determinar as quantidades de } \\
\text { substâncias envolvendo a proporção } \\
\text { dos materiais }\end{array}$ & $\begin{array}{l}\text { Verificação da conservação das } \\
\text { Determinação parcial dos valores; } \\
\text { Dificuldades de verificação da proporção. }\end{array}$ \\
\hline \multicolumn{2}{|r|}{ INSTRUMENTO 9} \\
\hline SÍNTESE DE CONTEÚDOS & $\begin{array}{l}\text { • as reações podem ser físicas ou químicas; } \\
\text { - reações físicas apenas com mudança de estado } \\
\text { físico; } \\
\text { • } \quad \text { reações químicas com alterações moleculares } \\
\text { com uma substância se transformando na outra; } \\
\text { - reagentes como substâncias iniciais antes de } \\
\text { ocorrer a transformação química; } \\
\text { - produtos como substâncias finais após ocorrer a } \\
\text { transformação química; } \\
\text { • após a transformação a massa do reagente é } \\
\text { igual a massa do produto. }\end{array}$ \\
\hline \multicolumn{2}{|r|}{ INSTRUMENTO 11} \\
\hline $\begin{array}{c}\text { QUESTÃO } 1 \\
\text { Item b: Determinar de valores de } \\
\text { massas das substâncias }\end{array}$ & $\begin{array}{l}\text { Proporção das amostras 12/7 e 15/7 (x2); } \\
\text { Aplicacão da conservação das massas em 18/7. }\end{array}$ \\
\hline $\begin{array}{c}\text { QUESTÃO } 2 \\
\text { Item b: Refletir se a massa inicial do } \\
\text { sistema é a mesma que a massa final?... }\end{array}$ & $\begin{array}{l}\text { Houve conservação de massas; } \\
\text { Soma das massas dos reagentes são iguais a dos } \\
\text { produtos junto com as sobras. }\end{array}$ \\
\hline \multicolumn{2}{|c|}{ APLICAÇÃ̃ DE CONHECIMENTOS } \\
\hline \multicolumn{2}{|c|}{ INSTRUMENTO 12} \\
\hline $\begin{array}{c}\text { QUEST } \tilde{A} \mathbf{O} 3 \\
\text { Itens a/b: Determinar os valores de } \\
\text { massa de } \mathrm{CO}_{2} \text { e } \mathrm{CO}\end{array}$ & $\begin{array}{l}\text { Obtenção das quantidades corretas de ambas as } \\
\text { substâncias; } \\
\text { Verificação de proporção entre as substâncias de uma } \\
\text { tiragem. }\end{array}$ \\
\hline $\begin{array}{c}\text { QUESTÃO } 4 \\
\text { Item a: Verificar a relação entre as } \\
\text { tiragens? cálculo das quantidades }\end{array}$ & $\begin{array}{l}\text { Quantidade incorreta pois considera novamente a } \\
\text { proporção das substâncias }\end{array}$ \\
\hline
\end{tabular}

Quadro 33. Acompanhamento individual na construção de conhecimentos conceituais e cognitivos do Aluno 3 referentes ao módulo 3. (Palavras "sublinhadas e em negrito", expressaram a construção de conhecimentos adequadamente e com mudanças significativas; palavras em "itálico e negrito" indicaram respostas que não utilizaram os conceitos corretos, a partir dos padrões científicos).

\begin{tabular}{|c|c|}
\hline \multicolumn{2}{|c|}{ Módulo 3: Proporções entre as massas numa transformação química } \\
\hline \multicolumn{2}{|c|}{ IDEIAS PRÉVIAS } \\
\hline \multicolumn{1}{|c|}{ INSTRUMENTO 2 } \\
\hline $\begin{array}{c}\text { QUESTÃO 4 } \\
\text { Calcular as massas }\end{array}$ & $\begin{array}{l}\text { Completou a tabela com os dois valores corretos; } \\
\text { Apresentou os cálculos; } \\
\text { Proporção entre I e II (x2) e I e III (x7). }\end{array}$ \\
\hline $\begin{array}{c}\text { QUESTÃO 8 } \\
\text { Calcular as produção de barrilha a } \\
\text { partir de 200 g de carbonato de cálcio } \\
\left(\mathrm{CaCO}_{3}\right) \text { na reação }\end{array}$ & Deixou a questão em branco. \\
\hline $\begin{array}{c}\text { QUESTÃ̃ 10 } \\
\text { Aplicar conhecimentos sobre as leis de }\end{array}$ & Deixou a questão em branco. \\
\hline
\end{tabular}




\begin{tabular}{|c|c|}
\hline conservação e proporção & \\
\hline $\begin{array}{l}\text { QUESTÃ } \mathbf{A} 11 \\
\text { Calcular o valor de massa de gás } \\
\text { carbônico }\end{array}$ & Deixou a questão em branco. \\
\hline \multicolumn{2}{|c|}{$\begin{array}{c}\text { CONSTRUÇÃO DE CONHECIMENTOS } \\
\text { E HABILIDADES COGNITIVAS }\end{array}$} \\
\hline \multicolumn{2}{|c|}{ INSTRUMENTO 10 (EM GRUPO) } \\
\hline $\begin{array}{c}\text { QUESTÃO 4 } \\
\text { Refletir sobre o que aconteceria se } \\
\text { fosse colocado mais bolinhas nos tubos } \\
1 \text { e } 2 \text {. }\end{array}$ & $\begin{array}{l}\text { O tubo } 2 \text { desenvolveria as características do tubo } 1 \text {, já o } \\
\text { tubo } 1 \text { poderia não reagir completamente devido à falta } \\
\text { de reagentes ou absorveria todo o líquido. }\end{array}$ \\
\hline $\begin{array}{l}\text { QUESTÃO 5 } \\
\text { Refletir sobre quando se misturam } \\
\text { reagentes, será que tudo se transforma } \\
\text { em produtos. }\end{array}$ & $\begin{array}{l}\text { Não, vai depender da capacidade de cada material e } \\
\text { se os reagentes estão balanceados para não haver } \\
\text { limitacões na transformacão. }\end{array}$ \\
\hline \multicolumn{2}{|c|}{ SÍNTESE DA CONSTRUÇÃO } \\
\hline \multicolumn{2}{|c|}{ INSTRUMENTO 11} \\
\hline $\begin{array}{c}\text { QUESTÃO } 2 \\
\text { Item c: Verificar da proporção de } \\
\text { massas das substâncias) }\end{array}$ & $\begin{array}{l}\text { Sim. A sobra de mercúrio dependerá da quantidade } \\
\text { de enxofre. }\end{array}$ \\
\hline $\begin{array}{l}\text { QUESTÃO 3 } \\
\text { Item a: cálculo da massa de gás } \\
\text { carbônico) }\end{array}$ & $\begin{array}{l}\text { Representacão da equacão química corretamente; } \\
\text { Representação das quantidades mínimas de cada } \\
\text { substância a partir de } 110 \text { g de amônia; } \\
\text { Verificação da quantidade de gás carbônico pela Lei } \\
\text { de conservação das massas. }\end{array}$ \\
\hline $\begin{array}{l}\text { QUESTÃ̃ } 3 \\
\text { Item b: Responder o porque que a } \\
\text { massa é mínima }\end{array}$ & Toda a amônia foi consumida. \\
\hline $\begin{array}{l}\text { QUESTÃO } 3 \\
\text { Item c: Refletir o que acontece para } \\
\text { uma massa maior de gás carbônico? }\end{array}$ & Não teria amônia para produzir nada. \\
\hline \multicolumn{2}{|c|}{ APLICAÇÃ̃ DE CONHECIMENTOS } \\
\hline \multicolumn{2}{|c|}{ INSTRUMENTO 12} \\
\hline $\begin{array}{l}\text { QUESTÃO 6 } \\
\text { Item b: Argumentar sobre relação de } \\
\text { proporção entre reagentes e produtos }\end{array}$ & $\begin{array}{l}\text { Sim. Verificação da Conservação das Massas em um } \\
\text { único experimento e proporção }\end{array}$ \\
\hline $\begin{array}{c}\text { QUESTÃO 6 } \\
\text { Item c: Determinar a quantidade do Sal } \\
\text { A e do precipitado produzido }\end{array}$ & $\begin{array}{l}\text { Determinação da quantidade do Sal e não determinou a } \\
\text { quantidade de precipitado produzido. }\end{array}$ \\
\hline
\end{tabular}

Assim como para os outros estudantes, no primeiro módulo a associação de fenômenos naturais como reações químicas e a conceituação de elementos químicos como moléculas são dificuldades do estudante 3. No instrumento 12, o estudante esboçou dificuldades no entendimento da proporção entre as quantidades de substâncias. Ao final do módulo, o aluno demonstrou total entendimento na classificação dos fenômenos químicos e ainda obstáculos em conceituar elementos e moléculas.

A respeito do segundo módulo, as dificuldades foram intensificadas em relação ao cálculo de massa de uma substância e a aplicação da conservação da massa das 
transformações químicas. Tais dificuldades persistiram praticamente até o final da aplicação da sequência, sendo superada no último módulo, instrumento 12, sendo que o estudante determinou as quantidades de substâncias e também aplicou as leis e conservação e proporção das massas de substâncias uma transformação química.

Para o terceiro módulo, tanto as dificuldades quanto as superações foram semelhantes ao segundo estudante. Concentraram-se no cálculo das massas, e no entendimento da conservação e proporção dos materiais.

Entendendo o aluno como o "sujeito de sua aprendizagem" torna-se necessário idealizar um cenário envolvendo o ensino e a aprendizagem de forma que este aluno participe de forma ativa do processo de ensino, sendo a aprendizagem o resultado de suas ações. Partilhando destes ideais, conhecer o aluno de forma individualizada durante o processo de construção de conhecimentos é de fundamental importância como contribuição na sua aprendizagem. Pois, a partir do conhecimento do nível de desenvolvimento do aluno conseguiremos visualizar dificuldades ou facilidades para a aprendizagem das competências, assim como a verificação da necessidade de uma maior ou menor ajuda no decorrer da aprendizagem (Zabala e Arnau, 2010).

Assim, nesta etapa de trabalho nos dedicamos justamente a tais investigações, de facilidades e dificuldades a respeito do conhecimento conceitual e cognitivo do aluno. Diagnosticamos que algumas vezes os alunos não conseguiram agir de forma eficaz na resolução de alguns problemas.

Conforme pontuam Zabala e Arnau (2010) e também partilhando de tais ideias como apropriadas para as reflexões atuais, diversas podem ser as razões que comprometeram uma ação competente de forma que as situações problematizadoras pudessem ter sido resolvidas em suas totalidades. Por exemplo, o fato de uma situação ser distinta da outra pode determinar que uma pessoa demonstre algumas competências em certas situações e não em outras. Ainda, devem ser considerados a predisposição e envolvimento dos alunos, os conhecimentos prévios sobre o tema, a forma como cada um entende o que está sendo proposto e também a transferência das informações para o contexto no qual dever ser aplicada.

Também, a partir dos resultados obtidos em nosso trabalho (vide, por exemplo, quadros 23 ao 31) e das análises descritas, observamos que os alunos apresentaram dificuldades conceituais e cognitivas como a dificuldade em identificar fenômenos naturais como sendo reações químicas, no balanceamento químico das reações, em cálculos de massas de materiais a partir da proposição da proporção das massas dos mesmos. 


\section{CONSIDERAÇÕES FINAIS}

As competências e habilidades estão presentes em todos os documentos oficiais que legislam sobre o currículo do Ensino Médio em nosso país. Entretanto, como destaca Miguel Arroyo:

não se implantarão propostas inovadoras listando o que teremos de inovar, listando as competências que os educadores devem aprender e montando cursos de treinamento para formá-los. É (...) no campo da formação de profissionais de Educação Básica onde mais abundam as leis e os pareceres dos conselhos, os palpites fáceis de cada novo governante, das equipes técnicas, e até das agências de financiamento, nacionais e internacionais (Arroyo, 2001, p. 151).

Leis, normas, parâmetros e diretrizes apenas fazem sentidos sem manifestarem sua real função social e histórica: garantir direitos e promover a justiça social. Direto à igualdade, liberdade, pluralidade, diversidade, respeito e sustentabilidade são os fundamentos da cidadania, condição indispensável para democracia. Desta forma, a Educação Básica deve ser vista sempre como um direito fundamental, pois é através dela que o indivíduo pode construir as condições para alcançar a possibilidade de exercer a plenitude de sua cidadania. Assim, no contexto atual, uma educação segmentada em componentes curriculares organizados sem interações, na mera transposição de conhecimentos teóricos e descontextualizados, mais do que baixa efetividade pedagógica, dificulta a construção de uma sociedade cidadã.

O ensino por competências e habilidades, ao buscar superar tais dificuldades, demanda na construção de conhecimentos uma participação ativa do estudante, através da articulação de conhecimentos conceituais e cognitivos.

Este trabalho buscou colaborar com este processo de aprendizagem ao apresentar a relação entre as legislações que normatizam o currículo escolar e o Exame Nacional do Ensino Médio e, a partir desta discussão, construir e aplicar uma proposta de ensino que realmente desenvolva as competências e habilidades químicas em estudantes do Ensino Médio.

Acreditamos que analisar as atividades através do método de Análise de Conteúdo (BARDIN, 1977) contribuiu com o entendimento das atuações dos estudantes. Os alunos que não resolveram as questões com eficácia tiveram uma atuação menos competente durante a resolução dos problemas já que não encontraram as soluções adequadas para os mesmos. E a partir das categorias criadas como resultados das respostas dos alunos, estas nos propiciaram uma reflexão e maior entendimento em relação as dificuldades encontradas pelos mesmos 
durante a resolução dos problemas. Optamos por analisar os dados coletados de duas formas: a partir de uma análise geral dos instrumentos e priorizando a aluno individualmente.

Os resultados das questões de baixa ordem apresentaram melhores rendimentos em questões algorítmicas. Segundo Zoller (1993), isso significa maior facilidade em recordar a informação, aplicar conhecimentos ou algoritmos memorizados. Quanto ao rendimento em questões que demandaram alta cognição, incialmente apresentou-se baixo, mas após a participação nas sequencias de atividades, houve um aumento gradual e significativo. O que representou o domínio das investigação e resolução de problemas muitas vezes pouco familiares aos alunos, tomada de decisões e desenvolvimento de pensamento crítico e avaliativo para encontrar soluções às questões (ZOLLER, 1993).

Mesmo diante de muitos resultados e reflexões importantes já apresentados e discutidos nas análises dos instrumentos, acreditamos que conhecer o aluno de forma individualizada em seu processo de aprendizagem foi muito importante para que pudéssemos acompanhar suas dificuldades e seus avanços. Ou seja, tais análises nos permitiram entender o que determinados alunos têm como conhecimento inicial, como foi sendo construído novos conhecimentos e em quais momentos e por quais motivos aquele aluno não conseguiu propor soluções adequadas em determinado problema. Conforme já discutido anteriormente, foram diversas as razões que comprometeram uma ação competente do estudante na resolução das questões. Poderíamos citar, por exemplo, dificuldades já levantadas por Zabala e Arnau (2010), como: a predisposição e envolvimento dos alunos, a forma como cada um entende o que está sendo proposto e também a transferência das informações para o contexto no qual dever ser aplicada. Outras dificuldades, de cunho conceitual, também se fizeram presente: identificar fenômenos naturais como sendo reações químicas, balanceamento químico das reações, cálculos de massas de materiais e compreensão das relações de conservação e proporção de massa das substâncias.

Acreditamos que ensinar por meio de competências e habilidades certamente corresponde a forma ideal de ensino. Entretanto existem alguns percalços no caminho, mas nada que inviabilize a proposta. A formação inicial de professores nem sempre o capacita para desenvolver um ensino por competências.

Os materiais didáticos ainda estão organizados por conteúdos, sendo que quando existe uma alternativa são pequenas caixas de textos ou atividades experimentais no final de cada capítulo. A estrutura das escolas muitas vezes não são adequadas, já que em sua maioria ou não possuem laboratório didático. 
Enfim, é um desafio ensinar Química por competência. Mas não podemos nos dar por satisfeitos ficando somente como expectadores. Como educadores temos a obrigação de enfrentar os desafios cotidianos da educação, através da reflexão e proposição de práticas educativas que possam contribuir com a superação das dificuldades conceituais e cognitivas dos alunos. A formação enquanto pesquisador contribui para a superação desta passividade, abrindo possibilidades para construção de alternativas que superem os desafios que a educação nos impõe.

O ENEM como sendo o exame de larga escala de maior importância em nosso país, visto ser o acesso dos estudantes para o Ensino Superior, torna-se um instrumento essencial no processo de minimização das desigualdades sociais. Assim, é preciso alinhar o que se espera dos alunos com a realização da prova a partir das questões propostas, com sua Matriz de Referência e também as práticas docentes. 
BRASIL. Lei 9.394/96. Lei de Diretrizes e Bases da Educação Nacional, de 20 de dezembro de 1996.

BRASIL. Secretaria de Educação Fundamental. Parâmetros curriculares nacionais: introdução aos parâmetros curriculares nacionais. Brasília : MEC/SEF, 1997.

BRASIL. Ministério da Educação. Instituto Nacional de estudos e pesquisas educacionais. ENEM Exame Nacional do Ensino Médio- Documento Básico. Brasília: MEC/INEP. 2000a.

Disponível em <http://www.dominiopublico.gov.br/download/texto/me000115.pdf>. Acessado em 26 de Setembro de 2016.

BRASIL. Ministério da Educação. Instituto Nacional de estudos e pesquisas educacionais. Exame Nacional do Ensino Médio: relatório final 1999. Brasília: INEP/MEC, 2000b.

BRASIL. Parâmetros Curriculares Nacionais para o Ensino Médio. 2000.

BRASIL. Ministério da Educação. Instituto Nacional de estudos e pesquisas educacionais. Matriz de referência para o ENEM. Brasília: MEC/INEP. 2009.

BRASIL. Diretrizes Curriculares Nacionais para a Educação Básica. Conselho Nacional de Educação. Ministério da Educação.2010.

BRASIL. Diretrizes Curriculares Nacionais para o Ensino Médio. Conselho Nacional de Educação. Ministério da Educação. 2012.

BRASIL. Ministério da Educação. Instituto Nacional de estudos e pesquisas educacionais. Matriz de Referência. Brasília: MEC/INEP, 2012.

Disponível:

http://download.inep.gov.br/educacao_basica/enem/downloads/2012/matriz_referencia_enem. pdf. Acesso em 14 de Janeiro de 2016.

BRASIL. Ministério da Educação. Instituto nacional de estudos e pesquisas educacionais. PORTARIA N 179, DE 28 DE ABRIL DE 2014. Dispõe sobre o processo de certificação, as competências das Instituições Certificadoras e do INEP e os requisitos necessários à obtenção de certificado de conclusão do Ensino Médio e declaração parcial de proficiência com a utilização dos resultados de desempenho obtidos no Exame Nacional do Ensino Médio ENEM. 2014 
AMAURO, N. C. Caracterização do nível de compreensão do conhecimento químico solicitado dos alunos egressos do ensino médio brasileiro. Dissertação de Mestrado. Mestrado na Área de Ciências em Físico-Química. Universidade de São Paulo. Instituto de Química de São Carlos. 2004.

AUSUBEL, D. P. Aquisição e retenção de conhecimentos: uma perspectiva cognitiva. Lisboa: Plátano, 2003.

APPLE, M.W. Trabalho docente e textos: economia política e de relações de classe e de gênero em educação. Porto Alegre: Artes Médicas, 1995.

ARROYO, Miguel. Política de conhecimento e desafios contemporâneos à escola básica entre o global e o local. In: BAQUERO, Rute; BROILO, Cecília (org.). São Leopoldo: Editora UNISINOS, 2001. Ciclos de Desenvolvimento Humano e Formação de Educadores - "Ofício do Mestre" - Imagens e auto-imagens. Vozes. 2. Ed.

BARDIN, L. Análise do Conteúdo. Lisboa: Editora 70. 1977.

BARROS, C. O. Discursos escolares sobre o ciclo do carbono. Dissertação de Mestrado. Mestrado em Ensino e História de Ciências da Terra. Universidade Estadual de Campinas. Instituto de Geociências. 2011.

BONANIMO, A.; SOUSA, S. Z. Três gerações de avaliação da educação básica no Brasil: interfaces com o currículo da/na escola. Educação e Pesquisa, v. 38. n. 2. p. 373-388, abr./jun. 2012.

BROIETTI, F. C. D. O ENEM, O Vestibular e o Ensino de Química: o caso da Universidade Estadual de Londrina. Tese de Doutorado. Doutorado em Educação para a Ciência e a Matemática. Universidade Estadual de Maringá. Centro de Ciências Exatas. 2013.

BROIETTI, F. C. D; SANTIN FILHO, O.; PASSOS. M. M. Mapeamento da produção científica brasileira a respeito do Enem (1998-2011). Revista Diálogo Educacional. v. 14, n. 41, p. 233-260. 2014.

CINTRA, E.P.; MARQUES JUNIOR, A. C.; SOUSA, E. C. Correlação entre a matriz de referências e os itens envolvendo conceitos de Química presentes no ENEM de 2009 a 2013. Revista Ciência e Educação. v. 22, n. 3, p. 707-725. 2016.

CISZEVSKI, E. de O. S. Reflexões sobre o ensino de Química baseadas no diálogo entre o ENEM e o Currículo Estadual Paulista. Dissertação de Mestrado. Mestrado Profissional em Ensino de Ciências e Matemática. Instituto Federal de Educação, Ciência e Tecnologia de São Paulo. 2016.

CRUZ, C. M. La historia de la ciencia en la futura enseñanza secundaria: reflexiones en torno al diseño curricular base. Enseñanza de las ciencias, v. 10, n. 1, p. 115-117. 1991. 
DELORS, J. et al Educação: um tesouro a descobrir. 10 ed. São Paulo: Cortez. Brasília: MEC/UNESCO, 2010.

DIAS, R. E.; LOPES, A. C. Competências na formação de professores no Brasil: o que (não) há de novo. Educação e Sociedade. Campinas. v.24, n.85, p.1155-1177. 2003.

DINIZ, R. E. da S. Concepções e Práticas Pedagógicas do Professor de Ciências. In: NARDI, Roberto (org). Educação para a Ciência - Questões Atuais no Ensino de Ciências. São Paulo: Escrituras Editora, 1998.

ELLERY, O.; de P. A análise das questões de Química no novo ENEM. Dissertação de Mestrado. Mestrado em Ensino de Ciências e Matemática. Universidade Federal do Ceará. Centro de Ciências. 2014.

FERNANDES, C. dos S. O Exame Nacional do Ensino Médio e a educação química: em busca da contextualização. Dissertação de Mestrado. Mestrado em Educação Científica e Tecnológica. Universidade Federal de Santa Catarina. Centro de Ciências Físicas e Matemáticas. 2011.

FERREIRA, E. M. Análise da Abrangência da Matriz de Referência do ENEM com Relação às Habilidades Avaliadas nos Itens de Matemática Aplicados de 2009 a 2013. Dissertação de Mestrado. Mestrado Profissional em Matemática em Rede Nacional - PROFMAT. Universidade de Brasília. Instituto de Ciências Exatas Departamento de Matemática. 2014.

FERREIRA, N. S. A. As pesquisas denominadas "Estado da Arte". Educação \& Sociedade, v. 23, n. 79, 2002.

FRANCO, M. L. P. B. Análise de conteúdo. 2. ed. Brasília: Liver Livro, 2012.

FREIRE, P. Pedagogia da Autonomia: saberes necessários à prática educativa. 12. ed. Rio de Janeiro: Paz e Terra, 1999.

FURIÓ, C.; AZCONA, R.; GUISASOLA, J. G. Y.; MUJIKA Concepciones de los estudiantes sobre uma magnitud olvidada en la enseñanza de la química: la cantidad de sustancia. Enseñanza de las Ciencias, v.11, n.2, p. 107-114. 1993

FURIÓ, C.; AZCONA, R.; GUISASOLA, J. Revisión de investigaciones sobre la enseñanza-aprendizaje de los conceptos cantidad de sustância y mol. Enseñanza de las Ciencias, Barcelona, v. 20 n. 2, p. 229-241, 2002.

KLEIN, R.; FONTANIVE, N. S.; Avaliação em larga escala: uma proposta inovadora. Em aberto, v. 15, n. 66, abr./jun. 1995.

MACEDO, E. Currículo e conhecimento: aproximações entre educação e ensino. Caderno de Pesquisa. v.42, n147,p.716-737, 2012.

MACEDO, L. Competências e habilidades: elementos para uma reflexão pedagógica. Brasília: INEP. 1999. 
MACENO, N. G.; PEREIRA-RITTER, J.; MALDANER, O. A.; GUIMARÃES, O. M.; A Matriz de referência do Enem 2009 e o desafio de recriar o currículo de química na educação básica. Química Nova na Escola, v. 33, n. 3, p. 153-159, 2011.

MASCIO. C. C. Exame Nacional do Ensino Médio (ENEM): articulações entre a educação Ciência, Tecnologia e Sociedade e a proposta nacional para o Ensino de Química. Dissertação de Mestrado. Mestrado em Ensino de Ciências e Matemática na área de Processos de Ensino e Aprendizagem. Universidade de São Carlos. Centro de Educação e Ciências Humanas. 2009.

MOEHLECKE, S.; $\mathbf{O}$ ensino médio e as novas diretrizes curriculares nacionais: entre recorrências e novas inquietações. Revista Brasileira de Educação. v.17, n.49, 2012.

MORTIMER, E. F.; MIRANDA, L. C. Transformações: concepções dos estudantes sobre reações químicas. Química Nova na Escola. n. 2, p. 23-26, 1995.

OLIVEIRA, A. P.; MOURÃO, M. G. M.; MACIEL, R.C; Avaliação por competência no ensino médio. Roteiro, Joaçaba. v. 36, n.2, 2011.

PERRENOUD, P.; Avaliação da excelência à regulação das aprendizagens: entre duas lógicas. Porto Alegre: Artmed, 1999.

POZO, J. I. A solução de problemas: aprender a resolver, resolver para aprender. Porto Alegre: Artmed, 1998.

POZO, J. I.; CRESPO, M. A. G.; A aprendizagem e o Ensino de Ciências: do conhecimento cotidiano ao conhecimento científico. 5. ed. Porto Alegre: Artmed, 2009.

PRIMI, R.; SANTOS, A. A. A.; VENDRAMINI, C. M. TAXA, V. F.; MULLER, F. A.;LUKJANENCKO, M. F.; SAMPAIO, I. S. Competências e Habilidades Cognitivas: Diferentes Definições dos Mesmos Construtos. Psicologia: Teoria Pesquisa. v.17, n. 2, 2001.

RICARDO, E. C.; Discussão acerca do ensino por competências: problemas e alternativas. Cadernos de Pesquisa. v.40, n.140, p.605-628, 2010.

ROGADO, J. A grandeza quantidade de matéria e sua unidade, o mol: algumas considerações sobre dificuldades de ensino e aprendizagem. Ciência \& Educação, Bauru, v. 10, n. 1, p. 63-73, 2004.

ROPÉ, F.; TANGUY, L. (Orgs.). Saberes e competências: o uso de tais noções na escola e na empresa. Campinas: Papiros, 1997.

SANTOS, J. M. C. T.; Exame nacional do ensino médio: entre a regulação da qualidade do ensino médio e o vestibular. Educar em Revista, Curitiba, Brasil: Editora UFPR. n. 40, p.195-205, 2011.

SANTOS, B. C. D. O Ensino de Química em um Curso de Educação Popular preparatório para o ENEM. Dissertação de Mestrado. Mestrado Profissional da Faculdade de Educação na área de Educação em Ciências. Universidade Federal de Pelotas. 2017. 
SAVIANI, D. A nova lei da educação: trajetória, limites e perspectivas. 5 ed. Campinas: Autores Associados, 1999.

SILVA, G. B. FELICETTI, V. L. Habilidades e competências na prática docente: perspectivas a partir de Situações-problema. Educação por Escrito. Porto Alegre, v.5, n. 1, jan-jun. 2014.

SILVA, E. L.; SOUZA, F. L.; MARCONDES, M. E. R. Transformações Químicas e Transformações Naturais: um estudo das concepções de um grupo de estudantes do ensino médio. Educacion Química, Abril, 2008. Disponível em: http://dialnet.unirioja.es/servlet/articulo?codigo=2676232.

SILVEIRA, F. L.; BARBOSA, M. C. B.; SILVA, R. Exame Nacional do Ensino Médio (ENEM): Uma análise crítica. Revista Brasileira de Ensino de Física. v. 37. n. 1, 2015.

SOUZA, J. R. da T. CTS no contexto do novo Enem e do Ensino de Química. Teste de Doutorado. Doutorado em Educação em Ciências e Matemáticas. Universidade Federal do Pará. Instituto de Educação Matemática e Científica. 2016.

SUART, R. C.; MARCONDES, M. E. R. As habilidades cognitivas manifestadas por alunos do ensino médio de química em uma atividade experimental investigativa. Revista Brasileira de Pesquisa em Educação em Ciências. v. 8, n. 2, 2008.

SUART, R. Habilidades cognitivas manifestadas por estudantes do ensino médio de química em atividades experimentais investigativas. Dissertação de Mestrado. Instituto de Física, Instituto de Química, Instituto de Biociências, Faculdade de Educação. Universidade de São Paulo. 2008.

VERONEZ, K, N. S.; PIAZZA, M. C. R. Estudo Sobre Dificuldades de Alunos do Ensino Médio com Estequiometria. In: Encontro Nacional em Educação em Ciências, 2007. Atas do VI ENPEC, 2007.

ZABALA, A. A prática educativa: como ensinar. Porto Alegre. Artmed, 1998.

ZABALA, A.; ARNAU, L. Como aprender e ensinar competências. Porto Alegre: Artmed, 2010.

ZOLLER, U. Are lecture and learning: are they compatible? Maybe for LOCS; unlikely for HOCS. Journal of Chemical Education, v.70, n.3, p.195-197, 1993.

ZOLLER, U., DORI Y.; LUBEZKY, A. Algorithmic and LOCS and. HOCS (Chemistry) Exam Questions: Performance and Attitudes of College Students. International Journal of Science Education. 24 (2), p.185-203, 2002. 


\section{APÊNDICE 1}

Instrumento 1 - Piloto de verificação de Habilidades específicas de Química

1. A água que chega às casas pela rede de distribuição de água recebe um tratamento prévio tendo em vista assegurar sua qualidade para o consumo humano. A água, uma vez captada, precisaria passar por um sistema de purificação, feito nas estações de tratamento, conforme representado abaixo:

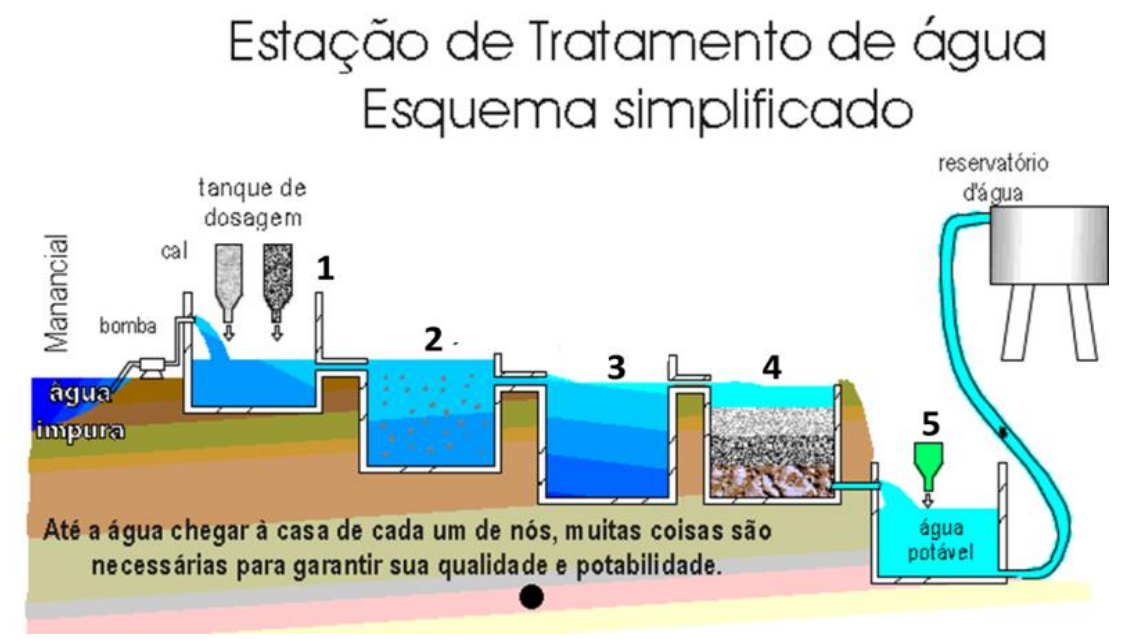

Relacione as etapas descritas com as representadas no esquema acima:
$\mathrm{A}=$ Decantação
$1-(\quad)$
$\mathrm{B}=$ Adição de cloro
$2-(\quad)$
$\mathrm{C}=$ Floculação
3- ( )
$\mathrm{D}=$ Adição de sulfato de alumínio
4- ( )
$\mathrm{E}=$ Filtração
5- ( )

2. Para explicar um fenômeno ao seu colega, Jorge, colocou água até a metade do copo, e uma rolha de silicone. Os dois amigos observaram que a rolha assim que colocada no copo afundou. Em seguida, Jorge adicionou um pouco de sal de cozinha dentro do mesmo copo, agitou até a completa dissolução do sal. A rolha subiu para a superfície do líquido. Jorge então questionou seu colega: Porque no início a rolha estava no fundo do copo e após a adição do sal ela subiu à superfície do líquido? Que reposta você daria a Jorge? 
3. Um grande avanço químico se deu com o desenvolvimento da síntese da barrilha $\left(\mathrm{Na}_{2} \mathrm{CO}_{3}\right)$, em 1791 por Nicolas Leblanc). A etapa final da síntese da barrilha está descrita a seguir. Considerando que sejam utilizados $200 \mathrm{~g}$ de carbonato de cálcio $\left(\mathrm{CaCO}_{3}\right)$ na reação, quanto deverá ser produzido de barrilha? Justifique sua resposta.

Dados: $\mathrm{Ca}(40 \mathrm{u}), \mathrm{C}(12 \mathrm{u}), \mathrm{O}(16 \mathrm{u}), \mathrm{Na}(23 \mathrm{u})$.

$$
\mathrm{Na}_{2} \mathrm{SO}_{4}+\mathrm{CaCO}_{3}+2 \mathrm{C} \longrightarrow \mathrm{Na}_{2} \mathrm{CO}_{3}+\mathrm{CaS}+2 \mathrm{CO}_{2}
$$

4. O debate em torno do uso da energia nuclear para produção de eletricidade permanece atual. Em um encontro internacional para a discussão desse tema, foram colocados os seguintes argumentos:

1. Uma grande vantagem das usinas nucleares é o fato de não contribuírem para o aumento do efeito estufa, uma vez que o urânio, utilizado como "combustivel”, não é queimado, mas sofre fissão.

2. Ainda que sejam raros os acidentes com usinas nucleares, seus efeitos podem ser tão graves que essa alternativa de geração de eletricidade não nos permite ficar tranquilos.

a) Um pesquisador que estava participando do encontro afirmou que os argumentos colocados acima são irrelevantes. Comente a afirmação do pesquisador.

b) Qual a sua opinião sobre os argumentos colocados.

5. Muitos professores utilizam a experimentação para enriquecer suas aulas. Uma professora realizou junto com seus alunos as experiências que seguem:

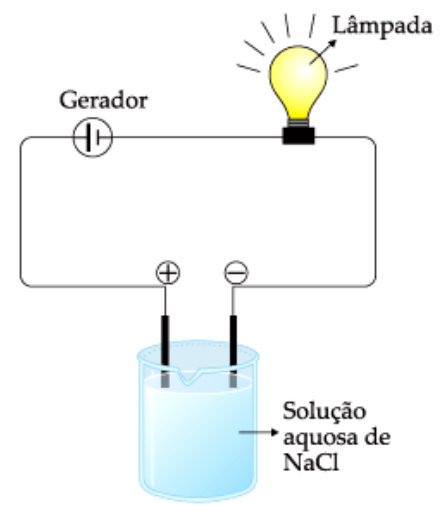

Experiência 1

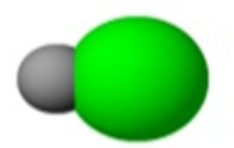

Sal de cozinha $-\mathrm{NaCl}$

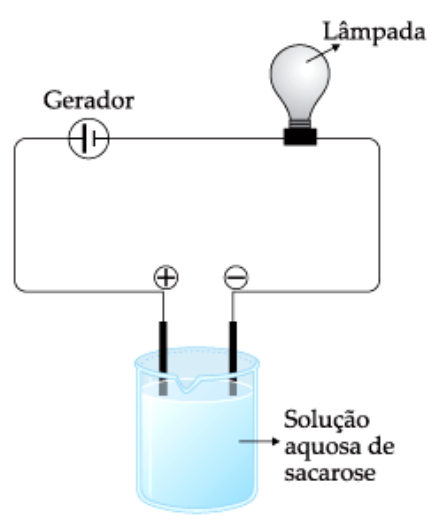

Experiência 2

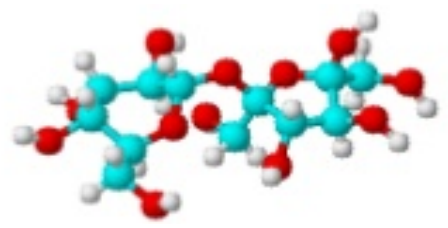

Sacarose $-\mathrm{C}_{6} \mathrm{H}_{12} \mathrm{O}_{6}$

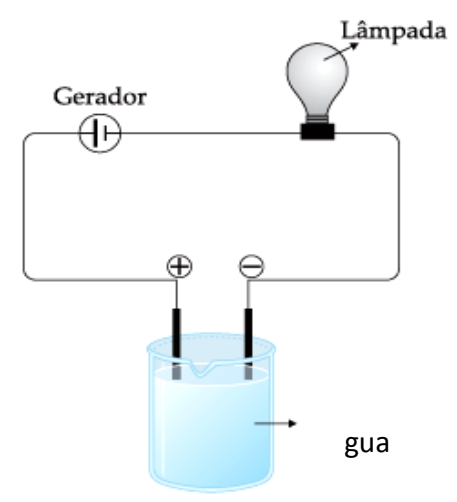

Experiência 3

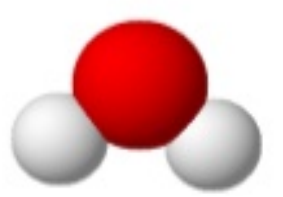

Água $-\mathrm{H}_{2} \mathrm{O}$ 
a) Como você explicaria o fato da lâmpada acender somente na experiência 1 ?

b) Pensando microscopicamente, ou seja, considerando as partículas que constituem essas substâncias, como você explicaria o fato da lâmpada acender?

6. Considere duas latas do mesmo refrigerante, uma na versão diet e outra na versão comum. Ambas contêm o mesmo volume de líquido (300 mL) e têm a mesma massa quando vazias. A composição do refrigerante é a mesma, exceto por uma diferença: a versão comum contém certa quantidade de açúcar, enquanto a versão diet não contém açúcar (a massa de adoçante artificial contida no refrigerante diet pouco contribui para a massa final, pois é da ordem de miligramas). Pensando-se duas latas fechadas do refrigerante, foram obtidos os seguintes resultados:

\begin{tabular}{|l|c|}
\hline \multicolumn{1}{|c|}{ Amostra } & Massa (g) \\
\hline Lata com refrigerante comum & 331,2 \\
\hline Lata com refrigerante diet & 316,2 \\
\hline
\end{tabular}

Por esses dados, pode-se concluir que a concentração em massa, em g/L, de açúcar no refrigerante comum é de, aproximadamente:

a) 0,020

b) 0,050

c) 1,1

d) 20

e) 50

7. O dia estava extremamente quente, e para aliviar o calor Miguel e Luíza decidiram preparar uma limonada. No entanto cada um preparou a sua, pois tinham formas diferentes de preparar a bebida. Partindo da ideia de que a solubilidade das substâncias em um mesmo solvente altera-se com a mudança de temperatura do sistema e considerando que os dois utilizaram a mesma quantidade de água, de gelo e de açúcar, em qual dos casos você acha que haverá maior quantidade de açúcar dissolvida? Justifique a sua resposta.

MIGUEL

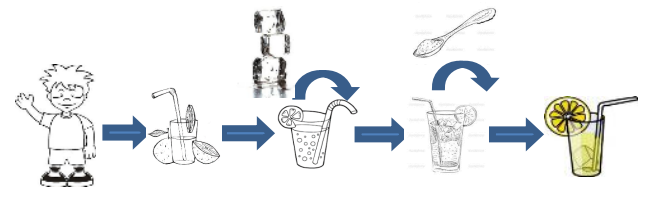

LUÍZA

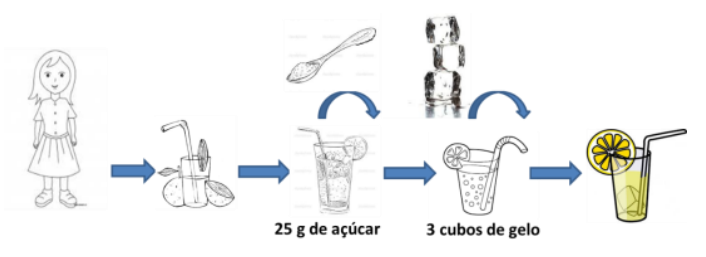


8. Os acidentes de trânsito, no Brasil, em sua maior parte são causados por erro do motorista. Em boa parte deles, o motivo é o fato de dirigir após o consumo de bebida alcoólica. A ingestão de uma lata de cerveja provoca uma concentração de aproximadamente $0,3 \mathrm{~g} / \mathrm{L}$ de álcool no sangue. A tabela abaixo mostra os efeitos sobre o corpo humano provocados por bebidas alcoólicas em função de níveis de concentração de álcool no sangue:

\begin{tabular}{c|l}
\hline $\begin{array}{c}\text { Concentração de } \\
\text { álcool no sangue }(\mathrm{g} / \mathrm{L})\end{array}$ & \multicolumn{1}{c}{ Efeitos } \\
\hline $0,1-0,5$ & Sem influência aparente, ainda que com alterações clínicas \\
\hline $0,3-1,2$ & Euforia suave, sociabilidade acentuada e queda da atenção \\
\hline $0,9-2,5$ & $\begin{array}{l}\text { Excitação, perda de julgamento crítico, queda da sensibilidade e das } \\
\text { reações motoras }\end{array}$ \\
\hline $1,8-3,0$ & Confusão mental e perda da coordenação motora \\
\hline $2,7-4,0$ & Estupor, apatia, vômitos e desequilíbrio ao andar \\
\hline $3,5-5,0$ & Coma e morte possível \\
\hline
\end{tabular}

(Revista Pesquisa FAPESP no 57, setembro 2000)

Uma pessoa que tenha tomado três latas de cerveja provavelmente apresenta

a) queda de atenção, de sensibilidade e das reações motoras.

b) aparente normalidade, mas com alterações clínicas.

c) confusão mental e falta de coordenação motora.

d) disfunção digestiva e desequilíbrio ao andar.

e) estupor e risco de parada respiratória.

9. Um escoteiro precisa acender uma fogueira antes que escureça. Para isso foi dar uma caminhada na mata para ver o que encontrava. Ele se deparou com duas situações diferentes:
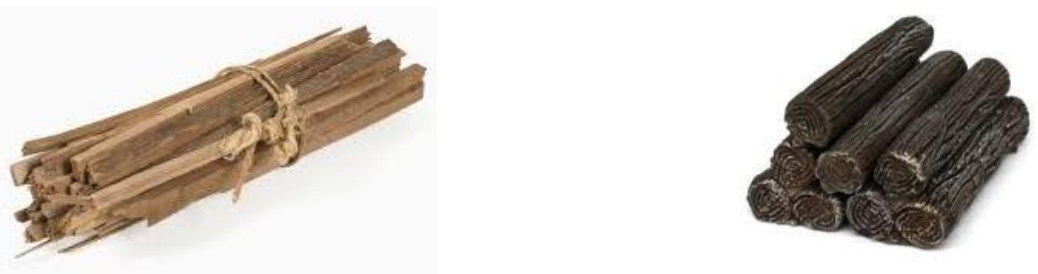

Considerando a mesma quantidade de madeira (em massa) em cada caso. Em sua opinião, qual foi a opção que o escoteiro escolheu? Explique sua resposta. 


\section{APÊNDICE 2}

Instrumento 2: Ficha de identificação do aluno

NOME DO ALUNO(A):

DATA DE NASCIMENTO:

ESCOLA DE ORIGEM:

QUAL CURSO VOCÊ PRETENDE PRESTAR VESTIBULAR?

QUAIS FACULDADES/UNIVERSIDADES PRETENDE PRESTAR VESTIBULAR?

VOCÊ JÁ PRESTOU VESTIBULAR ANTERIORMENTE? PARA QUAIS FACULDADES/UNIVERSIDADES?

VOCÊ JÁ FREQUENTOU ALGUM CURSINHO PREPARATÓRIO PARA VESTIBULARES? QUAL?

PORQUE VOCÊ PROCUROU ESTE CURSINHO ESPECIFICAMENTE?

VOCÊ JÁ FEZ PROVA DO ENEM? QUE NOTA TIROU?

VAI PRESTAR O ENEM ESTE ANO? POR QUÊ?

PARA QUE SERVE A PROVA DO ENEM? 


\section{APÊNDICE 3}

Instrumento 3: Diagnóstico de verificação de habilidades específicas.

\begin{tabular}{|l|l|}
\hline Nome: & Série: \\
\hline Escola: & Idade: \\
\hline Data: & Turma no Cursinho: \\
\hline Instruções: Este questionário é um instrumento de coleta de dados para uma pesquisa \\
de Mestrado do Programa Interunidades em Ensino de Ciências na modalidade ensino \\
de química da Universidade de São Paulo (USP). Pedimos a sua colaboração, para \\
isso, por favor, não converse com seu colega, não consulte material, nem qualquer \\
equipamento eletrônico. As suas respostas são muito importantes para que possamos \\
desenvolver uma pesquisa em ensino de ciências que possa contribuir com a \\
educação. Desde já agradecemos a sua colaboração!
\end{tabular}

1. Um estudante listou os seguintes processos como exemplos de fenômenos que envolvem reações químicas. No entanto o estudante cometeu alguns equívocos. Quais os fenômenos são considerados reações químicas? Justifique sua escolha para cada um deles.
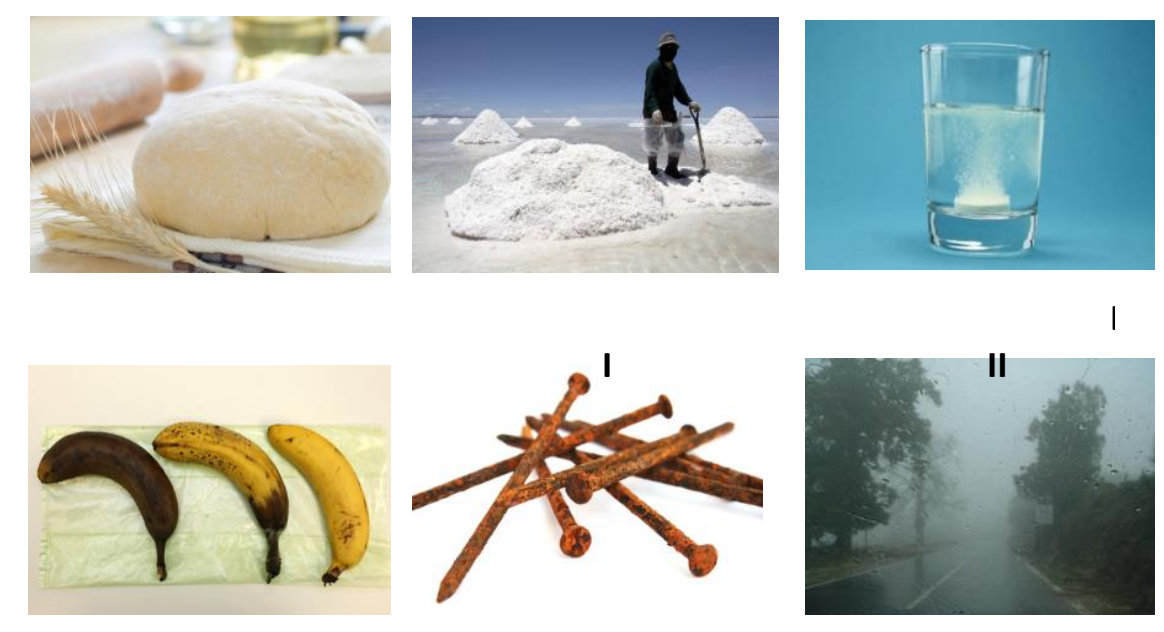

I. Fermentação da massa na fabricação de pães.

Justificativa:

II. Obtenção de sal por evaporação de água do mar.

Justificativa: 
III. Dissolução de um comprimido efervescente em água.

Justificativa:

IV. Amadurecimento de uma banana.

Justificativa:

V. Enferrujamento de um prego.

Justificativa:

VI. Precipitação da chuva.

Justificativa:

2. Você sabe o que significa massa molar? Qual é a diferença entre massa molar de uma substância e a massa de certa amostra da substância?

3. Considere os casos de transformações químicas a seguir:

\section{Calcinação do calcário}

calcário $\longrightarrow$ cal viva + gás carbônico

\section{Efervescência da água oxigenada}

água oxigenada $\longrightarrow$ água + gás oxigênio

\section{Formação do gás ozônio}

gás oxigênio $\longrightarrow$ gás ozônio

A análise desses casos confirma ou contraria a ideia de que são necessárias pelo menos duas substâncias para que ocorra uma transformação química? Explique.

4. O responsável técnico de um forno de calcinação de calcário elaborou um relatório sobre as três últimas tiragens da produção de cal. O relatório apresenta a seguinte tabela:

\begin{tabular}{|l|c|c|c|}
\hline Amostras & $\begin{array}{c}\text { Massa de calcário (t) } \\
(\mathbf{C a C O})\end{array}$ & $\begin{array}{c}\text { Massa de cal (t) } \\
(\mathbf{C a O})\end{array}$ & $\begin{array}{c}\text { Massa de dióxido de } \\
\text { carbono (t) } \\
\left(\mathbf{C O}_{2}\right)\end{array}$ \\
\hline I & 10,0 & 5,6 & 4,4 \\
\hline II & 20,0 & 11,2 & 8,8 \\
\hline III & 70,0 & & \\
\hline
\end{tabular}

Determine os valores que faltam na tabela e complete-a. Mostre todos os cálculos realizados.

5. O gás metano $\left(\mathrm{CH}_{4}\right)$ pode ser obtido nos tratamentos de esgoto, por meio de processos biológicos ocorridos em biodigestores. Esse gás, ao reagir com oxigênio $\left(\mathrm{O}_{2}\right)$, formará gás carbônico $\left(\mathrm{CO}_{2}\right)$ e água $\left(\mathrm{H}_{2} \mathrm{O}\right)$.

a) Represente a equação química do processo.

b) A densidade do gás metano é $0,656 \mathrm{~kg} / \mathrm{m}^{3}$. Qual é a massa de $1000 \mathrm{~L}$ desse gás? 
6. Aspartame é um adoçante dietético que apresenta potencial adoçante 200 vezes maior que o açúcar comum, permitindo seu uso em pequenas quantidades. O IDA (índice diário aceitável) desse adoçante é $40 \mathrm{mg} / \mathrm{Kg}$ de massa corpórea.

Disponível em: http://boaspraticasfarmaceuticas.com.

Acesso em: 27 fev. 201-2.

Com base nas informações do texto, qual a quantidade máxima recomendada de aspartame que uma pessoa de $70 \mathrm{Kg}$ de massa corporal pode ingerir por dia?

7. Nas indústrias siderúrgicas, o gás monóxido de carbono $(\mathrm{CO})$, formado na combustão incompleta do carvão, reagirá com o óxido de ferro III $\left(\mathrm{Fe}_{2} \mathrm{O}_{3}\right)$ extraído do minério de ferro e terá como produtos o ferro líquido $(\mathrm{Fe})$ e o gás dióxido de carbono $\left(\mathrm{CO}_{2}\right)$. Represente as transformações descritas acima devidamente balanceadas.

8. Um grande avanço químico se deu com o desenvolvimento da síntese da barrilha $\left(\mathrm{Na}_{2} \mathrm{CO}_{3}\right)$, em 1791 por Nicolas Leblanc. A etapa final da síntese da barrilha está descrita a seguir. Considerando que sejam utilizados $200 \mathrm{~g}$ de carbonato de cálcio $\left(\mathrm{CaCO}_{3}\right)$ na reação, quanto deverá ser produzido de barrilha? Justifique sua resposta.

\section{Dados:}

Massas molares (g/mol): Ca: 40, C: 12, O: 16, Na: 23

\section{$\mathrm{Na}_{2} \mathrm{SO}_{4}+\mathrm{CaCO}_{3}+2 \mathrm{C} \longrightarrow \mathrm{Na}_{2} \mathrm{CO}_{3}+\mathrm{CaS}+2 \mathrm{CO}_{2}$}

9. Foram realizadas algumas reações em laboratório sendo que o produto de cada uma delas foi recolhido em diferentes frascos, numerados de 1 a 4 . Considerando os dados abaixo você seria capaz de dizer quais os compostos armazenados em cada frasco?

\section{Dados:}

Bolinhas verdes: átomo de cloro $(\mathrm{Cl})$

Bolinhas cinzas pequenas: átomos de hidrogênio $(\mathrm{H})$

Bolinhas cinzas grandes: átomos de carbono (C)

Bolinhas vermelhas: átomos de oxigênio $(\mathrm{O})$

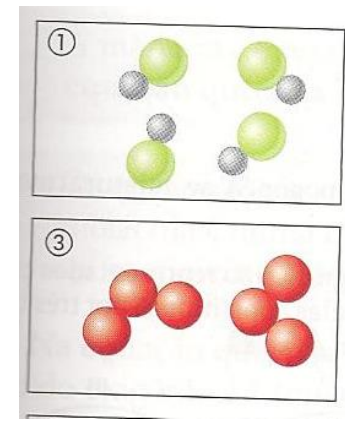

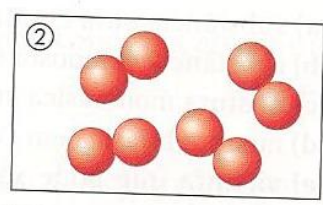

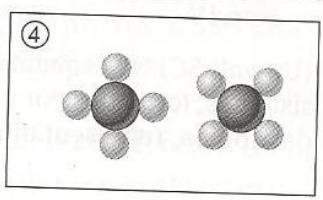

10. Devido à toxicidade do mercúrio, em caso de derramamento desse metal, costuma-se espalhar enxofre no local, para removê-lo. Mercúrio e enxofre reagem, gradativamente, formando sulfeto de mercúrio. Para fins de estudo, a reação pode ocorrer mais rapidamente se 
as duas substâncias forem misturadas. Usando esse procedimento, foram feitos dois experimentos, observe os dados:

\begin{tabular}{|c|c|c|c|c|}
\hline Experimentos & Mercúrio & Enxofre & $\begin{array}{c}\text { Produto } \\
\text { formado }\end{array}$ & Sobra \\
\hline I & $5,0 \mathrm{~g}$ & $1,0 \mathrm{~g}$ & $5,8 \mathrm{~g}$ & $0,2 \mathrm{~g}$ de enxofre \\
\hline II & $12,0 \mathrm{~g}$ & $1,6 \mathrm{~g}$ & $11,6 \mathrm{~g}$ & 2,0 de mercúrio \\
\hline
\end{tabular}

Mostre que os dois experimentos estão de acordo com a lei de conservação da massa (Lavoisier) e a lei das proporções definidas (Proust).

11. Amônia e gás carbônico podem reagir formando ureia e água. $\mathrm{O}$ gráfico abaixo mostra as massas de ureia e de água que são produzidas em função da massa de amônia, considerando as reações completas. A partir dos dados do gráfico e dispondo-se de $110 \mathrm{~g}$ de amônia, qual é o valor da massa aproximada, em gramas, de gás carbônico minimamente necessário para reação completa com essa quantidade de amônia?

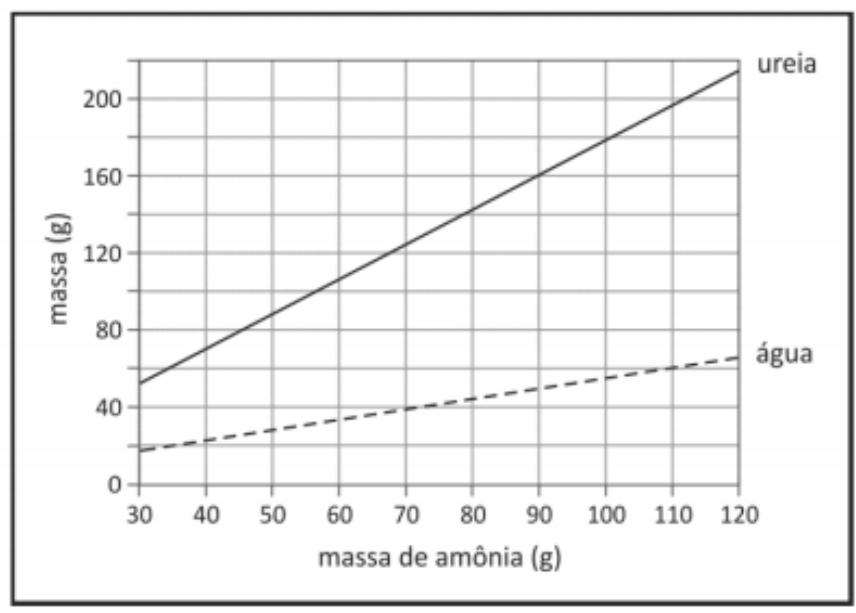

Descreva como chegou nos valores de massas. 


\section{APÊNDICE 4}

Instrumento 4: Coleta de dados sobre ideias iniciais a respeito de transformações químicas.

\begin{tabular}{|l|l|}
\hline Nome: & Série: \\
\hline Escola: & Idade: \\
\hline Data: & Turma no Cursinho: \\
\hline Instruções: Este questionário é um instrumento de coleta de dados para uma pesquisa \\
de Mestrado do Programa Interunidades em Ensino de Ciências na modalidade ensino \\
de química da Universidade de São Paulo (USP). Pedimos a sua colaboração, para \\
isso, por favor, não converse com seu colega, não consulte material, nem qualquer \\
equipamento eletrônico. As suas respostas são muito importantes para que possamos \\
desenvolver uma pesquisa em ensino de ciências que possa contribuir com a \\
educação. Desde já agradecemos a sua colaboração!
\end{tabular}

1. Com o passar do tempo, o homem adquiriu conhecimento para manipular os materiais através de transformações químicas. Mas você saberia citar uma transformação química? Justifique sua resposta.

2. Num frasco estava um líquido azul identificado como solução de sulfato de cobre. Nele foi colocado um prego em bom estado e previamente lixado. No outro dia o prego foi retirado e estava com uma camada de substância sólida escura ao seu redor enquanto o líquido ficou incolor. Em sua opinião o que aconteceu? Trata-se de uma transformação química? Explique.

3. Assinale com um X em quais das situações descritas está ocorrendo transformação química. Justifique cada uma das suas respostas citando quais possíveis evidências de que ocorreu uma transformação química.

( ) A fabricação de vinho a partir da uva é uma técnica milenar.

( ) Por sorte a explosão da panela de pressão não causou nenhum ferimento a Márcia.

( ) Desolado, observava o gelo derretendo em seu copo e ironicamente comparava-o ao seu coração.

( ) Com o passar dos tempos começou a sentir-se como a velha tesoura enferrujando no fundo da gaveta.

4. Com o amadurecimento da fruta vão se desenvolvendo também fatores internos que a apodrecerão. $\mathrm{O}$ calor, a umidade e a luz, aceleram o amadurecimento da fruta e posterior apodrecimento rápido. Ao contrário, o ar seco, a baixa temperatura e a ausência de luz retardam o amadurecimento. $\mathrm{O}$ apodrecimento de um fruto pode ser caracterizado como um processo químico? Justifique sua resposta. 


\section{APÊNDICE 5}

Instrumento 5: Roteiro da atividade experimental intitulada "Evidências de transformações da matéria"

\begin{tabular}{|l|l|}
\hline Nome: & Série: \\
\hline Escola: & Idade: \\
\hline Data: & Turma no Cursinho: \\
\hline Instruções: Este questionário é um instrumento de coleta de dados para uma pesquisa \\
de Mestrado do Programa Interunidades em Ensino de Ciências na modalidade ensino \\
de química da Universidade de São Paulo (USP). Pedimos a sua colaboração, para \\
isso, por favor, não converse com seu colega, não consulte material, nem qualquer \\
equipamento eletrônico. As suas respostas são muito importantes para que possamos \\
desenvolver uma pesquisa em ensino de ciências que possa contribuir com a \\
educação. Desde já agradecemos a sua colaboração!
\end{tabular}

\section{OBJETIVOS}

O objetivo principal desta atividade é identificar propriedades dos sistemas que facilitem a identificação de fenômenos químicos. As observações que você fará nesse experimento deverão ser anotadas na tabela que se encontra no final do roteiro.

\section{MATERIAIS E MÉTODOS}

- tubo de ensaio

- bicarbonato de sódio

- proveta

- cloreto de cálcio

- colher de café

- carbonato de sódio

- pastilhas de hidróxido de sódio

- sulfato de cobre pentaidratado

- solução de hidróxido de sódio

- vinagre (ácido acético)

-solução de ácido clorídrico (ácido

- óleo de cozinha muriático)

- sal de cozinha

- palha de aço 


\section{ETAPAS DA INVESTIGAÇÃO}

\section{TODAS AS OBSERVAÇÕES DEVEM SER REGISTRADAS NO QUADRO QUE ESTÁ NO FINAL DO ROTEIRO.}

\section{$\underline{\text { Teste } 1 \text { - Vinagre na cozinha }}$}

1. Coloque cerca de $5 \mathrm{~mL}$ de vinagre em três tubos de ensaio distintos. Numere cada um dos tubos.

2. No primeiro tubo, juntamente com o vinagre adicione $5 \mathrm{~mL}$ de óleo de cozinha. Observe e anote suas impressões.

3. No segundo tubo, juntamente com o vinagre adicione $1 / 2$ colher de (café) de sal de cozinha. Observe e anote suas impressões.

4. No terceiro tubo, juntamente com o vinagre adicione $1 / 2$ colher de (café) de bicarbonato de sódio. Observe e anote suas impressões.

6. Juntamente com seu grupo reflita sobre os seguintes questionamentos.

Observando cada um dos tubos o que está acontecendo?

Quais as principais diferenças entre cada um dos tubos?

Existe(m) evidência(s) de que está ocorrendo transformação da matéria em algum dos tubos?

Descreva.

\section{Teste 2 - Estudando a decomposição da água oxigenada}

1. Triture a batata no liquidificador, adicione $35 \mathrm{~mL}$ de água para facilitar o processo.

2. Filtre a mistura e reserve o filtrado (solução límpida).

3. Despeje $5 \mathrm{~mL}$ dessa solução obtida em um tubo de ensaio contendo $5 \mathrm{~mL}$ de água oxigenada e observe.

\section{Desenvolva uma hipótese para explicar o que ocorreu.}

\section{Teste 3 - Observando o comportamento dos sais}

1. Coloque cerca de $5 \mathrm{~mL}$ de água em um tubo de ensaio.

2. Adicione uma ponta de espátula de carbonato de sódio. Agite bastante.

3. Adicione uma ponta de espátula de cloreto de cálcio. Agite bastante.

4. Observe e anote suas impressões.

\section{Teste 4 - Adicãa de hidróxido de sódio, em pastilhas à água}

1. Coloque cerca de $5 \mathrm{~mL}$ de água em um tubo de ensaio.

2. Adicione cerca de 2 pastilhas de hidróxido de sódio à água contida no tubo. 
3. Observe e anote suas impressões.

\section{Teste 5 - Estudando a interacão de um ácido com uma base}

1. Coloque cerca de $5 \mathrm{~mL}$ da solução de ácido clorídrico em um tubo de ensaio.

2. Adicione cuidadosamente uma ponta de espátula de hidróxido de sódio no tubo de ensaio contendo o ácido. Agite com cuidado.

3. Envolva o tubo de ensaio com uma das mãos.

4. Observe e anote suas impressões.

Quadro para anotar as observações durante o experimento.

\begin{tabular}{|c|c|c|c|c|c|}
\hline & & Estado inicia & Durante a transformaçã & Estado fina & $\begin{array}{l}\text { Evidências de } \\
\text { transformaçã }\end{array}$ \\
\hline \multirow{4}{*}{ Teste 1} & Tubo 1 & & & & \\
\hline & Tubo 2 & & & & \\
\hline & Tubo 3 & & & & \\
\hline & Tubo 4 & & & & \\
\hline Teste 2 & Tubo 1 & & & & \\
\hline Teste 3 & Tubo 1 & & & & \\
\hline Teste 4 & Tubo 1 & & & & \\
\hline Teste 5 & Tubo 1 & & & & \\
\hline
\end{tabular}

\section{QUESTÕES}

1. Em alguns destes testes ocorreu à formação de um novo material? Caso positivo, indique em qual(is) teste(s). Justifique sua resposta.

2. No que você se baseou para concluir que não houve formação de novos materiais em um ou mais testes?

3. Ao adicionarmos sal de frutas em água, percebemos imediatamente uma efervescência. Trata-se de uma transformação da matéria? Caso afirmativo, qual(is) são as possíveis evidências de que está ocorrendo esta transformação?

4. Você já reparou que quando se coloca "bolinhas" de naftalina nos guarda-roupas (para evitar ataques de insetos), estas vão diminuindo de tamanho com o tempo, até desapareceram totalmente sem deixar nenhum resíduo? É um fenômeno químico? Justifique sua resposta tentando explicar o que ocorre. 


\section{APÊNDICE 6}

Instrumento 6: Coleta de dados sobre a leitura e análise de um texto de apoio sobre: "Chuva ácida" (Caderno do aluno, $1^{\mathrm{a}}$ série, vol. 2).

\begin{tabular}{|l|l|}
\hline Nome: & Série: \\
\hline Escola: & Idade: \\
\hline Data: & Turma no Cursinho: \\
\hline $\begin{array}{l}\text { Instruções: Este questionário é um instrumento de coleta de dados para uma pesquisa } \\
\text { de Mestrado do Programa Interunidades em Ensino de Ciências na modalidade ensino } \\
\text { de química da Universidade de São Paulo (USP). Pedimos a sua colaboração, para } \\
\text { isso, por favor, não converse com seu colega, não consulte material, nem qualquer } \\
\text { equipamento eletrônico. As suas respostas são muito importantes para que possamos } \\
\text { desenvolver uma pesquisa em ensino de ciências que possa contribuir com a } \\
\text { educação. Desde já agradecemos a sua colaboração! }\end{array}$ \\
\hline
\end{tabular}

\section{Chuva ácida}

Fabio Luiz de Souza e Luciane Hiromi Akahoshi

A chuva é naturalmente ácida, mesmo em locais não poluídos. Isso ocorre por causa da presença de dióxido de carbono $\left(\mathrm{CO}_{2}\right)$, que reage com o vapor de água da atmosfera formando o ácido carbônico $\left(\mathrm{H}_{2} \mathrm{CO}_{3}\right)$, conferindo um $\mathrm{pH}^{*}$ de 5,6 para essa chuva.

Entretanto, quando aumenta a quantidade de certos poluentes atmosféricos (dióxido de enxofre, $\mathrm{SO}_{2}$, e óxidos de nitrogênio), a chuva pode tornar-se excessivamente ácida em razão da interação desses gases com a água, produzindo principalmente ácido sulfúrico $\left(\mathrm{H}_{2} \mathrm{SO}_{4}\right)$ e ácido nítrico $\left(\mathrm{HNO}_{3}\right)$. Nesse caso, usa-se a expressão "chuva ácida".

Esses poluentes são liberados principalmente na queima de combustíveis de origem fóssil carvão e petróleo. O dióxido de enxofre pode ser produzido, por exemplo, na queima de carvão mineral, pois compostos de enxofre são encontrados como impurezas nesse combustível. Os óxidos de nitrogênio, porém, podem ser produzidos em combustões a altas temperaturas, como a que ocorre nos motores a explosão e em processos industriais. Nessas combustões, o próprio nitrogênio $\left(\mathrm{N}_{2}\right)$ e o oxigênio $\left(\mathrm{O}_{2}\right)$ do ar reagem para formar os óxidos de nitrogênio. 
A chuva ácida é considerada um problema de grande impacto ambiental, pois pode provocar a devastação de florestas, acidificando solos e matando plantas. Ela afeta também os ambientes aquáticos, provocando a morte de peixes e de outros animais. Outros problemas que ela causa são a transformação da superfície do mármore (carbonato de cálcio $-\mathrm{CaCO}_{3}$ ) de monumentos em gesso (sulfato de cálcio - $\mathrm{CaSO}_{4}$ ), provocando sua erosão, e a corrosão de materiais metálicos de edifícios e construções.

Elaborado especialmente para o São Paulo faz escola. * pH: escala utilizada para indicar o grau de acidez ou de basicidade de um material. Essa escala varia de $\mathrm{O}$ a 14. A $25^{\circ} \mathrm{C}$, o valor de $\mathrm{pH}=7$ indica materiais de caráter neutro; abaixo desse valor, os materiais têm caráter ácido; e acima desse valor, têm caráter básico ou alcalino.

\section{QUESTÕES PARA ANÁLISE DO TEXTO}

Após ler o texto, analise a figura e responda às seguintes questões:

1. Qual é a origem dos compostos que produzem a chuva ácida?

2. Quais são os efeitos da chuva ácida para o ambiente? E para o ser humano?

3. A formação de chuva ácida é uma transformação química? Justifique sua resposta?

4. Existe alguma evidência de que a chuva está ácida? Justifique sua resposta. 


\section{APÊNDICE 7}

Instrumento 7: Coleta de dados sobre a síntese dos alunos a respeito de toda discussão estabelecida.

\begin{tabular}{|l|l|}
\hline Nome: & Série: \\
\hline Escola: & Idade: \\
\hline Data: & Turma no Cursinho: \\
\hline Instruções: Este questionário é um instrumento de coleta de dados para uma pesquisa \\
de Mestrado do Programa Interunidades em Ensino de Ciências na modalidade ensino \\
de química da Universidade de São Paulo (USP). Pedimos a sua colaboração, para \\
isso, por favor, não converse com seu colega, não consulte material, nem qualquer \\
equipamento eletrônico. As suas respostas são muito importantes para que possamos \\
desenvolver uma pesquisa em ensino de ciências que possa contribuir com a \\
educação. Desde já agradecemos a sua colaboração!
\end{tabular}

Pensando em tudo que foi discutido até agora, se você fosse explicar para um colega o que seria uma transformação química como você descreveria? 


\section{APÊNDICE 8}

Instrumento 8: Roteiro da atividade experimental intitulada “A massa é conservada nas reações químicas”,

\begin{tabular}{|l|l|}
\hline Nome: & Série: \\
\hline Escola: & Idade: \\
\hline Data: & Turma no Cursinho: \\
\hline Instruções: Este questionário é um instrumento de coleta de dados para uma pesquisa \\
de Mestrado do Programa Interunidades em Ensino de Ciências na modalidade ensino \\
de Química da Universidade de São Paulo (USP). Pedimos a sua colaboração, para \\
isso, por favor, não converse com seu colega, não consulte material, nem qualquer \\
equipamento eletrônico. As suas respostas são muito importantes para que possamos \\
desenvolver uma pesquisa em ensino de ciências que possa contribuir com a \\
educação. Desde já agradecemos a sua colaboração!
\end{tabular}

\section{OBJETIVOS}

O objetivo principal desta atividade é compreender o que ocorre com a massa total antes e após a reação ocorrer e verificar se ocorre sua conservação das quantidades no final da reação. Para estabelecer uma comparação e melhor compreensão, o fenômeno deverá ser observado em um sistema aberto e em um sistema fechado.

\section{MATERIAIS}

- solução de ácido clorídrico

- espátula

- carbonato de cálcio

- tubo de ensaio

- balança

- recipiente de vidro

- solução aquosa de sulfato de cobre II

- solução aquosa de hidróxido de sódio

\section{PROCEDIMENTO EXPERIMENTAL}




\section{TODAS AS OBSERVAÇÕES DEVEM SER REGISTRADAS NO QUADRO QUE ESTÁ NO FINAL DE CADA TESTE.}

\section{TESTE 1}

\section{Interação entre ácido clorídrico e hidrogenocarbonato de sódio}

1. Coloque cuidadosamente $50 \mathrm{~mL}$ da solução de ácido clorídrico na garrafa.

2. Usando a espátula, adicione cerca de $2 \mathrm{~g}$ de hidrogenocarbonato de sódio ou carbonato de cálcio ao tubo de ensaio pequeno.

3. Transfira com cuidado o tubo de ensaio para dentro da garrafa, conforme a figura a seguir. Não deixe que a solução de ácido entre em contato com o hidrogenocarbonato de sódio nesse momento.

4. Pese todo o conjunto na balança: a garrafa com a solução de ácido, o tubo de ensaio contendo hidrogenocarbonato de sódio ou carbonato de cálcio e a tampa da garrafa (não se esqueça de pesar a tampa). Anote a massa de todo o sistema.

5. Assegure-se de que a garrafa esteja bem fechada.

6. Vire a garrafa para que o ácido entre em contato com o hidrogenocarbonato ou o carbonato.

Deixe ocorrer a reação até cessar a efervescência.

7. Com a garrafa ainda tampada, meça a massa do conjunto novamente. Anote o valor.

8. Destampe a garrafa e meça a massa do conjunto sem se esquecer de medir também a massa da tampa de garrafa. Anote o valor.

\begin{tabular}{|c|c|c|c|}
\hline \multicolumn{2}{|c|}{ Sistema no estado inicial } & \multicolumn{2}{|c|}{ Sistema no estado final } \\
\hline & & \multicolumn{2}{|c|}{ ABERTO } \\
\hline \multirow[t]{3}{*}{$\begin{array}{l}\text { Descrição (aspecto } \\
\text { visual) }\end{array}$} & Massa & $\begin{array}{l}\text { Descrição } \\
\text { (aspecto visual) }\end{array}$ & Massa \\
\hline & & \multicolumn{2}{|c|}{ FECHADO } \\
\hline & & $\begin{array}{l}\text { Descrição } \\
\text { (aspecto visual) }\end{array}$ & Massa \\
\hline
\end{tabular}

\section{TESTE 2}

\section{Interação entre sulfato de cobre II e hidróxido de sódio}

1. Coloque cerca de $5 \mathrm{~mL}$ de solução aquosa de sulfato de cobre II em um dos tubos de ensaio maiores e cerca de $5 \mathrm{~mL}$ de solução aquosa de hidróxido de sódio no outro tubo. 
2. Coloque os tubos com as soluções na estante para tubos de ensaio. Pese todo esse sistema (os tubos com as soluções e a estante). Anote o valor da massa na tabela a seguir.

3. Transfira a solução de sulfato de cobre II para o tubo de ensaio que contém a solução de hidróxido de sódio. Você acha que a massa do sistema vai variar?

4. Pese todo o sistema novamente, incluindo o tubo de ensaio que continha a solução de sulfato de cobre II. Anote na tabela o valor da massa. O valor de massa encontrado corresponde às suas previsões?

\begin{tabular}{|l|l|l|l|}
\hline \multicolumn{2}{|c|}{ Sistema no estado inicial } & \multicolumn{2}{c|}{ Sistema no estado inicial } \\
\hline $\begin{array}{l}\text { Descrição (aspecto } \\
\text { visual) }\end{array}$ & Massa & $\begin{array}{l}\text { Descrição } \\
\text { visual) }\end{array}$ & (aspecto \\
\hline & & & \\
\hline
\end{tabular}

\section{TESTE 3}

\section{Observando o comportamento dos sais}

1. Coloque cerca de $10 \mathrm{~mL}$ de água em um tubo de ensaio.

2. Adicione uma ponta de espátula de carbonato de sódio. Agite bastante.

3. Coloque uma ponta de espátula de cloreto de cálcio em outro tubo de ensaio.

4. Coloque os dois tubos em um frasco de vidro e pese.

5. Deixando tudo em cima da balança, transfira com cuidado o cloreto de cálcio para o tubo contendo o carbonato de sódio. Agite bastante o tubo e pese novamente todo o conteúdo, inclusive o tubo de ensaio vazio.

\begin{tabular}{|l|l|l|l|}
\hline \multicolumn{2}{|c|}{ Sistema no estado inicial } & \multicolumn{3}{c|}{ Sistema no estado inicial } \\
\hline $\begin{array}{l}\text { Descrição (aspecto } \\
\text { visual) }\end{array}$ & Massa & $\begin{array}{l}\text { Descrição } \\
\text { visual) }\end{array}$ & (aspecto \\
\hline & & & \\
\hline
\end{tabular}

\section{QUESTÕES}

1. Você considera que os três fenômenos observados neste experimento são transformações químicas? A partir de que evidência é possível fazer essa afirmação?

2. Para cada teste compare os valores obtidos para as massas do sistema antes e depois da reação. O que vocês podem constatar?

3. No experimento que houve alteração no valor da massa a que se atribui a diferença observada?

4. No experimento que não houve alteração no valor da massa a que se atribui essa observação? 


\section{APÊNDICE 9}

Instrumento 9: Reflexões sobre a Lei de Conservação das massas estabelecida por Lavoisier.

\begin{tabular}{|l|l|}
\hline Nome: & Série: \\
\hline Escola: & Idade: \\
\hline Data: & Turma no Cursinho: \\
\hline Instruções: Este questionário é um instrumento de coleta de dados para uma pesquisa \\
de Mestrado do Programa Interunidades em Ensino de Ciências na modalidade \\
Ensino de Química da Universidade de São Paulo (USP). Pedimos a sua colaboração, \\
para isso, por favor, não converse com seu colega, não consulte material, nem \\
qualquer equipamento eletrônico.
\end{tabular}

\section{QUESTÕES PARA REFLETIR}

1. O carvão é constituído basicamente de carbono (C), sendo o restante formado por materiais orgânicos não decompostos na carbonização da madeira. Na combustão do carvão, o carbono interage com o oxigênio do ar formando principalmente o gás carbônico. Observe o resultado de três experimentos e combustão do carvão que foram realizados em recipiente fechado e que as massas medidas foram aquelas apresentadas a seguir:

\begin{tabular}{|c|c|c|c|c|c|}
\hline \multirow{2}{*}{ Amostra } & \multicolumn{2}{|c|}{$\begin{array}{c}\text { Massas iniciais dos reagentes } \\
\text { (valores em gramas) }\end{array}$} & \multicolumn{2}{|c|}{$\begin{array}{c}\text { Massas iniciais dos } \\
\text { reagentes } \\
\text { (valores em gramas) }\end{array}$} & \multirow{2}{*}{$\begin{array}{r}\text { Energia } \\
\text { liberada } \\
\text { (Kcal) }\end{array}$} \\
\hline & $\begin{array}{l}\text { Carvão } \\
\text { (C) }\end{array}$ & $\begin{array}{c}\text { Gás } \\
\text { oxigênio } \\
\left(\mathrm{O}_{2}\right)\end{array}$ & $\begin{array}{l}\text { Dióxido de } \\
\text { carbono } \\
\left(\mathrm{CO}_{2}\right)\end{array}$ & Cinzas & \\
\hline I & 150 & 320 & 442 & 31 & 1020 \\
\hline II & 60 & 128 & 172 & 12 & 410 \\
\hline III & 23 & 48 & 66 & 5 & 156 \\
\hline
\end{tabular}

Comparando as quantidades dos reagentes em relação as quantidades dos produtos em cada um dos casos, é possível dizer que a massa do sistema inicial permaneceu a mesma depois da combustão do carvão? Se não, a que pode ser atribuída essa diferença?

2. O responsável técnico de um forno de calcinação de calcário elaborou um relatório sobre as três últimas tiragens da produção de cal. O relatório apresenta a seguinte tabela:

\begin{tabular}{|l|l|l|l|}
\hline Amostras & Massa de calcário (t) & Massa de cal (t) & Massa de \\
\hline
\end{tabular}




\begin{tabular}{|l|l|l|l|}
\hline & $\left(\mathrm{CaCO}_{3}\right)$ & $(\mathrm{CaO})$ & $\begin{array}{l}\text { dióxido de carbono }(\mathrm{t}) \\
\left(\mathrm{CO}_{2}\right)\end{array}$ \\
\hline $12 / 7$ & 10,0 & 5,6 & 4,4 \\
\hline $15 / 7$ & & 11,2 & \\
\hline $18 / 7$ & 12,0 & 6,7 & \\
\hline
\end{tabular}

Como se pode perceber, faltaram dados da massa de calcário usado no dia 15/7 e da massa de dióxido de carbono formado nos dia 15/7 e 18/7.

a) Identifique quais são os reagentes e produtos nesse processo.

b) Sabendo-se que a calcinação do carbonato de cálcio envolve o consumo de energia, proponha uma equação química que represente a calcinação do calcário e inclua o termo "energia" na equação.

c) Determine os valores que faltam na tabela e complete-as. Mostre os cálculos realizados. 


\section{APÊNDICE 10}

Instrumento 10: Síntese do conteúdo descrita pelos alunos.

\begin{tabular}{|c|c|}
\hline Nome: & Série: \\
\hline Escola: & Idade: \\
\hline Data: & Turma no Cursinho: \\
\hline \multicolumn{2}{|c|}{$\begin{array}{l}\text { Instruções: Este questionário é um instrumento de coleta de dados para uma pesquisa } \\
\text { de Mestrado do Programa Interunidades em Ensino de Ciências na modalidade ensino } \\
\text { de química da Universidade de São Paulo (USP). Pedimos a sua colaboração, para } \\
\text { isso, por favor, não converse com seu colega, não consulte material, nem qualquer } \\
\text { equipamento eletrônico. As suas respostas são muito importantes para que possamos } \\
\text { desenvolver uma pesquisa em ensino de ciências que possa contribuir com a } \\
\text { educação. Desde já agradecemos a sua colaboração! }\end{array}$} \\
\hline
\end{tabular}

\section{TERMOS CHAVES:}

Produto Conservação

Material Massa

química Reagente

Mistura Quantidade
Sistema inicial Sistema final

Transformação

UTILIZANDO ALgUMAS DAS PALAVRAS SUGERIDAS ACIMA E TAMBÉM

OUTRAS QUE VOCÊ ACHAR NECESSÁRIO, ESCREVA UM TEXTO QUE RESUME TUDO QUE VOCÊ APRENDEU ATÉ AGORA. 


\section{APÊNDICE 11}

Instrumento 11: Atividade experimental - "Quando se misturam reagentes, será que tudo se transforma em produtos",

\begin{tabular}{|l|l|}
\hline Nome: & Série: \\
\hline Escola: & Idade: \\
\hline Data: & Turma no Cursinho: \\
\hline Instruções: Este questionário é um instrumento de coleta de dados para uma pesquisa \\
de Mestrado do Programa Interunidades em Ensino de Ciências na modalidade ensino \\
de química da Universidade de São Paulo (USP). Pedimos a sua colaboração, para \\
isso, por favor, não converse com seu colega, não consulte material, nem qualquer \\
equipamento eletrônico. As suas respostas são muito importantes para que possamos \\
desenvolver uma pesquisa em ensino de ciências que possa contribuir com a \\
educação. Desde já agradecemos a sua colaboração!
\end{tabular}

\section{OBJETIVOS}

O objetivo principal desta atividade é realizar e observar a reação que ocorre entre sulfato de cobre e ferro. A atividade trata da transformação que ocorre entre a palha de aço e a solução de sulfato de cobre. O aluno deverá perceber que apesar de ocorrer a conservação das massas dos reagentes, nem sempre todo reagente é necessariamente convertido em outro produto.

\section{MATERIAIS}

- 1 estante para tubos de ensaio

- 2 rolhas para tubo de ensaio

- 3 tubos de ensaio

- 1 conta-gotas

- palhinha de aço

- solução de sulfato de cobre $(1 \mathrm{~mol} / \mathrm{L})$

\section{PROCEDIMENTO EXPERIMENTAL}

1. Numerar os tubos de 1 a 3.

2. Fazer duas bolinhas de palhinha de aço do tamanho.

3. Colocar uma bolinha no tubo 1 e a outra no tubo 2. Pingar sulfato de cobre nos tubos, como indicado a seguir: 


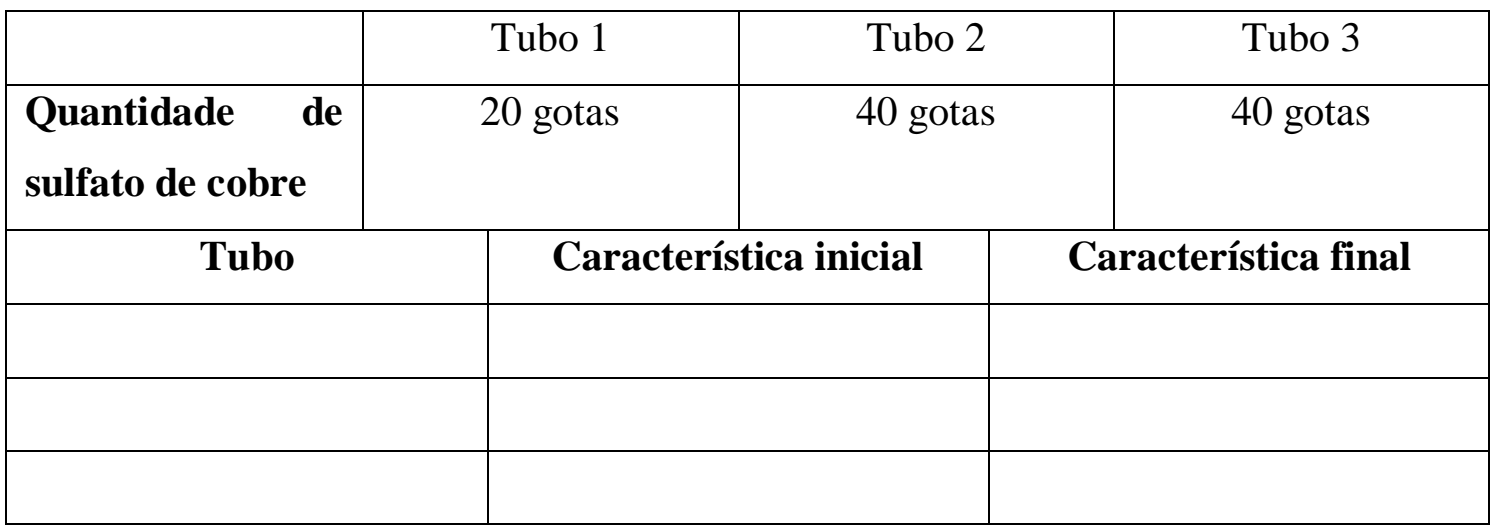

4. Tampar os tubos 1 e 2, esperar alguns minutos e agitar de vez em quando.

\section{QUESTÕES}

1. O que aconteceu com a palha de aço no tubo 1 ? E no tubo 2 ?

2. Como ficou a cor do sulfato de cobre no tubo 1 ? E no tubo 2 ?

3. Que utilidade você acha que teve o tubo 3?

4. O que aconteceria se fosse colocado mais bolinhas nos tubos 1 e 2?

5. Quando se misturam reagentes, tudo se transforma em produtos quaisquer que sejam as quantidades misturadas? 


\section{APÊNDICE 12}

Instrumento 12: Reflexões sobre a Lei de Conservação das massas estabelecida por Lavoisier e a Lei das Proporções de Proust.

\begin{tabular}{|c|c|}
\hline Nome: & Série: \\
\hline Escola: & Idade: \\
\hline Data: & Turma no Cursinho: \\
\hline \multicolumn{2}{|c|}{$\begin{array}{l}\text { Instruções: Este questionário é um instrumento de coleta de dados para uma pesquisa } \\
\text { de Mestrado do Programa Interunidades em Ensino de Ciências na modalidade } \\
\text { Ensino de Química da Universidade de São Paulo (USP). Pedimos a sua colaboração, } \\
\text { para isso, por favor, não converse com seu colega, não consulte material, nem } \\
\text { qualquer equipamento eletrônico. }\end{array}$} \\
\hline
\end{tabular}

\section{QUESTÕES PARA REFLETIR}

1. O responsável técnico de um forno de calcinação de calcário elaborou um relatório sobre as três últimas tiragens da produção de cal. O relatório apresenta a seguinte tabela:

\begin{tabular}{|l|l|l|l|}
\hline Amostras & $\begin{array}{l}\text { Massa de calcário }(\mathrm{t}) \\
\left(\mathrm{CaCO}_{3}\right)\end{array}$ & $\begin{array}{l}\text { Massa de cal }(\mathrm{t}) \\
(\mathrm{CaO})\end{array}$ & $\begin{array}{l}\text { Massa de } \\
\text { dióxido de carbono }(\mathrm{t}) \\
\left(\mathrm{CO}_{2}\right)\end{array}$ \\
\hline $12 / 7$ & 10,0 & 5,6 & 4,4 \\
\hline $15 / 7$ & & 11,2 & \\
\hline $18 / 7$ & 12,0 & 6,7 & \\
\hline
\end{tabular}

Como se pode perceber, faltaram dados da massa de calcário usado no dia 15/7 e da massa de dióxido de carbono formado nos dia 15/7 e 18/7.

a) Identifique quais são os reagentes e produtos nesse processo.

b) Determine os valores que faltam na tabela e complete-as. Mostre os cálculos realizados.

2. Devido à toxicidade do mercúrio, em caso de derramamento desse metal, costuma-se espalhar enxofre no local, para removê-lo. Mercúrio e enxofre reagem, gradativamente, formando sulfeto de mercúrio. Para fins de estudo, a reação pode ocorrer mais rapidamente se as duas substâncias forem misturadas. Usando esse procedimento, foram feitos dois experimentos, observe os dados: 


\begin{tabular}{|l|l|l|l|l|}
\hline Experimentos & Mercúrio & Enxofre & $\begin{array}{l}\text { Produto } \\
\text { formado }\end{array}$ & Sobra \\
\hline I & $5,0 \mathrm{~g}$ & $1,0 \mathrm{~g}$ & $5,8 \mathrm{~g}$ & $0,2 \mathrm{~g}$ de enxofre \\
\hline II & $12,0 \mathrm{~g}$ & $1,6 \mathrm{~g}$ & $11,6 \mathrm{~g}$ & 2,0 de mercúrio \\
\hline
\end{tabular}

a) Represente essa transformação, por meio de uma equação química, a partir das informações do texto, mesmo sem utilizar as fórmulas químicas.

b) Para cada um desses experimentos, a massa inicial do sistema é a mesma que a massa final? Você pode dizer que houve conservação da massa do sistema nessa transformação.

c) Pode-se afirmar que há uma proporção entre a massa do produto formado e as massas dos reagentes que efetivamente reagem. Como você poderia verificar essa proporção? Descreva seu raciocínio.

3. Amônia e gás carbônico podem reagir formando ureia e água. O gráfico abaixo mostra as massas de ureia e de água que são produzidas em função da massa de amônia, considerando as reações completas. A partir dos dados do gráfico e dispondo-se de 110 g de amônia, qual é o valor da massa aproximada, em gramas, de gás carbônico minimamente necessário para reação completa com essa quantidade de amônia? Por que essa massa é mínima? Se tivesse uma massa maior de $\mathrm{CO}_{2}$ seria produzida mais água e uréia? Justifique

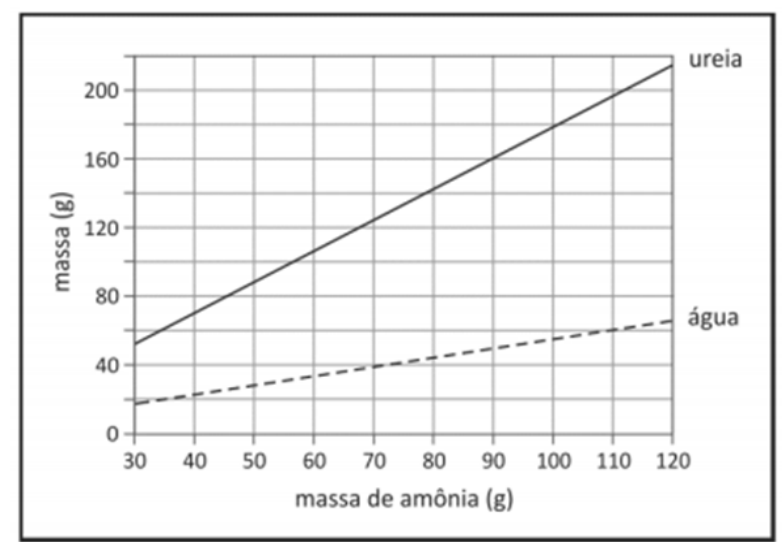

Algumas reflexões que podem auxiliar na resolução do problema...

- Como podemos representar essa transformação, por meio de uma equação química, a partir das informações do texto, mesmo sem utilizar as fórmulas químicas?

- Leia o texto novamente e procure entender quais as relações estabelecidas no gráfico com cada uma das substâncias 


\section{APÊNDICE 13}

Instrumento 13: Verificação final de conceitos e habilidades

1. A seguir estão relacionados vários fenômenos. Assinale aqueles que você considera que são transformações químicas e justifique a resposta dada a cada um deles.

\begin{tabular}{|l|l|l|}
\hline \multicolumn{1}{|c|}{ Fenômeno } & \multicolumn{1}{|c|}{$\begin{array}{c}\text { transformação } \\
\text { química? }\end{array}$} & Justificativas \\
\hline a) enferrujamento de um carro & & \\
\hline b) formação de bolor em alimentos & & \\
\hline c) evaporação da acetona & & \\
\hline d) desgaste de uma construção pela chuva & & \\
\hline e) queima de um Biocombustível & & \\
\hline f) respiração humana & & \\
\hline g) derretimento das calotas polares & & \\
\hline h) digestão de alimentos & & \\
\hline i) liberação de gás do refrigerante & & \\
\hline j) quebra de um copo de vidro & & \\
\hline k) coagulação do sangue & & \\
\hline l) cozimento de um ovo & & \\
\hline
\end{tabular}

2. Um professor de Química em uma de suas aulas colocou um pouco de vinagre dentro de uma garrafa e prendeu uma bexiga contendo bicarbonato de sódio no gargalo da garrafa, conforme representado no esquema (Figura 1):

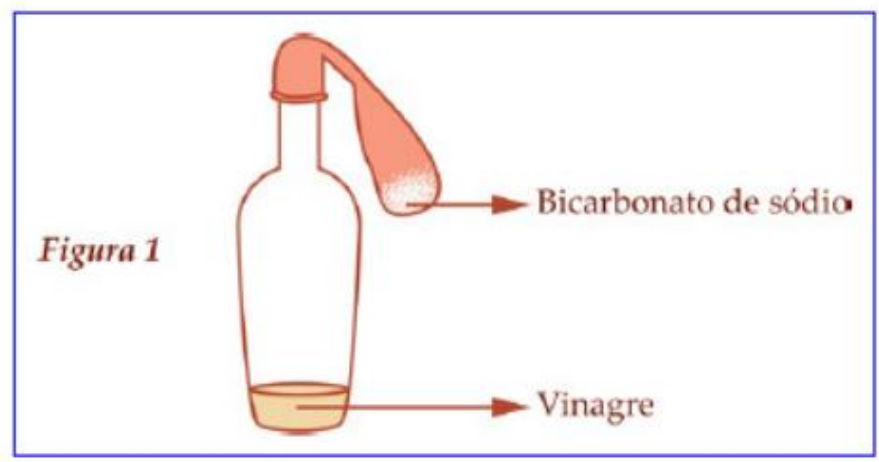


Em seguida, o professor esticou a ponta da bexiga de modo que todo o bicarbonato de sódio entrasse em contato com o vinagre contido na garrafa. Os alunos observaram a formação de uma efervescência e o enchimento do balão. Durante as discussões com seus alunos, chegouse a conclusão que se tratava de uma Transformação Química que envolvia a reação entre o bicarbonato de sódio e o vinagre com formação do acetato de sódio, água e gás carbônico.

a) Indique quais são os reagentes e os produtos envolvidos nesta reação.

b) Represente essa transformação por meio de uma equação química (não é necessário o uso de fórmulas químicas).

3. Nas indústrias siderúrgicas o gás monóxido de carbono $(\mathrm{CO})$, formado na combustão incompleta do carvão, reagirá com o óxido de ferro III $\left(\mathrm{Fe}_{2} \mathrm{O}_{3}\right)$ extraído do minério de ferro, ocorrendo a formação de ferro líquido $(\mathrm{Fe})$ e o gás dióxido de carbono $\left(\mathrm{CO}_{2}\right)$. O responsável técnico pelo monitoramento da reação elaborou um relatório sobre as três últimas tiragens da produção do ferro líquido. O relatório apresenta a seguinte tabela:

\begin{tabular}{|c|c|c|c|c|}
\hline Tiragem & $\begin{array}{c}\text { Massa do óxido } \\
\text { de ferro III (g) } \\
\left(\mathrm{Fe}_{2} \mathrm{O}_{3}\right)\end{array}$ & $\begin{array}{c}\text { Massa do } \\
\text { monóxido de } \\
\text { carbono }(\mathrm{g})\end{array}$ & $\begin{array}{c}\text { Massa do ferro } \\
(\mathrm{g})\end{array}$ & $\begin{array}{c}\text { Massa do dióxido } \\
\text { de carbono }(\mathrm{F})\end{array}$ \\
\hline 1 & 320 & 168 & 224 & $\mathrm{X}$ \\
\hline 2 & 800 & $\mathrm{Y}$ & 560 & 660 \\
\hline 3 & $\mathrm{Z}$ & 672 & $\mathrm{~W}$ & 1056 \\
\hline
\end{tabular}

Considerando que não há excesso de reagentes, e que toda a quantidade de reagentes se transformou em produtos em uma reação completa, responda os itens que se seguem:

a) Observe as tiragens 1 e 2 . Determine as quantidades de dióxido de carbono $\left(\mathrm{CO}_{2(\mathrm{~g})}\right)$ produzido na primeira tiragem e de monóxido de carbono $\left(\mathrm{CO}_{(\mathrm{g})}\right)$ consumido na segunda tiragem. 
b) Comparando as medidas obtidas da tiragem 1 com a tiragem 3 é possível estabelecer uma relação entre elas? Determine os valores das medidas que estão faltando da tiragem 3.

4. (Questão 59 - Enem 2012 - adaptado)

No Japão, um movimento nacional para a promoção da luta contra o aquecimento global leva o slogan: 1 pessoa, 1 dia, $1 \mathrm{~kg}$ de $\mathrm{CO}_{2}$ a menos! A ideia é cada pessoa reduzir em $1 \mathrm{~kg}$ a quantidade de $\mathrm{CO}_{2}$ emitida todo dia, por meio de pequenos gestos ecológicos como diminuir a queima de gás de cozinha.

Um hambúrguer ecológico? É pra já! Disponível em: http://lqes.iqm.unicamp.br. Acesso em: 24 fev. 2012 (adaptado).

A reação abaixo representa o processo de queima do gás de cozinha bem como quantidades, em gramas, das substâncias envolvidas na reação.

\begin{tabular}{|c|c|}
\hline 20 & $8 \mathrm{CO}_{2}+10 \mathrm{H}_{2} \mathrm{O}$ \\
\hline $\mathrm{C}_{4} \mathrm{H}_{10}$ & $\mathrm{CO}_{2}$ \\
\hline $116 \mathrm{~g}$ & $352 \mathrm{~g}$ \\
\hline
\end{tabular}

a) Qual a quantidade mínima, em gramas, desse gás que um japonês deve deixar de queimar para atender à meta diária?

b) No quadro foi representada a equação da reação de combustão do gás de cozinha (supondo que este gás seja formado apenas de butano). A equação foi balanceada adequadamente? Como você chegou a essa resposta?

5. Observe a imagem, que apresenta uma situação de intensa poluição do ar que danifica veículos, edifícios, monumentos, vegetação e acarreta transtornos ainda maiores para a população. Trata-se de chuvas com poluentes ácidos ou corrosivos produzidos por reações químicas na atmosfera.

Em A está destacado a presença de dois óxidos que participam do processo de reação química que resultará na acidez da chuva. Em B ocorrerão transformações químicas desses óxidos que resultarão na formação de ácidos que contribuirão para a geração da chuva ácida, como por exemplo, o ácido sulfúrico $\left(\mathrm{H}_{2} \mathrm{SO}_{4}\right)$. 


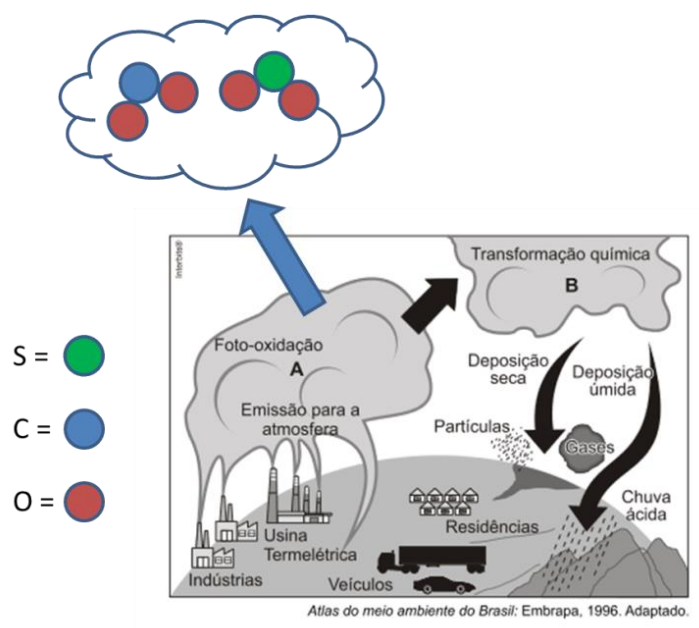

Considerando os dados descritos acima você seria capaz de dizer quais os óxidos descritos em A?

6. Adicionando-se solução aquosa de sal A uma solução aquosa de sal B, forma-se um precipitado em uma reação completa. Para se determinar a proporção entre os reagentes e o produto envolvido na transformação, fez uma série de 4 experimentos. As quantidades dos reagentes utilizadas foram descritas na seguinte tabela:

\begin{tabular}{|c|c|c|c|c|}
\hline \multicolumn{1}{|c|}{ Experimentos } & $\mathbf{1}$ & $\mathbf{2}$ & $\mathbf{3}$ & $\mathbf{4}$ \\
\hline Massa do Sal A (g) & 1,20 & 2,40 & 3,60 & 4,80 \\
\hline Massa do Sal B (g) & 0,60 & 1,20 & 1,80 & 2,40 \\
\hline
\end{tabular}

Após a realização de cada experimento foi construído um gráfico que relaciona as massas de um dos sais envolvidos na reação e do precipitado produzido.

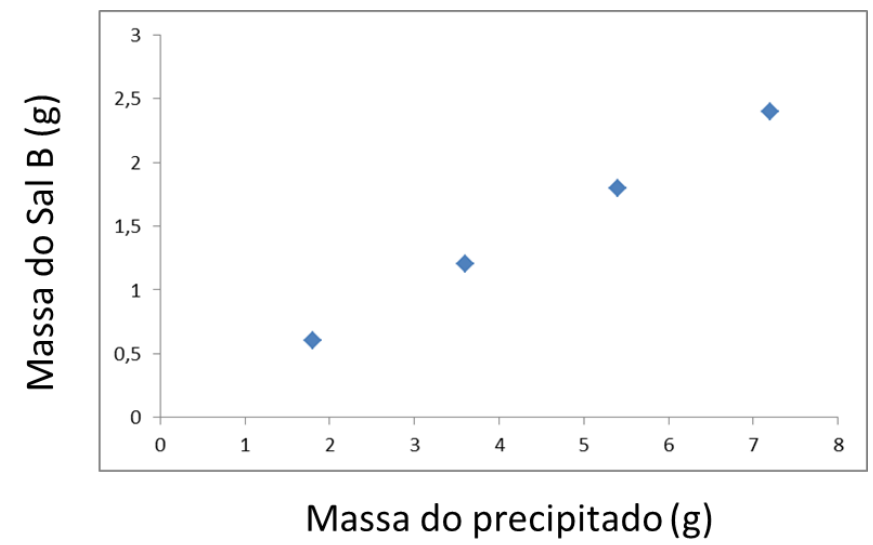

A partir da análise dos dados descritos:

a) Represente essa transformação por meio de uma equação química (não é necessário o uso de fórmulas químicas).

b) Você acha que existe alguma relação de proporção entre reagentes e produtos? Apresente alguns argumentos para a sua resposta.

c) Se você realizado um $5^{\circ}$ experimento utilizando 3,0 g do Sal B, seria possível determinar a quantidade necessária de Sal A e também a quantidade produzida do precipitado? 